UNIVERSIDADE DE SÃO PAULO INSTITUTO DE GEOCIENCIAS

\title{
MINERALOGIA DA JAZIDA DE COBRE DO RIBEIRÃO DO PERAU, PARANÁ
}

$d_{\text {rineu }} M_{\text {arques }} \delta_{o u z a}$ 


\title{
UNIVERSIDADE DE SÃO PAULO INSTITUTO DE GEOCIENEIAS
}
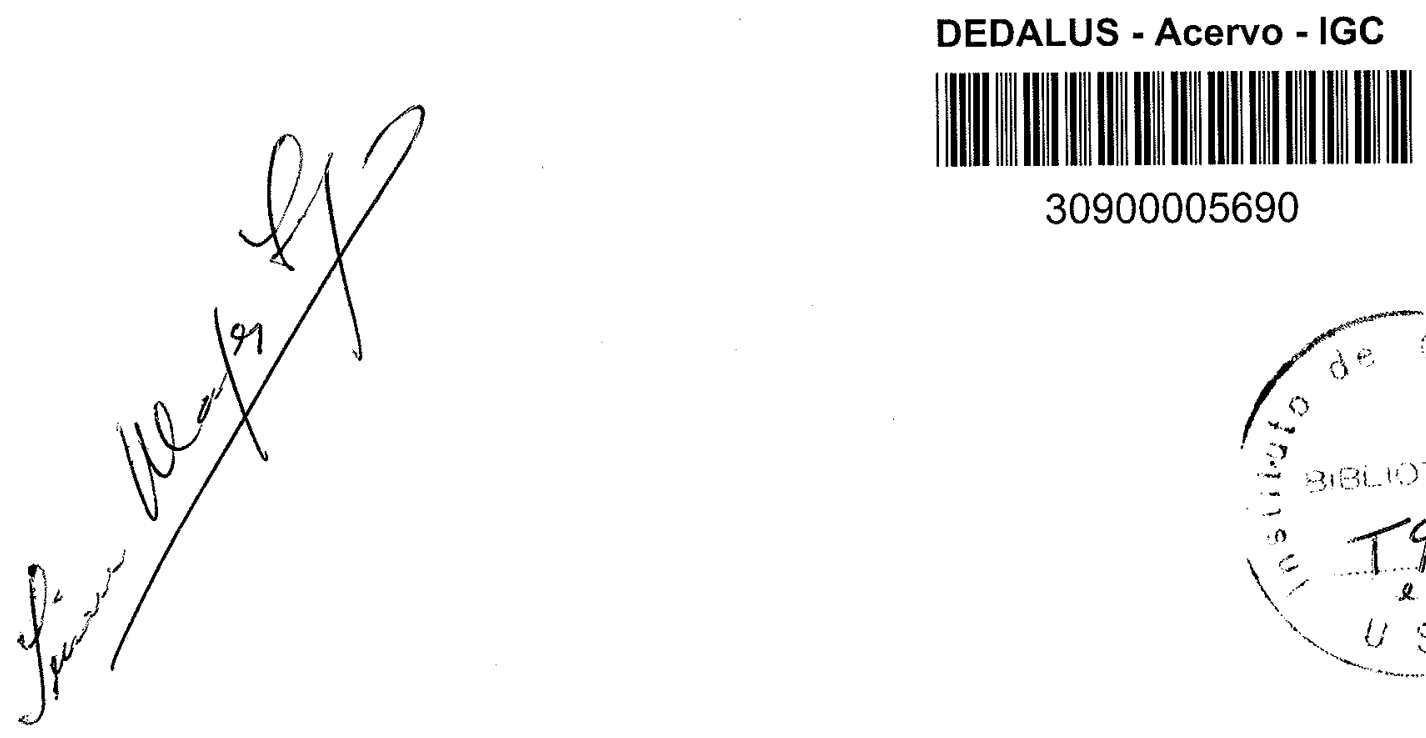

\section{MINERALOGIA DA JAZIDA DE COBRE DO RIBEIRÃO DO PERAU, PARANÁ}

\author{
Tese de doutoramento \\ apresentada ao IG - USP \\ Irineu Marques Oouza
}

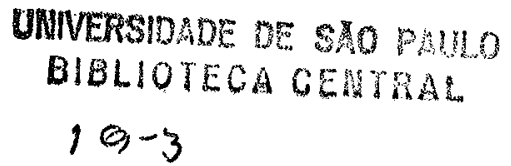


INDICE

Pāgina

RESUMO

IN TR ODUÇÃO

TRABALHOS ANTERIORES

ASPECTOS GEOLOGICOS REGIONAIS

ASPECTOS GEOLOGICOS LOCAIS

Litologia

Estratigrafia

18

Estruturas

Rochas encaixantes e portadoras de minério

Levantamento geofísico

Levantamento geoquímico

PETROGRAFIA

Filitos

$\mathrm{X}$ istos

Quartzitos

Anfibolitos e anfibólio-xistos

Rochas carbonāticas

Rochas calcio-silicatadas

Granito

Met amorfismo

MINERALOGIA

Metodologia

propriedades físicas e morfológicas

microscopia

seções polidas

difração de raios $X$

fluorescência

radioatividade 
Pāgina

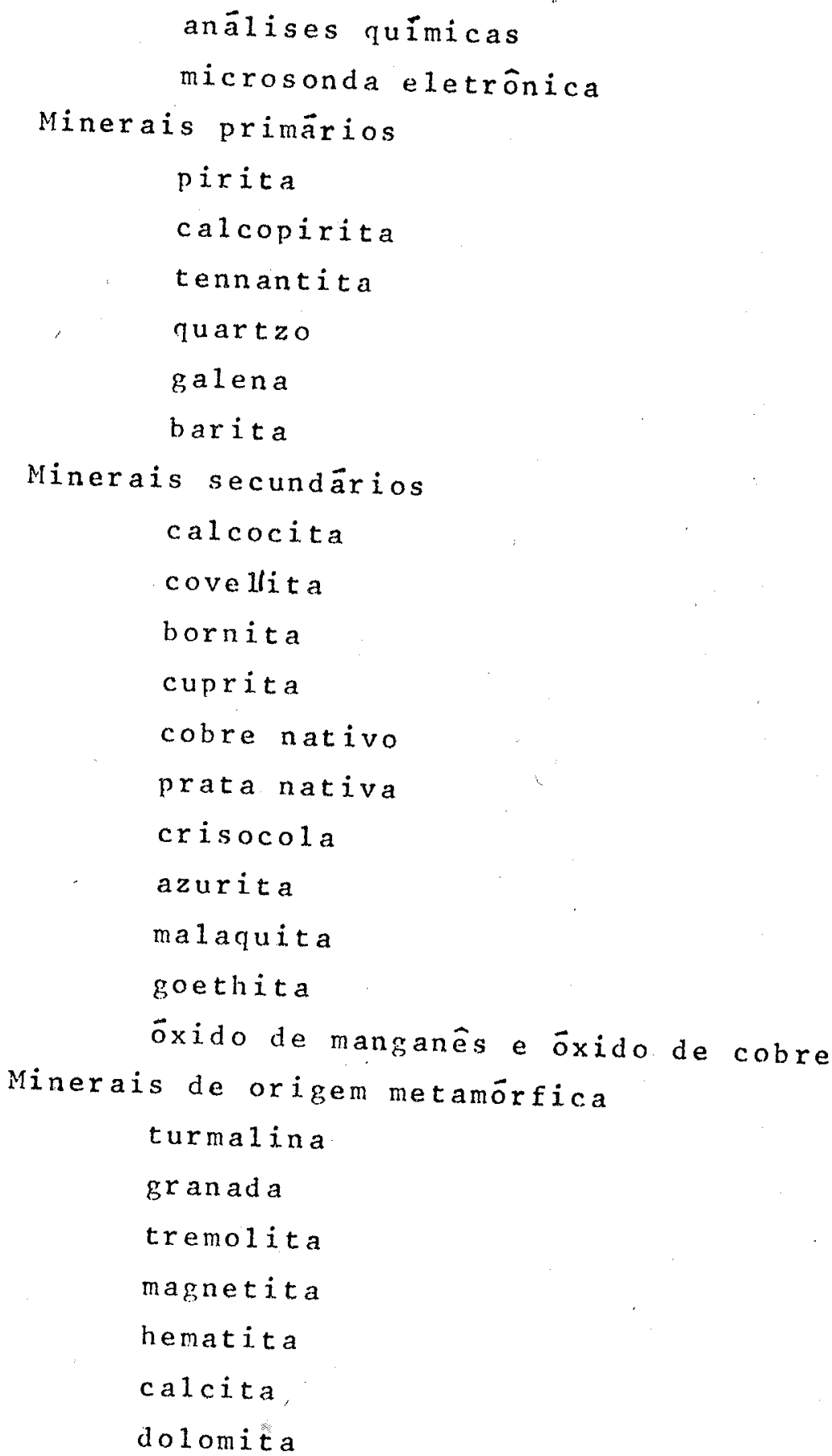

COMPARAÇÃO ENTRE ANĀLISES QUIMICAS E RESULTADOS DE MICROSONDA ELETRONICA

SEQUENCIA DE DEPOSIÇÃO E GENESE

AGRADECIMENTOS

B I BL IOGRAF IA 
FIG.3

MAPA GEOLÓGICO DA JAZIDA DE COBRE DO RIBEIRẢO DO PERAU, ADRIANÓPOLIS ESTADO DO PARANA

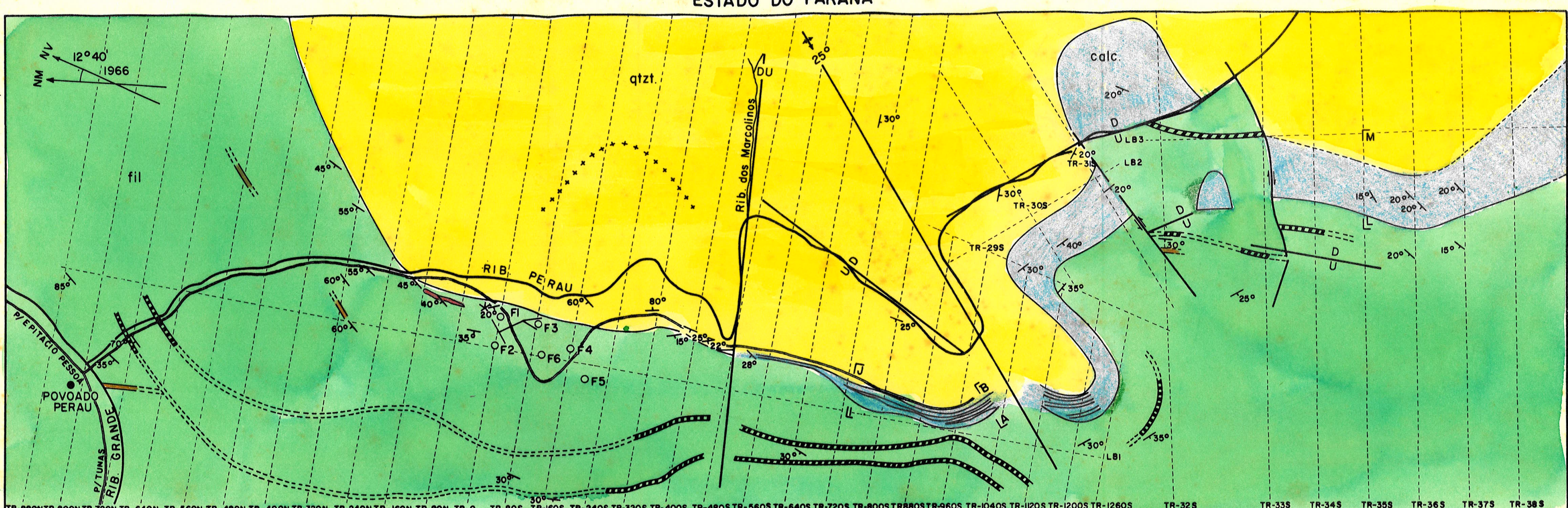

$$
\text { C. }
$$

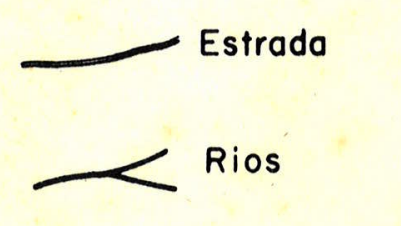

$<$ Drenagem

- Povoado

Contacto

-. Contato inferido

A B Perfis geológicos

D Falho

$T_{60^{\circ}} \quad$ Mergulho medido

$x^{x^{x^{x+x}}} x_{x}$ Escorregamento

$<$ Galerias

LB LB $=$ Linha Base

TR-80s' $-25^{\circ}+$ Anticlinal

o FI Furo de sonda com disponibilidade de dados geológicos

\section{$=:==:==$ Veios de quartzo}

Anfibólio xistos, anfibolitos

$\Longrightarrow$ Hematita xisto

fil Xistos, filitos

\begin{tabular}{|c|}
\hline calc Rochas carbonáticas \\
\hline
\end{tabular}

$q \dagger z \dagger$ Quartzitos 


\section{RE SUMO}

A jazida de cobre do Ribeirão do Perau localiza-se nas coordenadas geogräficas : $24^{\circ} 50^{\prime}$ de latitude sul e $49^{\circ} 00^{\circ}$ de longitude oeste, junto à confluência dos Ribei rões Grande e Perau, a 30 quilômetros sudeste do municípió de Adrianópolis, Estado do Parană, numa faixa de 3,1 quilôme tros quadrados.

A litologia é dada por quartzitos, rochas carbonäticas, filitos, xistos e anfibolio-xistos, do Grupo Açungui, sendo essas rochas consideradas pertencentes à For mação setuva. A região situa-se em zona de transição entré as fäcies de xistos verdes e anfibolito.

Os minerais primários são constituídos por pirita, calcopirita, tennantita, quartzo, rara galena e bari ta; os secundärios são: calcocita, covelita, bornita,cuprita, cobre nativo, prata nativa, crisocola, azurita, malaquita; o correndo como minerais metamórficos: turmalina, granada, tre molita, magnetita, hematita, calcita e dolomita.

A mineralização primäria encontra-se dissemi nada concordantemente com a estratificação dos quartzitos en quanto que a secundäria ocorre preenchendo cavidades ou fra turas das rochas carbonáticas ou mesmo em forma de filóes concordantes com a estratificação de quartzitos milonitizados.

Foram feitos estudos de cada mineral através das propriedades físicas e morfológicas; microscopia à luz transmitida e refletida; difração de raios $x$; fluorescencia; radioatividade; anālises térmicas; anālises químicas de miné rio e deu-se ênfase ao estudo dos minerais à microsonda eletrônica.

A gênese da jazida não pode ser explicada pe la teoria magmatista-hidrotermal clässica e nos estágios atuais de conhecimento admitiu-se a hipötese de deposição se dimentar e posterior reconcentração. 
o trabalho pretende contribuir para o conhecimento da paragênese e gênese da jazida afim de estabelecer futuramente um controle litológico e/ou estrutural que possa permitir ampliação das reservas de cobre na região em estudo. 


\section{INTRODUÇÃO}

A jazida de cobre do Ribeirão do Perau se 1o caliza entre as coordenadas geogräficas: $24^{\circ} 50^{\prime} ; 24^{\circ} 52^{\prime}$ de latitude sul e $49^{\circ} 00^{\prime} ; 48^{\circ} 57^{\prime}$ de longitude oeste (Fig. 2). Dista aproximadamente $30 \mathrm{~km}$, a sudeste da cidade de Adrianopolis no Estado do Paraná (Fig. 1). Esse percurso, na década de 1930 fazia parte do trajeto da estrada velha são Paulo Curitiba, hoje totalmente abandonada, de maneira que o acesso rodoviārio se torna precário na estação das chuvas.

As ocorrências de cobre foram descobertas provavelmente por volta de 1920 e no transcurso da segunda guerra, o complexo cuprífero do Perau foi explorado a céu aberto e transportado em fardos, sobre animais, até a estrada Curitiba - Capela do Ribeira, e daí conduzido de caminhão até Itapeva, onde era metalurgicamente tratado (Moraes,1956). Posteriormente a jazida pertenceu por vários anos à Mineração Cimento Portland Rio Branco que se desinteressou pelas pesquisas.

Em 1965 a área foi adquirida pelo Eletro São Marco Ltda que tem realizado pesquisas continuas, intensificadas, sobremaneira nos dois $\overline{1} 1 \mathrm{timos}$ anos. Pequena parte da jazida foi medicia, até o presente, mostrando 830.000 ton de minērio com $2 \%$ de teor em cobre e 180.000 ton de minério com teor $2,2 \%$. o minério é todo do tipo oxidado, não encontrando mercado no país, nem na forma natural, nem concentrado,e, em vista disso o laboratório de Pesquisas Químicas da Eletro são Marco desenvolveu técnicáprópria para tratamento desse tipo de minério, por hidrometalurgia, obtendo rendimento superior a $90 \%$ e com custo operacional inferior ao dos processos tradicionais de pirometalurgia. Uma unidade piloto esta sendo instalada em são paulo para produção de 5 ton mensais de cobre, que terá por finalidade dimensionar a hidrometalur gia a ser construida no Ribeirão do Perau. 


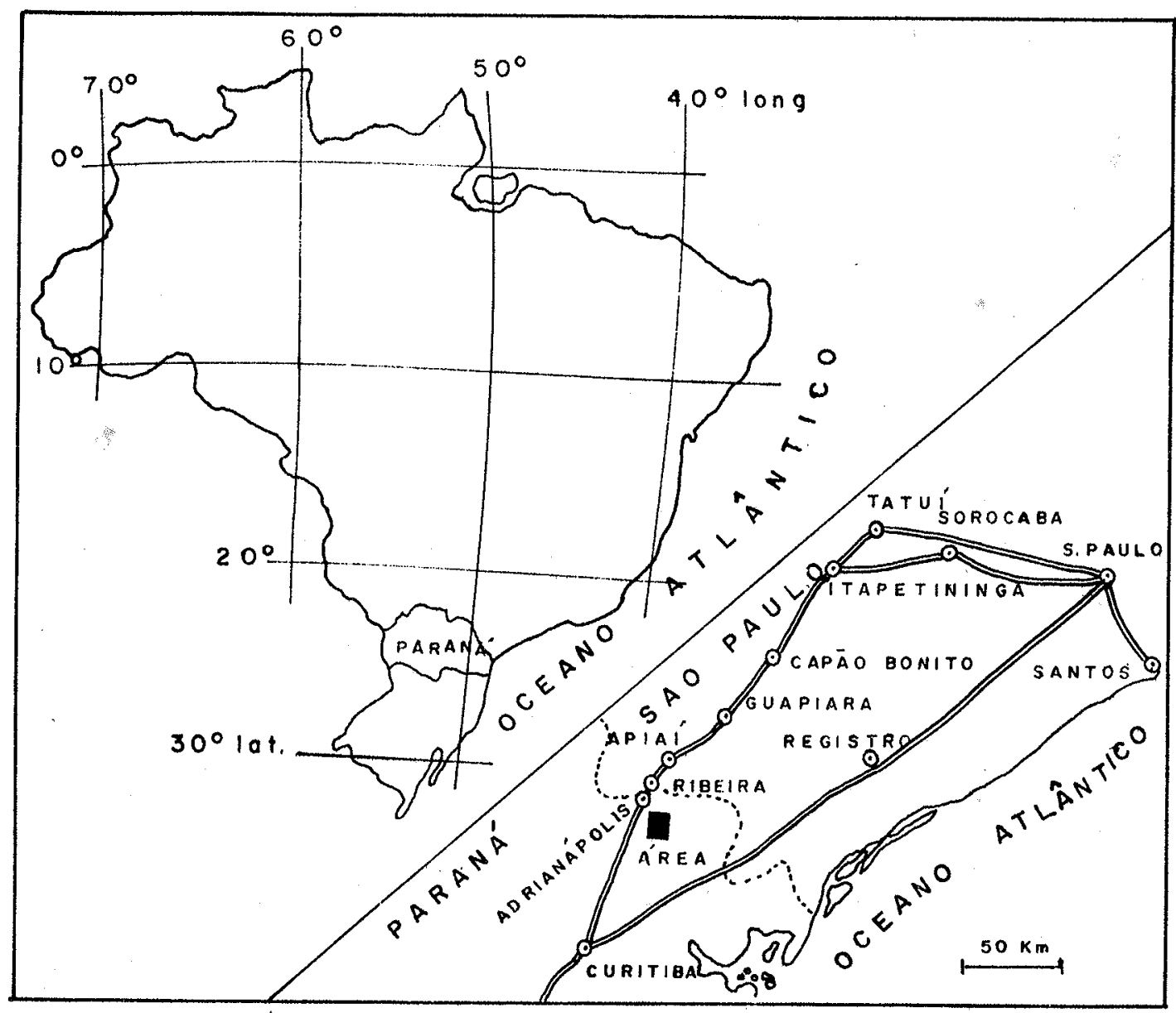

Fig. 1- SITUA\&Āo da ÁrEA 
A bibliografia anterior, específica sobre a jazida é escassa e, quando encontrada, faz parte em forma de citações, do conteúdo em trabalhos de caráter amplo e regional.

Moraes (1956) na $1^{\text {a }}$ Expedição Científica à Serra de Paranapiaba e Alto Ribeira cita em dois curtos pa răgrafos, sem fazer considerações, que o complexo cuprífero do Ribeirão do Perau é de origem hidrotermal, radioativo, com posto de cuprita, malaquita, calcopirita e calcantita, com teor de cobre metálico de 10 a $15 \%$.

Marini (1967) descrevendo os principais recursos minerais do Grupo Açunguí, no Estado de São Paulo, faz referência a 34 ocorrências de cobre distribuidas nos municí pios de Bocaiuva do Sul, Cerro Azul e Adrianōpolis, destacan do a ocorrência de Perau, encaixada em xistos e gnaisses da Formação Setuva.

Davino (1969) emprega o método de potencial expontâneo, cujas conclusões constam do capítulo seguinte, sobre aspectos geológicos locais. Souza (1970) descreve o es boço geológico das ocorrências de cobre no Ribeirão do Perau, citando as rochas e estratigrafia da jazida e sugerindo que a mineralização poderia pertencer a uma fase hidrotermal pois os minerais metálicos ocorrem em veios de quartzo.

Melcher et al., (1971) em Geologia da Folha de Apiaí, apresenta mapeamento regional que inclui a área do Ribeirão do Perau (Fig. 2). Cassedane (1971) fornece dados sobre a distribuição do cobre nas galenas do Vale do Ribeira, concluindo pela repartição do cobre nas galenas, como simplesmente condicionada pela paleogeografia, estritamente regida por fenômenos sedimentológicos. 


\section{ASPECTOS GEOLÓGICOS REGIONAIS}

As rochas do Grupo Açunguí (Almeida, 1964) fa zem parte do Geossinclínio Paraiba, que se estende desde o vale do Paraiba às fraldas da escarpa devoniana a oeste de Cu ritiba, no Paraná. Cordani et a1., (1971) situam as rochas epizonais que constituem o Grupo Açunguí como fazendo parte do cinturão orogénico Ribeira, localizado ao longo da costa oriental da Amërica do Sul, entre o sul do Estado da Bahia e Uruguai. A porfão norte, dentro da Geologia do Leste Paranaense (Fuck et al,, 1971) è ocupada em sua maior parte por me tassedimentos anqui e epimetamorficos de suposto ambiente mio geossinclinal pertencentes ao Grupo Açunguí. (Fig. 2).

As rochas dominantes são metassiltitos, fili tos, mármores calcários e dolomitos, quartzicos e metabasi tos cortados por batólitos e stocks graniticos tardi a póstectônicos, fortemente tectonizados e orientados NE-SW.Os me tassedimentos pertencem ao Prē-Cambriano Superior.

Marini et a1., (1967) (Tabela 1) dividem o Grupo Açunguí em quatro grandes unidades, através de critérios liotoestratigräficos: 1) Formação Setuva (Bigarella e Salamuni, 1956). 2) Formação Capiru (Bigarella e Salamuni, 1956). 3) Formação Votuverava (Bigare11a e Salamuni, 1958). 4) Formação Água Clara (Marini, 1967).

Ebert at al., (1971) estudando o's gnaisses da Formação Setuva e com base em anālises K/A (600 m.a.), con firma concordancia completa entre os filitos e quartzitos da Formação Capiru e os xistos e gnaisses da Formação Setuva. A Formação setuva é reorganizada em três andares, a saber:

Mica xistos (com quartzitos)

Gnaisses finos, escuros (com quartzitos)

Gnaisses leucocráticos de granulação mëdia até grosseira 
FIG 2 - LOCALIZACÃO DA JAZIDA DENTRO DA GEOLOGIA DA FOLHA DE APIAÍ, SP, PR

CONVENÇŌES

ENOZÓico
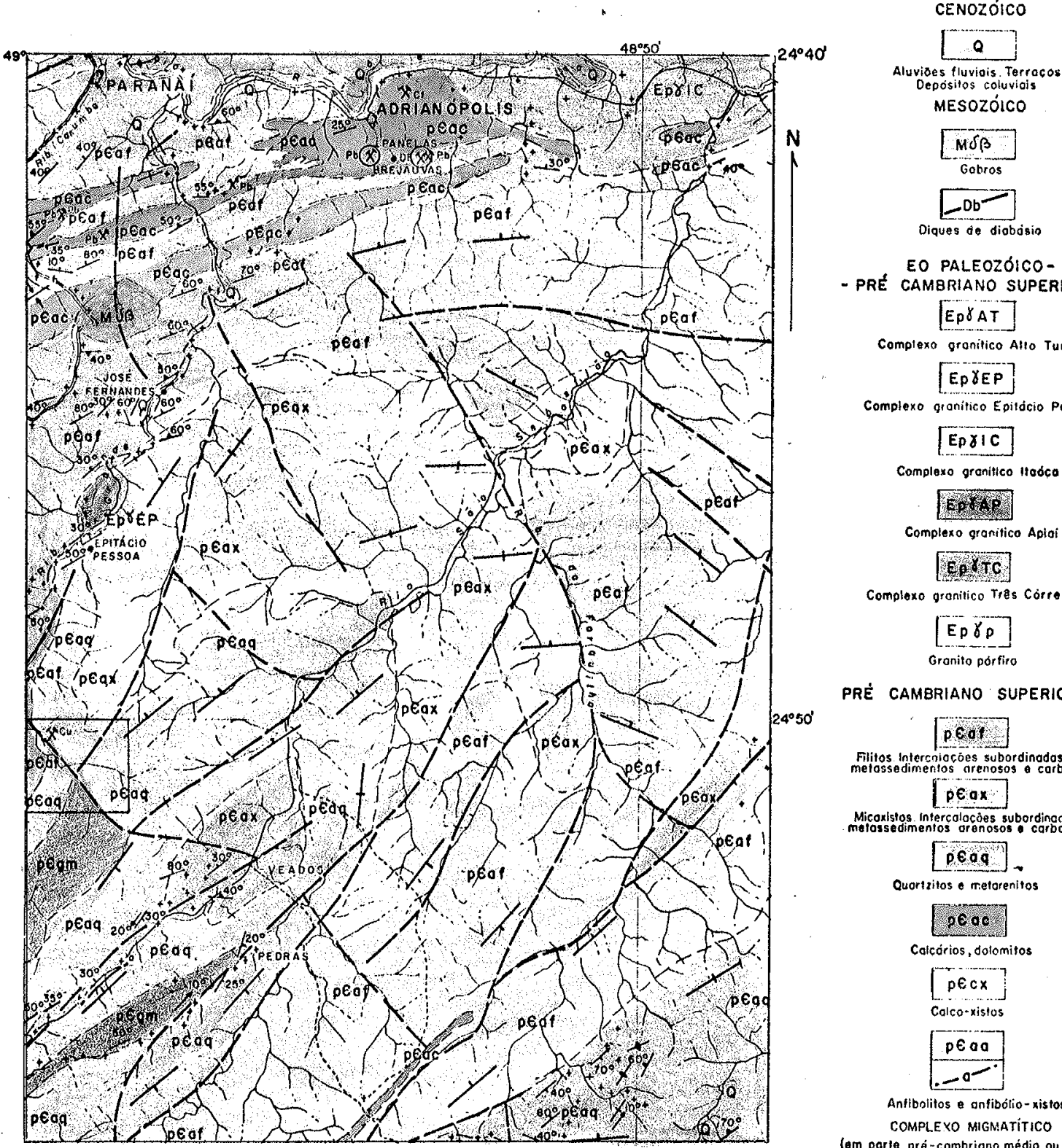

EO PALEOZÓICO-

- PRÉ cambriano superion Ep\&AT

Complexo gronitico Allo Turvo Ep

Complexo granítico Epitacio Pessoo Epric

Complexo granitico 110óca

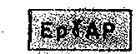

Complexo granifico Apiat

gertc

Complexo granitico Três Córregos

$\left[E_{p} \gamma_{p}\right]$

Granito portiro

PRÉ CAMBRIANO SUPERIOR

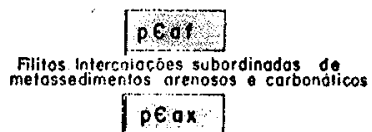

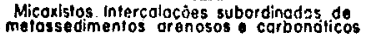

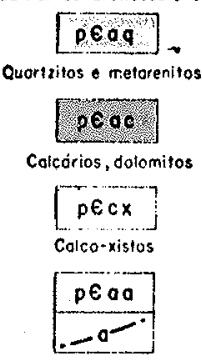

Antibolitos anfibólio-xistos

COMPLEYO MIGMATITICO

(om porto pré-combriano médio ou interior)

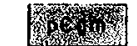

Gnaisses a migmalitos

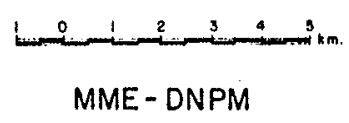

PROTEC - Projetos Técnicos e Obras de Engonhoria Ltda

Goologia por:

U.G. Cordanl

E.C. Damasceno

C.B. Gomes

G.C. Melcher

H.S. Lellis

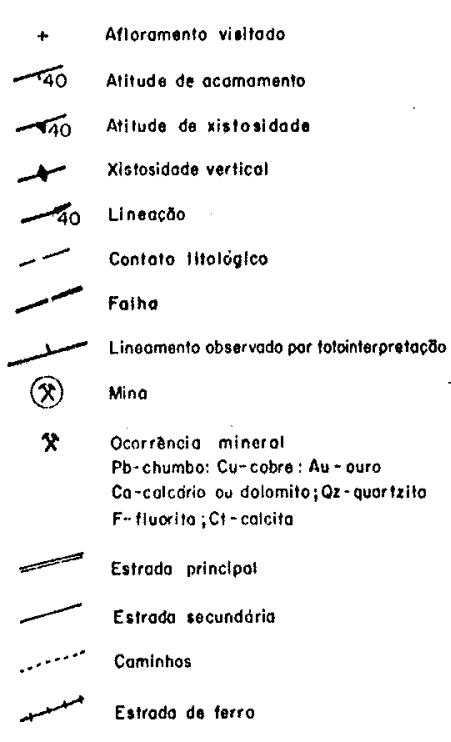

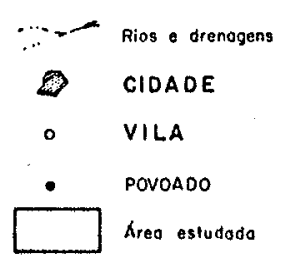

Areo estudada 
Tabe 1 a 1

Estratigrafia (Marini et a1, 1967)

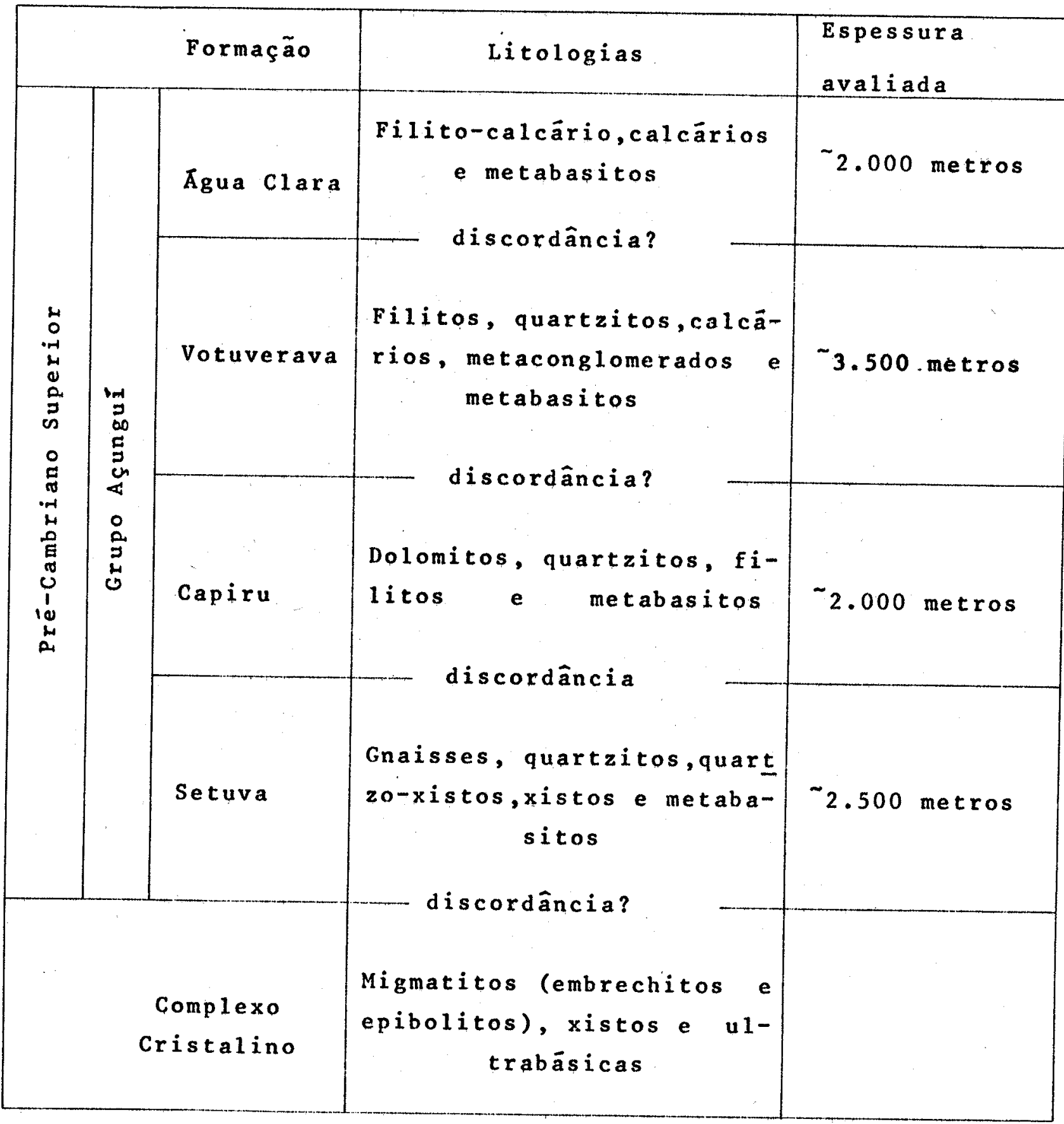

Na Fig. 2, ao norte, pode ser notado o complexo granítico Itaóca e um pequeno stock, eventualmente 1 i gado ao granito Varginha (Melcher et a1., 1971) que aflora, a este, nas proximidades de Epitácio Pessoa. o granito Itaó ca é postectónico e provocou metamorfismo de contato nos me tassedimentos encaixantes, com auréola estendendo-se por vá rios metros. 
Os diques de diabāsio (Melcher et a1.,1971), orientados para NW, quase sempre verticais, estão distribuidos por toda ārea. Uma ocorrência de rocha gābrica, a intrusão de Josë Fernandes, encaixada em filitos pode ser observa da a NE (Fig. 2).

os granitos intrusivos apresentam idade de $600 \mathrm{~m} . \mathrm{a}$. (Fuck et a1,, 1971). Cordani et al., (1971) conside ram uma fase tarditectónica com cerca de $61.0 \mathrm{~m}$.a., e a fase pós-tectónica principal com cerca de $540 \mathrm{~m} \cdot \mathrm{a}$.

Os quartzitos e xistos são mais resistentes aos processos morfoclimáticos es quartzitos se ressaltam na topografia formando as cristas mais elevadas. A drenagem é adaptada às fraturas como também controlada pela atitude das camadas. 


\section{ASPECTOS GEOLÓGICOS LOCAIS}

A região mapeada pelo autor, dentro da fo Tha de Apiai (Melcher et al., 1971) (Fig. 1) abrange. uma ärea de $3,1 \mathrm{~km}^{2}$ (Fig. 3), estando inteiramente localizada no município de Adrianópolis, Estado do Parana.

os trabalios de campo foram realizados en tre 1967-1972. A escassez de estradas era quase total de maneira que o levantamento geológico foi executado exclusivamente a pé. Como base de foto-interpretação foram uti 1izados aerofotos de Serviços Aerofotogramétricos Cruzeiro do Sul S.A., de Curitiba, dos voos de 1952 em escala $1: 25.000$ e de 1954 em escala 1:70.000.Para o mapeamento de detalhe (Fig. 3) foi traçada inicialmente uma linha base (LB 1) de $3 \mathrm{~km}$ de comprimento, aproximadamente paralela ao norte magnētico. Perpendicularmente à linha base foram tra çadas linhas transversais de 80 em 80 retros sendo tomada como ponto de partida a linha este-oeste que passa sobre a boca das galerias, denominada Tro (transversal zero), seguin do ao norte: TR80N, TR160N... ate TR880N, e ao sul: TR80S, TRl60S... ate TR1260S. Para poder-se acompanhar a minerali zação fizeram-se necessārias mais duas 1 inhas bases ( $L B$ e LB 3) com suas respectivas linhas transversais (Fig. 3). So bre as Iinhas citadas foram executados levantamentos geofí sicos, geoquímicos, como também foram abertas trincheiras, poços, furos de sondagens e confeccionados perfís (Figs. 4 e 5).

\section{Litologia}

As rochas da ārea da jazida são constituí das em termos gerais por xistos, quartzitos, rochas carbona ticas, anfibolio-xistos e raros veios de quartzo.

A - Os xistos abrangem a maior parte das rochas aflorantes, a oeste, na Fig. 3 , e pode-se observar, de modo geral, no cam po, uma transição gradual de filitos para micaxistos, de oeste para leste (Nelfi et al., 1965) na sequéncia: xistos 
FIG. 4 - PERFIL CO

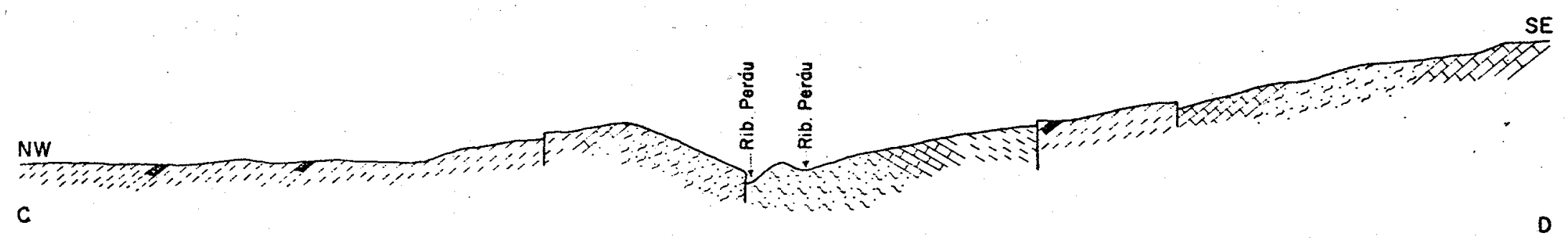

Xistos, filitos Anfibolio-xistos, anfibolitos

$E_{h}=E_{v}=80 \quad 0 \quad-80 \quad 160 \quad 280 \mathrm{~m}$ 


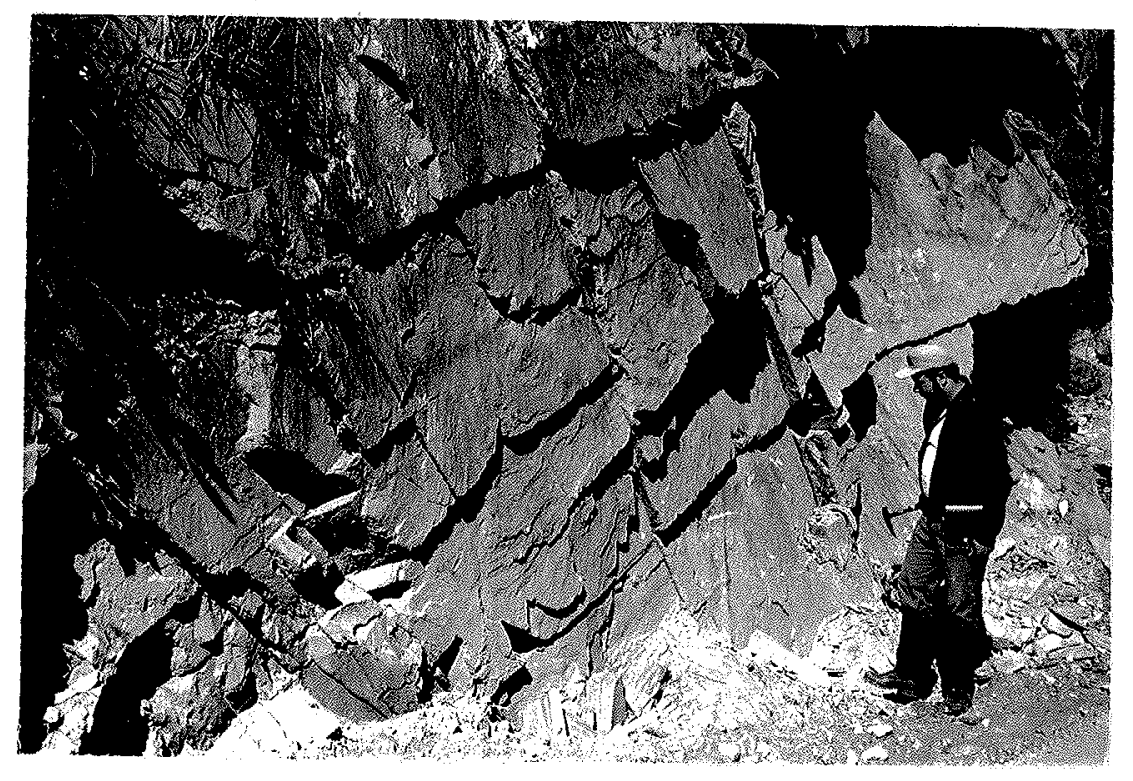

Foto 1 - Afloramento de xisto cinzento( 20 m de largura $x 8 \mathrm{~m}$ de altura) na TR $160 \mathrm{~N}$. A estrada corta perpen dicularmente a direção da camada. Atitude: $N 50 \mathrm{E}, 82^{\circ} \mathrm{NW}$. As diaclases a $N 45^{\circ} \mathrm{E}, 25^{\circ} \mathrm{SE}$ e $\mathrm{N} 40^{\circ} \mathrm{W}$, mergulho vertical, permitem o destacamento de blocos romboédricos.

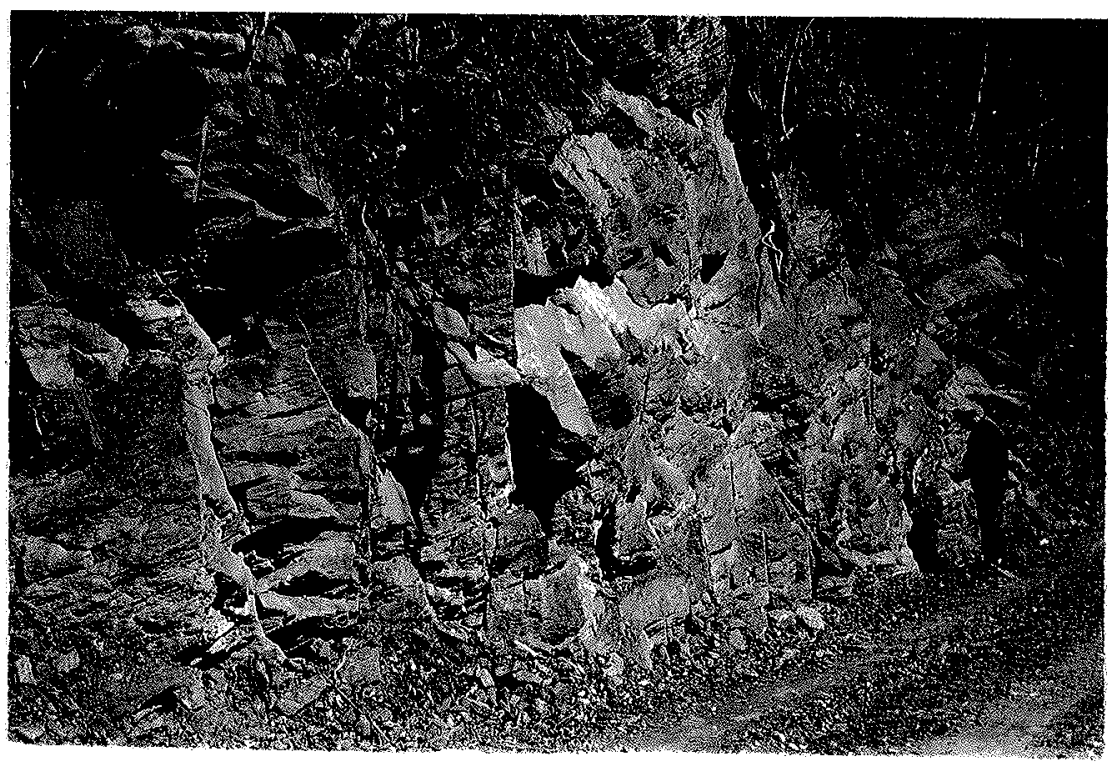

Foto 2 - Afloramento de $x i s t o$ compacto cinza, em corte recente de estrada, a $50 \mathrm{~m}$ ao Norte da TRO. (50 m de comprimento $x 5 \mathrm{~m}$ de altura).0 xisto $\bar{e}$ concordante com uma camada de rocha calcio-si licatada verde, de decímetros de espessura. 


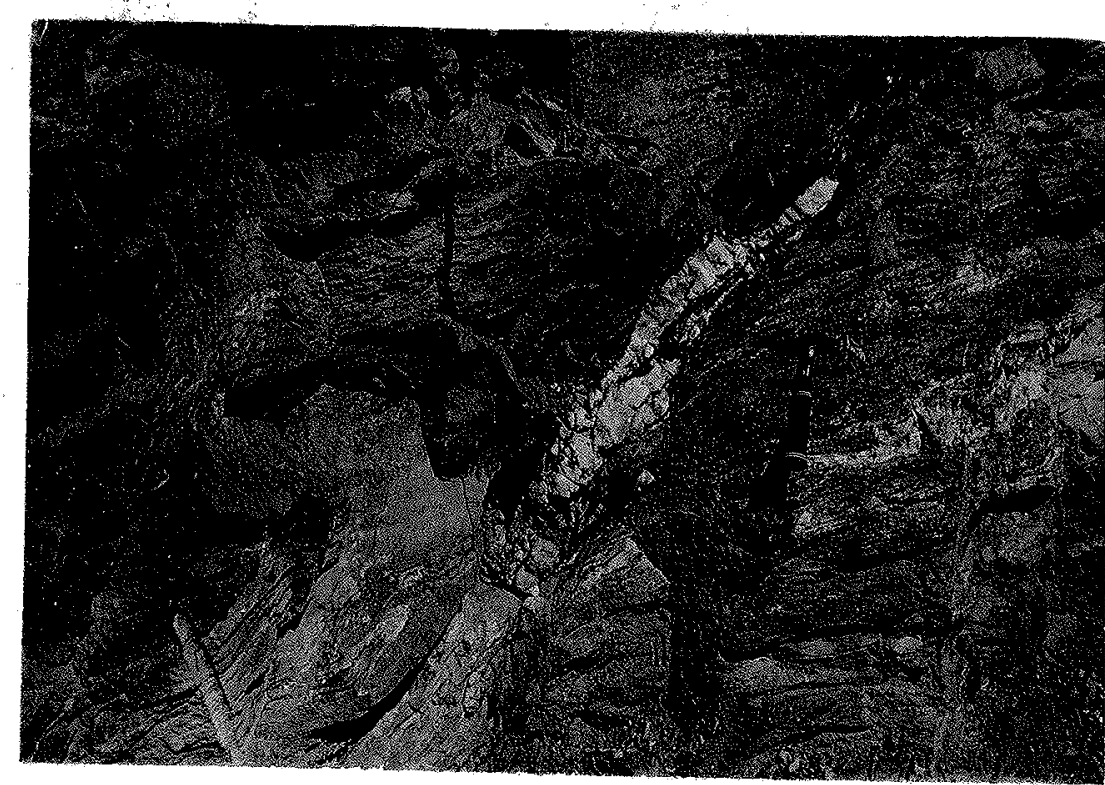

\begin{abstract}
Foto 3 - Detalhe do mesmo afloramento da foto anterior.Xisto compacto cin $z a$, intercalado por rocha calciosilicatada verde atravessada por veio de quartzo branco de $2 \mathrm{~m}$ de comprimento $\times 20 \mathrm{~cm}$ de largura.0 quartzo penetrou fratura préexistente associando-se a uma mi ca esverdeada.
\end{abstract}

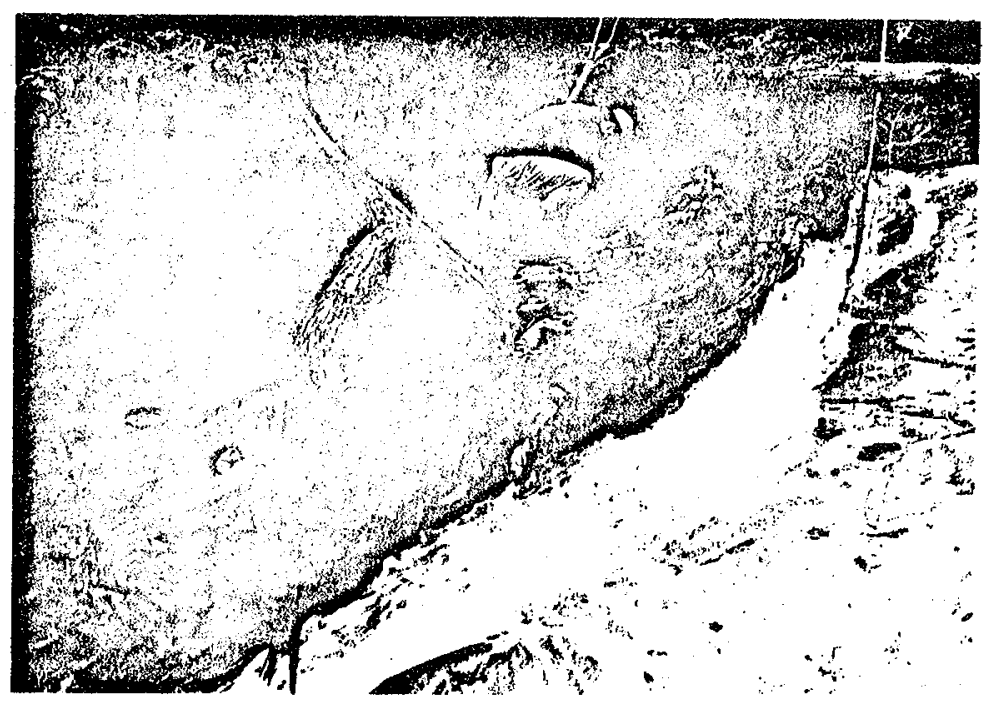

Foto 4 - Ribeirão dos Farias(Fig.2) encai xado no contato concordante de xisto com quartzito, nas proximi dades da confluência dos Ribeirões Caçador e Farias. Atitude: $\mathrm{N} 70 \mathrm{E}, 13^{\circ} \mathrm{NW}$. 
verdes, anfibolioxistos, granada xistos, estaurolita xisto. A coloração dessas rochas varia desde o verde ao cinza escu ro, às vezes, manchadas de vermelho ou amarelo nas zonas in temperizadas. As camadas são homogêneas, apresentando mais de $100 \mathrm{~m}$ de espessura com estratificação visivel pela alter nância de leitos de diversas comosicões. A xistosidade é sempre nítida e naralela, na maioria dos casos, à estratifi cação. A direção geral é $N E$ com mergulhos de $20^{\circ}$ a $60^{\circ} \mathrm{NW}$. B - Os quartzitos constituem camadas homogêneas, con estra tificação reconbecível, apresentando coloraça branca quan do compactos e amarela quando friáveis. São concordantes com os xistos a a estes se sotopõem, aflorando na parte es te da jazida, onde a espessura ultrapassa 100 metros.

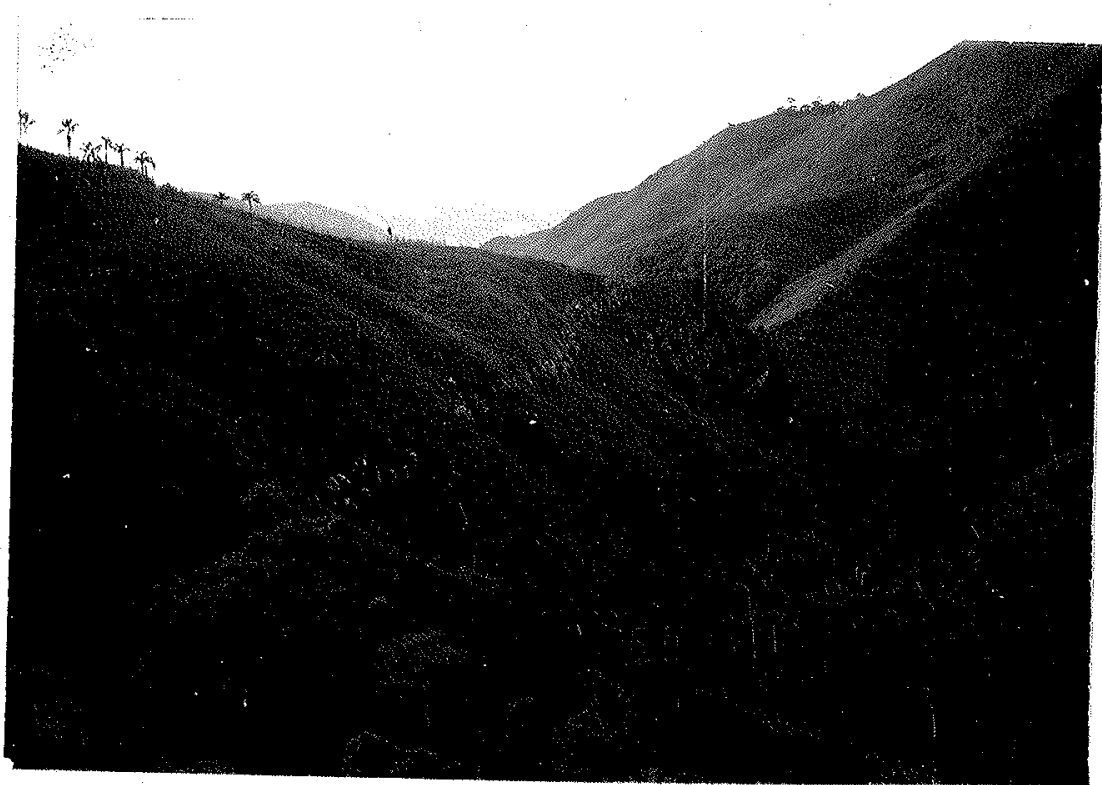

Foto 5 - Vista geral da parte Norte da Fig. 3. Note-se o forte escar pamento das encostas e a sran de profundidade do vale do Ri beirão do perau. A parte mais clara mostra o tono da canada de quartzito, mergulhando $30^{\circ}$ nara ocste.

Os quartaitos apresentam, localmente, peque nas lentes ricas en marnetita que dão à rocha um aspecto cin 
za escuro ou preto (Fig. 3 - TR $160 \mathrm{~N}$ ).

C - As rochas carbonāticas se comportam como uma lente in tercalada entre xisto e quartzito, a partir de TR $480 \mathrm{~S}$ (Fig. 3) alargando-se para a extremidade sul do mapa com espessu ra de até $60 \mathrm{~m}$. Falhamentos provocaram descontinuidades nas TR 1040S, TR 31 e TR 33 .

$$
\text { Os perfis esquemáticos (Fig. 5) e foto } 6 \text {, }
$$
localizados nas transversais: TR 35S, TR720S e TR1040S mostram que essas rochas não são contínuas e homogêneas mas apresentam intercalações ritmicas com quartzito. Veios de quartzo são frequentes e na maioria dos casos, concordantes. com a estratificação. A mineralogia das rochas calcárias é muito variāvel, desde camadas de calcita para até termos ri cos em silicatos.

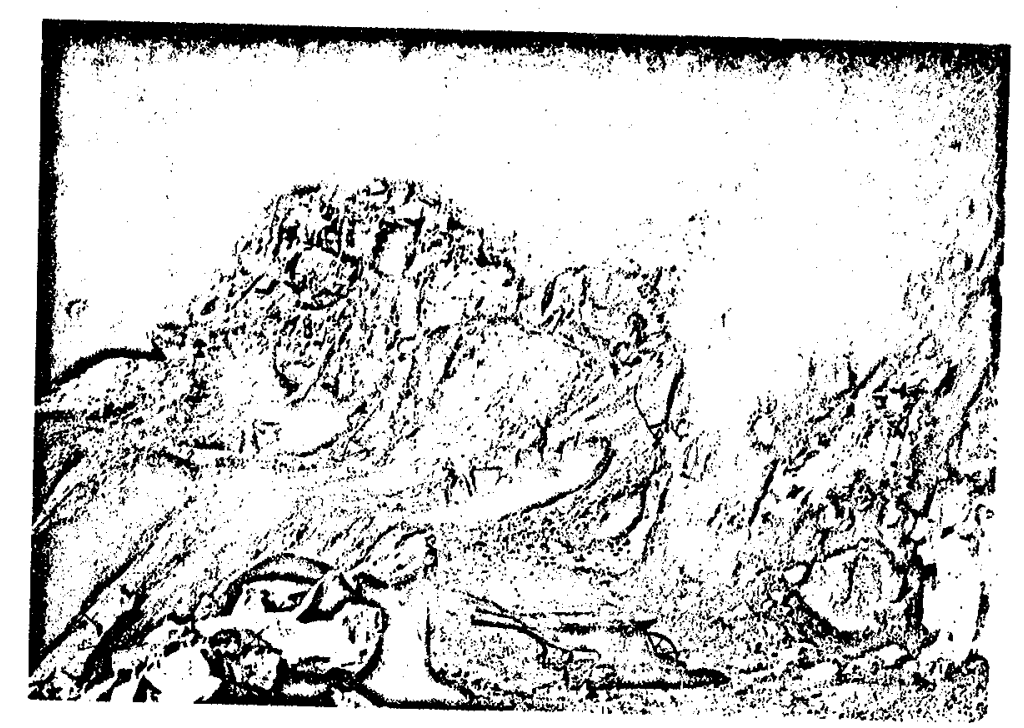

$\begin{aligned} \text { Foto } 6 \text { - } & \text { Afloramento de quartzito com } \\ & \text { intercalações rítmicas de ro } \\ & \text { chas carbonáticas (Trincheira } \\ & \text { do Faria, TR } 1200 \mathrm{~S}, \mathrm{Fig}, 3) \text {, Ati } \\ & \text { tude: N35 E, } 30^{\circ} \mathrm{NN} .\end{aligned}$



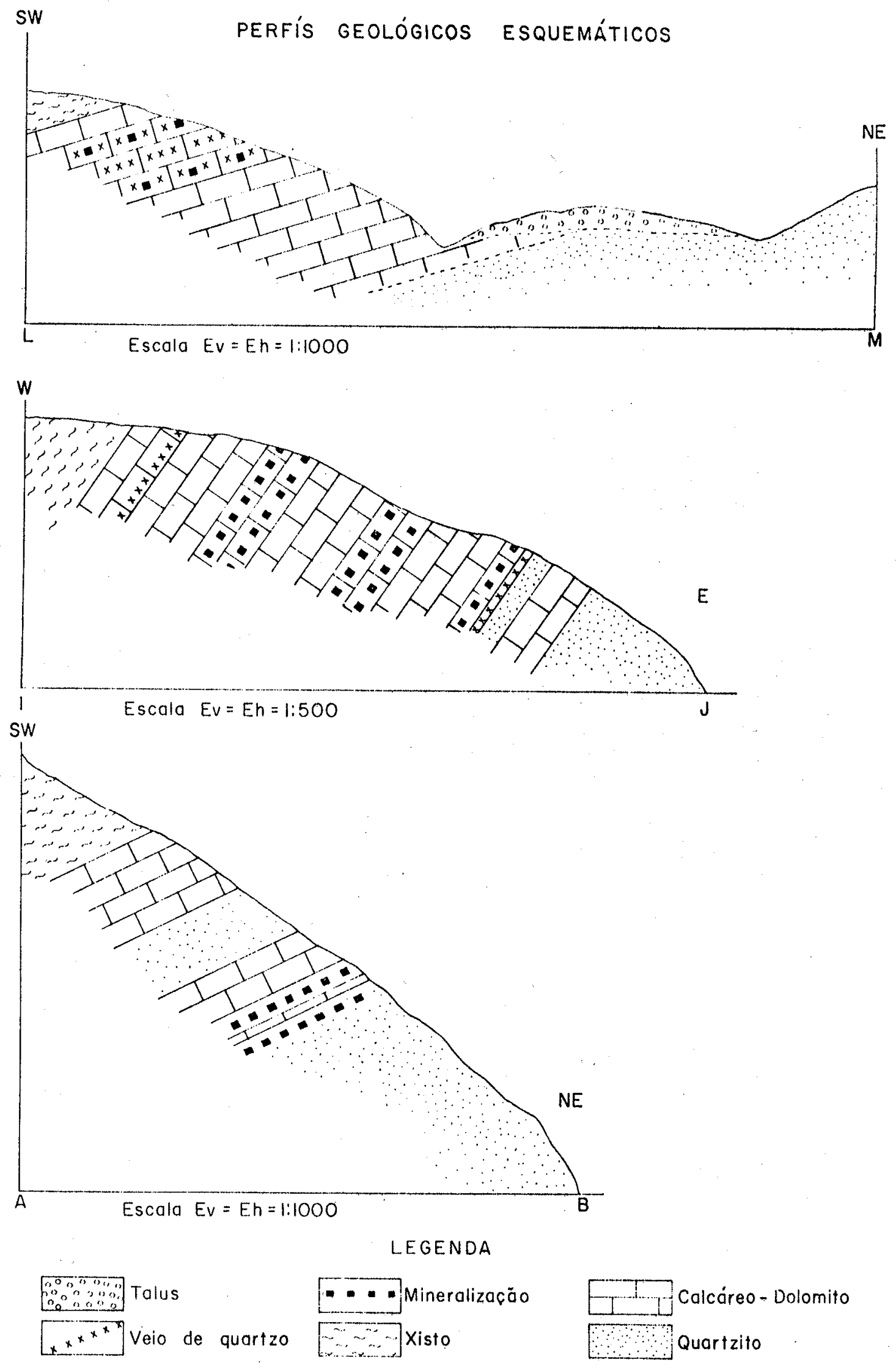
A Tabela 2 fornece anälises de duas amos tras de rochas calcärias desse afloramento TR1200s (Foto 6) e de acordo com o gräfico de Martinet e Sougy, em Cassedan ne $(1970)$, Fig. 6 correspondem aos termos dolomitos calca rios silicosos e calcärios.

Tabela 2

Anālise de Rochas Calcārias

$\begin{array}{rrr}\text { Perda ao Fogo }-28,44 & 41,55 \\ \text { CaO }-22,32 & 50,92 \\ \text { Hgo }-8,06 & 1,11 \\ \text { Sio }-41,10 & 6,21 \\ \text { Cobre }-0,08 & 0,21\end{array}$

REPRESENTAÇÃO GRÁFICA DE ROCHAS CARBONÁTICAS

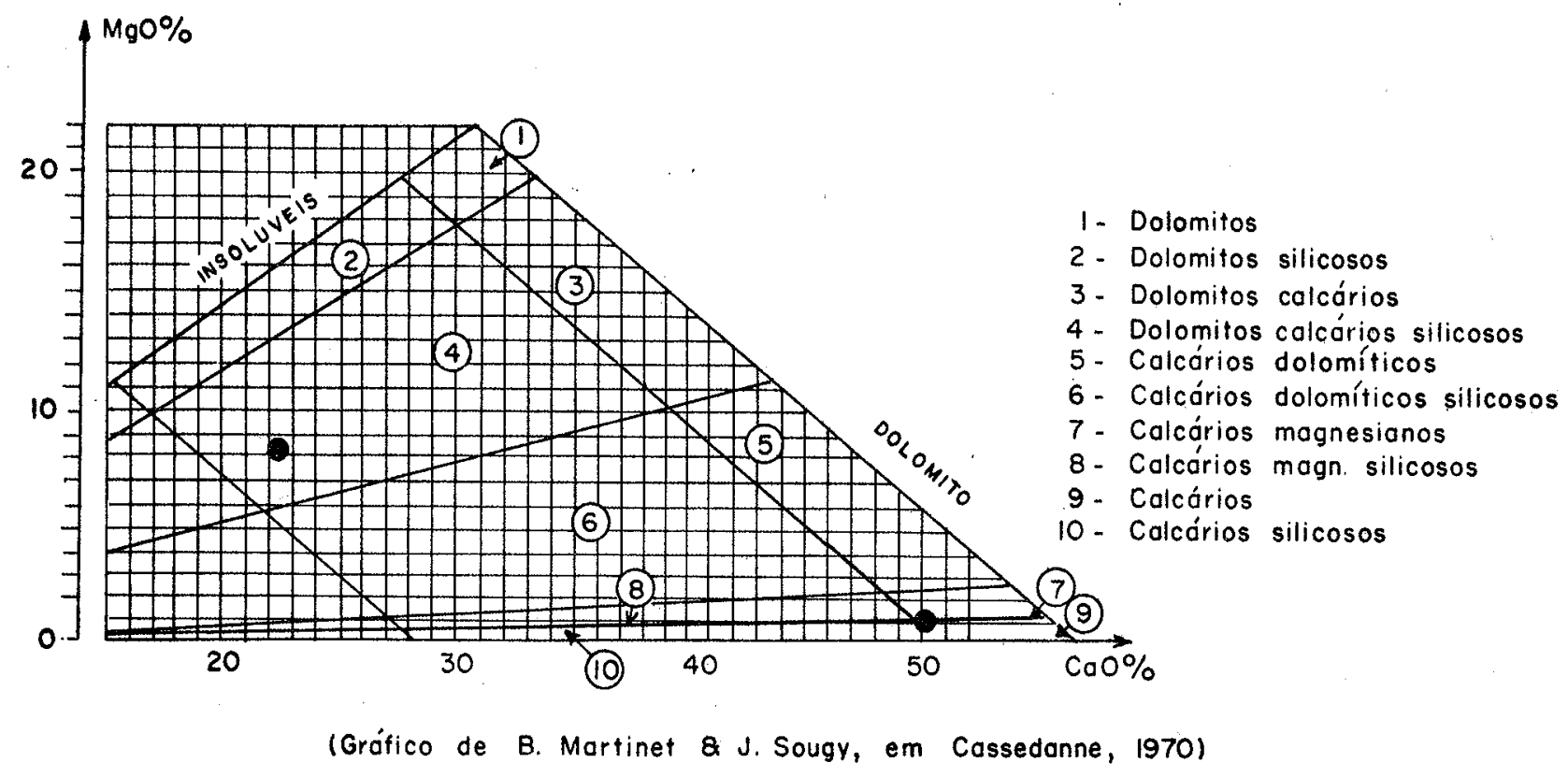

Fig. 6 
De acordo com Marini (1967), a primeira amos tra seria uma rocha calcária impura do termo dolomito calcí tico impuro $(\mathrm{MgO} / \mathrm{CaO}=0,36)$ e a segunda amostra seria uma ro cha calcāria semi-pura do termo calcārio magnesiano semi-puro ( $\mathrm{MgO} / \mathrm{CaO}=0,021)$.

D - Os anfibolio-xistos e anfibolitos (Fig. 3) exibem cores cinza escura, preta e esverdeada, em jazimentos lenticulares, encaixados nos xistos, com espessura máxima de até vinte me tros, em contatos geológicos não nítidos. Provavelmente cor respondem a"sil1s" ou derrames de composição basāltica, anteriores ao metamorfismo regional (Melcher, 1968).

E - Os veios de quartzo cortam diagonalmente o acamento dos xistos e, subordinadamente concordam com a estratificação dos quartzitos e das rochas carbonáticas. O quartzo apresenta coloração branca (Foto 3), com hābito maciço, não exibindo idiomorfismo e as associações mineralógicas mais comuns são com clorita, barita, hematita e turmalina preta. os mine rais associados exibem formas prōprias sendo que a turmalina também ocorre em forma milonitica, cimentando fraturas de quartzo.

\section{Estratigrafia}

A jazida (Fig. 3) apresenta afloramentos de quartzito na base, a seguir intercalados com rochas carbona ticas, sotopostas aos xistos, cujos termos são especificados na Tabela 3. A ārea mapeada (Fig. 3) faz parte da Formação Setuva (Marini, 1967) unidade inferior ao Crupo Açunguí sen do essa formação composta de gnaisses, xistos e quartzitos. Ebert (1971), propõe que o termo setuva seja reservado aos xistos e quartzitos, enquanto que os gnaisses podem ser, pre liminarmente denominados prē-Setuva.

As relações de contato entre a Formação Setú va e o Complexo Cristalino são obscuras supondo alguns autó res a existência de uma discordância separando esses dois conjuntos de rochas. Os contatos se fazem geralmente por fa 1has e o mapeamento executado não encontrou esses contatos. 0 contato superior da Formação setuva nem sempre possui di.s 
cordância nítida e não foi encontrada na ärea em estudo.

Os gnaisses não foram encontrados na ärea da jazida (Fig. 3), os filitos e xistos, muitas vezes com passa gem gradual ocupam a maior parte da ärea mapeada. Os termos carbonáticos se estendem para o sul. Os sedimentos quartzí ticos, com espessuras superiores a $100 \mathrm{~m}$ formam camadas homo gêneas. As ocorrências anfibolíticas, sempre associadas a xistos e filitos, apresentam forma tabular coincidente com a orientação geral das rochas encaixantes e podem corresponder a antigas intrusões bāsicas (Melcher, et a1., 1971).

Tabe'la 3

Estratigrafia

XIS TO

$$
\begin{aligned}
& \text { - xisto fraturado cinza claro. } \\
& \text { - lentes de magnetita quartzi } \\
& \text { to } \\
& \text { - anfibolio xisto } \\
& \text { - } \quad \text { isto compacto cinza escuro } \mathrm{s}^{\tilde{\mu}}
\end{aligned}
$$

ROCHAS CARBONATICAS

E QUARTZITOS
- rochas carbonāticas intercala das com quartzito, pelo menos em 8 camadas alternadas;veios de quartzo
- rochas carbonáticas com mala quita, crisocola, cuprita
- quartzito compacto com pirita e calco-pirita; com veios de quartzo
- quartzito fraturado
- magnetita quartzito
- quartzito compacto




\section{Estruturas}

A feição estrutural mais característica da jazida é dada por uma dobra assimétrica aberta (Fig. 4) com eixo do anticlinal na direção NE, com caimento $25^{\circ}$ SE.Värias falhas de gravidadc, verticais (Fig. 3), aproximadamente pa ralelas aos planos da dobra, podem ser verificadas no campo, assim como falhas transcorrentes, oblíquas aos mesmos planos. Diaclases verticais e horizontais são frequentes nos quartzi tos, predominando as diaclases oblíquas, nos xistos.

Rochas encaixantes e portadoras de minério

o estudo da mineralização levando em conta a estrutura, forma de jazimento e paragênese permitiu dividir a jazida em dois compartimentos denominados: ärea das gale rias e área do faria.

A - área das galerias

E limitada pela TRO (transversal zero) (Fig. 3) até a TR 480s. Sob a área compreendida pelas TRO e TR8OS estão localizadas galerias, onde o minērio ocorrem em forma de filões (Fotos 7 e 8) irregulares. Aí intenso falhamento (Foto 9) milonitizou preferencialmente os quartzitos encai xantes. Os vieiros oxidados atingem até 0,5 m de largura,po rëm são extensos em comnrimento, sendo observados por mais de uma centena de metros em extensão. A atitude geral é con cordante com a estratificação dos quartzitos, ressalvadas as discordâncias assumidas devido a pequenas dobras e falhas. A pesquisa em galerias revelou pelo menos quatro niveis de vieiros oxidados onde a mineralogia é constituída pela se guinte sequência quantitativa decrescente: cuprita, malaqui ta, crisocola, quartzo, sendo raros os cristais remanescentes de calcopirita.

As encaixantes desse minério oxidado são quartzitos friāveis, milonitizados, sendo normais as interca lações com tremolita quartzito (Foto 7). Há sempre contato 

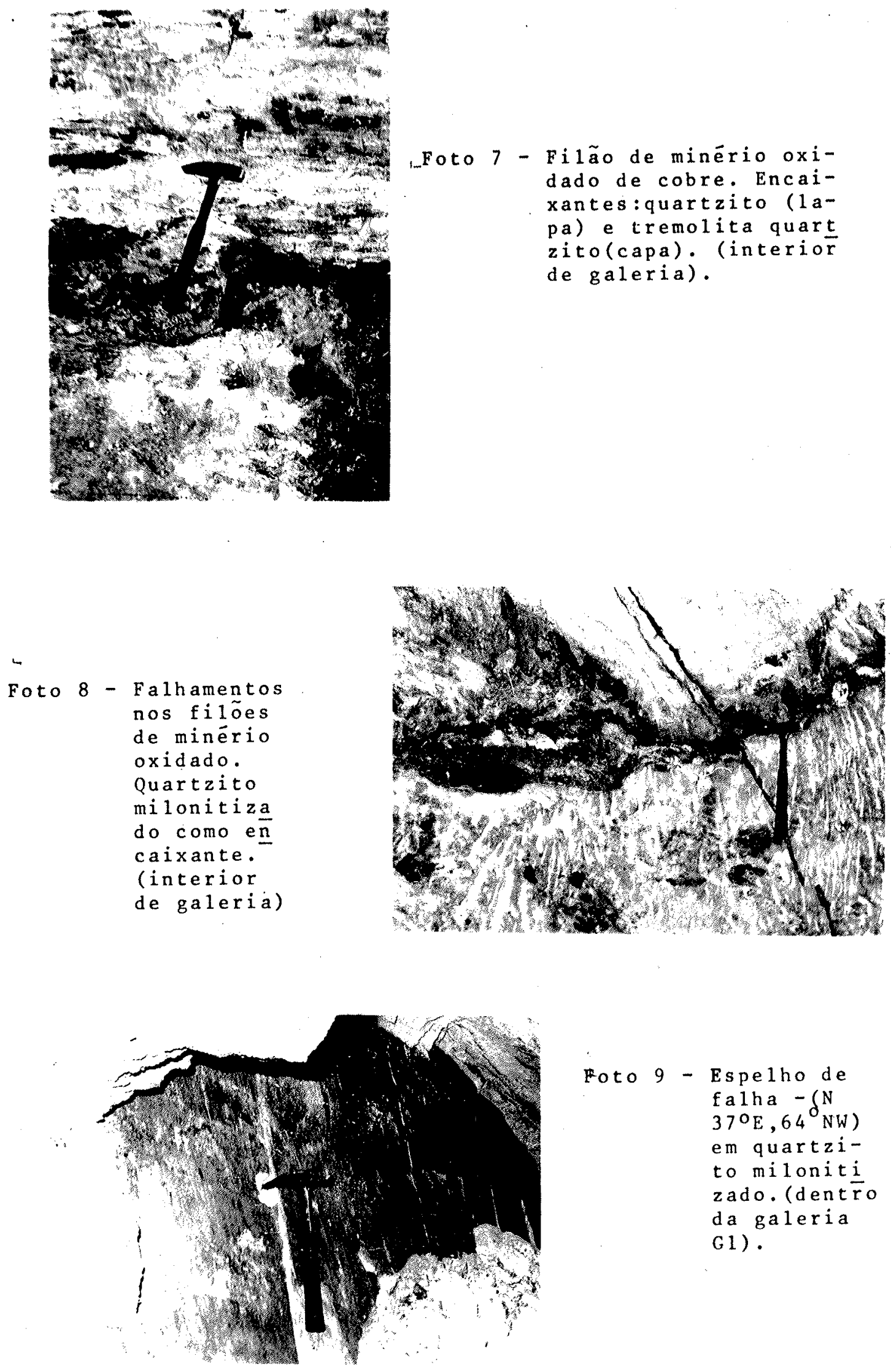
FIG. 7 PERFIS ENTRE FUROS DE SONDAGENS
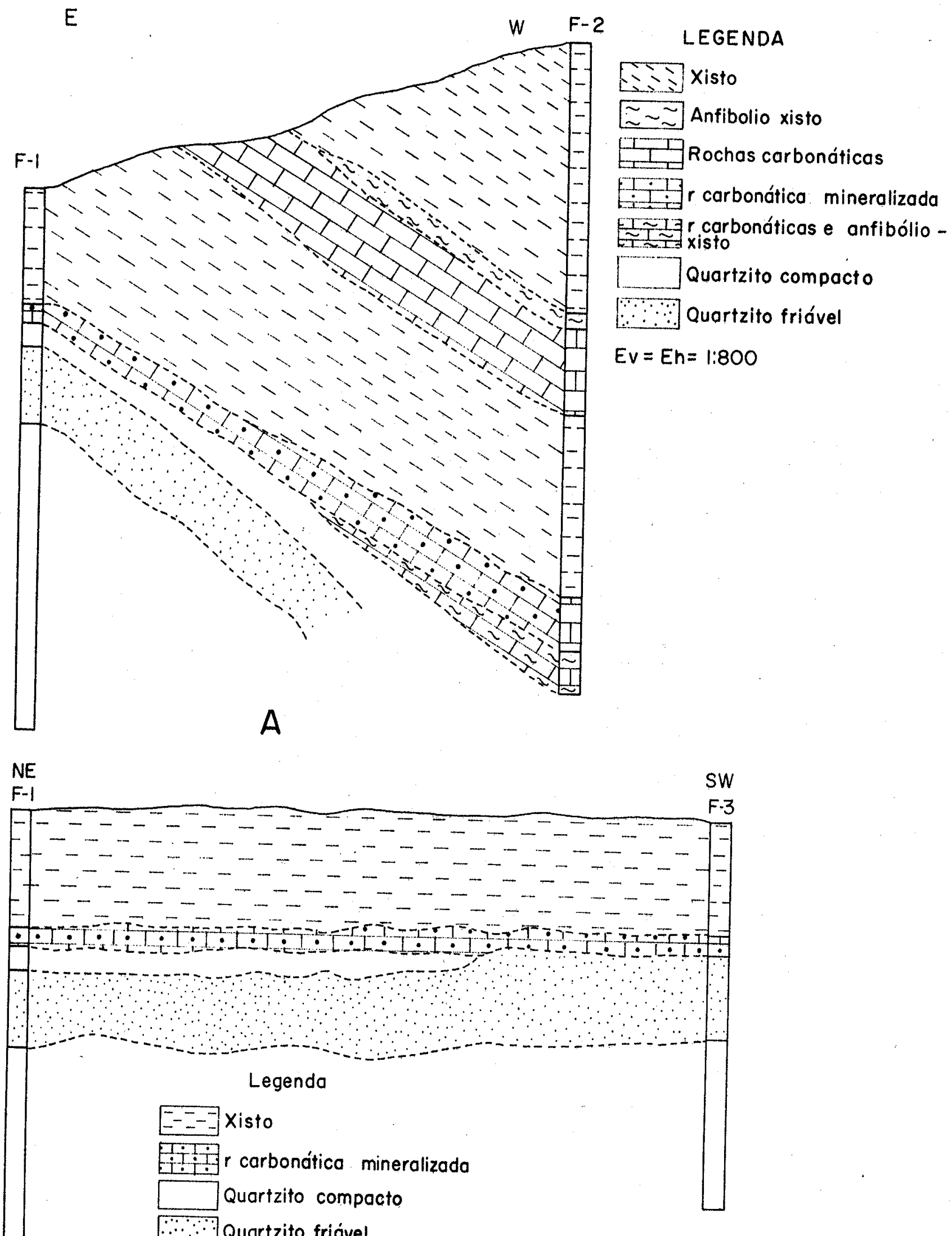

$E_{v}=E_{h}=1: 800$ 
brusco entre encaixantes e filóes de minerais de cobre (Fo tos 7 e 8). As anālises químicas mostram teores de 5 a $20 \%$ de cobre(tabela 28 , anāilise 6) nos vieiros e, $0,4 \%$ de cobre no volume total das galerias (Tabela 28 , anālise 7).

As sondagens sobre as galerias revelam uma "camada" de rochas carbonáticas com 4 m de espessura média por uma centena de metros de largura e comprimento, interca lada entre quartzito compacto (inferior) e xisto (superior), estendendo-se pelo menos entre as TRO e TR160s, abrangendo os furos F1 a F5. Essa camada não aflora e provavelmente deverā ter forma de uma lente de faces subparalelas. A Fig. (7-A) mostra o perfil entre FI e F2, com atitudes reais. A Fig. (7-B) mostra em perfil F1 e F3, um corte aproximada mente paralelo à direção geral das camadas. A mineraliza ção dessa lente é fornecida pela malaquita, associada a cal cita e dolomita, sendo ausentes os sulfetos. Anālises quí micas mostram teor médio de cobre de $1,5 \%$ (Tabela 28 , análi ses 1 a 5 ). O quartzito sotoposto não mostra mineralização. B - ärea do Faria

E limitada pela TR $480 \mathrm{~S}$ até a TR38S, no ex tremo sul da ārea de pesquisa. Á́ afloram intercalações rít micas (Foto 6) de rochas carbonäticas com quartzito, (Fig.3). Nesse pacote metassedimentar, as rochas carbonaticas apre sentam espessura de até $3 \mathrm{~m}$ em cada camada, somando o con
junto, espessura de 50 metros.

A característica principal da ärea do Faria não é a presença de rochas carbonāticas, pois estas podem ser as mesmas que mostram os testemunhos de sondagem, sob a ärea das galerias, mas sim, a mineralização que ocorre nos quartzitos sotopostos. Pirita e calcopirita são os princi pais minerais de minério, ocorrendo disseminados, isoladamente na matriz da rocha, por vezes formando cristais alinha dos segundo o acamamento dos quartzitos e instalando-se en tre as suturas dos grãos de quartzo. Concentraçós plana res de calcopirita são encontradas prenchendo fraturas nos 
quartzitos. Na região da TR 35S, a tennantita ocorre também preenchendo fraturas desses quartzitos, jä parcialmente oxi dada, produzindo azurita, malaquita e crisocola.

Nos contatos das intercalações quartzíticas com rochascalcio-silicatadas predominam os minerais oxidados: calcocita, covelita, bornita, cuprita, cobre nativo, criso cola, malaquita, goethita. Esses minerais, em forma de veios irregulares, instalam-se nas fraturas das rochas cita das, sendo que nas rochas carbonáticas hä predominância dé malaquita, em jazimentos tabulares concordantes ou discordan tes do acamanto dessas rochas.

Nas rochas carbonāticas da área do Faria a mineralização é do tipo oxidado, estando os minerais hipóge nos disseminados no quartzito compacto, sotoposto. Os veios de minerais oxidados exibem teores ao redor de $5 \%$ de cobre, (Tabela 28, anālises 8 e 9) sendo que o quartzito rico de pirita apresenta teores de cobre inferiores a $0,2 \%$ (Tabela 28 , anāise 10).

\section{Levantamento Geofísico}

Pela primeira vez no Brasil foi empregado o método de potencial expontâneo para pesquisa de cobre, Davino (1969). Para tanto foi utilizada a linha base (LB1) (Fig. 3) de $3 \mathrm{~km}$ de comprimento, aproximadamente paralela tanto ao Norte magnético como à direção do contato xisto-quartzito. Perpendicularmente à linha base foram feitas leituras nas transversais de 40 em 40 metros para este e para oeste. Como ponto de partida foi tomada a transversal zero (TRO), que passa sobre a boca das galerias de pesquisa (Fig. 3). os re sultados (Davino, 1969) nostraram duas anomalias principais: de - $400 \mathrm{mV}$ sobre a TR $80 \mathrm{~s}, 300 \mathrm{~m}$ ao sul e de - $250 \mathrm{mV}$ sobre a TR 560s, $240 \mathrm{~m}$ ao sul, situados em quartzito a centenas de metros do contato xisto-quartzito. As linhas de anomalias $e$ quipotenciais são alinhadas segundo a direção de xistosidade das rochas citadas. Davino (1969) chega a sugerir que as ano malias negativas podem não ser causadas por corpos de sulfe 
tos de cobre mas por eletrofiltração. A maior anomalia se causada por corpo de sulfetos, deve este ter seu topo a $100 \mathrm{~m}$ de profundidade. Esta dedução ainda não foi comprovada por sondagens.

Levantamento Geoquímico

A campanha geoquímica ana 1 isou 364 amostras de solo, coletadas em malha $80 \times 20 \mathrm{~m}$ sobre as transversais TR $80 \mathrm{~N}$, TRO, TR80S, TR160S, TR480S TR560s em profundidades de $0,80 \mathrm{~m}$. Para controle de variação de cobre em profundida de, a cada 100 metros, nas transversais, no sentido oeste ou este, a amostragem foi efetuada no mesmo ponto a 0,$2 ; 0,4$; 0,6 e $0,8 \mathrm{~m}$, sendo que no mesmo ponto os maiores valores fo ram encontrados a 0,6 e $0,8 \mathrm{~m}$ de profundidade. A dosagem química de cobre foi elaborada pelo método colorimétrico de biquinolina por comparação visual (precisão de $30 \%$ ). As ano malias mais interessantes e intensas foram notadas nos per $f$ is das TR480S entre 20 e 120 metros sul, de 50 a 1150 ppm e na TR560S, entre 20 e 140 metros sul, de 100 a 2250 ppm de cobre. Os resultados geoquímicos mostram concordância com os resultados geofísicos e as anomalias da TR560s foram comprovadas por abertura de trincheiras, ocorrendo minerais oxidados de cobre no contato xisto-quartzito. o levantamen to geoquímico mostrou que a pesquisa deve se orientar para a região de contato xisto-quartzito, onde a mineralização af 10 ra em vārios pontos esparsos. 
PETROGRAFIA

As rochas adjacentes à jazida de cobre do Ribeirão do Perau são metamorfitos pertencentes ao Grupo Açungui, cuja origem, segundo os autores (Maack, 1947;A1meida, 1964; Melfi et a1., 1965; Marini et a1.,1967), deriva de sedimentos depositados em ambientes de geossinclinal.

No Estado de São Paulo não existem ainda da dos precisos sobre a espessura do pacote metassedimentar, porém, no Estado do Paranā, Marini et al.,(1967) calculam valores superiores a $10.000 \mathrm{~m}$.

Na região, objeto do presente trabalho, as rochas do Grupo Açungui são representadas por filitos, xistos, quartzitos, calcärios, rochas cālcio-silicatadas e anfibolitos.

\section{Filitos}

os filitos são rochas relativamente comuns na área estudada. Frequentemente associam-se a outros metas sedimentos (calcários, quartzitos, xistos) sendo comum encontrar-se, em afloramentos de poucos metros de extensão, faixas pertencentes a essas diferentes rochas.

Macroscopicamente, possuem cores muito variadas, sendo mais comuns os tons creme e cinza, não sendo raros porém as cores esverdeadas, avermelhadas e arroxeadas, estas ültimas decorrentes da presença de óxido de ferro, proveniente da alteração dos minerais máficos por processos intempéricos. A foliação é sempre muito nítida(Foto 10) nes sas rochas, em algumas amostras é possível reconher-se estratificação que, no entanto, na maior parte das amostras, é paralela à xistosidade.

A sericita e o quartzo são usualmente os componentes essenciais. A sericita ocorre na forma de delga das palhetas incolores, enquanto que o quartzo alonga-se co mumente paralelamente $\bar{a}$ xistosidade. o quartzo ora entre- 


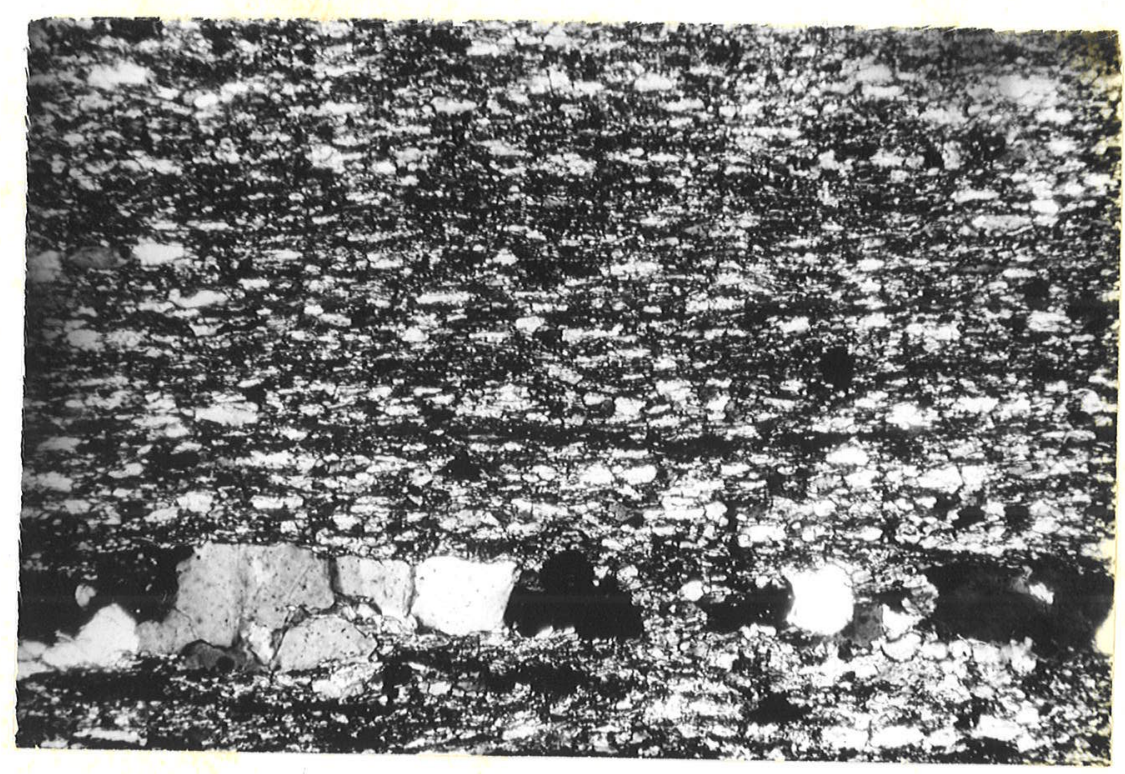

Foto 10 - Filito. Foliação muito nítida. Predominância de quartzo e seri cita. Subordinadamente clorita e biotita. Nicois cruzados. Aumento 210 vezes.

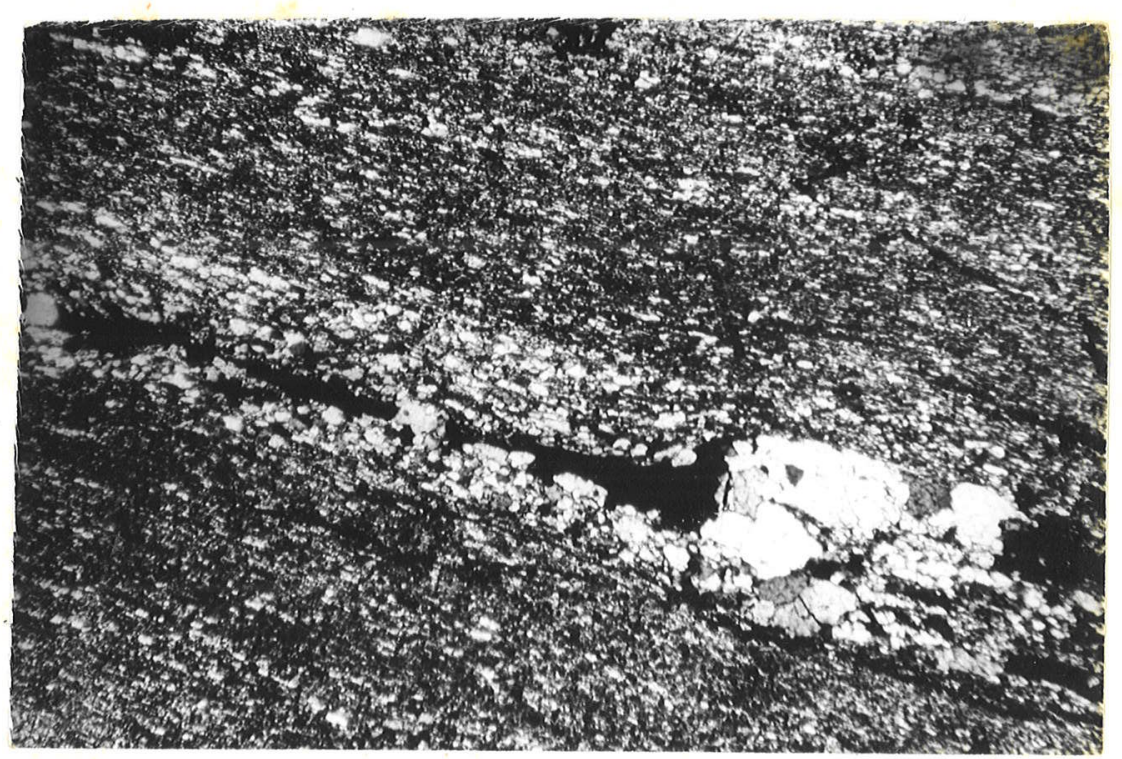

Foto 11 - Filito. Minerais acessórios: apatita,zircão,turmalina e grafita. Estä ora concentrada em faixas, ora sob forma dis seminada de fina "poeira" man chando zonas da amostra. Nícois cruzados. Aumento 80 vezes . 
meia-se aos cristais de sericita, ora forma delgadas faixas subordinadas às micáceas. Sericita constitui o mineral larga mente predominante. Clorita e biotita ( $z=$ verde ou marrom, $\mathrm{X}$ = amarelo claro ou incolor) são micas menos frequentes que a sericita. Em algumas amostras notaram-se microporfiroblastos de biotita $(z=$ vermelho, $x=$ amarelo), cujas dimensões alcançam $0,3-0,5 \mathrm{~mm}$, disseminadas nas rochas, e por vezes não concordando com a direção de xistosidade. Apatita, zircão, turmalina e opacos foram os acessórios observados. os opacos aparecem disseminados na rocha com tamanho semelhante aos demais minerais $(0,05$ a $0,10 \mathrm{~mm})$ usualmente, e também sob forma de fina "poeira" colorindo determinadas zonas das amostras (Foto 11).

A textura predominante nessas rochas ē a $1 e^{-}$ pidoblástica, embora as faixas quartzosas exibam textura gra noblástica. As texturas porfiroblästicas são raras, exemplificadas pelo caso supracitado, referente aos microfenocristais de biotita.

\section{Xistos}

Os xistos são macroscopicamente cinzentos ou avermelhados. A foliação é sempre muito nítida, não sendo ra ra a presença de pequenas dobras em vários afloramentos. Em algumas amostras é possível determinar-se a direção da antiga estratificação, que na maioria das vezes é coincidente com a direção de xistosidade.

\section{Mineralogicamente observa-se que dentre as} micas, ora predomina muscovita, ora biotita. Tais minerais ao lado do quartzo são usualmente os predominantes. o quartzo, ora está disseminado entre as micas ora constitui delgadas faixas onde è largamente predominante. Foram observadas biotitas verde e marrom, estas ültimas exibindo por vezes tons avermelhados. Tais minerais fazem parte da massa, mas também aparecem sob forma de porfiroblastos, ocorrendo, usualmente, neste caso, a variedade marrom-avermelhada. Estes porfiroblas tos, por vezes não acompanham a direção de xistosidade, evi denciando-se, nesses casos, fortes ângulos entre seu alonga- 


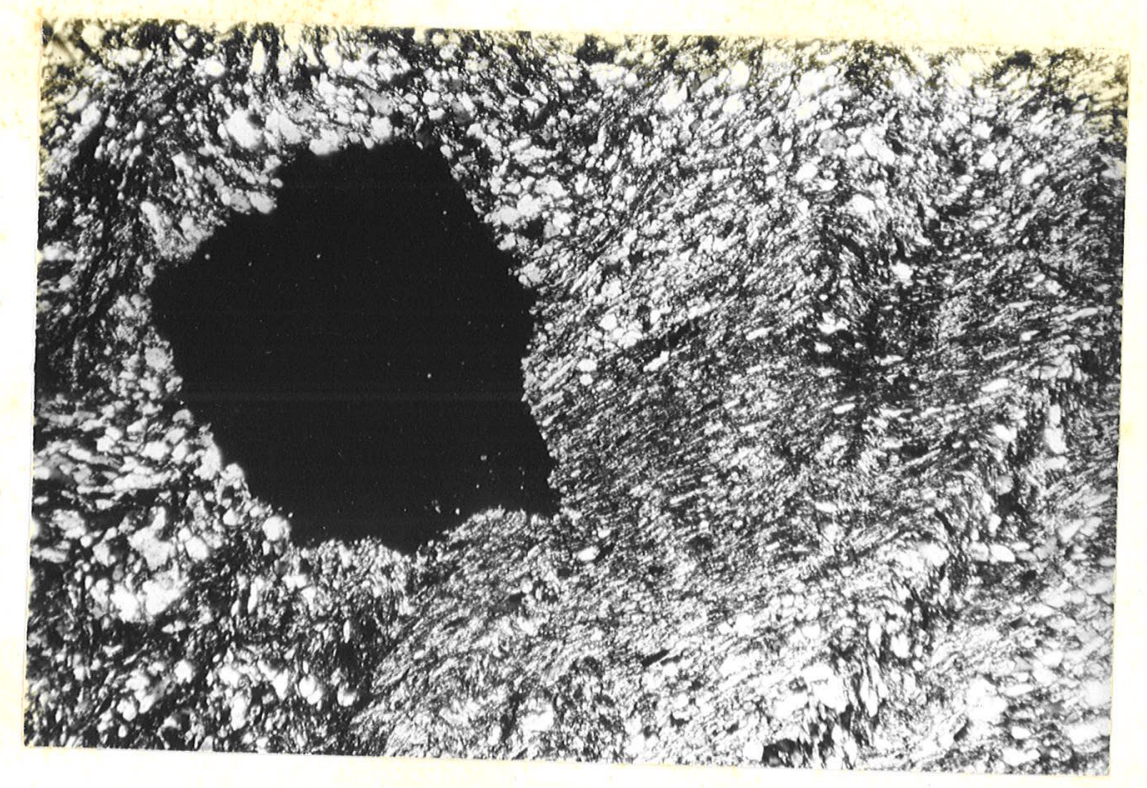

Foto 12 - Xisto. Porfiroblasto de grana da mostrando ter empurrado os leitos micáceos durante seu crescimento. Nícois cruzados. Aumento 80 vezes.

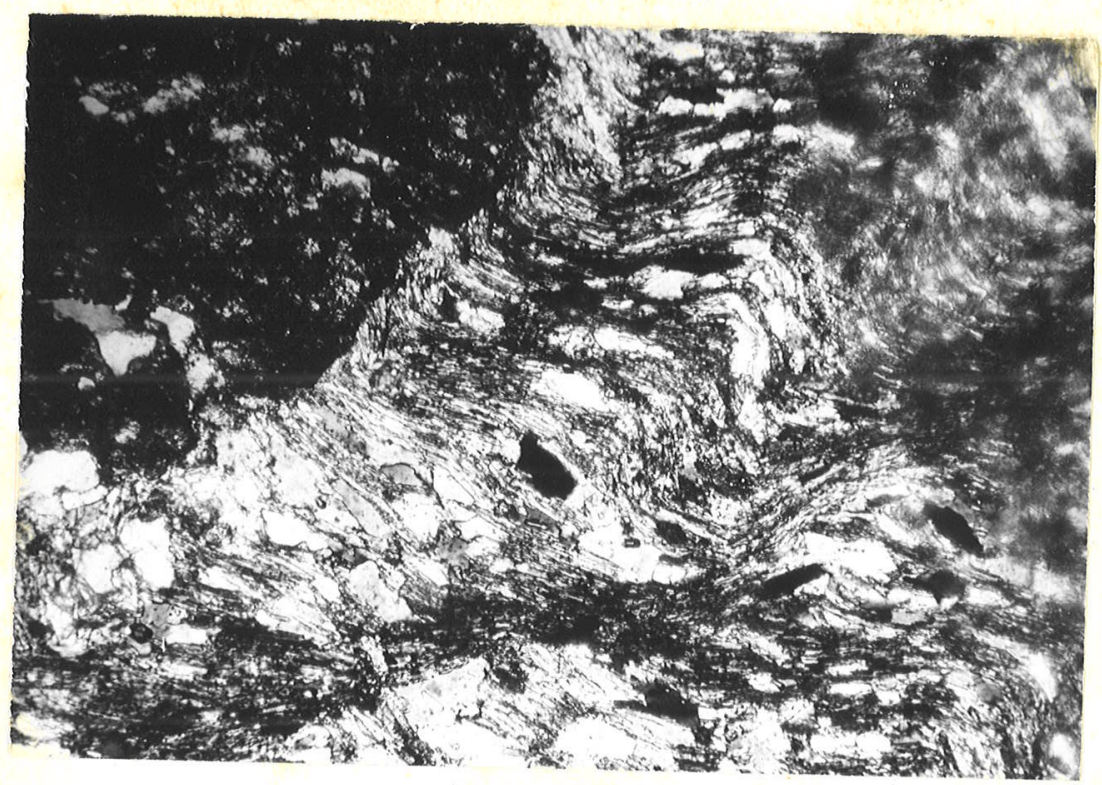

Foto 13 - Xisto. Porfiroblasto de grana da incluindo quartzo e minerais opacos. Nícois cruzados. Aumento 210 vezes. 


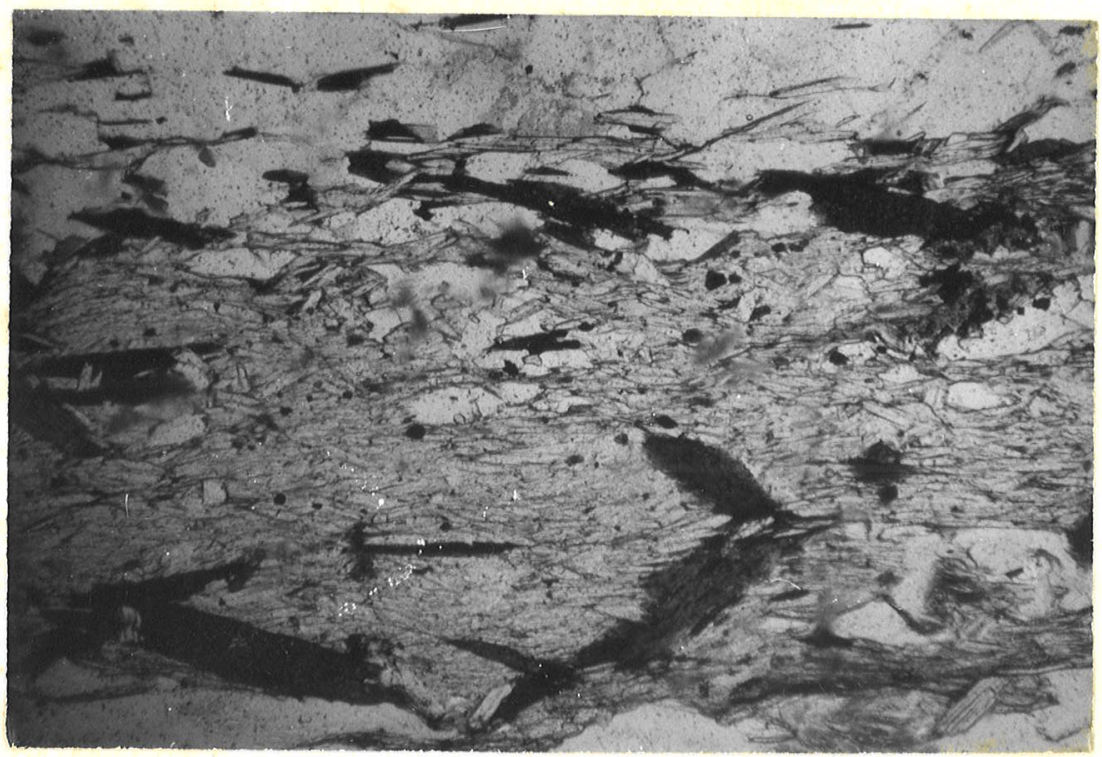

Foto 14 - Xisto. Porfiroblastos de estau rolita tendo quartzo como mine ral hospedeiro. Textura poiqui loblästica. Nícois cruzados. Au mento 210 vezes.

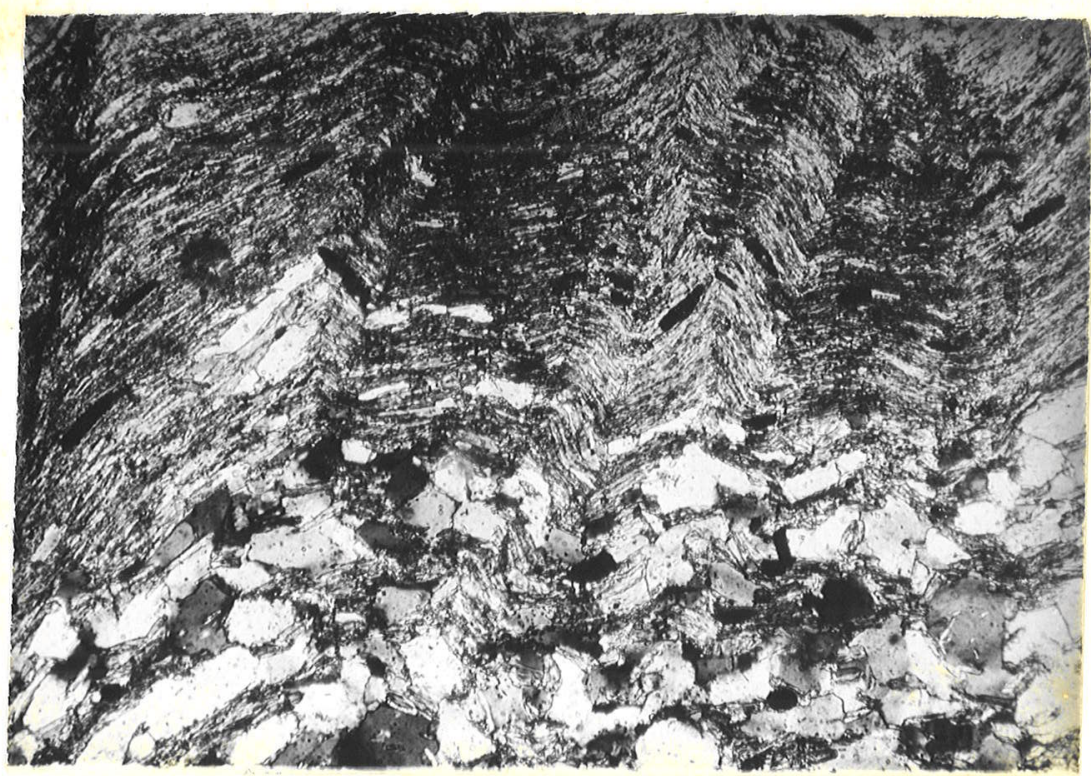

Foto 15 - Xisto. Microdobras e textura lepidoblästica. Textura grano b1ástica nas camadas quartzosas. Nícois cruzados. Aumento 210 vezes. 
mento e a xistosidade. Granadas e estaurolitas ocorrem também sob a forma de porfiroblastos. As granadas, mostram nati damente terem "empurrado" os leitos micäceos durante o seu crescimento (Foto 12) e são por vezes poiquiloblästicas, incluindo, nesses casos, comumente quartzo e opacos(Foto 13). os porfiroblastos de estaurolita (Foto 14), exibem muitas ve zes tendência ao idiomorfismo. A textura poiquiloblástica foi também observada neste caso, sendo comumente, quartzo o mineral incluido na estaurolita.

Além dos minerais acima citados foram observadas quantidades menores de minerais opacos, titanita, calcita, apatita e clorita, esta ültima usualmente proveniente da transformação de biotita. A granulação dos minerais situa -se em torno de 0,15 - 0,40 mm, exceção feita aos porfiro blastos, que variam de $0,70 \mathrm{~mm}$ (caso da biotita) até $2-4 \mathrm{~mm}$, exemplo dos porfiroblastos de granada e estaurolita.

A textura predominante nessas rochas è a lepidoblástica. Microdobras foram observadas em várias amostras (Foto 15). Nas camadas quartzosas foi notada textura granoblästica.

\section{Quartzitos}

Os metassedimentos quartzosos afloram geralmente sob forma de camadas intercaladas aos metassedimentos argilosos e carbonäticos.

os corpos quartzíticos são concordantes com a orientação geológica regional. Dobras de pequena amplitude foram verificadas em diversos afloramentos.

Macroscopicamente tais rochas são comumente brancas ou cinza claras. Tons avermelhados observados em värias amostras decorrem da pigmentação de óxido de ferro. A riqueza em magnetita observada às vezes, resultou em colora ções que variam de cinza escuro a preto.

Quartzo constitui cerca de $90 \%$ em volume ou mais da maioria das amostras analisadas. O tamanho desse mineral é variāvel, situando-se na maioria dos casos entre 0,1 


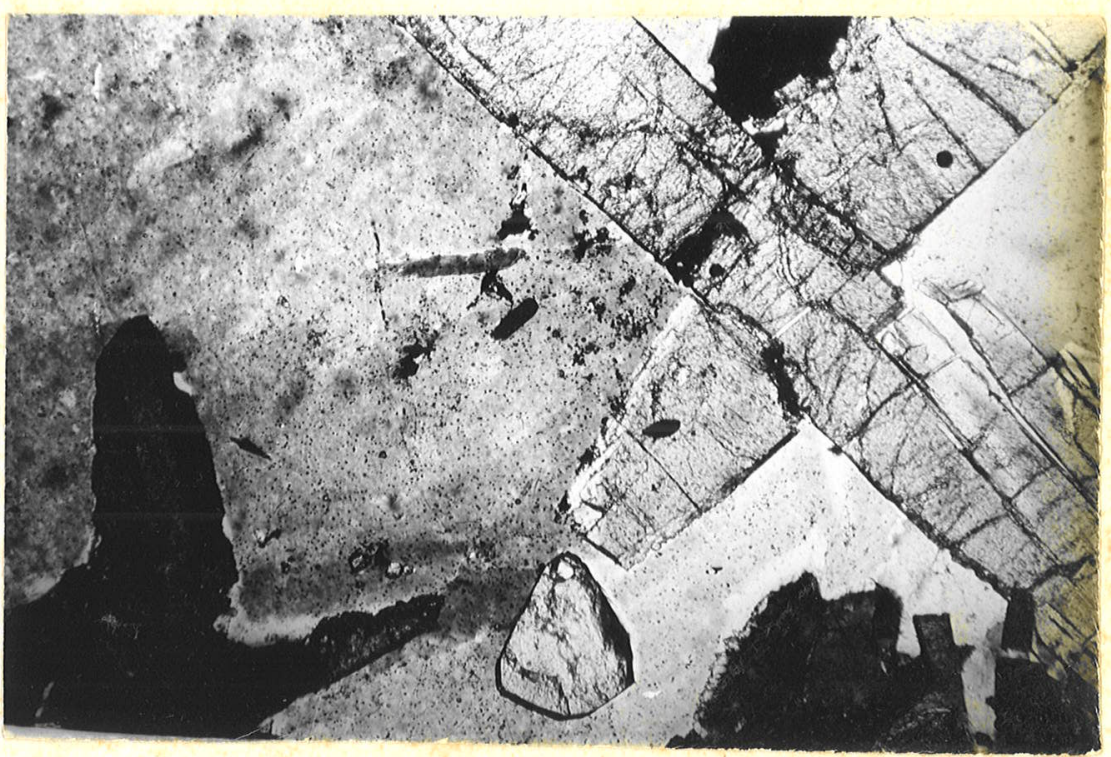
Foto 16 - Quartzito. Cristais de quartzo e turmalina,esta com tendência ao idiomorfismo; opacos comple tam a composição mineralógica. Nícois cruzados. Aumento 80 ve zes.

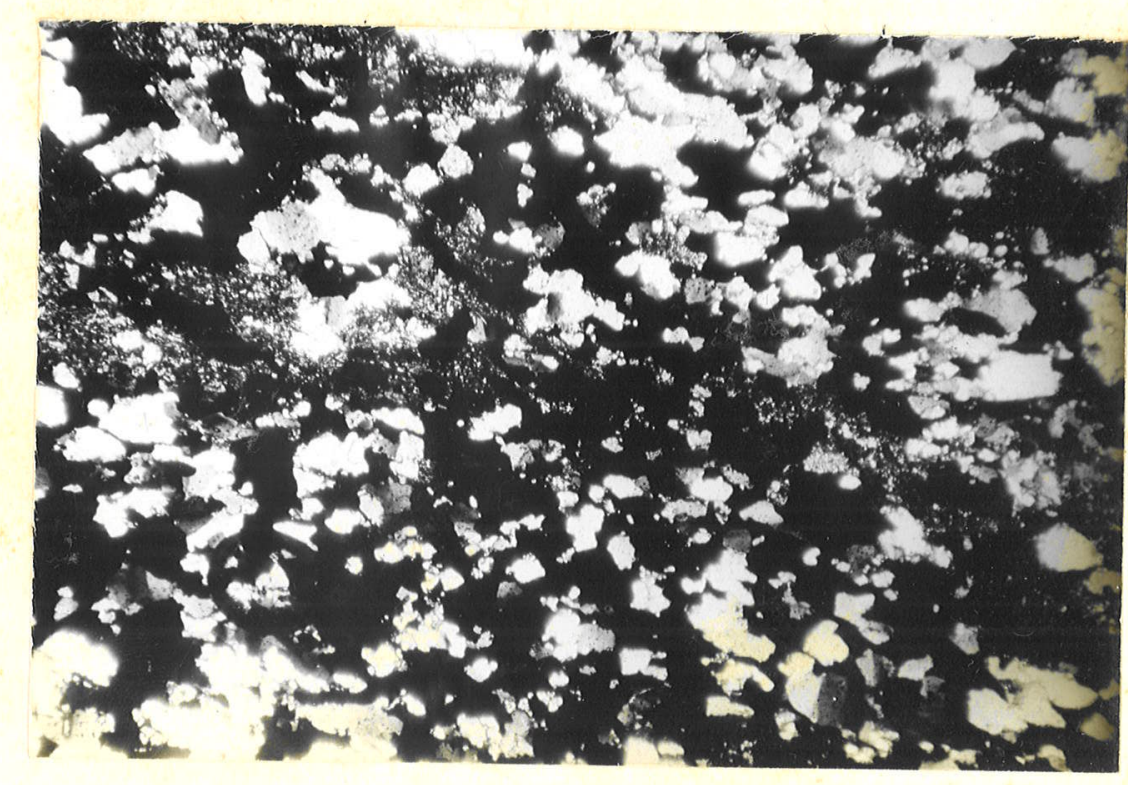

Foto 17 - Quartzito com magnetita. Cristais de magnetita e quartzo justapostos. Tremolita-actinolita concentrada em faixas de 1 gadas.Nícois cruzados. Aumento 27 vezes. 


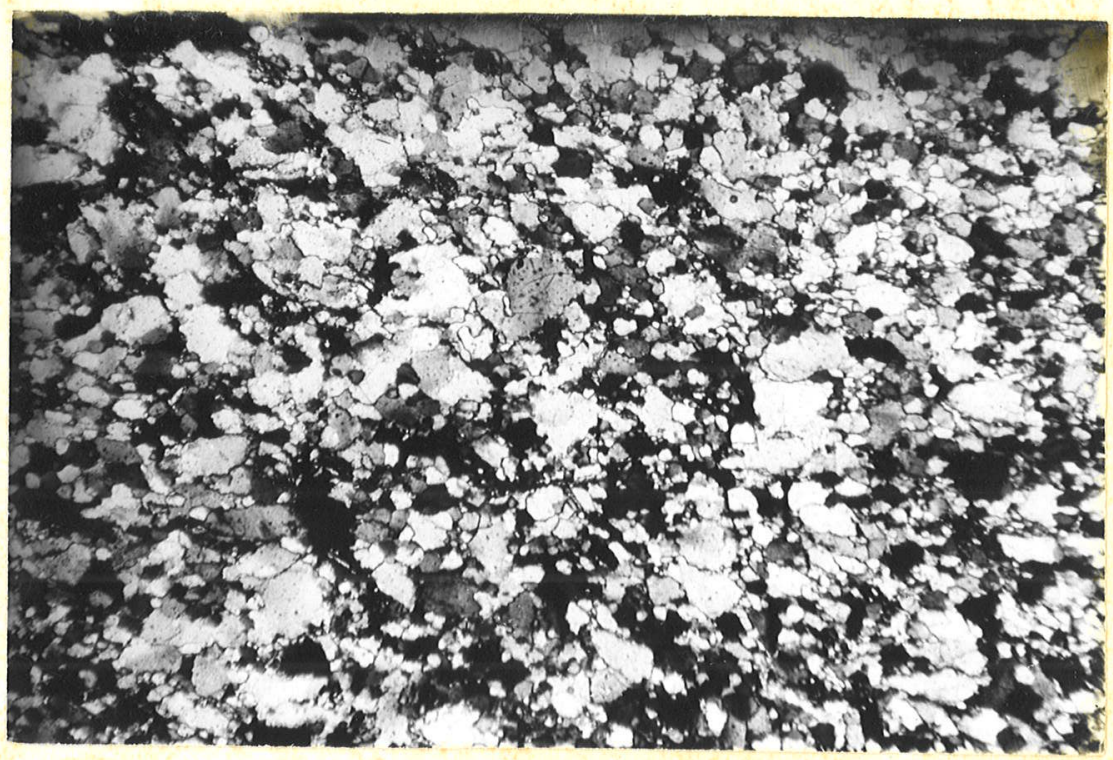

Foto 18 - Quartzito. Textura granoblästica. Cristais de quartzo e opacos. Nícois cruzados. Aumento 80 vezes.

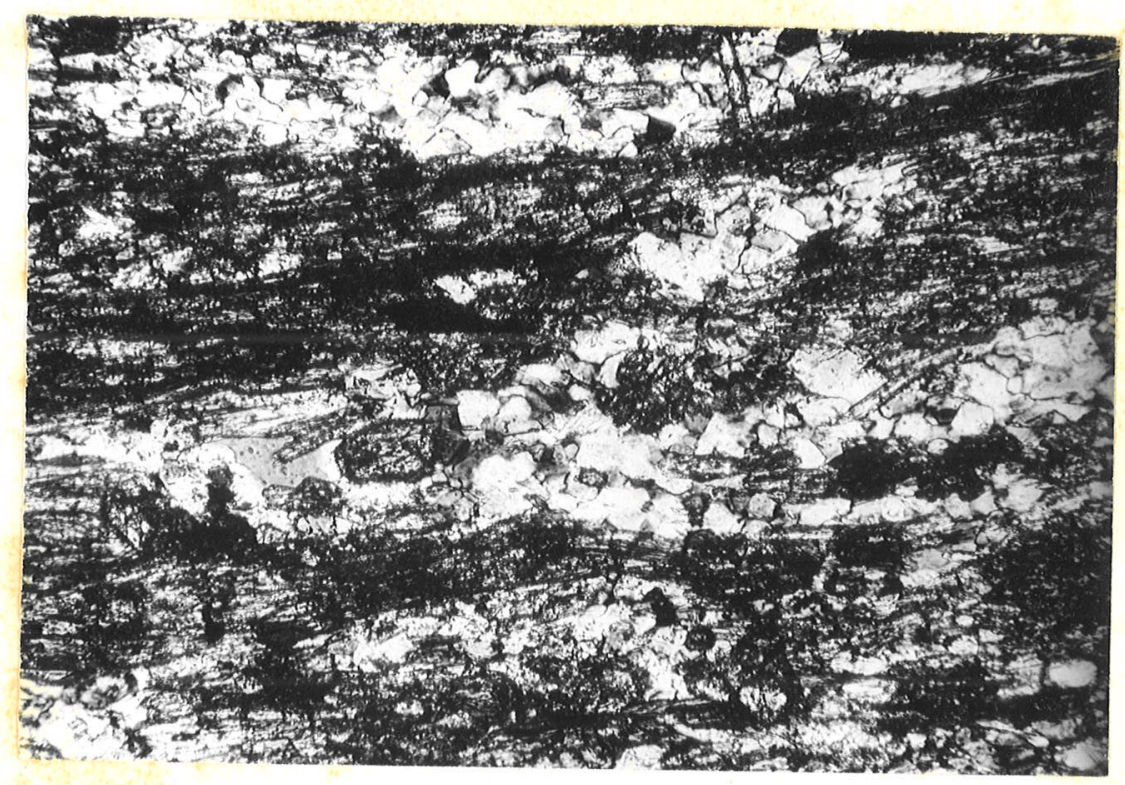
Foto 19 - Anfibölio xisto. Faixas claras constituidas por quartzo e pla- gioclásio e faixas escuras cons tituidas por hornblenda, clori- ta, biotita e opacos. Nícois cruzados. Aumento 80 vezes.


a $0,5 \mathrm{~mm}$. Opacos, zircão, sericita e biotita são acessörios. Numa das amostras observadas, porém, a granulação dos cristais de quartzo mostrou-se nitidamente maior alcançando cer ca de $4 \mathrm{~mm}$. Nessa amostra ocorre tambëm cerca de $10 \%$ de tur malina $(\omega=\operatorname{marrom}, \xi=\operatorname{amarelo} c 1 a r o)$, cujos cristais exi bem tendência ao idiomorfismo. Além desses minerais ocorre quantidade insignificante de opacos (Foto 16).

Alëm desse tipo de metassedimento quartzoso claro, ocorrem também quartzitos escuros.

Tais rochas exibem quantidades semelhantes de quartzo e magnetita que perfazem cerca de 90-95\% da amos tra (Foto 17). Anfibölio do grupo tremolita-actinolita ocor re em quantidades subordinadas, sendo tambēm identificados rarissimos cristais de calcita. Nessas rochas, cuja granula ção varia de $0,1-0,5 \mathrm{~mm}$, quartzo e magnetita se justapõesem formar zonas com predominância de um ou outro mineral. A tremolita-actinolita porém $(z=$ verde-claro a incolor, $X$ = incolor e $2 \mathrm{~V}(-)$ alto) tende a se concentrar em delgadas faixas.

A textura dessas rochas è granoblästica (Fo to 18). Em varias amostras porēm é vísivel a tendencia à orientação dos grãos de quartzo paralelamente à xistosidade. Tal orientação torna-se bem mais visível em razão do incremento da porcentagem de micas. Sinais de deformação foram tambēm assinalados em varias amostras, sendo representa das pela extinção ondulante do quartzo e mais raramente por textura em moldura exibida por esse mineral.

Nos meta-arenitos e metassiltitos alëm de quartzo, ocorrem também pequenas quantidades subordinadas de sericita, biotita, plagioclásio, feldspato potásico, opacos e zircão, minerais esses que somados atingem no maximo $10 \%$ em volume. Nessas rochas é possivel notar-se sinais da antiga textura sedimentar. Em muitos casos, os anti gos contornos dos grãos de quartzo são visíveis, notando-sé - crescimento posterior desses grãos, originando então a atual textura granoblästica. 
Anfibolitos e anfibölio-xistos Värias ocorrências de corpos anfiboliticos
foram observadas. Possuem espessura de um a vinte metros e formam lentes concordantes aos metassedimentos regionais.

Macroscopicamente tais rochas exibem côr cinza-escura, preta ou esverdeada. Existem tipos granobläs ticos e amostras nas quais a xistosidade é nítida (Foto 19).

A hornblenda e o plagioclásio são os mine $r$ ais essenciais nos anfibolitos, perfazendo usualmente 85$-90 \%$ das amostras em volume. Quartzo ocorre em quantidades subordinadas, aparecendo tambëm em quantidades menores epí doto, opacos, biotita, apatita, clorita e titanita. A horn blenda tem $Z=$ verde, $X=$ amarelo e $2 \mathrm{~V}(-)$ mëdio a alto. Em várias amostras foram observados núcleos mais claros e bor das mais escuras. o plagioclásio exibe comumente geminação segundo a lei da albita, ocorrendo mais raramente geminados segundo a lei do periclínio. Sua composição oscila em tor no de $A n_{25}-A_{35^{\circ}}$ Sericitização é fenômeno relativamente comum nesses minerais, ocorrendo raramente inclusões de epí doto. Quartzo está presente em quantidade razoável, alcan çando $10 \%$ em värias amostras. O epídoto presente pertence a variedade pistacita e ocorre comumente sob forma de mine ral primário. Em raros casos observou-se epídoto de dimen sões reduzidas, incluido em plagiocläsio, sendo portanto produco de sua transformação. Clorita é comumente secundá ria proveniente da transformação de biotita e hornblenda.

A textura nessas rochas è geralmente grano blāstica. A granulação dos minerais situa-se usualmente em torno de $0,6-1 \mathrm{~mm}$, sendo em geral os minerais fëlsicos me nores que as hornblendas. Em algumas amostras notaram-se sinais de deformação traduzidas pelo quebramento de mine rais, especialmente, plagioclásio e quartzo.

\section{Rochas carbonäticas}

Exibem cores claras, brancas ou cinzentas ou róseas.Não obstante, tonalidades cinza ou pretas foram tam 


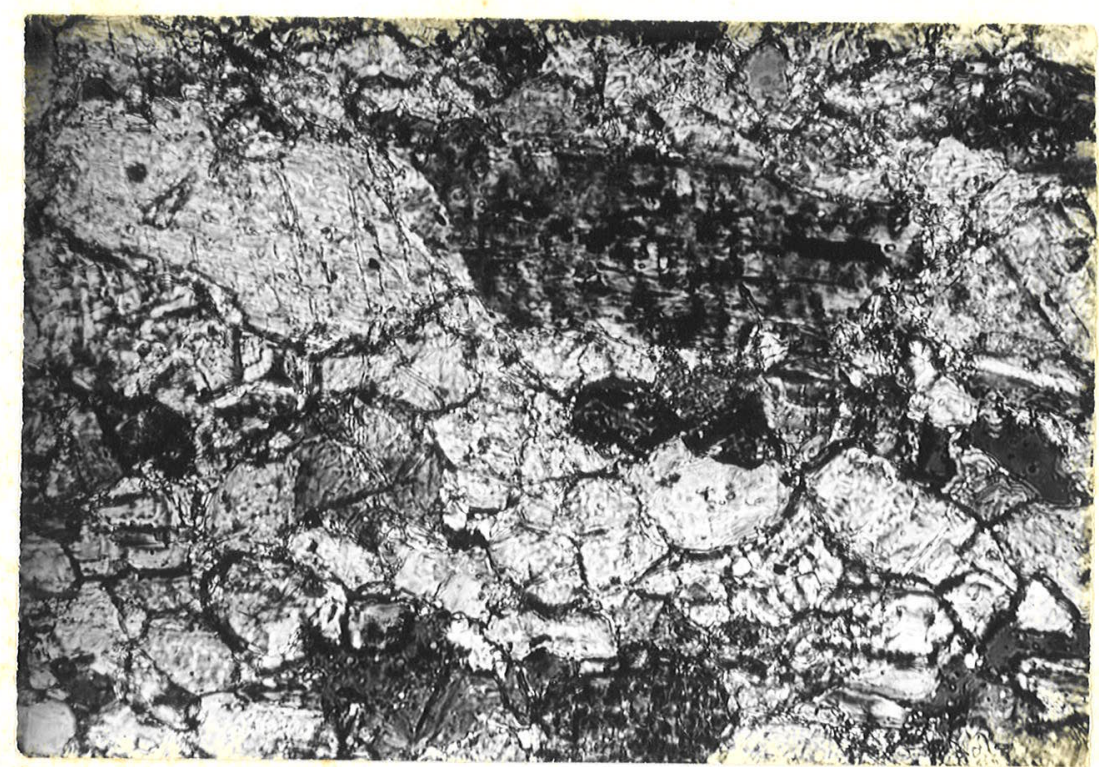
Foto 20 - Rocha carbonätica. Calcita e do lomita constituindo cerca de $95 \%$ em volume. Flogopita e tremoli- ta. Textura granoblástica. Ní- cois cruzados. Aumento 170 ve- zes.

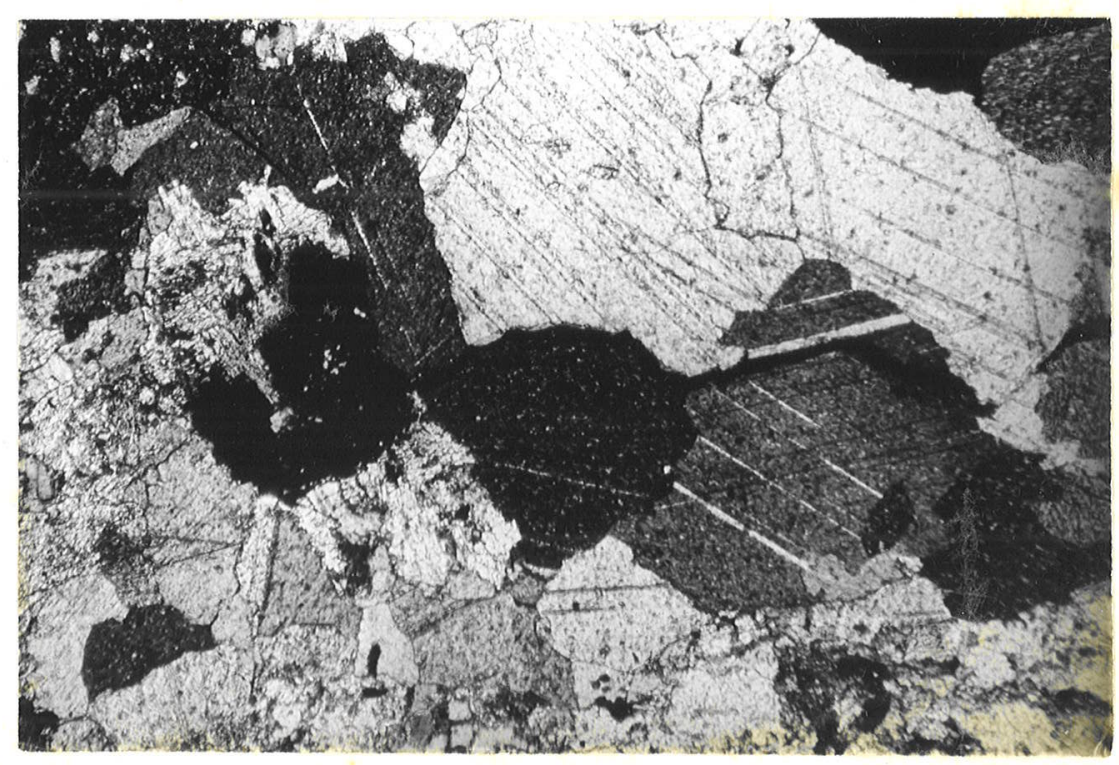
Foto 21 - Rocha calcária mostrando banda recristalizada com carbonatos xenomorfos. Nícois cruzados.Au- mento 80 vezes.


bém observadas.

A composição nineralógica dessas rochas é da da por calcita e dolomita largamente predominantes, constituindo cerca de $95 \%$ em volume das amostras. Mica, provàvel mente flogopita, anfibólios do grupo tremolita actinolita ( = incolor a verde c1aro, $X=$ incolor, $2 \mathrm{~V}(-)$ alto), opacos e titanita são acessórios. A textura dessas rochas é granobläs tica (Foto 20). Em algumas amostras, nota-se leve alongamento preferencial dos minerais segundo a direção de xistosidade. A granulação é fina, em torno de 0,05 a $0,1 \mathrm{~mm}$, porêm em vários casos notaram-se bandas recristalizadas, onde os carbonatos atingiram dimensões, bem maiores, da ordem de até $3 \mathrm{~cm}$. Os carbonatos são comumente xenomōrficos. Geminação po lissintética é fenômeno usual nesses minerais (Foto 21).

\section{Rochas cálcio-silicatadas}

Rochas cálcio-silicatadas são muito comuns mais ao sul na área investigada (Fig. 3). Associam-se às rochas carbonáticas e apresentam cores que variam do cinza cla ro ao cinza escuro; tons avermelhados não são, porëm, muito raros. Ocorrem sob forma de corpos de pequena espessura, con cordantes com os demais metassedimentos. Por vezes mostramse bandeados, alternando-se, nestes casos, växias faixas com predominância de minerais como quartzo e feldspato, anfi bólio, calcita e hornblenda (Foto 22).

Vê-se, pois, que a mineralogia dessas rochas é variāvel de afloramento para afloramento, fato que reflete a heterogeneidade do sedimento inicia1. Nas faixas carbonāti cas predominam calcita e dolomita. Os minerais cälcio-silica tados mais comuns são hornblenda e tremolita, sendo diopsídio mais raro. Além desses minerais, quartzo, feldspato potássico, plagioclásio (andesina, labradorita), biotita, tita nita, opacos e turmalina tambëm foram determinados. A textura dessas rochas é predominantemente granoblästica, e a granulação varia de 0,1 a $3 \mathrm{~mm}$. 


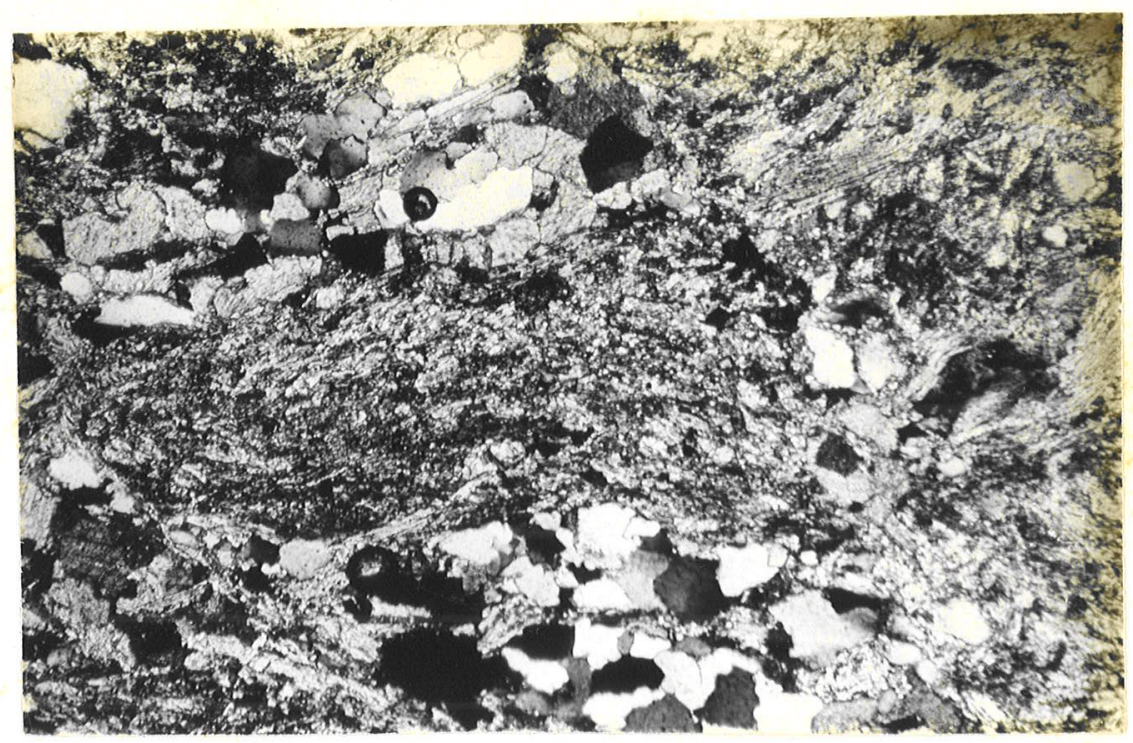

Foto 22 - Rocha calcio-silicatada. Faixas de quartzo, calcita e dolomita, feldópato e anfibólio. Nícois cruzados. Aumento 80 vezes.

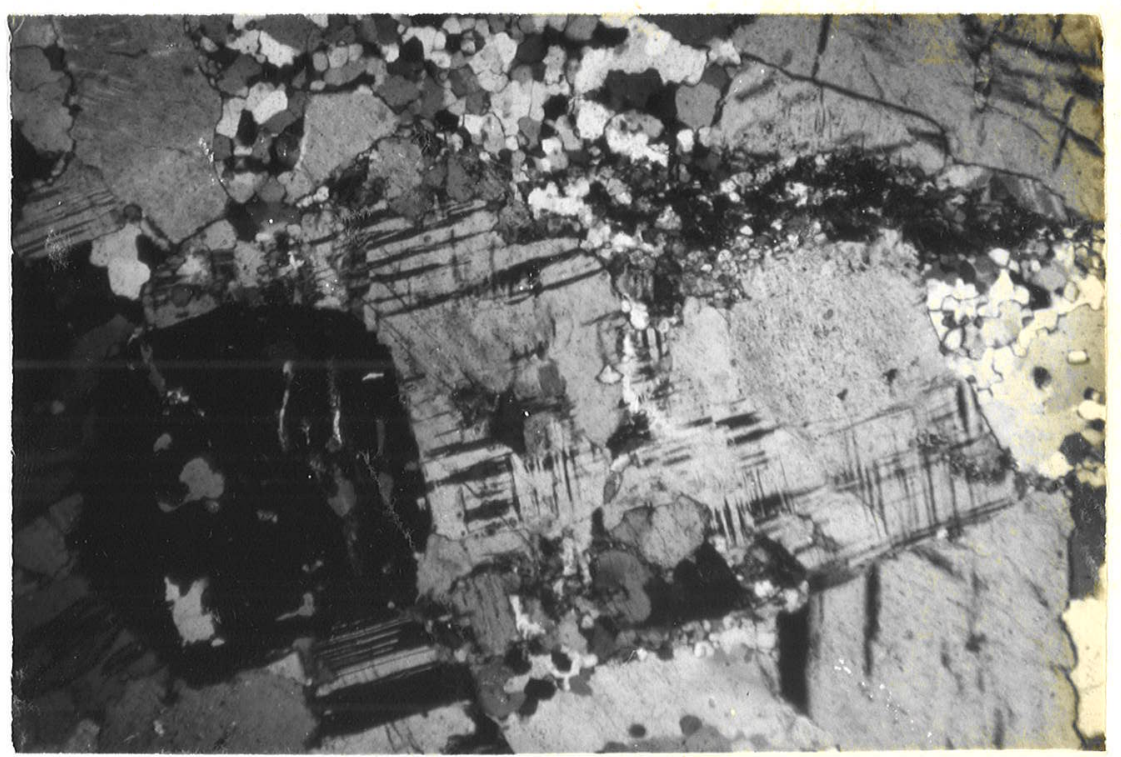

Foto 23 - Granito. Textura hipidiomörfica a xenomörfica granular, parcia1 mente milonitizada. Microclinio, quartzo, plagioclásio, anfibólio e granada. Nícois cruzados. Aumento 240 vezes. 
Granito

(Fig, 3).

Os granitos não ocorrem na ärea mapeada

o granito descrito, denominado Epitäcio,es tá aproximadamente $15 \mathrm{~km}$ a nordeste da confluência dos ri beirões Grande e Peräu e faz parte do mapeamento executado por Melcher et a1., (1971), (Fig. 2), sendo um corpo de pe quena extensão em volume aflorante.

Foxam visitados vários afloramentos, todos pertencentes a borda dessa intrusão, e as amostras coleta das possuem orientação incipiente dos minerais, fato jă ob servado por Fuck (1967) e Melcher (1968), sendo frequente a presença de granada vermelha (Foto 23).

Macroscopicamente os granitos exibem côr cinza clara e granulação grosseira.

ilicroscopicamente apresentam textura hipi diomörfica a xenomörfica granular cataclasada (Foto 23). Os minerais presentes são: microclínio, quartzo, plagioclásio, anfibólio, epídoto e granada como acessório. Näo foram en contrados minerais opacos. O microclinio apresenta-se ém cristais com diâmetro de ate $7 \mathrm{~mm}$, constituindo os graõs maiores e mais abundantes na rocha. E comum a geminação em grade, deformada por esforços. o quartzo apresenta granula ção fina, com $1 \mathrm{~mm}$ de diâmetro e se encontra disseminado en tre os demais componentes do granito. E comum a extinção ondulante e frequente as fraturas nas bordas.

o plagioclásio ocorxe subordinadamente ao microclínio e quartzo, estando sausuritizado. E provave1 mente do tipo oligocläsio e apresenta-se geminado segundo a lei da Albita. O anfibölio possui granulação semelhante à do quartzo, estando sempre alterado seja cloritizado ou 1 i monitizado. O epídoto aparece sempre como alteração dos plagiocläsios e anfibólios, em quantidades inferiores a $1 \%$. A granada é o unico acessōrio, com granulação ao redor de $1 \mathrm{~mm}$ de diâmetro, incluindo grãos de quartzo. Fstä fratura da do mesmo modo que os outros minerais da rocha. 


\section{Metamorfismo}

os autores que estudaram o metamorfismo regional das rochas do Grupo Açunguí do Vale do Rio Ribeira de Iguape (Marini et a1., 1967; Melcher et a1., 1968), situam-no, na sua maior parte, na fäcies dos xistos verdes(Turner e Verho ogen, 1960). Segundo Marini et a1., (1967), as formações Capim, Votuverava e Āgua clara têm grau metamórfico correspondente à fácies dos xistos verdes, aumentando o grau sómente na Formação Setuva, situada na base do Grupo. Segundo Me1cher et al., (1968) toda a região setentrional do vale do rio Ribeira de Iguape pertence a fäcies dos xiscos verdes, havendo aumento de grau sōmente na região meridional, representada pela transição de filitos para xistos pertencentes a fácies anfibolito, alëm de migmatitos e gnaisses.

Na região estudada as observações efetuadas vêm corroborar as observações daqueles autores. Com efeito, através da descrição petrogrä́ica das rochas, observa-se a presença de filitos, metarenitos e metassiltitos, e rochas calcárias, todas portadoras de minerais de baixo grau metamörfico pertencentes a fäcies dos xistos verdes. Ocorrem tam bém xistos, anfibolitos e rochas calcärias e cálcio-silicata das, cujas associações mineralógicas são pertencentes a fäcies anfibolito. Em varias dessas rochas, principalmente nas rochas calcārias e cälcio-silicatadas, nota-se a presença de certo desequilíbrio metamórfico, evidenciado pela presença, lado a lado, de minerais de fácies anfibolito e xistos verdes. Este fato porém não è estranho, principalmente levandose em consideração que a região situa-se em zona de transição entre as duas fácies metamórficas. 
HINERALOCIA

lietodologia

amostragem

() autor vem acompanhando a pesquisa da jazi da desde seu início, em 1965, até esta data, de modo que te ve oportunidade de visitar todos afloramentos, trincheiras, poços e galerias, bem como estudar os testemunhos de sonda gens e acompanhar os estudos geofisicos e geoquímicos.

As amostras cujos resultados de estudo cons tam do presente trabalho foram retiradas a partir dos traba lhos executados pelos métodos de pesquisa citados, segundo critérios diversos de prospecção, julgados isoladamente os mais apropriados, tanto no sentido horizontal como vertical da jazida. Muitos dos dados apresentados serviram tambëm como base para avaliação da reserva de minério então pesqui sada.

Tendo-se dado ênfase de cunho mineralögico, é natural que a proveniência dos minerais seja de pontos de maior concentração dentro das ocorrências. Tomou-se o cui dado de se obter sempre amostras representativas de seçöes ou compartimentos, representados no mapa geolögico, pelos limites das linhas transversais (TR).

propriedades físicas e morfolögicas

Para estudo das propriedades mineralögicas os cristais de 2 a $5 \mathrm{~mm}$ foram separados manualmente por es pátula ou quando se necessitou de concentraçöes de minerais de tamanho menor, normalmente disseminados em rocha, fez-se uso de britagem, moagem, peneiramento (até $0,149 \mathrm{~mm}$ de aber tura de malha), lavagem, secagem(em estufa até $100^{\circ} \mathrm{C}$ ) e se paração por gravimetria em bromoformio ou por separador mag nético Frantz. Para o caso de minerais de valores pröximos de peso específico, foi usada solução de clerici (Vassar, 
1925). A separação dos minerais propiciou sua nos diversos métodos descritos a seguir.

utilização

As propriedades fisicas e morfolögicas dos minerais tais como côr, brilho, transparência, fratura, cli vagem e häbito foram estudadas, a princípio, sob lupa binocu lar de aumento até 32 vezes.

microscopia

o estudo optico foi realizado ao microscópio polarizador, em grăos minerais previamente passados em penei ra 80 "meshes" $(0,177 \mathrm{mr})$, em cujos grãos foram observados pleocrosimo, clivagem, fratura, häbito, emalguns casos a morfologia e tambẻm medição dos índices de refração.

Para a determinação de indices de refração de alguns minerais, pelo método de imersão, usou-se de bate ria de líquidos Cargille, série $M$, empregando-se luz de só dio.

Algumas lâminas delgadas foram confecciona das com montagem em bálsamo do Canadā, para estudo de textu ra e inclusões dos minerais de cobre e de ganga. Trinta 1âa minas de rocha foram utilizadas no estudo petrográfico.

seções polidas

As seções polidas foram preparadas no Depar tamento de Geologia Economica e Geofísica do Instituto de Geociências da Universidade de são paulo com finalidade de estudo microscópico à luz refletida, paralela ou convergente, e para anälises à microsonda eletrônica, motivos pelos quais foram confeccionadas seções de minerais metálicos e não metālicos.

A técnica e instrumentos utilizados resumem-

-se:

1) As amostras com uma superfície cortada são introduzidas em moldes cilíndricos de plästico de $25 \mathrm{~mm}$ de diâmetro inter no por $18 \mathrm{~mm}$ de altura. As formas develil ser previamente un 
tadas com separol, posto a secar a ar, durante 10 minutos.

2) A mistura plástica contém a seguinte composição:

polylite $8001,100 \mathrm{cc}$

Monômero de estireno $15 \mathrm{cc}$

Acelerador de cobalto $0,5 \mathrm{cc}$

Catalizador WikK $1,5 \mathrm{cc}$

Após o catalizador, que é adicionado como ül timo reagente, adicionam-se 2 a 3 gotas de azul de metileno para clarificar a solução. Depois de derramada a mistura

plástica sobre a amostra, dentro da forma espera-se 3 a 4 ho ras para o endurecimento.

3) o polimento inicial é manual, amostra por amostra, em 1 i $x a$ de carborundum apoiada em plano inclinado sob jato suave e constante da água. A operação para cada lixa é feita no intervalo de 3 a 5 minutos. A sērie de lixas, em ordem de sequência é constituỉda nor: carborundum 240, 320,400 e 600 . 4) 0 polimento seguinte ë executado com carborundum 800 , em pó, a seco, sobre placa de vidro plano, durante 3 a 4 minu tos.

5) 0 polimento com carborundum 1000 , na etapa seguinte, é feito com o pó ( $30 \mathrm{~g})$ e Nujol $(50 \mathrm{~g})$ en placa de vidro plana, durante 3 a 4 minutos.

6) o último polimento manual é feito como no item anterior, u sando-se carborundum 1400 . Entre as mudanças de operações dos itens 3,4 e 5 a lavagem é feita com ägua e entre os itens 5,6 e 7 , a lavagem è com água e detergente.

o procedimento posterior de polimento é fei to em politriz automática marca Struers, DP 10 de fabricação dinamarquesa. Consta de um disco plästico recoberto por um pano adesivo impregnado com pasta de diamante. Sobre o dis co colocam-se 6 seções a serem polidas, protegidas superior mente por uma cäpsula onde se instalam 4 a 5 pesos padrões, dependendo da dureza da amostra. A pasta de diamante ( 10 pingos) é distribuida manualmente sobre o pano, onde alcool lubrificante $\bar{e}$ gotejado na razão de 1 gota em 2 segundos. 0 disco possui velocidade padronizada.

7) Usa-se primeiramente o disco no 7 e pasta de diamante ñ? 
7 durante 45 a 50 minutos, com 4 a 5 pesos sobre cada amos tra.

8) Passa-se para discono 3 e pasta no 3, permanecendo em operação durante 25 a 30 minutos, com 3 pesos sobre cada amos tra.

9) Usa-se discono 1 e pasta no 1, durante 15 minutos com 3 pesos sobre cada amostra.

10) Finalmente é utilizado o discono $1 / 4$ e pasta $1 / 4$, duran te 10 minutos, com 2 pesos sobre cada amostra.

Na fase de mudança dos discos, as amostras são lavadas com água e detergente sendo que os discos são 1a vados somente quando são utilizados materiais pulverulentos ou moles como alguns compostos de manganês e grafite. o aca bamento é executado em máquina vibradora, do tipo vibromet polisher, de fabricação Buehler, Ltd., que consta de um dis co metälico recoberto por feltro, com velocidade padrão que trabalha com óxido de alumínio e ägua. As amostras ficam sol tas em contato com o feltro, protegidas superiormente por formas de aço, permitindo movimento circular e vibratório,em intervalo de 10 a 15 minutos. A lavagem final é feita por alcool.

A preservação das seções polidas, por longo tempo, é eficiente em dissecador a vácuo e a curto prazo po dem ser bem conservadas e resguardadas de oxidação, acondicio nando-as em tubos de filmes fotogräficos (35 mm) envoltas e comprimidas por algodão medicinal.

difração de raios $x$

0 equipamento empregado nas pesquisas reali zadas é de marca Norelco utilizando-se anticátodo de cobre $(\mathrm{CuK \alpha}=1,5418 \AA)$ em regime de $15 \mathrm{~mA}$ e $35 \mathrm{kV}$ num intervalo de 20 a 24 horas. O método de Debye-scherrer foi o mais em pregado, segundo a técnica de Azarroff et al., (1958), em câa maras de pó de $114.59 \mathrm{~mm}$ de diâmetro, pois o primeiro propó sito do presente trabalho foi a identificação e confirmação das espécies mineralögicas estudadas, isoladamente, ou em 
mistura de diversas fases. Procurou-se também atravēs desse método a determinação dos parâmetros unitārios de turmalina.

Fez-se uso do difratômetro Norelco para amos tras em quantidades disponíveis para aplicação do método. Pa ra amostras menores que décimos de rnilimetros, de maior dia metro ou de caráter aparentemente amorfo ou facilmente amor fizāveis por trituração (Camargo, 1965) foi utilizada a câma ra de Gandolfi com a técnica descrita por Arruda (1971).

Identificação dos minerais de cobre. Tabela de "d" s - Camargo (1965) confeccionou uma tabela de "d" s para identificação de minerais uraniferos e propõe que ou tras tabelas sejam organizadas para outros grupos de mine rais que com frequência se apresentam em estado pulverulento ou subricroscópico, como os minerais argilosos, limoníticos, niquelíferos, minerais de manganês e possivelmente minerais de rocha.

As tabelas ASTM ( $X-r a y$ powder pattern file) de espaçamentos "d" do sistema Hanawalt ou Fink, ordenam as intensidades relativas (I/Io) das três ou oito raias mais in tensas do diagrama de pó, em ordem decrescente, sendo o pro cesso mais eficiente para rāpida identificação de substân cias puras.

Quando se procura estudar minerais de miné rio, especialmente do tipo oxidado, onde há dificuldade de separação dos componentes, a identificação roentgenogräfica torna-se bastante difícil por motivo de superposição das raias de fraca intensidade. Esse fato acarreta formação de raias de intensidade mais elevada, tornando às vezes impossi vel a identificação.

A Tabela 4 foi organizada obedecendo os valo res decrescentes de "d" $s$, com suas respectivas intensidades. 0 limite inferior foi considerado $1,29 \AA$ porque no decorrer da classificação encontrou-se intensidade 55 para os mine rais eucairita e cromita de cobre II. Abaixo desse valor,os "d"s dos diversos minerais praticamente se confundem, não sendo característicos para identificação. 
A tabela foi confeccionada a partir de da dos de Frondel (1958) e contēm 120 minerais de cobre.A eles foram acrescidos quartzo, calcita, dolomita, siderita, rodo crosita, barita, epídoto, limonita e goethita que compõem (Bateman, 1959) os minerais de ganga. Por motivo de exten são da tabela não foram classificados os minerais que fre quentemente se associam aos minerais de cobre e nem aqueles onde o cobre pode ser obtido como subproduto. 
ESPACAMENTOS INTERPLANARES DE MINERAIS DE COBRE

\begin{tabular}{|c|c|c|c|c|c|}
\hline$d(A)$ & I & Mineral & $d(\Lambda)$ & I & Mineral \\
\hline 28,0 & 100 & Tyrolita & 6,73 & 50 & Тигquена \\
\hline 14,1 & 80 & Tyrolita & 6.70 & 70 & Fillstita \\
\hline 12,9 & 100 & Ktenasita & 6,59 & 10 & Dioptiatio \\
\hline 12,5 & 30 & Shattuckita & 6,52 & 100 & Liroconiti \\
\hline 11,90 & 100 & Mixiti & 6,50 & 67 & Brochantita \\
\hline 11,72 & 5 & Renierita & 6,5 & 10 & Peitrceita \\
\hline 11,5 & 5 & Germanita & 6,47 & 30 & Refuesitat \\
\hline 11,5 & 100 & Vallerita & 6,46 & 100 & Liroconiti \\
\hline 11,00 & 100 & Arseniato hislratado de Cu II & 6,46 & 5 & Enargita \\
\hline $10,25 ?$ & 5 & Renicritit & 6,45 & 10 & Kenatitit \\
\hline 10,10 & 20 & Mixiti & 6.14 & 50 & Dolurofanita \\
\hline 10,6 & 30 & Roqueraita & 6,42 & 40 & Paxita \\
\hline 10,4 & 5 & $\begin{array}{l}\text { Sulfato penta hidratado de } \\
\text { colire }\end{array}$ & 6,41 & 50 & Novikita \\
\hline 10.4 & 100 & Lindickerita & 6,40 & 50 & Cialeneita \\
\hline 10,2 & 100 & Lindiackerita & 6,40 & 30 & Calconiclerita \\
\hline 10.2 & 100 & Cianotrichita & 6,34 & 40 & Brochantiti: \\
\hline 10,15 & 100 & Mіндеiita & 6,35 & 10 & Cianotrichita \\
\hline 10.1 & 5 & Germenitit & 6,13 & 100 & Krorlunkit: \\
\hline 9.98 & 40 & Plancheita & 6,30 & 30 & Clinoclanita \\
\hline 9.9 H & 20 & Novikitia & $6,2.5$ & 20 & Ciuprobinmutitia \\
\hline 9,91 & 40 & Shattuckita & 6.25? & 5 & Cirrmanitit \\
\hline 9.62 & 100 & 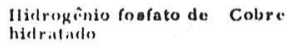 & 6,17 & 70 & I'urquanat \\
\hline 9.09 & 50 & Turquenit & $\begin{array}{l}10,17 \\
6,14\end{array}$ & $\begin{array}{l}70 \\
40\end{array}$ & $\begin{array}{l}\text { Fiturtita } \\
\text { Linntiakeritit }\end{array}$ \\
\hline 9.03 & 50 & Fauntitit & 6,11 & 5 & Cirrmanititis \\
\hline 9,02 & 5 & Roсрuсніт: & $(6,1)^{5}$ & 5 & Renieritu \\
\hline $8,96 ?$ & 5 & Renieritil & 6,05 & 20 & Rickk.urdit.. \\
\hline B.,77? & 5 & Germanitit & $6,0,3$ & но & Liroconit., \\
\hline 8,63 & 5 & Cimetrichitn & 6,01 & 26 & Antleritit \\
\hline H. 51 & 25 & Calcencitit & $i, 00$ & 10 & T'urquentat \\
\hline 8,3 & 60 & Crinocolit & 6,00 & 10 & Pesircuila \\
\hline 8,18 & 7 & Covelita & 5,99 & 55 & Malaquita \\
\hline 8,04 & 40 & Lindackerita & $5,9 H$ & 40 & Faustita \\
\hline 8,18 & 7 & Covelita & 5,94 & 30 & Vandenbrandeisa \\
\hline 8,13 & 30 & Zoisita & 5,97 & 3 & Bournonita \\
\hline 8,06 & 60 & Silicato de cobre e bário & 5,95 & 90 & Liroronitit \\
\hline 8,04 & 40 & Lindackerita & 5,93 & 40 & $\begin{array}{l}\text { Arseniato hidratado de: } \\
\text { cobre (II) }\end{array}$ \\
\hline . 7,99 & 25 & Clinozoisita & 5,92 & 20 & Veszelyta \\
\hline 7,98 & 5 & Epícloto & 5,91 & 70 & Olivenita \\
\hline 7,85 & 10 & Langita & 5,90 & 40 & Linclackerita? \\
\hline 7,82 & 50 & $\begin{array}{l}\text { Silicato de entrôncio a } \\
\text { cobre }\end{array}$ & 5,90 & 20 & Lindlackerita \\
\hline 7.80 & 8 & Brochantita & 5,89 & $(3-5)$ & Brochantita \\
\hline 7,79 & 20 & gama Calcopirita & 5,86 & 90 & Ktenasita. . \\
\hline 7,77 & 5 & Roguesiti & 5,86 & 40 & Calciovolborthita \\
\hline $7,6,3$ & 40 & (egyptian blue) & $5, \mathrm{H} 5$ & 90 & Libethenita \\
\hline 7,6 & 30 & Clinoclanita & 5,81 & 13 & Bsournonitia \\
\hline 7,56 & 20 & Paxit: & 5,80 & 20 & Fatustiti \\
\hline 7,50 & 10 & Renicriti & 5,78 & 40 & Tyrrellita \\
\hline 7,50 & 10 & Gormanita & 5,77 & 20 & Turquina \\
\hline 7,41 & ul & Malnqquita & 5.75 & 100 & Valleriita \\
\hline 7,38 & 50 & Emplectita & 5,75 & $2 B$ & Paxita \\
\hline 7,38 & 20 & Calcostibinita & 5,73 & 35 & $\begin{array}{l}\text { Sulfiato penta hidratado de } \\
\text { colire. }\end{array}$ \\
\hline 7,3 & 10 & Freibergita & 5.72 & 1,0 & S.lignlanita \\
\hline 7,29 & 25 & Veszelyita & 5,72 & 30 & Crisocola \\
\hline 7,28 & 100 & Dioptí́вio & 5,69 & 5 & Cromitu de cobre \\
\hline 7,26 & 100 & Volborthita & $5,6.8$ & 30 & Lautit: \\
\hline 7,25 & 80 & $\begin{array}{l}\text { Vanadato hidratado básico de } \\
\text { cobre: }\end{array}$ & 5,68 & 20 & $\begin{array}{l}\text { Sulfato penta hidratado de } \\
\text { cobree }\end{array}$ \\
\hline 7,19 & 30 & Ktenasita & $5,6.8$ & 10 & Withichunitit \\
\hline 7,12 & 100 & Langita & $5.6,4$ & 7 & - Bsurmonitit \\
\hline 7,1 & 100 & Spangolita & $5,6.1$ & 20 & Langita \\
\hline 7,02 & 5 & Germanita & 5,60 & 30 & Tyroliti \\
\hline 7,02 & 3 & Epídoto & 5.59 & 100 & Bandyliti: \\
\hline 7,01 & 20 & Lindgrenita & 5,56 & 20 & Roquesitit \\
\hline 6,97 & 30 & Vesignicita & 5,53 & 75 & Eske:bornita \\
\hline 6,96 & 50 & Bisgueita & 5,50 & 100 & Disboleita \\
\hline 6,96 & 40 & Veazelyita & 5,49 & 20 & Krochnkita \\
\hline $\begin{array}{l}6,94 \\
6,91\end{array}$ & $\begin{array}{r}40 \\
100\end{array}$ & $\begin{array}{l}\text { Vulcanita } \\
\text { Gerhardtita }\end{array}$ & 5,48 & 55 & $\begin{array}{l}\text { Sulfato pentil hiclratado de } \\
\text { cobre }\end{array}$ \\
\hline 6,90 & 50 & $\begin{array}{l}\text { Hidrogênio foufato hidratido } \\
\text { de cobrc }\end{array}$ & $\begin{array}{l}5,4 H \\
5,47\end{array}$ & 50 & $\begin{array}{l}\text { Cornetita } \\
\text { Cianotrichitil }\end{array}$ \\
\hline 6,80 & 11 & Antlerita & $\begin{array}{l}5,47 \\
5,47\end{array}$ & $\begin{array}{l}50 \\
30\end{array}$ & $\begin{array}{l}\text { Cianotrichitit } \\
\text { Vandenbrandeita }\end{array}$ \\
\hline
\end{tabular}

\begin{tabular}{|c|c|c|c|c|c|}
\hline$d(A)$ & 1 & Mineral & $d(A)$ & I & Mineral \\
\hline 5,47 & 20 & Carrollita & 4.93 & 20 & Dolerotanita \\
\hline 5,46 & 100 & Paratacamita & 4,93 & $\dot{6}$ & Brochantita \\
\hline 5,45 & 1 & Brochantita & 4,70 & 40 & Seligmanita \\
\hline 5,44 & 100 & Eriocalcita & 4.7 & 10 & Emplectita \\
\hline 5,42 & 5 & $\begin{array}{l}\text { Silicato de cobree } \\
\text { bario }\end{array}$ & 4,7 & 10 & Clinoclasita \\
\hline 5,4 & 100 & Sulvanita & 4,69 & 19 & Bonattita \\
\hline 5,4 & 78 & Brochantita & 4,69 & 13 & Malaquita \\
\hline 5,49 & 100 & Atacamita & 4,68 & 15 & Zoisita \\
\hline 5,40 & 23 & Antleritia & 4,67 & 10 & Calcostibinita \\
\hline $5,3 \mathrm{H}$ & 10 & gama Calcopirita & $4, i i \dot{0}$ & 50 & Callcocita \\
\hline 5,37 & 30 & Pjsanitil & 4,66 & 40 & Mottramita \\
\hline 5,37 & 5 & Estanita & 4,66 & 40 & Paratacamita \\
\hline 5,36 & 40 & Brochantita & 4,66 & 20 & $\begin{array}{l}\text { Sulfato penta hidratado de } \\
\text { colbre }\end{array}$ \\
\hline 5,36 & 40 & Ktenaaita & 4,65 & 20 & Turquesa \\
\hline 5. 36 & 5 & $\begin{array}{l}\text { Silicato de cestrôncio } \\
\text { c cobre }\end{array}$ & 4,65 & 14 & Veszelyita \\
\hline 5,35 & 60 & Cormulitit & 4.65 & 2 & Dolerophanita \\
\hline 5,32 & 30 & L.tnpit.1 & $4,6,4$ & $\%$ & Kitenasita \\
\hline 5,31 & 10 & Germanita & 4,62 & 1 & Eipidoto \\
\hline 5,30 & 100 & Murclochit.. & 4,61 & 20 & Finstita \\
\hline 5,10 & 90 & Midróxidu de cobre & 4. 60 & so & Sulfeto de cobre mognésio \\
\hline 5,30 & 5 & Renierila & 4,60 & 50 & Cobre magnésio \\
\hline 5,3 & 5 & Froibergita & 4. 110) & 30 & Duititit \\
\hline 5,27 & 50 & 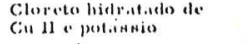 & $\begin{array}{l}7,54 \\
4,54\end{array}$ & 70 & Murdochita \\
\hline 5,27 & 40 & 'Iyroliti & $\begin{array}{l}4,54 \\
4,54\end{array}$ & 50 & Veaignicita \\
\hline 5,26 & 90 & Vanclenterandectit & $\begin{array}{l}1,54 \\
+1,54\end{array}$ & 10 & Armeniato hidratide de Gobre(1) \\
\hline 5,26 & so & Cinnotrichitat & $\begin{array}{l}4,54 \\
4,57\end{array}$ & 20 & Cuprodencloizitit \\
\hline 5,26 & 20 & Framatinita & $\begin{array}{l}4,57 \\
+, 56\end{array}$ & + & Clinozoisita \\
\hline $5,2.5$ & 15 & Silicatu de cobrese bírio & $\begin{array}{l}4,36 \\
4,55\end{array}$ & 10 & Gerhardtita \\
\hline 5,32 & 15 & (enypti.un bluw) & 4,55 & $\begin{array}{l}40 \\
30\end{array}$ & Wittichenit. \\
\hline 5,22 & 10 & Wittichenita & 4,53 & 100 & Cornetita \\
\hline 5,22 & 10 & Cornubita & 4,53 & 20 & $\begin{array}{l}\text { Cornwallita } \\
\text { Lindackerita }\end{array}$ \\
\hline 5,21 & 20 & Volborthitit & 4,53 & 10 & $\begin{array}{l}\text { Lindackerita } \\
\text { Cornubita }\end{array}$ \\
\hline $5,2.1$ & 9 & Sulfato penta hidratado de & 4.52 & 10 & $\begin{array}{l}\text { Cornubita } \\
\text { Lindackerita? }\end{array}$ \\
\hline 5,2 & 5 & cobre & 4,52 & 9 & Antlerita \\
\hline 5.19 & 10 & Tetracdrita & 4,50 & 25 & Calcocita \\
\hline 5,18 & 60 & Luzonita & 4,49 & 80 & Erinita \\
\hline 5,15 & 55 & Lindackeritia & 4,49 & 10 & Turquesa \\
\hline 5,15 & 25 & $\begin{array}{l}\text { Azurita } \\
\text { Sulfato penta hiciratiado da }\end{array}$ & 4,48 & 30 & Veszelyita \\
\hline 3,13 & 23 & $\begin{array}{l}\text { Sulfato penta hiciratiado de } \\
\text { cobre }\end{array}$ & $\begin{array}{l}4,48 \\
4,46\end{array}$ & 20. & $\begin{array}{l}\text { Faustita } \\
\text { Mixita }\end{array}$ \\
\hline 5,15 & 6 & Brochantita & 4,44 & 100 & Vandenbrandeita \\
\hline 5,15 & 5 & Lindgrenita & 4,44 & 50 & Tyrolita \\
\hline 5.12 & so & Descloiziti & 4,44 & 17 & Barita \\
\hline 5,10 & 6 & Veszelyita & 4,44 & 10 & Pisanita \\
\hline 5,09 & 65 & Bonattitn & 4,44 & 8 & Clinozoisita \\
\hline 5,08 & 30 & Azurita & 4,43 & 100 & Plancheitia \\
\hline 5.07 & 80 & Mottramita & 4,43 & 100 & Shattuckita \\
\hline 5,07 & 60 & Cornetita & 4,43 & 50 & Sulfeto de cobre magnésio \\
\hline 5,07 & 10 & Cianotrichita & 4,43 & 50 & Cobre magnésio \\
\hline 5,06 & 30 & Krochnkita & 4,43 & 10 & Crisocola \\
\hline 5,06 & 20 & A.rseniato hidratido de $\mathrm{C}$ & 4,42 & 70 & Silicato de cobre e bário \\
\hline 5,05 & 75 & Malaquita & 4,40 & 100 & Bonattita \\
\hline 5,05 & $(3-5)$ & Brochantita & 4,40 & 25 & Calcocita \\
\hline 5,03 & 50 & Zoisita & 4,38 & 20 & Cuprobismutita \\
\hline 5,03 & 40 & Duftita & 4,38 & 10 & gama Calcopirita \\
\hline 5,01 & .40 & Eipidoto & 4,38 & 1 & Brochantita \\
\hline 5,01 & 35 & Clinozoisita & 4,35 & 60 & Banciylita \\
\hline 5,00 & 100 & Alaciamita & 4,35 & 30 & Seligmanita \\
\hline $4.9 \%$ & 11 & Aæuriti: & 4,35 & 15 & Bournonita \\
\hline 1.98 & 10 & Lindlackeritit? & 4,35 & 10 & Gerhareltita \\
\hline 4,97 & 60 & Gocthiti & 4,34 & 35 & Lindigrenita \\
\hline 4,97 & 60 & Plancheitil & 4,34 & 30 & Tyrolita \\
\hline 4,97 & 50 & $\begin{array}{l}\text { Hidrogênio fosfato hi- } \\
\text { dratado de colbre }\end{array}$ & 4,33 & 40 & Silicato de estrôncio e cobre \\
\hline . .97 & 5 & Lindgrenitit & 4,33 & 8 & Liroconita \\
\hline 4,96 & 60 & Cuprodescloizita & 4,32 & 50 & Paxita \\
\hline 4,96 & 50 & Vesignieita & 4,32 & 20 & Germanita \\
\hline 4.96 & 10 & Lautita & 4,32 & 14 & Vorselyita \\
\hline 4,96 & 10 & Galcosicleritia & 4,31 & 40 & Cornubita \\
\hline 4,96 & 3 & Brochantita & 4,31 & 20 & Renierita \\
\hline 4,95 & 70 & Shattuckita & 4,3 & 60 & Clinoclasita \\
\hline & & & 4,30 & 10 & Betechtinita \\
\hline
\end{tabular}




\begin{tabular}{|c|c|c|}
\hline$d(A)$ & 1 & Mineral \\
\hline 4,29 & 90 & Cornetita \\
\hline 4,29 & 5 & Freibergita \\
\hline 4,29 & 5 & Kroenkita \\
\hline 4,28 & 13 & $\begin{array}{l}\text { Sulfato penta hidratado de } \\
\text { colore }\end{array}$ \\
\hline 4. 28 & 10 & D) jurleita \\
\hline 4,27 & 50 & Calcocita \\
\hline 4,26 & 35 & Quartzo alfa \\
\hline 4,26 & 30 & Langita \\
\hline 4,26 & 20 & Ktenasita \\
\hline 4,25 & 60 & Descloizita \\
\hline 4,25 & 8 & Zoisita \\
\hline 4,25 & 1 & Brochantita \\
\hline 4,24 & 60 & Mottramita \\
\hline 4,23 & 20 & Linclackerita \\
\hline 4,21 & 50 & Duftita \\
\hline 4,20 & 10 & Dioptáвio \\
\hline 4,19 & 60 & Olivenita \\
\hline 4,19 & 20 & Faustita \\
\hline 4,19 & 10 & Volborthita \\
\hline 4,18 & 100 & Goethita \\
\hline 4,18 & 75 & Calcoryanita \\
\hline 4,18 & 40 & Mixitn \\
\hline 4,18 & 10 & Turquesa \\
\hline 4,18 & 10 & Calcosiderita \\
\hline 4,15 & 75 & Caciovolborthita \\
\hline 4,15 & 60 & Diaboleita \\
\hline 4,15 & 55 & Lindgrenita \\
\hline 4,15 & 40 & Cuprodescloizita \\
\hline 4,15 & 10 & Tenantita \\
\hline 4,15 & 5 & Pisitniti \\
\hline 4,14 & 40 & Krochnkitit \\
\hline 4,13 & 60 & Bandylita \\
\hline 4,13 & 8 & Antlerita \\
\hline 4,12 & 50 & Gerharcltita \\
\hline 4,11 & 10 & Libethenita \\
\hline 4,10 & 30 & Meneghinita \\
\hline 4,09 & 30 & Ktenasita \\
\hline 4,08 & 30 & Aikinita \\
\hline 4,08 & 20 & Bournonita \\
\hline 4,08 & 20 & Novakita \\
\hline $4,0 \mathrm{H}$ & 10 & Bornita \\
\hline 4,06 & 70 & Dioptásio \\
\hline 4,06 & 30 & Bisgeeita \\
\hline 4,06 & 20 & Seligmanita \\
\hline 4,06 & 10 & Turquesa \\
\hline 4,05 & 40 & Faustita \\
\hline 4,05 & 40 & Zoirita \\
\hline 4,04 & 80 & Lindackerita \\
\hline 4,03 & 40 & Paratacamita \\
\hline 4,03 & 10 & Silicato de cobre e bário \\
\hline 4,03 & 10 & Volborthita \\
\hline 4,03 & 3 & Dolomita \\
\hline 4,02 & .14 & Eriocalcita \\
\hline 4,01 & 10 & Tyrolitit \\
\hline 4,00 & 40 & Descloizita \\
\hline 4,00 & 40 & Dinbolcita \\
\hline 4,00 & 11 & $\begin{array}{l}\text { Sulfato penta hidratado de } \\
\text { colbre }\end{array}$ \\
\hline 4,00 & 10 & Paxita \\
\hline 4,00 & 10 & Pisanita \\
\hline 4,00 & 5 & Clinoclaeita \\
\hline 3,99 & 60 & $\begin{array}{l}\text { Sulfato penta hidratado de } \\
\text { cobre }\end{array}$ \\
\hline 3.99 & 40 & Epídoto \\
\hline 3,99 & 40 & Mottramita \\
\hline 3,99 & 30 & Clinozoisitit \\
\hline 3,98 & 10 & Strommicrita \\
\hline 3,97 & 30 & Vandenbrandeita \\
\hline 3.96 & 35 & Bonattita \\
\hline 3,96 & 10 & $\begin{array}{l}\text { Ilidropinio fosfato hidratado } \\
\text { de colbre }\end{array}$ \\
\hline 3,95 & 60 & Lindackerita \\
\hline 3,95 & 40 & Alfa diomeykita \\
\hline 3,95 & 30 & Duftita \\
\hline 3,95 & 10 & Gerharcltita \\
\hline 3,95 & 10 & Liroconita \\
\hline 3,95 & 5 & Lautita \\
\hline
\end{tabular}

\begin{tabular}{|c|c|c|}
\hline$d(A)$ & 1 & Minęral \\
\hline 3,75 & 2 & Dolerophanita \\
\hline 3,94 & 100 & $\begin{array}{l}\text { Arereniato hidrataclo do } \\
\text { colere }\end{array}$ \\
\hline 3.94 & 20 & Mixita \\
\hline 3,93 & 70 & $\begin{array}{l}\text { Arseniato hidratido de } \\
\text { cobre (II) }\end{array}$ \\
\hline 3,93 & 70 & Ktenasita \\
\hline 3,93 & 20 & Bisgecita \\
\hline 3,93 & 20 & Cornubita \\
\hline 3,92 & 50 & Liroconitia \\
\hline 3,92 & 20 & Cuprodescloizita \\
\hline 3,92 & 6 & Calcocyanita \\
\hline 3,91 & 100 & 13rochantita \\
\hline 3,91 & 40 & $\begin{array}{l}\text { Cloreto hidratado de co- } \\
\text { bre (II) e potássio }\end{array}$ \\
\hline 3,91 & 20 & Liroconsta \\
\hline 3,90 & 85 & Drochantita \\
\hline 3,90 & 56 & Barita \\
\hline 3,90 & 20 & E:rinita \\
\hline 3,89 & 10 & Djurleitit \\
\hline 3,88 & 90 & Cynnitrichita \\
\hline 3, 48 & 30 & Silicato de estróncio e obre \\
\hline 3,86 & 20 & Fiskebornita \\
\hline 3. $\mathrm{H6}$ & 20 & Nakasritit \\
\hline 3,36 & 12 & Calcita \\
\hline 3,86 & 3 & Azurita \\
\hline 3.85 & 50 & Calcocita \\
\hline 3,85 & 40 & Vandenbrandeita \\
\hline 3,85 & 20 & Lindackerita \\
\hline 3,84 & 35 & Bournonita \\
\hline 3,83 & 80 & Villeritit \\
\hline 3,83 & 30 & Wittichenitit \\
\hline $3, \mathrm{H}_{3}$ & 5 & Tyrolita \\
\hline 3,82 & 60 & Paxita \\
\hline 3,82 & 25 & Culcocita \\
\hline 3,80 & 40 & Olivenitit \\
\hline 3,80 & 10 & Novakita \\
\hline 3,80 & 7 & Azurita \\
\hline 3,79 & 16 & Antlerita \\
\hline 3,79 & 5 & Aikinita \\
\hline 3,78 & 90 & Egyptian Blue \\
\hline 3.77 & 100 & Calcosiderita \\
\hline 3,77 & 50 & Calcocita \\
\hline 3,77 & 50 & Pisanita \\
\hline 3,77 & 12 & Barita \\
\hline 3,76 & 35 & Calcopirita \\
\hline 3,76 & 1 & Epídeto \\
\hline 3,75 & 20 & Djurleiti \\
\hline 3,75 & 10 & Fiamatinitit \\
\hline 3,75 & 5 & Renicritil \\
\hline 3,74 & 5 & Bisguentit \\
\hline 3,73 & 100 & Ilidróxiclo de cobre \\
\hline 3.73 & 75 & Calcocitit \\
\hline 3,73 & 60 & Ktenisitia \\
\hline 3,73 & 40 & Calciovolborthita \\
\hline 3,73 & 5 & Germanita \\
\hline$-3,72$ & 60 & Micrsitit \\
\hline 3,72 & 40 & Nakisecita \\
\hline 3,72 & 12 & Clinozoirita \\
\hline 3,72 & 10 & Perarceita \\
\hline 3,72 & 5 & Silicito de cobre e bário \\
\hline 3,72 & 2 & Eriocalcita \\
\hline 3,71 & 85 & $\begin{array}{l}\text { Sulfato penta hidratado de } \\
\text { cobre }\end{array}$ \\
\hline 3,71 & 60 & Krochnkita \\
\hline 3,71 & 15 & Dioptíaico \\
\hline 3,70 & 90 & Mencghinita \\
\hline 3,69 & 85 & Mallaquitia \\
\hline 3. 69 & 70 & Libethernitit \\
\hline 3,69 & 20 & Bournonita \\
\hline 3,69 & 10 & Freibergiti \\
\hline $3,6,9$ & 10 & Tetratulestat \\
\hline 3,69 & ? & Hemattit." \\
\hline 3,69 & i" & Lisoscmitit \\
\hline 3,69 & 5 & 5 Dolonita \\
\hline 3,69 & 2 & 2 birincialcita \\
\hline 3. 6.8 & 100 & D Faustitit \\
\hline 3,68 & 70 & 0 Cornetit: \\
\hline
\end{tabular}

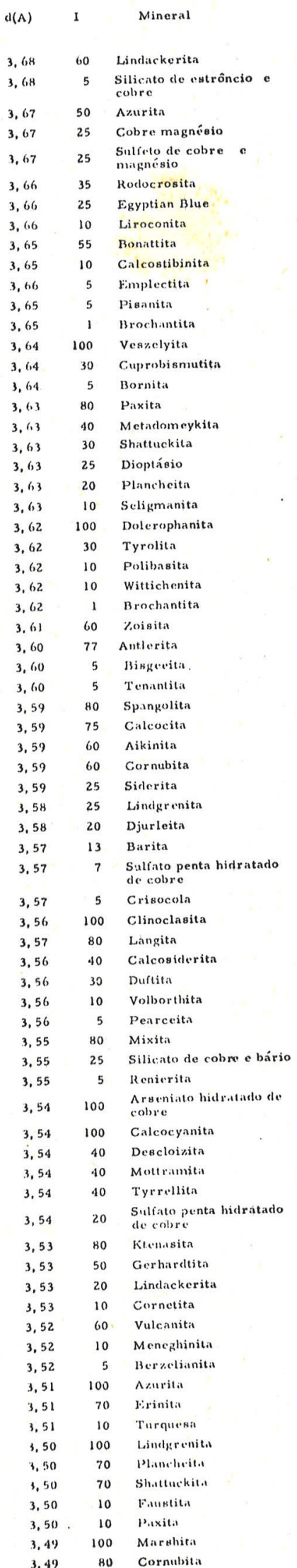

\begin{tabular}{|c|c|c|}
\hline$d(A)$ & $x$ & Mineral \\
\hline 3.49 & 40 & Epidoto \\
\hline $3,+9$ & 40 & Cubanita \\
\hline 3,49 & 10 & Calciovolborthita \\
\hline 3.49 & 10 & Vandenbrandeita \\
\hline 3,48 & 30 & Veszelyita \\
\hline 3,48 & 7 & $\begin{array}{l}\text { Sulfato penta hidratado } \\
\text { de cobre }\end{array}$ \\
\hline 3,48 & 5. & Bornita \\
\hline 3,48 & 5 & Polibasita \\
\hline 3,47 & 40 & Cuprodescloizita \\
\hline 3,47 & 30 & Vulcanita \\
\hline 3,47 & 25 & Calcocita \\
\hline 3,47 & 25 & Clinozoisita \\
\hline 3.47 & 25 & Lindgrenita \\
\hline 3,47 & 10 & Vesignieita \\
\hline 3,46 & 70 & Stromeyerita \\
\hline 3,46 & 50 & Pseudomalaquita \\
\hline 3,46 & 30 & Cornwallita \\
\hline 3,46 & 25 & Sulfato hidratado de cobre \\
\hline 3,46 & 5 & Cuprobismutita \\
\hline 3,45 & 60 & Gerhardtita \\
\hline 3,45 & 20 & $\begin{array}{l}\text { Vanadato hidratado basi- } \\
\text { co de cobre }\end{array}$ \\
\hline 3,45 & 17 & $\begin{array}{l}\text { Sulfato penta hidratado } \\
\text { de cobre }\end{array}$ \\
\hline 3,45 & 5 & Eucairita \\
\hline 3,44 & 100 & Barita \\
\hline 3,44 & 70 & Turquesa \\
\hline 3,44 & 60 & Faustita \\
\hline 3.44 & 50 & $\begin{array}{l}\text { Silicnto de estrôncio } \\
\text { e cobre }\end{array}$ \\
\hline 3,43 & 100 & Sulfato hidratado de cobre \\
\hline 3,43 & 30 & Tyrolitin \\
\hline 3,42 & 50 & Bonattita \\
\hline 3,421 & 10 & Cornubita \\
\hline 3,42 & 5 & Germanita \\
\hline 3,41 & 60 & Nakas eita \\
\hline 3,41 & 40 & Lindackerita \\
\hline 3,41 & 25 & Calcocita \\
\hline $3,+1$ & 20 & Alfa domeykita \\
\hline 3,40 & 40 & Vandenbrandeita \\
\hline 3.40 & 31 & Antlerita \\
\hline 3,40 & 20 & Shattuckita \\
\hline 3,40 & 14 & Liroconita \\
\hline 3,40 & 4 & Dolerophanita \\
\hline 3,39 & 70 & Galcosiderita \\
\hline 3,39 & 40 & Paratacamita \\
\hline $3,3 \mathrm{~s}$ & 100 & $\begin{array}{l}\text { Silicato de cobre e } \\
\text { bírio }\end{array}$ \\
\hline 3,39 & 80 & Sulfato hidratado de cobre \\
\hline 3,39 & 50 & Djurleita \\
\hline 3,38 & 35 & Cyanotrichita \\
\hline 3,38 & 30 & Ktenasita \\
\hline 3,39 & 5 & Idiatita \\
\hline $3,3 i$ & 8 & Clinozoisita \\
\hline 3,37 & 7 & Epícloto \\
\hline 3,37 & 5 & Pisanita \\
\hline 3,30 & so & Egyptian blue \\
\hline 3,34 & 60 & Goethita \\
\hline 3,36 & 20 & Liroconita \\
\hline 3,36 & 5 & $\begin{array}{l}\text { Hidrogênio fosfato hidra- } \\
\text { tado de cobre }\end{array}$ \\
\hline 3,35 & 80 & Rickardita \\
\hline 3,35 & 58 & Tyrrellita \\
\hline 3,35 & 40 & Carrollita \\
\hline 3,35 & 10 & Djurleita \\
\hline 3,35 & 10 & Novakita \\
\hline 3,34 & 100 & Quartzo alfa \\
\hline 3,34 & 100 & $\begin{array}{l}\text { Silicito de estrôncio o } \\
\text { cubre }\end{array}$ \\
\hline $3,3.4$ & 30 & Descloizita \\
\hline $3,3+$ & 30 & Krochnkita \\
\hline $3,1.4$ & 10 & Renierila \\
\hline 3,34 & 10 & Wiltichenita \\
\hline 3,34 & 9 & Antleriti \\
\hline 3,34 & 5 & Bournonit. \\
\hline 3.34 & s & Germanita \\
\hline 3,34 & 4 & Calcocyanita \\
\hline 3,34 & 2 & Vulcanita \\
\hline
\end{tabular}




\begin{tabular}{|c|c|c|c|c|c|c|c|c|c|c|c|}
\hline$i(A)$ & I & Mineral & $d(A)$ & 1 & Mineral & $\|(\Lambda)$ & 1 & Mineral & $\mathrm{d}(\Lambda)$ & 1 & Mineral \\
\hline 3,33 & 90 & Berzelianita & 3,19 & 90 & Polibasita & 3.08 & 10 & Novakita & 3,00 & 20 & Gerhardtitia \\
\hline 3,33 & 80 & Stromeyerita & 3,19 & 80 & Aikiniti: & 3.07 & 100 & Calcopirita gama & 3,00 & 20 & Turquesa \\
\hline 3,33 & 60 & Cornubita & 3,19 & 80 & Lindiackerita & 3,07 & 100 & Famatinita & 3,00 & 18 & Antleritia \\
\hline 3,33 & 50 & Calcocita & 3,19 & 50 & Egyptian blue & 3.07 & 100 & Cuprobismutita & 3,00 & 5 & Idaita \\
\hline 3,32 & 70 & Plancheita & 3,19 & 40 & Brochantita & 3,07 & 60 & Stromeyerita & 2.99 & 40 & Duftita \\
\hline 3,32 & 60 & Koutekita & 3,19 & 30 & Djurleita & 3,07 & 10 & Gerharcltita & 2.99 & 40 & Nakaseita \\
\hline 3,32 & 50 & Biнgeciti & 3.19 & 15 & 1.ppicletes & 3,07 & 10 & Mencghinita & 2.99 & $25^{\circ}$ & Bournonita \\
\hline 3,32 & 7 & B rocautlth & 3,19 & 10 & Limlgroniti: & 3,07 & 10 & Pis.ınit.ı & $\therefore, \%$ & 20 & Finetitia \\
\hline 3,32 & 2 & Eriocalcita & 3,18 & no & Lindlackerita & 3.07 & 4 & Eriocalcit., & 2,99 & 10 & Lautita \\
\hline 3,32 & 2 & Zoisita & 3.18 & 75 & Calcocita & 3,06 & 100 & Calcopirita beta & 2.98 & 100 & Olivenita \\
\hline 3,31 & 100 & Diaboleita & 3,18 & 58 & Tyrrellitin & 3,06 & 100 & Renicrita & 2.98 & 80 & Tyrolita \\
\hline 3,31 & но & Shittucklt:i & 3,18 & 50 & Dinptínio & 3,06 & R() & Mithroginion fostinto hidra. & 2,98 & 60 & Cornubit: \\
\hline 3,31 & 75 & Calcocita & 3,18 & 40 & Arseniato hidratide de & & & tacke de cobre & 2.98 & io & Cuprodencloiziti: \\
\hline 3,31 & 67 & Barita & 3,6 & 40 & cobre II & 3.06 & 70 & Cornwillitit & 2,98 & 40 & Volborthita \\
\hline 3,31 & 11) & Bornita & 3.18 & 35 & Bonattita & 3,06 & 15 & $\begin{array}{l}\text { Sulfiato pentil hidratado de } \\
\text { colire }\end{array}$ & 2.98 & 17 & Malaquita \\
\hline 3,31 & 30 & Mottramilta & 3,18 & 30 & $\begin{array}{l}\text { Krorbnkit. } \\
\text { Langit:I }\end{array}$ & 3.06 & $(1-2)$ & Hrochantit.: & 2.94 & 1 & 13rochantita \\
\hline 3,30 & 100 & $\begin{array}{l}\text { Nakan cita } \\
\text { Sulfato penta hidratado de }\end{array}$ & 3,18 & 20 & & 3,06 & 1 & 1.pílutu & 2,97 & so & Vandenbrindeita \\
\hline 3. 30 & 60 & $\begin{array}{l}\text { Sulfato penta hidratado de } \\
\text { cobre }\end{array}$ & 3,18 & 17 & $\begin{array}{l}\text { Sulfiato penta hidratado de } \\
\text { colire }\end{array}$ & 3.05 & 100 & Emplectita & 2,97 & 50 & Vesignieita \\
\hline 3,30 & 50 & Paxita & 3,18 & 16 & $\begin{array}{l}\text { Clinozoisita } \\
\text { Riagreita }\end{array}$ & 3,05 & 100 & Germanita & 2,97 & 40 & Pseudomalaguita \\
\hline 3. 30 & 25 & Dioptísio & 3,18 & 10 & $\begin{array}{l}\text { Risgerita } \\
\text { Vulcanita }\end{array}$ & 3,05 & 75 & Calcocita & 2.97 & 40 & Seligmanita \\
\hline 3,29 & 100 & Egyptian blue & 3.18 & 2 & $\begin{array}{l}\text { Vulcanita } \\
\text { Cornetita }\end{array}$ & 3,05 & 60 & Cornuliti & 2,97 & 20 & Bonattitit \\
\hline 3,29 & 100 & Meneghinita & 3,17 & 80 & $\begin{array}{l}\text { Cornetita } \\
\text { Erinita }\end{array}$ & 3.05 & 40 & Domeykita alfa & 2.97 & 5 & E.nargita \\
\hline 3,29 & 100 & Valleriita & 3.17 & 80 & Erinita & 3,05 & 40 & Egyptiam blue & 2,97 & 3 & $\begin{array}{l}\text { Sulfato penta hidratido } \\
\text { colbre }\end{array}$ \\
\hline 3,28 & 70 & Turquesa & 3,17 & 60 & $\begin{array}{l}\text { Arseniato hidratado de } \\
\text { colyre }\end{array}$ & 3,05 & 30 & Sulfato penta hidratado de & 2,96 & 80 & Mixita \\
\hline 3,28 & 60 & Fauatita & 3,17 & 4 & Cillocyanita & 3,05 & 20 & $\begin{array}{l}\text { cobre } \\
\text { Turquesa }\end{array}$ & 2,96 & 50 & Calcocita \\
\hline 3,23 & 40 & Lindackerita & 3,16 & 100 & Paxita & 3,05 & 10 & $\begin{array}{l}\text { Turquesa } \\
\text { Digenita }\end{array}$ & 2.96 & 20 & Bisgecita \\
\hline 3,28 & 30 & Djurleita & 3,16 & 100 & Ruquesita & 3,04 & 100 & $\begin{array}{l}\text { Digenita } \\
\text { Cornetita }\end{array}$ & 2.96 & 20 & Langita \\
\hline 3,28 & 20 & Cuprodescloizita & 3.16 & 40 & Novakita & 3,04 & 100 & $\begin{array}{l}\text { Cornetita } \\
\text { Luzonita }\end{array}$ & 2,96 & 20 & Lindgrenita \\
\hline 3,28 & 14 & Covelita & 3,16 & 15 & Cynnotrichita & & & Luzonita & 2,96 & 10 & Wittichenita \\
\hline 3,28 & 10 & Calciovolborthita & 3.15 & 10 & Eucairita & 3,04 & 70 & $\begin{array}{l}\text { Silicato de estrôncio e } \\
\text { cobre }\end{array}$ & 2,96 & 5 & Germanita \\
\hline 3,28 & 9 & Bonattit: & 3.15 & 10 & Dularophlanitit & 3,04 & 67 & Covelita & 2,96 & 5 & Renierita \\
\hline $3,1.8$ & 5 & Jolil., нік., & 3.14 & 11111 & 1.1..11.1. & 3.04 & 6.0 & Klonatuit., & 2.96 & 3 & Azurita \\
\hline$\therefore 24$ & 1 & Broulsitrititis & 3.14 & Ho & Cilinos:lanita & 3.0 .1 & 10 & Cy.tuntrichitit & 2.95 & 75 & Citloositit \\
\hline 3,27 & 90 & Krochnkita & 3,14 & 75 & $\begin{array}{l}\text { Sulfito hidratado de } \\
\text { cobre }\end{array}$ & 3,04 & 40 & Deacloizita & 2.95 & 60 & Ktenasit., \\
\hline 3,27 & 75 & Calcocita & & & & 3,04 & 30 & Djurlsit, & 2.95 & 50 & Cornetita \\
\hline 3,27 & 60 & Idnitil & $\begin{array}{l}3,14 \\
3,13\end{array}$ & $\begin{array}{r}60 \\
100\end{array}$ & $\begin{array}{l}\text { Calciovolborthita } \\
\text { Calcostibiniti }\end{array}$ & 3,04 & 20 & Pseudomalaquita & 2,95 & 40 & Lindickerita \\
\hline 3,27 & 40 & $\begin{array}{l}\text { Cloreto hidratado de cobre II } \\
\text { e potásaio }\end{array}$ & $\begin{array}{l}3,13 \\
3,13\end{array}$ & $\begin{array}{r}100 \\
80\end{array}$ & $\begin{array}{l}\text { Calcostibiniti } \\
\text { Cuprodescloirita }\end{array}$ & 3,04 & 5 & Bifgerita & 2.95 & 25 & Veszelyita \\
\hline 3,27 & 10 & Betechtinita & $\begin{array}{l}3,13 \\
3,13\end{array}$ & 70 & $\begin{array}{l}\text { Cuprodescloirita } \\
\text { t.mplectita }\end{array}$ & 3,04 & 5 & Roquesitia & 2,95 & 20 & Famitinita \\
\hline 3,27 & 5 & Pseudomalaquita & 3 & & $\begin{array}{l}\text { L.mplectita } \\
\text { Cloreto hidratado de }\end{array}$ & 3,03 & 100 & Calcita & 2,95 & $5 B$ & Cuprobismutita \\
\hline 3,26 & 100 & Durtita & 3,13 & 50 & $\begin{array}{l}\text { Cloreto hidratado de } \\
\text { cobre Il e potásaio }\end{array}$ & 3,03 & 100 & Calcopiriti & 2.94 & 100 & Tenantita \\
\hline 3,26 & 50 & Mixita & 3.13 & 20 & Vanclenbrancleita & $\begin{array}{l}3.03 \\
3.03\end{array}$ & 90 & Arsenosulvanita & 2,94 & $70 \mathrm{~B}$ & $\begin{array}{l}\text { Arseniato hidratado de } \\
\text { cobre II }\end{array}$ \\
\hline 3,26 & 20 & Bournonita & 3,13 & 10 & Pisanita & $\begin{array}{l}3,03 \\
3,03\end{array}$ & 70 & Erinita & 2.94 & 20 & Brocantita \\
\hline 3,26 & 20 & Sulfato penta hidratado de cobre & 3,12 & 100 & E. staniti & $\begin{array}{l}3,03 \\
3,03\end{array}$ & 40 & Mottramitit & 2,93 & 90 & Betecintinita \\
\hline 3,26 & 10 & Tyrolita & 3,12 & 60 & $\begin{array}{l}\text { Silicato lo estrôncio e } \\
\text { cobre }\end{array}$ & $\begin{array}{l}3,03 \\
3,03\end{array}$ & 35 & Clinozoisita & 2,93 & 80 & Diaboleita \\
\hline 3,25 & 80 & Murdochita & & 50 & Sulvanita & $\begin{array}{l}3,03 \\
3,03\end{array}$ & 30 & Rickardita & 2,93 & 75 & Calcocita \\
\hline 3,25 & 40 & Cuprobismutita & $\begin{array}{l}3,12 \\
3,12\end{array}$ & $\begin{array}{l}50 \\
30\end{array}$ & $\begin{array}{l}\text { Sulvanita } \\
\text { Culbanita }\end{array}$ & $\begin{array}{l}3,03 \\
3,03\end{array}$ & 20 & Gerharditita & 2,93 & 60 & Cornubita \\
\hline 3,25 & 20 & Vandenbrandeita & 3,12 & 20 & PBeudomalaquita & $\begin{array}{l}3,03 \\
3,03\end{array}$ & 20 & Fiustita & 2,93 & 40 & Shattuckita \\
\hline 3,25 & 16 & Nakascita & 3,12 & 5 & Plancheita & $\begin{array}{l}3,03 \\
3,03\end{array}$ & 10 & Paxiti & 2,93 & 30 & Pseudomalnquita \\
\hline 3,25 & 6 & Clinozoisita & 3,11 & 50 & Peirceita & $\begin{array}{l}3,03 \\
3.03\end{array}$ & 8 & Veszelyita & 2,93 & 20 & Gerharditita \\
\hline 3,24 & 100 & Mottramita & 3,11 & 25 & Calcocita & $\begin{array}{l}3,03 \\
3,02\end{array}$ & 1 & Brochantita & 2,93 & 10 & Cyanotrichita \\
\hline 3,24 & 65 & Bonattita & 3,11 & 20 & Shattuckita & $\begin{array}{l}3,02 \\
3,02\end{array}$ & 100 & Emplectita & 2,92 & 90 & Libethenita \\
\hline 3,24 . & 30 & Pisanita & 3,11 & 10 & Linelgreniti & $\begin{array}{l}3,02 \\
3,02\end{array}$ & 80 & Tyrrellita & 2,92 & 80 & Crisocola \\
\hline 3,23 & 100 & Miersita & 3,10 & 100 & Emplectita & $\begin{array}{l}3,02 \\
3,02\end{array}$ & 60 & Calcosiclerita & 2,92 & 80 & Krochnkita \\
\hline 3,23 & 100 & Dercloizita & 3,10 & 100 & Lautiti & $\begin{array}{l}3,02 \\
3,029\end{array}$ & 17 & Malinquita & 2.92 & 60 & Faustiti \\
\hline 3,23 & 90 & Emplectita & 3.10 & 97 & Bariti & $\begin{array}{l}3,029 \\
3,02\end{array}$ & 12 & Marshita & 2,92 & 20 & Brochantita \\
\hline 3,23 & 80 & $\begin{array}{l}\text { Valleriita } \\
\text { Sillicato de estrôncio c cobre }\end{array}$ & 3,10 & 60 & Bornita & $\begin{array}{l}3,02 \\
3,02\end{array}$ & 9 & Cuprita & 2,92 & 20 & Cuprodescloizita \\
\hline 3,23 & 30 & Silicato de estróncio c cobre & 3,10 & 60 & Cornubita & $\begin{array}{l}3,02 \\
3,01\end{array}$ & 5 & Mottramita & 2,92 & 15 & Dioptísio \\
\hline 3,23 & 5 & $\begin{array}{l}\text { Tenantita } \\
\text { Vulcanita }\end{array}$ & 3,10 & 40 & Turquesa & $\begin{array}{l}3,01 \\
3,01\end{array}$ & $(20-30)$ & Novikita & 2,92 & 10 & Lindigrenita \\
\hline 3,23 & 2 & Vulcanita & 3,10 & 35 & Zoisita & $\begin{array}{l}3,01 \\
3,01\end{array}$ & 30 & Djurlsiti & 2,92 & 10 & Liroconita \\
\hline 3,22 & 100 & $\begin{array}{l}\text { Cubanita } \\
\text { Enargita }\end{array}$ & 3,10 & 20 & Djurleita & $\begin{array}{l}3,01 \\
3,01\end{array}$ & 25 & Cromita de cobre II & 2,92 & 9 & Azurita \\
\hline 3.22 & 100 & $\begin{array}{l}\text { Enargita } \\
\text { Seligmanita }\end{array}$ & 3,10 & 11 & Azurita & $\begin{array}{l}3,01 \\
3,01\end{array}$ & 10 & Dioptásio & 2,92 & 8 & Luzonita \\
\hline 3.22 & 30 & $\begin{array}{l}\text { Seligmanita } \\
\text { Covelita }\end{array}$ & 3,09 & 40 & Kroehnkita & $\begin{array}{l}3,01 \\
3,01\end{array}$ & 10 & $\begin{array}{l}\text { Langitin } \\
\text { Liroconita }\end{array}$ & 2,91 & 80 & Meneghinita \\
\hline 3,22 & 28 & $\begin{array}{l}\text { Covelita } \\
\text { Brochantita }\end{array}$ & 3,09 & 40 & Lindackerita & $\begin{array}{l}3,01 \\
3,01\end{array}$ & 10 & $\begin{array}{l}\text { Liroconita } \\
\text { Piganita }\end{array}$ & 2,91 & 80 & Turquesa \\
\hline 3,22 & 2 & $\begin{array}{l}\text { Brochantita } \\
\text { Dolerophanita }\end{array}$ & 3,09 & 40 & Pscudomalaquita & $\begin{array}{l}3,01 \\
3,01\end{array}$ & 10 & $\begin{array}{l}\text { Pisanita } \\
\text { Bornita }\end{array}$ & 2,91 & 5 & Liroconita \\
\hline 3.22 & 2 & $\begin{array}{l}\text { Dolerophanita } \\
\text { Vesignicita }\end{array}$ & 3,09 & 16 & Antlerita & $\begin{array}{l}3,01 \\
3,01\end{array}$ & 5 & $\begin{array}{l}\text { Bornitn } \\
\text { Brochantita }\end{array}$ & 2,90 & 100 & Epídoto \\
\hline 3,21 & 100 & $\begin{array}{l}\text { Vesignicita } \\
\text { Digenita }\end{array}$ & 3,08 & 80 & Betechtinita & $\begin{array}{l}3,01 \\
3,00\end{array}$ & 1 & Brochantita & 2,90 & 80 & Descloizita \\
\hline 3,21 & 40 & $\begin{array}{l}\text { Digenita } \\
\text { Metadomeykita }\end{array}$ & 3,08 & 80 & Bandylita & 3,00 & $\begin{array}{l}100 \\
100\end{array}$ & $\begin{array}{l}\text { Freibergita } \\
\text { Pearceita }\end{array}$ & 2.90 & 60 & Plancheita \\
\hline 3,21 & 20 & $\begin{array}{l}\text { Metadomeykita } \\
\text { Emplectita }\end{array}$ & 3,08 & 60 & Lindlickerita & 3,00 & $\begin{array}{l}100 \\
100\end{array}$ & $\begin{array}{l}\text { Pearceita } \\
\text { Polibasita }\end{array}$ & 2,90 & 20 & Bournonita \\
\hline 3,20 & 90 & $\begin{array}{l}\text { Emplectita } \\
\text { Silicato de cobre e bário }\end{array}$ & 3,08 & 40 & Enargita & 3,00 & $\begin{array}{l}100 \\
100\end{array}$ & $\begin{array}{l}\text { Polibasita } \\
\text { Tetraedrita }\end{array}$ & 2,90 & 20 & Langita \\
\hline 3,20 & 80 & $\begin{array}{l}\text { Silicato de cobre e bário } \\
\text { Brocantita }\end{array}$ & 3.08 & 40 & Faustita & 3,00 & $\begin{array}{r}100 \\
90\end{array}$ & $\begin{array}{l}\text { Tetraedriti } \\
\text { Calcostibinita }\end{array}$ & $\cdot 2,90$ & 20 & Novakita \\
\hline 3,20 & 42 & $\begin{array}{l}\text { Brocantita } \\
\text { Ktenasita }\end{array}$ & & & & 3,00 & $\begin{array}{l}90 \\
90\end{array}$ & $\begin{array}{l}\text { Calcostibinitin } \\
\text { Egyptian blue }\end{array}$ & 2,90 & 111 & $\begin{array}{l}\text { Sulfato penta hidratado } \\
\text { cobre }\end{array}$ \\
\hline 3,20 & 30 & Ktenasita & 3,08 & 40 & 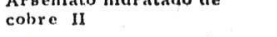 & 3.00 & 50 & Liroconita & 2,90 & 5 & $\begin{array}{l}\text { cobre } \\
\text { Pisinita }\end{array}$ \\
\hline 3,20 & 20 & Spangolita & 3,08 & 40 & Silicato de cobre e bário & 3,00 & 40 & Bonattita & 2,89 & 80 & Faustita \\
\hline 3,20 & 16 & Nakaвeita & 3,08 & 30 & Volborthita & 3,00 & 40 & Cubanita & 2,89 & 80 & Nakaseita \\
\hline 3,19 & 95 & E skebornita & 3,08 & 20 & Valleritia & 3,00 & 30 & Clinoclasita & 2,89 & 70 & Tyrrellita \\
\hline
\end{tabular}




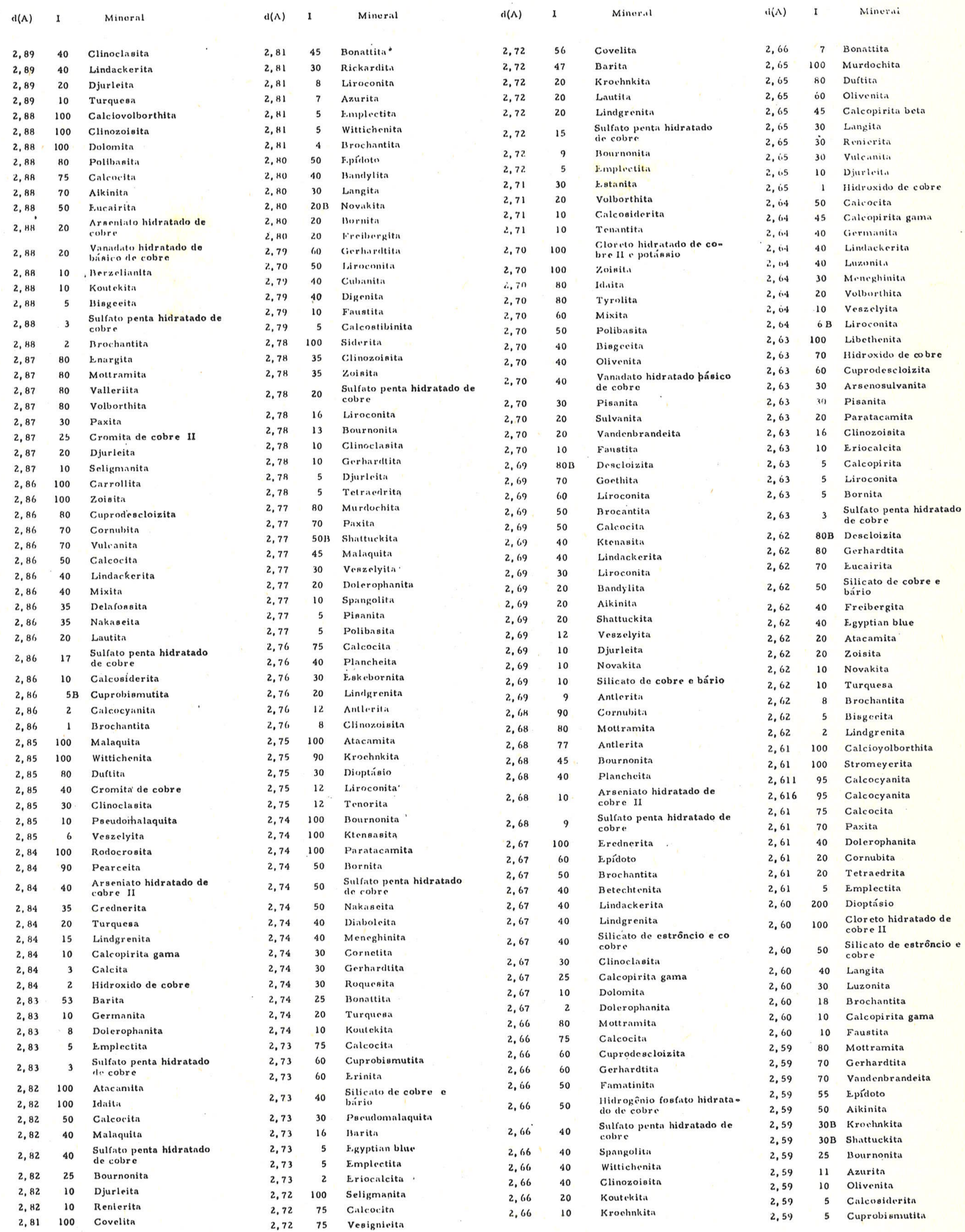




\begin{tabular}{|c|c|c|c|c|c|c|c|c|c|c|c|}
\hline $\mathrm{d}(\mathrm{A})$ & I & Mineral & $d(A)$ & I & Mineral & $d(A)$ & I & Mineral & $d(A)$ & I & Minerai \\
\hline 2,59 & 5 & Djurleita & 2,52 & 75 & Calcocita & 2,46 & 30 & Lautita & 2,40 & 20 & Lindgrenita \\
\hline 2,58 & 80 & Cuprodescloizita & 2,52 & 55 & Mallaquitit & 2,46 & 30 & Plancheita & 2,40 & 20 & Tenantita \\
\hline 2,58 & 80 & Diaboleita & 2,52 & 40 & Aticimita & 2,46 & 30 & Shattuckita & 2,40 & 20 & Turquesa \\
\hline 2,58 & 55 & Goethita & 2,52 & 40 & Faustiti & 2,46 & 20 & Lindgrenita & 2,40 & 20 & Vandenbrandeita \\
\hline 2,58 & 40 & Egyptian blue & 2,52 & 40 & Turquesa & 2,460 & 14 & Brochantita & 2,40 & 10 & Calciovolbor thita \\
\hline 2,58 & 30 & Clinozoinita & 2,52 & 20 & Azurit.t & 2,166 & 10 & Brochantita & 2,40 & 10 & Dolomit., \\
\hline 2,58 & 20 & $\begin{array}{l}\text { Sulfato hidratado de } \\
\text { cobre }\end{array}$ & $\begin{array}{l}2,52 \\
2,52\end{array}$ & $\begin{array}{l}20 \\
10\end{array}$ & $\begin{array}{l}\text { Gerhardlita } \\
\text { Epídoto }\end{array}$ & 2,46 & 10 & Brocantita & 2,40 & 9 & $\begin{array}{l}\text { Sulfato penta hidratado } \\
\text { de cobre }\end{array}$ \\
\hline 2,58 & 20 & Wittichenita & 2,52 & 10 & $\begin{array}{l}\text { Epídeto } \\
\text { Cornubitat }\end{array}$ & 2,46 & 10 & $\begin{array}{l}\text { Cloreto hidrutado de } \\
\text { colrece potísuio }\end{array}$ & 2,40 & 5 & Digenita \\
\hline 2,58 & 18 & Delafossita & 2,52 & 5 & Aikinitit & 2,46 & 10 & Tetriedrita & 2,40 & 5 & Lautitit \\
\hline 2,58 & 10 & Turquen:i & & 5 & Sulfate penta hidrataclo & 2,46 & 5 & Calcosideriti & 2,398 & 100 & Culcocita \\
\hline $2,5 \mathrm{H}$ & 9 & Benrาumbt" & 2,52 & 3 & de coblene & 2,46 & 55 & lint.nitlit & $2,31)$ & no & Prenulomalinquit.r \\
\hline 2,58 & 5 & Sulfiato penta hiddratado & 2,51 & 40 & 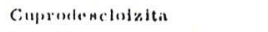 & 2,46 & 4 & Boldrophlunita & $2,31)$ & 70 & Lipidutus \\
\hline & & de cobre & 2,51 & 35 & Azurita & 2,45 & 10 & Tyroliti & 2,39 & 70 & Olivenita \\
\hline $\begin{array}{l}2,57 \\
2,57\end{array}$ & 60 & Duftita & 2,51 & 20 & Cubanitat & 2,45 & 5 & Silicito do estrôncio e & 2,39 & 60 & Planchoita \\
\hline $\begin{array}{l}2,57 \\
2,57\end{array}$ & 6,0 & Ktonianiti & 2,51 & 20 & Lamblacheritit & & & & 2,39 & 50 & Calcocita \\
\hline $\begin{array}{l}2,57 \\
2,57\end{array}$ & 60 & Mixita & 2,51 & 18 & Sulfato hidlrattado de & 2.46 & 1 & zoinilia & 2,39 & 40 & Cornubita \\
\hline $\begin{array}{l}2,57 \\
2,57\end{array}$ & 40 & Linclackerita & & & cohre & 2,44 & 80 & Goethita & 2,39 & 40 & Gerhardtita \\
\hline $\begin{array}{l}2,57 \\
2,57\end{array}$ & 30 & Domeykitn alfa & 2,51 & 5 & Djurleitil & 2,44 & 70 & Koutekita & 2,39 & 40 & Lindickerita \\
\hline 2,57 & 20 & Cirmitit de cobre & 2,51 & 5 & bigyptian blue & 2,44 & 55 & Diopt.ísio & 2,39 & 40 & Silicato de cobre e bário \\
\hline 2,57 & 7 & Bournonita & 2,50 & 100 & Ditafossita & 2,44 & 50 & Calcocitil & 2,39 & 35 & Cyanotrichita \\
\hline 2,57 & 2 & Eriocalcita & 2,50 & 90 & Tyrrellita & 2,44 & 40 & Cornubita & 2,39 & 30 & Calcosiderita \\
\hline 2,57 & 2 & Lindgrenita & 2,50 & 40 & Bornita & 2,44 & 40 & Liroconita & 2,39 & 30 & Wittichenita \\
\hline 2,57 & 1 & $\begin{array}{l}\text { Sulfato penta hidratado } \\
\text { de cobre }\end{array}$ & 2,50 & 30 & Azurita & 2,44 & 30 & Cornetita & 2,39 & 20 & Betechtenita \\
\hline & 100 & $\begin{array}{l}\text { de cobre } \\
\text { Cornubita }\end{array}$ & 2,50 & 26 & Antlerita & 2,44 & 30 & Novakita & 2,39 & 20 & Clinozoisita \\
\hline 2,56 & 85 & $\begin{array}{l}\text { Cornubita } \\
\text { Antlerita }\end{array}$ & 2,50 & 25 & Linclgrenita & 2,44 & 20 & Descloizita & 2,39 & 20 & Famatinita \\
\hline 2,56 & 80 & $\begin{array}{l}\text { Antlerita } \\
\text { Volborthita }\end{array}$ & 2,50 & 20 & Cornetitit & 2,44 & 10 & Paxitit & 2,39 & 20 & Rodocrosita \\
\hline 2,56 & & $\begin{array}{l}\text { Volborthita } \\
\text { Vanadato hidratado bá Bico }\end{array}$ & 2,50 & 20 & Novakita & 2,44 & 10 & Seligmanita & 2,39 & 7 & Brocantita \\
\hline 2,56 & 60 & $\begin{array}{l}\text { Vanadato hidratado bá íco } \\
\text { de cobre }\end{array}$ & 2,50 & 16 & Hidroxido de cobre & 2,44 & 10 & Turquesa & 2,39 & 5 & Mottramita \\
\hline 2,56 & 50 & Calcocitn & 2,50 & 12 & Clinozoisita & 2,44 & 7 & Epídoto & 2,39 & 5 & Roquesita \\
\hline 2,56 & 50 & Selignıanita & 2,50 & 5 & Runicrit: & 2,44 & 5 & $\begin{array}{l}\text { Sulfato penta hidratado } \\
\text { de cobre }\end{array}$ & 2,39 & 4 & Antlerita \\
\hline 2,56 & 50 & Vesignieita & 2,49 & 60 & Lingita & 2,44 & 2 & Barita & 2,38 & 90 & Djurleita \\
\hline 2,56 & 10 & Calcostibinita & 2,49 & 50 & Gerhardtita & 2,43 & 20 & Bandylita & 2,38 & 80 & Volborthita \\
\hline 2,56 & 10 & Faustita & 2,49 & 50 & $\begin{array}{l}\text { Paxita } \\
\text { Crisocola }\end{array}$ & 2,43 & 20 & Cuprodescloizita & 2,38 & 40 & Novakita \\
\hline 2,56 & 10 & Koutekita & 2,49 & 45 & $\begin{array}{l}\text { Crisocola } \\
\text { Bonattita }\end{array}$ & 2,43 & 18 & Clinozoisita & 2,38 & 30 & Clinoclasita \\
\hline 2,56 & 10 & Pseudomalaquita & 2,49 & 40 & $\begin{array}{l}\text { Bonattita } \\
\text { Eucairita }\end{array}$ & 2,43 & 16 & Sulfato hidratado de & 2,38 & 25 & Clinozoisita \\
\hline 2,56 & 10 & Metadomeykita & 2,49 & 40 & Eucairita & & & cabre & 2,38 & 20 & Cuprodescloizita \\
\hline 2,56 & 7 & $\begin{array}{l}\text { Sulfato penta hidratado } \\
\text { de cobre }\end{array}$ & 2,49 & 40 & Clinoclasita & 2,430 & 13 & Antlerita & 2,38 & 20 & Egyptian blue \\
\hline 2,56 & 5 & $\begin{array}{l}\text { de cobre } \\
\text { Aikinita }\end{array}$ & 2,49 & 40 & Pearceita & 2,43 & 10 & Liroconita & 2,38 & 14 & Brochantita \\
\hline 2,56 & 5 & $\begin{array}{l}\text { Aikinita } \\
\text { Renierita }\end{array}$ & $2,49^{\circ}$ & 15 & Vulcanita & 2,43 & 7 & Sulfato penta hidratado & 2,38 & 10 & Duftita \\
\hline 2,55 & & & 2,49 & 14 & $\begin{array}{l}\text { Calcita } \\
\text { Cuprobismutita }\end{array}$ & 2,439 & 6 & de cobre & 2,38 & 10 & Langita \\
\hline 2,55 & 100 & $\begin{array}{l}\text { Arseniato hidratado de } \\
\text { cobre }\end{array}$ & 2,49 & 5 & $\begin{array}{l}\text { Cuprobismutita } \\
\text { Germanita }\end{array}$ & 2,43 & $\begin{array}{l}6 \\
5\end{array}$ & $\begin{array}{l}\text { Antlerita } \\
\text { Bisgeeita }\end{array}$ & 2,38 & 10 & Paxita \\
\hline 2,55 & 100 & Cromita de cobre II & $\begin{array}{l}2,49 \\
2,49\end{array}$ & $\begin{array}{r}55 \\
5\end{array}$ & $\begin{array}{l}\text { Germanita } \\
\text { Wittichenita }\end{array}$ & 2,43 & 2 & $\begin{array}{l}\text { Bisgeeita } \\
\text { Dolerophanita }\end{array}$ & 2,38 & 5 & Estanita \\
\hline 2,55 & 60 & Stromeyerita & $\begin{array}{l}2,49 \\
2,48\end{array}$ & $\begin{array}{r}5 \\
100\end{array}$ & $\begin{array}{l}\text { Wittichenita } \\
\text { Cornubitit }\end{array}$ & 2,42 & 95 & $\begin{array}{l}\text { Dolerophanita } \\
\text { Crednerita }\end{array}$ & 2,38 & 5 & Renierita \\
\hline 2,55 & 50 & Libethenita & 2,48 & $\begin{array}{r}100 \\
6,0\end{array}$ & $\begin{array}{l}\text { Cornubiti } \\
\text { Eakeloornita }\end{array}$ & 2,42 & 6,0 & $\begin{array}{l}\text { Crednerita } \\
\text { Ktenasita }\end{array}$ & 2,38 & 3 & Bournonita \\
\hline 2,55 & 30 & Tenantita & 2,48 & $\begin{array}{l}1,0 \\
40\end{array}$ & $\begin{array}{l}\text { Eakelornita } \\
\text { Dirboleita }\end{array}$ & 2,42 & 60 & $\begin{array}{l}\text { Ktenasita } \\
\text { Pscudomalaquita }\end{array}$ & 2,37 & 80 & Valleriita \\
\hline 2,55 & 20 & Descloizita & 2,48 & $\begin{array}{l}40 \\
40\end{array}$ & $\begin{array}{l}\text { Diaboleita } \\
\text { Goothita }\end{array}$ & 2,42 & 50 & $\begin{array}{l}\text { Pscudomalaquita } \\
\text { Galcocyanita }\end{array}$ & 2,37 & 50 & Carrollita \\
\hline 2,55 & 10 & Djurleita & 2,48 & 25 & $\begin{array}{l}\text { Goothita } \\
\text { Veszelyita }\end{array}$ & 2,42 & 40 & $\begin{array}{l}\text { Calcocyanita } \\
\text { Idaita }\end{array}$ & 2,37 & 30 & Cubanita \\
\hline 2,55 & 7 & Bonattita & 2,48 & 20 & $\begin{array}{l}\text { Veszelyita } \\
\text { Koutekita }\end{array}$ & 2,42 & 40 & $\begin{array}{l}\text { Idaita } \\
\text { Polibasita }\end{array}$ & 2,37 & 30 & Metadomeykita \\
\hline 2,55 & 3 & $\begin{array}{l}\text { Sulfato penta hidratado } \\
\text { de cobre }\end{array}$ & 2,48 & 20 & $\begin{array}{l}\text { Koutekita } \\
\text { Valleriita }\end{array}$ & 2,42 & 20 & $\begin{array}{l}\text { Polibasita } \\
\text { Domeykita alfa }\end{array}$ & 2,37 & 30 & Pearceita \\
\hline 2,54 & 80 & Bandylita & 2,48 & 14 & $\begin{array}{l}\text { Valleriita } \\
\text { Barita }\end{array}$ & 2,42 & 20 & $\begin{array}{l}\text { Domeykita alfa } \\
\text { Faustita }\end{array}$ & 2,37 & 10 & Calcopirita gama \\
\hline 2,54 & 70 & Spangolita & 2,48 & 10 & Duftita & 2,42 & 20 & $\begin{array}{l}\text { Faustita } \\
\text { Malaquita }\end{array}$ & 2,37 & 10 & $\begin{array}{l}\text { Vanadiato hidratado básico } \\
\text { de coibre }\end{array}$ \\
\hline 2,54 & 40 & Clinoclisita & 2,47 & 100 & Cromita do cobro & 2,42 & 20 & Silicato de cobre o & 2,37 & 5 & Descloizita \\
\hline 2,54 & 40 & Rickarclita & 2,47 & 75 & Calcocita & & & bario & 2,37 & 5 & Germanita \\
\hline 2,54 & 30 & Cornetita & 2,47 & 70 & Olivenitit & 2,42 & 20 & Rickardita & 2,37 & 4 & Dolerophanita \\
\hline 2,54 & 25 & Azu:ita & 2,47 & 30 & Freibergita & 2,42 & 9 & Bomattita & 2,36 & 60 & Shattucikita \\
\hline 2,54 & 18 & Dolerophisnita & 2,47 & 30 & Liroconita & 2,42 & 5 & Euplectiti & 2,36 & 50 & Calcocita \\
\hline 2,54 & 10 & Gerhardtita & 2,47 & 30 & Maliqquitit & 2,42 & 4 & Brochantitita & 2,36 & 50 & Spangolita \\
\hline 2,54 & 10 & Paxita & 2,47 & 30 & Vanaclato hiclratado bá Bico & 2,41 & 50 & Calcocyanita & 2,36 & 13 & Bournonita \\
\hline 2,54 & 8 & Dolomita & 2,47 & 30 & $\begin{array}{l}\text { fo cobre } \\
\text { Vesignicita }\end{array}$ & 2,41 & 40 & $\begin{array}{l}\text { Sulfato penta hidratado de } \\
\text { cobre }\end{array}$ & 2,36 & 12 & Hidróxido de o cobre \\
\hline 2,53 & 75 & Catcrocita & 2,47 & 20 & $\begin{array}{l}\text { Vesignicita } \\
\text { Faustit: }\end{array}$ & 2,41 & 38 & Cobre magnésio & 2,36 & 12 & Veszelyita \\
\hline 2,53 & 67 & Brocantita & 2.47 & 20 & Silicato de estrôncio e & 2,41 & 38 & Sultato cle cobre magnésio & 2,30 & 10 & Silicato de cobre e bário \\
\hline 2,53 & 60 & Ktenasita & 2,47 & 20 & cobre & 2,41 & 10 & Hiclrogênio fosfato hidra- & 2,36 & 8 & Clinozoisita \\
\hline 2,53 & 60 & Polibasita & 2,47 & 20 & Turquesa & & & taido de cobre & 2,36 & 4 & Eriocnlcita \\
\hline 2,53 & 49 & Tenorita & 2,47 & 14 & Liroconita & 2,41 & 10 & Neneghinita & 2,35 & 60 & Betechtenita \\
\hline 2,53 & 30 & Zоiнita & 2,47 & 10 & Arseniato hidratado de & 2,41 & 8 & Veszelyita & 2,35 & 50 & Gornubita \\
\hline 2,53 & 25 & Cyanotrichita & & & cobre II & 2,41 & 5 & Djurleita & 2,35 & 40 & Faustita \\
\hline 2,53 & 20 & Erednerita & 2,47 & 10 & Calciovolloorthita & 2,41 & 5 & Mottramita & 2,35 & 40 & Turquesa \\
\hline 2,53 & 15 & Colbre magné ilo & 2,47 & 10 & Djurleita & 2,40 & 100 & Calcocita & 2,35 & 30 & Vulcanita \\
\hline 2,53 & 15 & Sulfeto de cobre magné & 2,47 & 5 & Egyptian blue & 2,40 & 100 & Cornwallita & 2,35 & 20 & Koutekita \\
\hline 2,53 & 10 & Lautita & 2,47 & 5 & Mottramita & 2,40 & 60 & Cromita de cobre II & 2,35 & 16 & Hidróxido de cobre \\
\hline 2,53 & 8 & Veszelyita & 2,46 & 100 & Cuprita & 2,40 & $\sin x$ & Libethenita & 2,35 & 10 & Mixita \\
\hline 2,53 & 6 & Eriocalcita & 2,46 & $100 \mathrm{~B}$ & Erinita & 2,40 & · & Shattuckita & 2,35 & 9 & $\begin{array}{l}\text { Sulfato penta hidratado } \\
\text { de cobre }\end{array}$ \\
\hline 2,53 & 5 & Blsgeeita & 2,46 & 80 & Mixita & 2,40 & 40 & $\begin{array}{l}\text { Sulvanita } \\
\text { Zoisita }\end{array}$ & 2,35 & 55 & Freibergita \\
\hline 2,53 & 5 & Digenita & 2,46 & 75 & Calcocita & 2,40 & 40 & $\begin{array}{l}\text { Zoisita } \\
\text { Dioptísio }\end{array}$ & 2,34 & 40 & Emplectita \\
\hline 2,52 & 100 & Brochantita & 2,46 & 50 & Betechtenita & 2,40 & 30 & Dioptísio & 2,34 & 30 & Seligmanita \\
\hline 2.52 & 100 & Tenorita & 2,46 & 35 & Malitquitit & 2,40 & 20 & Faustita & 2,34 & 30 & Tyrolit. \\
\hline
\end{tabular}




\begin{tabular}{|c|c|c|c|c|c|c|c|c|c|c|c|}
\hline $\mathrm{d}(\mathrm{A})$ & 1 & Mineral & $\mathrm{d}(\mathrm{A})$ & I & Mineral & $d(A)$ & $\mathrm{I}$ & Mincral & $d(A)$ & I & Minera! \\
\hline 2,34 & 20 & Sidorita & 2,29 & 40 & Betechtenita & 2,23 & 30 & $\begin{array}{l}\text { Silicató de estrôncio } \\
\text { e cobre }\end{array}$ & 2,17 & 20 & Cuprobismutita \\
\hline 2,34 & 13 & Maliaquita & 2,29 & 40 & Faustitit & 2.23 & 25 & $\begin{array}{l}\text { c cobre } \\
\text { Delafoseita }\end{array}$ & 2,17 & 20 & Novakita \\
\hline 2,34 & 11 & Bonattita & 2,29 & 40 & Turquesa & 2,23 & 25 & & 2,17 & 20 & Wittichenita \\
\hline 2,34 & 10 & Calciovolbor thita & 2,29 & 30 & Krochnkita & 2,23 & 20 & $\begin{array}{l}\text { Arseniato hidratado de } \\
\text { cobre }\end{array}$ & 2,17 & 10 & Digenita \\
\hline $2 ; 34$ & 10 & $\begin{array}{l}\text { Hidrogênio fosfato hidrata- } \\
\text { do de cobre }\end{array}$ & 2,29 & 30 & $\begin{array}{l}\text { Vanadato hidratado } \\
\text { básico de cobre }\end{array}$ & 2,23 & 20 & Cornetita & 2,17 & 10 & Dioptásio \\
\hline 2,34 & 10 & Krochnkita & 2,29 & 25 & Linclgrenita & 2,23 & 20 & Mixita & 2,17 & 5 & Bournonita \\
\hline 2,34 & 5 & Emplectita & 2,29 & 13 & Azurita & 2,23 & 16 & Sulfato hidratado de & 2,17 & 5 & Plancheita \\
\hline 2,34 & 5 & Wittichenita & 2,29 & 13 & Brocantita & 2,23 & & cobre & 2,17 & 5 & Tenantita \\
\hline 2,34 & 4 & Veszelyita & 2,29 & 10 & Arseniato hidratado de & $\begin{array}{l}2,23 \\
2,23\end{array}$ & $\begin{array}{l}10 \\
10\end{array}$ & Calciovolborthita & 2,17 & 1 & $\begin{array}{l}\text { Sulfato penti hiciatado } \\
\text { de cobre }\end{array}$ \\
\hline 2,33 & 60 & Ktenasita & 2,29 & 10 & Calciovolborthita & 2,23 & $\begin{array}{l}10 \\
10\end{array}$ & Duftita & 2,16 & 50 & $\begin{array}{l}\text { de cobre } \\
\text { Koutekita }\end{array}$ \\
\hline 2,33 & 60 & Zoisita & $\begin{array}{l}2,29 \\
2,28\end{array}$ & 100 & Cobre magnésio & 2,23 & $\begin{array}{r}10 \\
6\end{array}$ & Zoisita & 2,16 & 40 & $\begin{array}{l}\text { Koutekita } \\
\text { Emplectita }\end{array}$ \\
\hline 2,33 & 20 & Bisgecita & & & Sulfato penta hidratado & 2,23 & $\begin{array}{l}6 \\
5\end{array}$ & $\begin{array}{l}\text { Quartzo alfa } \\
\text { Bournonita }\end{array}$ & 2,16 & 40 & $\begin{array}{l}\text { Emplectita } \\
\text { Paxita }\end{array}$ \\
\hline 2,33 & 20 & Fumatinita & 2,28 & 100 & $\begin{array}{l}\text { de cobre } \\
\text { de }\end{array}$ & 2,22 & $\begin{array}{r}5 \\
70\end{array}$ & $\begin{array}{l}\text { Bournonita } \\
\text { Azurita }\end{array}$ & 2,16 & 25 & $\begin{array}{l}\text { Paxita } \\
\text { Epidoto }\end{array}$ \\
\hline 2,33 & 20 & Polibasita & $2,2.8$ & 100 & Sulfeto de cobre magnésio & 2,22 & $\begin{array}{l}70 \\
30\end{array}$ & $\begin{array}{l}\text { Azurita } \\
\text { Crednerita }\end{array}$ & 2,16 & 25 & $\begin{array}{l}\text { Epidoto } \\
\text { Calcopirita gama }\end{array}$ \\
\hline 2,33 & 17 & Azurita & 2,28 & 80 & Micrsita & 2,22 & $\begin{array}{l}30 \\
30\end{array}$ & $\begin{array}{l}\text { Crednerita } \\
\text { Enargita }\end{array}$ & 2,16 & 20 & $\begin{array}{l}\text { Calcopirita gama } \\
\text { Aikinita }\end{array}$ \\
\hline 2,33 & 10 & $\begin{array}{l}\text { Cloreto Hidratado de cobre } \\
\text { II e potásió }\end{array}$ & 2,28 & 50 & Duftita & 2,22 & $\begin{array}{l}30 \\
30\end{array}$ & $\begin{array}{l}\text { Enargita } \\
\text { Mottramita }\end{array}$ & 2,16 & 20 & $\begin{array}{l}\text { Silicato de estrôncio e } \\
\text { cobre }\end{array}$ \\
\hline 2,33 & 10 & Olivenita & 2,28 & 35 & Azuriti: & 2,22 & 25 & Calcocita & 2,16 & 15 & Azurita \\
\hline 2,33 & 5 & Sulfato penta hidratado & 2,28 & 30 & Kenasita & 2,22 & 20 & Lindackerita & 2,16 & 10 & Liroconita \\
\hline 2,33 & 5 & & 2,28 & $30 \mathrm{~B}$ & Novakita & 2,22 & 10 & Lautita & 2,16 & 7 & Malaquita \\
\hline 2,33 & 4 & $\begin{array}{l}\text { Tetracdrita } \\
\text { Veszelyita }\end{array}$ & 2,28 & 25 & Epicloto & 2,22 & $10 \mathrm{~B}$ & Shattuckita & 2,16 & 5 & Bournonita \\
\hline 2,33 & 2 & $\begin{array}{l}\text { Veszelyita } \\
\text { Dolerophanita }\end{array}$ & 2,28 & 18 & Calcita & 2,21 & 40 & Cromita de cobre & 2,16 & 5 & Germanita \\
\hline 2,32 & 96 & $\begin{array}{l}\text { Dolerophanita } \\
\text { Tenorita }\end{array}$ & 2,28 & 17 & Malaquita & 2,21 & 40 & Cuprodescloizita & 2,16 & 5 & Olivenita \\
\hline 2,32 & 60 & $\begin{array}{l}\text { Tenorita } \\
\text { Ktenasita }\end{array}$ & 2,289 & 16 & Clinozoisita & 2,21 & 30 & Liroconita & 2,16 & 5 & Renierita \\
\hline 2,32 & 50 & Calcocita & 2,282 & 16 & Clinozoisita & 2,21 & 30 & Kroelukita & 2,15 & 60 & Ktenasita \\
\hline 2,32 & 50 & Poeudomalaquita & 2,28 & 12 & Quartzo alfa & 2,21 & 30 & Volborthita & 2,15 & 50 & Liroconita \\
\hline 2,32 & 50 & Pearceita & $\begin{array}{l}2,28 \\
2,28\end{array}$ & 8 & Liroconitit & 2,21 & $\begin{array}{l}25 \\
20\end{array}$ & $\begin{array}{l}\text { Calcocita } \\
\text { Seligmanitat }\end{array}$ & 2,15 & 40 & Domeykita alfa \\
\hline 2,32 & 40 & Silicato de estrôncio & $\begin{array}{l}2,28 \\
2,28\end{array}$ & $\begin{array}{l}7 \\
5\end{array}$ & $\begin{array}{l}\text { Barita } \\
\text { Djurleita }\end{array}$ & $\begin{array}{l}2,21 \\
2,21\end{array}$ & $\begin{array}{l}20 \\
16\end{array}$ & $\begin{array}{l}\text { Seligmanita } \\
\text { Liroconita }\end{array}$ & 2,15 & 30 & Cornetita \\
\hline & & e cobre & 2,28 & 5 & Wittichenit: & 2,21 & 9 & Bonattita & 2,15 & 20 & Gerhaxdtita \\
\hline 2,32 & $\begin{array}{l}40 \\
30\end{array}$ & Turques:i & 2.28 & 3 & Sulfate) penta hidratido & 2,21 & 5 & Est:initin & $\begin{array}{l}2,15 \\
2,15\end{array}$ & 10 & $\begin{array}{l}\text { Betchlenita } \\
\text { Clinozoisitio }\end{array}$ \\
\hline 2,32 & $\begin{array}{l}30 \\
30\end{array}$ & Egyptian blue & 2,28 & ${ }^{3}$ & de cobre & $2,2.1$ & 4 & Erioculcit. & & 10 & Clinozoisital \\
\hline $\begin{array}{l}2,32 \\
2,32\end{array}$ & $\begin{array}{l}30 \\
20\end{array}$ & Vulcanita & 2,24 & 1 & Brochantitu & 2.21 & 3 & Sultiato penta hidratado & $\begin{array}{l}2,15 \\
2,15\end{array}$ & 10 & Lindgrenita \\
\hline 2,32 & $\begin{array}{l}20 \\
20\end{array}$ & Pisanita & 2,27 & 60 & Cuprodoncloizita & 2,21 & 3 & de cobre & $\begin{array}{l}2,15 \\
2,14\end{array}$ & 2 & $\begin{array}{l}\text { Dolerophanita } \\
\text { Calcosiderita }\end{array}$ \\
\hline 2,32 & $\begin{array}{l}20 \\
15\end{array}$ & Plincheita & 2,27 & 50 & Fegyptian blue & 2,20 & 75 & Calcocita & & 40 & Calcosiderita \\
\hline 2,32 & $\begin{array}{l}15 \\
10\end{array}$ & Barita & 2,27 & 10 & Lindackerita & 2,20 & 50 & Vandenbrandeita & $\begin{array}{l}2,14 \\
2,14\end{array}$ & 40 & $\begin{array}{l}\text { Cornubita } \\
\text { Paratacamita }\end{array}$ \\
\hline 2,32 & 10 & Calcocyanita & 2,27 & 35 & Bonattita & 2,20 & 40 & Irlaita & 2,14 & 40 & $\begin{array}{l}\text { Paratacamita } \\
\text { Clineclasita }\end{array}$ \\
\hline 2,32 & 10 & Novikita & 2,27 & 35 & Dioptitaio & 2,20 & 40 & Latugitit & 2,14 & 30 & Clinoclasita \\
\hline 2,32 & 5 & Dioptá日io & 2,27 & 30 & Liroconita & 2,20 & 40 & Paxita & 2,14 & 30 & $\begin{array}{l}\text { Hidrogentio iostitu hidratide } \\
\text { de cobre }\end{array}$ \\
\hline 2.32 & $4 B$ & Liroconita & 2,27 & 20 & Aikinita & 2,20 & 35 & Dioptáвio & & 11 & Sulfato penta hidratado de \\
\hline 2,31 & Bo & Gerhardtita & 2,26 & 100 & At:iciunita & 2,20 & 27 & Barita & $2 ; 14$ & 11 & cobre \\
\hline 2,31 & 50 & Eriniti & 2,26 & 100 & Paraticamita & 2,20 & 20 & Ktennsitan & 2,14 & 10 & Liroconita \\
\hline 2,31 & 40 & Calcostibinita & 2,26 & 35 & Iliclroxiclo de cobre & 2,20 & 20 & Novakita & 2,14 & 10 & Gocthita \\
\hline 2,31 . & 30 & Tenorita & 2,26 & 30 & Nakascita & 2,20 & 20 & Paraticamita & 2,14 & 5 & Djurleita \\
\hline 2,31 & 25 & Cyanotrichita & 2,26 & 30 & $\begin{array}{l}\text { Silicito de cobre e } \\
\text { bírio }\end{array}$ & 2,20 & 20 & Polibasita & 2,14 & 5 & Kroehnkita \\
\hline 2,31 & 20 & Fананіti & & 25 & bitrio & 2,20 & 10 & Cubanita & 2,14 & 5 & Pearceita \\
\hline 2,31 & 20 & Vinclenbrandeita & $\begin{array}{l}2,26 \\
2,26\end{array}$ & $\begin{array}{l}25 \\
20\end{array}$ & $\begin{array}{l}\text { Azuritit } \\
\text { Cornubita }\end{array}$ & 2,20 & 10 & $\begin{array}{l}\text { Silicato de cobre e } \\
\text { bírio }\end{array}$ & 2,14 & 5 & Polibasita \\
\hline 2,31 & 17 & Malaquita & $\begin{array}{l}2,26, \\
2,26\end{array}$ & $\begin{array}{l}20 \\
15\end{array}$ & $\begin{array}{l}\text { Cornulita } \\
\text { Calcopirita gama }\end{array}$ & 2,207 & $(3-5)$ & $\begin{array}{l}\text { bírio } \\
\text { Brochantita }\end{array}$ & 2,13 & 100 & Eucairita \\
\hline 2,31 . & 10 & Covelita & $\begin{array}{l}2,26 \\
2,26\end{array}$ & 14 & Brochantita & & $\begin{array}{r}(3-5) \\
3\end{array}$ & $\begin{array}{l}\text { Brochantita } \\
\text { Sulfato penta hidratido }\end{array}$ & 2,13 & 69 & Antlerita \\
\hline 2,31 & 7 & Antlerita & 2,26 & 3 & Beurnonit:i & 2,20 & 3 & & 2,13 & 60 & Atacimita \\
\hline 2,31 & 5 & Calcosiclerita & 2,25 & 60 & Goethita & 2,202 & 2 & Brochantita & 2,13 & 56 & Marbhita \\
\hline 2,31 & 3 & $\begin{array}{l}\text { Sulfato penta hidratado } \\
\text { de cobre }\end{array}$ & 2,25 & 40 & Betechtenita & 2,19 & 40 & Atacamita & 2,13 & 50 & Bisgeeita \\
\hline 2,30 & 90 & Murdochita & 2,25 & 25 & Sulfato hiclratado de & 2,19 & 30 & Dolounita & 2,13 & 37 & Cuprita \\
\hline 2,30 & 70 & Cornubita & 2,25 & & cobre & 2,19 & 30 & Meneghiniti & 2,13 & 25 & Calcocita \\
\hline 2,30 & 60 & Descloizita & 2,24 & 50 & Calcocita & 2,19 & 20 & Mixita & 2,13 & 25 & Cromita de cobre II \\
\hline 2,30 & 60 & Lihethenita & 2,24 & 40 & Clinoclasita & 2,19 & 14 & Brochantita & 2,13 & 25 & Siderita \\
\hline 2,30 & 60 & Mottramita & 2,24 & 40 & Cornubita & 2,19 & 13 & Brocantita & 2,13 & 20 & Bornita \\
\hline 2,30 & 50 & Clinoclasita & 2,24 & 30 & Descenizita & 2,19 & 10 & Duftitia . & 2,13 & 14 & Nakaseita \\
\hline 2,30 & 40 & Shattuckita & 2,24 & 30 & Meneghinita & 2,19 & 10 & Pseudomalaquita & 2,13 & 10 & Novakita \\
\hline 2,30 & 20 & Paxita & 2,24 & 30 & Muttramita & 2,19 & 10 & Sulfato pentat hidratado & 2,13 & 10 & Egyptian blue \\
\hline 2,30 & 12 & Calcocyanita & 2,24 & 20 & Galcostibinita & & & de cobre & 2,13 & 10 & Shattuckita \\
\hline 2,30 & 10 & Goethita & 2,24 & 20 & Clinoclisita & 2,18 & $\begin{array}{l}60 \\
50\end{array}$ & Gocthit: & 2,13 & 8 & Sulfeto de cobre e magnésio \\
\hline 2,30 & 10 & Koutekita & 2,24 & 20 & Cubanita & 2,18 & 50 & Calcocitu & 2,13 & a & Cobre magnésio \\
\hline 2,30 & 10 & Meneghinita & 2,24 & 20 & Koutckitia & 2,18 & 40 & Banciylitn & 2,13 & 5 & Bisgecita \\
\hline 2,30 & 10 & Tyrrellita & 2,24 & 10 & Eakebornit: & 2,18 & 30 & $\begin{array}{l}\text { Cloreto hiclratado de cobre } \\
\text { II : potíteio }\end{array}$ & 2,13 & 5 & Idlitita \\
\hline 2,30 & 8 & Brochantita & 2,24 & ) & Bournomitit & 2,18 & 30 & Pearceita & 2,13 & 5 & Metadomeykita \\
\hline 2,30 & 7 & Bournonita & 2,24 & 5 & Emplectita & 2,18 & 20 & Cornubita & 2,13 & 5 & Renierita \\
\hline 2,30 & 6 & Barita & 2,24 & 5 & Pearceitit & 2,18 & 20 & Famatinita & 2,12 & 80 & Barita \\
\hline 2,30 & 5 & Lautita & 2,24 & 5 & Vulcanita & 2,18 & 20 & Faustita & 2,12 & 40 & Faustita \\
\hline 2,30 & $5 B$ & Cuprobismutita & 2,24 & 1 & $\begin{array}{l}\text { Sulfato penta hidratado } \\
\text { de cobre }\end{array}$ & 2,18 & 20 & Malaquita & 2,12 & 40 & Mixita \\
\hline 2,30 & 5 & $\begin{array}{l}\text { Sulfato penta hidratado } \\
\text { de cobre }\end{array}$ & 2,23 & 60 & Erinita & 2,18 & 12 & Veszelyita & $\begin{array}{l}2,129 \\
2,12\end{array}$ & $\begin{array}{l}40 \\
30\end{array}$ & $\begin{array}{l}\text { Turcinesa } \\
\text { Calcostibinita }\end{array}$ \\
\hline 2,30 & 4 & $\begin{array}{l}\text { de cobre } \\
\text { Antlerita }\end{array}$ & 2,23 & 50 & Pвeudomalaquita & 2,18 & 10 & Aikinita & 2,12 & 20 & Milaquita \\
\hline 2,30 & 44 & $\begin{array}{l}\text { Antlerita } \\
\text { Clinozoisita }\end{array}$ & 2,23 & 40 & Faubtit: & 2,17 & 50 & Gerharcltita & 2,12 & 10 & Meneghinita \\
\hline 2,29 & 100 & Diaboleita & 2,23 & 40 & Turquesa & 2,17 & 40 & Emplectita & 2,12 & 10 & Pseudomala quita \\
\hline 2,29 & 80 & Valleriita & 2,23 & 30 & Freibergita & 2,17 & 40 & Spangolita & 2,12 & 10 & Tetraedrita \\
\hline 2,29 & 75 & Verignieita & 2,23 & 30 & Meticlomeykita & 2,17 & 30 & Lautita & 2,12 & 10 & Volborthita \\
\hline & & & & & & 2,17 & 27 & Rodocrosita & 2,12 & 9 & Quartzo alfa \\
\hline
\end{tabular}




\begin{tabular}{|c|c|c|}
\hline$d(A)$ & I & Mineral \\
\hline $2,12^{\circ}$ & 8 & Veszelyita \\
\hline 2,12 & 6 & Clinozoisita \\
\hline 2,12 & 3 & Brociantiti \\
\hline 2,12 & 1 & 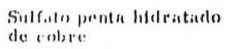 \\
\hline 2,11 & 80 & Dioptásio \\
\hline 2,11 & 60 & Ktenarita \\
\hline 2,11 & 50 & Calcocita \\
\hline 2,11 & 40 & Algodonita \\
\hline 2,11 & 40 & Epidoto \\
\hline 2,11 & 40 & Erinita \\
\hline 2,11 & 30 & Gerhardtita \\
\hline 2,11 & 30 & Seligmanita \\
\hline 2,11 & 30 & $\begin{array}{l}\text { Vanadato hidratado bá } \\
\text { sico de cobre }\end{array}$ \\
\hline 2,11 & 20 & Krochnkita \\
\hline 2,11 & 10 & Plancheita \\
\hline 2,11 & 10 & Zoi gita \\
\hline 2,11 & 5 & Bornita \\
\hline 2,10 & 90 & Murdochita \\
\hline 2,10 & 76 & Barttil \\
\hline 2,10 & 60 & Descloizita \\
\hline 2,10 & 50 & Mottramita \\
\hline 2,10 & 40 & Clinoclasita \\
\hline 2,10 & 20 & Polibasita \\
\hline 2,10 & 20 & Stromeyerita \\
\hline 2,10 & 13 & Bournonita \\
\hline 2,10 & 11 & Bonattita \\
\hline 2,10 & 10 & Cornwallita \\
\hline 2,10 & $10 B$ & Novikita \\
\hline 2,10 & 10 & Tyrolita \\
\hline 2,10 & 7 & Azurita \\
\hline 2,10 & 5 & Djurleita \\
\hline 2,10 & 5 & Latutita \\
\hline 2,10 & 5 & Wittichenita \\
\hline 2,10 & 1 & $\begin{array}{l}\text { Sulfito penta hidrata- } \\
\text { do de cobre }\end{array}$ \\
\hline 2,09 & 60 & Cornubita \\
\hline 2,09 & 30 & $\mathrm{P}_{\text {Beudomalequita }}$ \\
\hline 2,09 & 25 & Clinozorisita \\
\hline 2,09 & 20 & Cuprobismutita \\
\hline 2,09 & 20 & Mixita \\
\hline 2,09 & 20 & Pearccita \\
\hline 2,09 & 18 & Calcita \\
\hline 2,09 . & 15 & Goethita \\
\hline 2,09 & 10 & Shaltuckita \\
\hline 2,09 & 8 & Calcocyanita \\
\hline 2,09 & 8 & Nakisenita \\
\hline 2.09 & 6 & Coveliti \\
\hline 2,09 & 6 & $\begin{array}{l}\text { Sulfiato hidratido } \\
\text { de cobre }\end{array}$ \\
\hline 2,09 & 5 & $\begin{array}{l}\text { Silicito de cobree } \\
\text { birio }\end{array}$ \\
\hline 2.09 & 4 & Errocalcita \\
\hline 2,08 & 100 & Cobre \\
\hline 2.08 & 100 & Koutektli: \\
\hline 2,08 & 100 & Metidumeykita \\
\hline 2.08 & 60 & Cuprodescloizita \\
\hline 2,08 & 50 & Mottramita \\
\hline 2,08 & 30 & Paxita \\
\hline 2,08 & 10 & Germanita \\
\hline 2,08 & 10 & Pisanita \\
\hline 2,08 & 7 & $\begin{array}{l}\text { Sulfito penta hidratado } \\
\text { de cobre }\end{array}$ \\
\hline 2,08 & 6 & Antleriti \\
\hline 2,08 & 6 & Delafossita \\
\hline 2,08 & 5 & Bisgceita \\
\hline 2.08 & 5 & Olivenita \\
\hline 2,08 & $5 B$ & Lindgrenita \\
\hline 2,08 & 2 & Dolerophanita \\
\hline 2,07 & 100 & Rickardita \\
\hline 2,07 & 80 & Diaboleita \\
\hline 2,07 & 80 & Strmeyerita \\
\hline 2,07 & 50 & Cornubita \\
\hline 2,07 & 50 & Meneghinita \\
\hline 2,07 & 50 & Turquesa \\
\hline 2,07 & 40 & Calcosiderita \\
\hline 2,07 & 40 & Libethenita \\
\hline 2,07 & 40 & Noyakita \\
\hline
\end{tabular}

\begin{tabular}{|c|c|c|c|}
\hline $\mathrm{d}(\mathrm{A})$ & 1 & Mineral & $d(A)$ \\
\hline 2,07 & 30 & Liroconita & 2,03 \\
\hline 2,07 & 20 & $\begin{array}{l}\text { Cloreto hidratado de } \\
\text { cobre II e potía日io }\end{array}$ & 2,02 \\
\hline 2,07 & 17 & M.ilinquilit & $2,0 ?$ \\
\hline 2,07 & 11 & Btm.111t.. & $2,02$. \\
\hline 2,07 & 10 & Brociantita & 2,02 \\
\hline 2,07 & 10 & Kroehnkita & 2,02 \\
\hline 2,07 & 10 & Spingolita & 2,02 \\
\hline 2,07 & 8 & Veszelyita & 2,02 \\
\hline 2,07 & 5 & Cyinotrichita & 2,02 \\
\hline 2.07 & 5 & Renierita & 2,02 \\
\hline 2,07 & 5 & Tenantita & 2,02 \\
\hline 2,07 & 4 & Hiclroxiclo de cobre & \\
\hline 2,06 & 70 & Cornetita & 2,02 \\
\hline 2,06 & 65 & Zoisita & 2,02 \\
\hline 2,06 & 40 & Freibergita & 2,02 \\
\hline 2,06 & 30 & Lautiti & 2,02 \\
\hline 2,06 & 20 & Calciovolborthita & 2,02 \\
\hline 2,06 & 20 & Nakaseita & 2,02 \\
\hline 2,06 & 20 & Pearceita & 2,02 \\
\hline 2,06 & 18 & Antlerita & 2,02 \\
\hline 2,06 & 11 & Eppieloto & 2,01 \\
\hline 2,06 & 10 & Clinozoisita & 2,01 \\
\hline 2,06 & 10 & Djurleita & 2,01 \\
\hline 2,06 & 10 & Polibasita & 2,01 \\
\hline 2,06 & 8 & $\begin{array}{l}\text { Sulfato hirlratado de } \\
\text { cobre }\end{array}$ & 2,01 \\
\hline 2,06 & 6 & Erincalcita & 2,01 \\
\hline 2,06 & 613 & Liroconita & 2,01 \\
\hline 2,06 & 5 & Dolomitit & 2,01 \\
\hline 2,06 & 5 & ligyptian blue & 2,01 \\
\hline 2,06 & 5 & Finargita & 2,01 \\
\hline 2,06 & 5 & Plancheita & 2,01 \\
\hline 2,05 & 100 & Domeykita alfa & 2,01 \\
\hline 2,05 & 70 & Ficustita & 30 \\
\hline 2,05 & 70 & Murclochita & 2,01 \\
\hline 2,05 & 60 & $\begin{array}{l}\text { Valeriata } \\
\text { Clinocliagita }\end{array}$ & 2,01 \\
\hline 2,05 & 50 & $\begin{array}{l}\text { Clinocliasita } \\
\text { Duftita }\end{array}$ & 2,00 \\
\hline 2,05 & 40 & $\begin{array}{l}\text { Duftita } \\
\text { Paratacismita }\end{array}$ & 2,00 \\
\hline 2,05 & 40 & $\begin{array}{l}\text { Paratacimita } \\
\text { Azurita }\end{array}$ & 2,00 \\
\hline 2,05 & $\begin{array}{l}23 \\
20\end{array}$ & $\begin{array}{l}\text { Azurita } \\
\text { Lindiackerita }\end{array}$ & 2,00 \\
\hline $\begin{array}{l}2,05 \\
2,05\end{array}$ & $\begin{array}{l}20 \\
20\end{array}$ & $\begin{array}{l}\text { Lindiackerita } \\
\text { Rickarliti }\end{array}$ & 2,00 \\
\hline 2,05 & 20 & Vulcamita & 2,00 \\
\hline 2,05 & 20 & Wittichenita & 2,00 \\
\hline 2,05 & 9 & Maliaquita & 2,00 \\
\hline 2,05 & 3 & Azuriti & 2,00 \\
\hline 2,05 & 3 & $\begin{array}{l}\text { Sulfitor pentil hidratado } \\
\text { de colree }\end{array}$ & 2,00 \\
\hline 2,04 & 40 & $P_{\text {iixiti: }}$ & 2,00 \\
\hline 2,04 & 30 & Ktenasita. & 2,00 \\
\hline 2,04 & 30 & Volborthita & 2,00 \\
\hline $2,0.4$ & 25 & Cotleocitit & 2,00 \\
\hline 2,04 & 10 & P'isinitit & 2,00 \\
\hline 2,04 & 10 & Shattuckitil & 2,00 \\
\hline 2,04 & 10 & Tetracelritat & 2,00 \\
\hline 2,04 & 10 & 'Pyrreliti & 2,00 \\
\hline 2,04 & 7 & Covelita & 2,00 \\
\hline 2,04 & 5 & Djurleitit & 2,00 \\
\hline 2,04 & $\cdot 5$ & Requesita & 2,00 \\
\hline 2,04 & 5 & Seligmanita & 1,99 \\
\hline 2,04 & 1 & Epicioto & 1,99 \\
\hline 2,03 & 100 & Cubro magnésio & 1,99 \\
\hline 2,03 & 100 & $\begin{array}{l}\text { Sulfato de cobre } \\
\text { magnésio }\end{array}$ & 1,99 \\
\hline 2,03 & 100 & Vulcanita & 1,99 \\
\hline 2,03 & 60 & Vandenbrandeita & 1,99 \\
\hline 2,0 . & 40 & Erinita & 1,99 \\
\hline 2,03 & 35 & Cyanotrichita & 1,99 \\
\hline 2,03 & 30 & Dioptisio & 1,99 \\
\hline 2,03 & 30 & $\begin{array}{l}\text { Silicato de cobre } \\
\text { e bário }\end{array}$ & $\begin{array}{l}1,99 \\
1,99\end{array}$ \\
\hline 2,03 & 20 & Aikinita & \\
\hline 2,03 & 20 & Antlerita & 1,98 \\
\hline 2,03 & 20 & Atacamita & 1,98 \\
\hline 2,03 & 20 & Eucairita & 1,98 \\
\hline 2,03 & 5 & Bournonita & 1,98 \\
\hline 2,03 & 5 & Renierita & 1,98 \\
\hline 2,03 & 5 & $\begin{array}{l}\text { Silicato de estrôncio } \\
\text { c coblere }\end{array}$ & $\begin{array}{l}1,98 \\
1,98\end{array}$ \\
\hline
\end{tabular}

\begin{tabular}{|c|c|}
\hline I & Mineral \\
\hline 3 & $\begin{array}{l}\text { Sulfato penta hidratado } \\
\text { de cobre }\end{array}$ \\
\hline 100 & Berzelianita \\
\hline 100 & Koutokita \\
\hline 100 & Motiutemeykita \\
\hline 60 & Turquesa \\
\hline 50 & Calcocita \\
\hline 50 & Faustita \\
\hline 35 & Dioptísio \\
\hline 30 & Polibasita \\
\hline $20 \mathrm{ST}$ & Libethenitit \\
\hline 20 & $\begin{array}{l}\text { Sulfito pentia hidratado } \\
\text { de cobre }\end{array}$ \\
\hline 14 & Dolerophanita \\
\hline $10 B$ & Cornubita \\
\hline 6 & Zoisitil \\
\hline 5 & Maliqquita \\
\hline 5 & Meneghinita \\
\hline 5 & Plincheita \\
\hline 4 & Calcocyanita \\
\hline 1 & Epidoto \\
\hline 60 & Betechtenita \\
\hline 40 & Pearceita \\
\hline 20 & $\begin{array}{l}\text { Cloreto hidratado de } \\
\text { cobre II e estrôncio }\end{array}$ \\
\hline 20 & Cornwallita \\
\hline 20 & Goethita \\
\hline 20 & Nakaseita \\
\hline 15 & Dolomita \\
\hline 10 & $\begin{array}{l}\text { Silicates te estrôncio } \\
\text { o colse }\end{array}$ \\
\hline 10 & PBendomalaquita \\
\hline 8 & Clinozoiatit \\
\hline 7 & Brocantitia \\
\hline 5 & $\begin{array}{l}\text { Silicato de bário e } \\
\text { cobre }\end{array}$ \\
\hline 3 & Azurita \\
\hline 1 & $\begin{array}{l}\text { Sulfato penta hidratado } \\
\text { de cobre }\end{array}$ \\
\hline 60 & Diaboleita \\
\hline 48 & Antlerita \\
\hline 40 & Paratacamita \\
\hline 40 & Paxita \\
\hline 30 & Cutencita \\
\hline 30 & $\begin{array}{l}\text { Silicato dee estrôncio } \\
\text { e colbre }\end{array}$ \\
\hline 23 & Rodocrosita \\
\hline 20 & Egyptian blue \\
\hline 20 & Kroehnkit:t \\
\hline 20 & Pisanita \\
\hline 10 & Calcosideritit \\
\hline 5 & Calcocita \\
\hline 5 & Cuprobismutita \\
\hline 5 & Dioptísio \\
\hline 5 & Gerbardtit: \\
\hline 4 & Calcocyanita \\
\hline 2 & Eriocalciti \\
\hline 2 & Liroconita \\
\hline 2 & Veszelyita \\
\hline 1 & Epitoto \\
\hline 1 & $\begin{array}{l}\text { Sulfito penta hidratado } \\
\text { de cobre }\end{array}$ \\
\hline 80 & Novakita \\
\hline 70 & Stromeycrita \\
\hline 25 & Calcocita \\
\hline 20 & Mixita \\
\hline 20 & Tenantita \\
\hline 11 & Malaquita \\
\hline 10 & Faustiti \\
\hline $10 \mathrm{~B}$ & Shattuckita \\
\hline 10 & Turquesa \\
\hline 5 & Liroconita \\
\hline 3 & $\begin{array}{l}\text { Sulfato penta hidratado } \\
\text { de cobre }\end{array}$ \\
\hline 100 & Algodinnita \\
\hline 100 & Koutekila \\
\hline 60 & Spangolita \\
\hline 50 & Rickardita \\
\hline 40 & Aikinita \\
\hline 40 & Famitinita \\
\hline 40 & Erinitit \\
\hline
\end{tabular}

\begin{tabular}{|c|c|c|}
\hline $\mathrm{d}(\mathrm{A})$ & I & Mineral \\
\hline 1,98 & 30 & Bouruonita \\
\hline 1,98 & 25 & Calcocita \\
\hline 1,98 & 20 & Wittichenita \\
\hline 1,98 & 15 & Zninita \\
\hline 1,98 & 9 & $\begin{array}{l}\text { Sulfiton penta hadritude } \\
\text { de cobre }\end{array}$ \\
\hline 1,972 & $100^{\circ}$ & Calcocita \\
\hline 1,97 & 100 & Digenita \\
\hline 1,97 & 75 & Calcocita \\
\hline 1,97 & 40 & Cornubitit \\
\hline 1,97 & 40 & Erinita \\
\hline 1,97 & 40 & Seligmanita \\
\hline 1,97 & 30 & Descloizita \\
\hline 1,97 & 30 & $\begin{array}{l}\text { Vanadato hidratado básic } \\
\text { de cobre }\end{array}$ \\
\hline 1,97 & 20 & Cubanita \\
\hline 1,97 & 20 & Egyptian blue \\
\hline 1,97 & 20 & Libethenita \\
\hline 1,97 & 20 & Metadomeykita \\
\hline 1,97 & 10 & Calciovolborthita \\
\hline 1,97 & 10 & Calcocyanita \\
\hline 1,97 & $10 \mathrm{~B}$ & Gerhardtita \\
\hline 1,97 & 10 & Lindgrenita \\
\hline 1,97 & 10 & Olivenita \\
\hline 1,97 & 6 & Clinozoisita \\
\hline 1,97 & 5 & Clinoclasita \\
\hline 1,97 & 5 & Polibasita \\
\hline 1,97 & 4 & Dolerophanita \\
\hline 1,96 & 100 & Eskebornita \\
\hline 1,96 & 90 & Djurleitn \\
\hline 1,90 & 60 & $\begin{array}{l}\text { Cloreto hidratado de co- } \\
\text { bre II e potíssio }\end{array}$ \\
\hline 1,96 & 50 . & Domeykita alfa \\
\hline 1,96 & 40 & Meneghinita \\
\hline 1,96 & 40 & Paxita \\
\hline 1,96 & 30 & Calcosiderita \\
\hline 1,96 & 30 & Mottramita \\
\hline 1,96 & 30 & Siderita \\
\hline 1,96 & 20 & Emplectita \\
\hline 1,96 & 20 & Kroehnkita \\
\hline 1,96 & 20 & Pseudomalaquita \\
\hline 1,96 & 20 & Pisanita \\
\hline 1,96 & 17 & Malaquita \\
\hline 1,90 & 10 & Calcocyanita \\
\hline 1,96 & 16 & Nakaseita \\
\hline 1,96 & 15 & Bournonita \\
\hline 1,90 & 13 & Brocintita \\
\hline 1,96 & 10 & Cromita de cobre 11 \\
\hline 1.96 & 10 & Duitita \\
\hline 1,96 & 10 & Emplectita \\
\hline 1,96 & 10 & Turquesa \\
\hline 1,196 & 5 & Cyanotrichila \\
\hline 1,96 & 5 & Laintiti: \\
\hline 1,96 & 1 & $\begin{array}{l}\text { Sulfuto penta hidratado } \\
\text { de cobre }\end{array}$ \\
\hline 1,95 & 90 & Djurleita \\
\hline 1,95 & 90 & Novakita \\
\hline 1,95 & 80 & Bandylita \\
\hline 1,95 & 80 & Miersita \\
\hline 1,95 & 60 & Cornubita \\
\hline 1,95 & 40 & Atacamita \\
\hline 1,95 & 30 & Aikinita \\
\hline 1,95 & 30 & Bournonita \\
\hline 1,95 & 30 & Cuprobismutita \\
\hline 1,95 & 25 & Calcocita \\
\hline 1,95 & 20 & Cornetita \\
\hline 1,95 & 20 & Cuprodescloizita \\
\hline 1,95 & 20 & Lindackerita \\
\hline 1,95 & 15 & Dioptásio \\
\hline 1,95 & 10 & Luzonita \\
\hline 1,95 & 6 & Clinozoisita \\
\hline 1,95 & 3 & Tenorita \\
\hline 1,95 & 2 & Antlerita \\
\hline 1,94 & 80 & Roque sita \\
\hline 1,94 & 75 & Calcocita \\
\hline 1,94 & 70 & Betechtenita \\
\hline 1,94 & 20 & Azurita \\
\hline 1,94 & 15 & Malaquita \\
\hline 1,94 & 15 & $\begin{array}{l}\text { Silicato de bário e } \\
\text { cobro }\end{array}$ \\
\hline
\end{tabular}




\begin{tabular}{|c|c|c|}
\hline$d(A)$ & 1 & Mineral \\
\hline 1.94 & 10 & Mixita \\
\hline 1,94 & 10 & Pseudomalaquita \\
\hline 1,94 & 10 & $\begin{array}{l}\text { Silicato de estrôncio e } \\
\text { cobre }\end{array}$ \\
\hline 1,941 & 9 & Malaquita \\
\hline 1,94 & 9 & Antlerita \\
\hline 1,94 & 5 & $\begin{array}{l}\text { Sulfato penta hidratado } \\
\text { de cobre }\end{array}$ \\
\hline 1,94 & 4 & Veazelyita \\
\hline 1,94 & 2 & $\begin{array}{l}\text { Sulfato hidratado de } \\
\text { cobre }\end{array}$ \\
\hline 1,94 & 1 & Barita \\
\hline 1,93 & 100 & Bornita \\
\hline 1,93 & 70 & Ktenasita \\
\hline 1,93 & $50 \mathrm{~B}$ & Shattuckita \\
\hline 1,93 & 20 & Carrollita \\
\hline 1,93 & 20 & Lindgrenita \\
\hline 1,93 & 20 & Plancheita \\
\hline 1,93 & 20 & Turquesa \\
\hline 1,93 & 11 & Bonattita \\
\hline 1,93 & 10 & Duftita \\
\hline 1,93 & 10 & Koutekita \\
\hline 1,93 & 10 & Meneghinita \\
\hline 1,93 & 10 & Polibatitn \\
\hline 1,93 & 9 & $\begin{array}{l}\text { Sulfinto penta hidratado } \\
\text { de cobre }\end{array}$ \\
\hline 1,93 & 7 & Barita \\
\hline 1,93 & 5 & Bournonita \\
\hline 1,93 & 5 & Olivenita \\
\hline 1,92 & 70 & Estanita \\
\hline 1,92 & 60 & Tyrrellita \\
\hline 1,92 & 60 & Gerhardtta \\
\hline 1,92 & 40 & Gocthita \\
\hline 1,92 & 20 & Kroehnkita \\
\hline 1.92 & 10 & Vesignieita \\
\hline 1,92 & 7 & Antlerita \\
\hline 1,92 & 5 & Bournonita \\
\hline 1,92 & 5 & Calcitio \\
\hline 1,92 & 2 & Hidrúxiclo dle cobre \\
\hline 1,92 & 2 & Venzelyitil \\
\hline 1,91 & 100 & Valeriita \\
\hline 1,91 & 80 & Sulvanitin \\
\hline 1,91 & 60 & Libethenita \\
\hline 1,91 & 50 & Noviakita \\
\hline 1,91 & 50 & Seligmanita \\
\hline 1,91 & 40 & Cornubita \\
\hline 1,91 & 30 & Freibergita \\
\hline 1,91 & 25 & Calcocita \\
\hline 1,91 & 20 & $\begin{array}{l}\text { Hidrogênio fosfato hidrata - } \\
\text { do de cobre }\end{array}$ \\
\hline 1,91 & 20 & Liroconita \\
\hline 1,91 & 20 & Mottramita \\
\hline 1,91 & 20 & Paxita \\
\hline 1,91 & 17 & Calcita \\
\hline 1,91 & 17 & Malaquita \\
\hline 1,91 & 16 & Nakaseita \\
\hline 1,91 & 10 & Clinoclasita \\
\hline 1,91 & 10 & Pcieceita \\
\hline 1,91 & 10 & $\begin{array}{l}\text { Vanidato hidratado bá } \\
\text { de cobre }\end{array}$ \\
\hline 1,91 & 10 & Vandenbrancleita \\
\hline 1,91 & 9 & $\begin{array}{l}\text { Sulfato penta hidratado } \\
\text { de cobre }\end{array}$ \\
\hline 1.91 & 6 & Liroconita \\
\hline 1,91 & 5 & Cromita de cobre \\
\hline 1,91 & 5 & Enargita \\
\hline 1,91 & 5 & Wittichenita \\
\hline 1,91 & 1 & Epídoto \\
\hline 1,90 & 100 & Valleriita \\
\hline 1,90 & 80 & Lautiti \\
\hline 1,90 & 50 & Calcocita \\
\hline 1,90 & 40 & Turquesa \\
\hline 1,90 & 25 & Covelita \\
\hline 1,90 & 20 & Lindgrenita \\
\hline 1,90 & 20 & Zoisita \\
\hline 1,90 & 10 & Delafossita \\
\hline 1.90 & 10 & $\begin{array}{l}\text { Sulfato penta hidratado } \\
\text { de cobre }\end{array}$ \\
\hline 1,90 & 9 & Bonattita \\
\hline 1,90 & 7 & Azurita \\
\hline
\end{tabular}

\begin{tabular}{|c|c|c|}
\hline $\mathrm{d}(\Lambda)$ & 1 & Mineral \\
\hline 1,90 & 5 & Bournonita \\
\hline 1,90 & 2 & Veszelyita \\
\hline 1,89 & 100 & Ilnita \\
\hline 1,89 & 80 & Famatinita \\
\hline 1,89 & 75 & Covelita \\
\hline 1,89 & 60 & Paratacamita \\
\hline 1,89 & 60 & Polibnsiti \\
\hline 1,89 & 60 & Strmeyerita \\
\hline 1,89 & 50 & Cilleocita \\
\hline 1,89 & 40 & Betechtenita \\
\hline 1,89 & 40 & Diabole ita \\
\hline 1,89 & 30 & Calcostibinita \\
\hline 1,89 & 30 & Descloizita \\
\hline 1.89 & 30 & Wittichenita \\
\hline 1,89 & 20 & Aikinita \\
\hline 1,89 & 15 & Eghyptian blue \\
\hline 1,89 & 13 & Malaquitat \\
\hline 1,89 & 11 & $\begin{array}{l}\text { Sulfato penta hidratado } \\
\text { de cobre }\end{array}$ \\
\hline 1,89 & 10 & Cornetita \\
\hline 1,89 & 10 & Cornubita \\
\hline 1,89 & 10 & Pinanitn \\
\hline 1,89 & 10 & Tetriedrita \\
\hline 1,89 & 10 & Tyrolita \\
\hline 1,89 & 4 & Crednerita \\
\hline 1,89 & 3 & Antlerita \\
\hline 1,89 & 33 & Brociantita \\
\hline 1,88 & 90 & Calcopirita Rama \\
\hline 1,88 & 70 & Domeykit: alfa \\
\hline 1,88 & 60 & Paxita \\
\hline 1,88 & 50 & Murclochita \\
\hline 1,88 & 40 & Cuprode ac loixita \\
\hline $1.8 \mathrm{BH}$ & 35 & Nitkingeitis \\
\hline 1, 84 & 30 & Ktenasita \\
\hline 1,88 & 25 & Lindgrenita \\
\hline 1,88 & 20 & Oliveniti \\
\hline 1,88 & 10 & Dioptíaio \\
\hline 1,88 & 10 & $\begin{array}{l}\text { Silicate de birita e } \\
\text { cobrese }\end{array}$ \\
\hline 1,88 & 10 & $\begin{array}{l}\text { Siliciato de eatrôncio } \\
\text { o cobre }\end{array}$ \\
\hline 1.88 & 7 & $\begin{array}{l}\text { Sulfito penta hidratado } \\
\text { cle: colbru }\end{array}$ \\
\hline 1,88 & 5 & Buurmonitit \\
\hline 1,88 & 5 & Pearceita \\
\hline 1,88 & 55 & Plancheita \\
\hline 1,87 & 100 & Novikitin \\
\hline 1,87 & 100 & Valleriata \\
\hline 1,87 & 100 & Calcocitit \\
\hline 1,87 & 100 & Djurleita \\
\hline 1,87 & 95 & Calcopirita beta \\
\hline 1,87 & 80 & Germanit.ı \\
\hline 1,87 & 80 & Renierita \\
\hline 1,87 & 50 & Calcocita \\
\hline 1,87 & 50 & Duftita \\
\hline 1,87 & 40 & Meneghinit:i \\
\hline 1,87 & 30 & Mottramita \\
\hline 1,87 & 30 & Vandentratandeita \\
\hline 1,87 & 25 & Nakascita \\
\hline 1,87 & 20 & Calcosiderita \\
\hline 1,87 & 17 & Calciti \\
\hline 1,87 & 10 & Clinozoinita \\
\hline 1,87 & 5 & Azurita \\
\hline 1.87 & 5 & Digenita \\
\hline 1,87 & 5 & Cuprobismutita \\
\hline 1,87 & 5 & Gerhardtita \\
\hline 1,879 & 2 & Veszelyita \\
\hline 1,872 & 2 & Veszelyita \\
\hline 1,87 & 1. & Eirincilcita \\
\hline 1,86 & 80 & Cubanita \\
\hline 1,86 & 60 & Epídoto \\
\hline 1,86 & 40 & Descloizita \\
\hline 1,86 & 40 & Libethenita \\
\hline 1,86 & 40 & Calcopirita \\
\hline 1,86 & 40 & Erinita \\
\hline 1,86 & 30 & Bournonita \\
\hline 1,86 & 30 & Emplectita \\
\hline 1,86 & $25 \%$ & Tenorita \\
\hline 1,86 & 25 & Calcocita \\
\hline
\end{tabular}

\begin{tabular}{|c|c|c|}
\hline$\triangleleft(A)$ & 1 & Minerial \\
\hline 1,86 & 20 & $\begin{array}{l}\text { Silicato de bárioe } \\
\text { cobre }\end{array}$ \\
\hline 1,86 & 20 & Clinozoisita \\
\hline 1,86 & 15 & Vulcanita \\
\hline 1,86 & 10 & Cobre magnésio \\
\hline 1,86 & 10 & Cyanotrichita \\
\hline 1,869 & 10 & Dioptásio \\
\hline 1,86 & 10 & Eucairita \\
\hline 1,86 & 10 & $\begin{array}{l}\text { Sulfeto de cobre } \\
\text { magnésio }\end{array}$ \\
\hline 1.862 & 5 & Dioptásio \\
\hline 1,86 & 2 & Dolerophanita \\
\hline 1,86 & 1 & Hidróxicio de cobre \\
\hline I, H5 & 100 & Arsenosulvanita \\
\hline 1,85 & 100 & Llaita \\
\hline 1,85 & 90 & Enargita \\
\hline 1,85 & 90 & Luzonita \\
\hline I. 85 & so & Calcopirita \\
\hline 1,85 & 80 & Freibergita \\
\hline 1,85 & 60 & Diaboleita \\
\hline 1,85 & 60 & $\begin{array}{l}\text { Cloreto hidratado de } \\
\text { II e potíssio }\end{array}$ \\
\hline 1,85 & 50 & Paxita \\
\hline 1,85 & 40 & Bandylita \\
\hline 1,85 & 40 & Cuprodescloizit. \\
\hline 1,85 & 30 & Kroehnkitia \\
\hline 1,45 & 30 & Calcosiderita \\
\hline 1,85 & 20 & Teenantita \\
\hline 1,85 & 20 & Pseudomadirquiti: \\
\hline 1,85 & 20 & Pisanita \\
\hline 1,85 & $20 \mathrm{~B}$ & Gerhardtita \\
\hline 1,85 & 16 & Barita \\
\hline 1,85 & 10 & Bornit: \\
\hline 1,85 & 10 & Cornubitit \\
\hline 1,85 & 10 & Volborthitit \\
\hline 1,45 & 10 & Slintluckita \\
\hline 1,85 & 10 & Duitita \\
\hline 1,85 & 8 & Venzclyita \\
\hline I. 85 & 8 & liriocalcit. \\
\hline 1,85 & 5 & Polibiastit \\
\hline 1, BS & 5 & Renieriti \\
\hline 1.85 & 3 & Azurita \\
\hline 1,85 & 3 & Ml.ılıquitit \\
\hline 1,84 & 40 & T'urquesit \\
\hline 1,84 & 40 & Seligmanita \\
\hline 1,84 & 40 & Eskebornita \\
\hline 1.84 & 30 & $\begin{array}{l}\text { Silicato de estrincio } \\
\text { e cobre }\end{array}$ \\
\hline 1,84 & 30 & Zoisita \\
\hline 1,84 & 25 & Calcocita \\
\hline 1,84 & 20 & Mixita \\
\hline 1,84 & 20 & Clinoclasitia \\
\hline 1,84 & 20 & Galciovollorthit: \\
\hline 1,84 & 10 & Novakita \\
\hline 1,84 & 10 & Meneghinita \\
\hline $1, \mathrm{Ba}$ & 5 & Dolomita \\
\hline $1, \mathrm{BA}$ & 5 & Pl.ncheitit \\
\hline 1,84 & 5 & $\begin{array}{l}\text { Silicato de bário e } \\
\text { colre. }\end{array}$ \\
\hline 1,84 & 2 & $\begin{array}{l}\text { Sulfato hiciratide de } \\
\text { cobre }\end{array}$ \\
\hline 1,83 & 100 & Betechtenita \\
\hline 1,83 & 80 & Parratacamita \\
\hline 1,83 & 60 & Diaboleita \\
\hline 1,83 & 60 & Tutraedrita \\
\hline 1.83 & 60 & Egyptian blue \\
\hline 1,83 & 50 & Penrceita \\
\hline 1.83 & 40 & Gilleostibinita \\
\hline 1,83 & 12 & Antlerita \\
\hline 1,83 & 10 & $\begin{array}{l}\text { Silicato de estrôncio } \\
\text { cobre }\end{array}$ \\
\hline 1,83 & 10 & Lautita \\
\hline 1,83 & 7 & Azurita \\
\hline 1.83 & 5 & Olivenita \\
\hline 1,83 & 5 & Liroconita \\
\hline 1,83 & 5 & Dioptítio \\
\hline 1,83 & 5 & Cornetit. \\
\hline 1,83 & 5 & Gerhardtita \\
\hline 1,83 & 5 & Mottramita \\
\hline 1,83 & 1 & Eriocalcita \\
\hline
\end{tabular}

\begin{tabular}{|c|c|c|}
\hline$d(\mathrm{~A})$ & 1 & Miner..1 \\
\hline 1.82 & 80 & Atrcamita \\
\hline 1,82 & 60 & Carrollita \\
\hline 1.82 & 40 & Shattuckita \\
\hline 1.82 & 40 & Turquesa \\
\hline 1.82 & 40 & Cornubita \\
\hline 1,82 & 32 & Marshita \\
\hline 1,82 & 30 & Ktenasita \\
\hline 1,82 & 30 & Vesignieita \\
\hline 1,82 & 30 & Wittichenita \\
\hline 1,82 & 17 & Azurita \\
\hline 1,82 & 17 & Brocantita \\
\hline 1,82 & 12 & Rodoc rosita \\
\hline 1.82. & 10 & Duftita \\
\hline 1,82 & 10 & Dioptásio \\
\hline 1.82 & 10 & Caiciovolborthita \\
\hline 1,82 & 9 & Bonattita \\
\hline 1,82 & 6 & Veszelyita \\
\hline 1.82 & 5 & Cuprobismutita \\
\hline 1,82 & 5 & Cyanotrichita \\
\hline 1,82 & 5 & Pearceita \\
\hline 1,82 & 44 & Eriocalcita \\
\hline 1,81 & 50 & Paxita \\
\hline 1,41 & 40 & Plancheita \\
\hline 1.81 & 40 & Erinita \\
\hline 1,81 & 30 & Lanngita \\
\hline 1,81 & 20 & Rickinrdita \\
\hline 1,81 & 17 & Quartzo alfa \\
\hline 1,81 & 15 & Antlerita \\
\hline 1.81 & 10 & Duitita \\
\hline 1,81 & 10 & Kroehnkita \\
\hline 1,81 & 10 & Yandenbrandeita \\
\hline 1,81 & 10 & Clinozoisita \\
\hline 1,81 & 10 & Turquesa \\
\hline 1.81 & 10 & Cubanita \\
\hline 1,81 & 8 & $\begin{array}{l}\text { Sulfato hidratado de } \\
\text { cobre }\end{array}$ \\
\hline 1,81 & 5 & Renierita \\
\hline 1,81 & 5 & Aikinita \\
\hline 1,81 & 5 & Calcostibinita \\
\hline 1,81 & 5 & $\begin{array}{l}\text { Silicato de estrôncio o } \\
\text { cobre }\end{array}$ \\
\hline 1,81 & 4 & Dolerophanita \\
\hline 1, so & so & Tenantita \\
\hline 1,80 & 80 & Valleriita \\
\hline 1,80 & 70 & Spangolita \\
\hline 1,80 & 50 & Goethita \\
\hline 1,80 & 50 & Mixit. \\
\hline 1,80 & 46 & Cobre \\
\hline 1,80 & 30 & Metadomeykita \\
\hline 1.80 & 30 & Sulvanita \\
\hline 1,80 & 30 & Emplectita \\
\hline 1,40 & 20 & Dolonitia \\
\hline 1.80 & 20 & Clinoclasita \\
\hline 1,80 & 20 & Libethenita \\
\hline 1.80 & 20 & Dolonita \\
\hline 1,80 & 20 & $\begin{array}{l}\text { Cloreto hidratado de } \\
\text { cobre il e potís sio }\end{array}$ \\
\hline 1,80 & 10 & Freibergita \\
\hline 1, 40 & 5 & jioptásio \\
\hline 1,80 & 5 & Pisanita \\
\hline 1,80 & 2 & Antlerita \\
\hline 1,79 & 70 & Paxita \\
\hline 1,79 & 70 & Shattuckita \\
\hline 1,79 & 50 & Calcocita \\
\hline 1,79 & 40 & Cornubita \\
\hline 1.79 & 40 & Lautita \\
\hline 1,79 & 20 & Cornetita \\
\hline 1.79 & 20 & Meneghinita \\
\hline 1.79 & 17 & Siderita \\
\hline 1,79 & 10 & Liroconita \\
\hline 1,79 & 9 & Azurita \\
\hline 1,79 & 6 & $\begin{array}{l}\text { Sulfato hidratado de } \\
\text { cobre }\end{array}$ \\
\hline 1,79 & 6 & Hidroxido de cobre \\
\hline 1.79 & 5 & Seligmanita \\
\hline 1,79 & 5 & Germanita \\
\hline 1,79 & 5 & Idaita \\
\hline 1,78 & 60 & Koutekita \\
\hline 1,78 & 50 & Calcocita \\
\hline
\end{tabular}




\begin{tabular}{|c|c|c|c|c|c|c|c|c|c|c|c|}
\hline$i(\Lambda)$ & $\mathbf{I}$ & Mineral & $\|(\Lambda)$ & 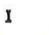 & Mineral & $d(A)$ & I & Mineral & $d(A)$ & I & Minerai \\
\hline$\therefore .78$ & $50 \mathrm{~B}$ & Mottramita & 1,75 & 10 & Plincheita & 1,71 & 6 & Antleritit & 1,67 & 10 & Metadomeyikita \\
\hline 1,78 & 50 & Descloizita & 1.75 & 10 & Spangolita & 1,71 & 6 & Liroconita & 1,67 & 10 & Plancheit.ı \\
\hline 1,78 & $40 \mathrm{~B}$ & Gerhardtita & 1,75 & 9 & Barita & 1,71 & 6 & $\begin{array}{l}\text { Sulfato hillyatado } \\
\text { de cobre }\end{array}$ & 1.67 & 7 & Quartzo alfa \\
\hline 1,78 & 40 & Atacamita & 1,75 & 5 & Duftita & & & de cobre & 1,67 & 6 & Dolerophanita \\
\hline 1,78 & 40 & Egyptian blue & 1,75 & 3 & Azurita & 1,71 & 5 & Eucairita & 1,67 & ó & Hidróxido de cobre \\
\hline 1,786 & 30 & Dolomita & 1,75 & 1 & Antlerita & 1,71 & 5 & Emplectita & 1,67 & . 5 & Dioptásio \\
\hline 1.781 & 30 & Dolomita & 1,74 & 70 & Seligmanita & 1,71 & 1 & Zois it: & 1,67 & 5 & Guprobismutita \\
\hline 1.78 & 30 & Tyrolita & 1,74 & 60 & Cornubita & 1,70 & 90 & Ktenasiti & 1,177 & 5 & Pearceita \\
\hline .78 & 30 & Novakita & 1,74 & 60 & Atacianita & 1,70 & 40 & Egyptian blue & 1,66 & to 0 & Roquesita \\
\hline 1,78 & 30 & Volborthita & 1,74 & 60 & Erinita & 1,70 & $30 \mathrm{~B}$ & Paxita & 1,66 & 50 & Libethenita \\
\hline 1,78 & 20 & Nakaseita & 1,74 & 50 & Koutukita & 1,70 & 30 & Rickardita & 1,66 & $40 \mathrm{~B}$ & Cornubita \\
\hline 1.78 & 20 & Famatinita & 1,74 & 40 & Cuprodescloizita & 1,70 & 30 & Stromeyerita & 1,66 & 40 & Diaboleita \\
\hline 1,78 & 20 & Turquesa & 1,74 & 40 & Lantita & 1,70 & 30 & Polibasita & 1,66 & 40 & Goethita \\
\hline 1,78 & 10 & Lindgrenita & 1,74 & 33 & Brocantita & 1,70 & 30 & Seligmanita & 1,66 & $20 \mathrm{~B}$ & Lindgrenita \\
\hline 1,78 & 10. & Duftita & 1,74 & 20 & Ktenasita & 1,70 & 30 & Tyrolita & 1,66 & $20 \mathrm{~B}$ & Paxita \\
\hline 1,78 & 10 & Polibarita & 1,74 & 20 & Corretiti & 1,70 & 20 & Gerhardtita & 3,66 & 20 & Vulcanita \\
\hline 1,74 & 9 & Azurita & 1,74 & 12 & Crednerita & 1.70 & 19 & Cromiti de cobre II & 1,66 & 10 & Barita \\
\hline 1,78 & 6 & Liroconita & 1,74 & 10 & Eskobornita & 1,70 & lii & Nakisoita & 1,66 & 10 & Rickardita \\
\hline 1,78 & 5 & Digenita & 1,74 & 10 & Paxita & 1,70 & 15 & Dioptásio & 1,66 & 8 & Hidróxido de cobre \\
\hline 1,78 & 5 & Tetraedrita & 1,74 & 10 & Polibasita & 1,70 & 10 & Pisanita & 1,66 & 5 & $\begin{array}{l}\text { Silicato de bárioe } \\
\text { cobre }\end{array}$ \\
\hline 1,78 & 5 & Emplectita & 1,74 & 10 & Freibergita & 1,70 & 10 & Cornetita & & & Sulfuto de cobre \\
\hline 1,78 & 5 & $\begin{array}{l}\text { Sillicato de estrônció } \\
\text { e robre }\end{array}$ & 1,74 & 10 & Olivenita & 1,70 & 10 & $\begin{array}{l}\text { Liroconiti } \\
\text { Sulfato hidratado de }\end{array}$ & 1,66 & 5 & magnésio \\
\hline 1,78 & 3 & Bariti & 1,74 & 10 & Vesignicita & 1,70 & 6 & $\begin{array}{l}\text { Sulrato hidratado de } \\
\text { cobre }\end{array}$ & 1,66 & 5 & Cobre magnósio \\
\hline 1,78 & 2 & Tenorita & 1.74 & B & Liroconita & 1.70 & 2 & Dolerophanitia & 1,66 & 5 & Pisanita \\
\hline 1,78 & 2 & Venzelyita & 1,74 & 5 & Gorhardtita & 1,70 & 22 & Vuleanita & 1,66 & 5 & Emplectita \\
\hline 1,77 & 70 & Murclochita & 1,74 & 5 & Marshita & 1.70 & 1 & Epíloto & 1.60 & 4 & Zoisita \\
\hline 1,77 & 50 & Cilleocita & 1,74 & 5 & C.1costibinita & 1,69 & 55 & Dioptínio & 1,66 & 3 & Antleritn \\
\hline 1,77 & 50 & Mixita & 1,74 & 5 & 'Tonimlita & 1,69 & 50 & Goethitit & 1,60 & 1 & Eipidoto \\
\hline 1,77 & 40 & Liingita & $\begin{array}{l}1,74 \\
1,74\end{array}$ & 4 & Verzelyita & 1,69 & 30 & Stromeyerita & 1,66 & 1 & Azurita \\
\hline 1,77 & 35 & $\begin{array}{l}\text { Silicato de bário o } \\
\text { cobre }\end{array}$ & $\begin{array}{l}1,74 \\
1,74\end{array}$ & $\begin{array}{l}1 \\
1\end{array}$ & $\begin{array}{l}\text { Cupritii } \\
\text { Lipréloto }\end{array}$ & 1,69 & 30 & Pearceita & 1,65 & 80 & Duscloizita \\
\hline 1,77 & 30 & Calcocyanita & 1,73 & 60 & $\begin{array}{l}\text { Eipietoto } \\
\text { Einnrpitit }\end{array}$ & $1,(19)$ & 30 & Froibergitit & 1,65 & 60 & Bandylyliti \\
\hline 1,77 & 30 & Goethita & 1.73 & 50 & $\begin{array}{l}\text { Emargiti } \\
\text { P'Heuclomalaquita }\end{array}$ & 1.69 & 20 & Clinoclasit.. & $1.1,5$ & 40 & Selygmanita \\
\hline 1,77 & 30 & Nikinitit & 1.735 & 45 & $\begin{array}{l}\text { Siderita } \\
\text { Sillation }\end{array}$ & 1,69 & 20 & Cubaniti & 1.65 & 35 & Delatonsita \\
\hline 1,77 & 30 & Krochnkita & 1,73 & 40 & $\begin{array}{l}\text { lalerita } \\
\text { Ielojtit }\end{array}$ & 1,69 & 20 & Djurleit.. & 1.65 & 30 & Bornita \\
\hline 1,77 & 30 & Roclocrositn & 1.73 & 40 & Stromeyerita & 1,69 & 15 & Bonittit.1 & 1,65 & 30 & $\begin{array}{l}\text { Emplectita } \\
\text { Silicato du estrôncio a }\end{array}$ \\
\hline 1,77 & 20 & $\begin{array}{l}\text { Arseniato hidratado } \\
\text { de cobre }\end{array}$ & 1,730 & 35 & Sirlerita & $\begin{array}{l}1,69 \\
1,69\end{array}$ & $\begin{array}{l}10 \\
10\end{array}$ & $\begin{array}{l}\text { Olivenita } \\
\text { Tyrrellita }\end{array}$ & 1.65 & 20 & $\begin{array}{l}\text { Silicato do estrôncio a } \\
\text { cobre }\end{array}$ \\
\hline 1,77 & 10 & Dioptíisio & $\begin{array}{l}1.73 \\
1.73\end{array}$ & 34 & Coveliti & 1,69 & 10 & Cornubitia & 1.65 & 20 & Olivenita \\
\hline 1,77 & 10 & Meneghinita & 1,73 & 30 & Cillciovolborthita & 1,69 & 10 & Famatinita & 1,65 & 20 & Ten.ıntitit \\
\hline 1,77 & 10 & Duftita & 1,73 & 30 & $\begin{array}{l}\text { Silicato de estrôncio } \\
\text { e cobro }\end{array}$ & 1,69 & 5 & Tenantita & 1,65 & 20 & Polybasita \\
\hline 1,77 & 1 & Epirloto & 1,73 & 20 & Wittichenita & 1,69 & 5 & Lautita & 1.65 & 20 & Tenantita \\
\hline 1,76 & 100 & Tyrrellita & 1,73 & 10 & Shattuckita & 1,69 & 4 & Erincalcita & 1,65 & 20 & Novakita \\
\hline 1,76 & 70 & Betechtenita & 1,73 & $10 \mathrm{~B}$ & Novakita & 1,69 & 3 & Azurita & 1.65 & 20 & Mottramita \\
\hline 1,76 & 50 & Calcostibinita & 1,73 & 5 & Meneghinita & 1,68 & 40 & Erinita & 1,65 & 15 & Bonattita \\
\hline 1,76 & 40 & Erinita & 1,72 & 80 & Berzelianita & 1,68 & $30 B$ & Paxita & 1,65 & 10 & $\begin{array}{l}\text { Hidrogênio fosfato hidratado } \\
\text { de cobrc }\end{array}$ \\
\hline 1,76 & 40 & Pseudomalaquita & 1,72 & 70 & Goethita & 1,68 & 30 & Digenita & 1,65 & 10 & Vesignieita \\
\hline 1,76 & 40 & Paratacamita & 1,72 & 40 & Mixita & 1,68 & 30 & Wittichenita & 1,65 & 10 & Freibergita \\
\hline 1,76 & 40 & Cuprodescloizita & 1,72 & 3.5 & Miderńxido de nobre & 1,68 & 20 & Mixita & 1,65 & 5 & Aikinita \\
\hline 1,76 & 33 & Rodocrosita & 1,72 & 30 & Clinoclasita & 1,68 & 10 & Betechitenit: & 1,65 & 3 & Azurit.. \\
\hline 1,76 & 30 & Wittichenita & 1,72 & 30 & Gerhardtita & 1,68 & 10 & Djurleita & 1,65 & 3 & Quartzo alfa \\
\hline 1,76 & 25 & Vulcanita & 1,72 & 25 & Lindlgrenita & 1,68 & 10 & Tetriedrita & 1,64 & 80 & Mottramita \\
\hline 1,76 & 20 & Fumatinita & 1,72 & 25 & Dioptásio & 1,68 & 10 & Calcostibinita & 1,64 & 50 & Duitita \\
\hline 1,76 & 20 & Bandylita & 1,72 & 20 & Cornubita & 1,68 & 10 & Shattuckita & 1,64 & 45 & Cromita de cobre \\
\hline 1,76 & 15 & Lindgrenita & 1,72 & 20 & Turquesa & 1,68 & 9 & Antlerita & 1,64 & 40 & Valeriita \\
\hline 1,76 & 12 & Dolerophanita & 1,72 & 11 & Bonattita & 1,68 & 8 & $\begin{array}{l}\text { Sulfato hidratido do } \\
\text { colre }\end{array}$ & 1,64 & 40 & Estinita \\
\hline 1,76 & 11 & Bonattita & 1,72 & 10 & Cubanita & 1,68 & 8 & Zoisita & 1,64 & 40 & Paratacamita \\
\hline 1,76 & 10 & Shattuckita & 1,723 & 6 & Barita & 1,68 & 7 & Barita & 1,64 & 40 & Betechtenita \\
\hline 1,76 & 10 & Pisanita & 1,726 & 5 & Barita & 1,68 & 6 & Clinoroisita & 1,64 & 40 & Lautita \\
\hline 1,76 & 10 & Clinozoisita & 1,72 & 5 & Plinchoita & 1,68 & 5 & Cyanotrichita & 1,64 & 30 & Spangolita \\
\hline 1,76 & 9 & Barita & 1,72 & 5 & Renierita & $1,6 \mathrm{H}$ & 5 & Meneghinita & 1,64 & 20 & Clinoclasita \\
\hline 1,76 & 6 & Veszelyita & 1,72 & 5 & Germanita & 1.68 & 5 & Iilaita & 1,64 & 13 & Brocantita \\
\hline 1,76 & 5 & Emplectita & 1,72 & 5 & Tetraedrita & $1,68$. & 1 & Epídoto & 1,64 & 10 & Krocnhkita \\
\hline 1,76 & 5 & Germanitit & 1.72 & 5 & $\begin{array}{l}\text { Sulfite de cobre } \\
\text { magnínio }\end{array}$ & 1,67 & Bo & Eskebornita & 1,64 & 6 & Dolerophanita \\
\hline 1.75 & 100 & Dit.13roleitiat & 1,72 & ", & 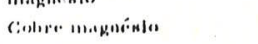 & 1.617 & no & Cirrrillitit & 1,64 & 5 & Tetracdrita \\
\hline 1,75 & 70 & Cubatnitat & 1,72 & 5 & Mottrimilit & $1,1,7$ & 60 & Diabulditit. & $1,6,3$ & 100 & Con,rederencloizit. \\
\hline 1,75 & 50 & Stromeyerita & 1.72 & 3 & Azuriti & 1,67 & 5013 & Krochnkitit & 1,63 & 65 & Eprítoto \\
\hline 1,75 & 40 & Liroconita & 1,71 & 80 & Paraticamita & 1,67 & 40 & Atacamit، & 1,63 & 60 & Idaita \\
\hline 1,75 & 40 & Deacloiaita & 1,71 & 70 & Libethenita & 1.67 & 30 & Volborthiti & 1.63 & 55 & Calcopirita gama \\
\hline 1,75 & 30 & Kroehnkita & 1,71 & 50 & Ilidrogênio fosfato hidra. & 1,67 & 20 & Pseudomalaquita & 1,63 & 50 & Mixita \\
\hline 1,75 & 30 & Cornwallita & & & tado de cohre & 1.672 & 20 & Turquesa & 1,63 & 50 & Vandenbrardeita \\
\hline 1,75 & 25 & Dioptásio & 1,71 & 40 & Meneghinita & 1,677 & 20 & Turquesa & 1,63 & 45 & Crisocola \\
\hline 1,75 & 20 & Metadomeykita & 1,71 & 40 & Atacamita & 1.67 & 20 & Novakita & 1,63 & 40 & Sulvanita \\
\hline 1,75 & 20 & Emplectita & 1,71 & 30 & Duftita & 1,67 & 14 & Barita & 1.63 & 40 & Turquesa \\
\hline 1,75 & 20 & Egyptian blue & 1,71 & 30 & Cuprobiemutita & 1,67 & 12 & Galcocyanita & 1,63 & $30 \mathrm{~B}$ & Ktenasita \\
\hline 1,75 & 20 & $\begin{array}{l}\text { Cloreto hidratado de } \\
\text { cobre II e potássio }\end{array}$ & 1,71 & 30 & Volborthita & 1,67 & 10 & Brocantita & 1,63 & 25 & $\begin{array}{l}\text { Silicato de bário e } \\
\text { cobre }\end{array}$ \\
\hline & & & 1,71 & 8 & Tenorita & 1,67 & 10 & Cyanotrichita & 1,63 & 20 & Dioptásio \\
\hline
\end{tabular}




\begin{tabular}{|c|c|c|}
\hline$d(A)$ & 1 & Mineral \\
\hline 1,63 & 20 & Egyptian blue \\
\hline 1,63 & 20 & $\begin{array}{l}\text { Cloreto hidratado de cobre } \mathrm{I} \\
\text { e potássio }\end{array}$ \\
\hline 1,63 & 16 & Antlerita \\
\hline 1,63 & 1613 & Clinuzoisita \\
\hline 1,63 & 10 & Stromeyer ita \\
\hline 1,63 & 10 & Cornubita \\
\hline 1,63 & 10 & Goethita \\
\hline 1,63 & 8 & Barita \\
\hline 1,63 & 8 & Hidróxiclo de cobre \\
\hline 1,63 & 7 & Bonattitat \\
\hline 1,63 & 5 & Metaclomeykita \\
\hline 1,63 & 5 & Pisanita \\
\hline 1,63 & 4 & Eriocalcita \\
\hline 1,63 & 3 & Covelita \\
\hline 1,63 & 2 & Eriocalcita \\
\hline 1,62 & 100 & Murdochita \\
\hline 1,62 & 70 & Shattuckita \\
\hline 1,62 & 60 & Erinita \\
\hline 1,62 & 60 & Libethentta \\
\hline 1,62 & 50 & Duftita \\
\hline 1,62 & 40 & Gromita de cobre II \\
\hline 1.62 & 40 & Paxita \\
\hline 1,62 & 40 & Plancheita \\
\hline 1.62 & 30 & Estanita \\
\hline 1,62 & 20 & Lindackerita \\
\hline 1.62 & 20 & Calcostilsinita \\
\hline 1,62 & 11 & Epídoto \\
\hline 1,62 & 10 & Pseudomalaquita \\
\hline 1,62 & 10 & Olivenita \\
\hline 1,62 & 5 & $\begin{array}{l}\text { Silicato de estrôncio e } \\
\text { cobre }\end{array}$ \\
\hline 1,62 & 4 & Calcita \\
\hline 1,61 & 75 & Zoisita \\
\hline 1,61 & 70 & Famatinita \\
\hline 1,61 & 60 & Calciovolborthita \\
\hline 1,61 & 60 & Lautita \\
\hline 1,61 & 40 & Paratacamita \\
\hline 1,61 & 40 & Mixita \\
\hline 1,61 & 40 & Mottramita \\
\hline 1,61 & 30 & $\begin{array}{l}\text { Silicato de estrôncio e } \\
\text { cobre }\end{array}$ \\
\hline 1,61 & 30 & Vesignieita \\
\hline 1,61 & 25 & Crednerita \\
\hline 1,61 & 20 & Clinoclasita \\
\hline 1,61 & 20 & Cubanita \\
\hline 1,61 & 20 & Seligmanita \\
\hline 1,61 & 20 & Bonattita \\
\hline 1,61 & 10 & Cyanotrichita \\
\hline 1,61 & 10 & Kroehnkita \\
\hline 1,61 & 10 & Polibasita \\
\hline 1,61 & 10 & Freibergita \\
\hline 1,61 & 10 & $\begin{array}{l}\text { Vanadato hidratado básico } \\
\text { de cobre }\end{array}$ \\
\hline 1,61 & 8 & Cobre magnéaio \\
\hline 1,61 & 8 & Sulfeto de cobro magnério \\
\hline 1,61 & 6 & $\begin{array}{l}\text { Sulfitte de cobro } \\
\text { hi.tritaclo }\end{array}$ \\
\hline $1,6,1$ & 5 & Emplertitit \\
\hline 1,61 & 4 & Dolerophanita \\
\hline 1,60 & 80 & Alactanitit \\
\hline $1,6,0$ & 70 & Citcopirita bota \\
\hline $1,6,0$ & 50 & Goethiti \\
\hline 1,60 & $40 \mathrm{~B}$ & Esyptian blue \\
\hline 1,60 & 40 & Dencloizita \\
\hline 1,60 & 40 & Enargita \\
\hline 1,60 & 40 & $\begin{array}{l}\text { Araeniatt) hillratado do } \\
\text { colbe } 11\end{array}$ \\
\hline 1,60 & 30 & Aikinita \\
\hline 1,60 & 30 & Olivenita \\
\hline 1,60 & 20 & Lindackerita \\
\hline 1,60 & 20 & Cubanita \\
\hline 1,60 & 20 & Mixita \\
\hline 1,60 & 20 & Pseudomalaquita \\
\hline 1,60 & 20 & Turquesa \\
\hline 1,60 & 20 & Eskebornita \\
\hline 1,60 & 15 & $\begin{array}{l}\text { Silicato de bárioe } \\
\text { cobre }\end{array}$ \\
\hline 1,60 & 13 & Brocantita \\
\hline 1,60 & 110 & Calcostibinita \\
\hline
\end{tabular}

\begin{tabular}{|c|c|c|c|c|c|}
\hline$d(\Lambda)$ & I & Mineral & $a(A)$ & I & Mineral \\
\hline 1,60 & 10 & Cornubita & 1,57 & 5 & Cyanotrichita \\
\hline 1,60 & 10 & Wittichenita & 1,57 & 5D & Egyptian blue \\
\hline 1,60 & 8 & Covelita & 1,573 & 4 & Dolerophanita \\
\hline 1,60 & 8 & Calcita & 1,56 & 100 & Irititia \\
\hline 1,60 & 5 & Carrollitit & 1,56 & 80 & Alacimnita \\
\hline 1,60 & 5 & Tenantita & 1,56 & 65 & Goethita \\
\hline 1,60 & 4 & Dolerophanita & 1,56 & 60 & Shattuckita \\
\hline 1,60 & 1 & Quartzo alfa & 1,56 & 50 & Descloizita \\
\hline 1,59 & 70 & Germanita & 1,56 & 40 & Spangoliti \\
\hline 1,59 & 70 & Latyomita & 1,56 & 40 & Pseudlomalaquita \\
\hline 1,59 & 70 & Calcopirita gama & 1,56 & 30 & Plancheita \\
\hline 1,59 & 60 & Renierit: & 1,56 & 30 & Tetracelrita \\
\hline 1,59 & 60 & Callsopirita & 1,56 & 23 & Brocantita \\
\hline 1,59 & 60 & Valleriita & 1,56 & 20 & Seligmanita \\
\hline 1,59 & 60 & Cuprode ac loizita & 1,56 & 20 & Gerhardtita \\
\hline 1,59 & 50 & Cornubitia & 1,54 & 20 & Emplectita \\
\hline 1,59 & 50 & Einargit., & 1,56 & 2.0 & Turquesi \\
\hline 1,59 & 40 & Șhattuckita & 1,56 & 10 & Novakita \\
\hline 1,59 & 30 & 1,ingitit & 1,56 & 10 & Biagecita \\
\hline 1,59 & 25 & Zoisita & 1,56 & 10 & Emplectita \\
\hline 1,59 & 20 & Lindgrenita & 1,56 & 10 & Mixita \\
\hline 1,59 & 20 & Fitmatinita & 1,56 & 8 & Dolonita \\
\hline 1,59 & 20 & $\begin{array}{l}\text { Polibiasita } \\
\text { Sulfato hidratado de }\end{array}$ & 1,568 & 6 & $\begin{array}{l}\text { Sulfato hidratado de } \\
\text { cobre }\end{array}$ \\
\hline 1,59 & 16 & $\begin{array}{l}\text { Sulfito hidratado de } \\
\text { cobre } \\
\text { Azuritis }\end{array}$ & 1,562 & 6 & $\begin{array}{l}\text { Sulfato hidratado clo } \\
\text { cobre }\end{array}$ \\
\hline 1,59 & $\begin{array}{l}15 \\
11\end{array}$ & $\begin{array}{l}\text { Azurita } \\
\text { Epídoto }\end{array}$ & 1.56 & 5 & $\begin{array}{l}\text { Sulieto cle cubre e } \\
\text { magnésio }\end{array}$ \\
\hline 1,59 & $\begin{array}{l}11 \\
10\end{array}$ & $\begin{array}{l}\text { Epídoto } \\
\text { Bingecita }\end{array}$ & 1,56 & & $\begin{array}{l}\text { magnésio } \\
\text { Cobre magnésio }\end{array}$ \\
\hline 1,59 & 10 & Paxita & 1,56 & 5 & Olivenita \\
\hline 1,59 & 10 & Novikita & 1,56 & 5 & Tenantita \\
\hline 1,59 & 8 & Barita & 1,56 & 5 & Germanita \\
\hline 1,593 & 7 & Barita & 1,56 & 5 & Renierita \\
\hline 1,590 & 5 & Pisanita & 1,56 & 5 & Pearceita \\
\hline 1,595 & 2 & Vulcanita & 1,56 & 5 & Azurita \\
\hline 1,59 & 90 & Arsenosulvanita & 1,56 & 2 & Calcocyanita \\
\hline 1,58 & & $\begin{array}{l}\text { Arsenosulvanita } \\
\text { Libethenita }\end{array}$ & 1,55 & 80 & Murdocinita \\
\hline 1,58 & & $\begin{array}{l}\text { Libethenita } \\
\text { Freibergita }\end{array}$ & 1,55 & 80 & Diaboleita \\
\hline 1,58 & & $\begin{array}{l}\text { Freibergita } \\
\text { Gerharelrita }\end{array}$ & 1,55 & 60 & Libethenita \\
\hline 1,58 & & $\begin{array}{l}\text { Gerhareltita } \\
\text { Lindackerita? }\end{array}$ & 1,55 & 60 & Cuprodescloizita \\
\hline 1,58 & & $\begin{array}{l}\text { Lindackerita? } \\
\text { Duftita }\end{array}$ & 1,55 & $50 \mathrm{~B}$ & Paxita \\
\hline 1,58 & & & 1,55 & 40 & Enargita \\
\hline 1,58 & 20 & $\begin{array}{l}\text { Silicate de estróncio } \\
\text { e cobre } \\
\text { Turquesa }\end{array}$ & 1,55 & 37 & Covelitia \\
\hline 1,58 & 20 & $\begin{array}{l}\text { Turquesa } \\
\text { Cornwallita }\end{array}$ & 1,55 & 30 & Langita \\
\hline 1,58 & 20 & $\begin{array}{l}\text { Cornwallita } \\
\text { Stromeyerita }\end{array}$ & 1,55 & 20 & Domeykita alfa \\
\hline 1,58 & 20 & Stromeyerita & 1,55 & 20 & Gerhardtita \\
\hline 1,58 & 15 & $\begin{array}{l}\text { Cromita de cobre II } \\
\text { Tenorita }\end{array}$ & 1,55 & 10 & Cubanita \\
\hline 1,58 & 14 & $\begin{array}{l}\text { Tenorita } \\
\text { Calcocyanita }\end{array}$ & 1,55 & 10 & Polibasita \\
\hline 1,584 & 12 & $\begin{array}{l}\text { Calcocyaniţa } \\
\text { Calcocyanita }\end{array}$ & 1,55 & 10 & Kroehnkita \\
\hline 1,580 & 10 & $\begin{array}{l}\text { Calcocyanita } \\
\text { Eucairita }\end{array}$ & 1,55 & 10 & Calcostibinita \\
\hline 1,58 & 10 & $\begin{array}{l}\text { Eucairita } \\
\text { Krochnkita }\end{array}$ & 1,55 & 8 & Calcocyanita \\
\hline 1,58 & 10 & $\begin{array}{l}\text { Krochnkita } \\
\text { Bornita }\end{array}$ & 1,55 & 5 & Mottramita \\
\hline 1,58 & 10 & $\begin{array}{l}\text { Bornita } \\
\text { Cubanita }\end{array}$ & 1,55 & 5 & Plancheita \\
\hline 1,58 & 5 & $\begin{array}{l}\text { Cubanitat } \\
\text { Wittichenita }\end{array}$ & 1,55 & 3 & Azurita \\
\hline 1,58 & 5 & $\begin{array}{l}\text { Witlichenita } \\
\text { C.alcitil }\end{array}$ & 1,55 & 2 & Dolerophanitit \\
\hline $1,5 \mathrm{H}$ & 2 & $\begin{array}{l}\text { C.tcitil } \\
\text { firiosileitat }\end{array}$ & 1,55 & 1 & Rodocrouita \\
\hline $1,5 \mathrm{H}$ & 2 & $\begin{array}{l}\text { Eriocilleita } \\
\text { Ciemariltitil }\end{array}$ & 1,54 & 60 & Valleriita \\
\hline 1,57 & so & Cienharillitil & 1,54 & 40 & Cornetit.i \\
\hline 1,57 & so & 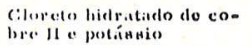 & $\begin{array}{l}1,5.4 \\
1,5.4\end{array}$ & 40 & Calcusiclerit.t \\
\hline 1,57 & 70 & Cormulbit. & $\begin{array}{l}1,5.1 \\
1,5,1\end{array}$ & 10 & Clineslintiti \\
\hline 1,57 & 70 & lirinit, & & 90 & Mottritnit:4 \\
\hline 1,57 & 60 & Lazonita & $1,5.4$ & $T$ & Bandylit.1 \\
\hline 1,57 & 40 & Paraticamita & 1,54 & 30 & Lamiltumitit \\
\hline 1,57 & 40 & Cornetita & $1,5.4$ & 2013 & Crosineratit \\
\hline 1,57 & 3013 & Ktenianitia & $1,5,4$ & 20 & Turques: \\
\hline 1,57 & 20 & Colloupirita & 1,54 & 15 & Cyatnotrichit. \\
\hline 1,57 & 20 & Calc iovolborthita & 1,54 & 15 & Quartzo alfia \\
\hline 1.57 & 15 & Vule:initi: & 1,54 & 10 & Dolomila \\
\hline 1,57 & 15 & Coveliti & 1,54 & 10 & Vandenbrandeita \\
\hline 1,57 & 13 & Lipictoto & $1,5.4$ & 10 & Freibergit., \\
\hline 1,57 & 10 & Pisanita & 1,54 & 10 & Novakita \\
\hline 1,57 & 10 & Estiniti & 1,54 & 10 & Cornubita \\
\hline 1,57 & 10 & Stromeyeriti & 1,54 & 5 & Wittichenitit \\
\hline 1,57 & 10 & Vandenbrandeita & 1,54 & 5 & Pcarcetta \\
\hline 1,57 & 10 & $\begin{array}{l}\text { Vanadito hidratado baai- } \\
\text { co de cobre }\end{array}$ & 1,54 & 5 & Emplectita \\
\hline 1,57 & $10 \mathrm{~B}$ & & 1,54 & 4 & Calcocyanita \\
\hline 1,57 & 6 & Dolerophanita & 1,54 & 2 & Lindgrenita \\
\hline & & & 1,53 & 80 & Diaboleita \\
\hline
\end{tabular}

\begin{tabular}{lll}
$d(A)$ & I & \multicolumn{1}{c}{ Mineral } \\
& & \\
1,53 & 60 & Murdochita \\
1,53 & 50 & Tenantita \\
1,53 & 40 & Mixita \\
1,53 & 40 & Duftita \\
1,53 & 30 & Paxitn \\
1,53 & 30 & Calcopirita gama
\end{tabular}

$1,53 \quad 30^{*}$ Seligmanita

$1,53 \quad 30$ Libethenita

$1,53 \quad 30 \begin{aligned} & \text { Cloreto hidratado de co- } \\ & \text { bre II e potássio }\end{aligned}$

$1,53 \quad 30 \quad$ Calciovolborthita

$1,5320 \quad \begin{aligned} & \text { Vanadato hidratado bábico } \\ & \text { de cobre }\end{aligned}$

1,5320 Brocantita

$1,53 \quad 20 \quad$ Pseudomalaquita

$1,53 \quad 18 \quad$ Barita

$1,53 \quad 13$ Rodocrosita

$1,53 \quad 10$ Bornitit

$1,53 \quad 10 \quad$ Lantita

$1,53 \quad 10$ Bisgeeita

$1,53 \quad 10$ Spangolita

$1,53 \quad 10 \quad$ Algodonita

$1,53 \quad 10$ Meneghinita

$1,53 \quad 10 \quad$ Vulcanita

$1,53 \quad 10 \quad$ Eskebornita

$1,53 \quad 7 \quad$ Epídoto

1,532 Dolerophanita

$1,52 \quad 70$ Cornubita

$\begin{array}{lll}1,52 & 60 & \text { Ktenasita } \\ 1,52 & 40 & \text { Paratacamita }\end{array}$

1,5230 Aikinita

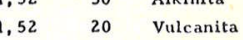

$\begin{array}{lll}1,52 & 20 & \text { Vulcanita } \\ 1,52 & 20 & \text { Rickardita }\end{array}$

$1,52 \quad 20$ Luzonita

$1,52 \quad 20$ Valleriita

$1,52 \quad 15$ Silicato de bário e

1,5211 Barita

$1,52 \quad 10 \quad$ Kroehnkita

$1,52 \quad 10 \quad$ Tyrrellita

$1,52 \quad 10$ Renierita

$1,52 \quad 10$ Germanita

$1,52 \quad 10 \quad$ Turquesa

$1,52 \quad 10 \quad$ Egyptian blue

1,527 Azurita

$1,52 \quad 5 \quad$ Cyanotrichita

$1,52 \quad 5$ Calcita

1,525 Silicato de estrôncio

1,522 Lindgrenita

$1,51 \quad 60$ Cornubita

$1,51 \quad 60$ Goethita

$1,51 \quad 40$ Delafossita

1,5130 Descloizita

$1,51 \quad 27$ Cuprita

$1,51 \quad 20$ Turquesa

$1,51 \quad 10$ Brocantita

$1,51 \quad 11 \quad$ Amaritia

$1,51 \quad 10$ Domeykitat alfa

$1,51 \quad 10 \quad$ Vanderibrondeitil

$1,51 \quad 10$ lireilererpitit

$1,51 \quad 10 \quad$ cinlocopirita bet.1

$1,51 \quad 10$ Pisitulti

$1,51 \quad 10 \quad$ Verignieita

$1,51 \quad 10$ Arsenesulvanita

1,51 10 Betechtenita

1,517 Mirelita

$1,51 \quad 5$ Calcopirita

$1,58 \quad 4$ Calcita

$1,510 \quad 3$ Calcita

1,512 Dolcrophanita

$1,50 \quad 60$ Erinita

1,50 60 volborthita

$1,50 \quad 40$ Tyrreluta

$1,50 \quad 40$ Libethenita

$1,50 \quad 30$ Cornetita

1,50 30 Cromita de cobre II

1,5020 Descloizita

$1,50 \quad 20$ Langita 


\begin{tabular}{|c|c|c|}
\hline$d(A)$ & I & Mineral \\
\hline 1,50 & 20 & Valleriita \\
\hline 1,50 & 20 & Atacamita \\
\hline 1,50 & 20 & Tenorita \\
\hline 1,50 & 20 & Pecudomalaquita \\
\hline 1,50 & 20 & Sulvanita \\
\hline 1,50 & 20 & Cubanita \\
\hline 1,50 & 20 & Novakita \\
\hline 1.50 & 20 & Siderita \\
\hline 1,50 & 10 & Pearceita \\
\hline 1,50 & 10 & Carrollita \\
\hline 1,50 & 10 & Wittichenita \\
\hline 1,50 & 10 & Shattuckita \\
\hline 1,50 & 9 & Azurita \\
\hline 1,50 & 5 & Germanita \\
\hline 1,50 & 5 & - Tetraedrita \\
\hline 1,50 & 5 & $\begin{array}{l}\text { Hidrogênio fosfato hidrata- } \\
\text { do de cobre }\end{array}$ \\
\hline 1,50 & 5 & Idaita \\
\hline 1,49 & 100 & Crisocola \\
\hline 1,49 & 70 & Cornubita \\
\hline 1,49 & 60 & Ktenasita \\
\hline 1,49 & 50 & Olivenita \\
\hline 1,49 & 50 & Koutekita \\
\hline 1,49 & 40 & Spangolita \\
\hline 1,49 & 40 & Cuprodescloizita \\
\hline 1,49 & 30 & Clinorlasita \\
\hline 1,49 & 30 & Duftita \\
\hline 1,49 & 30 & Mottramita \\
\hline 1,49 & 20 & Pseudomalaquita \\
\hline 1,49 & 20 & Turque 8 a \\
\hline 1,49 & 20 & Miersita \\
\hline 1,49 & 20 & $\begin{array}{l}\text { Cloreto hidratado de cobre } \\
\text { Il e potísaio }\end{array}$ \\
\hline 1,49 & 20 & Calleiuvolborthitit \\
\hline 1,49 & 10 & Petirceitat \\
\hline 1,49 & 10 & Lindgrenita \\
\hline 1,49 & 10 & $\begin{array}{l}\text { Silicato de estrôncio e } \\
\text { cohre }\end{array}$ \\
\hline 1,49 & 6 & Hiclróxiclo de cobre \\
\hline 1,49 & 5 & Lautita \\
\hline 1,49 & 55 & Cornwallita \\
\hline 1,49 & 5 & Aikinit.i \\
\hline 1,49 & 5 & Renierita \\
\hline 1,49 & 5 & Meneghinita \\
\hline 1,49 & 5 & Cyanotrichita \\
\hline 1,49 & 3 & Barita \\
\hline 1,49 & 2 & $\begin{array}{l}\text { Sulfato hidratado de } \\
\text { cobre }\end{array}$ \\
\hline 1,49 & 1 & Dolomita \\
\hline$\therefore 48$ & 40 & Paratacamita \\
\hline 1,48 & 35 & Cromita de cobre \\
\hline 1,48 & 30 & Mottramita \\
\hline 1,48 & 30 & Seligmanita \\
\hline 1,48 & 30 & Langita \\
\hline 1,48 & 20 & Shattuckita \\
\hline 1,48 & 20 & $\begin{array}{l}\text { Silicato de bário e } \\
\text { cobre }\end{array}$ \\
\hline 1,48 & 20 & Domeykita alfa \\
\hline 1,48 & 20 & Freibergita \\
\hline 1,48 & 20 & Vandenbrandeita \\
\hline 1,48 & 10 & Meneghinita \\
\hline 1,48 & 10 & Famatinita \\
\hline 1,48 & 10 & Aikinita \\
\hline $1,1 \mathrm{H}$ & 10 & Jegyptian bluo \\
\hline 1,48 & 5 & $\begin{array}{l}\text { Sulfeto de cobro } \\
\text { magnésio }\end{array}$ \\
\hline 1,48 & 5 & Fimplectita \\
\hline 1,48 & 5 & Cobre magnéslo \\
\hline 1,48 & 2 & Dolcrophanita' \\
\hline 1,47 & 60 & Libethenita \\
\hline 1,47 & $50 \mathrm{~B}$ & Mixita \\
\hline 1,47 & 40 & Calcosiderita \\
\hline 1,47 & 30 & Vesignieita \\
\hline 1,47 & 20 & Ktenasita \\
\hline 1,47 & 20 & Atacamita \\
\hline 1,47 & 20 & Valleriita \\
\hline 1,47 & 11 & Azurita \\
\hline 1,47 & 10 & Plancheita \\
\hline 1,47 & 10 & Barita \\
\hline
\end{tabular}

\begin{tabular}{|c|c|c|c|c|c|}
\hline$d(A)$ & I & Mineral & $\mathrm{d}(\mathrm{A})$ & I & Mineral \\
\hline 1,47 & 10 & Cornetiti & 1,44 & 5 & Descloizitat \\
\hline 1,47 & 10 & Clinoclasita & 1,44 & 5 & Wittichenita \\
\hline 1,47 & 10 & Turquesa & 1,44 & 5 & Germanita \\
\hline 1,47 & 10 & Volborthita & 1,44 & 5 & Renierita \\
\hline 1,47 & 8 & Ilirlróxido de cobro & 1,44 & 4 & Dolomita \\
\hline 1,47 & 5 & Bornita & 1,44 & 3 & Azurita \\
\hline 1,47 & 5 & Renierita & 1,44 & 2 & Dolerophanita \\
\hline 1,47 & 5 & Germanita & 1,43 & 60 & Paratacamita \\
\hline 1,47 & 5 & Emplectiti & 1,43 & 60 & Shattuckita \\
\hline 1,47 & 2 & Calciti & 1,43 & $40 B$ & Libethenit: \\
\hline 1,46 & 50 & Cornubita & 1,43 & 30 & Berzelianita \\
\hline 1,46 & 40 & Gocthit: & 1,43 & 30 & Clineclinsita \\
\hline 1,46 & 40 & Paratacamita & 1,43 & 30 & Pseuciomal aquita \\
\hline 1,46 & 30 & Betechtenita & 1,43 & 30 & Credneriti: \\
\hline 1,46 & 20 & Kroehnkita & 1,43 & 20 & Famatinita \\
\hline 1,46 & 20 & Famatinita & 1,43 & 20 & Turquesa \\
\hline 1,46 & 17 & Brocantita & 1,43 & 20 & Spangolita \\
\hline 1,46 & 10 & Pearceita & 1,43 & 20 & Ktenasita \\
\hline 1,46 & 10 & Pscudomalaquita & 1,43 & 20 & Delafossitit \\
\hline 1,46 & 10 & $\begin{array}{l}\text { Tenantita } \\
\text { Descloizita }\end{array}$ & 1,43 & 20 & $\begin{array}{l}\text { Silicato de estroncio e } \\
\text { cobre }\end{array}$ \\
\hline $\begin{array}{l}1,46 \\
1,46\end{array}$ & $\begin{array}{l}10 \\
10\end{array}$ & $\begin{array}{l}\text { Descloizita } \\
\text { Cloreto hillratado de } \\
\text { cobre e potísio }\end{array}$ & 1,43 & 20 & $\begin{array}{l}\text { Cloreto hidratado de co- } \\
\text { bre It e potiassio }\end{array}$ \\
\hline 1,46 & 6 & Covelita & 1,43 & 20 & Calcocyanita \\
\hline 1,46 & 6 & Hitlróxido te cobre & 1,43 & 15 & Vulcanita \\
\hline 1,46 & 5 & Dolomita & 1,43 & 12 & Hidlróxido de cobre \\
\hline 1,46 & 5 & Tetraedrita & 1,43 & 10 & Dolomita \\
\hline 1,46 & 5 & \multirow{2}{*}{$\begin{array}{l}\text { Siliciato de estrôncio e } \\
\text { colbre }\end{array}$} & 1,43 & 10 & Meneghiniti \\
\hline 1,46 & 5 & & 1,43 & 10 & Tenamita \\
\hline 1,46 & 4 & $\begin{array}{l}\text { Egyptian blue } \\
\text { Dolerophanita }\end{array}$ & 1,43 & 10 & Volloortinita \\
\hline 1,45 & 7013 & $\begin{array}{l}\text { Dolerophanita } \\
\text { Libethenita }\end{array}$ & 1,43 & 9 & Azurita \\
\hline 1,45 & 60 & $\begin{array}{l}\text { Libethenita } \\
\text { Banclylitil }\end{array}$ & 1,43 & 7 & Eipilloto \\
\hline 1,15 & 60 & $\begin{array}{l}\text { Biandyliti: } \\
\text { Goectliti" }\end{array}$ & 1,43 & 5 & Esyptian blue \\
\hline 1,45 & 50 & $\begin{array}{l}\text { Gocelliti: } \\
\text { Koutekitil }\end{array}$ & 1,43 & 5 & 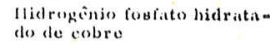 \\
\hline 1,45 & 40 & Murdochita & 1,43 & 5 & Cromiti: de cobre \\
\hline 1,45 & 35 & Zoisitat & 1,43 & 5 & Cornwillitin \\
\hline 1,45 & 30 & Duftit: & 1,43 & 5 & Cubanita \\
\hline 1,45 & 20 & Cialciovolborthita & 1,43 & 5 & Renierit: \\
\hline 1,45 & 20 & Mottramita & 1,43 & 5 & Krochnkita \\
\hline 1,45 & 20 & Turquesa & 1,42 & 60 & Stromeyerita \\
\hline 1,15 & 20 & Emplectita & 1,42 & 50) & Goethita \\
\hline 1,45 & 20 & Stromeyerita & 1,42 & 30 & Rickardita \\
\hline 1,45 & 20 & Langita & 1,42 & 30 & Pseudomalaquita \\
\hline 1,45 & 15 & Epírloto & 1,42 & 30 & Cromita de cobre \\
\hline 1,45 & 10 & Emplectita & 1,42 & 20 & Bornita \\
\hline 1,45 & 10 & Wittichenita & 1,42 & 20 & Turquesa \\
\hline 1,45 & 10 & Eucairita & 1,42 & 20 & Lautita \\
\hline 1,45 & 10 & Cornubitit & 1,42 & 18 & Calcocyanita \\
\hline 1,45 & 10 & Vandenbrandeita & 1,42 & 16 & Siclerita \\
\hline 1,45 & 10 & Cyanotrichita & 1,42 & 10 & Volborthita \\
\hline $1,45^{\circ}$ & 6 & \multirow{2}{*}{$\begin{array}{l}\text { Sulfato hiciratado de } \\
\text { cobre }\end{array}$} & 1,42 & 10 & Zoisita \\
\hline 1,45 & 5 & & 1,42 & 10 & Enargita \\
\hline 1,45 & 3 & $\begin{array}{l}\text { Egyptian blue } \\
\text { Barrita }\end{array}$ & 1,42 & 10 & Freibergita \\
\hline 1,45 & 3 & $\begin{array}{l}\text { Barita } \\
\text { Quartzo alfa }\end{array}$ & 1,42 & 10 & Moneghinita \\
\hline 1,458 & 2 & $\begin{array}{l}\text { Quartzo alfa } \\
\text { Eriocalcitit }\end{array}$ & 1,42 & 10 & Vuleanita \\
\hline 1,456 & 1 & $\begin{array}{l}\text { Eriocalcita } \\
\text { Eriocalcita }\end{array}$ & 1,42 & 8 & Baritn \\
\hline 1,45 & 1 & $\begin{array}{l}\text { Eriocalcita } \\
\text { Roclocrosita }\end{array}$ & 1,42 & 6 & Crednerita \\
\hline 1,45 & 1 & $\begin{array}{l}\text { Roclocrosila } \\
\text { Calcocyanita }\end{array}$ & 1,42 & 5 & Egyptian blue \\
\hline 1,44 & 60 & $\begin{array}{l}\text { Calcocysnita } \\
\text { Erinita }\end{array}$ & 1,42 & 3 & Calcita \\
\hline 1,44 & 50 & $\begin{array}{l}\text { Erinita } \\
\text { Metadomeykita }\end{array}$ & 1,42 & 2 & Hidroxido de cobre \\
\hline 1,14 & 40 & $\begin{array}{l}\text { Metadomeykita } \\
\text { Ielitita }\end{array}$ & 1,42 & 1 & Rodocrosita \\
\hline $1, \cdots$ & 小) & $\begin{array}{l}\text { Iclitita } \\
\text { Cromitit du coubro II }\end{array}$ & 1,41 & 60 & Atncamita \\
\hline 1,44 & 40 & $\begin{array}{l}\text { Cominjtit de colbet If } \\
\text { Mixitit }\end{array}$ & 1,11 & 50 & Sc:Lismanit.. \\
\hline 1,44 & 40 & $\begin{array}{l}\text { Mixiti } \\
\text { Tyrrellita }\end{array}$ & $1,4 \mathrm{i}$ & 30 & Mikinita \\
\hline 1,44 & $(30-40)$ & $\begin{array}{l}\text { Tyrrellita } \\
\text { Novakita }\end{array}$ & 1,41 & 30 & Clinoclasita \\
\hline 1,44 & 30 & $\begin{array}{l}\text { Novakita } \\
\text { Calcostibinita }\end{array}$ & 1,41 & 20 & Cornetitat \\
\hline 1,44 & $20 \mathrm{~B}$ & $\begin{array}{l}\text { Calcostibinita } \\
\text { Cornubita }\end{array}$ & 1,410 & 15 & Tenorita \\
\hline 1,44 & 20 & $\begin{array}{l}\text { Cornubita } \\
\text { Luzonita }\end{array}$ & 1,418 & 12 & Tenorita \\
\hline 1,44 & 20 & $\begin{array}{l}\text { Luzonita } \\
\text { Carrolitit }\end{array}$ & 1,41 & 10 & Cobre magnésio \\
\hline 1,44 & 20 & $\begin{array}{l}\text { Carrolitit } \\
\text { Alacimita }\end{array}$ & 1,41 & 10 & $\begin{array}{l}\text { Sulfeto de cobre } \\
\text { magnésio }\end{array}$ \\
\hline 1,44 & 17 & Brociantita & 1,41 & 10 & Plancheita \\
\hline 1,44 & 15 & Cobre magnésio & 1,41 & 8 & Crednerita \\
\hline 1,44 & 15 & Sulfeto de cobre & 1,41 & 5 & Domeykita alia \\
\hline 1,44 & 10 & $\begin{array}{l}\text { magnésio } \\
\text { Cornetita }\end{array}$ & 1,41 & 5 & Tetraedrita \\
\hline 1,44 & 10 & $\begin{array}{l}\text { Cornetita } \\
\text { Silicato de bário e }\end{array}$ & $1,4 !$ & 5 & Cubanita \\
\hline & 10 & $\begin{array}{l}\text { Silicato de bário e } \\
\text { cabre }\end{array}$ & 1,41 & 5 & Calcopirita gama \\
\hline
\end{tabular}

\begin{tabular}{|c|c|c|}
\hline$d(A)$ & I & Minerit \\
\hline 1,41 & 5 & Krochnicitit \\
\hline 1,41 & $5 B$ & Cyanotrichita \\
\hline 1,41 & 4 & Dolomita \\
\hline 1,41 & 1 & Quartzo alfa \\
\hline 1,40 & io & Klenitsit.. \\
\hline 1,40 & 100 & Cuprodescloizitia \\
\hline 1,40 & 60 & Descloizita \\
\hline 1,40 & 50 & Erinita \\
\hline 1,40 & 40 & Murdochita \\
\hline 1,40 & 30 & Epídoto \\
\hline 1,40 & 30 & Betechtenita \\
\hline 1,40 & 30 & Novakita \\
\hline 1,40 & 20 & Rickardita \\
\hline 1,40 & 20 & Tyrrellita \\
\hline 1,40 & 20 & Cornubita \\
\hline 1,40 & 20 & Mixita \\
\hline 1,40 & 20 & Mottramita \\
\hline 1,40 & 17 & Brocantita \\
\hline 1,40 & 10 & $\begin{array}{l}\text { Silicato de estrôncio e } \\
\text { cobre }\end{array}$ \\
\hline 1,40 & 10 & $\begin{array}{l}\text { Vanadato hidratado bási } \\
\text { de cobre }\end{array}$ \\
\hline 1,40 & 10 & Wittichenita \\
\hline 1,40 & 10 & Cornwallita \\
\hline 1,40 & 10 & Pearceita \\
\hline 1,40 & 10 & Koutekita \\
\hline 1,40 & 5 & Plancheita \\
\hline 1,40 & 5 & Freibergita \\
\hline 1,40 & 3 . & Azurita \\
\hline 1,40 & $1^{\circ}$ & Zoisita \\
\hline 1,39 & 50 & Shattuckita \\
\hline 1,39 & 50 & Goethita \\
\hline 1,39 & 40 & Pseudomalıquita \\
\hline 1,39 & 40 & B.undyliti: \\
\hline 1,31$)$ & 30 & Menephininta \\
\hline 1,39 & $20 \mathrm{~B}$ & Libethenita \\
\hline 1,39 & 20 & Spangolita \\
\hline 1,39 & 20 & Atncamita \\
\hline 1,39 & 20 & Mottramita \\
\hline 1,39 & 20 & Egyptian blue \\
\hline 1,39 & 10 & Metadomeykita \\
\hline 1,39 & 10 & Crertherita \\
\hline 1,39 & 10 & Vulcanita \\
\hline 1,39 & 10 & Digenita \\
\hline 1,39 & 10 & Cornubita \\
\hline 1,39 & 10 & Cubanita \\
\hline 1,39 & 10 & Clinoclasita \\
\hline 1,39 & 10 & Turquesa \\
\hline 1,39 & 8 & Siderita \\
\hline 1,39 & 6 & Covelita \\
\hline 1,39 & 5 & Azurita \\
\hline 1,39 & 5 & Renierita \\
\hline 1,39 & 5 & Lautita \\
\hline 1,39 & 5 & Descloizita \\
\hline 1,39 & 5 & $\begin{array}{l}\text { Silicato de estrôncio e } \\
\text { cobre }\end{array}$ \\
\hline 1,39 & 4 & Calcocyanita \\
\hline 1,38 & 50 & Eskebornita \\
\hline 1,38 & 45 & Zoisita \\
\hline 1,38 & 40 & Bandylita \\
\hline 1,38 & 40 & Paxita \\
\hline 1,38 & 40 & Paratacamita \\
\hline 1,38 & 30 & Duftita \\
\hline $1,3 H$ & 25 & Eipítlot) \\
\hline 1,38 & 20 & Egyptian blue \\
\hline 1,38 & 20 & Mixita \\
\hline 1,38 & 20 & Cuprodescloizita \\
\hline 1,38 & 19 & Tenorita \\
\hline 1,38 & 15 & Dolomita \\
\hline 1,38 & 11 & Marshita \\
\hline 1,38 & 10 & Aikinita \\
\hline 1,38 & 10 & Clinoclasita \\
\hline 1,38 & 10 & Wittichenita \\
\hline 1,38 & 7 & Quartzo alfa \\
\hline 1,38 & 5 & Calcopirita gama \\
\hline 1,38 & 5 & Eucairita \\
\hline 1,38 & 5 & Tetraedrita \\
\hline 1,38 & 5 & Tenantita \\
\hline
\end{tabular}




\begin{tabular}{|c|c|c|c|c|c|c|c|c|c|c|c|}
\hline$\|(\wedge)$ & 1 & Minutral & 川(A) & 1 & Pineral & $A(A)$ & 1 & Mineral & $d(\dot{A})$ & 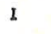 & Minerai \\
\hline 1,38 & 3 & Azurita & 1,35 & 20 & Pseudomalaquita & 1,33 & 25 & Egyptian blue & 1,31 & 20 & Cobre magnésio \\
\hline 1,38 & 2 & Hidróxido de cobre & 1,35 & 20 & Atacamita & 1,33 & 20 & Bandylita & 1,31 & 10 & Egyptian blue \\
\hline 1,37 & 70 & Koutekita & 1,35 & 20 & Govthita & 1,33 & 20 & Turquesa & 1,31 & 5 & Silicato de bárioe \\
\hline 1,37 & 60 & Cornubita & 1,35 & 15 & Silicuto de estrôncio e & 1,33 & 20 & Aikinita & & & cobre \\
\hline 1,37 & 40 & Goethita & & & & 1,33 & 20 & Rickardita & 1,31 & 5 & Eucairita \\
\hline 1,37 & 40 & Erinita & 1,35 & 110 & Pearcoita & 1,33 & 18 & Delafossita & 1,31 & 55 & Cubanita \\
\hline 1,37 & $40 \mathrm{~B}$ & Libethenita & 1,35 & 10 & Cornubita & 1,33 & 10 & Credinerita & 1,31 & 4 & $\begin{array}{l}\text { Hidróxido de } \\
\text { cobre }\end{array}$ \\
\hline 1,37 & 30 & Seligmanita & 1,35 & $\begin{array}{l}10 \\
10\end{array}$ & $\begin{array}{l}\text { Seligmanita } \\
\text { Aikinita }\end{array}$ & 1,33 & 10 & Spangolita & 1,31 & & Renierita \\
\hline 1,37 & 20 & Famatinita & 1,35 & $\begin{array}{l}10 \\
10\end{array}$ & $\begin{array}{l}\text { Aikinita } \\
\text { Clinoclasita }\end{array}$ & 1,33 & 10 & Novakíta & 1,30 & 50 & Betechtenita \\
\hline 1,37 & 20 & Atacamita & 1,35 & $\begin{array}{l}10 \\
10\end{array}$ & $\begin{array}{l}\text { Clinoclasita } \\
\text { Рівпnita }\end{array}$ & 1,33 & 8 & Dolomita & 1,30 & 50 & Domeykita alfa \\
\hline 1,37 & $20 \mathrm{~B}$ & Kroehnkita & 1,35 & $\begin{array}{l}10 \\
10\end{array}$ & $\begin{array}{l}\text { Piвanita } \\
\text { Spangolita }\end{array}$ & 1,33 & 5 & Vulcanita & 1,30 & 40 & Luzonita \\
\hline 1,37 & 20 & Langita & 1,35 & $\begin{array}{r}10 \\
7\end{array}$ & $\begin{array}{l}\text { Spangolita } \\
\text { Covelita }\end{array}$ & 1,33 & 5 & Emplectita & 1,30 & 30 & Plancheita \\
\hline 1,37 & 20 & Silicato de bário e cobre & 1,35 & $\begin{array}{l}7 \\
5\end{array}$ & $\begin{array}{l}\text { Covelita } \\
\text { Vulcanita }\end{array}$ & 1,33 & 5 & Bornita & 1,30 & 20 & Descloizita \\
\hline 1,37 & 20 & Bornita & 1,35 & 5 & $\begin{array}{l}\text { Vulcanita } \\
\text { Tenantita }\end{array}$ & 1,33 & 2 & Calcita & 1,30 & 20 & Sulvanita \\
\hline 1,37 & 19 & Tenorita & 1,35 & 5 & $\begin{array}{l}\text { Tenantita } \\
\text { A\%urita }\end{array}$ & 1,32 & 80 & Koutekita & 1,30 & 20 & Tyrrellita \\
\hline 1,37 & 12 & Calcoryanita & 1,354 & 4 & $\begin{array}{l}\text { A\%urita } \\
\text { Maruhita }\end{array}$ & 1,32 & 60 & Goethit: & 1,30 & 20 & Langita \\
\hline 1,37 & 10 & Roquesita & $\begin{array}{l}1,35 \\
1,358\end{array}$ & 3 & $\begin{array}{l}\text { Maruhita } \\
\text { Azurita }\end{array}$ & 1,32 & 60 & Cuprodencloizita & 1,30 & 10 & Eakcbornita \\
\hline 1,37 & 10 & Cubanita & $\begin{array}{l}1,358 \\
1,35\end{array}$ & 1 & $\begin{array}{l}\text { Azurita } \\
\text { Calcita }\end{array}$ & 1,32 & 6013 & Libethenitia & 1,30 & 10 & Famatinita \\
\hline 1,37 & 10 & Pseudomalaquita & $\begin{array}{l}1,35 \\
1,353\end{array}$ & 1 & $\begin{array}{l}\text { Calcita } \\
\text { Eriocilcita }\end{array}$ & 1,32 & 55 & Calcopirita gama & 1,30 & 10 & Turquesa \\
\hline 1,37 & 10 & Turquesa & $\begin{array}{l}1,353 \\
1,350\end{array}$ & 1 & $\begin{array}{l}\text { Eriocilcita } \\
\text { Eriocalcita }\end{array}$ & 1,32 & 50 & Luzonita & 1,30 & 10 & Calcostibinita \\
\hline 1,37 & 10 & Brocantita & $\begin{array}{l}1,350 \\
1,34\end{array}$ & 50 & $\begin{array}{l}\text { Eriocalcita } \\
\text { Famatinita }\end{array}$ & 1,32 & 45 & Calcopiritab beta & 1,30 & 10 & Calciovolborthita \\
\hline 1,37 & 10 & Rodocrosita & $\begin{array}{l}1,34 \\
1,34\end{array}$ & 40 & $\begin{array}{l}\text { Famatinita } \\
\text { Cuprode } 8 \text { cloizita }\end{array}$ & 1,32 & 40 & Metadomeykita & 1,30 & 7 & Tenorita \\
\hline 1,37 & 10 & Mottramita & $\begin{array}{l}1,34 \\
1,34\end{array}$ & 40 & $\begin{array}{l}\text { Cuprodescloizita } \\
\text { Cornubita }\end{array}$ & 1,32 & 40 & Lautita & 1,30 & 6 & Calcocyanita \\
\hline 1,37 & 9 & Quartzo alfa & 1,34 & $40 \mathrm{~B}$ & $\begin{array}{l}\text { Cornubita } \\
\text { Libethenita }\end{array}$ & 1,32 & $20 \mathrm{~B}$ & $\begin{array}{l}\text { Mixita } \\
\text { Seligmanita }\end{array}$ & 1,305 & 6 & Calcocyanita \\
\hline 1,37 & 5B & $\begin{array}{l}\text { Cyanotrichita } \\
\text { Azurita }\end{array}$ & 1,34 & 35 & $\begin{array}{l}\text { Libethenita } \\
\text { Calcopirita gama }\end{array}$ & 1,32 & 20 & $\begin{array}{l}\text { Seligmanita } \\
\text { Germanita }\end{array}$ & 1,30 & 5 & Bornita \\
\hline 1,37 & 5 & $\begin{array}{l}\text { Azurita } \\
\text { Calcostibinita }\end{array}$ & 1,34 & 30 & $\begin{array}{l}\text { Calcopirita gama } \\
\text { Sulvanita }\end{array}$ & 1,32 & 20 & $\begin{array}{l}\text { Germanita } \\
\text { Pseudomalaquita }\end{array}$ & 1,30 & 5 & Hidrogênio fosfato \\
\hline $\begin{array}{l}1,37 \\
1,37\end{array}$ & $\begin{array}{l}5 \\
5\end{array}$ & $\begin{array}{l}\text { Calcostibinita } \\
\text { Emplectita }\end{array}$ & 1,34 & 30 & Pseuclomalaquita & $\begin{array}{l}1,32 \\
1,32\end{array}$ & $\begin{array}{l}20 \\
20\end{array}$ & $\begin{array}{l}\text { Pseudomalaquita } \\
\text { Atacamita }\end{array}$ & 1,30 & 5 & \\
\hline $\begin{array}{l}1,37 \\
1,37\end{array}$ & $\begin{array}{l}5 \\
5\end{array}$ & $\begin{array}{l}\text { Emplectita } \\
\text { Vulcanita }\end{array}$ & 1,34 & 30 & Zoisita & 1,32 & 20 & $\begin{array}{l}\text { Atacamita } \\
\text { Miersita }\end{array}$ & 1,30 & 5 & Calcopirita \\
\hline 1,37 & $\begin{array}{l}5 \\
5\end{array}$ & $\begin{array}{l}\text { Vulcanita } \\
\text { Descloisita }\end{array}$ & 1,34 & 30 & Betechtenita & 1,32 & 20 & Vandenbrandeita & & & Aikinita \\
\hline 1,37 & 5 & $\begin{array}{l}\text { Descloisita } \\
\text { Hidrogênio fosfato hidrata- }\end{array}$ & 1,34 & 30 & Shattuckita & 1,32 & & & 1,30 & 5 & Vulcanita \\
\hline 1,37 & 5 & $\begin{array}{l}\text { Hidrogênio fosfato hidrata- } \\
\text { do de cobre }\end{array}$ & 1,34 & 20 & Estanita & & 10 & Meneghinita & 1,30 & 4 & Hidróxido de cobre \\
\hline 1,37 & 5 & Plancheita & 1,34 & 20 & Turquesa & $\begin{array}{l}1,32 \\
1,32\end{array}$ & 10 & Renierita & 1,30 & 1 & Roducrosita \\
\hline 1,37 & 4 & Hidróxido de cobre & 1,34 & 20 & Eskebornita & $\begin{array}{l}1,32 \\
1,32\end{array}$ & 10 & Carrollita & 1,29 & $50 \mathrm{~B}$ & Shattuckita \\
\hline 1,36 & 50 & Goethita & 1,34 & $20 \mathrm{~B}$ & Mixita & $\begin{array}{l}1,32 \\
1,32\end{array}$ & 10 & Emplectita & 1,29 & 40 & Goethita \\
\hline 1,36 & 30 & Descloizita & 1,34 & 10 & Tyrrellita & $\begin{array}{l}1,32 \\
1,32\end{array}$ & 10 & Calcopirita & 1,29 & 30 & Freibergita \\
\hline 1,36 & 20 & Domeykita alfa & 1,34 & 10 & Calcostibinita & 1,32 & 10 & Turquesa & 1,29 & 20 & Miersita \\
\hline 1,36 & 20 & Garrolita & 1,34 & 10 & Koutekita & 1,32 & 10 & Emplectita & 1,29 & 20 & Atacamita \\
\hline 1,36 & 20 & Vinclenbranduita & 1,34 & 7 & Brociantita & 1,32 & 10 & Cornetita & 1,29 & 20 & Algodonita \\
\hline 1,36 & 20 & Estanita & 1,34 & 5 & Gicrmanita & 1,32 & 10 & Vulcanita & 1,29 & 20 & Fumatinita \\
\hline 1,36 & 20 & Cuprodescloizita & 1,34 & 5 & Eucairita & 1,32 & 6 & Ilidróxido de cobre & 1,29 & 20 & Zoisita \\
\hline 1,36 & 10 & Eriocalcita & 1,34 & 55 & Enargita & 1,32 & 5 & Digentta & 1,29 & 17 & Azurita \\
\hline 1,36 & 10 & Cornetita & 1,34 & 5 & Covelita & 1,31 & 80 & Idaita & 1,29 & 12 & Delafossita \\
\hline 1,36 & 10 & Empletita & 1,34 & 5 & Silicato de bário e & 1,31 & 50 & Arsenosulvanita & 1,29 & 10 & Spangolita \\
\hline 1,36 & 5 & Lautita & 1,34 & & cobre & 1,31 & 20 & Sulfeto de cobre & 1,29 & 10 & Mixita \\
\hline 1,36 & 2 & Zoisita & 1,34 & 1 & Hidróxiclo de cobre & 1,31 & 20 & magnésio & 1,29 & 10 & Wittichenita \\
\hline 1,35 & 60 & Novakita & 1,348 & 1 & Eriocalcita & & 20 & Bandylita & 1,29 & 10 & Lautita \\
\hline 1,35 & 50 & $\begin{array}{l}\text { Cloreto hidratado de cobre II } \\
\text { epotássio }\end{array}$ & $\begin{array}{l}1,33 \\
1,33\end{array}$ & 70 & $\begin{array}{l}\text { Erinita } \\
\text { Mottramita }\end{array}$ & 1,31 & 20 & $\begin{array}{l}\text { Cloreto hidratado de cobre } \\
\text { II e potássio }\end{array}$ & 1,29 & 5 & $\begin{array}{l}\text { Silicato de bário e } \\
\text { cobre }\end{array}$ \\
\hline 1,35 & 40 & Erinita & $\begin{array}{l}1,33 \\
1,33\end{array}$ & 50 & $\begin{array}{l}\text { Mottramita } \\
\text { Cornwallita }\end{array}$ & 1,31 & 20 & Spangolita & 1,29 & 5 & Bornita \\
\hline 1,35 & 30 & Shattuckita & $\begin{array}{l}1,33 \\
1,33\end{array}$ & $30 \mathrm{~B}$ & $\begin{array}{l}\text { Cornwallita } \\
\text { Freibergita }\end{array}$ & 1,31 & 20 & Brocantita & 1,29 & 5 & Rickąrdita \\
\hline 1,35 & 30 & Betechtenita & $\begin{array}{l}1,33 \\
1,33\end{array}$ & 30 & $\begin{array}{l}\text { Freibergita } \\
\text { Crisocola }\end{array}$ & 1,31 & 20 & Freibergita & 1,29 & 55 & Eucairita \\
\hline 1,35 & 30 & Lautita & $\begin{array}{l}1,33 \\
1,33\end{array}$ & 30 & $\begin{array}{l}\text { Crisocola } \\
\text { Descloizita }\end{array}$ & 1,31 & 20 & Berzelianita & 1,29 & 5 & Emplectita \\
\hline 1,35 & 20 & Siderita & $\begin{array}{l}1,33 \\
1,33\end{array}$ & 30 & $\begin{array}{l}\text { Descloizita } \\
\text { Plancheita }\end{array}$ & 1,31 & 20 & Cromita de cobre & 1,29 & 5 & Tetraedrita \\
\hline & & & & 30 & Plancheita & & & & 1,29 & 5 & Tenantita \\
\hline & & & & & & & & & 1,29 & 55 & Cromita de cobre II \\
\hline & & & & & & & & $\therefore$ & 1,291 & 4 & Calcocyanita \\
\hline & & & & & & & & $\cdots$ & 1,290 & 4 & Calcocyanita \\
\hline & & ' & & & & & & & 1,29 & 2 & Dolomita \\
\hline & & & & & & & & & $\begin{array}{l}1,29 \\
1,29\end{array}$ & $\begin{array}{l}2 \\
2\end{array}$ & $\begin{array}{l}\text { Eriocaletta } \\
\text { Calcita }\end{array}$ \\
\hline
\end{tabular}


fluorescência e radioatividade

Moraes et al., (1956), citam que "o miné rio do Ribeirão do Perau, aliās radioativo, é um complexó de cuprita, malaquita, calcopirita e calcantita, com teor de cobre metālico de 10 a $15 \%$ e era extraído a cēu aberto". A citação de Moraes et al. (1956) continua descrevendo que: "Embora não faça parte do material colhido pela 1 a Expedição Científica à Serra de Paranapiacaba e Alto Ri beira é oportuno registrar que o minério de cobre mais rico do país, o complexo cuprífero do Perau, da bacia do Ribeirão Grande, no município de Bocaiva do sul é pos suidor de radioatividade". As citaçóes acima levaram a investigação de fluorescência e radioatividade.

Fluorescência - Foram tomadas dez amos tras de minério, as mesmas descritas para anälise quími ca e depois de moídas, pulverizadas e passadas em penei ra 200 "meshes " $(0,149 \mathrm{~mm})$ foram confeccionadas lixas desses minérios como descreve Camargo (1965) e submeti das a ação direta de raios $X$ pois o ion uranilo apresen ta fluorescência verde ou amarela sob ação de luz solar. de luz ultra-violeta ou raios X.

Os raios X utilizados foram produzidos por tubo de cobre, $\operatorname{CuK} \alpha=1,5418 \AA$, do tipo policromático ou mo nocromätico filtrado por niquel. As reaçōes observadas aos raios X foram negativas. Embora se repetisse a operaça por três vezes nenhuma fluorescência foi notada. Não foi tenta do oxame de fluorescência em minerais isolados porque tó 
dos os minerais de cobre da jazida do Ribeirão do Perau pos suem $\mathrm{Cu}, \mathrm{Fe}, \mathrm{OH}$ e demais elementos e segundo Camargo (1956) os elementos citados e mais $\mathrm{Pb}$, Mo e V são inibidores ou en venenadores impedindo o aparecimento de fluorescência nos minerais que apresentam o ion uranilo.

Radioatividade - As dez amostras citadas fo ram submetidas inicialmente ao exame de contador Geiger-Muller, de fabricação nacional construído pelo Instituto de Física da Universidade de São Paulo, marca IFUSP, calibra do para escalas de $0,01-0,1-1$ - 10 - miliroentgen por hora, que não dectetou anomalias radioativas.

As amostras sofreram então preparo para a técnica auto-radiogrä́fica para raios gama, Camargo (1965), cujo método permite desvendar mesmo pequena radioatividade que poderia ter passado despercebida pelo contador Geiger-Muller.

As amostras moídas, passadas em peneira 200 "meshes" $(0,149 \mathrm{~mm})$ coladas em lâmina de vidro com adesivo colatudo Duco foram colocadas em contato direto com filme (Sakura, X-ray film-medical JX/14x14) e envoltas em papel preto e placa de chumbo. o conjunto foi mantido em väcuo, em dissecador, permanecendo quarenta dias. A revelação dos filmes não acusou mancha alguma de radioatividade.

O resultado das anälises levam a se pensar que o minërio de cobre (minerais de cobre e rochas encaixan tes) do Ribeirão do Perau não seja radioativo pois as dez amostras escolhidas são representativas da jazida. 0 fato porém não exclui a possibilidade de uma concentração radio ativa em rochas encaixantes ainda não dectectadas em pesqui sa de campo.

estudo térmico

o estudo tërmico foi utilizado como método auxiliar na identificação dos minerais malaquita, azurita e crisocola. Empregou-se o equipamento marca Thermoflex, mo delo CAT-8001, de fabricação Rigaku-Denki, pertencente á. 
Departamento de Geologia do Instituto de Pesquisas Tecnológi cas da Universidade de São Paulo. As constantes empregadas foram: padrão de alumina, termo-par alumel-cromel, cápsula de platina, taxa de aquecimento $10^{\circ} \mathrm{C}$ por minuto e velocidade do papel, 2 milímetros por minuto.

anălises químicas

As anālises químicas foram executadas no La boratório de Química da Divisão de Engenharia do Material da Produção de Metais Raros do Instituto de Pesquisa e Desenvol vimento do Centro Técnico da Aeronäutica (CTA), em são José dos Campos, S.P.

Procurou-se mostrar o teor médio de cobre em amostras representativas de perfis de trincheiras, segmentos de testemunhos de sondagens, e vieiros de galeria e encaixan tes de minério filonar. Foram utilizados métodos tradicio nais de via ümida e espectrografia de absorção atômica para os elementos: $\mathrm{Pb}, \mathrm{Mn}, \mathrm{Ca}, \mathrm{Mg}, \mathrm{Na}, \mathrm{Ag}, \mathrm{Cu}, \mathrm{Al}, \mathrm{Ti}, \mathrm{K}, \mathrm{P}, \mathrm{S}$ e Au.

microsonda eletrônica

As anāises por microsonda eletrônica foram executadas com o equipamento marca Jeol, modelo $\mathrm{J} \mathrm{X} \mathrm{A-5,ins}$ talado na Divisão de Engenharia do Material da Produção de Metais Raros do Instituto de Pesquisa e Desenvolvimento do Centro Tecnológico da Aeronáutica (CTA), em São José dos Campos, S.P.

lartins (1972) descreve os componentes prin cipais desta microsonda como os seguintes:

1. Um sistema de óptica eletrônica que per mite focalizar o feixe de elétrons, oriundos do canhão ele trónico, acelerados entre 3 a $50 \mathrm{kV}$ com corrente de $10^{-5}$ a $10^{-9} \mathrm{~A}$, sobre a amostra, com diâmetro de um micron, sob vācuo da ordem de $10^{-5}$ tor $r$.

2. Um sistema de espectrômetros de raios $X$ que permite o exame da radiação característica emitida pela 
elemento em anālise. Esse sistema consta de dois espectrô metros de raios $x$ do tipo Johan de raio de curvatura $R=280 \mathrm{~mm}$, com ângulo de Bragg convertido em mm pela förmula:

$$
L=\frac{R \quad \lambda}{d}
$$

onde: $\lambda=$ comprimento dos raios $X$ em anälise; $R=280 \mathrm{~mm}$ e d é a constante reticular do cristal analisador, no caso: LiF $(2 \mathrm{~d}=4,027 \AA) ; \operatorname{PET}(2 \mathrm{~d}=8,742 \AA) ; \operatorname{RAP}(2 \mathrm{~d}=27,165 \AA)$ e $\mathrm{ST}(2 \mathrm{~d}=98,0 \AA)$. Os detectores são: um contador proporcional selado de Kr para radiações curtas e um contador proporcio nal de fluxo de argônio (90\%) e metano (10\%).

3. Um microscōpio öptico que permite a ob servação direta das regiões em anālise.

Quando um feixe de elêtrons acelerados in cide sobre uma amostra, parte desses elétrons ë espalhada em proporção direta ao nümero atômico $Z$. Esses elétrons que sofreram espalhamento elästico são denominados elé trons retroespalhados, os quais são captados para composi ção de imagens. Os ätomos excitados pelos elëtrons acelé rados emitem raios $x$ característicos, continuos, detectados por espectrômetro que pode destacar a distribuição do ele mento em anälise, na amostra, desde o boro até o urânio,de acordo com a tëcnica descrita no item d.

As imagens obtidas podem ser dos seguintes tipos:

a) eletrônica ou de composição: obtida pe los detectores que captam os elétrons primärios retroespa lhados no material em análise. Pode ser positiva ou nega tiva, de acordo com a polaridade do tubo catódico.

As tonalidades entre o branco e o preto des sas imagens são funções do nümero atômico, mostrando mais brilhantes os elementos químicos mais pesados (Fig. 8) na imagem positiva. 


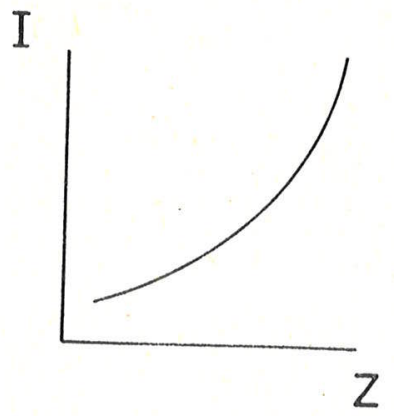

Fig. 8

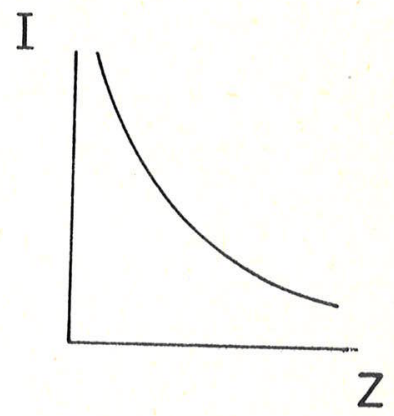

Fig. 9

b) de elétrons secundārios: conseguida por outros detectores que captam os elétrons secundärios emiti dos pelo elemento em anālise. Eutilizada para amostras não perfeitamente polidas que consequentemente apresentam certa topografia. ( $\bar{E}$ tambëm a imagem mais empregada nos microscó pios de varredura.)

c) de absorção ou de corrente absorvida: ob tida quando se converte em imagein a diferença da intensidade dos feixes catödicos incidentes e espalhados. possui compor tamento conträrio à imagem citada no item a, obedecendo a função da Fis. 9 .

d) imagem " $\mathrm{X}$ " ou de distribuição dos elemen tos: formada pela intensidade de raios $X$ característicos dos elementos cm anälise. Pode ser: 1) bidimensional fornecendo a distribuição dos elementos em anälise, um a um, dentro do campo focalizado; 2) linear (imagem de varredura linear ou perfil) ao longo de uma linha horizontal com $400 \mu \mathrm{m}$ de exten são máxima; 3) pontual, quando um fejxe de elétrons de 1 um de diâmetro incide sobre um ponto escolhido no elemento a analisar. A anälise nontual é quantitativa quando comparada com padrão conhecido. A profundidade de penetração de elé trons primärios incidentes numa amostra é dada por: 
$\mu \mathrm{m}=0,033\left(\mathrm{E}_{\mathrm{o}}{ }^{1,7}-\mathrm{E}_{\mathrm{K}}{ }^{1,7}\right) \frac{\mathrm{A}}{\rho \mathrm{Z}} \quad($ Casting, 1952)

onde:

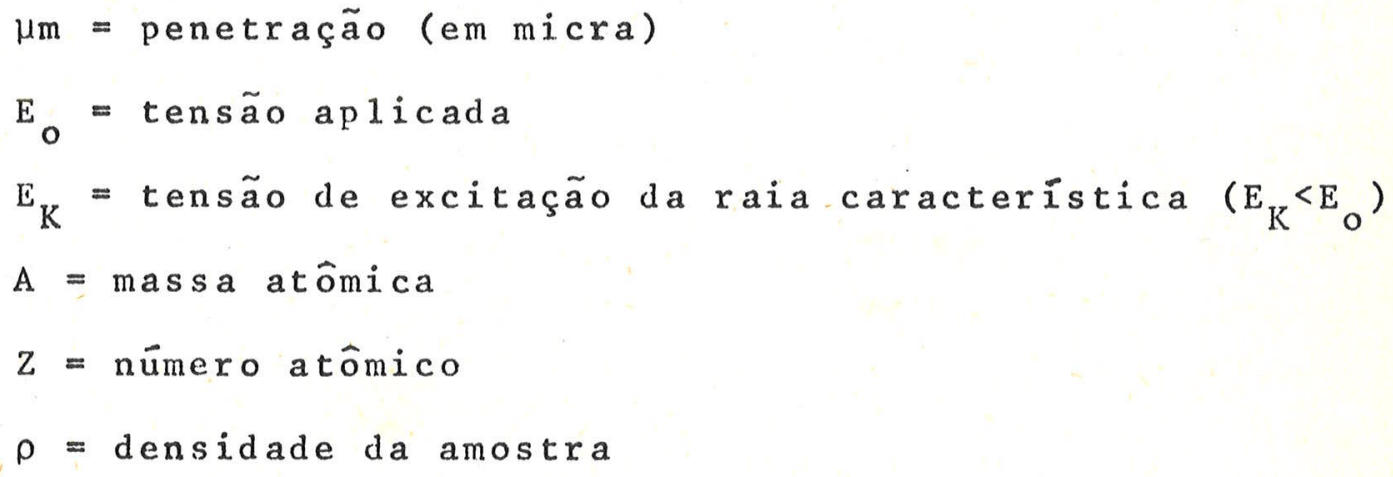

As imagens podem abranger os seguintes cam pos de estudo:

$400 \times 400 \mu \mathrm{m} ; 200 \times 200 \mu \mathrm{m} ; 100 \times 100 \mu \mathrm{m} ; 50 \times 50 \mu \mathrm{m}$;

$25 \times 25 \mu \mathrm{m}$ e $15 \times 15 \mu \mathrm{m}$ dos quais correspondem os aumentos res pectivos de $300 ; 600 ; 1200 ; 2$ 500; 5000; e 10000 vezes.

As substâncias não condutoras elétricas de vem ser recobertas por uma película metälica transparente ao feixe de elétrons. No processo de metalização fez-se uso de equipamento marca Jeol, tipo JEE-48 que opera em vácuo de $10^{-4}$ torr, a $25 \mathrm{~V}$, com corrente variäve1 dependendo do metal a ser volatizado. A metalização pode ser feita com Au, Ag, $\mathrm{Cu}, \mathrm{Zn}, \mathrm{A} 1, \mathrm{Pt}, \mathrm{e} \mathrm{C}$. A éspessura da camada metálica sobre a seção polida varia de acordo com a quantidade do metal posto a volatizar e com o tempo de opcração, sendo sempre inferior a $100 \AA$.

Os trabalhos realizados constam de anälises qualitativas, sendo as amostras escolhidas entre os mine rais mais representativos (homogêneos e não decompostos)den tre as seções polidas previamente estudadas. As seções po lidas utilizadas obedeceram o mesmo processo de confecção já descrito em item anterior e por não serem condutores elé tricos foram submetidas à metalização com Au, Al ou Cu, de pendendo dos elementos relacionados para estudo. Para melho rar ainda mais a condutividade elétrica, as seções citadas tiveram a parte plástica recoberta por emulsão de prata me tālica. 
No presente estudo foram examinadas prefe rencialmente imagens descritas nos itens a, $\underline{b}$ e d sendo que as fotos apresentadas mostram as distribuições dos elemen tos nos diversos minerais analisados. Quando a presença de um elemento importante ocorre em porcentagem de ppm cada fo to vem acompanhada de um perfil linear de varredura eletrô nica mostrando a concentração do elemento ao longo da linha indicada pois essa técnica permite maior possibilidade de deteção. Quando o perfil de varredura não caracterizava su ficientemente a variação de um elemento, executaram-se con tagens pontuais em zonas previamente escolhidas das amos tras, durante um tempo pré-determinado. Os elementos de maior interêsse mineralógico geralmente em média de trinta para cada espécie mineral, foram selecionados pelo exame bi bliográfico prévio. Convém ressaltar que os resultados das anālises de um determinado elemento, neste trabalho, não constituem média estatística de uma espécie mineral. As se ções polidas continham vārios cristais da mesma espécie, de maneira que foram varridos eletronicamente cinco a seis mi nerais semelhantes sendo registrados fotograficamente os re sultados de um só cristal. De qualquer maneira só houve pos sibilidade de estudo de uma única seção polida por espêcie mineralögica. 
Minerais primários

pirita

A pirita ocorre associada ao quartzito e a ro chas carbonáticas (Foto 24). Em ambas as rochas, o mineral esta disseminado, ora alinhado concordantemente com a estratificação dos quartzitos, ora possuindo certa orientação incipiente com a orientação geral dos grãos do quartzo.

A pirita tambēm pode ocorrer entre as suturas dos grãos de quartzo (Foto 25), ou englobando ou totalmente englobada por quartzo. Associa-se à calcopirita e raramente a veios centimétricos de galena, discordantes da estrutura das rochas acima citadas.

Propriedades morfológicas - os cristais são sempre isolados não tendo sido encontrados agregados cristalinos. o häbito cübico nem sempre ocorre, predominando o habito desproporcionado com frequência de (100).

A granulação é submilimétrica chegando cristais raramente a diâmetros de $3 \mathrm{~mm}$.

vărios cristais de pirita foram separados das rochas e estudados sob lupa binocular. Os que possuem hábito predominantemente cübico apresentam combinação de cubo e rom bododecaedro (Fig. 10). A forma $\{100\}$ está representada geralmente pelas faces (100), (100), (010) e (0T̄o). A forma $\{110\}$ apresenta somente as faces (110) e (T10). Nas faces ci

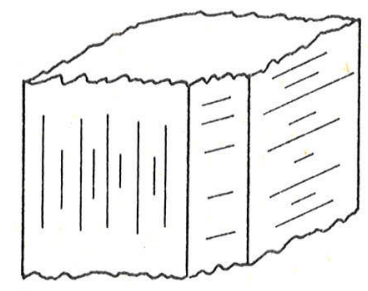



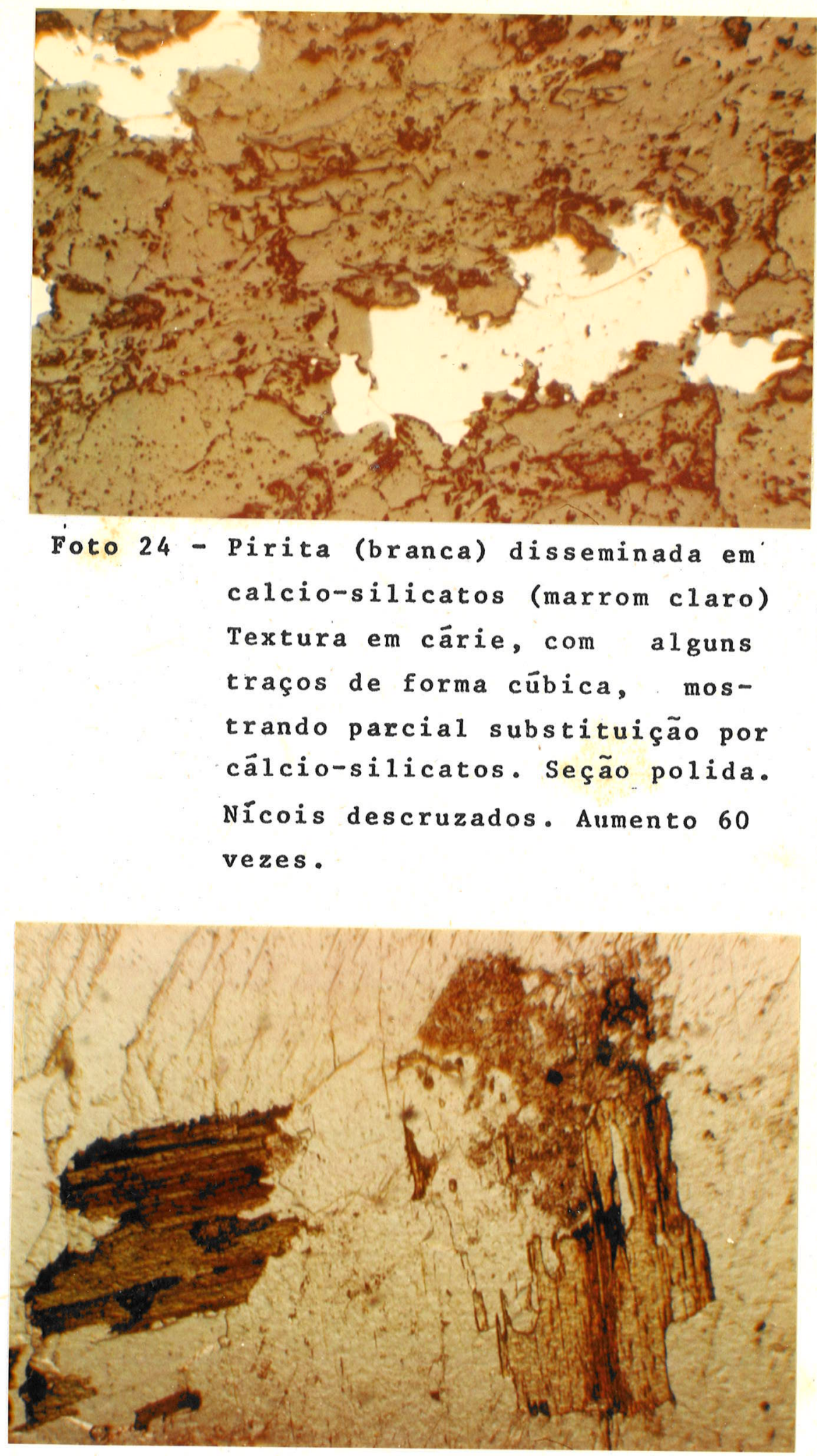

Foto 25 - Cristais de pirita (amarela) disseminados no quartzito. Con tornos sub retos, estrias para lelas de clivagem,e quartzo englobado. Nícois parcialmente cruzados. Aumento 60 vezes. 
tadas frequentemente ocorrem estrias (Fig.10), devidas prova velmente ao desenvolvimento de duas formas num cristal $\{100\}$ e $\{210\}$ sendo uma predominante (Deer, 1962).

\section{Propriedades físicas - A côr è quase sempre} amarelo latão, às vezes com película externa amarelo-escuro. A pirita é opaca, de brilho metálico, com traço preto acasta nhado. Não foi notada clivagem em individuos macroscópicos e a fratura é subconcoide. Em seção polida apresenta refletividade muito elevada, côr branca levemente amarelada, não apresentando pleocroísmo de reflexão; sob nícois cruzados e isótropa. Quando ocorre nas rochas calcio-silicatadas (Foto 24) os contornos são nítidos, sub retos, não hā borda de rea ção nas pequenas bordas de corrosão.Ās vezes hä nódulos inter nos de oxidação. Raramente se associa a cristais de calcocita. Quando ocorre no quartzito as bordas de corrosão são mais acentuadas e macroscopicamente são sempre visíveis estrias paralelas de clivagem. E frequente o englobamento de quartzo. (Foto 25).

Microsonda eletrônica - Estudaram-se à microsonda eletrônica dois cristais de pirita imersos em matriz de rocha calcio-silicatada(Foto 3). Foi utilizado aumento de $300 \times$ em campo de $400 \mathrm{\mu m}^{2}$, para se abranger concomitantemen te dois cristais de pirita, de tal modo que nos perfis dos elementos pudesse ser vista a discrepância de variação dos mesmos.

A Fig. 11 mostra a distribuição dos minerais das Fotos 26 a 36 ou seja: dois cristais de pirita,quartzo e carbonatos, estes ūltimos verificados através de diagramas de pó de raios-X. o cristal maior de pirita apresenta uma in clusão milimétrica e o cristal menor contém duas inclusões, todas de quartzo.

A Fig. 12 mostra a sintese da distribuição dos elementos encontrados nas Fotos 26 a 36 .

Os elementos pesquisados foram: $S, F e, S i, K$, $\mathrm{Mg}, \mathrm{Ca}, \mathrm{Au}, \mathrm{Ni}, \mathrm{Co}, \mathrm{As}, \mathrm{Mn}, \mathrm{Sb}, \mathrm{Cu}, \mathrm{Pt}$ e Ag. Os tres ültimos 


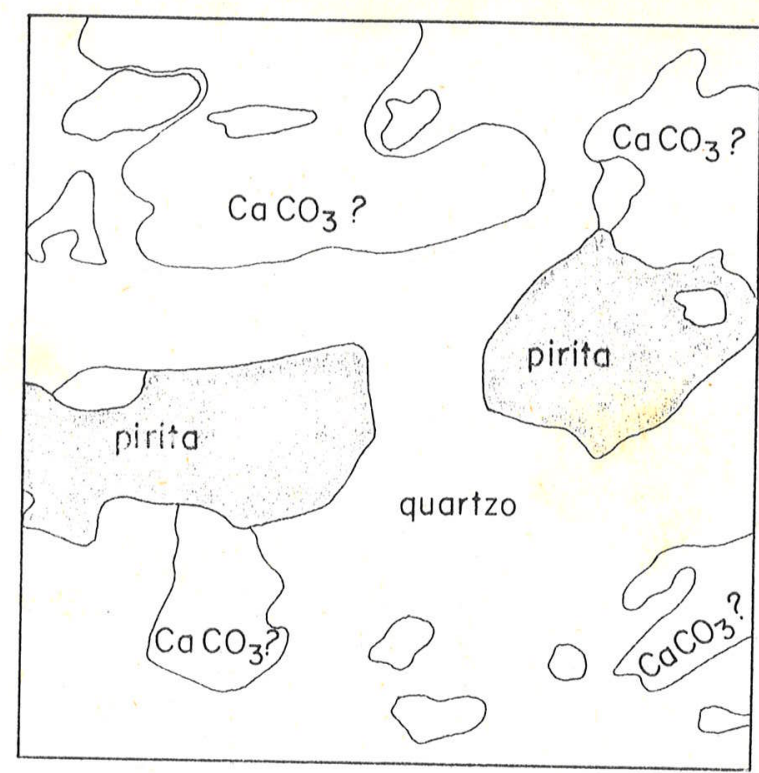

Fig. 11 - Distribuiçäo dos minerais das fotos 26 a 36 de microsonda eletrônica.

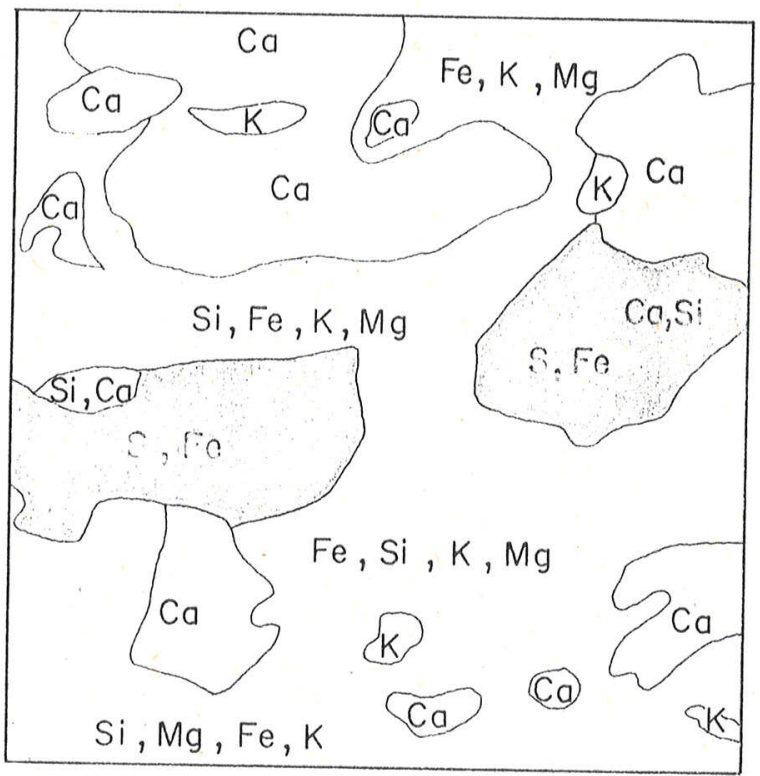

Fig.12 - Resumo da distribuição dos ele mentos encontrados nas fotos 26 a 36 de microsonda eletrônica. 


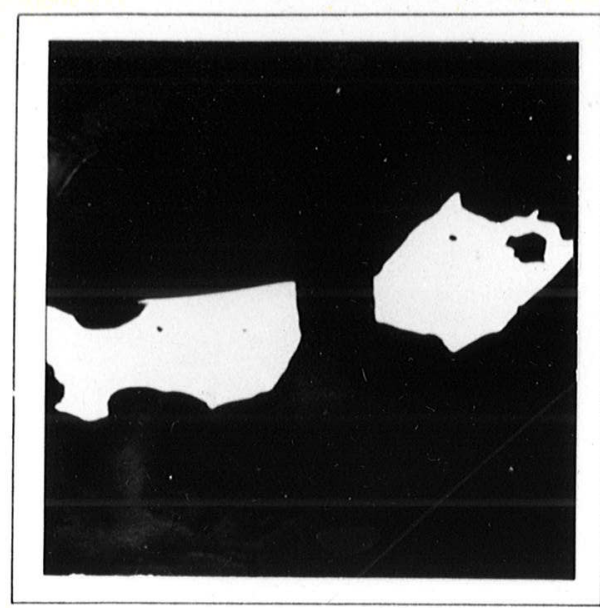

Foto 26 - Imagem eletrônica de Pirita (branca), quartzo (cinza c1aro)e carbonatos (cinza escuro). Campo $400 \mathrm{\mu m}^{2}$.

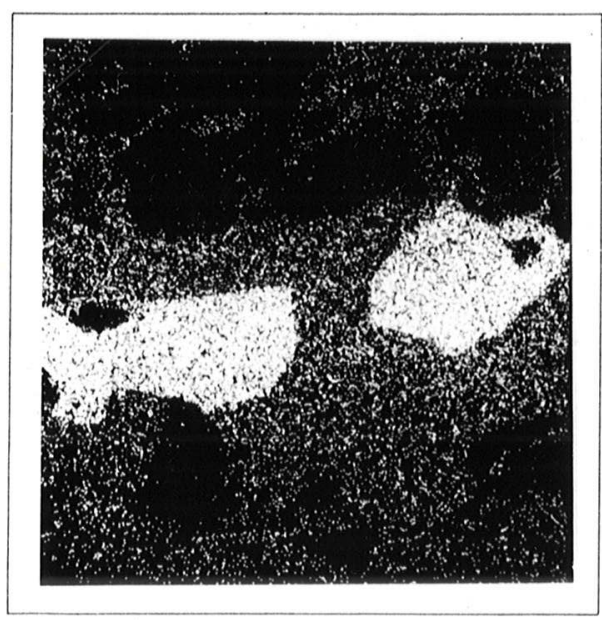

Foto 28 - Imagem "X" Fe Ko mesma zona

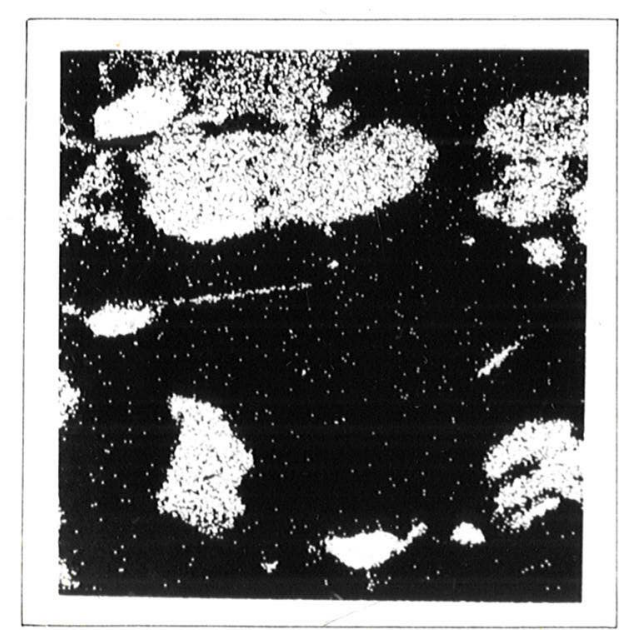

Foto 30 - Imagem "X" Ca Ka mesma zona
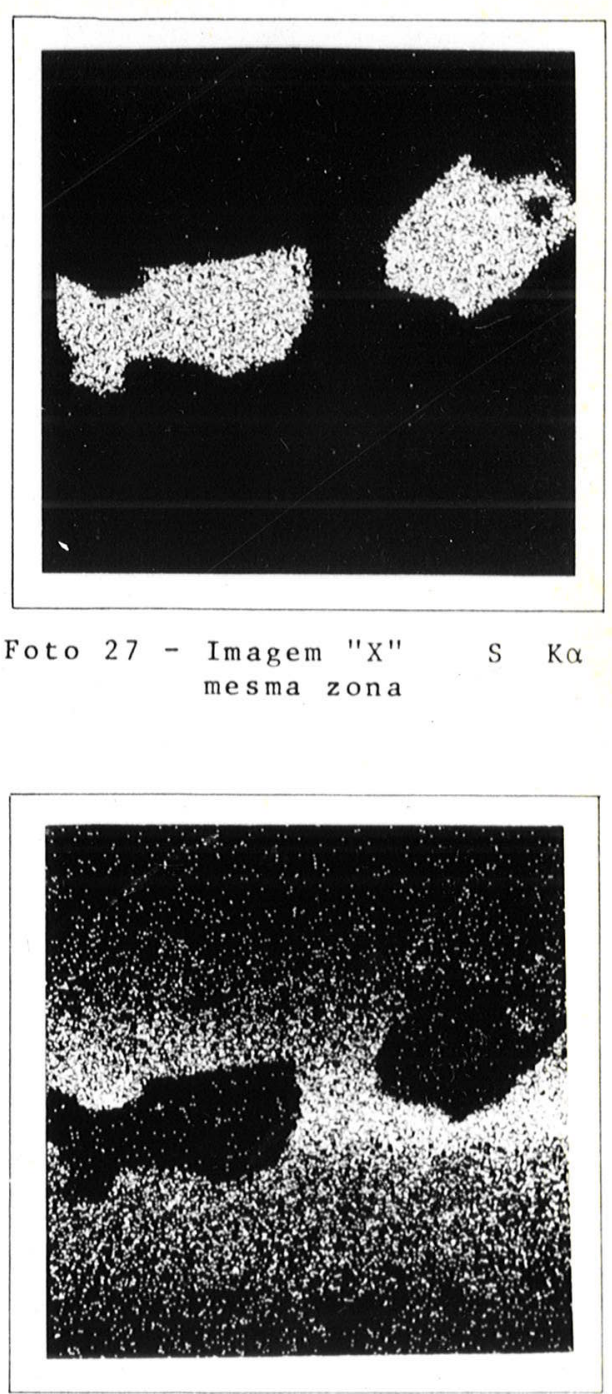

Foto 29 - Imagem "X" Si $K \alpha$ mesma zona

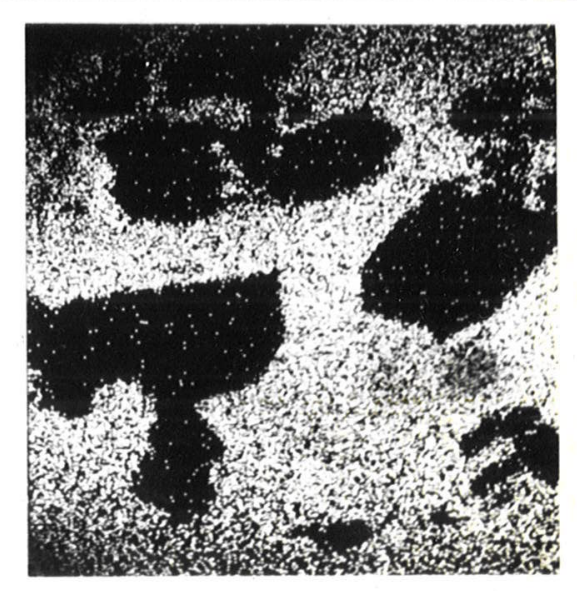

Foto 31 - Imagem "X" K Ka mesma zona 

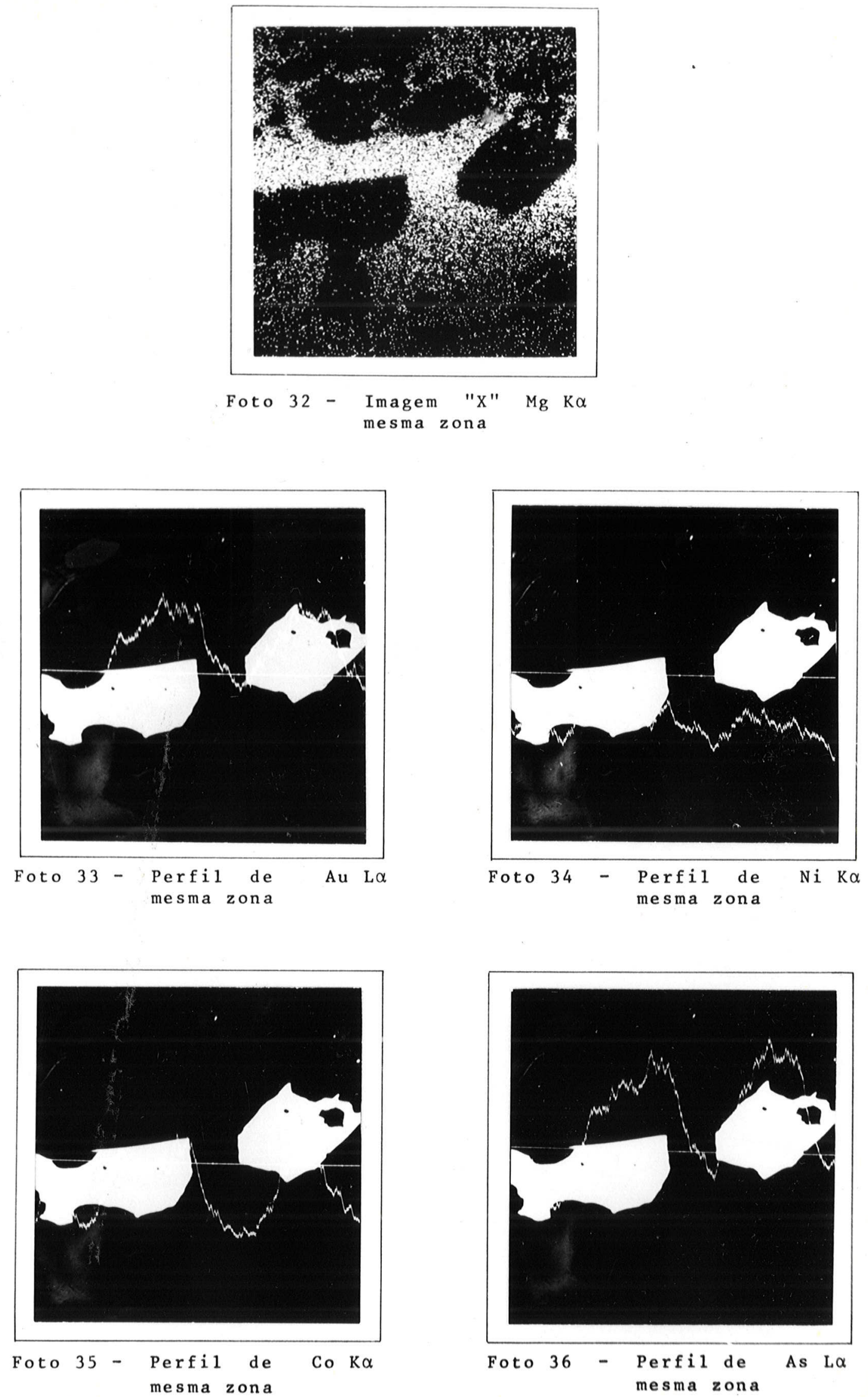
não foram determinados tanto em varredura, como em perfil.

o enxofre estä presente só nas piritas (Foto 27). O ferro esta concentrado nas piritas e contaminando quartzo, não ocorrendo nos carbonatos (Foto 28).

o silicio (Foto 29), o potässio (Foto 31) e - magnësio (Foto 32) estão concentrados só no quartzo.o cá cio (Foto 30) aparece distribuido nos carbonatos.

Os perfis de ouro (Foto 33), niquel (Foto 34), cobalto (Foto 35) e arsênico (Foto 36) mostram a concentração desses elementos somente nas piritas, não estando presentes tanto no quartzo como no carbonato. A sequência quantitativa decrescente deve ser: As, $A u, C o$ e Ni, sendo que cálculos aproximados para o Ni resultam em 50 a 100 ppm. o Mn e o Sb acham-se distribuidos de modo similar ao cobalto. A substituição de Fe por Ni parece aumentar o tamanho da cela unitäria da pirita (Bannister, 1940, Peacock and Smith, 1941; de Deer, 1962).

As pequenas concentrações de $\mathrm{Ni}$, Co e Mn na pirita do Ribeirão do Perau não devem ser resultado da presença de minerais tais como: $\mathrm{NiS}_{2}$ (vaesita), Cos 2 (cattieri ta) e $\mathrm{MnS}_{2}$ (hauerita). E improvävel haver solução sölida de $\mathrm{FeS}_{2}$ e $\mathrm{NiS}_{2}$. A quantidade de Au é superior à média geral. presente em pirita (10 ppm).

A presença de As è considerada por alguns au tores como responsável pelo fenômeno de pequena anisotropia, (Stanton, 1957: de Deer, 1962), porêm a pirita estudada não è anisotröpica.

Paragênese - A pirita é o sulfeto (Deer,1962) mais abundante e de distribuição mais vasta. As ocorrências são de värios tipos e as condições geolögicas as mais diver sas. Pode ser encontrada em contatos metamörficos de depós tos minerais, associada com sulfetos de cobre e outros metais, como um mineral skarn e como um sublimado vulcânico.

Foram confeccionados värios diagramas de di fratometria de raios-X. Utilizaram-se monocristais ou po ob 
tido da homogeneização das piritas contidas nas rochas citadas, através de britagem, moagem e separação em bromofórmio.

Os diagramas de pö (Tabela 5) mostram que a pirita do Ribeirão do perau não pode ser confundida com pirrotita ou marcassita.

Não foram encontradas inclusões de calcopiri ta, pirrotita, esfalerita, galena, ouro e tenantita. Não há associação intergranular com calcopirita (Freund, 1966),magnetita e hematita. Ocorre lado a lado com calcopirita sendo notada substituição da pirita por calcocita e quartzo.

As bordas de oxidação são pouco frequentes, não sendo abundantes cristais falhados ou esmigalhados indicando cataclase. Não forma concreções, não é oolítica e não se percebeu crescimento zonado, tambēm não ocorrem materiais argilosos e sericiticos produzindo textura framboedal, sugerindo origem orgânica.

A pirita é hipidiomórfica e as formas crista linas não bem desenvolvidas são geralmente encontradas em se dimentos ou depósitos hidrotermais de baixa temperatura (Deer, 1962).

A razão dos isótopos $32 \mathrm{~s}: 34 \mathrm{~s}$ é mais alta na pirita formada a partir de sedimentos em baixa temperatura do que na pirita de origem magmática, hidrotermal e de conta to metassomático (Vinagradov et a1., 1956; de Deer, 1962).

Pirita e magnetita não formam associação es tāvel acima de $675^{\circ} \mathrm{C}$. Pirita-Pirrotita em associação com hematita ou magnetita não são estāveis acima de $700^{\circ} \mathrm{C}$. Acima de $743^{\circ} \mathrm{C}$ pirita possui uma faixa estreita de estabilidade enquanto que a hematita e pirrotita voltam a uma associação es táve1.

o quartzo incluso na pirita apresenta textura poiquiloblástica. Se a cristalização da pirita é posterior à recristalização das rochas, o quartzo teria penetrado vazios em estāgio mais avançado. Por outro lado, a falta de preenchimento das fraturas das rochas por pirita e a concor dância com a oxientação geral dos grãos de quartzo (às vezes 
disposta perpendicularmente à direção dos esforços), tanto nos quartzitos como nas rochas carbonáticas e calcio-silicata das sugere a cristalização da pirita no mesmo evento geológico, isto é, na mesma fase de metamorfismo, podendo a origem ser anterior à cristalização das rochas. 
Tabe 1 a 5

Diagrama de Pirita

Rib. Perau

$\begin{array}{lr}d(\AA) & I / I \\ 3,13 & 40 \\ 2,72 & 70 \\ 2,44 & 60 \\ 2,21 & 60 \\ 1,92 & 40 \\ 1,63 & 100\end{array}$

1,45

1,04

1,00

0,95

20

Ref. Swanson et al.

$\mathrm{d}(\AA) \quad I / I_{0} \quad h k 1$

$3,12 \div 36 \quad 111$

$2,70 \quad 84 \quad 200$

$2,42 \quad 66 \quad 210$

$2,21 \quad 52 \quad 211$

$1,91 \quad 40 \quad 220$

$1,63 \quad 100 \quad 311$

$1,56 \quad 14 \quad 222$

$1,50 \quad 20 \quad 230$

$1,44 \quad 24 \quad 321$

$1,24 \quad 12 \quad 331$

$1,21 \quad 14 \quad 420$

$1,18 \quad 7 \quad 421$

$1,15 \quad 6 \quad 332$

$1,10 \quad 6 \quad 422$

$1,04 \quad 27 \quad 511$

$\begin{array}{lll}1,00 & 8 & 432\end{array}$

$0,98 \quad 6 \quad 521$

$0,95 \quad 12 \quad 440$

$0,90 \quad 1.5 \quad 600$

$\begin{array}{lll}0,87 & 8 & 611\end{array}$

$0,85 \quad 7 \quad 620$

$0,82 \quad 4 \quad 533$

$0,81 \quad 4 \quad 622$

$\begin{array}{lll}0,79 & 5 & 631\end{array}$

$\operatorname{CuK} \alpha=1,5418 \AA$, Filtro Ni

24 horas $\quad 30 \mathrm{kV} \quad 15 \mathrm{~mA}$

Filme n: 25372

Câmara de Gandolfi $114,6 \mathrm{~mm} \emptyset$

(monocristal) 
calcopirita

o sulfeto de cobre mais importante da ja zida do Ribeirão do Perau é a calcopirita, encontrada junta mente com a pirita nas camadas de quartzitos, de modo disse minado, acompanhando o acamamento das rochas (Foto 37). Pode preencher fraturas nos quartitos formando agregados crista linos compactos, desenvolvidos de forma tabular e acompanhan do os espaços abertos nos planos de diaclasamento. No conta to quartzito-calcārio, a calcopirita apresenta värios está gios de oxidação, ora com núcleo remanescente, ora totalmen te substituida por malaquita e crisocola.

$\mathrm{Na}$ ärea intensamente falhada visivel nas galerias, a calcopirita é encontrada no núcleo dos vieiros de minêrio de cobre oxidado, sendo o único sulfeto aỉ identi ficável. Esses veios acompanham a estratificaça dos xistos e quartzitos cizalhados, com certa irregularidade, variando a possança de milímetros a dezenas de centimetros. Nessa forma de jazimento os minerais associados são a cuprita, ma laquita, crisocola e material limonitico. A calcopirita tam bém se associa a agregados cristalinos de turmalina, ém veios de posição diagonal aos xistos.

Propriedades morfolögicas - Os cristais de calcopirita ocorrem isoladamente ou em agregados cristali nos. Nestes ūltimos, o hābito prismätico é de difícil reco nhecimento, mesmo ao microscópio polarizador, sob luz reflé tida. Os cristais isolados, mais raros (Foto 37) exibem fa ces prismäticas. Algumas formas de aspecto biesfenoidal pú deram ser reconhecidas, sendo ausente as faces estriadas de escalenoedro. O häbito é desproporcionado, pois os cristais acompanham a estratificação de quartzitos intensamente dia clasados.

Os diagramas de difração de raios $x$, (Ta bela 6), na câmara de pó, ou na câmara de Gandolfi, indicam que a calcopirita é tetragonal. A calcopirita pode apresen tar formas de baixa a alta temperatura, sendo a primeira te 


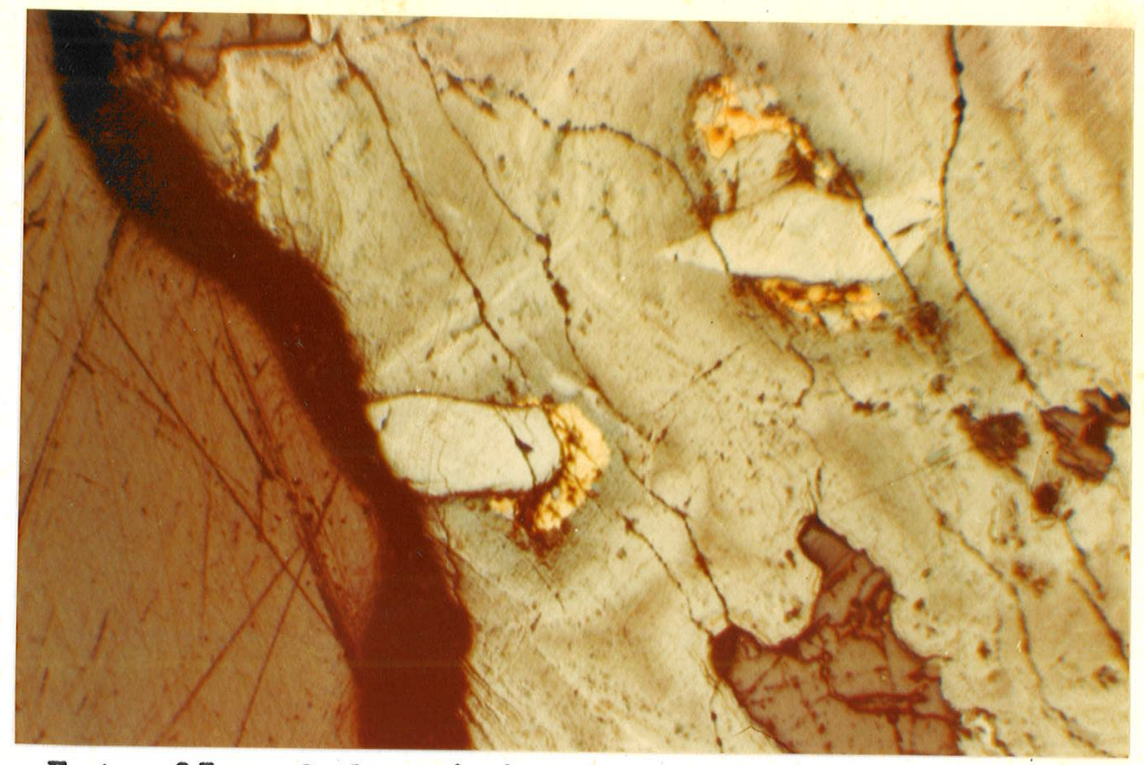

Foto 37 - Calcopirita(amarela) dissemina da em quartzito (cinza) e mate rial limonitico (marrom). Text $r a$ bandeada e elongação dos cristais de calcopirita perpen dicularmente à direção dos es = forços provàvelmente em estado plastico durante o metamorfismo do quartzito-(Edwards, 1954). Seção polida. Nícois descruzados. Aumento 60 vezes.

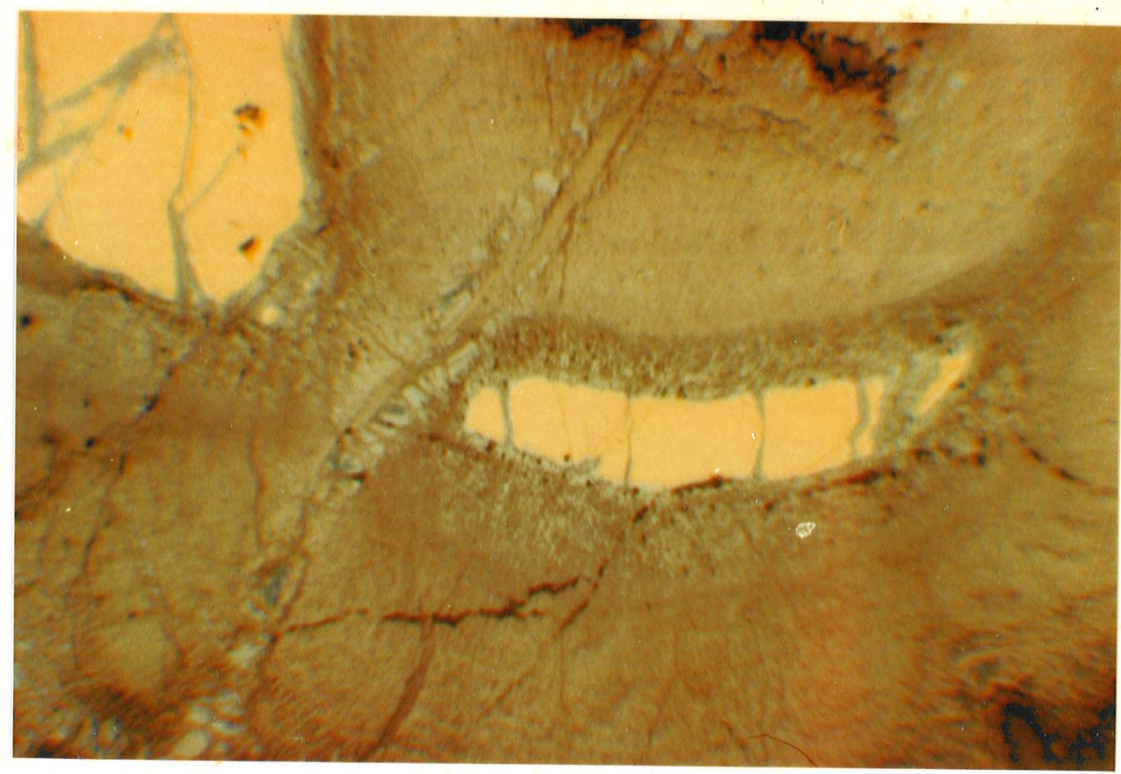

Foto 38 - Calcopirita (amarela) sendo substituida por calcocita (azul clara) e covelina (azul escura) e material limonitico no quartzo (marrom). Seção polida. Nícois descruzados. Aumento 200 veres. 


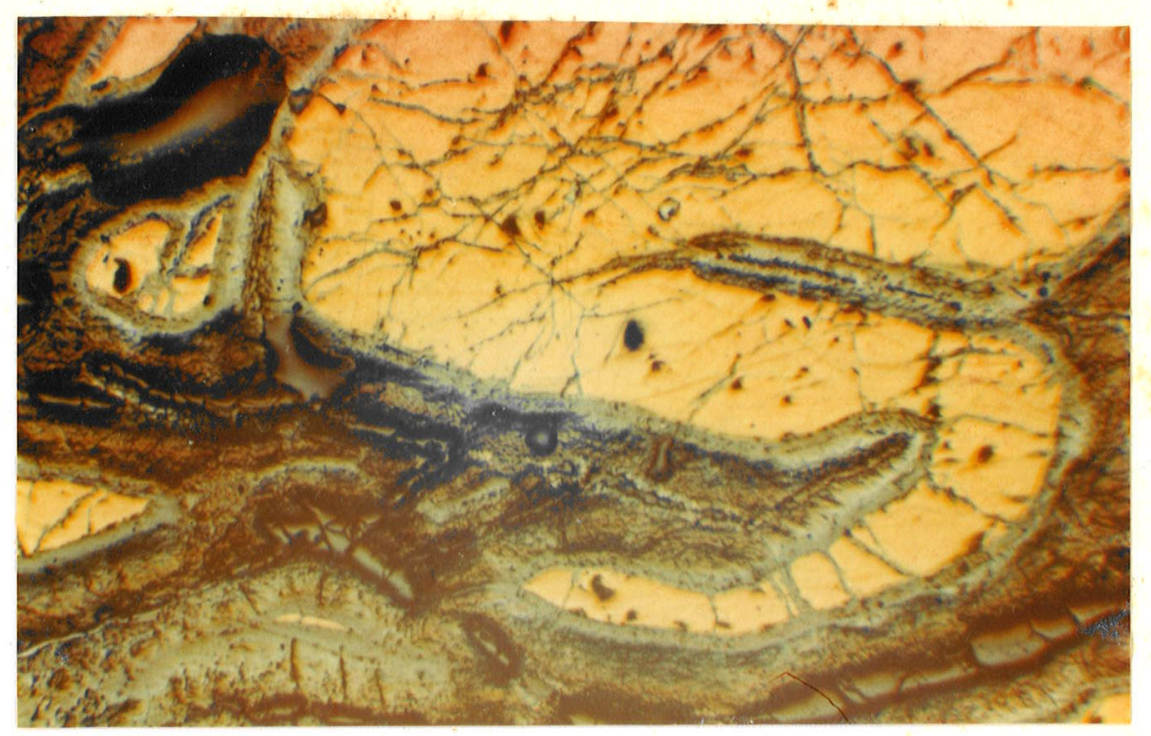

Foto 39 - Textura zonal na calcopirita (amarela), consistindo em bandas de calcocita(azul)e (1imonita in dígena (marrom)no centro das frä turas. Seção polida. Nícois des= cruzados. Aumento 30 , vezes.

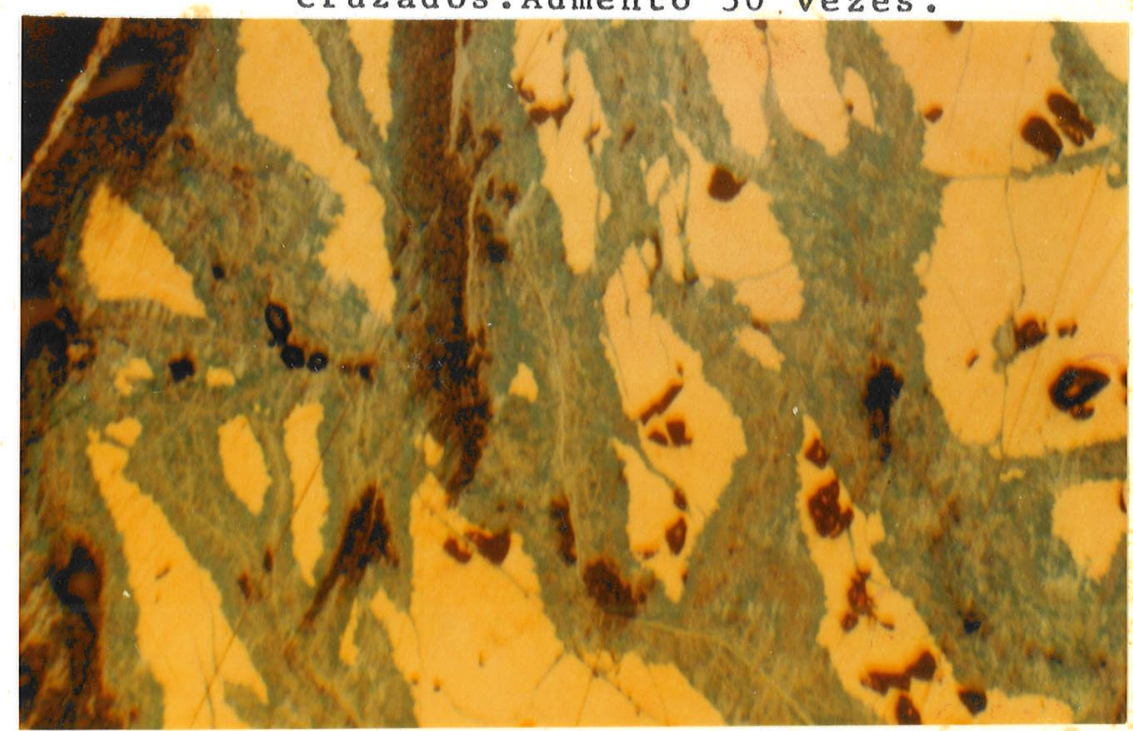

Foto 40 - Calcopirita (amarela)sendo substituida por covelita(azul escuro)e calcocita (azul clara). A textura em rede é caracterizada por soluções penetrantes em paragênese supérgena.A substituição proporciona forma alongada a calcopirita.Em giro de $90^{\circ} \mathrm{ha}$ alternância de pleocroismo de monstrando haver uma possive $1^{-}$ relação clivagem-substituição. As manchas escuras nos cristais de calcopirita são devidas à formação de material. 1imonitico. Seção polida. Nícois descruzados. Aumento 120 vezes. 
tragonal (Donnay et Kullerud, 1958; em Deer, 1962), com cela unitäria contendo $4 \mathrm{Cu} F e S_{2}$, e estrutura similar à da esfa lerita. A forma de alta temperatura è cübica e isoestrutú ral da esfalerita.

o dimorfismo de calcopirita foi estudado por Hiller e Probsthain (1956)e por Shima (1962), que concor dam na temperatura de inversão a $540-550^{\circ} \mathrm{C}$.

Propriedades físicas - A côr $\vec{e}$ amarelo avermelhado, às vezes com película vermelha de oxidação. A calcopirita é opaca, de brilho metálico, com traço preto es verdeado. Macroscopicamente não apresenta clivagem facilmen te distinguivel e a fratura é irregular. Em seções polidas apresenta côr amarelo intenso, elevada refletividade e traços de planos de clivagem geralmente preenchidos por substi tuição de outros minerais.

A calcopirita encontrada nos quartzitos associa-se, quando em decomposição, à calcocita, covelita (Fo tos 38 e 40), bornita e limonita indígena (Foto 39). Quando presente nas rochas carbonáticas decompõe-se em malaquita, crisocola e material limonitico.

$$
\text { Microsonda eletrônica - Värios cristais }
$$

de calcopirita foram examinados à microsonda eletrônica tendo sido escolhidos aqueles em matriz de quartzo (dos quartzi tos), por se tratar de espécimes em estägio de não decomposi ção ou substituição por outros minerais. As fotos 41 e $4 \overline{2}$ fornecem as imagens de dois cristais de calcopirita em campo de $200 \times 200 \mu \mathrm{m}$ e $400 \times 400 \mu \mathrm{m}$ respectivamente.

Os elementos: cobre (Fotos 43 e 44), ferro (Fotos 45 e 46) e enxofre (Foto 48) mostram perfeito recobri mento nos individuos cristalinos selecionados. A foto 47 fornece a distribuição do silício na matriz de quartzo. o cobre possui estágio inicial de concentração nas bordas da calcopirita. 


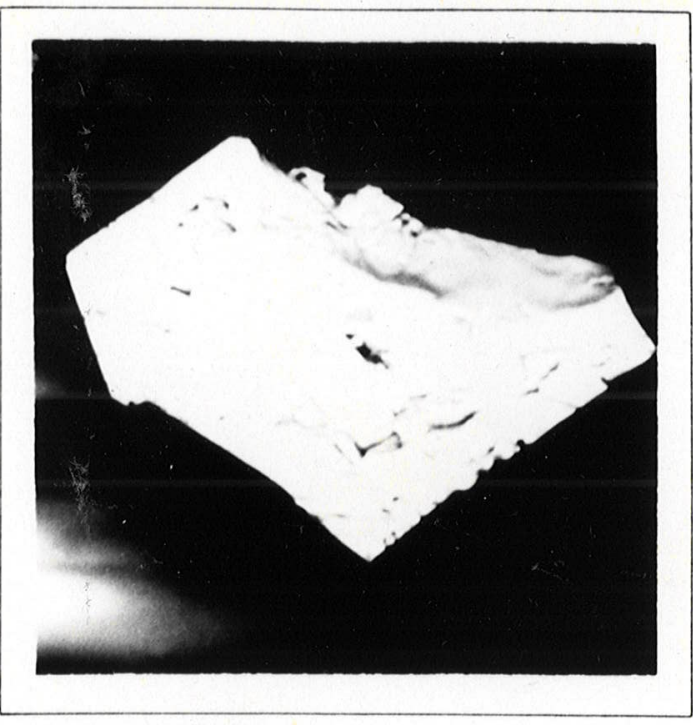

Foto 41 - Imagem eletrônica de calcopirita. E. retroespa$1 \mathrm{hados} .200 \times 200 \mu \mathrm{m}$.

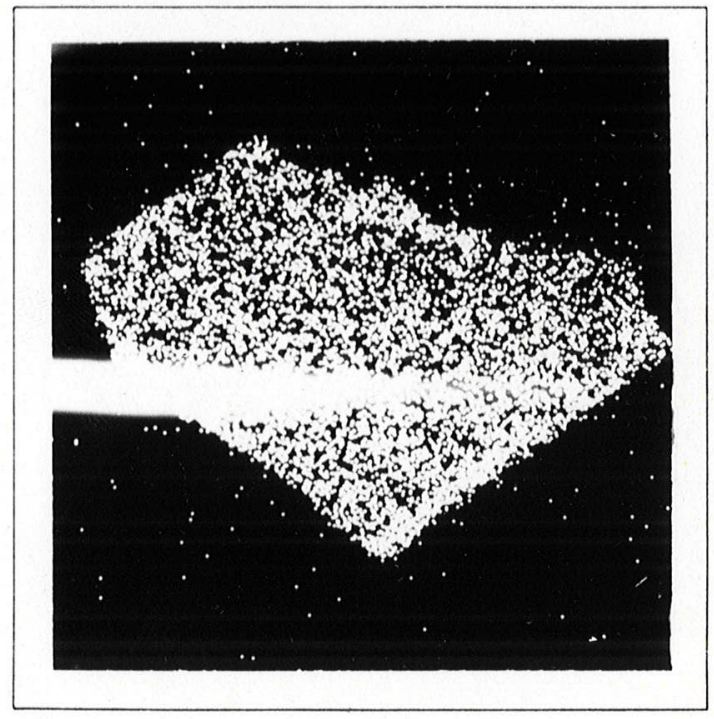

Foto 43 - Imagem "X" $\mathrm{Cu} \mathrm{K} \alpha$ $200 \times 200 \mu \mathrm{m}$.

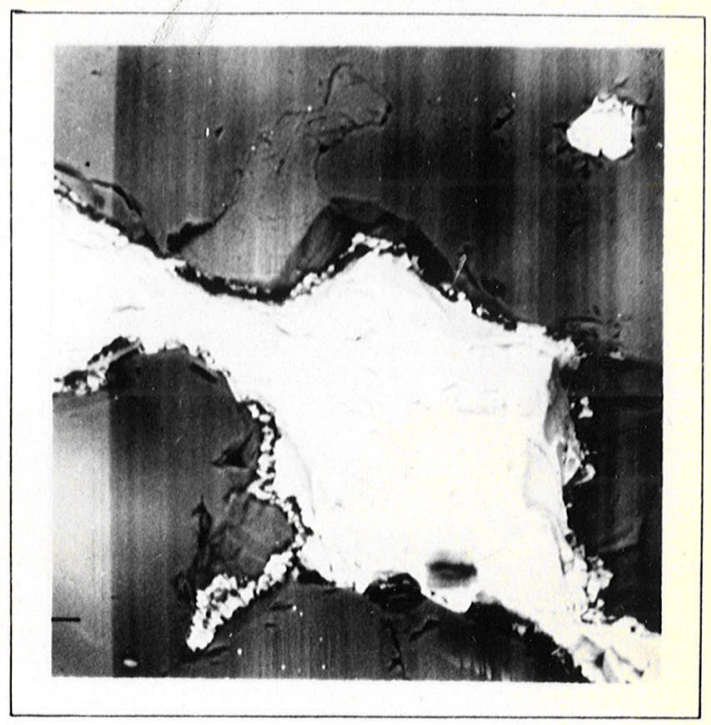

Foto 42 - Imagem eletrônica de calcopirita. E. retroespa1 hados. $400 \times 400 \mu \mathrm{m}$.

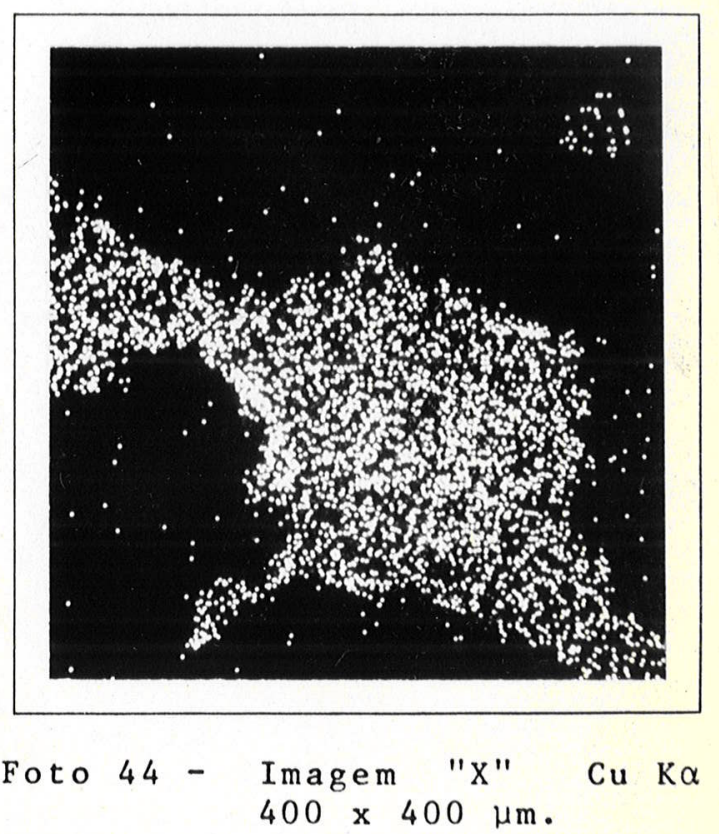




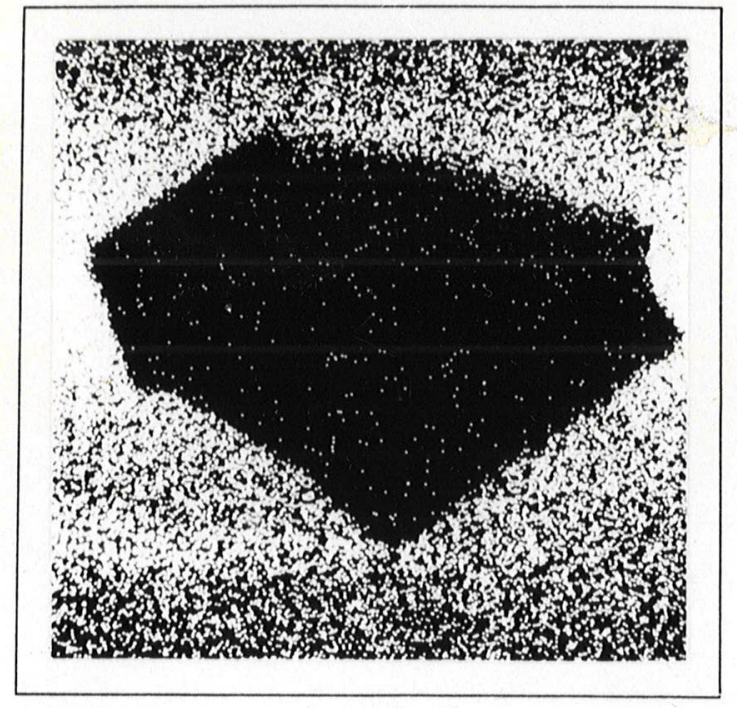

Foto 45 - Imagem "X" Fe K $\alpha$ $200 \times 200 \mu \mathrm{m}$.

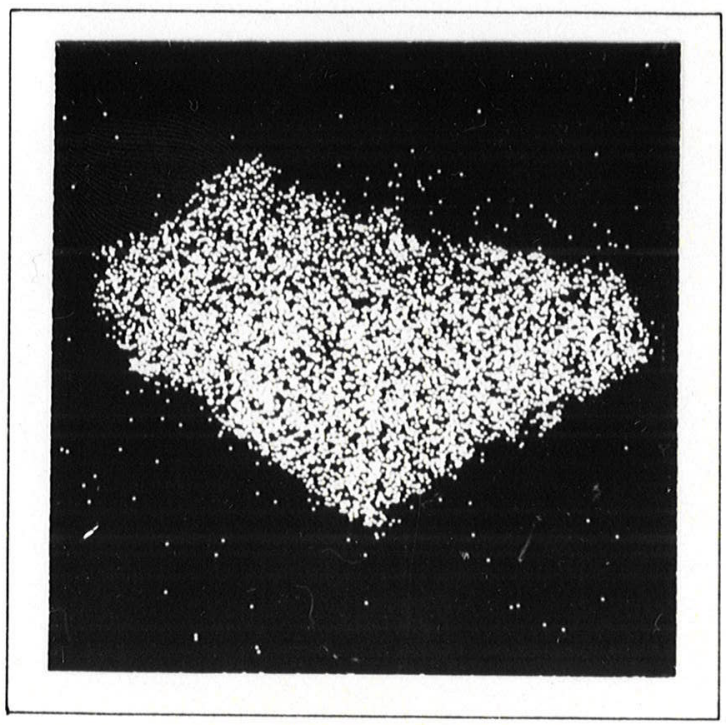

Foto 47 - Imagem "X" Si $\mathrm{K} \alpha$ $200 \times 200 \mu \mathrm{m}$.

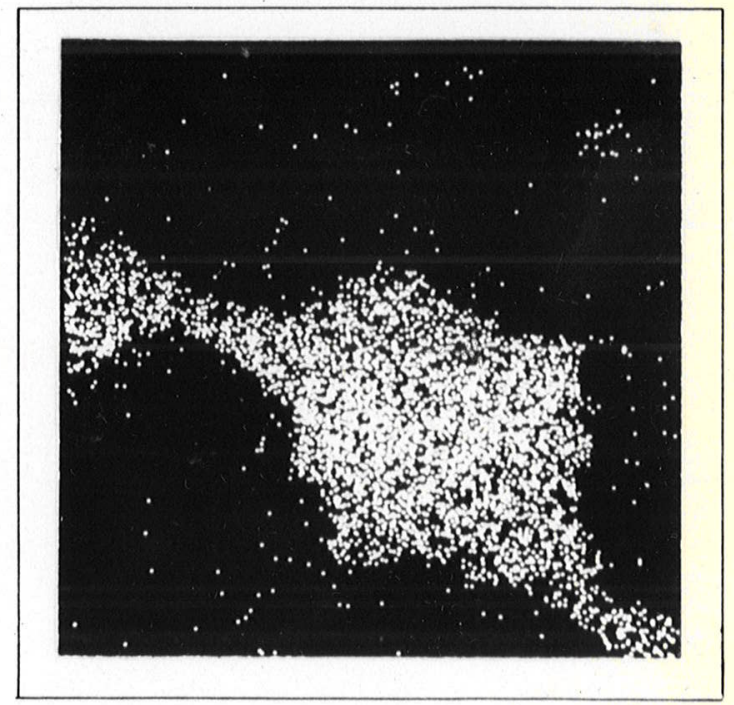

Foto 46 - Imagem "X" Fe K $400 \times 400 \mu \mathrm{m}$.

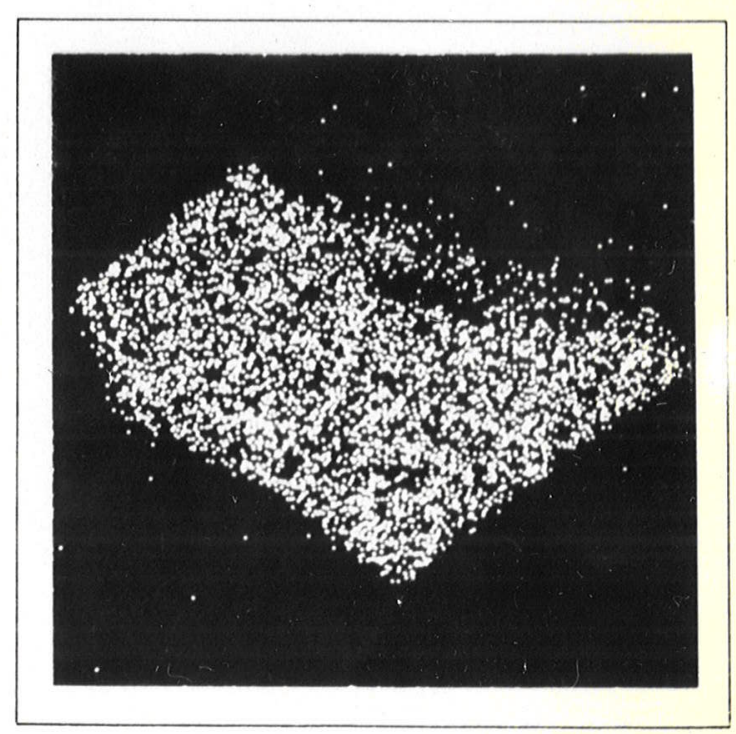

Foto 48 - Imagem "X" Si $\mathrm{K} \alpha$ $400 \times 400 \mu \mathrm{m}$. 
o estudo em microsonda estendeu-se

para

outros cristais e perfis de varredura foram executados até em campos menores, $100 \times 100 \mu m$ (aumento de 1200 vezes) não sendo percebidos os seguintes elementos: $\mathrm{Zn}, \mathrm{Sn}, \mathrm{Ge}, \mathrm{Ni}, \mathrm{Co}$, $\mathrm{Ag}, \mathrm{Au}, \mathrm{Pb}, \mathrm{Mn}, \mathrm{As}, \mathrm{Se}, \mathrm{Pt}$ e $\mathrm{Pd}$. O fato parece mostrar que - Zn não está substituindo cobre ou ferro na calcopirita e que não ocorrem outros membros do mesmo grupo estrutural tais como stanita ( $S n)$ e germanita (Ge). A distribuição de Co e Ni frequentemente é menor em calcopirita (Gavelin et al., em Deex, 1962) do que na pirita, fato observado na jazida do Ribeirão do Perau.

Os elementos-traço Ag, Au, $P t, P b, M n$ subs tituem $\mathrm{Cu}$ ou Fe, e As e Se substituem o $\mathrm{S}$, porém essas substituições näo podem ser suspeitadas nos cristais analisa dos. Pt e Pd apresentam-se mais concentrados em calcopirita que em outros sulfetos metälicos, fato que levou à uma pes quisa prolongada porēm sem resultados satisfatōrios.

Paragênese - A calcopirita é encontrada juntamente com outros sulfetos entre os minerais primārios de origem magmätica e em veios metalíferos nas rochas ígneas. Pode ser formada por metassomatismo e substituições em conta tos metamōrficos devido a soluções sulfurosas magmáticas. Quando ocorre em sedimentos pode ter-se formado durante a se dimentação ou ser o produto de soluções infiltradas depois da sedimentação. Como mineral secundário pode estar presen te nas zonas de oxidação de jazidas de cobre formando-se có mo produto de reação entre pirita e bornita (Filimonova,1952 em Deer, 1962).

A calcopirita do Ribeiräo do Perau e a pi rita, as quais ocorrem nos quartzitos, provavelmente são de origem primária e tenham se formado antes do metamorfismo so frido por estas rochas. As principais evidências se devem ao alongamento desses cristais perpendicularmente à direção dos esforços e à forma isomorfa tetragonal. o exame à microsonda eletronica exclui a possibilidade de lame 
Tabe1a 6 .

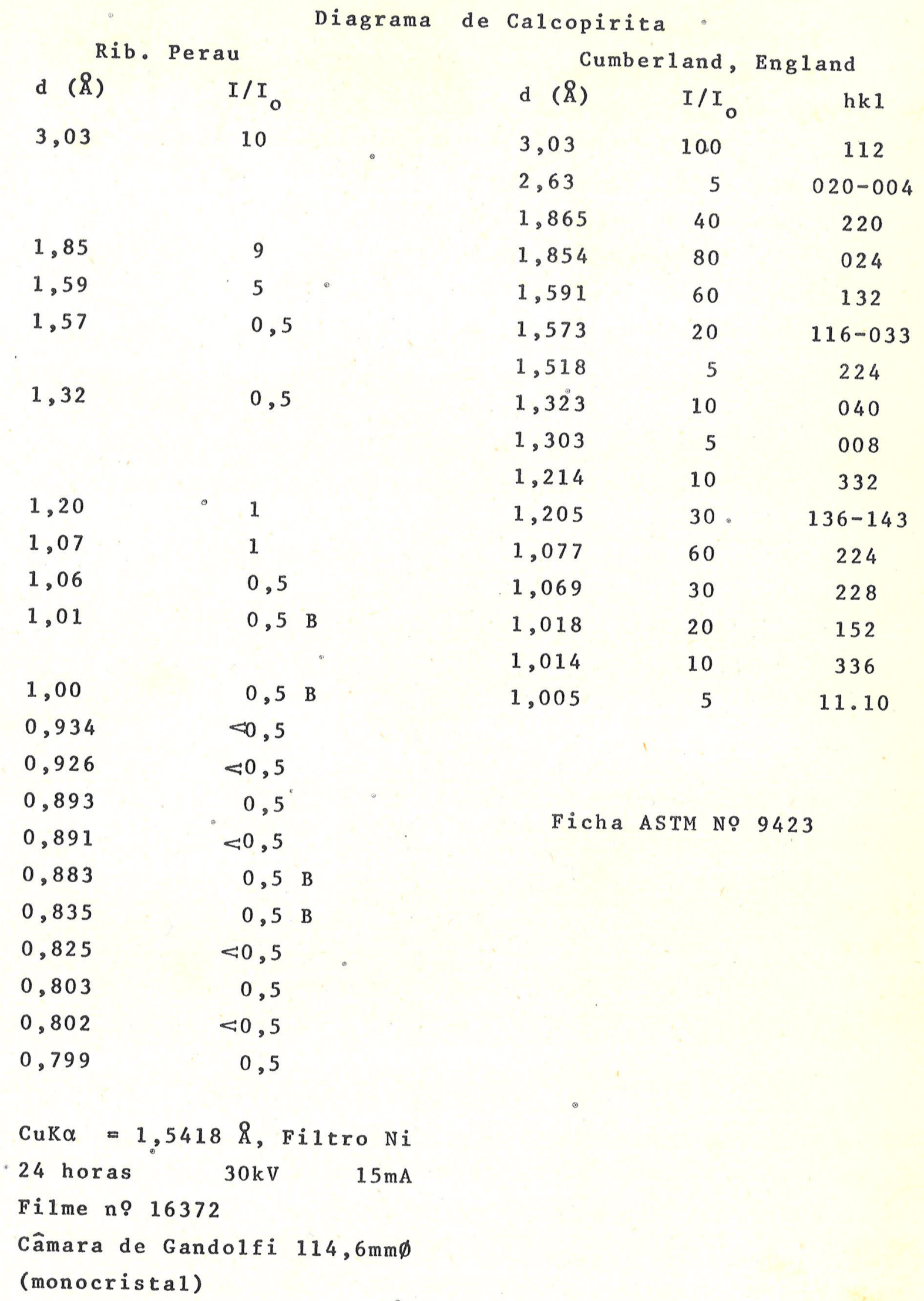


las de exsolução e de substituição estrutural pelos elemen tos quimicos estudados fornecidos pela literatura.

tennantita

A tennantita se associa normalmente a vieiros de quartzo que se entremeiam concordantemente com a estratificação dos quartzitos e rochas carbonáticas.Pequenas vênulas de quartzo podem apresentar jazimento discordante, preenchendo fraturas nos quartzitos. o mineral mais frequen temente associado à tennantita, alêm do quartzo, è a azurita, ocorrendo tambẻm, em proporção muito inferior, a malaqui ta. As ocorrências de tennantita na ärea da jarida do Ribei rão do Perau são verificadas a partir da trincheira TR 33 até o extremo sul do mapa geolögico (Fig. 3).

(1934) estudaram a estrutura cübica da sërie tennantita-te traedrita mostrando a variação de parâmetro da aresta da cé la unitäria para a substituição de As por Sb.

os espëcimens estudados são agregados cris talinos, cimentados por azurita e quartzo. 0 häbito posui aspecto maciço e compacto. Vários cristais, separados das rochas e examinados sob lupa binocular, não mostraram evidên cias de formas geométricas definidas, sendo sempre observa dos indivíduos desproporcionados sem motivos de figuras de crescimento, corrosão ou de clivagem. A granulação média se situa entre 2 a $3 \mathrm{~mm}$. A tennantita é opaca, de brilho meta lico, com côr branco cinzento (tambëm denominada cobre cin zento, Winche11, 1967). Não foi notada clivagem em indivi duos micro ou macroscópicos e a fratura apresenta reentrân cias subconcöides. Em seção polida observa-se refletividade moderada (menor que a da galena) e côr branco cinzento. Sob nicóis cruzados mostra isotropia com extinção completa (Uytenbogaardt, 1951).

As propriedades öpticas (Maske et al., 1971) variam de acordo com a composição. O aumento de cobre 


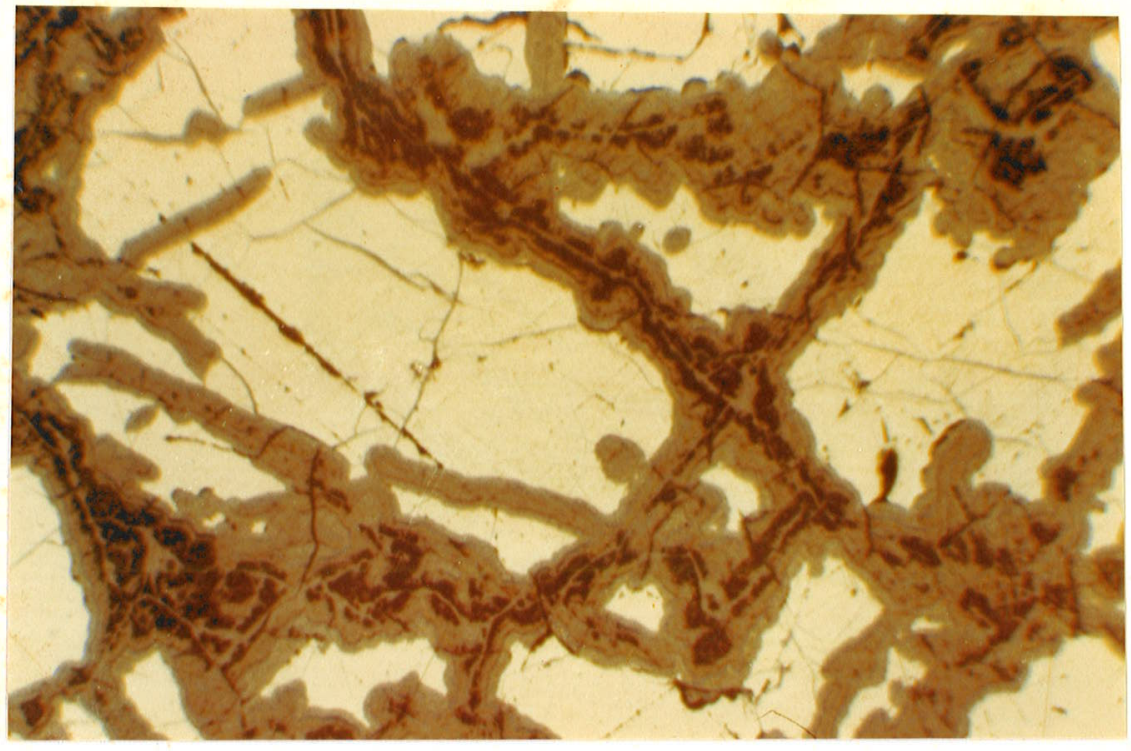

Foto 49 - Tennantita (branca)com textura em rede.A textura em "cá rie" evidencia a subs tituição progressiva por crisocola (marrom claro) e material 1imonítico (marrom escu ro). Seção polida.Nícois descruzados. Aumento 60 vezes.

Foto 50 - (superior) Tennantita (marrom es cura e verde escura), crisocola (verde claro), limonita (faixas amarelas), malaquita (verde médio)e quart zo(marrom). Seção po= Iida. Nícois descruza dos. Iluminação convergente, dest acando as cores dos minerais. Aumento 200 ve zes.
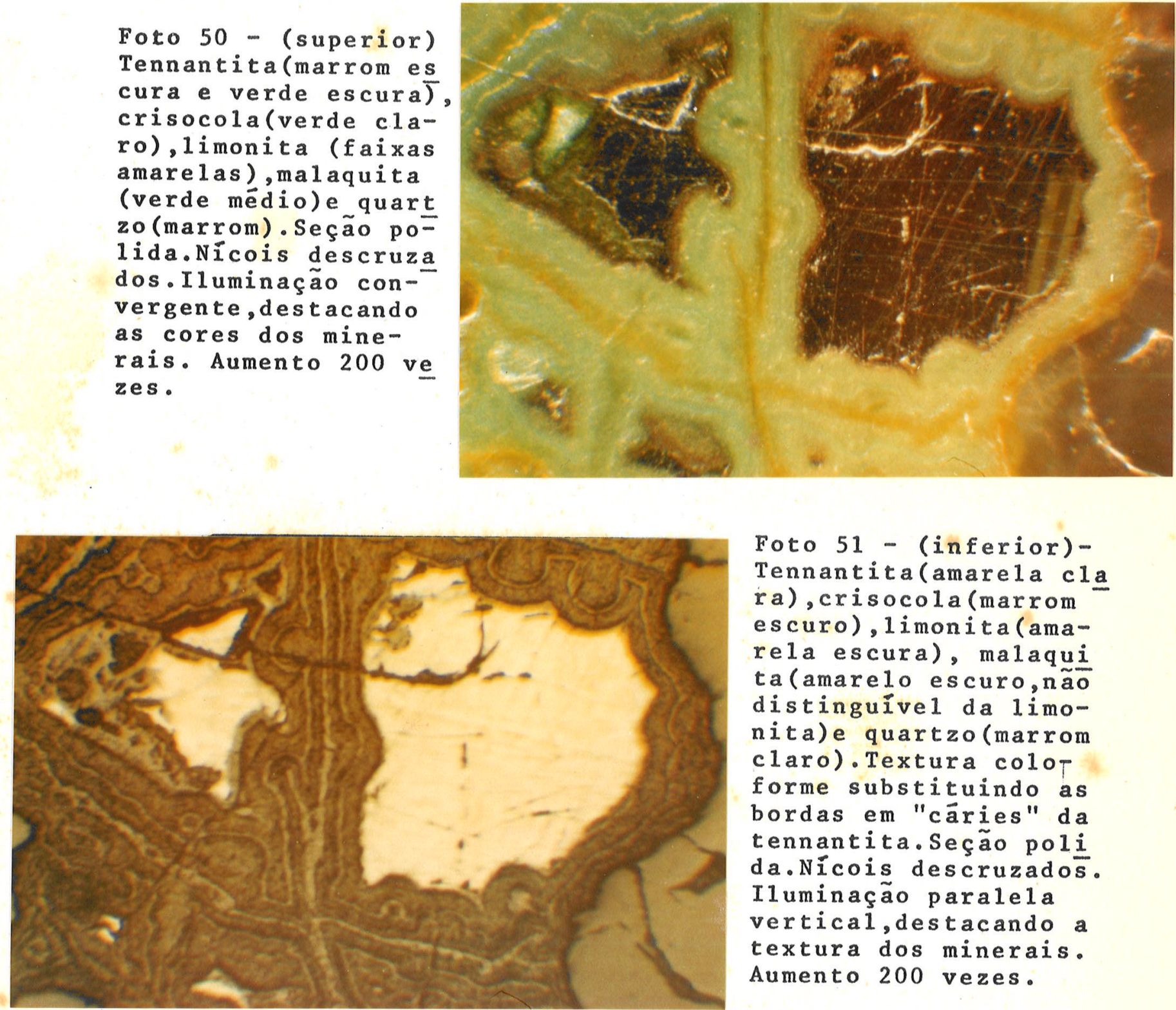

Foto 51 - (inferior)Tennantita (amarela cla ra), crisocola (marrom escuro), 1 imonita (amarela escura), malaqui ta (amarelo escuro, não distinguivel da 1 imonita)e quartzo(marrom claro). Textura colot forme substituindo as bordas em "cáries" da tennantita. Seção poli da.Nícois descruzados. Il uminação paralela vertical, destacando a textura dos minerais. Aumento 200 vezes. 
muda a côr verde oliva para cinza e provoca aumento de refle tividade.

Os difratogramas de raios $x$ (Tabela 7) in dicam que o mineral em estudo è membro mais pröximo de ten nantita dentro da sërie tennantita-tetraedrita.

Os espécimeas coletados provieram de aflo ramentos naturais ou artificiais, da zona de oxidação, mori vo que favorece a frequência de textura em rede observada ém seção polida. As malhas das redes são constituídasepor tex tura coloforme que invadem as "cäries" da tennantita (Fotos 49,50 e 51 ).

Microsonda eletrônica - A figura 13 e fo to 52, mostram respectivamente a distribuição dos elementos e a imagem eletrônica do campo estudado de tennantita $400 \mathrm{X}$ $400 \mu \mathrm{m}$.

o cobre (roto 53) estä concentrado nos cristais de tennantita porëm se encontra distribuido mai ou menos igualmente em todo campo focalizado. o zinco ( Foto 54)estä homogeneamente distribuido na tennantita não ocorren do na zona oxidada. o arsênico (Foto 55) se concentra na tennantita e invade um pouco a zona oxidada. 0 antimonio(Fo to 56) se apresenta nitidamente mais concentrado na rennanti ta. Devido a difexença entre os pesos atômicos de Sb e As, este ültimo elemento, embora menos abundante em imagem ele trônica està quantitativamente mais distribuido que o $\mathrm{sb}$.

- Ferro (Foto 57) pertence à "molëcula"de tennantita mas a sua concentração acompanha as bordas de de composição.

o enxofre (Foto 58) embora muito concen trado, limita-se aos cristais de tennantita, não formando ou tros sulfetos mais oxidados de cobre junto às bordas de rea
ção.

o cälcio (Foto 59) se localiza na zona o xidada da tennantita tendo preferência para recobrir cobre e ferro, distribuindo-se de maneira oposta ao silicio (Foto 60). 


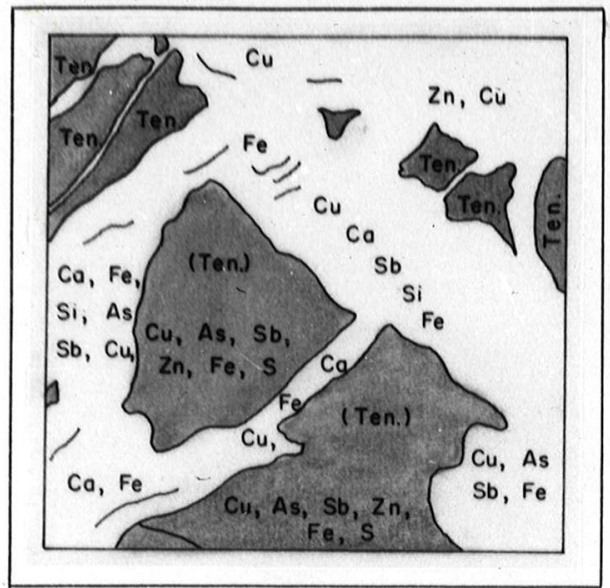

Fig. 13 - Distribuição dos ele mentos na Tennantita $=$ Ten

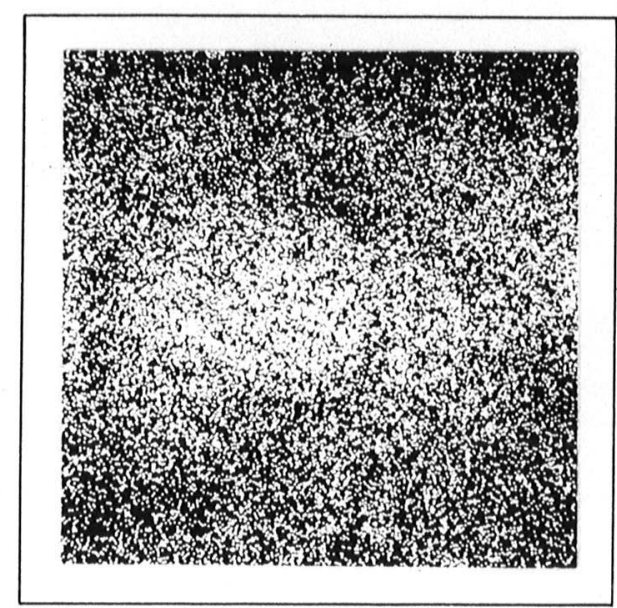

Foto 53 - Imagem "X" Cu K mesma zona

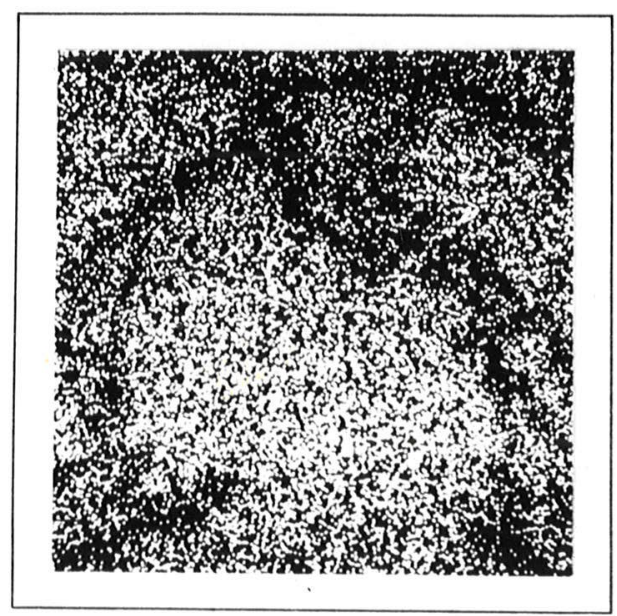

Foto 55 - $\begin{gathered}\text { Imagem "X" As } \\ \text { mesma zona }\end{gathered}$

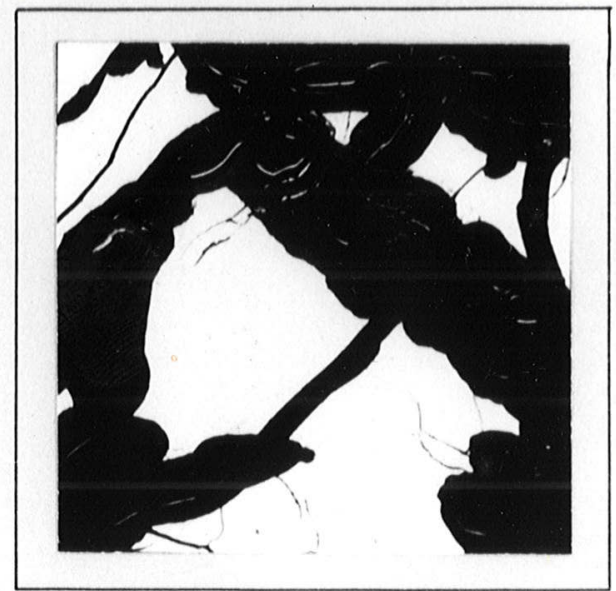

Foto 52 - Imagem eletrônica de tennantita (branca). E.re troespalhados. $400 \times 400 \mu \mathrm{m}$.
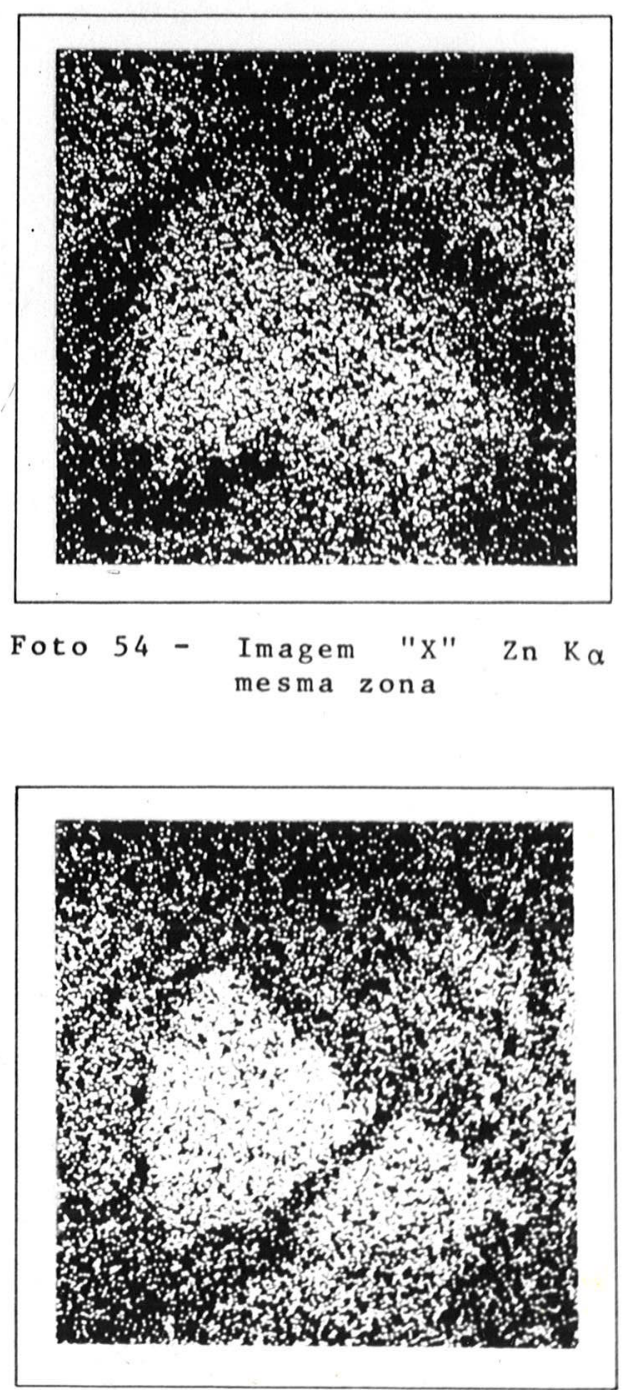

Foto 56 - Imagem "X" $\mathrm{Sb} \mathrm{L}_{\alpha}$ 


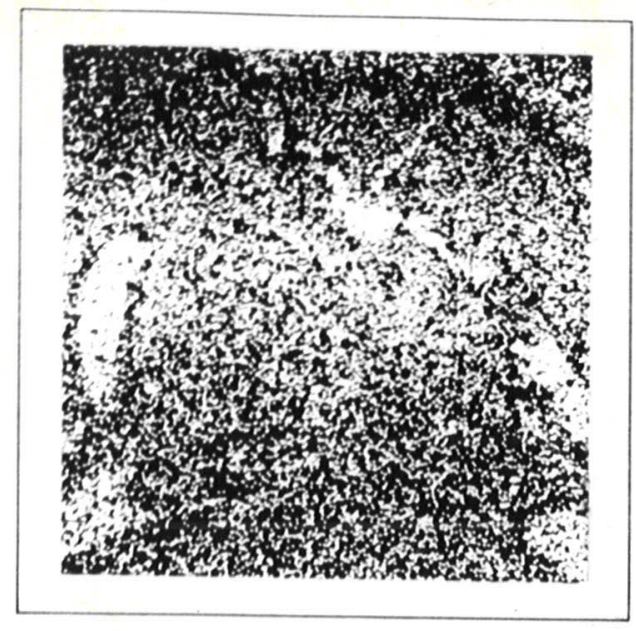

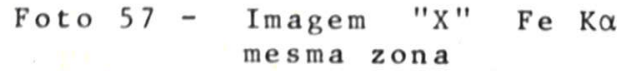

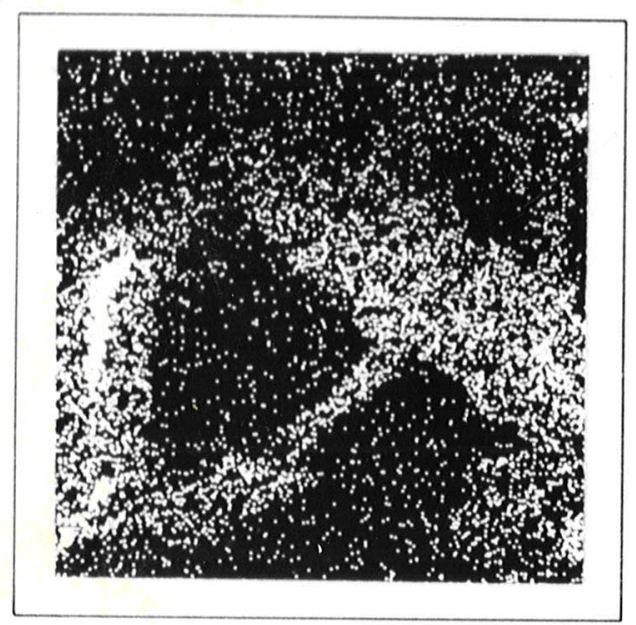

Foto 59 - Imagem "X" Ca K $\alpha$ mesma zona

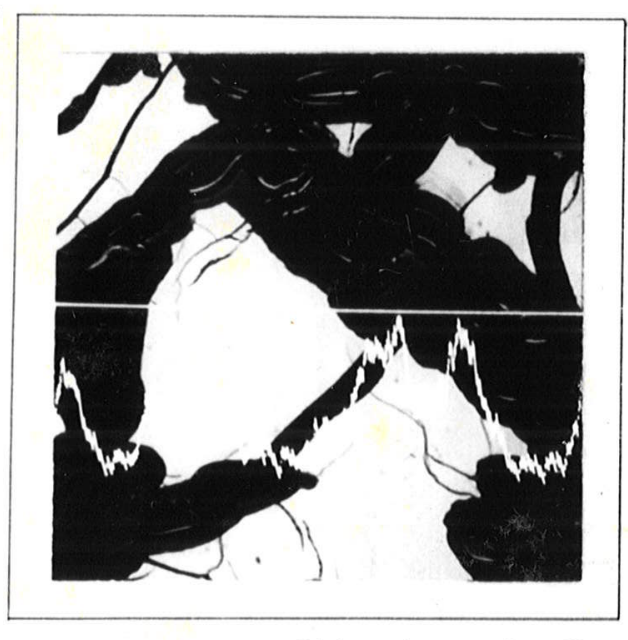

Foto 61 - Perfil de Ag $\mathrm{K} \alpha$
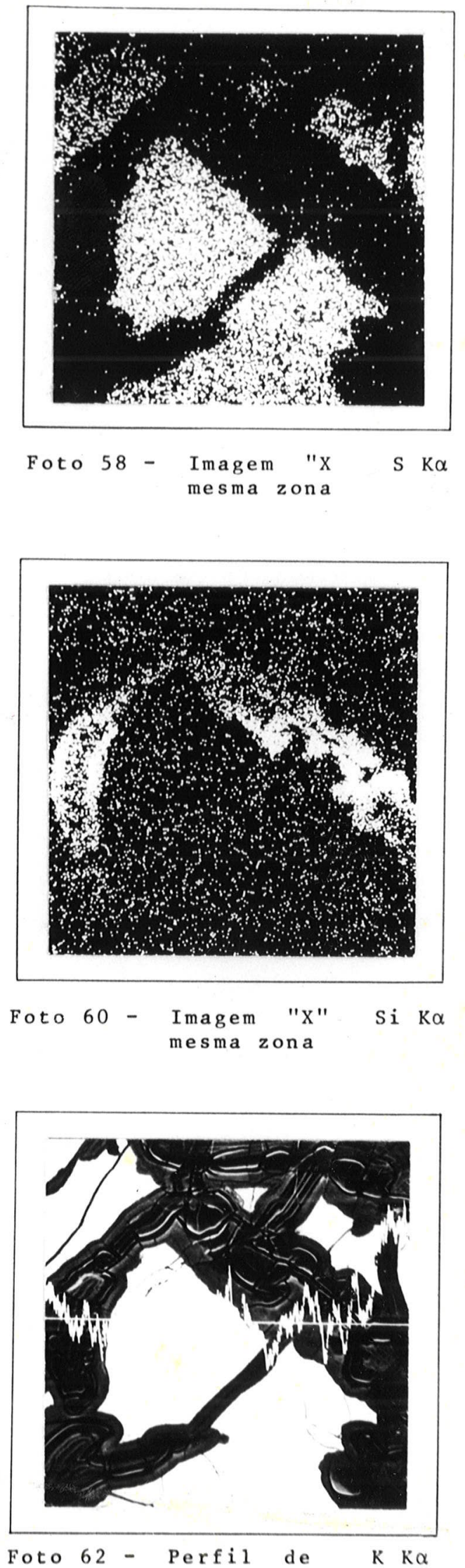
A prata (Foto 61), pesquisada através de perfis de varreduras, mostra maior distribuição nas bordas de decomposição porēm está também presente na tennantita. o formato agudo dos picos de variação de prata sugere que este elemento não faz parte da fórmula química da tennantita mas deve estar micro concentrado em forma metálica. A pequena quantidade de prata elimina possibilidade de intercrescimentos de tennantita com stromeyerita $\left(\mathrm{Cu}_{2} \mathrm{SAg}_{2} \mathrm{~S}\right)$ e pierargirita $\left(3 \mathrm{Ag}_{2} \mathrm{~S} \cdot \mathrm{Sb}_{2} \mathrm{~S}_{3}\right)$.

o potässio (Foto 62) apresenta distribui ção irregular, com pequenas concentrações internas e exter nas à tennantita sendo que a maior anomalia coincide com grande incidência de silicio.

Anälises à microsonda eletrônica de seis cristais de tennantita, pertencentes a três seções polidas não constataram: $\mathrm{P}, \mathrm{S} n, \mathrm{Mn}, \mathrm{Co}, \mathrm{Ni}, \mathrm{Se}, \mathrm{Pb}, \mathrm{Pt}, \mathrm{Mg}, \mathrm{Bi}$ e $A u$, sendo o As sempre muito abundante.

A ausência de $\mathrm{Pb}$ indica que a tenntita não forma intercrescimentos com galena (Uytenbogaardt, 1951) e não estä sendo substituída por galena ou seligmanita (2 $\mathrm{PbSCu}_{2} \mathrm{SAs}_{2} \mathrm{~S}_{3}$ ). A distribuição homogênea de Fe, Cu e $\mathrm{S}$ dentro da tennantita sugere não haver intercrescimentos mi merquíticos com calcopirita. A invasão dos elementos: Fe,As e Sb para a zona de oxidação parecem corroborar com a afir mação de que a tennantita não estä sendo substituída por ax senopirita (Fe As $\mathrm{S}$ ), famatinita ( $\left.\mathrm{Cu}_{2} \mathrm{~S} 4 \mathrm{Cu} \mathrm{S}(\mathrm{Sb}, \mathrm{As})_{2} \mathrm{~S}_{3}\right)$ enargita ( $\mathrm{Cu}_{2} \mathrm{~S} 4 \mathrm{CuS}\left(\mathrm{AsSb}_{2} \mathrm{~S}_{3}\right)$ e calcopirita (CuFes ${ }_{2}$ ).

Se se considerar os estägios de migração dos elementos da sërie tennantita $\mathrm{Cu}_{10}(\mathrm{Zn}, \mathrm{Fe}, \mathrm{Cu})_{2} \mathrm{As}_{4} \mathrm{~S}_{13}-$ tetraedrita $\mathrm{Cu}_{10}(\mathrm{Zn}, \mathrm{Fe}, \mathrm{Cu})_{2} \mathrm{Sb}_{4} \mathrm{~S}_{13}$, (Winche11, 1967) pode-se perceber através de anălises à microsonda eletrônica que - ferro é o primeiro elemento a migrar e consequentemente a se oxidar, concentrando-se nas bordas externas, combinando-se preferencialmente com o cälcio. A migração dos elementos pa ra fora da tennantita estä ordenada na sequência: Cu, As e $\mathrm{Sb}$. Quanto ao $\mathrm{Zn}$, este poderia estar se concentrando ou em fase incipiente de migração para fora da tennantita. 0 com 


\section{Diagrama de Tenantita}

Rib . Perau

\section{d ( $($ )}

2,95

2,74

2,56

2,41

2,19

2,09

2,01

1,87

1,81

1,76

1,66

1,62

1,54

1,48

1,45

1,28

1,26

1,22

1,19

1,17

1,16

1,14

1,10

1,08

1,05

1.,04

0,87

0,97

0,94

0,92

0,91

mais 9 raias

$\operatorname{CuK} \alpha=1,5418$ \&, Filtro Ni

24 horas $\quad 30 \mathrm{kV} \quad 15 \mathrm{~mA}$

Filme no 9772

Câmara de Gando1fi $114,6 \mathrm{~mm} \emptyset$

(monocrista1)
Binnental, Suiça

d $(\AA)$

4,15

3,60

3,23

2,94

2,71

2,55

2,40

2,17

2,07

1,994

1,855

1,801

1,746

1,695

1,653

1,608

1,568

1,535

1,467

1,439

1,386

1,358

1,296

1,274

1,254

1,217

1,185

1,169

1,139

1,126

1,100

1,086

1,074

1,052

1,041

0,870

$I / I_{0}$

h k 1

10

112

5

022

5

100

10

222

30

20

123

004

$114-033$

233

224

015-134

125

044

$035-334$

$006-244$

$116-235$

026

145

226

444

$055-345$

127-336

246

237-156

008

118-147

356

$138-347$

266

048

$019-338$

129-167

466

$039-158$

$239-367$

448

0,970

0,954

0,937

0,922

Ficha ASTM No 11-102 
portamento do enxofre $\vec{e}$ nitidamente de concentração na mole cula de tennantita. 0 mineral mostra texturas de substitui ção, onde os elementos mais resistentes à formação de compos tos parecem ser $\mathrm{Zn}$ e $\mathrm{S}$.

Paragênese - A tennantita ocorre associa da a calcārios, em zonas de fratura (Peterson, 1942) ou ém forma de vieiros juntamente com outros minerais de cobre (Winche11, 1967). Associa-se à pirita, galena, esfalerita, pirargirita e outros minerais de cobre. Pode substituir ba rita, pirita, esfalerita (Lindgren, 1935) e enargita. Podé ser substituida por galena, seligmannita, arsenopirita, fama tinita, enargita, calcopirita e stromeyerita (Uytenbogaardt, 1951).

E considerada mineral sempre hipógeno (Bateman, 1968) e é tida como tal na mina de prata de Ashbrook, Utah (Peterson, 1942), associada a intercrescimen tos de pirargirita, galena e quartzo.

Ramdohr (1969) considera que a tennantita é mais comum a partir de fase hidrotermal de sequência magmá tica, podendo ser encontrada em contatos metassomáticos e pegmatiticos; em ocorrências hidrotermais, epitermais e sub vulcânicas; e em depósitos metamörfícos.

A tennantita $\bar{e}$ o membro mais comum da so lução sölida com tetraedrita (Maske et al., 1971) porēm é ra ramente o mineral de maior abundância em depösitos minerais sendo contudo encontrada pelo menos em traços nos jazimentos de minérios sulfetados.

\section{quartzo}

Ribeirão do Perau, tanto como integrante do minêrio primärio e secundario, como das rochas encaixantes. Quartzo e serici ta são os componentes essenciais dos filitos. Nos xistos, a ocorrência é só subordinada às micas. E constituinte prin cipal dos quartzitos, perfazendo $90 \%$ ou mais, do volume dessas rochas. Nos anfibolitos e anfibólio-xistos a quantidade é inferior somente à horblenda e plagiocläsio. Nas rochas 
calcio-silicatados o quartzo è menos abundante que horblen da e tremolita.

Pode ser encontrado com häbito maciço e coloração branca, em filões, com fraçöes de milïmetro até dezenas de centimetros de espessura por dezenas de metros de comprimento, associado à barita, turmalina, calcopirita e material limonitico, cortando diagonalmente o acamamento dos xistos (Foto 3 ).

Na zona de minério oxidado das galerias ocorre, às vezes, em forma de geodos, de milimetros a centi metros de diâmetro, formando agregados cristalinos subpara lelos de individuos, com faces prismäticas bem desenvolvidas e com milimetros de comprimento. o quartzo dos geodos é ge ralmente incolor.

galena

A galena (PbS) na jazida do Ribeirão do Perau ocorre em pequena quantidade, não constituindo mine rio. As ocorrências estão sempre associadas a veios de quartzo e barita com menos de um decimetro de largura por dezenas de metros de extensão, fato comprovado por aflora mentos artificiais em poços de pesquisa. A atitude dos veios ê diagonal aos xistos e filitos e estão sempre encai xados nessas rochas. Hä afloramentos naturais na superfi cie, porêm a galena é quantitativamente insignificante ém relação à barita associada. Rara pirita e quartzo podem es tar presentes junto à galena. Não se exclui a possibilidade de serem encontradas inclusões de pirtotita em intercres cimentos eutëticos (Hewitt, 1938; de Deer, 1962).

Propriedades morfolögicas - Ocorre como individuos cristalinos milimetricos disseminados em matriz de barita, ou formando agregados cristalinos de 2 a $5 \mathrm{~cm}$ na maior dimensão.

o häbito cübico é o predominante, poden do apresentar-se maciço ou granular (Dana, 1894) devido ao tamanho milimëtrico dos agregados cristalinos. Em seçōes 


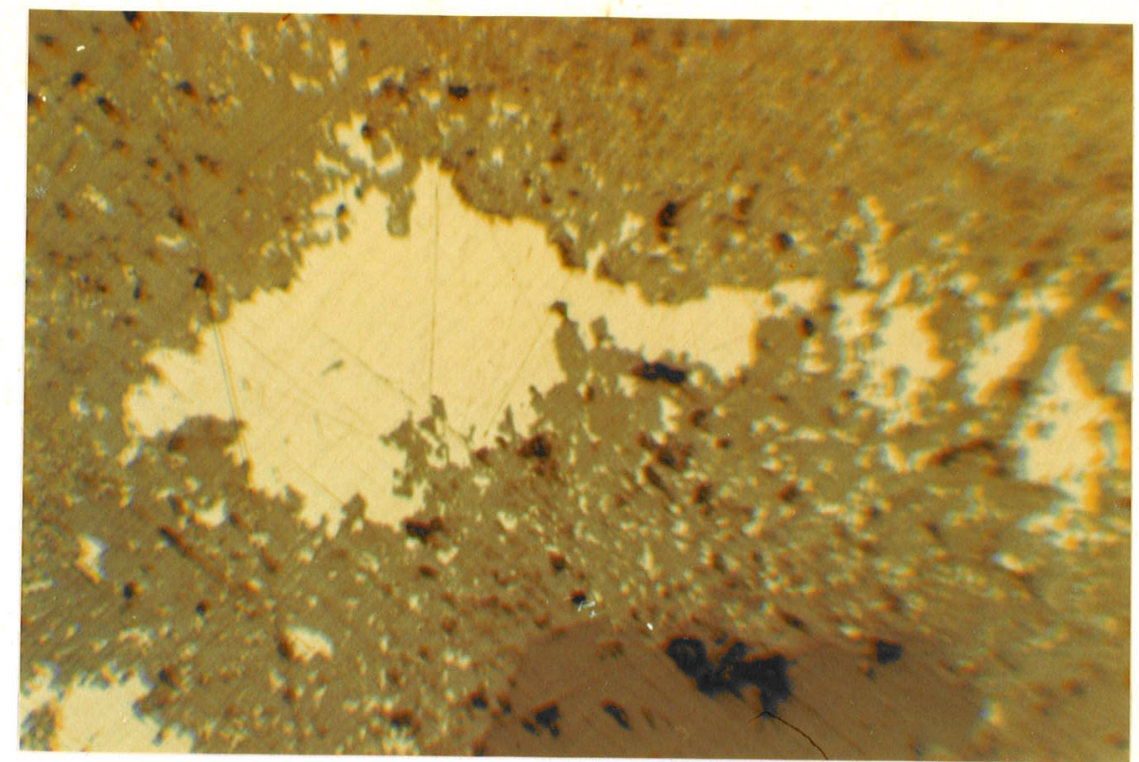

Foto 63 - Galena(branca) em quartzo (cin za). Textura em cärie. Seção polida. Nícois descruzados. Au mento 130 vezes.

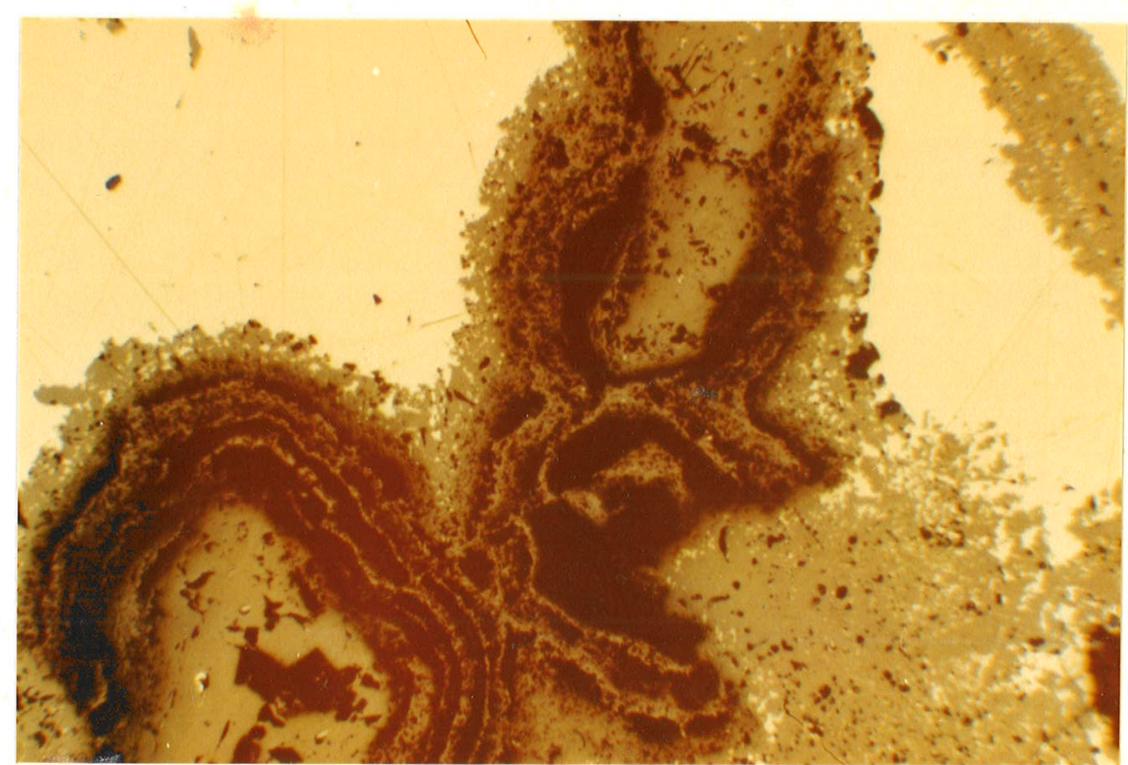

Foto 64 - Galena (branca) em quartzo(cin $z a)$ Textura coloforme (marrom) de ōxido de chumbo. Seção poli da. Nícois descruzados. Aumento 200 vezes. 
polidas (Fotos 63 e 64 ) os cristais são hipidiomörficos. Não foi encontrada geminação.

Propriedades físicas - A côr ê cinza-chum bo (Leinz et al., 1962) é opaca de brilho metälico, com tra co branco prateado, apresentando clivagem cübica $\{001\}$ e fra tura subconcóide. A partição \{111\} não foi observada.

Sob luz refletida mostra baixa dureza de polimento, elevada refletividade, côr branca, não apresentan do faces triangulares de geminação. E isötropa entre nícois cruzados. Está sempre associada a quartzo ou barita, em am bos os casos apresentando contornos nitidos porém não retos. A testura suturada e a em cärie são as predominantes em rela ção aos minerais da matriz, (Fotos 63 e 64). Nos cristais não foram encontradas películas de oxidação.

\section{Microsonda eletrônica - A foto 65 mostra}

a imagem eletrônica de alguns cristais de galena (aumento de 1200 vezes) de côr clara, imersos em matriz de enxofre (Foto 66) e de chumbo (Foto 67). A maior concentração des ses elementos coincide com a posição dos cristais de galena propriamente ditos, pois na parte clara (Foto 65) foram de tectadas 7670 contagens por segundo em dez segundos e na parte escura 5400 contagens.

Os demais elementos pesquisados e não en contrados foram: $\mathrm{Se}, \mathrm{Ag}, \mathrm{Bi}, \mathrm{Fe}, \mathrm{Zn}, \mathrm{Mn}, \mathrm{Cu}, \mathrm{Sn}, \mathrm{Hg}, \mathrm{As}, \mathrm{Ba}$, $\mathrm{Ti}, \mathrm{Au}, \mathrm{Ni}, \mathrm{Co}, \mathrm{Mg}, \mathrm{Pt}, \mathrm{Ca}, \mathrm{Cr}, \mathrm{V}, \mathrm{Ge}, \mathrm{Yb}, \mathrm{Ga}, \mathrm{Sc}, \mathrm{Mo}, \mathrm{Cd}, \mathrm{Sr}$ e Y.

o selênio poderia ocorrer em substituição ao enxofre provocando aumento da cela unitária.

os elementos pesquisados e não determinados vêm corroborar com a afirmação (Deer, 1962) de que a substituição do $\mathrm{Pb}$ na galena não è muito frequente.

A ausência de Ag e Bi leva à não formação de soluções ou exsoluções de $\mathrm{Ag} \mathrm{Bi} \mathrm{S}_{2}$ (matildita) ou $\mathrm{Ag}_{2} \mathrm{~s}$ (acanthita). Concentrações altas de Bi e Ag na galena são inferidas devido a temperaturas altas de formaça (Schroll, 1955; de Deer, 1962). o ferro, o zinco, o manganēs, o cobre 


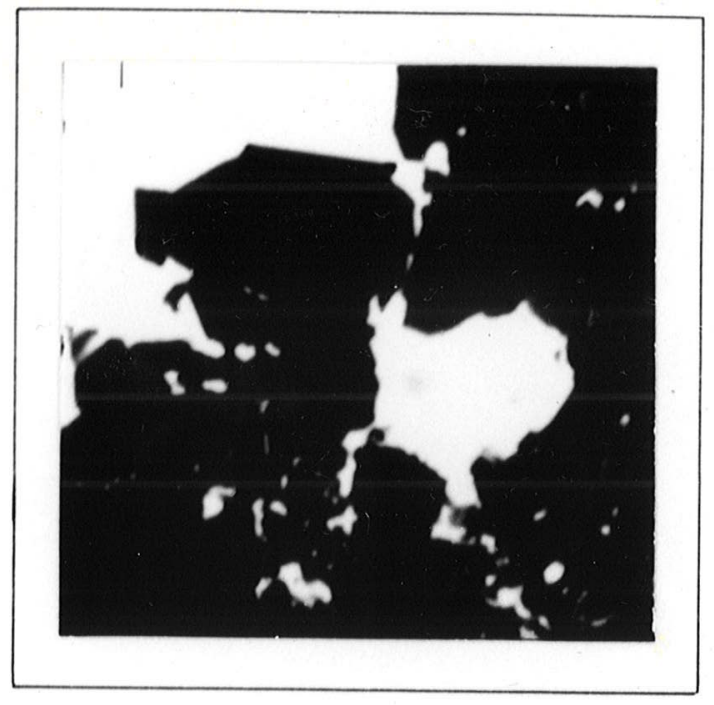

Foto 65 - Imagem eletrônica de galena(branca). E. retroespalhados. 100 x $100 \mu \mathrm{m}$.

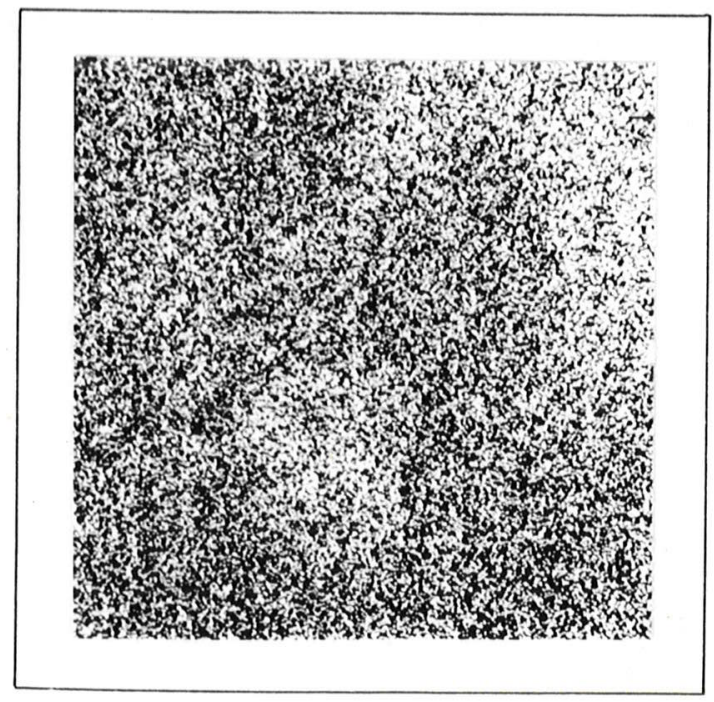

Foto 67 - $\underset{\text { mesma zona }}{\text { Imagem } \mathrm{X} \text { " Pb L } \alpha}$

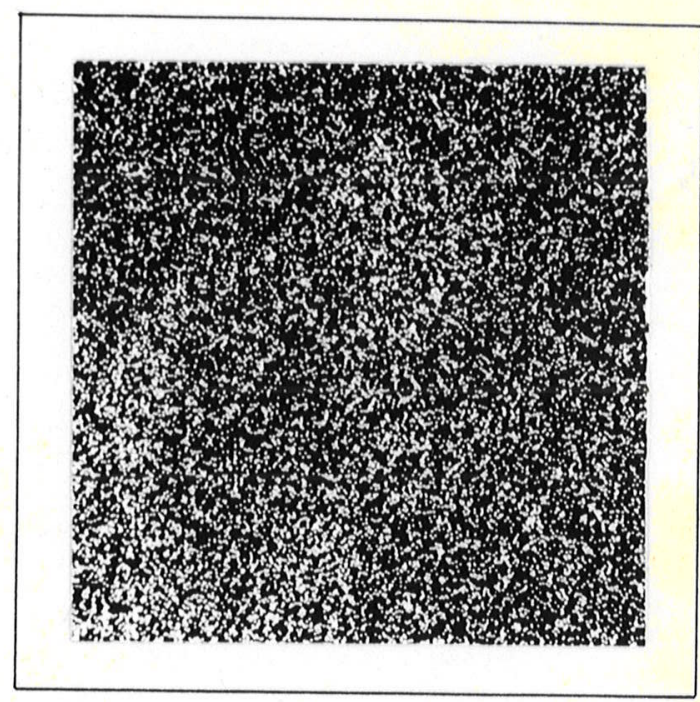

Foto 66 - $\begin{aligned} & \text { Imagem "X" } \\ & \text { mesma zona }\end{aligned}$

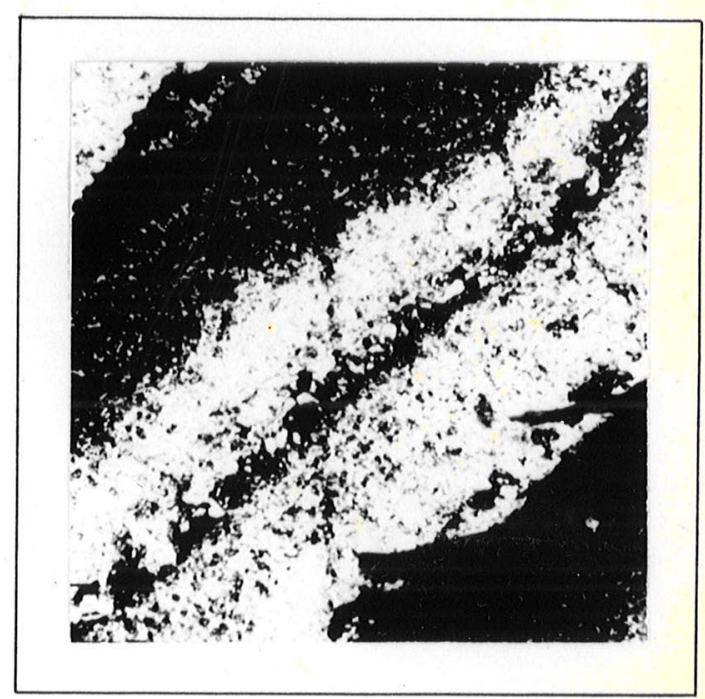

Foto 68 - Imagem eletrônica dos aneis que acompanham galena. E. retroespalhados. 400 x $400 \mu \mathrm{m}$. 
e estanho, não presente, indicam a falta de associação res pectiva com os minerais: esfalerita (Fe, Mn, Zn), calcopirita e tetraedrita.

A galena é capaz de formar soluções söli das com diversos minerais de prata a altas temperaturas, mas a temperaturas normais pode acomodar não mais que $0,1 \%$ de prata na sua estrutura. A galena argentifera, Edwards (1954), contēm menos que $0,1 \%$ de prata distribuida homogeneamente e se a quantidade for maior invariavelmente contera minerais de prata de 1 a 2 microns de diâmetro, inclusos e orientados segundo\{111\}. 0 campo de anälise pela microsonda eletrônica abrangeu $100 \times 100 \mu \mathrm{m}$ ño tendo sido detectada prata metāi ca.

A prata não existe em forma livre mas po deria fazer parte do reticulo cristalino da galena em forma de cătion substituindo chumbo. Neste caso a concentração se ria pequena, de dificil detectação eletrônica devido à proxi midade dos números atômicos da $\mathrm{Ag}$ e $\mathrm{Pb}$, permitindo que esté absorva a radiação emitida pela Ag e mascarando a presença desta.

Nesterova (1958) em Deer 1962, conclui a partir de diversas anālises de galena, que Ag, Bi, Sb, Sn e Cu não fazem parte da sua estrutura cristalina, mas existem em outros minerais na forma de inclusões. A falta desses elementos nas amostras de galena do Riberrão do Perau pode ria levar a concluir pela não existência desses tipos de in clusões, o que não deve ser admitido como definitivo, ten do-se em vista que as anälises por microsonda eletrônica neste estudo não têm efeito estatistico.

Em todas seções polidas de galena estuda das notou-se a presença de material com textura coloforme (setores circulares concêntricos, foto 68), o qual não pode ser identificado por diversos métodos de difração de raios X (Tabela 8).

o exame à microsonda eletrônica revela que essas estruturas são essencialmente öxidos de $\mathrm{Pb}, \mathrm{Zn}, \mathrm{Mn}$, Fe e S. A figura 14 mostra a distribuição desses elementos 
pelas diversas faixas, num campo de $400 \times 400 \mu m$ (aumento de 300 vezes).

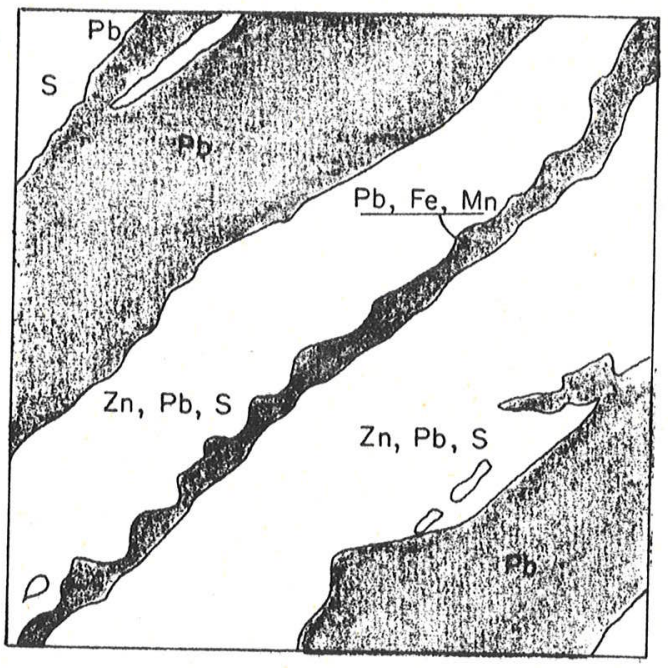

Fig. 14 Distribuição dos elementos da ima gem eletrônica da foto, 68

Nas faixas claras (Foto 68), predominam $S$, $\mathrm{Pb}$ e $\mathrm{Zn}$ e nas escuras aparecem subordinadamente esses mesmos elementos com predominância do $\mathrm{Pb}$. O Mn sö ocorre na forma de öxido na estreita faixa escura diagonal. Em contraste e letrônico de relevo é possível notar sulcos nas partes escu ras, denotando menor dureza em relação às partes claras.

Paragênese - A galena frequentemente ocor re junto com esfalerita e os minérios de chumbo e zinco ge ralmente contém quantidades recuperäveis de $\mathrm{Cu}, \mathrm{Ag}$; $\mathrm{Sb}$ e $\mathrm{Bi}$ (Deer, 1962).

Pode ter origem hidrotermal de baixa tem peratura quando ocorre associada a sedimentos, porêm quando ocorre em forma de veios ou substituindo outros minerais em pegmatitos, è tida como de origem em alta temperatura. A tex tura coloforme dos öxidos de $\mathrm{Pb}, \mathrm{S}, \mathrm{Zn}, \mathrm{Mr}$ e Fe tem faces convexas voltadas para a galena, indicando ser esta a super ficie mais jovem (Edwards, 1954). A curvatura das faixas é considerada como manifestação de efeitos de tensão em mate rial viscoso ou de origem coloidal, como resultado de um ar 
Tabe1a 8

\section{Diagrama de Galena}

Rib . Perau

d (8)

$I / I_{0}$

$3,42 \quad 100$

2,95

2,09

1,81

1,80

1,47

1,35

1,32

1,20

1,13

1,03

1,00

0,98

0,93

0,89
100

90

70

50

30

30

40

40

20

5

10

10

10

5
Nat. Lead Co.

d (\&)

$I / I_{0}$

hk 1

3,429

84

111

2,969

100

200

2,099

57

220

1,790

35

311

1,714

16

222

1,484

10

400

1,362

10

331

1,327

17

420

1,212

10

422

1,1424

6

511

1,0489

440

1,0034

531

0,9893

600

0,9386

620

0,9050

2

533

0,8952

622

0,8568

444

0,8312

3

711

0,8232

640

$\mathrm{CuK} \alpha=1,5418 \AA$, Filtro $\mathrm{Ni}$

24 horas $\quad 30 \mathrm{kV} \quad 15 \mathrm{~mA}$

Ficha ASTM No 5-0592

Filme no 21170

Câmara $114,6 \mathrm{~mm} \emptyset$ 
ranjo colunar radial de cristais com eixo maior normal à fas ce livre plana de onde procede a cristalização. A textura coloforme indica deposição a temperaturas baixas.

0 chumbo e o enxofre provém indubitave1 mente da galena, o que não ocorre com o Fe e Zn. o öxido de ferro é depositado em forma de gel, "solidificando-se" ainda no estado amorfo e o öxido de manganês, em forma de ge1, possui grande capacidade de absorver sais de outros me tais, no caso o zinco. A forma de jazimento da galena, as relações com as rochas encaixantes, os caracteres texturais e a migração de seus elementos para formar textura colofor me sugerem origem hidrotermal de baixa temperatura.

barita

A barita foi identificada nos primeiros estägios da pesquisa de campo sob a forma de cascalhos, reco brindo uma parte da superficie da jazida, nas proximidades do contato xisto com quartzito, entre a TR80 S até a TR240S. (Fig. 3.) Esses blocos rolados possuem forma elipsoídica e são recobertos por uma película de material limonitico com poros de alguns milímetros de diâmetro, lembrando cavi dades produzidas por limonita indigena. A quebra desses blocos revela que a barita se compõe de agregados cristali nos de côr branca, com típica textura sacaröide.

A barita ocorre tambëm em veios de quart zo e galena com decímetros de largura por dezenas de me tros de extensão de atitude diagonal a acamamento dos xis tos e filitos.

Em seções polidas a barita foi encontra da associando-se ora à cuprita, cobre nativo, calcocita,ma laquita, crisocola, quartzo, turmalina e pixita e ora pre enchendo fraturas microscöpicas de dolomita associada à calcita, tennantita, crisocola, malaquita e quartzo.

Propriedades físicas - A côr è branca,o brilho vitreo, clivagem perfeita e opticamente è biaxial positiva. Os agregados cristalinos apresentam textura sa 
Tabe 1 a 9

\section{Diagrama de Barita}

Rib . Perau
d ( $(\AA)$
$I / I_{0}$

4,36

3,89

3,72

3,54

3,43

3,31

3,08

2,82

2,72

2,47

2,31

\section{0}

60

10

30

100

70

100

50

50

20

20

2,20

5

2,10

2,05

90

20

1,92

1,85

1,78

5

1,75

1,70

1,63

10

1,58

1,53

1,42

20
Ref. Swanson and Fuyat

d (\&)

I / I

hk 1

4,44

4,34

3,90

3,77

3,576

3,442

3,317

3,101

2,834

2,734

2,726

2,481

2,444

2,322

2,303

2,281

2,209

2,120

2,104

2, 056

1,947

1,930

1,857

1,787

1,760

1,754

1,726

1,723

1,681

1,673

1,669

1,636

1,593

1,590

1,534

1,495

1,474

1,457

1,426
17

36

57

12

31

100

67

97

53

16

47

14

2

15

6

7

27

80

76

23

1

7
16

9

9

9

5

6

7

10

8

8
7

18

3

10

3

8
200

011

111

201

002

210

102

211

112

301

020

212

311

220

103

302

221

113

312

410

222

321

303

004

031

313

131

501

230

421

114

231

132

502

323

024

124

521

$610-133$

CuK $\alpha=1,5418$ \&, Filtro Ni

20 horas $\quad 30 \mathrm{kV} \quad 15 \mathrm{~mA}$

Câmara de Gandolfi $114,6 \mathrm{~mm} \emptyset$

Ficha ASTM NN: 5-0448

(monocristal)

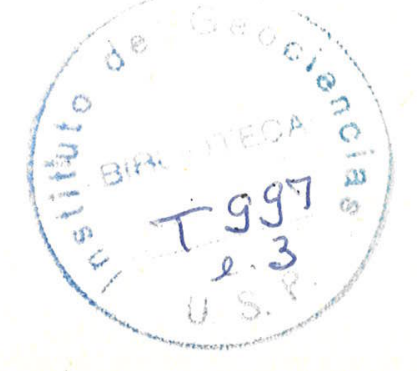


caróide. A Tabela 9 fornece os resultados obtidos por difra tometria de raios $x$.

Paragênese - A barita ocorre frequentemen te como mineral de ganga em veios metaliferos hidrotermais ou formando concreções em rochas sedimentares (Deer, 1962). Pode se associar aos minerais: galena, esfalerita, quartzo, calcita, dolomita, siderita e fluorita. Pode ser formadora de veios que cortam granicos e a origem magmática foi sugeri da para os jazimentos com forma de vesiculas em riólito pốr firo (Frank et al., em Deer, 1962).

Em jazimento de veios hidrotermais ocorre associada a fluorita ocupando as zonas externas de baixa tem peratura enquanto que a fluorita se dispöe nas regiões mais centrais dos veios. Ainda em forma de veios pode ser o pro duto residual de intemperismo de calcärios.

A barita pode ser encontrada em calcārios, arenitos, folhelhos e argilitos. Associada as depósitos de magnetita e hematita em Namaqualand, Africa do Sul, é consi derada como produto de substituição metassomática de quartzí to (Mathias, 1940, em Deer, 1962).

Em relação à barita do Ribeirão do Perau poderia ser aventada a origem residual de intemperismo de calcärios para os blocos rolados de superficie. os veios de barita com quartzo e galena devem estar relacionados a origem hidrotermal de baixa temperatura.

\section{Minerais secundários}

calcocita

Na jazida do Ribeirão do Perau, a calcoci ta ocorre circundando cristais de calcopirita disseminados em quartzito (Fotos 69 e 70), em grãos microscöpicos que dão ao conjunto um aspecto semelhante a textura zonal. Em dia clasamentos existentes no contato de rochas carbonáticas com quartzicos, hä ocorrēncias de massas macroscöpicas de calco cita em associação com covelita, malaquita, material limoni 

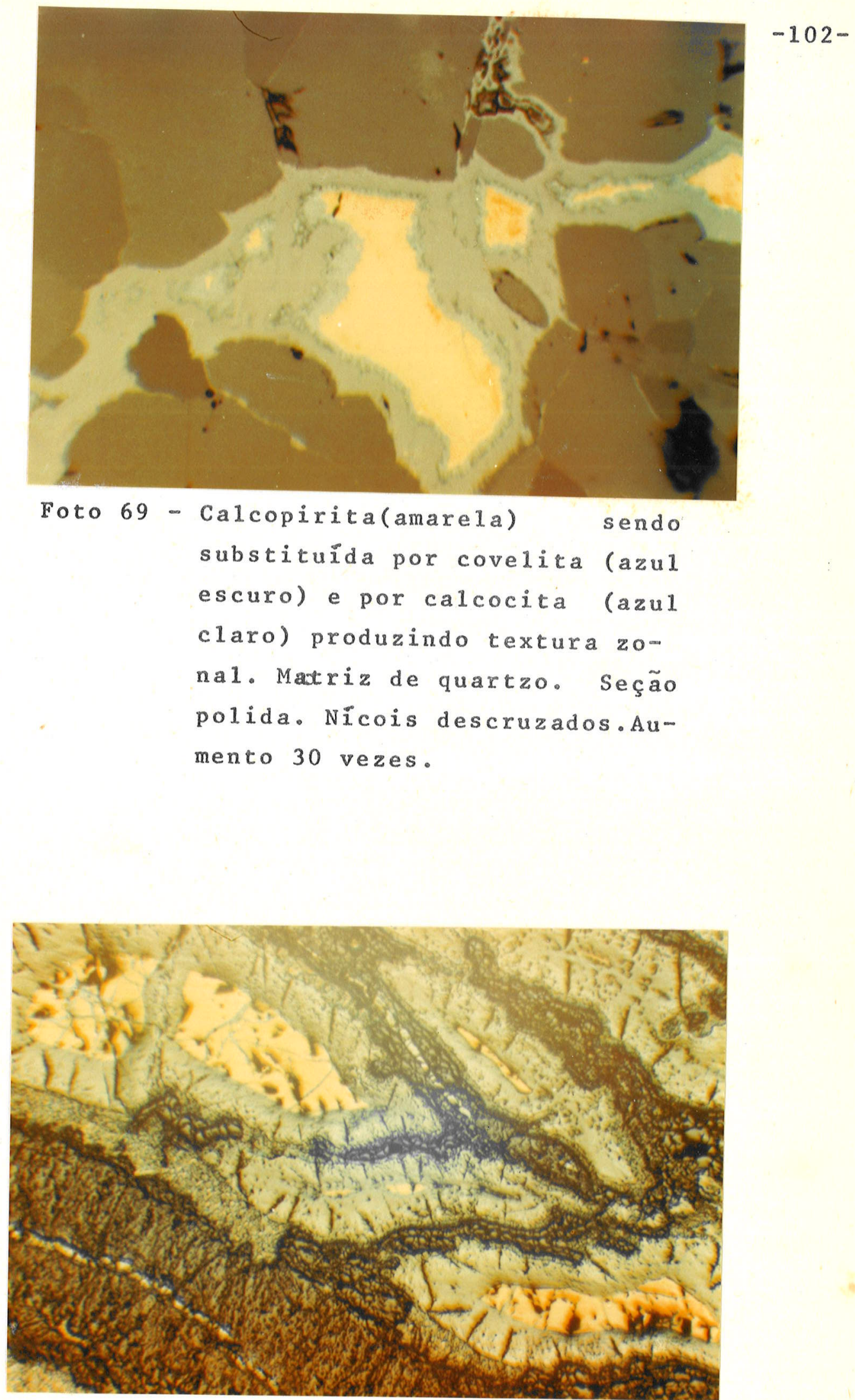

Foto 70 - Textura zonal consistindo de bandas de calcocita (cinza cla ro) e material limonitico (mar rom) resultado da substituição progressiva de calcopirita(ama rela). Seção polida.Nicois descruzados.Aumento 30 vezes. 
tico e quartzo. Os cristais dessa forma de jazimento,preen chendo fraturas, são um tanto raros e quando ocorrem, formam agregados cristalinos cujos cristais são percebidos micros copicamente.

Propriedades fisicas - Em mineral opa co: de brilho metälico pouco intenso, de côr preto cinzento. Sob 1 uz refletida apresenta fraca anisotropia, refletivida de mëdia e côr branca. A Tabela 10 contēm o diagrama de dí fração de raios $X$ que permite distinguir calcocita de dige nita, cujos difratogramas mostram espaçamentos interplana res com valores semelhantes.

Microsonda eletrônica - Para estudo em microsonda eletronica foi escolhido parte de um veio centi métrico de calcocita em matriz de quartzo. Focalizou-se um campo na borda desse mineral, para observar contraste e re 1ação com outros cristais. A figura 15 mostra a distribui ção dos minerais observados e os elementos químicos neles encontrados. A foto 71 mostra a imggem eletrônica em campo de $400 \times 400 \mu \mathrm{m}$.

o cobre (Foto 72) exibe maior concentração na calcocita e menor espalhamento na malaquita. 0 fer ro (Foto 73) estä contido no material limonitico que circun da o lado direito do campo. o silicio (Foto 74) se concen tra em duas manchas inclusas na calcocita e se sobrepóe ao ferro em uma ärea bastante restrita. A foto 75 fornece a imagem topogräica que mostra com maior clareza os contor nos de calcocita, malaquita e limonita. o aluminio (Foto 76) se distribui homogeneamente por todos minerais em quan tidade irrisöria, presença que è justificada porque a meta lização da amostra foi executada com esse elemento. o per fil de bärio localiza um pequeno cristal de barita no canto inferior diréto da foto 77. o perfil de enxofre, em campo reduzido. $200 \times 200 \mathrm{\mu m}$ (Foto 78) ao longo da calcocita $\left(\mathrm{Cu}_{2} \mathrm{~S}\right)$, se mantēm estävel atè uma queda brusca ao passar so bre um cristal de covelita ( $C u S$ ). A variação do enxofre se comporta exatamente oposta à esperada, porēm, ofato ë explicado pela maior absorção dos elétrons retroespalhados 


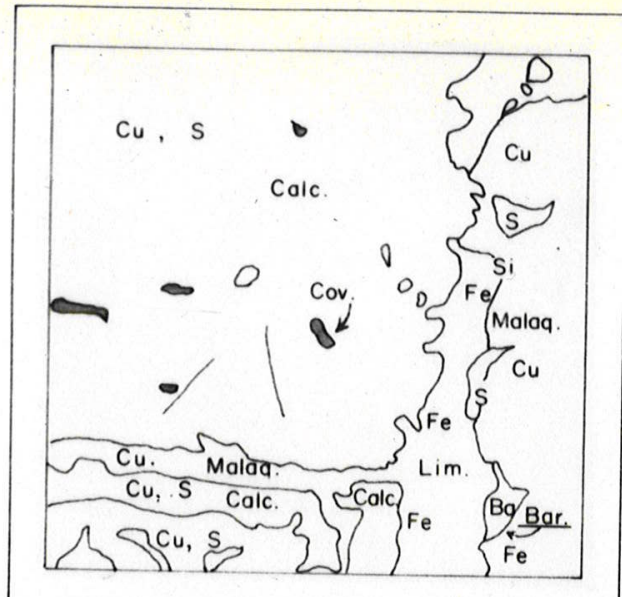

Fig.15-Distribuição dos elementos dos minerais da foto 71. Cov. =Cove 1 it a C a $1 \mathrm{c}=\mathrm{Ca} 1 \mathrm{coc}$ ita; $\mathrm{Bar}=\mathrm{Ba}$ rita; Malaq $=$ Malaquita; Lim $=$ Limon $\bar{i}$ t a

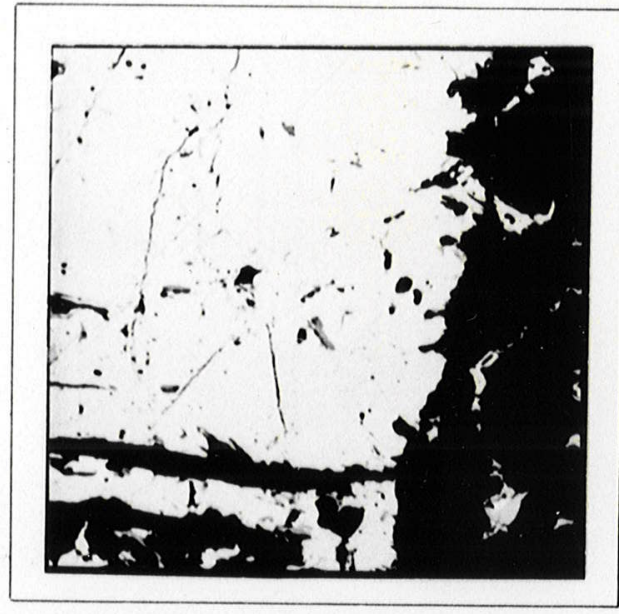

Foto 71 - Imagem eletrônica de calcocita. E. retroespalha dos. $400 \times 400 \mu \mathrm{m}$.

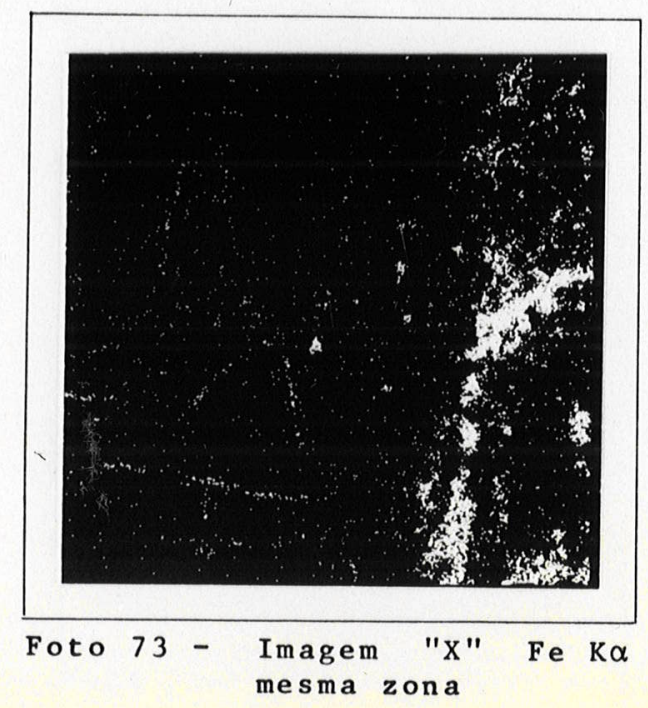

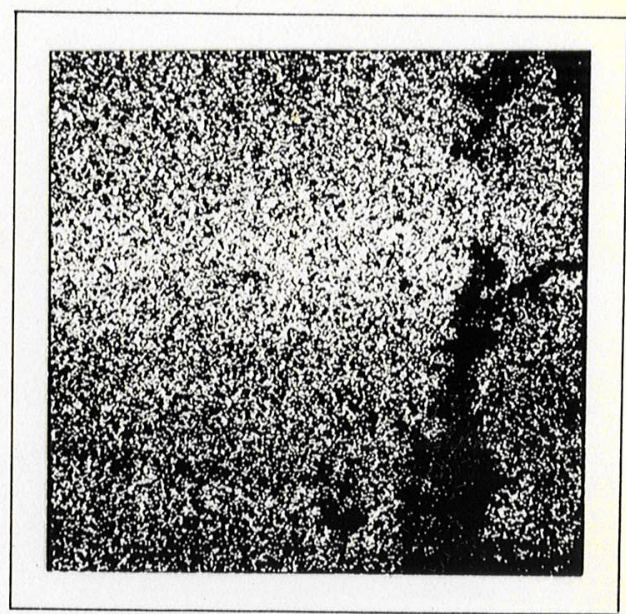

Foto 72 - Imagem "X" Cu K $\alpha$ mesma zona

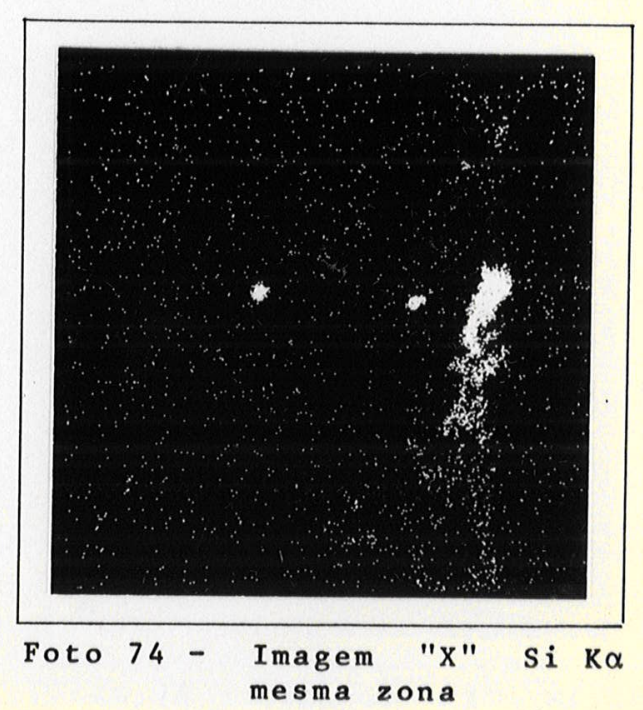




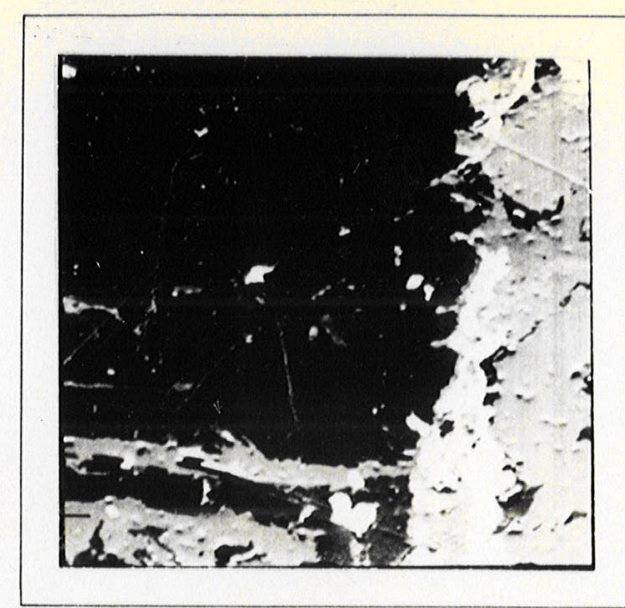

Foto 75 - Imagem eletrônica Topografia. $400 \times 400 \mu \mathrm{m}$.
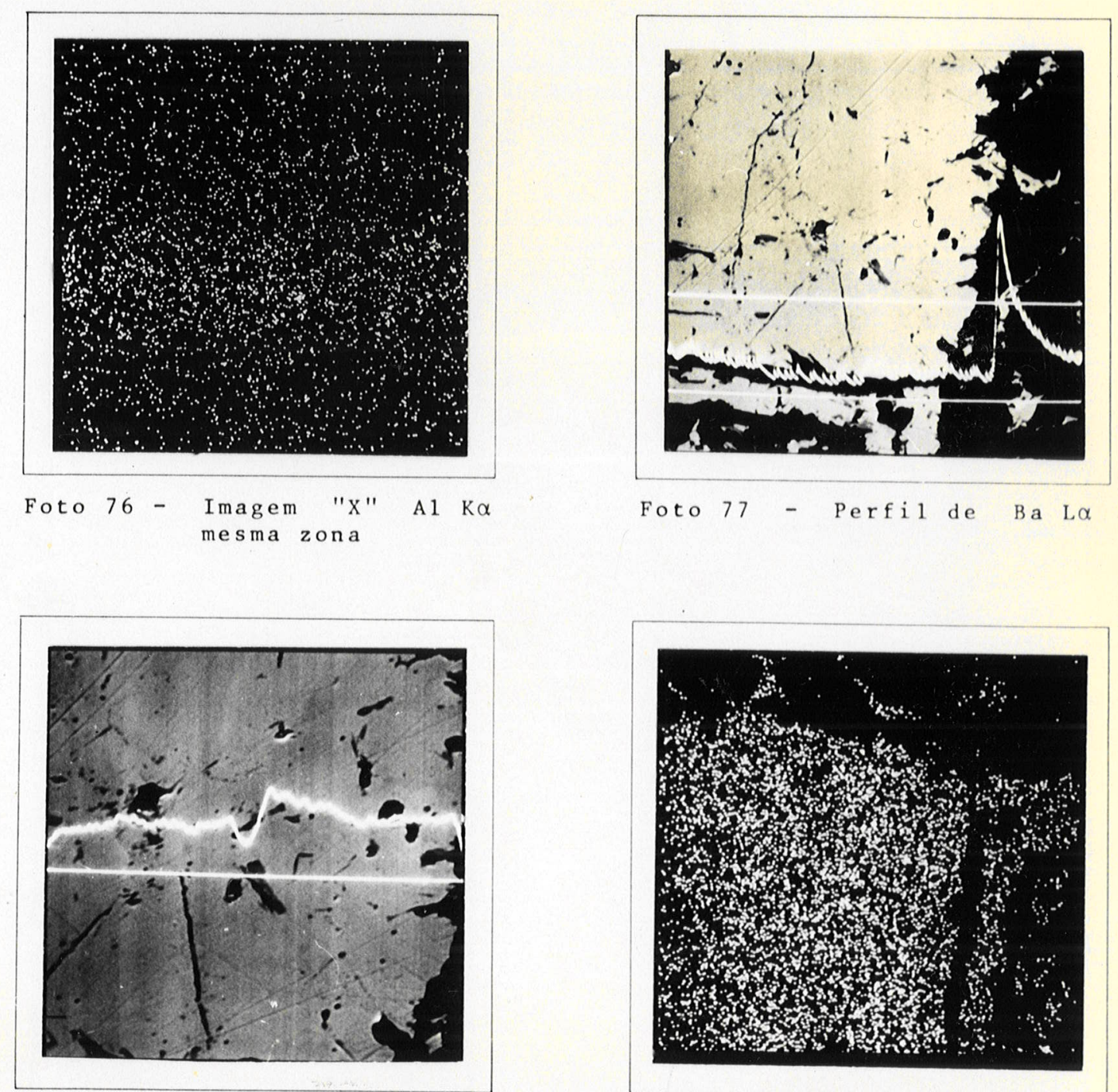

Foto 78 - Perfil de S. 200 x $200 \mu \mathrm{m}$.

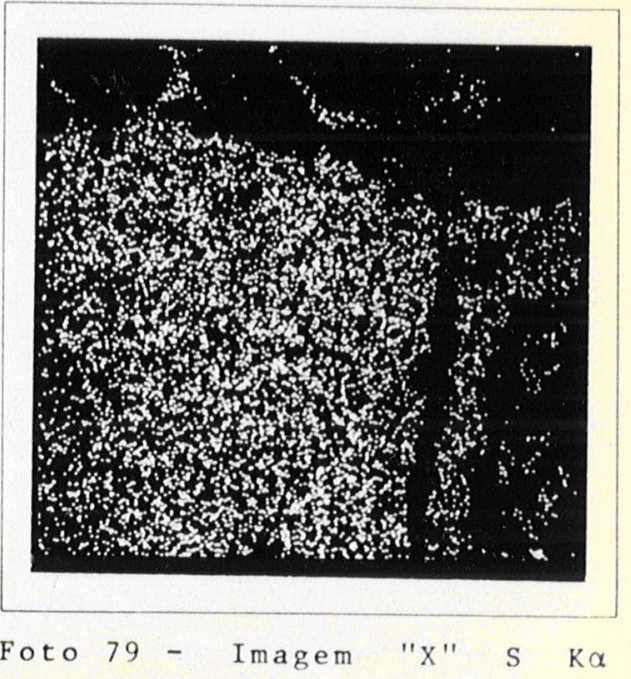


na cavidade da covelita que possui dureza 1,5 em relação à dureza 3,0 da calcocita. As observaçóes do enxofre são com pletadas pela imagem da foto 79. O călcio marca sua presen ça em um ponto insignificante, incluso na covelita. os ele mentos: Mn, $\mathrm{Cr}, \mathrm{Ni}, \mathrm{Zn}, \mathrm{Ti}, \mathrm{Co}, \mathrm{Au}, \mathrm{As}, \mathrm{P}, \mathrm{Sn}, \mathrm{Sb}, \mathrm{Na}, \mathrm{K}$, $\mathrm{Ag}, \mathrm{Sr}, \mathrm{Pd}, \mathrm{Pt}, \mathrm{Bi}, \mathrm{Ge}$ e Se foram pesquisados, porëm não se encontram presentes na regiäo focalizada.

o campo em estudo mostra que a calcocita estä sendo substituida internamente por covelita e externamente por malaquita e material limonítico. Hä também asso ciação com quartzo e barita.

Ao microscópio essa mesma seção polida mostra, sob luz refletida, relíquias de pirita de forma eliptica sendo substituida por covelita. A calcopirita, se anteriormente presinte, deve ter sido substituida totalmen te pela calcocita, pois quando esta invade região onde cal copirita e pirita estão associadas aquela $\vec{e}$ a primeira a ser transformada, pois essa substituição envolve, entre ou tros fatores, a redução de volume, fator seletivo de substi tuição (Edwards, 1954). Ainda na mesma associação mineraló gica podem ser encontradas formas (reliquias) pseudomorfas de galena com facetas triangulares de clivagem jä substitui das por limonita e quartzo.

Paragênese - A presença de calcocitta-covelita em quantidade nos depósitos de cobre, indicam sulfe tos de enriquecimento supërgeno. Estudos realizados ém Kennecott, Alaska; Butte, Montana e Northern Rodhesian, mos tram que a calcocita maciça e covelita associadas são de origem provavelmente hipögena, porque ambas constituem in tercrescimentos semelhantes aos obtidos por soluções sóli das desses dois minerais quando lentamente esfriados (Edwards, 1.954).

Posnjak et a1., (1915) demonstram que a solubilidade da covelita em calcocita é ao redor de $100^{\circ} \mathrm{C}$. Posteriormente Bateman (1952) determinou que $30 \%$ de coveli ta se disoolve em calcocita acima de $75^{\circ} \mathrm{C}$ resultando solu ção sölida, porém a calcocita não se dissolve em covelita.. 


$$
\begin{array}{rc}
\text { Tabela } & 10 \\
\text { Diagrama de Calcocita }
\end{array}
$$

Rib. Perau

d ( $($ )

3,38

3,20

3,11

3,05

2,90

2,82

2,71

2,66

2,57

2,52

2,48

2,39

1,95

1,87

1,69

1,64

1,54

1, 51
$\mathrm{I} / \mathrm{I}_{\mathrm{o}}$

30

5

5

5

5

5

5

5

5

5

5

70

100

100

20

10

5

5
Ref.M.A. Peacock (Mëxico)

d ( $\AA)$

3,93

3,77

3,60

3,39

3,31

3,21

3,05

2,97

2,88

2,84

2,73

2,67

2,58

2,54

2,47

2,40

2,34

2,22

2,14

2,06

1,969

1,937

1,870

1,787

1,695

1,645

1,588

1,514

1,471

1,351

1,278

1,119

1,074

0,974

$\operatorname{CuK} \alpha=1,5418 \AA$, Filtro Ni

24 horas $\quad 30 \mathrm{kV} \quad 15 \mathrm{~mA}$

Filme n: 3772

Câmara de Gandolfi $114,6 \mathrm{~mm} \emptyset$

(monocristal)
$\mathrm{I} / \mathrm{I}_{\mathrm{O}} \quad$ hkI

$\begin{array}{cc}5 & 300 \\ 10 & 133-320-062 \\ 10 & 260 \\ 30 & 340-080 \\ 10 & 233-153 \\ 20 & 180\end{array}$

20

5

20

5

10

10

5

10

20

70

5

20

10

10

80

5

100

5

40

20

5

20

5

10

30

10

10

10

Ficha ASTM NO 9328
$342-082$

400

420

191

$362-440-402$

282

380

304

460

$372-344-084$

$520-274$

006

0.12 .2

275

600

$580-504$

(3122-01.24-346-086)

366-395-406

604-0160

$682-644-0162$

0126

$684-3162-0164$

3126 
Essa solução sólida, se esfriada lentamente, se demistura ao redor de $75^{\circ} \mathrm{C}$ com o crescimento de lâminas de covelita orien tados segundo plano $\{111\}$ da calcocita.

A calcocita estävel a baixa temperatura ē ortorrōmbica e o aquecimento a $91^{\circ} \mathrm{C}$ a transforma na polimor fa cübica. Com o resfriamento hă reversão, permanecendo tra ços de clivagem cūbica. Buerguer (1941), determinou o ponto de inversão da calcocita ortorrōmbica para a polimorfa hexa gonal a $105^{\circ} \mathrm{C}$. A estrutura cübica existe, mas se forma ao redor de $435^{\circ} \mathrm{C}$ (Roseboom, 1966).

Segundo Ramdohr (1969) a calcocita pode se originar de soluçōes hipógenas abaixo de $103^{\circ} \mathrm{C}$; de soluções supérgenas independentemente e de soluções supērgenas dependentes, isto é, como uma cimentação sobre outros sulfe tos.

Na calcocita da jazida em estudo não

ram observados intercrescimentos provocados por soluçöes sö lidas e a quantidade desse mineral nas ocorrências pesquisa das é insignificante em relação à calcopirita e pirita. os exames roentgenográficos e as propriedades opticas indicam forma ortorrômbica, sendo, provavelmente, originada por enri quecimento supérgeno em temperaturas inferiores a $75^{\circ} \mathrm{C}$.

covelita

A covelita ocorre como resultado da oxida ção de sulfetos primários, ora formando textura de borda nos cristais de calcopirita, ora preenchendo fraturas de calcoci ta (Foto 80). As massas de minêrio oxidado que contēm cove lita apresentam aspecto heterogêneo com coloração azul escu ro, de alta densidade, formando associação mineralögica com posta de pirita, calcopirita, covelita, calcocita, quartzo, crisocola, malaquita, azurita e material limonitico.

Propriedades físicas - mineral opaco,de brilho submetälico, de côx cinza escuro. Sob luz refletida apresenta baixa dureza de polimento, refletividade média e côr azul escuro azul claro. E caracterizada pelo intenso 
pleocroísmo de reflexão e cores variadas sob efeitos de ni cois cruzados.

A Tabela 11 contēm os diagramas de difração de raios X de covelita e calcopirita, pois não se conseguiu macroscopicamente a separação dessas duas variedades de mi nerais.

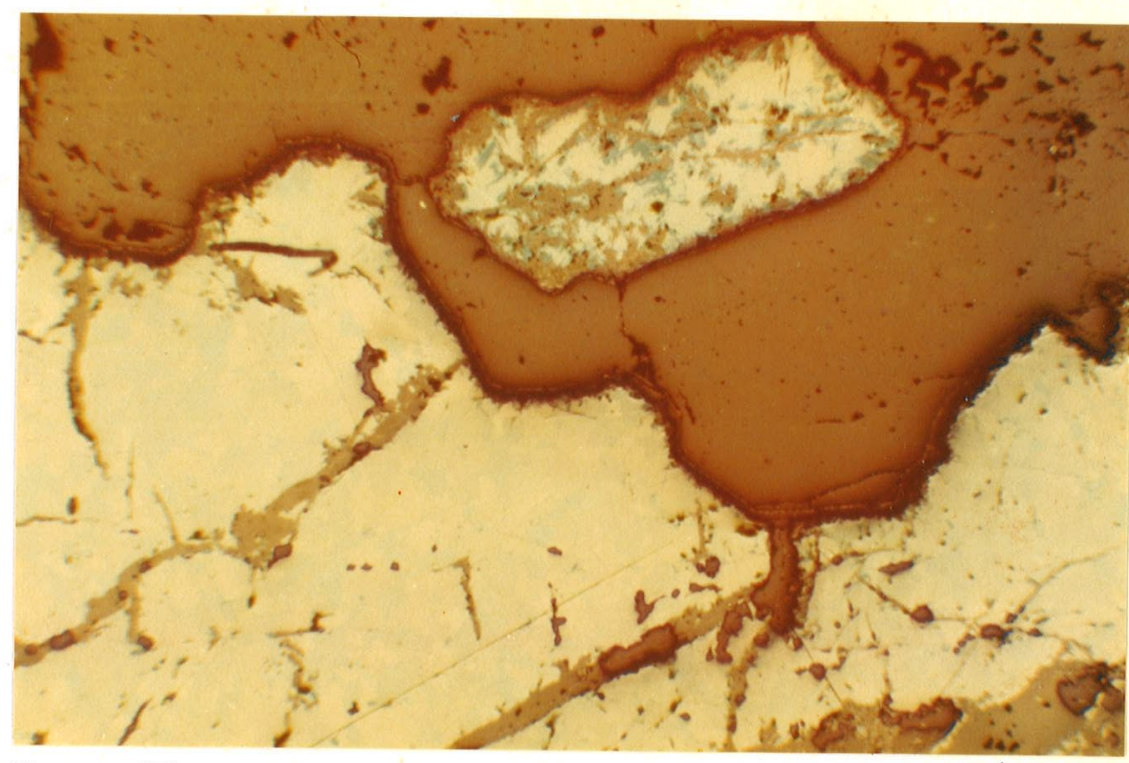

Foto 80 - calcocita (amarela) em matriz de quartzo (marrom escuro), co velita (azul escuro) substituin do calcocita, a partir de fraturas. Seção polida. Nícois des cruzados. Aumento 300 vezes.

Microsonda eletrônica - Para estudo em micro sonda eletrônica foi escolhido um cristal de calcopirita, com textura em borda, causada pela formação de calcocita e covelita. A figura 16 sintetiza e localiza os diversos ele mentos estudados em campo ampliado de $400 \times 400 \mu m$.

A foto 81 é a imagem dos elëtrons retroespa1 hados sobre calcopirita, calcocita, covelita e quartzo. o cobre (Fotos 82 e 88 ) concentra sua distribuição na sequên cia: calcopirita, covelita, calcocita. o ferro (Foto 83) se distribui homogeneamente na calcopirita e calcocita sen do ausente no campo da covelita. O silício (Foto 84) está contido no quartzo e em quantidade insignificante na faixa de calcocita. 


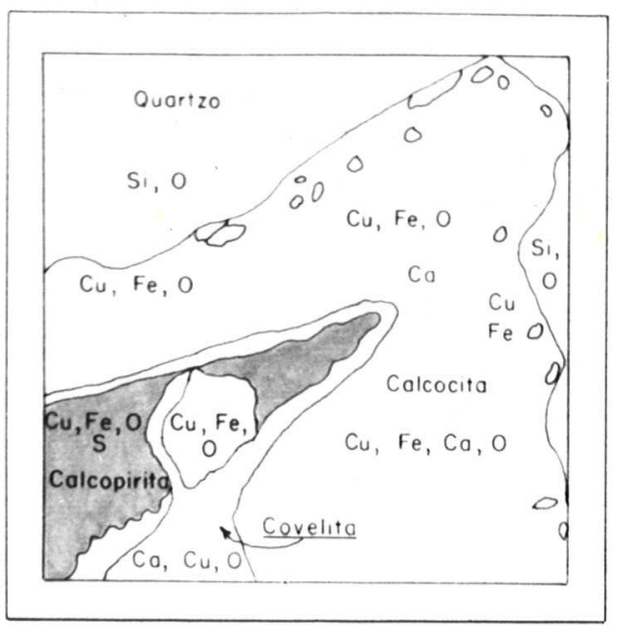

Fig.16-Distribuição dos elemen tos em calcopirita, covelita e quartzo, respectivos às fotos 81 a 89

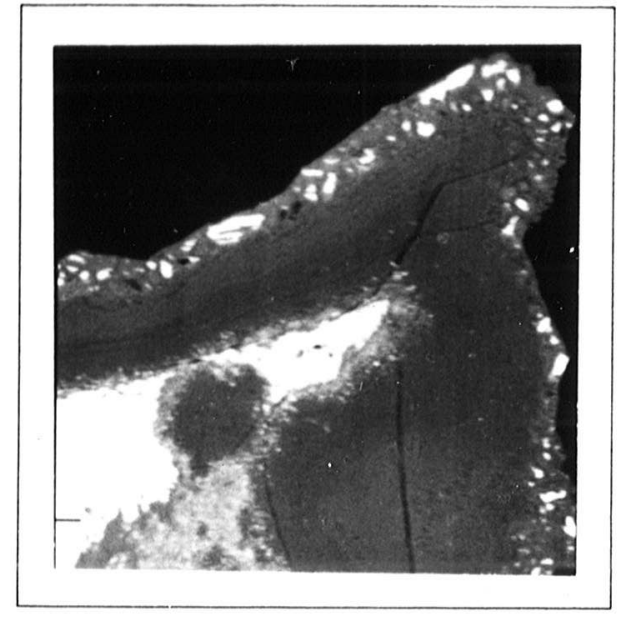

Foto 81 - Imagem eletrônica de calcopirita(branca)calcocita (cinza escura) e covelita (cin za clara,em matriz de quartzo).

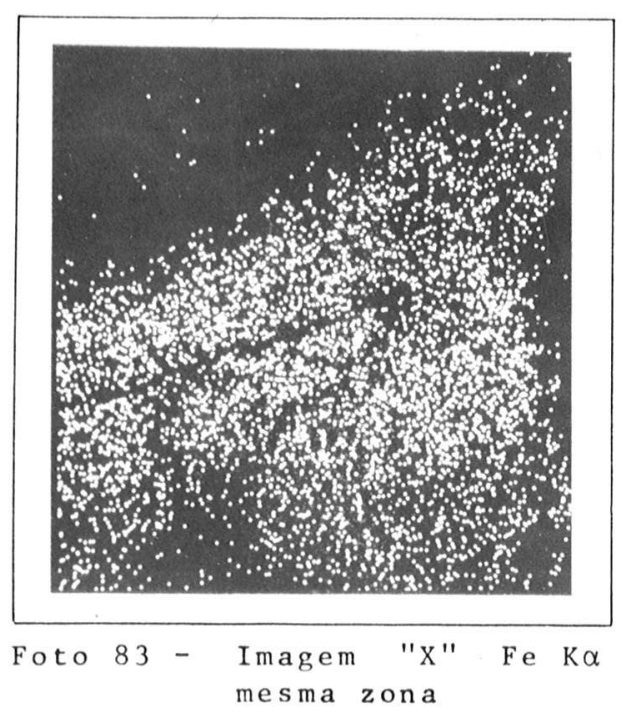

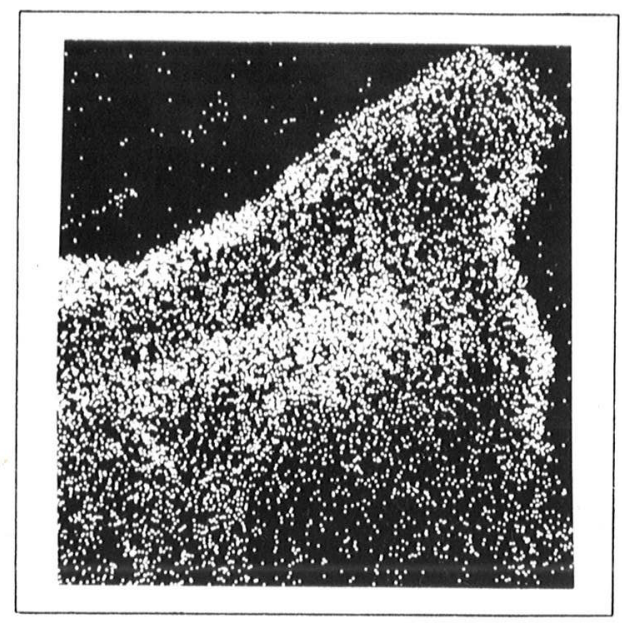

Foto 82 - Imagem "X" Cu K mesma zona. $400 \times 400 \mu \mathrm{m}$.

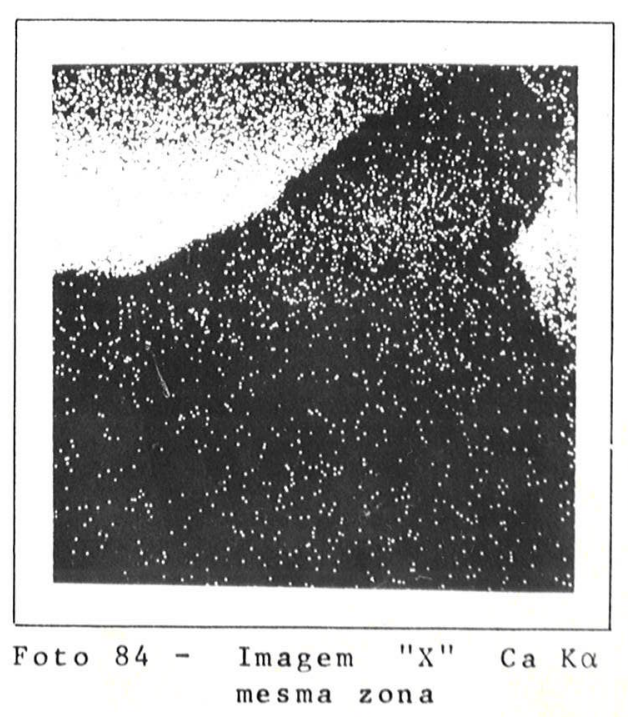




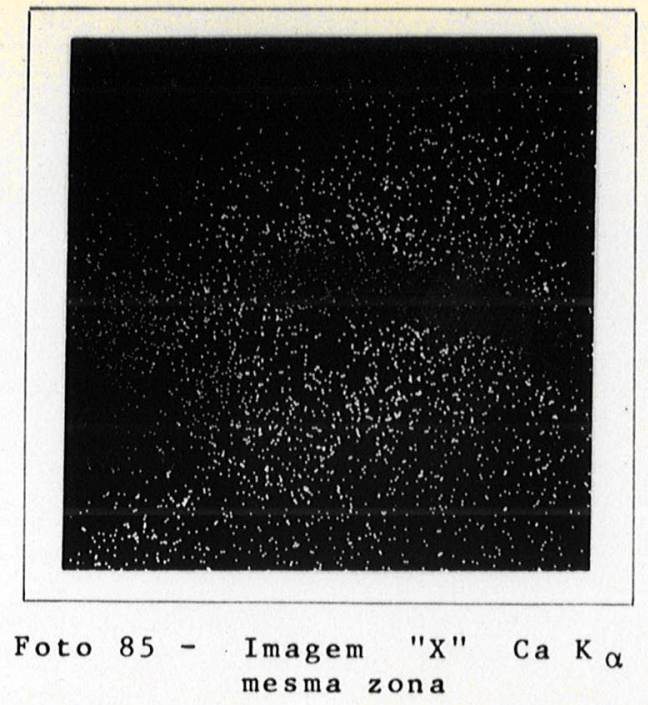

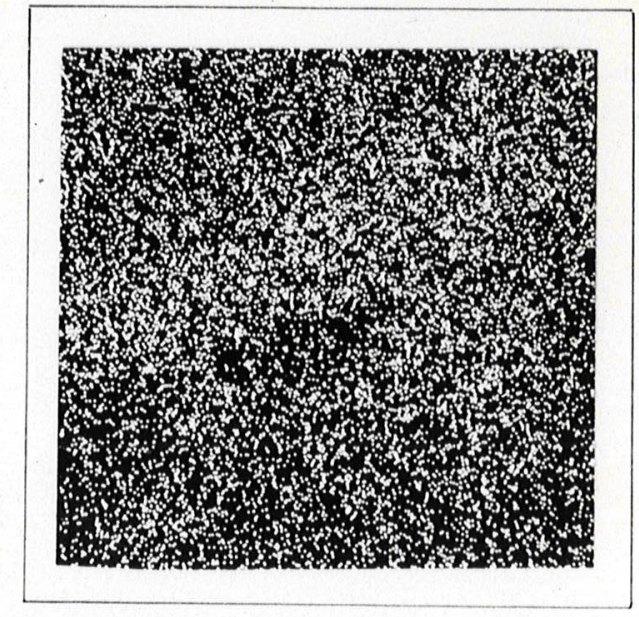

Foto 86 - Imagem "X" $0 \quad \mathrm{~K}_{\alpha}$ mesma zona

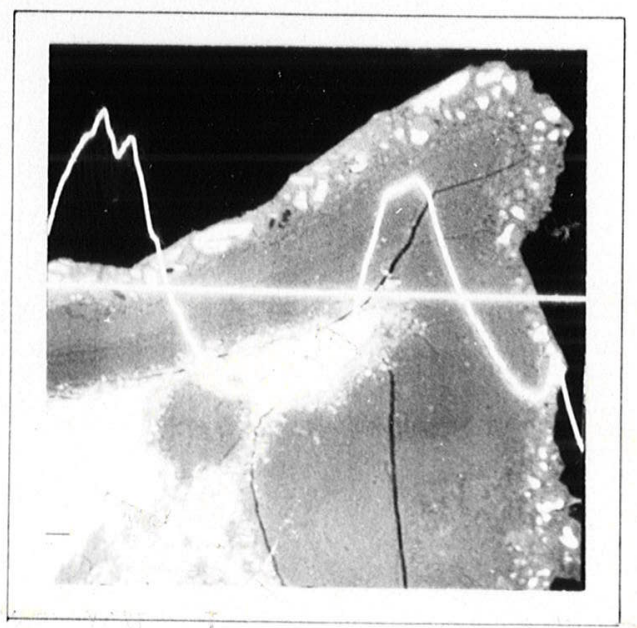

Foto 88 - Perfil de concentra ção de $\mathrm{Cu} \mathrm{Ka}$

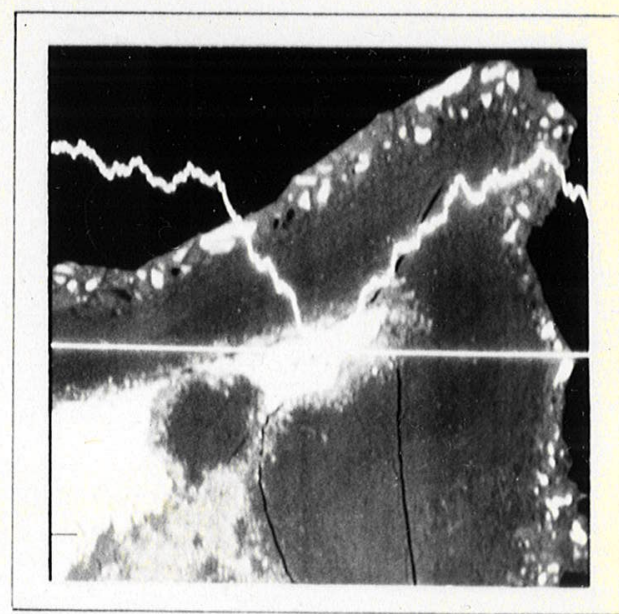

Foto 87 - Perfil de concentra çao de $0 \mathrm{~K} \alpha$

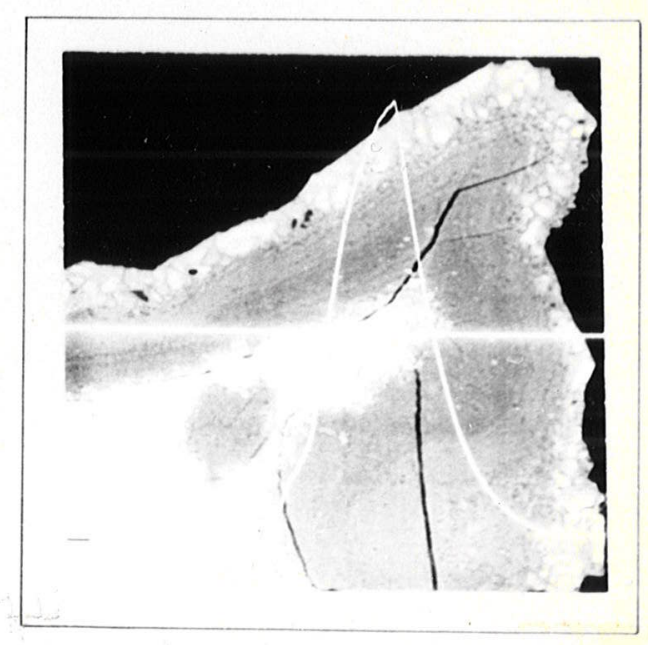

Foto 89 - Perfil de concentração de $S \mathrm{~K} \alpha$ 
Tabe1a 11

Diagramas de Covelita e Calcopirita

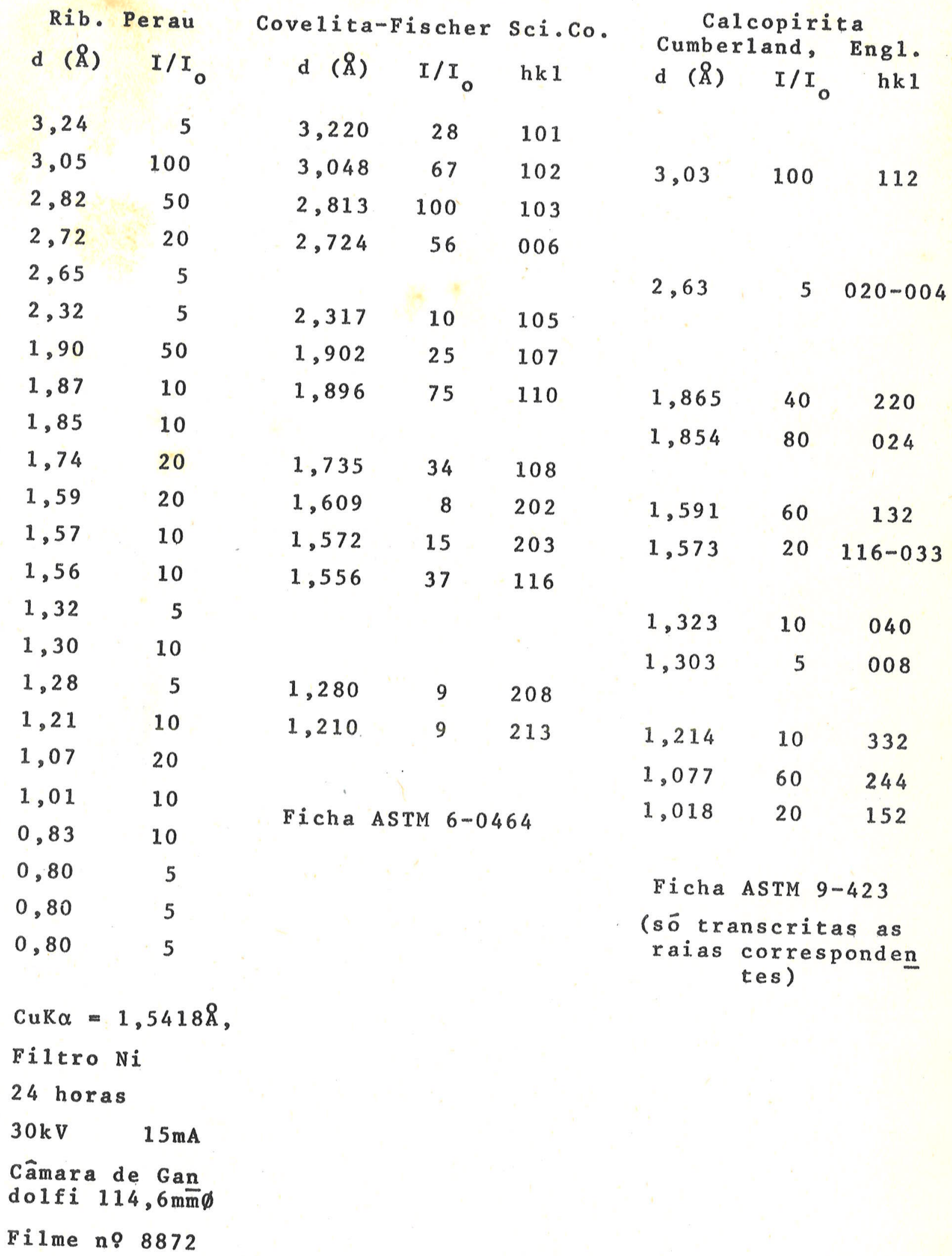


o cálcio (Foto 85) contamina toda região dos minerais de cobre. A quantidade desse elemento evidencia que não deve pertencer à molecula desses minerais e certamente deriva dos metassedimentos calcärios intercalados $\bar{a}$ rocha quartzífera de onde provém a seção polida.

o oxigênio (Foto 86), está presente em ordem crescente nos minerais: calcopirita, covelita, calcocita (Fo to 87) sendo obtidas $564 \mathrm{cont} / \mathrm{s}$ em $10 \mathrm{~s}$, na calcopirita e 1390 cont/s na covelita. O enxofre (foto 89) tem comporta mento oposto ao do oxigênio.

Além dos elementos citados, foram pesquisados mais dezoito elementos sem resultados positivos, ou sejam: $\mathrm{Mn}, \mathrm{Cr}, \mathrm{Co}, \mathrm{Ni}, \mathrm{Zn}, \mathrm{Pb}, \mathrm{Na}, \mathrm{Bi}, \mathrm{As}, \mathrm{Au}, \mathrm{Sb}, \mathrm{Ag}, \mathrm{Hg}, \mathrm{Ir}, \mathrm{Pt}$, A1. Ti e Se.

A covelita se desenvolve no estägio inicial de substituição de calcopirita, porëm pode ocorrer em forma de veios ao longo de fraturas e como bordas de substituição ao redor de cristais isolados de calcopirita (Edwards, 1954). Em estägio mais avançado de oxidação poderä haver formação de cuprita, carbonatos de cälcio, enquanto oferro é precipi tado em forma de material limonitico.

bornita

As incidências de bornita no conjunto de mine rais de cobre da jazida do Ribeirão do Perau são escassas tan to nas pesquisas superficiais onde ocorrem minérios oxidados como em testemunhos de sondagens de até $80 \mathrm{~m}$ de profundidade.

Durante a fase de prospeção de campo até ago ra empreendida, a bornita tem-se mostrado acompanhando a cal copirita, como película de oxidação desse mineral, exibindo sua côr característica vermelho acastanhado iridescente, que posteriormente se transforma em azu1-pavão.

Propriedades físicas - A forma cristalina não e definida, pois se adapta às bordas e fraturas de calcopiri ta (Fotos 90 e 91); $\vec{e}$ opaca de brilho metälico, com fratura 

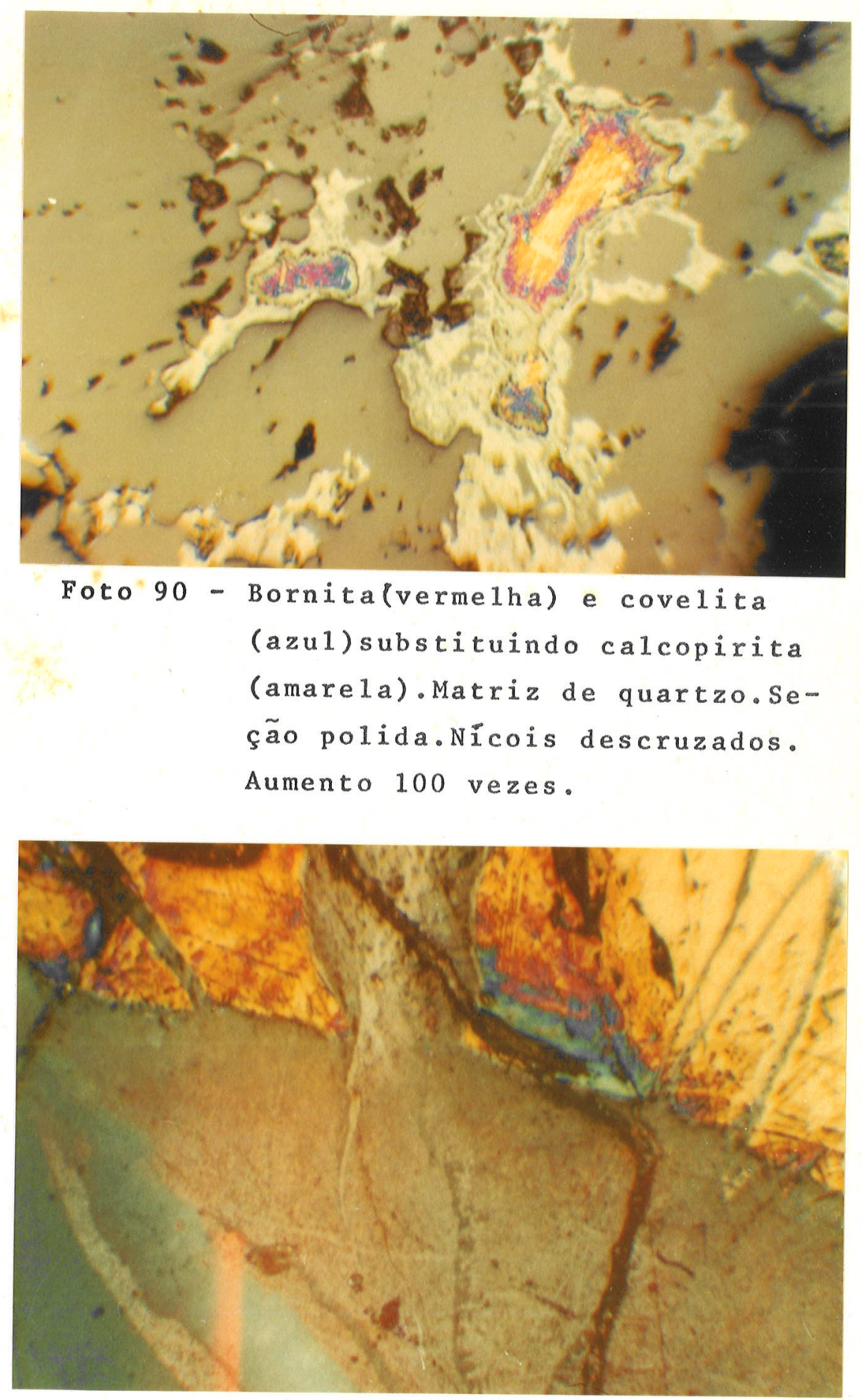

Foto 91 - Bornita(azu1-pavão e verme1ha) substituindo as bordas e fraturas de calcopirita(amarela). Limonita(marrom)e crisocola (azul claro). Seção polida. Iluminação convergente.Nicois à $50^{\circ}$. Aumento 100 vezes. 
irregu $1 a x$.

Os difratogramas de raios $x$, obtidos pelos më todos de Debye-Scherrer e de Gandolfi mostraram sempre espa çamentos interplanares predominantes de calcopirita onde raias de bornita, calcocita e outros minerais de cobre ocor reram subordinadamente. Em 1 uz refletida apresenta isotro pia; média dureza de polimento; refletividade mêdia; cor ro sa claro que por räpida oxidação se transforma em rosa escu ro ou azul.

Por se tratar de um mineral que constitui pe lícula de oxidação de calcopirita, os exemplares obtidos no campo, depois de parte utilizados em difração de raios X, qua se sempre se perderam no pó extraído durante a confecção das seções polidas, de sorte que não foram obtidas amostras sufi cientemente representativas para serem utilizadas em estudo $\bar{a}$ microsonda eletrônica.

Estrutura - Kullerud et al. (1960) mostram duas formas de bornita: cübica com $a=21,94 \pm 0,06$ A e outra ortorrômbica, com cela pseudo tetragonal amb=21,90 $\pm 0,06 \mathrm{~A}$, $c=10,95 \pm 0,03 \mathrm{~A}, j \bar{a}$ descrita por Frueh (1950).

Marimoto e Ku1lerud (1961), em experiências com bornitas sintēticas determinaram três fases cristalinas: a de alta temperatura, cúbica de face centrada, com a $=5,50$ $\pm 0,001 \mathrm{~A}, Z=1$; a de forma metaestävel, cübica, $F \mathrm{~d} 3 \mathrm{~m}$ e Fד3 m com $a=10,94 \pm 0,002 \mathrm{~A}, Z=8$; e a de baixa temperatu$\mathrm{ra}$, tetragona1, $\mathrm{P} \overline{4} 2 \mathrm{c}$, pseudo $\overline{\mathrm{I}} 42 \mathrm{~d}, \mathrm{a}=10,94 \pm 0,02 \mathrm{~A}, \mathrm{c}=21,88$ $\pm 0,004 \mathrm{~A}, \mathrm{Z}$ 16. As temperaturas de transição são $226 \pm 3^{\circ} \mathrm{C}$ e $230 \pm 3^{\circ} \mathrm{C}$.

Fases de equilibrio e soluções sölidas - Yund e Kullerud (1960) estudaram o sistema Cu-Fe-S em uma série de seções isotermais para mostrar as variações das soluções sölidas das diversas fases em função da temperatura. $\mathrm{A} 700^{\circ} \mathrm{C}$ as fases condensadas do sistema são: solução sölida de borni ta, solução sölida de calcopirita, pirita, solução sólida de pirrotita, cobre, ferro e enxofre líquido. A solução sölida de bornita inclui digenita e calcocita. o campo de estabili 
dade da bornita $\vec{e}$ o mesmo jä apresentado por Mervin e Lombard, em 1937. o limite da solução sólida de bornita, de acordo com os värios autores é dificil de ser determinado porque, à temperatura ambiente, sö podem ser delimitadas composições de äreas restritas.

Bornita com menos que $57 \%$ de Cu não pode ser delimitada à temperatura ambiente pois constitui uma solu ção que contēm bornita com lamelas de calcopirita em pa drões típicos de exsolução. A composição de bornita e cal copirita não pode ser precisamente determinada, sendo os vá lores obtidos, membros das respectivas soluções sólidas.

Calcopirita-bornita: De acordo com Schwartz (1931) esses minerais formam extensas soluções sólidas a temperaturas acima de $475^{\circ} \mathrm{C}$. Abaixo dessa temperatura ocor re demistura, cusa textura depende do mineral em excesso. Em esfriamento rápido e em excesso de bornita, hā formação de lamelas de calcopirita nos planos $\{111\}$ da bornita; se a calcopirita é predominante formam-se lamelas de bornita o rientadas $\{111\}$ nos planos de calcopirita. Em esfriamento lento, a solução se difunde para as bordas do grão hospedei ro e este se segrega em forma de grãos livres formando tex tura granular. o mineral "höspede" jā dissolvido adquire forma alongada, estreita, instalando-se junto às bordas ou no contato do grão hospedeiro formando textura de borda.

Paragênese - A bornita tem sido encontrada disseminada em rochas intrusivas bäsicas, em depósitos meta mörficos de contato, em pegmatitos, em vieiros de quartzo e diques monzoniticos. Raramente os cristais são euhedrais. Considerada de origem primäria, porém alguns autores tambēm a consideram de origem secundäria. Geralmente se associa à calcopirita sendo posterior a esta.

Gilbert (1925) mostra que bornita e pirrotita tendem ser mutualmente exclusivos, isto é, um corpo de minério que contẻm um desses minerais, não contẻm o outro.

Parece que bornita, rica em cobre e pobre em ferro, ocorre em depösitos de alta temperatura onde hä ca 
rência de pirita e pirrotita. Nos depósitos onde houve sufi ciente ferro para formar pirita e pirrotita, em geral, todo cobre se concentra na calcopirita, em detrimento à formação de bornita.

cuprita

A cuprita, um dos minerais de abundância se cundāria na jazida de cobre do Ribeirão do Perau, ocorre ém forma de pequenas massas ou filetes, preanchendo fraturas centimétricas existentes no quartzito, no contato com rochas carbonáticas. Eencontrada fazendo parte dos vieiros de mi nério de cobre que se encaixam no quartzito friāvel das gale rias. Os minerais associados são sempre cobre nativo, calcó cita, malaquita, crisocola e quartzo, existindo, em associa ção mais rara, barita, turmalina e pirita.

Propriedades físicas - Apresenta côr vermelho acastanhado, forma irregular, com contornos que adaptam às margens dos minerais ela associados, faltando as formas ca racterísticas $\{111\},\{100\}$ e $\{110\}$. Opticamente ë isötropa, mostrando massas de tonalidades azul claras, (E11ert, 1969) com fraco pleocroísmo. Em seção polida è distinguida sobre tudo pelas reflexões internas vermelhas sob nicois cruzados. Não foram observadas clivagens, porëm as fraturas revelam a1 teração para malaquita e crisocola.

$$
\text { Microsonda eletrônica - A figura } 17 \text { e a foto }
$$

92 mostram a distribuiçäo dos elementos encontrados em cris tais de cuprita envolvidos por calcocita, associados a quart 20 .

o cobre (Foto 93) está concentrado na cuprita e é abundante tambēm na calcocita. o silício (Foto 94) evi dencia a presença de quartzo, tornando-se raro no restante do campo estudado $(100 \times 100 \mu \mathrm{m})$. o ferro (Foto 95) possui larga distribuição na calcocita e é pouco frequente na cupri ta, sendo ausente no quartzo. 0 chumbo, segundo o perfil da foto 96, se concentra na cuprita e tanto a calcocita externa como a interna à cuprita praticamente não apresentam chumbo. 


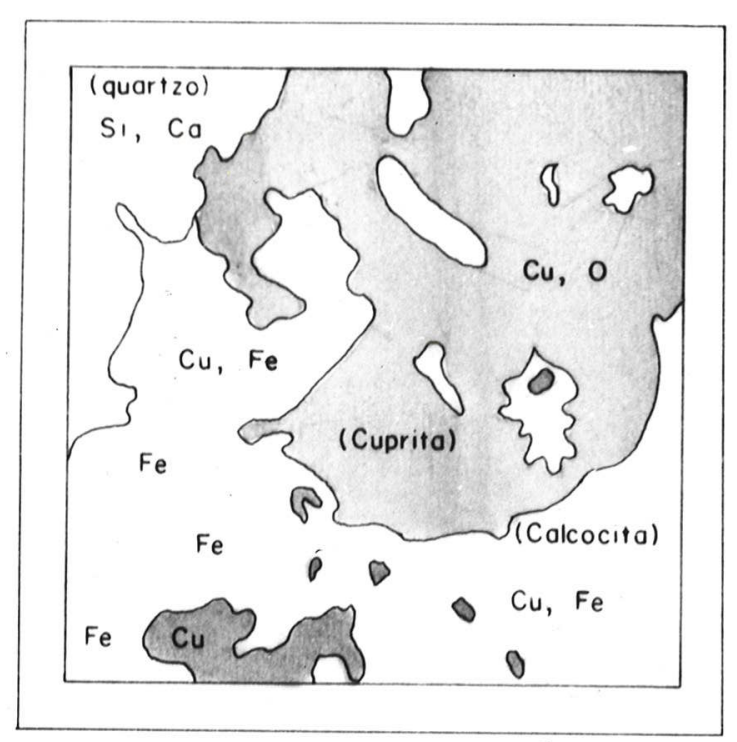

Fig. 17 - Distribuição dos elementos em Cuprita, Calcocita e Quartzo

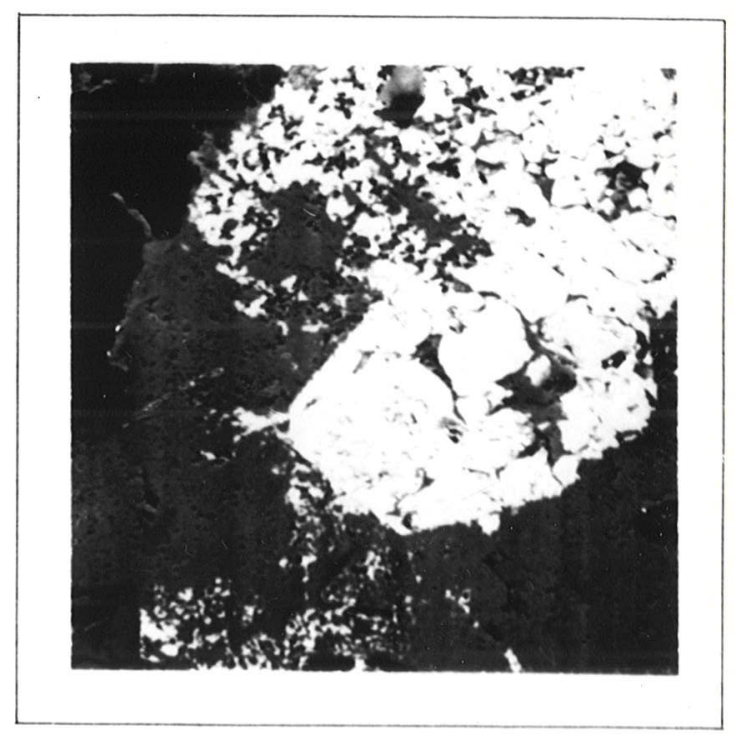

Foto 92 - Imagem eletrônica de cuprita (branca) e calcocita (cinza escura) e quartzo (preto). E. retroespalhados. $100 \times 100 \mu \mathrm{m}$.

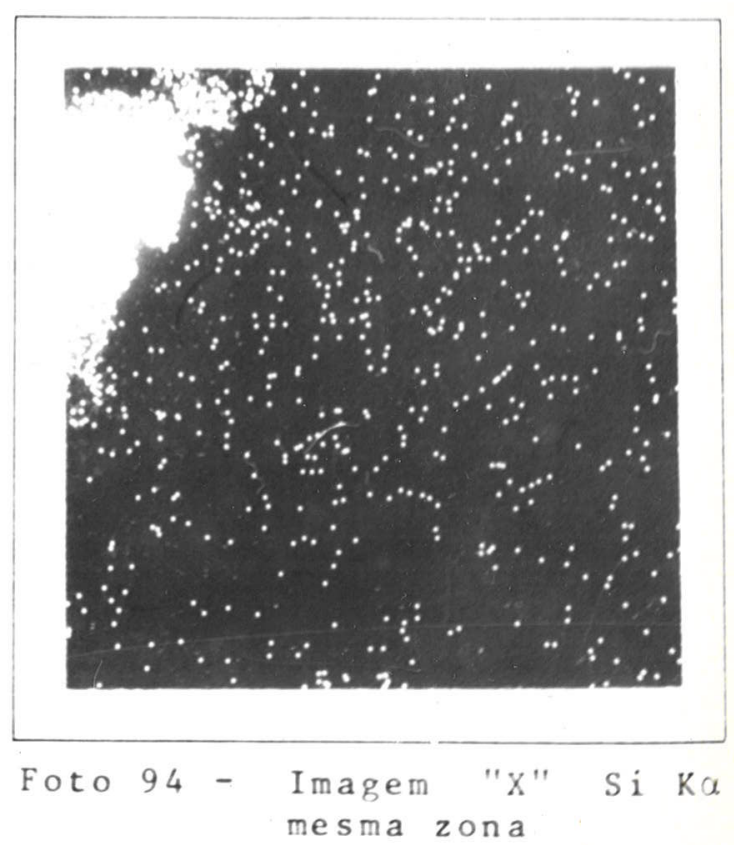



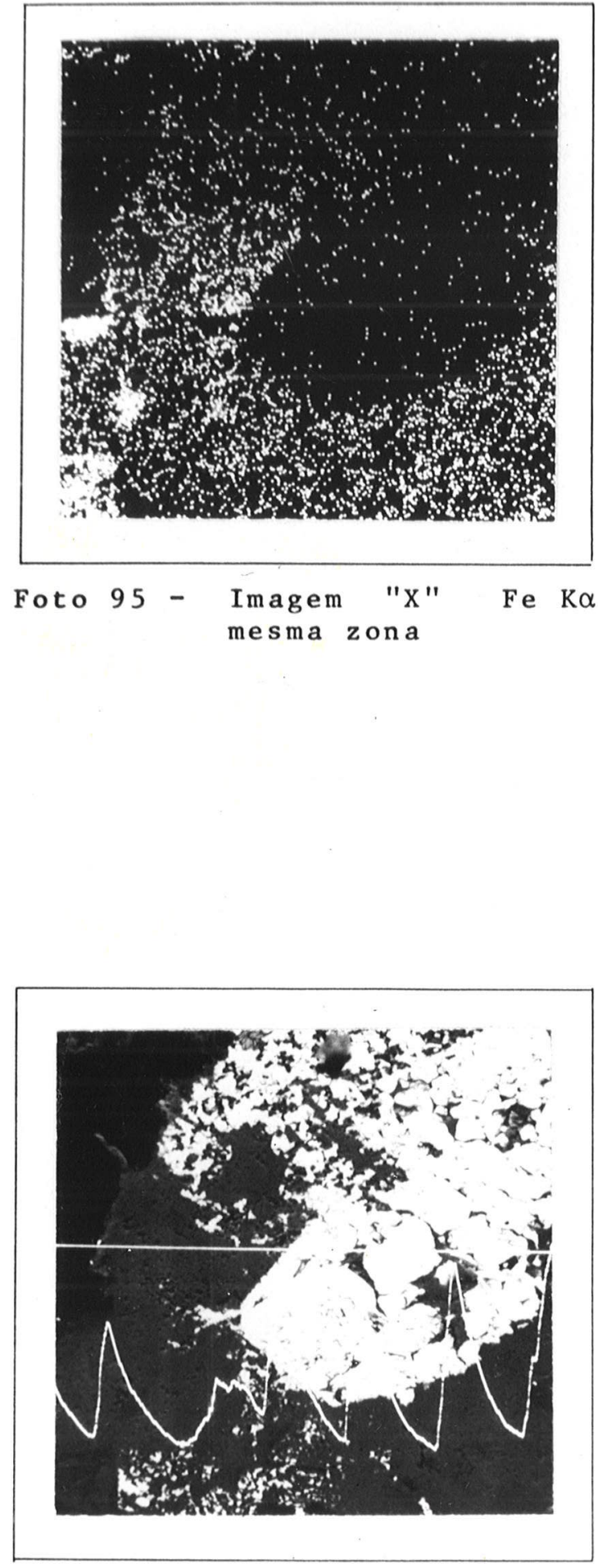

Foto 97 - Perfil de concentração de $\mathrm{S} K \alpha$

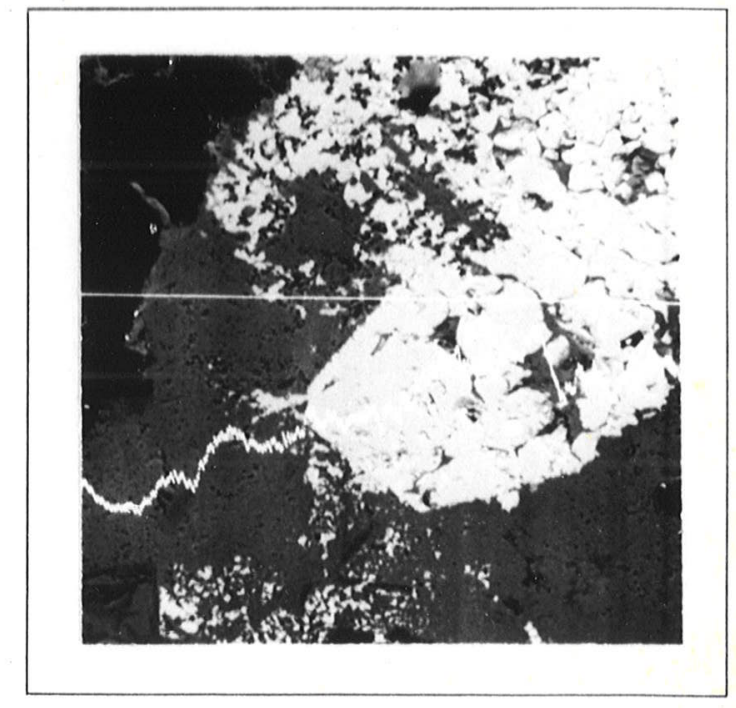

Foto 96 - Perfil de concentração de $\mathrm{Pb} L \alpha$

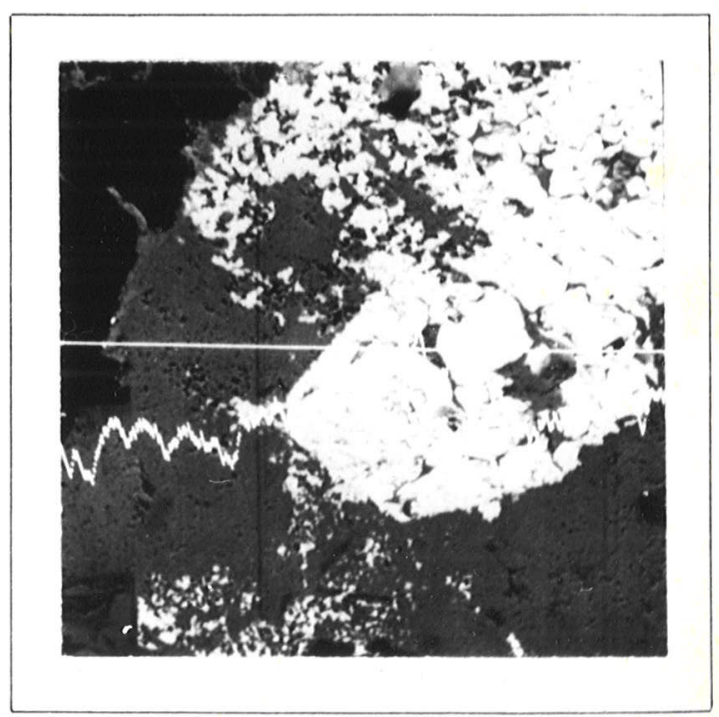

Foto 98 - Perfil de concentração de Au $\mathrm{L} \alpha$ 
o perfil de enxofre (Foto 97), com características elevações e depressões evidencia concentrações esparsas sobre as mas sas de calcocita internas à cuprita.

o ouro (Foto 98) se concentra na cuprita,atin gindo minimos nas massas de calcocita internas ao cobre metá lico. 0 arsênico teve suspeitada sua presença mas quando a concentração é inferior a $100 \mathrm{ppm}$ sua $x$ adiação pode ser absor vida pelo chumbo ou mesmo pela camada de alumínio da metaliza ção da amostra. o cálcio ocorre em pequena proporção só na região do quartzo e o oxigênio foi decectado na cuprita.Foram negativas as contagens para $\mathrm{Zn}, \mathrm{Ni}, \mathrm{Mn}, \mathrm{Cr}, \mathrm{Co}, \mathrm{Na}, \mathrm{Ag}, \mathrm{Bi}$, Ir, e Pt.

Paragênese - A cuprita ë geralmente produto de alteração de sulfetos de cobre. Substitui frequentemente cal cocita e cobre metälico e pode conter remanescências desses minerais, alterando-se frequentemente em malaquita. Pode in cluir diminutas "ampolas" de cobre metälico que se originam simultaneamente e que não devem ser devidas a substituição (Uytenbogaardt, 1951). A oxidação de calcopirita, em primei ro estägio produz covelita, alterando-se posteriormente para cuprita ou carbonatos de cobre e material limonitico. A subs tituição completa de calcopirita é caracterizada pela forma ção de cuprita e material limonitico (Edwards, 1954).

$$
\text { Associa-se com goethita, tenorita, calcocita, }
$$
bornita, covelita, calcopirita, pirita e marcasita (Winchell, 1967). A ocorrência de enxofre, em pontos concentrados na cuprita do Ribeirão do Perau e na calcocita inclusa ou externa à cuprita, e mais, a abundāncia de ferro na cuprita pare cem conduzir à inferência que estes elementos devem ter tido como fonte original a calcopirita. A associação com malaqui ta, crisocola e material limonitico revelam sem düvida uma fa se de oxidação. Por outro lado o ouro e chumbo da cuprita não devem provir da calcopirita pois estes elementos não foram de tectados neste mineral, em anāises à microsonda eletrônica, mas tão somente ocorrem na pirita. Parece correto supor que a pirita tambëm tenha sofrido oxidação e liberado ouro e chum bo, juntamentecom sulfato érrico. 
cobre nativo

As ocorrências de cobre nativo na jazida do Ribeirão do Perau se relacionam à parte superior das camadas de quartzitos, na zona de contato com as intercalaçós de ro chas carbonäticas. A forma de jazimento, até agora encontra da é constituida por filetes de cuprita, com centimetros de largura e de comprimento, não contínuos, adelgaçandorse re pentinamente, encaixados nas fraturas dos quartzitos e dis cordantes com o acamamento dessas rochas. A composição mine ralógica desses filetes inclui cuprita, cobre nativo, calcoci ta, malaquita, crisocola, quartzo, turmalina, alguma pirita e raros cristais microscopicos de barita.

Propriedades fisicas - Os cristais se apresen tam disseminados em matriz de cuprita (Tabela 12) sem orien tação preferencial, com forma anedral, às vezes exibindo con tornos retos (Fotos 99 e 100). A côr $\vec{e}$ vermelha intensa; o häbito e granular, maciço, com indivíduos variando de 1 a 4 mm, em sua maior dimensão. Em seção polida os cristais exi bem refletividade extremamente elevada, cor avermelhada, du reza média de polimento, não sendo observada clivagem. Sob nícois cruzados há total isotropia.

Microsonda eletrônica - A figura 18 e foto 102 mostram o aspecto e textura dos cristais de cobre nativo, en voltos por cuprita, estudados em campo de $400 \times 400 \mu \mathrm{m}$.

o elemento cobre (Foto 103) se concentra prin cipalmente no cobre nativo e na cuprita. o oxigênio (Fotos 104 e 106), obviamente se distribui predominantemente na cupr $\underline{i}$ ta sendo que sua incidência no cobre nativo, permite inferir que este mineral se encontra em fase de oxidação.

0 ouro (Foto 105) em imagem de perfil revela maior preferência para se instalar no cobre metálico sendo que sua presença tambẻm è marcada na cuprita. Não hä aumen to de concentração desse elemento nas bordas do mineral có bre nativo e a falta de flutuação sugere que não hã zoneamen to ciclico. 


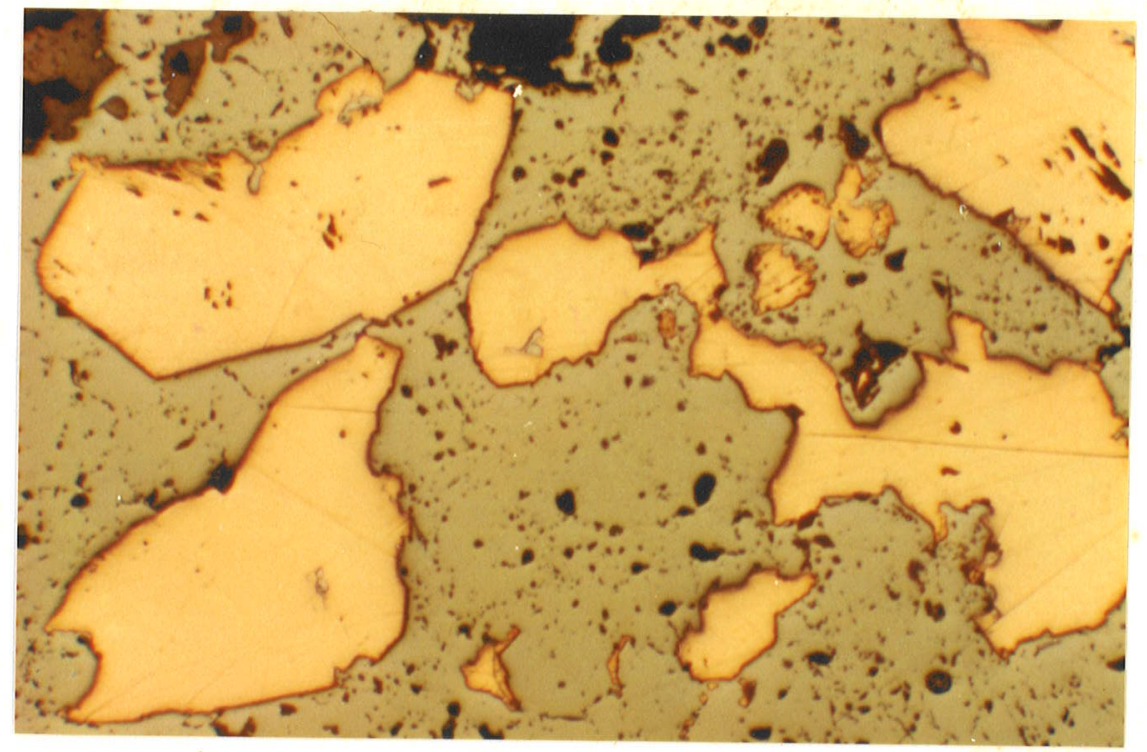

Foto 99 - Cobre nativo(amare10) dissemina do em matriz de cupr $\bar{i}$ ta(creme); e quartzo (preto). Seção polida. Nicois descruzados. Au mento 50 vezes.

Foto 100 - Cobre nativo (amare 1o) apresen tando inclusões de cuprita (marrom claro), quartzo (preto). Seção polida. Nícois descruzados. Aumento 200 vezes.
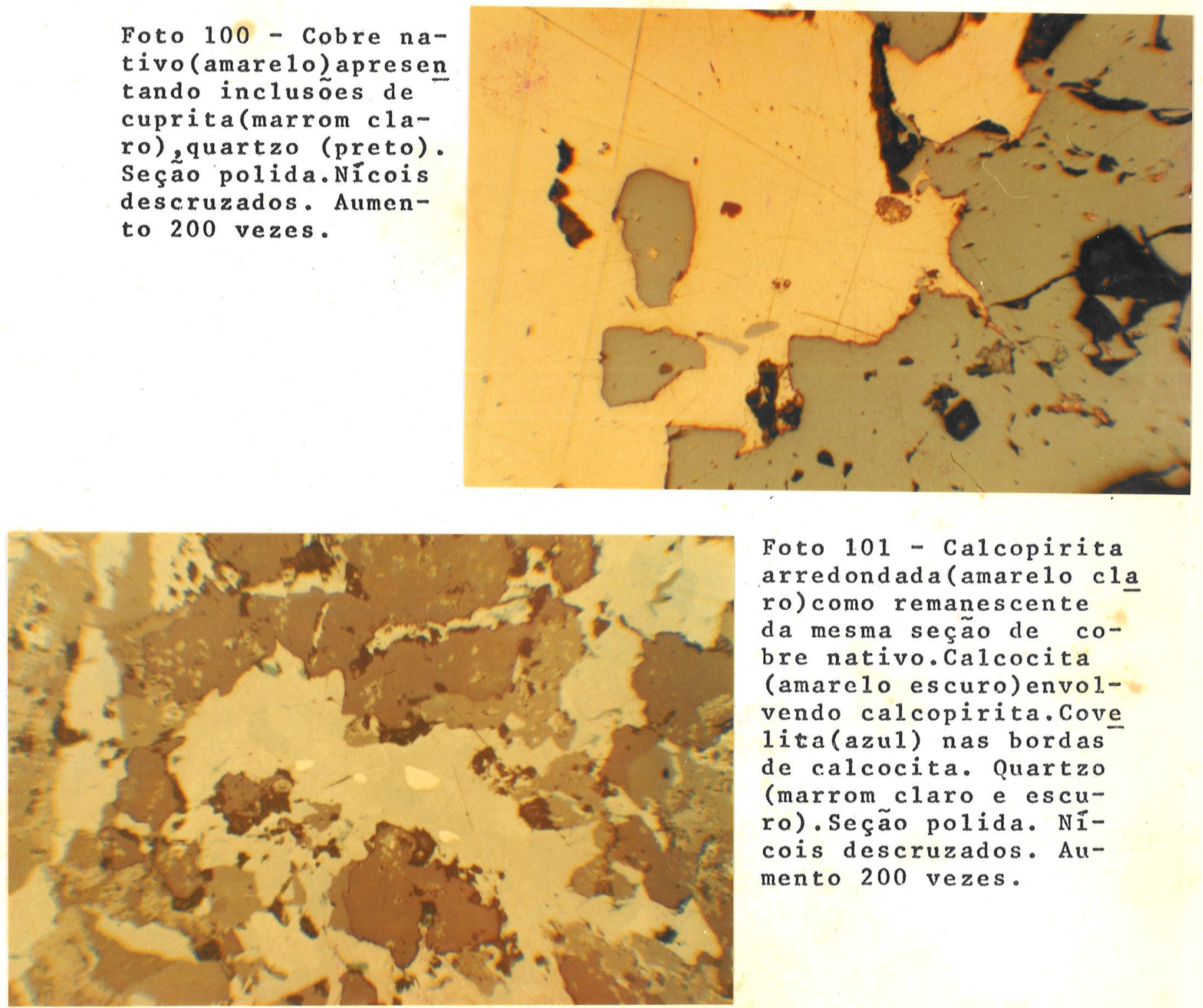

Foto 101 - Calcopirita arredondada (amare lo cla ro) como remanescente da mesma seção de cobre nativo.Calcocita (amarelo escuro) envolvendo calcopirita. Cove 1ita (azu1) nas bordas de calcocita. Quartzo (marrom claro e escuro). Seção polida. Nicois descruzados. Aumento 200 vezes. 


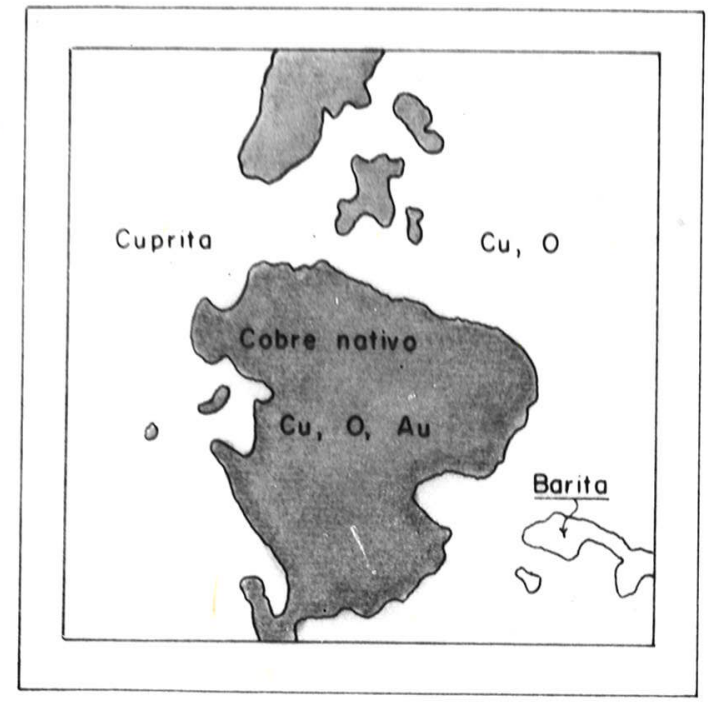

Fig. 18 - Distribuição de elementos em Cobre nativo, Cuprita e Barita

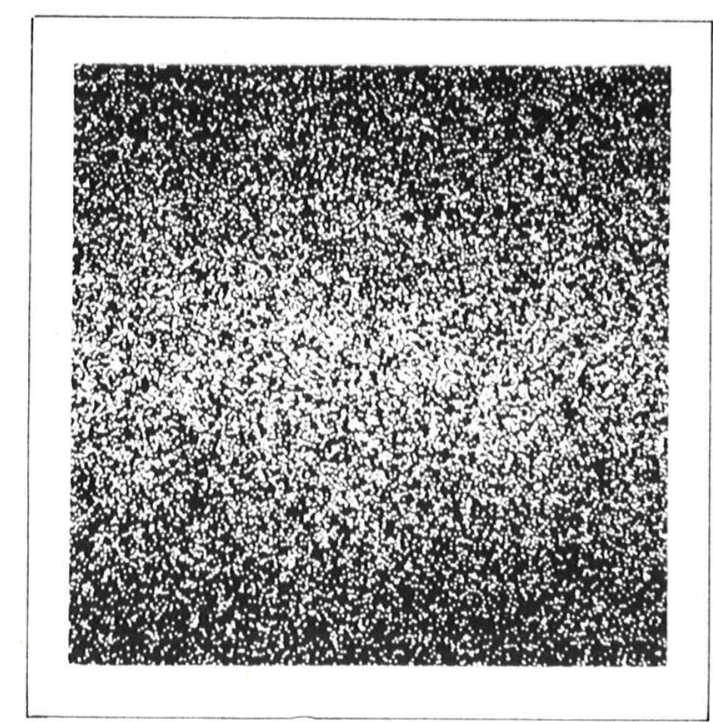

Foto 103 - Imagem "X" $\mathrm{Cu} \mathrm{K \alpha}$ mesma zona

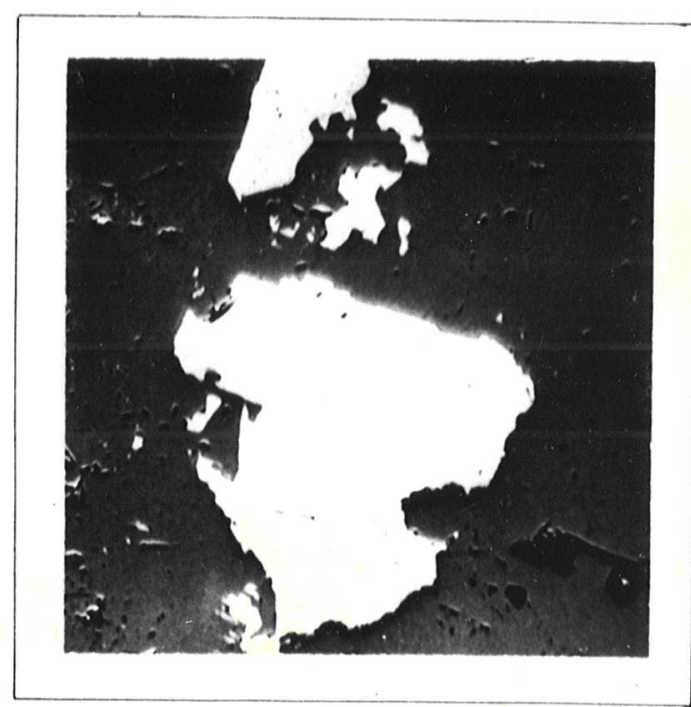

Foto 102 - Imagem eletrônica de cobre nativo(branco), cupri ta (cinza escura)e barita(preta). E.retroespa 1 hados. 400 $\mathrm{x} 400 \mu \mathrm{m}$.

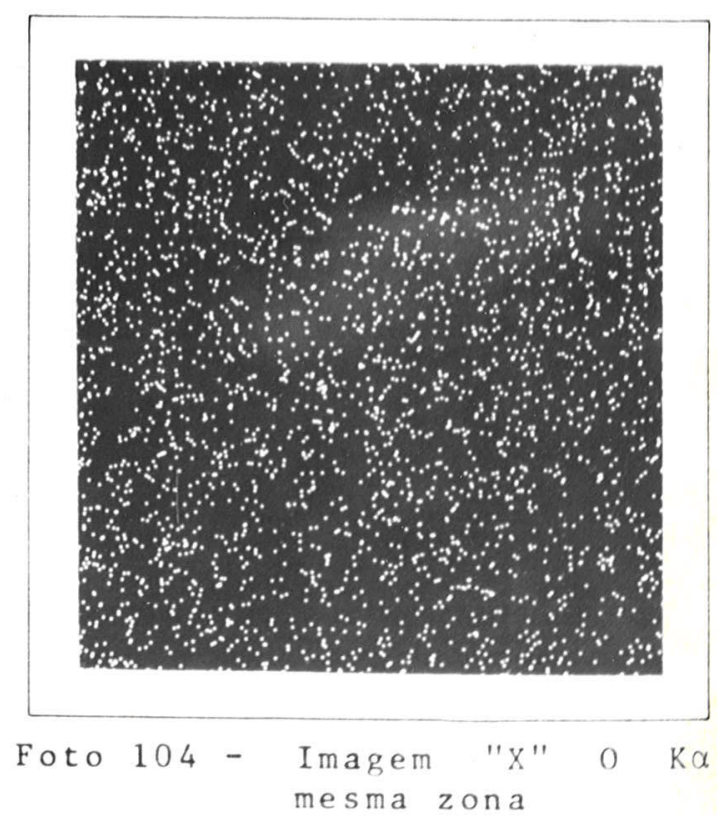




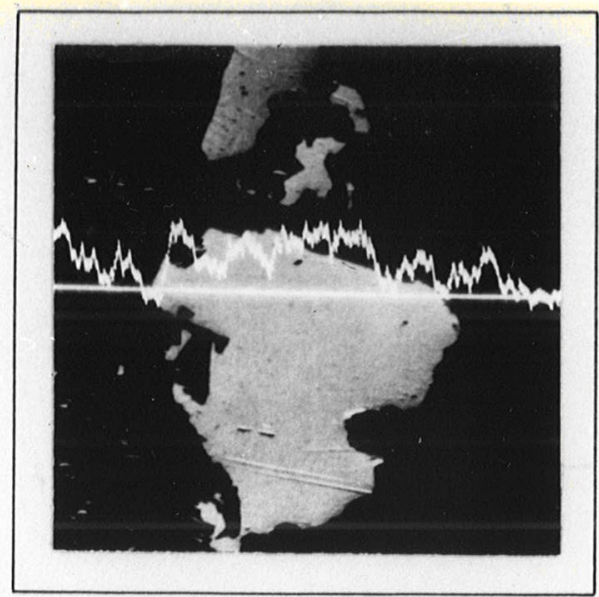

Foto 105 - Perfil de Au L $\alpha$

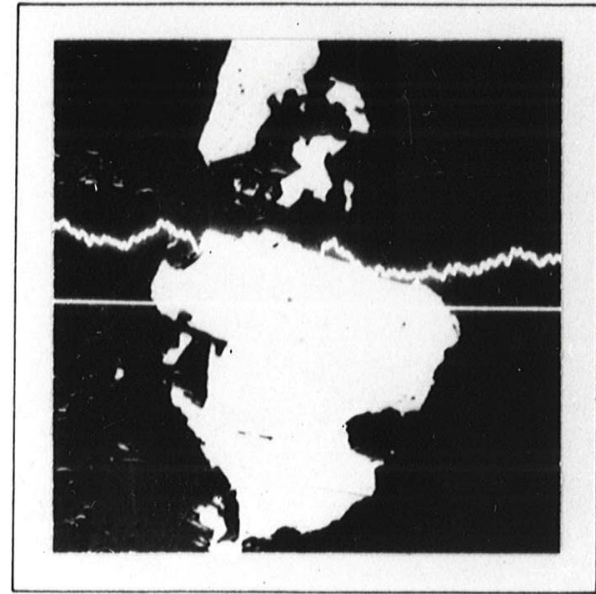

Foto 106 - Perfil de $0 \mathrm{~K} \alpha$

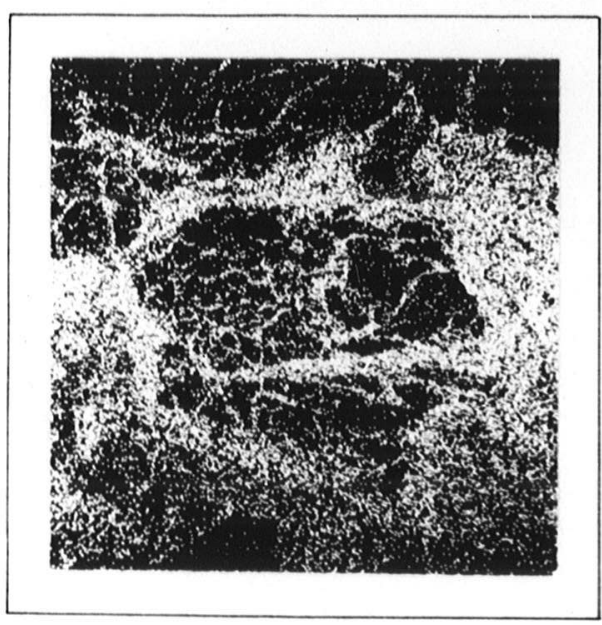

Foto 108 - Imagem "X" de Cu K $\alpha$ mesma zona da foto anterior.E. retroespalhados $.400 \times 400 \mu \mathrm{m}$.

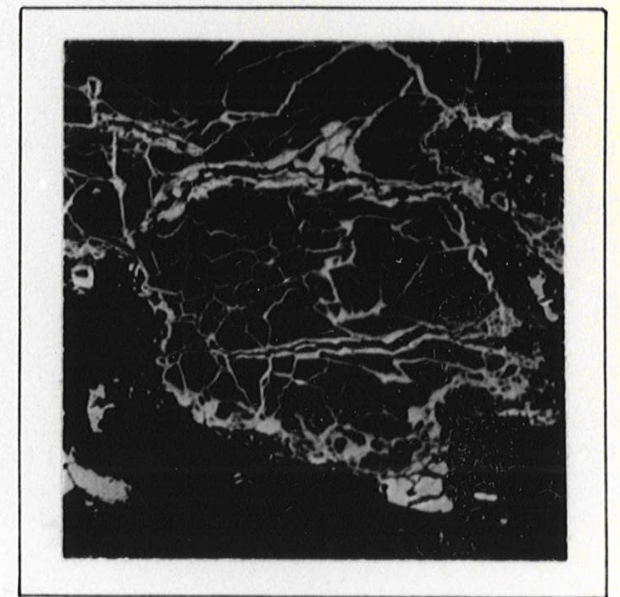

Foto 107 - Imagem eletrônica de pirita substituida nas fra turas por calcocita e quartzo.

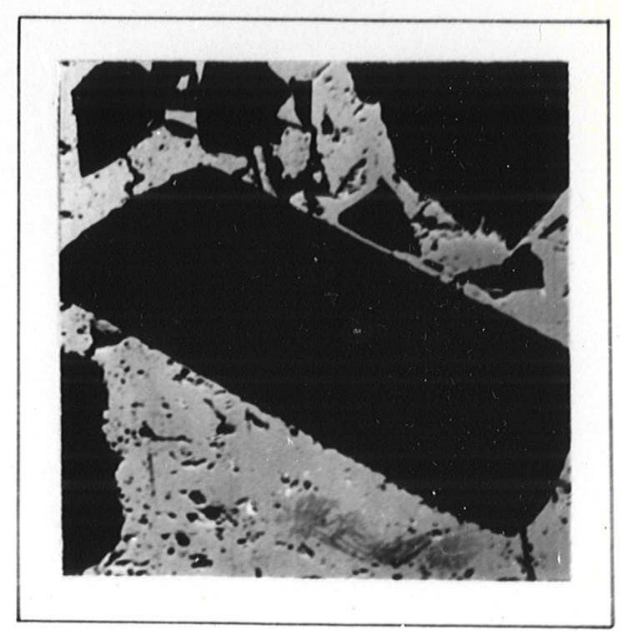

Foto 109 - Imagem eletrônica de cristais de turmalina em matriz de cuprita e cobre nativo.E.retroespalhados. $400 \times 400 \mu \mathrm{m}$. 
No campo estudado foram percebidos pontos es parsos representados por quartzo na matriz de cuprita, um cristal de barita e um silicato de cālcio, próximo à barita. Não foram detectados: Al, Fe, Mn, Cr, Ni, Co, Zn, As, Pt, Se, $\mathrm{Bi}, \mathrm{Pb}, \mathrm{Hg}, \mathrm{Sb}, \mathrm{Na}, \mathrm{S}$ e Ag.

Deve ser destacada a ausência de $\mathrm{Ni}$, pois a presença deste elemento, em quantidade anômala, indica ori gem do cobre nativo a partir de rochas máficas (Forbes, 1969). A foto 107 mostra um cristal de pirita, em outra região da mesma seção polida de cobre nativo, entrecortada por veios de calcocita. O ferro e enxofre se distribuem em todo campo focalizado e o cobre (Foto 108) se concentra na calcocita. Não hä arsênico. A foto 109 exibe cristais idiomorfos de turmalina rica em Fe, Mg, Si e Al, e pobre de Mn, associada a cobre nativo e cuprita.

Origem do cobre nativo - a) Cobre supérgeno. o cobre supërgeno mostra duas texturas distintas, sendo mais comum a do tipo zonal, denominada oolitica por carpenter e Fisher (Edwards, 1954) e igualmente descrita pelo termo colo forme. Essa textura pode ser originada de quatro maneiras: 1) por deposição de camadas sucessivas em cavidades, a par tir de soluções supersaturadas de carbonato; 2) por precipi tação rítmica a partir de um gel que contenha solução de sul fato de cobre com hidróxido de ferro coloidal; 3) por substi tuição de minerais preexistentes que jā apresentavam textura zonal, como limonita e malaquita; 4) por deposição a partir de fusão (porém o calor rapidamente destroi a textura).

Carpenter e Fisher em Edwards, 1954 a partir de experiências com soldas de cobre demonstraram que abaixo de $400^{\circ} \mathrm{C}$ não hä alteração visível na textura do cobre, começando a recrista lização a $450^{\circ} \mathrm{C}$ e tornando-se geral a $500^{\circ} \mathrm{C}$. Acima de $500^{\circ} \mathrm{C}$ a textura consiste de cristais alotriomorficos com bandas de geminação (tîpica textura de recristalização dos metais obtidos artificialmente). A temperaturas mais altas as marcas zonais se tornam mais largas e menos distintas como produto de difusão e a $750^{\circ} \mathrm{C}$ obtêm-se uma textura de recristalização homogênea. A textura zonal é interpretada por estes autores como prova de deposição do cobre a baixa temperatura e a tex 


\section{Diagramas de Cobre Nativo e Cuprita}

Rib Perau

d ( $\&$ ) I/I。

$3,01 \quad 10$

$2,72 \quad 5$

$2,47 \quad 30$

$2,28 \quad 5$

$2,10 \quad 100$

1,81

50

$1,51 \quad 30$

$1,29 \div 80$

$1,23 \quad 10$

$1,20 \quad 5$

$1,09 \quad 80$

$1,06 \quad 5$

$1,04 \quad 30$

$0,97 \quad 10$

$0,95 \quad 10$

$0,90 \quad 20$

$0,87 \quad 10$

$0,83 \quad 60$

$0,82 \quad 5$

$0,80 \quad 50$

$\mathrm{CuK} \alpha=1,5418 \&$, Filtro Ni

20 horas

$30 \mathrm{kV} \quad 15 \mathrm{~mA}$

Câmara de Gandolfi $114,6 \mathrm{~mm} \emptyset$ (monocristal)
Cobre

Ref.Swanson and Tatge

d ( $) \quad \mathrm{I} / \mathrm{I}$ 。 hk 1

2,088

100

111

1,808

46

200

1,278

20

220

., 743

1

1,510

27

1,287

17

1,233

4

1,0900

17

311

1,0436

5

222

$0,9038 \quad 3 \quad 400$

$0,8293 \quad 9 \quad 331$

$0,8083 \quad 8 \quad 420$

$0,8216 \quad 3$

$0,9795 \quad 4 \quad 331$

$0,9548 \quad 3 \quad 420$

$0,8715 \quad 3 \quad 422$

511

Ficha ASTM - 4-0836 Ficha ASTM - 5-0667 
tura de recristalização é aceita como prova de aquecimento durante o metamorfismo.

A segunda textura apresentada pelo cobre pérgeno é a textura em espinha de peixe, obtida por ataque químico, caracterizada por zonas paralelas e simétricas ao songo de um eixo. Indica deposição a baixa temperatura, es tando o cobre limitado por algum fator, como dendritos ou mi nerais esqueléticos.

b) Cobre hipögeno. Earacterizado por apre sentar textura de recristalização ou "textura de solda" simi lar à obtida em experiências de solda a temperaturas acima de $500^{\circ} \mathrm{C}$. O cobre de origem hipögena do distrito do Lago su perior, E.U.A., é tido como depositado em condições epiter mais, a temperaturas entre 100 a $250^{\circ} \mathrm{C}$. Carpenter e Fisher (em Edwards, 1954) descrevem o fato explicando que o metal foi depositado a partir de soluçóes aquosas a baixas tempora turas e subsequentemente recristalizado por metamorfismo ter mal. Uma evidência para o caso em questão, ë a presença de inclusões de prata metälica, sinal de não formação de liga entre os dois metais, pois a solução sölida cobre - prata inicia no intervalo $600-650^{\circ} \mathrm{C}$.

0 cobre nativo estudado não apresenta textura secundäria zonal característica, embora possa ser de origem supérgena pois contém pouco ouro, não em forma de inclusões, mas provavelmente em solução sölida e se associa a minerais tipicamente de zona de oxidação, ou sejam: cuprita,covelita, malaquita e crisocola.

A favor da origem hipógena poderiam ser leva dos em conta: a textura, que mais se aproxima do tipo recris talização; as reliquias de pirita e de calcopirita (Foto 10í) e os minerais associados: barita e turmalina.

prata nativa

A prata nativa (Figura 19 e Fotos 110 e 111)foi encontrada em värias seções polidas entre grãos de pirita,cal copirita e quartzo, em matriz de quartzito compacto. Os cris 


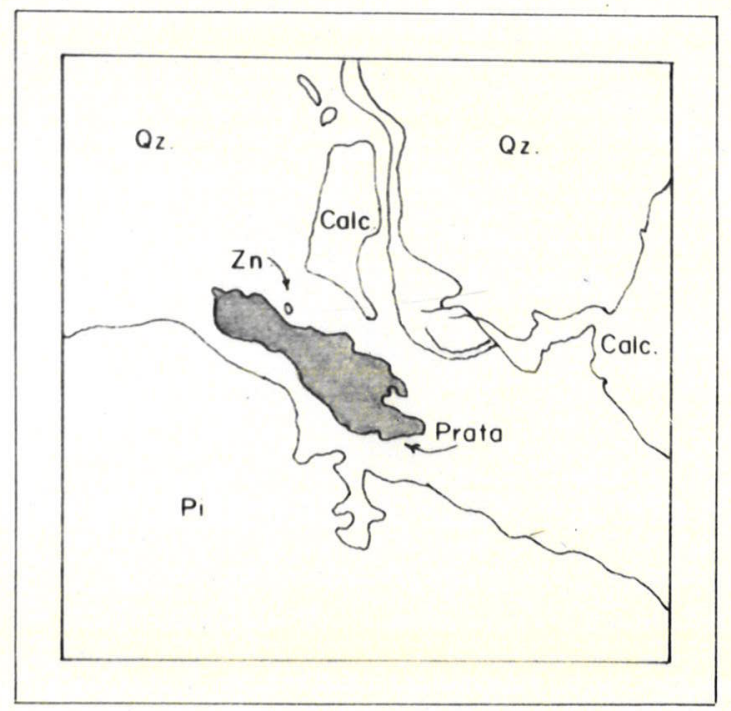

Fig. 19 - Distribuição dos mine rais da foto 110: Prata, Pi=Pi= rita, Calc. = Calcopirita, $Q z=$ Quartzo e $Z_{n}=$ Zinco. $400 \mathrm{x}$ $400 \mu \mathrm{m}$.

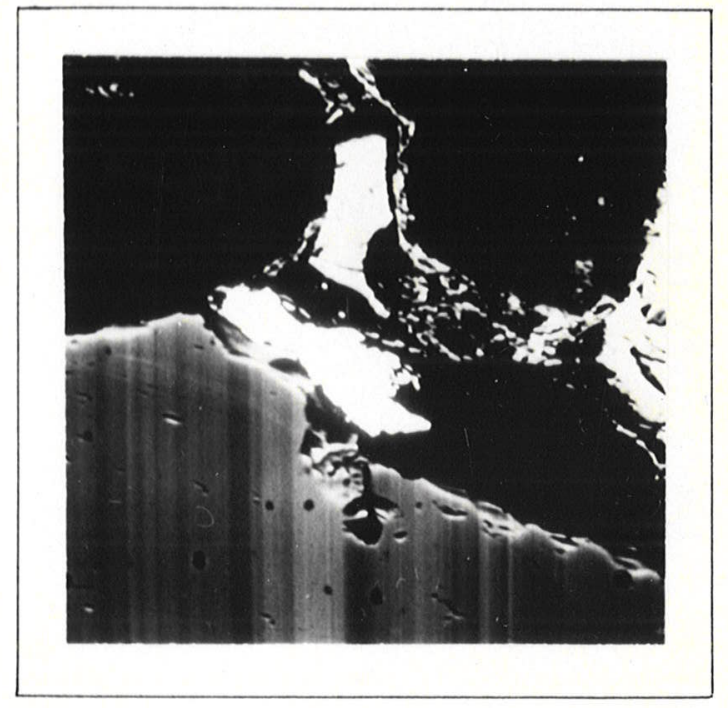

Foto 110 - Imagem eletrônica de prata nativa (branca), calco pirita, pirita (cinza) e quart zo (preto). E. retroespalhados. $400 \times 400 \mu \mathrm{m}$.

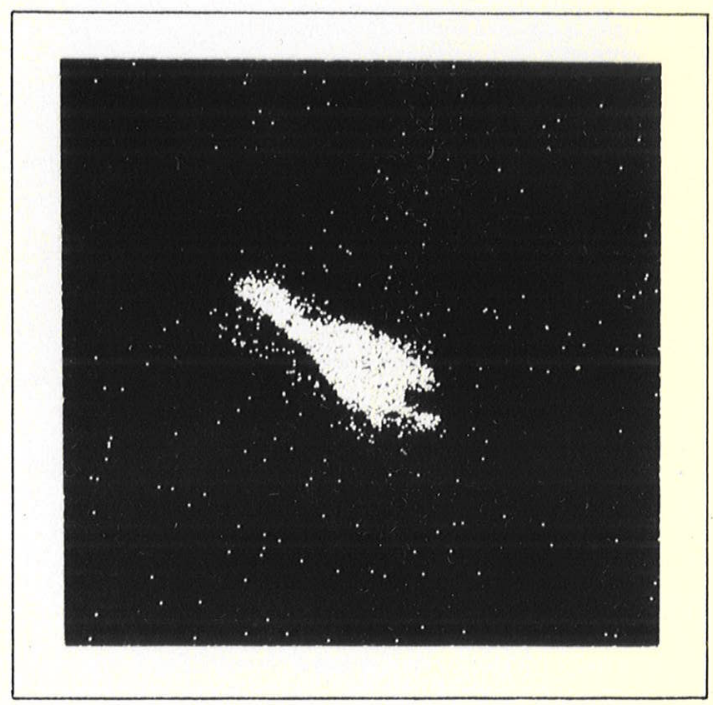

Foto 111 - Imagem "X" Ag L $\alpha$ 
tais de pirita e calcopirita estão alinhados paralelamente à estratificação dos quartzitos. Macroscopicamente, a prata não foi percebida no minério de jazida, e àmicrosonda ele trônica, foi detectada como elemento constituinte da tennan tita. A presença de prata foi revelada, a principio,através de anälises quimicas (Tabela 28). O estudo da prata nati $v a$ à microsonda eletrônica se deteve nos elementos $\mathrm{S}, \mathrm{Cu}, \mathrm{Si}$, $\mathrm{Sb}, \mathrm{O}$ e Au.

o enxofre, cobre, silicio, antimônio e ouro estão ausentes. sendo que o ouro foi pesquisado en detalhe, em campo mais redurido, abrangendo sô o mineral prata nativa, através de perfis lineares do feixe eletrônico.

o oxigênio estä presente em quantidade reduzi da em todo campo, fornecendo, sobre a prata, 13493 cont/s em $10 \mathrm{~s}$, contra $9400 \mathrm{cont} / \mathrm{s}$ do "background". No mesmo cam po, a calcopirita produriu 4490 cont/s contra um"blackground" de 3877 cont/s, donde se conclui que o oxigênio pertence pro vavelmente à camada superficial de oxidação da prata e da cal copirita.

0 zinco ocorre concentrado em um ponto próxi mo da prata nativa (Fig. 19) com diâmetro ao redor de um mie cron. Não ocorre na forma de sulfeto, mas certamente combi nado com oxigênio.

Paragênese - A prata nativa pode formar solu ções sölidas com o ouro (electrum) em todas proporçöes, fre quentemente associando-se à pirita, galena, calcocita, esfa lerita, sendo encontrada especialmente ern forma de veios nas rochas igneas e metamörficas (Winchel1, 1967). Pode ser for mada a partir da decomposição de argentita (Uytenbogaardt, 1961) e substitui váxios sulfetos, inclusive tennantita.

Pode ter origem supërgena, exibindo (como o cobre metälico), textura zonal e origem hipögena, mostrando textura espinha de peixe (Edwards, 1954), onde a temperatura de recristalização é superior a $200^{\circ} \mathrm{C}$, excluidos os efeitos de metamorfismo.

De acordo com Romdohr (1969) a prata nativa é 
precipitada a partir de soluções ascendentes como produto de soluções hidrotermais, assim como precipitada a partir de soluções descendentes como produto do transporte na superfi cie das äguas. No primeiro caso pode substituir calcopiri ta, galena, e minerais de Ni e Co. No segundo caso forma peliculas finas sobre galena, esfalerita, bornita e calcoci ta.

Na seção estudada, a calcopirita e pirita,as sociada à prata nativa estão localizadas nas suturas dos grãos de quartzo do quartzito, região isenta de oxidação em bora a calcopirita a apresente, exibindo textura zonal, onde se concentram ferro e silicio. A anomalia punctiforme de Zn, não em forma de sulfeto, tambëm indica zona oxidada, sen do que este elemento poderia provir da tennantita, ou da es falerita, ja que foram encontrados indicios deste mineral em outras seções polidas. Possivelmente a prata tenha como fonte a tennantita, sendo originada por soluções ascendentes.

crisocola

A crisocola e a malaquita, associadas, consti tuem o minêrio oxidado de maior abundância na jazida do Ri beirão do Peräu. Ocorre frequentemente em superficie,tendo sido determinada em quase todos os furos de sondagens, até $64 \mathrm{~m}$ de profundidade. A maior concentração está intimamen te ligada à calcopirita das camadas de quartzito e subordina damente acompanha a malaquita das rochas carbonaticas im pregnadas em minerais de cobre.

mais rara ou mesmo ausente nos bolsões ou
veidados e compostos de cuprita, malaquita, oxidos de ferro, que ocorrem nas galerias de pesquisa.

Propriedades morfológicas - A crisocola pos sui aspecto coloforme, com estrutura concêntrica (Foto 113) preenchendo ou revestindo cavidades das rochas; o häbito $\vec{e}$ maciço quando associada ao quartzo (Foto 112) apresentando, menos frequentemente, os hảbitos reniforme, mamelonar e bo 


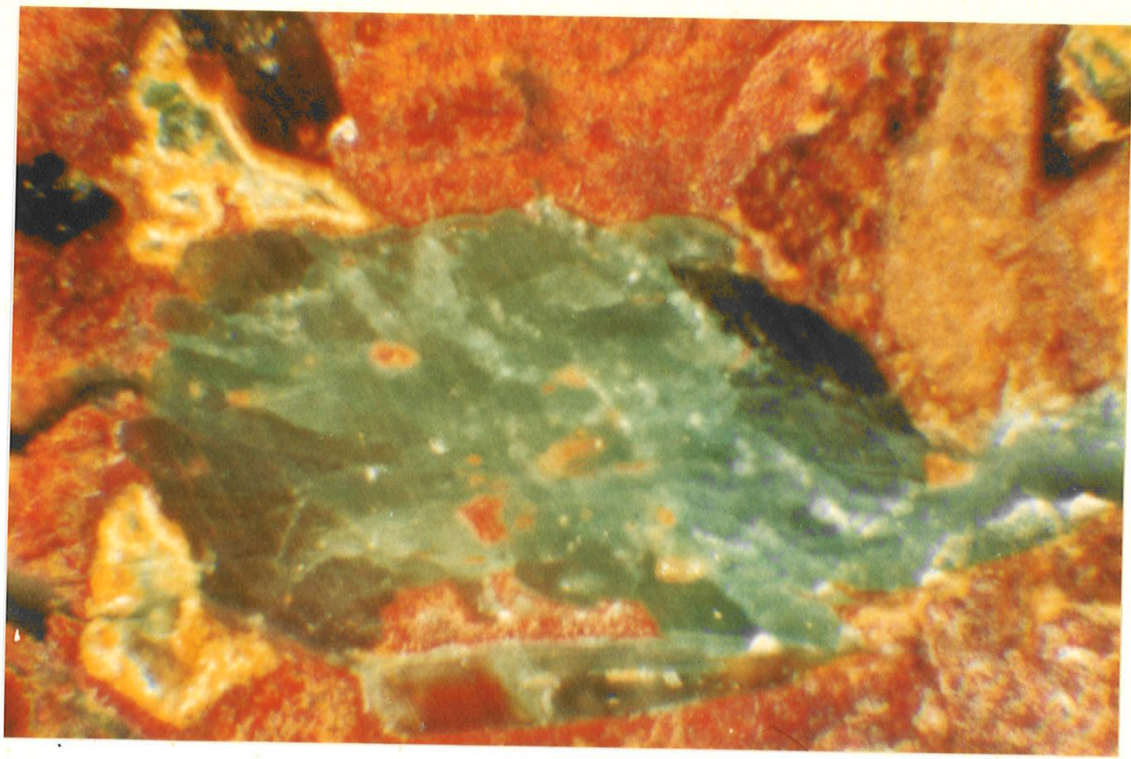

Foto 112 - Crisocola (azul esverdeada) e material limonítico (amarelo e vermelho) no quartzo. Seção po1 ida. Iluminação convergente. Nicois descruzados. Aumento 40 vezes.

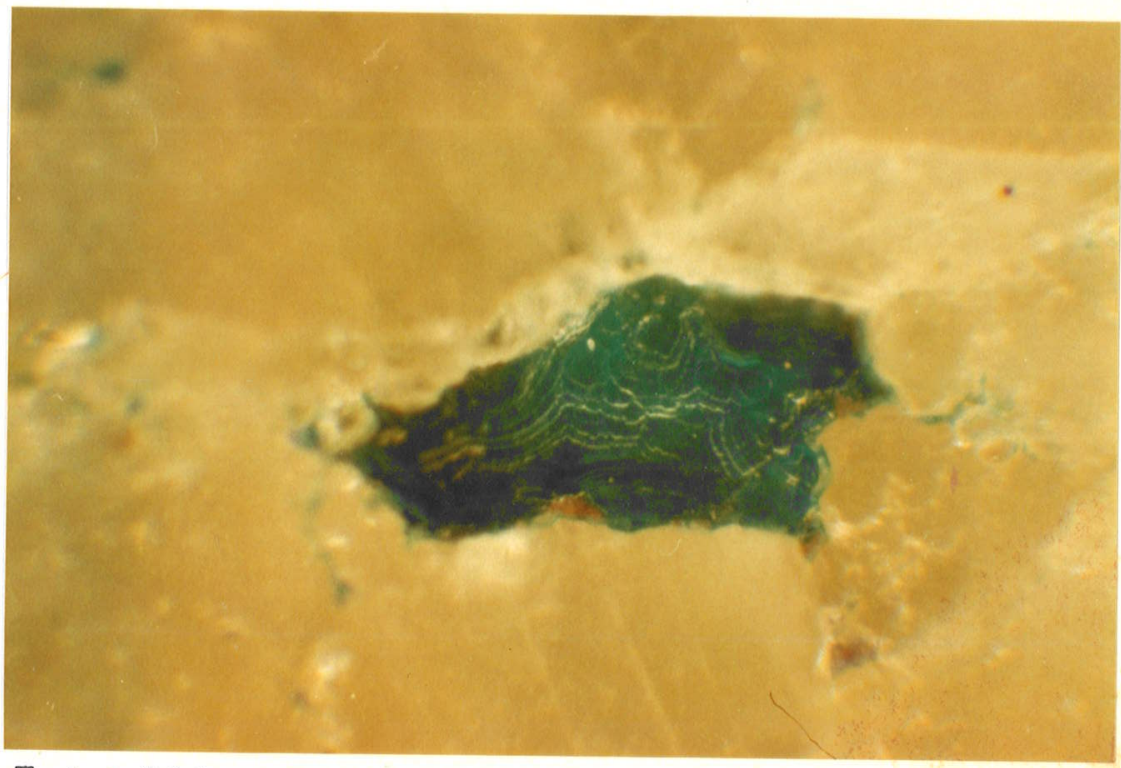

Foto 113 - Crisocola (azu1) exibindo estru trura concentrica.Quartzo (amarelo). Seção polida. Iluminação convergente. Nicois descruzados. Aumento 200 vezes. 
trioidal. A granulação varia de milimętrica a centimêtrica. cas de textura Propriedades fisicas - As camadas concêntri curo apresentam tonalidades aruis de es curo a claro, às vezes quase branca, em ritmo alternado. ó britho ë seríceo o traço branco e azulado, mostrando fratu ra concóide. Etranslúcida e fracamente pleocröica sob luz refletida. Os diagramas de pó de difração de raios $x$, com crisocola moída e passada em peneira de 200 "meshes", não apresentam raias de reflexão indicando que o mineral é amor fizāvel por trituração (Camargo, 1965).

Os diagramas de pö de raios X da crisocola são muito fracos, semelhantes ao padrão de um gel rico em metal (Throop et al., 1971), diferindo essencialmente do pa drão de mineral bem cristalizado. Os diagramas de raios $X$ estudados foram obtidos com monocristais, em câmara de Gan dolfi (Arruda, 1971) e mesmo assim as raias são largas e di fusas, indicando cristalizaçäo incipiente.

Foote e Bradley, 1913 (em Troop et a1.,1971) sugeriram que a crisocola é um hidrogel ou precipitado gela tinoso contendo ions de cobre, silica e ägua. Newberg,1967 (em Troopet a1., 1971) mostra que o zoneanente da crisocola contêm alguns microns de largura, com variaçóes de composição química. Van Dosterwych - Gastuche, 1971 (em Troop et a1. 1971) sugerem que a crisocola possui uma estrutura em cadeia semelhante a palygorskita.

A variação da composição química da crisoco $1 a$ è devida à sua formação a partix de gel. Se as soluções aquosas estão supersaturadas de sîlica hä polimerização pa ra formar particulas coloidais. o gel floculado consiste de silica altamente polimerizada, onde os ions de polissili catos impöem uma barreira de energia considerāvel, impedindo a si prōprios de formar uma estrutura cristalina (Troop et a1., 1971). Se os ions de cobre em solução são precipi tados com silica, o cobre pode se dispersar em forma desor denada.

A Tabela 13 compara a crisocola do Ribeirão do Perau com outras cinco amostras de värias procedências, 
podendo-se notar a discrepância nos valores dos espaçamentos interplanares.

o maior nümero de raias de reflexão dos dia gramas de difração de raios X obtidos por Arruda (1971) e pe 1o presente trabalho advém provavelmente de os resultados, em ambos os casos, terem sido obtidos a partir de monocristais.

A Tabela n: 14 mostra o resumo dos resultados de ATD de crisocola constantes do fichärio SCIFAX (1970). Acrescentaram-se os valores obtidos por Arruda (1971) e os da crisocola do Ribeirão do Perau. Hä discrepância dos valo res para as oito crisocolas comparadas.

pröximos aos obtidos por Arruda (1971). (Fig. 20).

A crisocola em estudo tem valores de ATD mais

Fig. 20 - Curva de ATD de crisocola do Rib do Perau

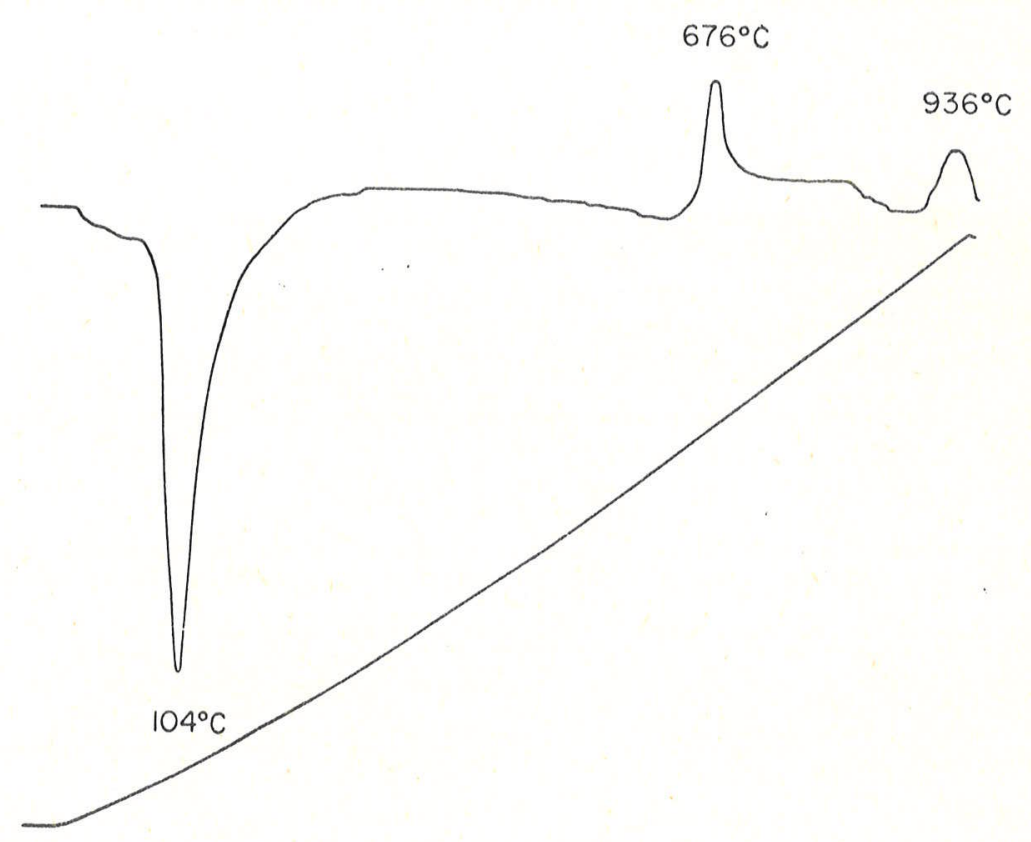


Tabela 13

Diagramas de Crisocola

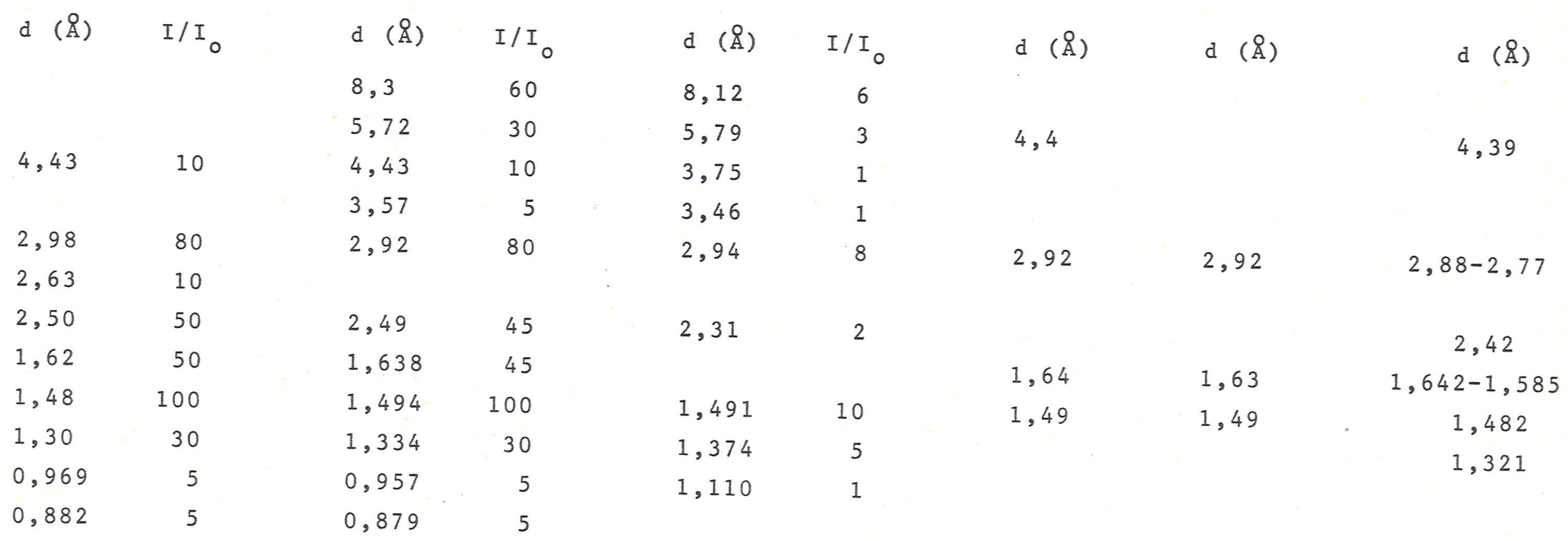

Referencias:

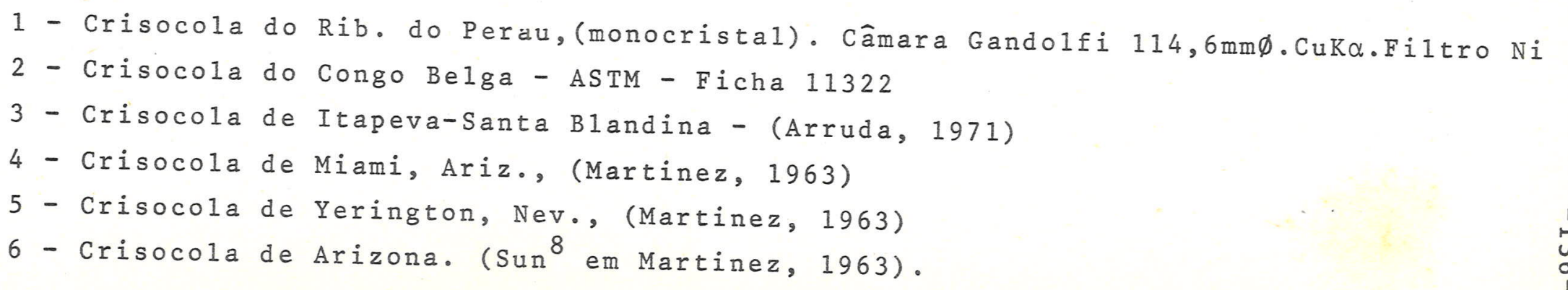


Tabela 14

Resumo dos resultados de ATD de Crisocola - Scifax, 1970

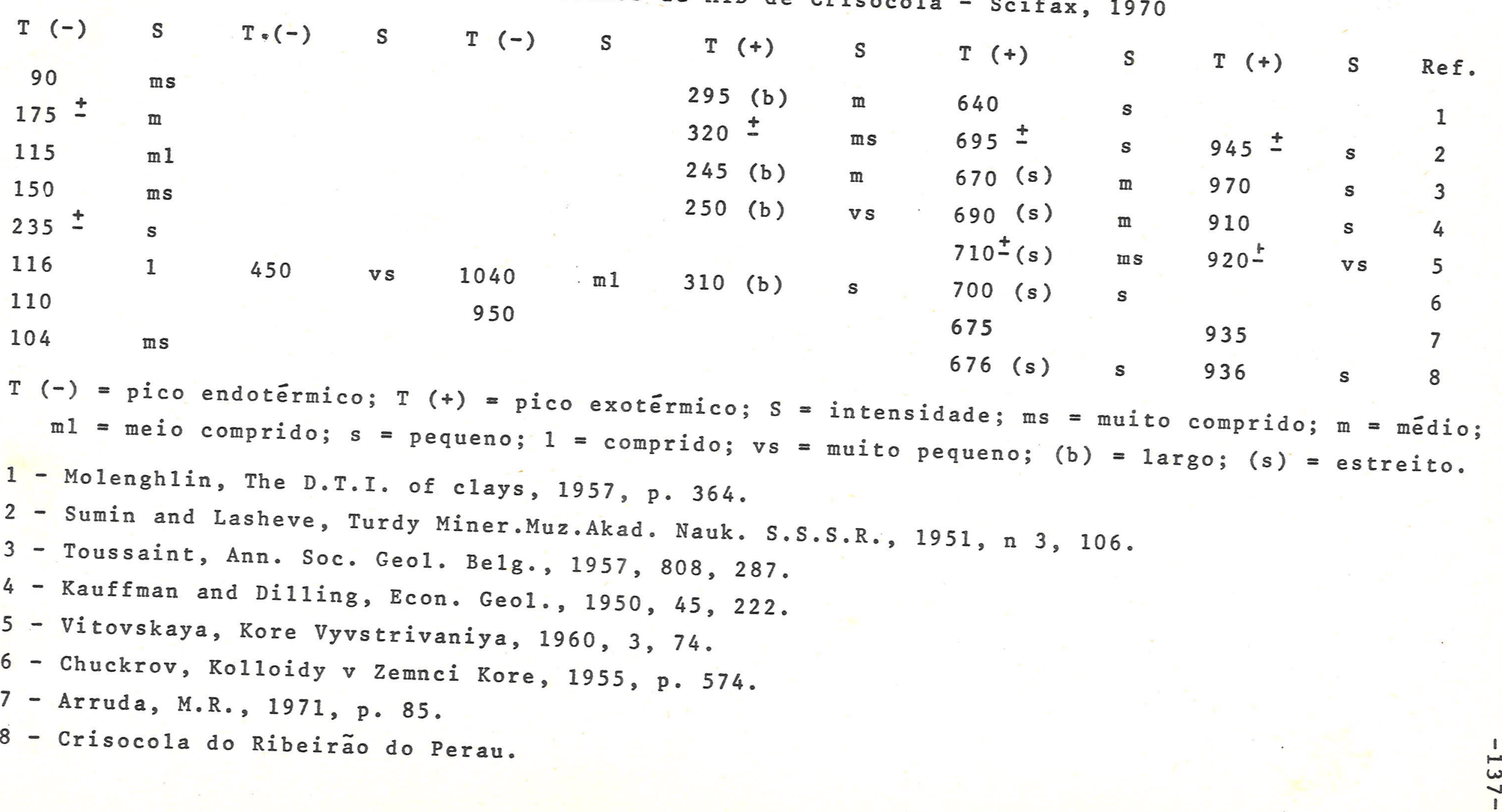


Microsonda eletrônica -

Seis exemplares

de crisocola, de uma amostra de seção polida, foram estuda dos na microsonda eletrônica, tendo fornecido os mesmos re sultados registrados nas fotos de um outro cristal analisado. A figura 21 mostra o resumo da distribuição dos elementos en contrados. O campo abrange $400 \times 400 \mathrm{\mu m}$ atravēs de imagens de elétrons retrodifundidos.

A crisocola apresenta estrutura concêntrica com faixas de diversas tonalidades entre o branco e o preto (Foto 114) e com distribuição variāvel de elementos.

0 cobre se concentra mais nas bordas do que no centro do cristal (Foto 115), porém mantêm-se constante dentro de cada faixa, como se percebe no perfil da foto 116.

o silicio aparece concentrado na matriz de quartzo (Foto 119) e mais diluído na crisocola, na razão de $54000 \mathrm{cont} / \mathrm{s}$ por $5050 \mathrm{cont} / \mathrm{s}$, em $10 \mathrm{~s}$, respectivamente.

o ferro (Foto 117) varia pouco em perfil de varredura, estando mais concentrado no centro, porêm a varia ção para as bordas é insignificante, apresentando $1701 \overline{4}$ cont/s nas bordas contra 17600 cont/s no centro, em $10 \mathrm{~s}$.

o ouro (Foto 118), o chumbo (Foto 120) e ar sênico se comportam de modo inverso ao cobre, isto ë, mais concentrados na porção central da crisocola, sendo que o chumbo existe em maior proporção que o ouro, ambos porém quantitativamente insignificantes em relação ao cobre.

0 oxigênio estā presente em quantidade despre sivel, provavelmente não formando óxidos simples.

Os elementos: $\mathrm{S}, \mathrm{Zn}, \mathrm{Ge}, \mathrm{Ni}, \mathrm{Co}, \mathrm{Mn}, \mathrm{Se}, \mathrm{Pt}$, $A g, S n, P, C$ e $K$ não ocorrem nas amostras de crisocola estudadas.

A crisocola negra pode conter 0,45 a $8,00 \%$ de Mn (Throop et al, 1971) e a ausência deste elemento na cri socola do Ribeirão do Perau vem excluíla dessa variedade, so mente reconhecível pela côr e teor de Mn. 


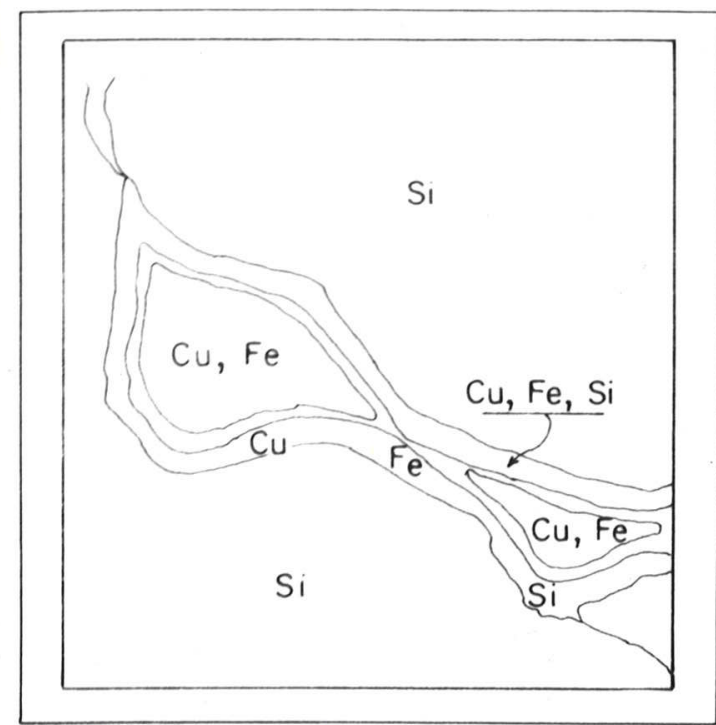

Fig. 21 - Distribuição dos elementos em crisocola e quart so. $400 \mathrm{x} 400 \mathrm{~m}$.

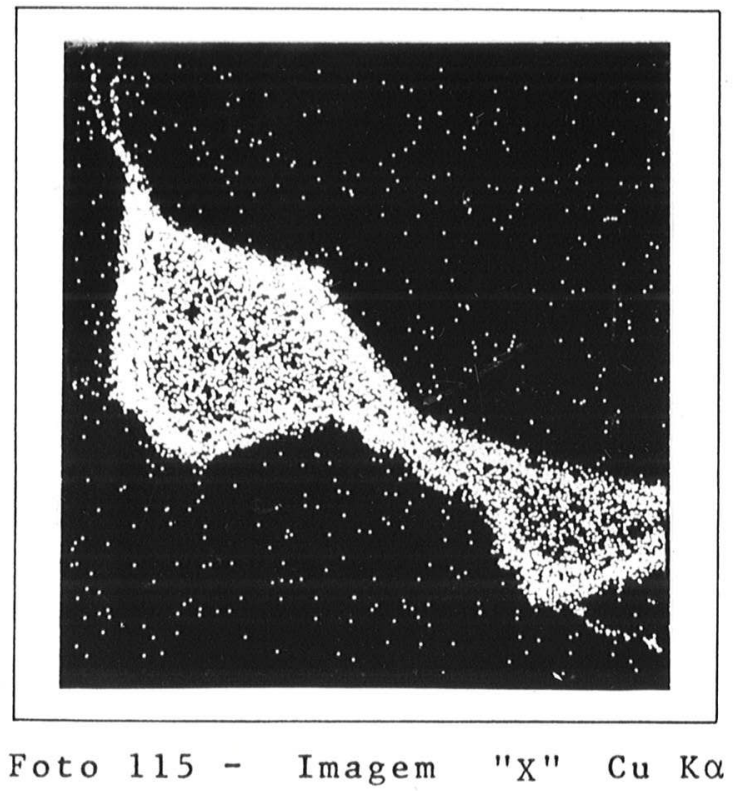

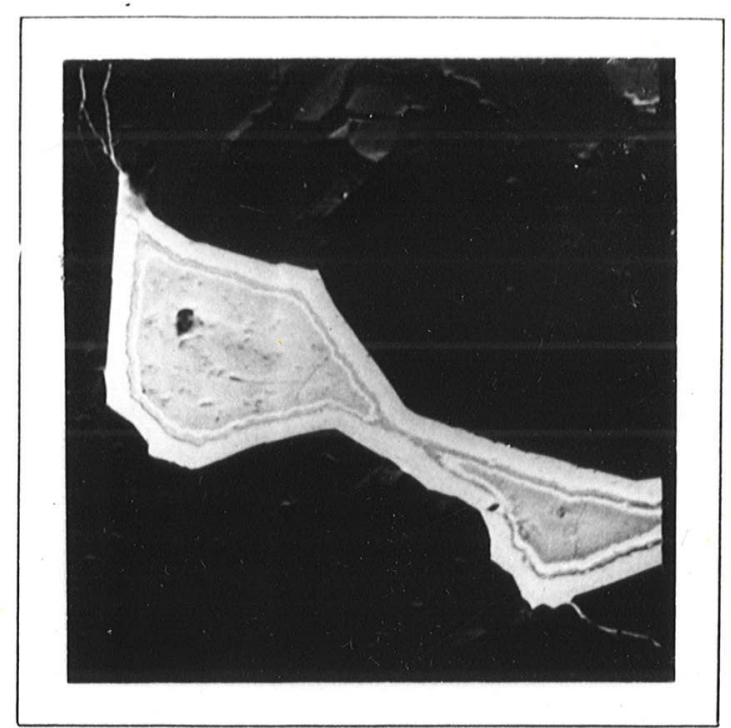

Foto 114 - Imagem eletrônica de crisocola. E. retroespalhados. $400 \times 400 \mu \mathrm{m}$.

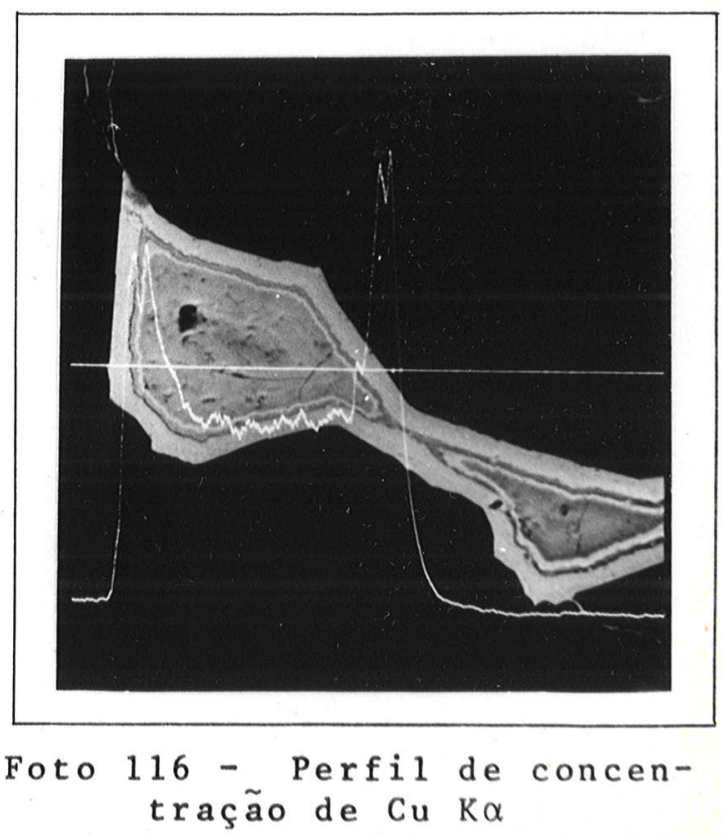




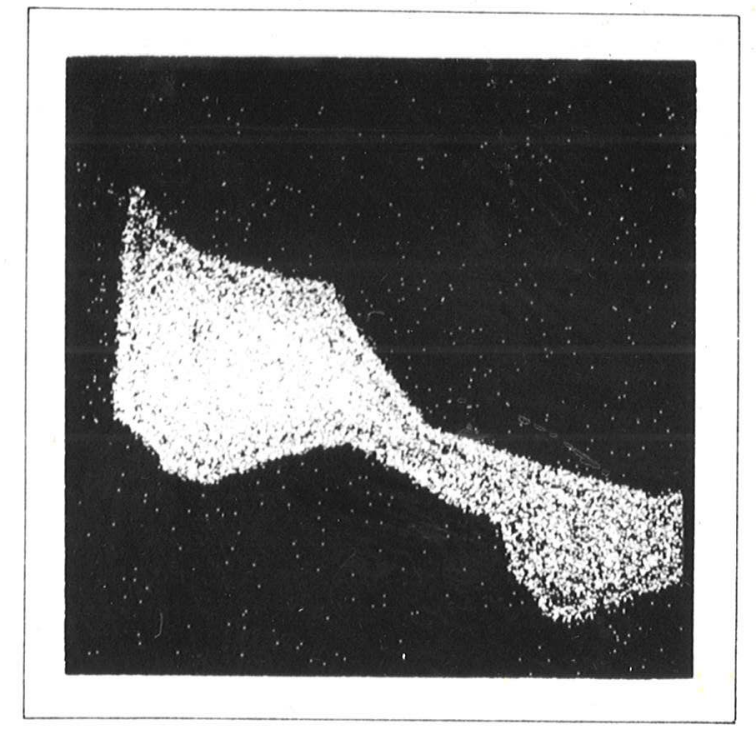

Foto 117 - Imagem "X" Fe Ka

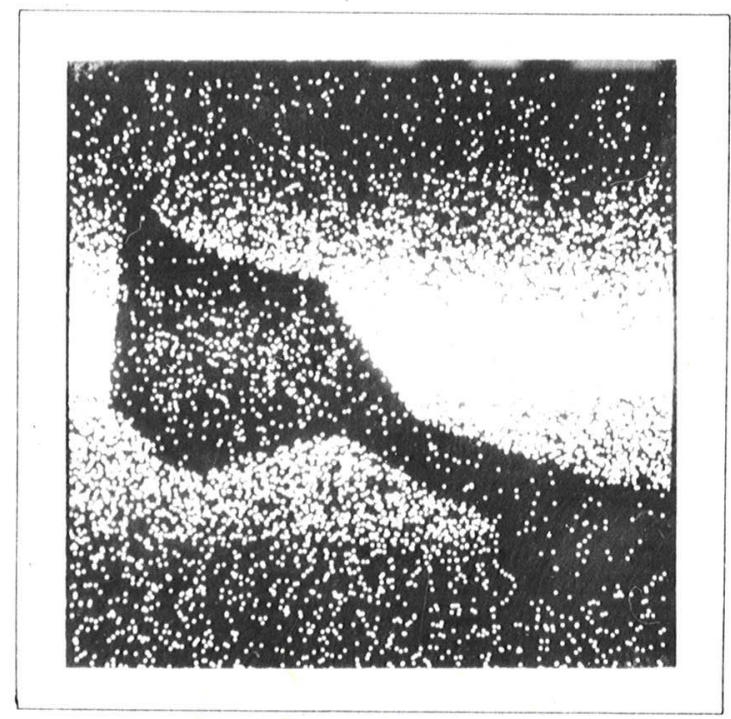

Foto 119 - Imagem "X" Si Lo.

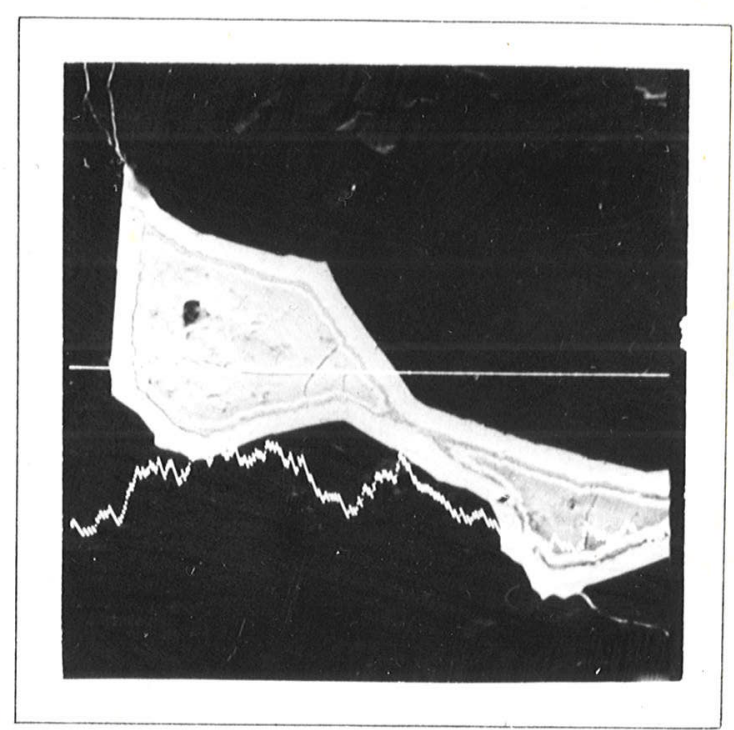

Foto 118 - Perfil de concentra

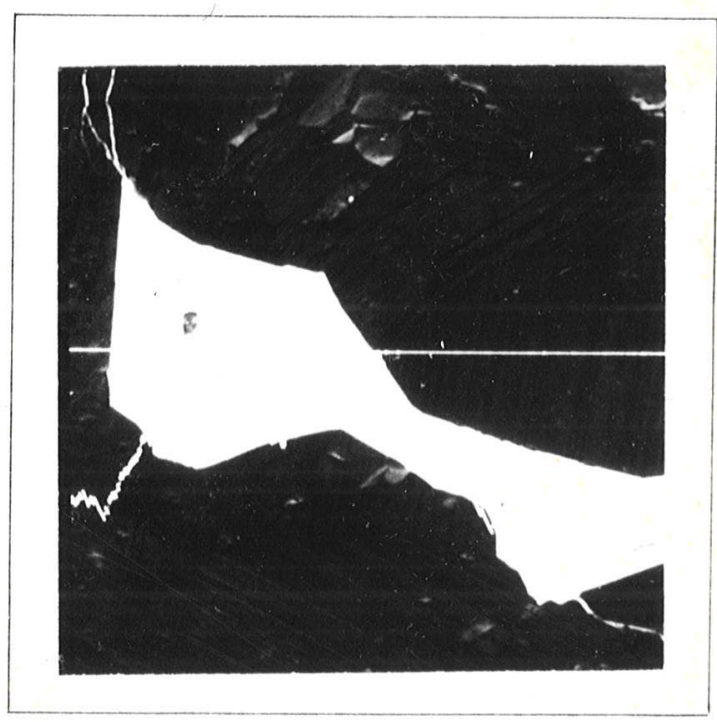

Foto 120 - perfil de concentra ção de $\mathrm{Pb} L \alpha$ 
Paragênese - A crisocola é um dos minerais mais largamente distribuidos junto à superfície dos grandes depösitos de cobre, particularmente em climas áridos, onde a fonte do metal foi removida; sendo resistente ao intempe rismo se constitui em importante guia de prospecção.

Na jazida em estudo a crisocola associa-se à calcopirita dos quartzitos e a cavidades de aspecto ligeira mente cúbico, preenchidas por limonita indígena, possivelmente formadas por decomposição de pirita. A sílica neces säria à formação da crisocola seria proveniente da dissolu ção de silicatos do quartzito ou do próprio quartzo.

A calcopirita seria a fonte de cobre, porém $A u, P b$ e As não foram encontrados na calcopirita. O Au e As poderiam provir da pirita. A crisocola do Ribeirão do Perau é um mineral secundärio formado provavelmente a par tir de soluções aquosas.

azurita

A azurita se associa aos minerais da zona o xidada da jazida, ocorrendo junto à tennantita, crisocola, malaquita, calcita, dolomita e quartzo. A sua presença é rara junto à pirita e à calcopirita, porēm é sempre acompa nhada por material limonitico (Foto 121).

Propriedades físicas - A azurita do Ribeirão do Perau normalmente possui aspecto pulverulento quando re cobre crisocola, malaquita, dolomita e quartzo. Quando pre enche fraturas ou cavidades em rochas calcio-silicatadas, po de adquirir aspecto fibroso. (Foto 122.) A côr ë azul inten so e o brilho vítreo. Em lâminas delgadas apresenta traços de clivagem, pleocroismo e anisotropia.

Os diagramas de raios X estudados (Tabela 16) foram obtidos com monocristais, em câmara de Gandolfi e mes mo assim hä frequência de espaçamentos interplanares de ou tros cristais como: hidröxido de cobre, lindackerita e sul fato penta hidratado de cobre. 


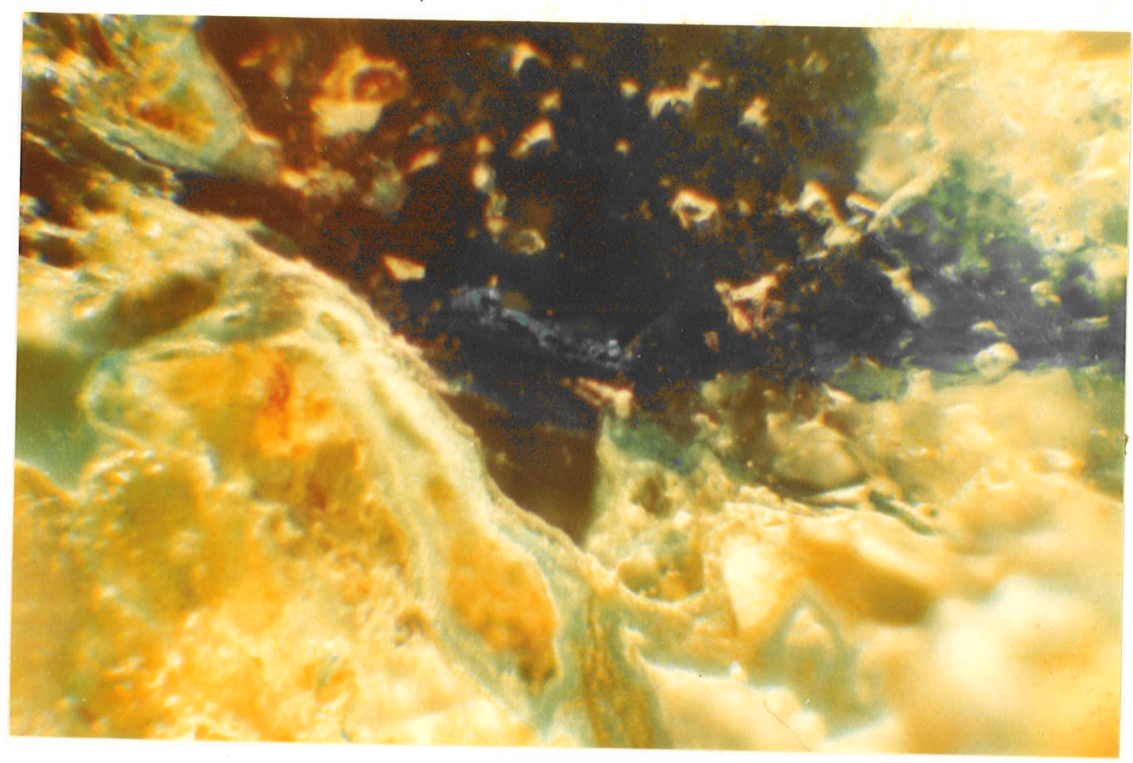
Foto 121 - Massa de azurita(azu1) em quartzo impregnado por mate- rial limonitico(tons amarela- dos)e crisocola(verde). Seção polida.Iluminação convergente. Nicois descruzados.Aumento 200 vezes.

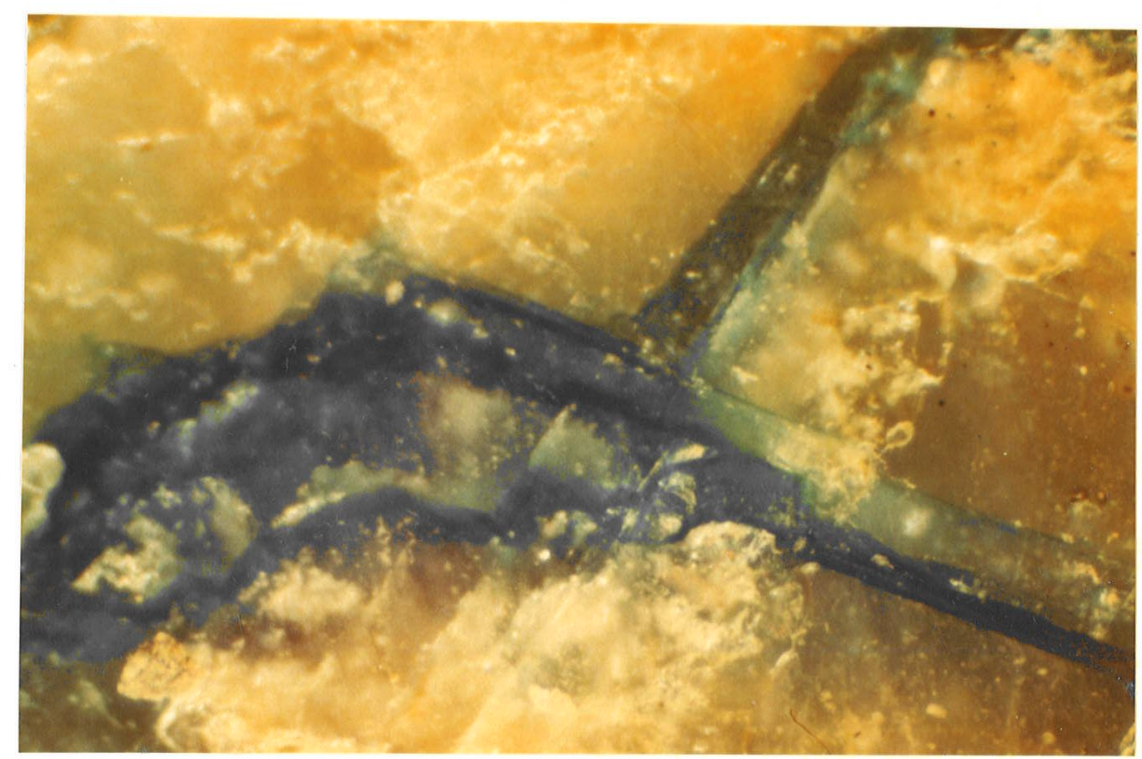

Foto 122 - Azurita fibrosa(azul)preenchen do fraturas em quartzito limonitizado(tons amarelos). Seção polida. Iluminação convergente. Nicois descruzados. Aumento 120 vezes. 
Tabela 15

T (-)

40
S

$\begin{array}{cc}\mathrm{T}(-) & \mathrm{S} \\ 410 & \mathrm{~m}\end{array}$

b

$570 \quad \mathrm{~m}$
$420-430$
390
430
$315 \pm 10$

$\mathrm{S}$

$$
\mathrm{T}(-)
$$

1050

1100

m

\section{5}

s de

$\mathrm{S}$

m 1

$\begin{array}{lll}740 & \mathrm{~m} & 2\end{array}$

$\begin{array}{lll}740 & \mathrm{~m} & 2\end{array}$

ATD de Azurita

1

Referência

1

.

3
4
1050
5
6

T (-) pico endotērmico; S=intensidade;m=mëdio;ml=meio com-
prido; b = largo

1 - Ivanova, Zap. Vsesyuz. Miner.Obshsch.,1961,90,50.Scifax, 1970

2 - Azurita do Ribeirão do Perau

3 - Webb e Heystek (1957), em Godinho (1964)

4 - Kauffman e Dilling (1950), em Godinho (1964)

5 - Beck (1950), em Godinho (1964)

6 - Godinho, M.M. (1964) - Contribuição para o conhecimento do comportamento térmico da malaquite e azurite: Mémórias e Notícias, no $57, p .7-19$.

Fig. 22 - Curva de ATD de azurita - Rib. do Perau

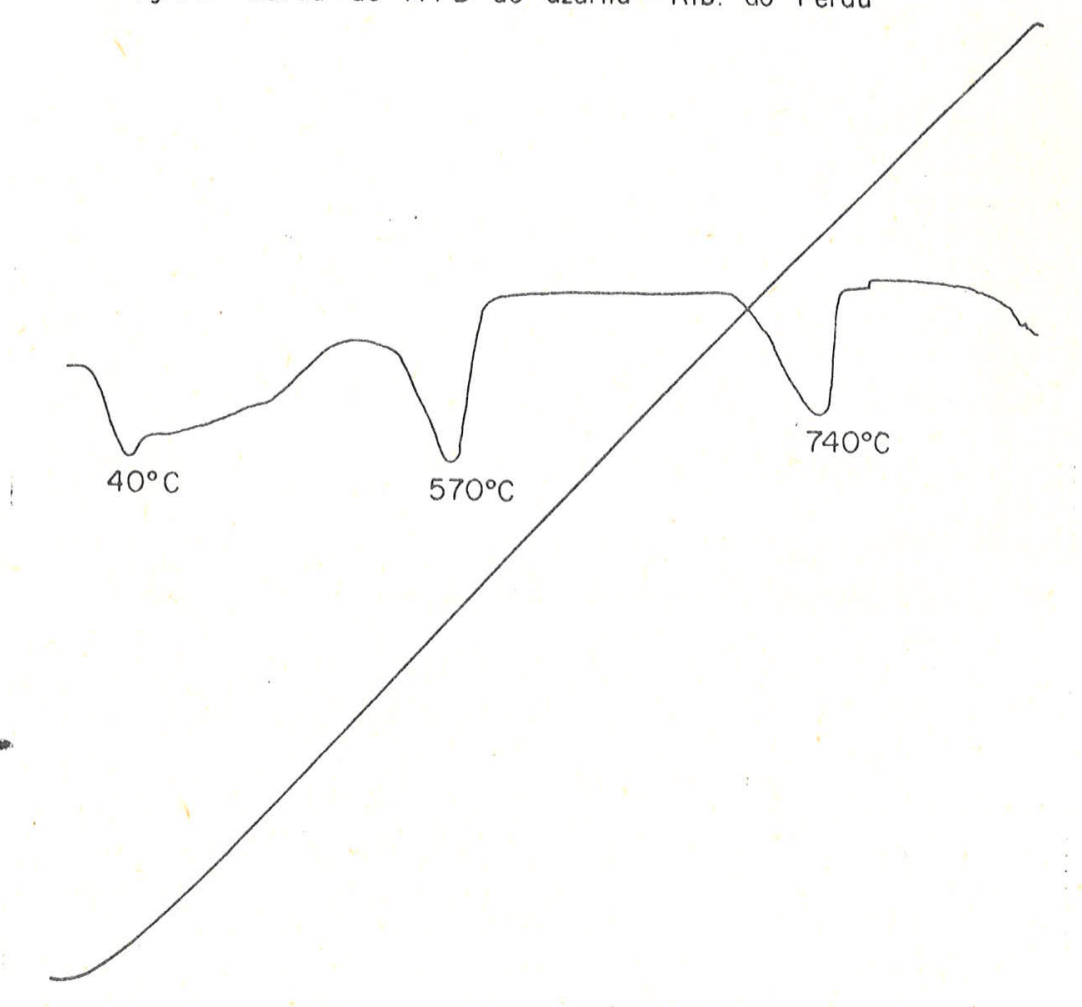


A Tabela 15 mostra o resumo dos resultados de ATD de azurita. Ha discrepância dos valores para a azurita do Ribeirão do Perau com os demais da tabela. Um dos fato res principais para explicação dessa anomalia, se deve à di ficuldade de separação de amostras puras, pois a azurita es tá sempre associada à crisocola, malaquita, dolomita e quart 2o, de difícil liberação. Por outro lado, a quantidade ne cessäria para anälise de ATD (Fig. 22) exigiu que se fizesse uso de azurita pulverulenta, que recobre, em forma de pelícu 1a, os minerais citados.

0 pico endotérmico a $40^{\circ} \mathrm{C}$ (Fig. 22)mostra que hä impurezas de crisocola $\left(50-175^{\circ} \mathrm{C}\right)$ e corresponde à perda de āgua absorvida (Martinez, 1963).

A reação endotérmica a $570^{\circ} \mathrm{C}$ deve tambëm ser devida à interação de azurita ecrisocola $\left(350-650^{\circ} \mathrm{C}\right)$, reação esta que se deve a desidroxilação (Martinez, 1963).

o pico endotérmico anômalo a $740^{\circ} \mathrm{C}$, provavel mente se deve à presença dos seguintes minerais: calcocita, $780^{\circ} \mathrm{C}$, Levy (1958); dolomita, $740^{\circ} \mathrm{C}$, Berg et al. (1944); ten nantita, $760^{\circ} \mathrm{C}$, Levy (1958) e calcopirita, $740^{\circ} \mathrm{C}$, Levy (1958), (Referências: fichärio SCIFAX, 1970), sendo menos proväveis os dois uैltimos minerais citados.

Microsonda eletrônica - A figura 23 mostra um cristal de azurita circundado por cristais aneuhedrais de do lomita, cimentados por crisocola (Foto 123). o cobre (Foto 124) se distribui através dos intersticios dos grãos de dolo mita concentrando-se na crisocola e subordinadamente na azu rita. O ferro (Foto 125) encontra-se pouco espalhado em to do campo estudado, apresentando maior anomalia em pequena parte da azurita. o zinco (Foto 126) acompanha a distribui ção do cob̆re tendo preferência para se localizar na crisoco 1a. O arsênico (Foto 127) recobre parte do campo pertencente ao cobre, mas concentra-se homogeneamente tanto na criso cola com o em uma seção de azurita. o aluminio (Foto 128) possui concentração preferencial em forma de faixas dentro da azurita, porém, para uma avaliação quantitativa,dever-se-ia subtrair o aluminio que compõe a pelicula metalizadora. 


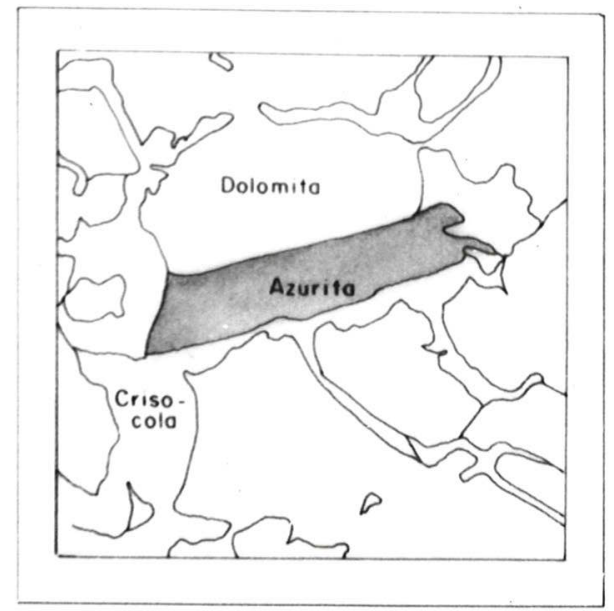

Fig. 23 - Azurita em matriz

de dolomita. Campo 200 x $200 \mu \mathrm{m}$.

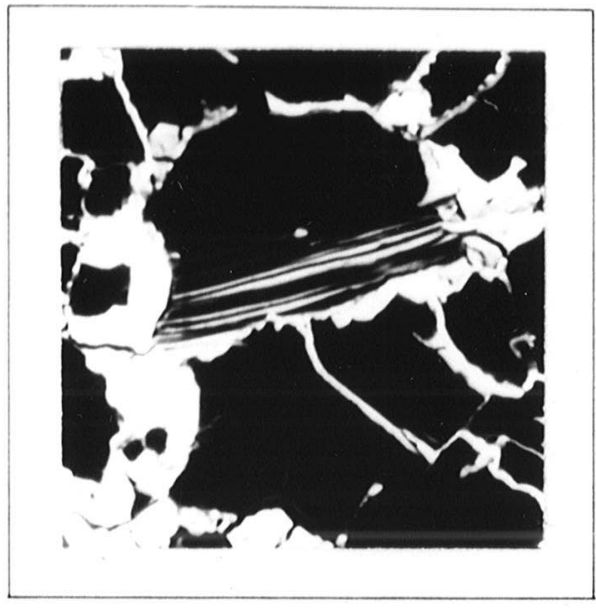

Foto 123 - Imagem eletrônica de azurita, dolomita e crisocola.E.retroespalhados, 200 x $200 \mu \mathrm{m}$.

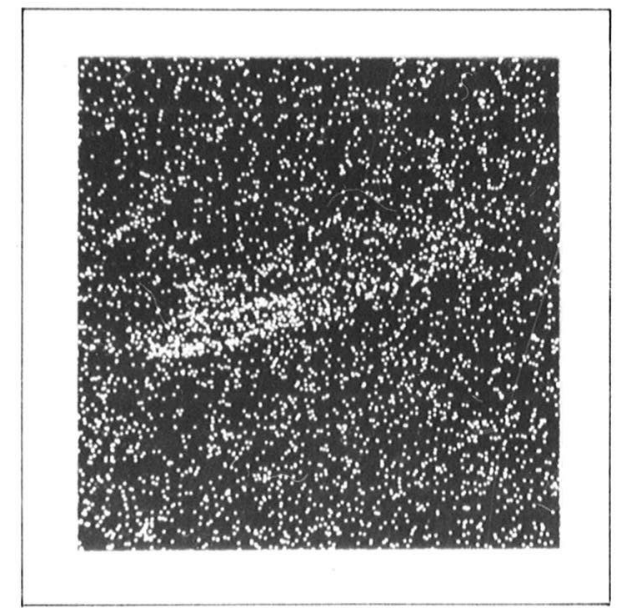

Foto 125 - Imagem "X" Cu K $\alpha$ mesma zona

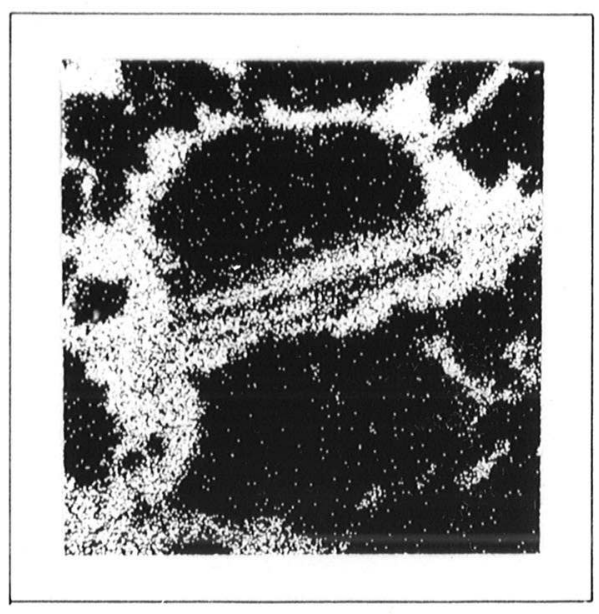

Foto 124 - Imagem "X" $\mathrm{Cu} \mathrm{K} \alpha$

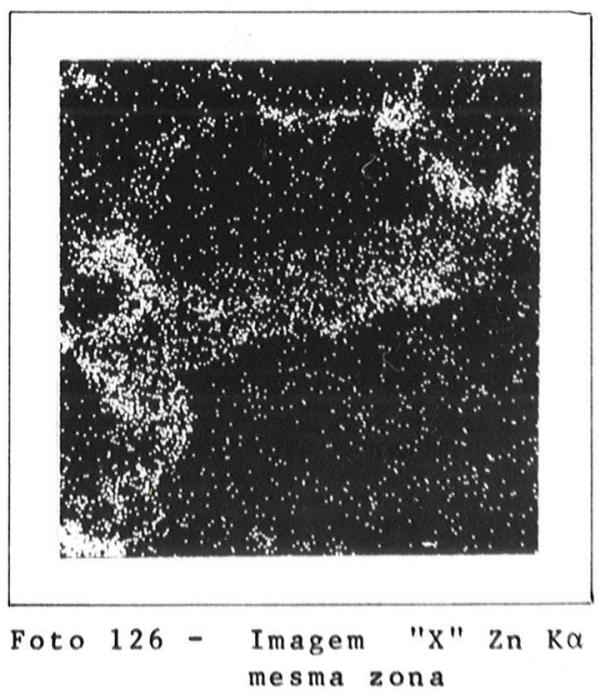



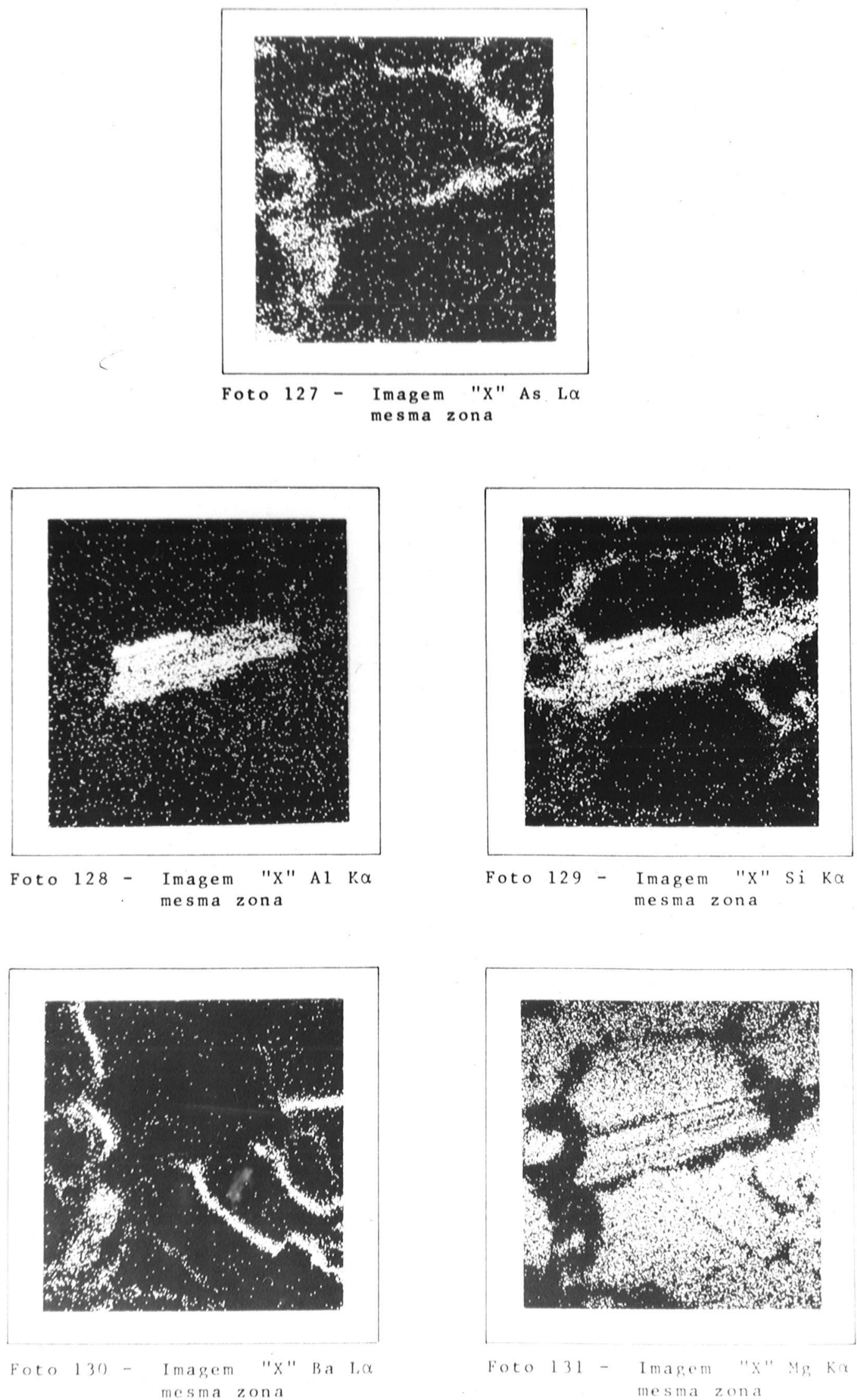

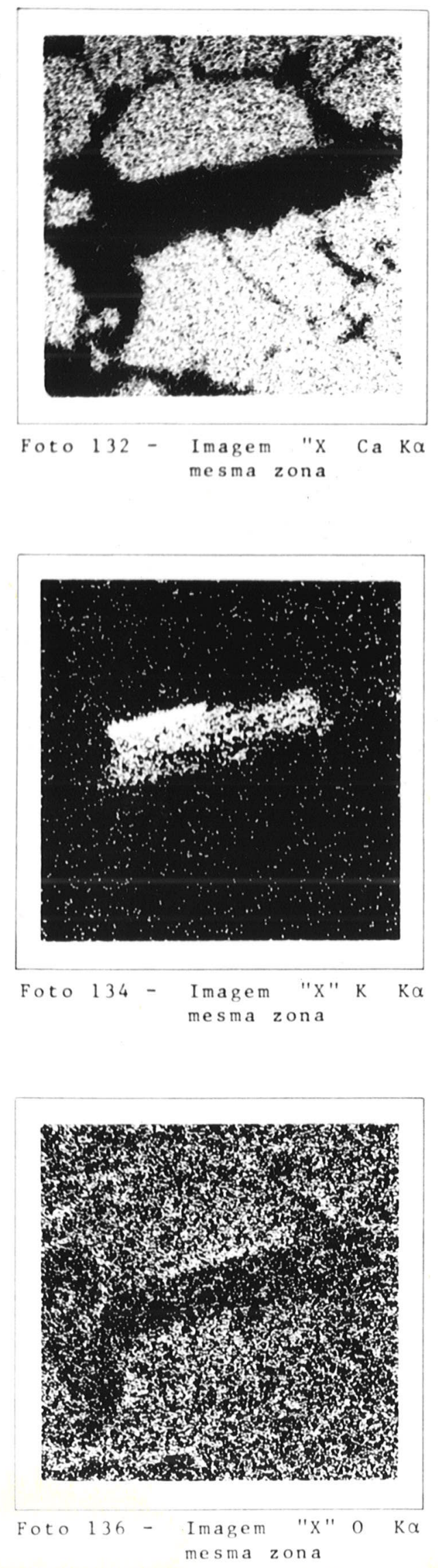
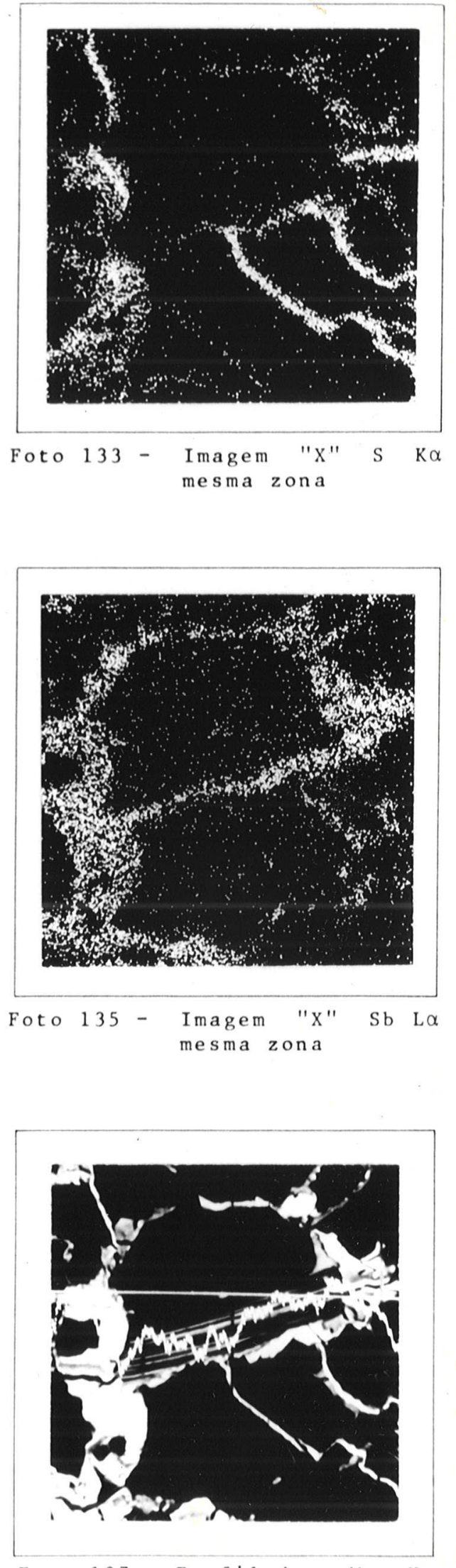

Foto 137 - Perfil de $M$ n $K \alpha$ 
da seção polida. o silicio (Foto 129) recobre parte do cam po abrangido pelo cobre e a concentraçäo abundante na azuri ta é devido ao grande aumento de imagem e sobretudo ao efei to de proximidade dos detectores de elétrons retroespalhados no centro do campo focalizado. o bärio (Foto 130) distribui-se em forma de veios, cortando tanto os cristais de dolomi ta como os de crisocola. o magnésio (Foto 131) tem preferên cia pela dolomita, ocorrendo em menor proporçäo na azurita e é ausente na crisocola. o cálcio (Foto 132) tem comportamento oposto ao cobre, instalando-se somente na dolomita, sen do o elemento mais abundante no campo focalizado. o enxofre (Foto 133) recobre perfeitamente o bário mostrando que os cristais de dolomita estão atravessados por veios microscö picos de barita.

o potássio (Foto 134) tem preferência para se associar ao aluminio no cristal de azurita. o antimônio (Foto 135) recobre parcialmente o cobre, sendo distribuido homogeneamente por toda crisocola e concentrando-se numa fai xa de azurita. o oxigênio (Foto 136) concentra-se preferen cialmente na dolomita, crisocola e barita, ocorrendo menos abundantemente na azurita. A detecção do oxigênio é dificul tada pelas proximidades do ângulo de captação do aluminio é pela proximidade do cristal analizador junto à amostra. As contagens para o oxigênio, em $10 \mathrm{~s}$, foram: $3710 \mathrm{cont} / \mathrm{s}$ na azurita, 3970 cont/s na barita, 2640 cont/s na dolomita e $1450 \mathrm{cont} / \mathrm{s}$ devidas a "background". O perfil de manganês (Foto 137) evidencia que este elemento prefere concentrar-se na dolomita, ficando ausente na azurita.

Não foram encontrados os elementos: Cr, Ir,Pt, $\mathrm{Pb}, \mathrm{Bi}, \mathrm{P}, \mathrm{Na}, \mathrm{Ag}$ e $\mathrm{Au}$, sendo este ültimo procurado tambēm atravês de linhas de perfis.

Paragênese - A azurita ocorre em regiões cal cärias (Winchell, 1967) e se altera mais facilmente para ma laquita, raramente cuprita e cobre metälico.

Segundo Delsner (1966) a azurita pertence à paragênese hidrotermal, associando-se aos minerais: barita, carbonatos, malaquita, goethita, bornita, covelita, lepido 
Rib. Perau

$\begin{array}{lc}d(A) & I / I_{0} \\ 5,61 & 5 \\ 5,34 & 95 \\ 4,22 & 10 \\ 3,77 & 5 \\ 3,64 & 80 \\ 3,50 & 100 \\ 3,30 & 25 \\ 3,08 & 30 \\ & \\ 2,81 & \\ 2,79 & 20 \\ 2,57 & 20 \\ 2,51 & 20 \\ 2,33 & 90 \\ 2,27 & \\ & 30 \\ & \\ & \\ & \\ 2,30\end{array}$

2,16

2,15

2,10

2,01

1,94

1,89

1,87

1,81

1,78

1,75

1,72

1,68

1,64

1,59

1,56

1,55

1,52

1,50

1,47

1,43

1,41

1,40

1,38

1,37

mais 64 inhas até $d=0,97 \AA$

CuKa $=1,5418 \AA$, Filtro $\mathrm{Ni}$ 20 horas $\quad 30 \mathrm{kV} \quad 15 \mathrm{~mA}$ Filme n: 28-3-71

Câmara de Gandolfi $114,6 \mathrm{~mm} \emptyset$ (monocrista1)

\section{Diagrama de Azurita}

Kingston, Ontario, Canadā
d $(\AA)$
$\mathrm{I} / \mathrm{I}_{\mathrm{o}}$
hk 1

5,15

70

011-002

3,89

3,79

3,66

3,52

5

012

20
40

110

100

111-102

3,10

2,97

2,91

20

I1 2

013

20

020

2,80

2,58

2,51

2,46

2,33

2,28

2,26

2,22

2,16

021

20

T13-004

20

60

113-120

121

014

30

30

30

30

10

T22 -210

21 11

023-211

2,09

2,00

10

114

1,94

1,89

1,87

1,82

1,78

1,75

1,72

1,69

1,64

114

123

015

1,59

1,56

1,55

1,52

1,51

1,47

1,45

1,42

1,41

1,40

1,38

1,37

5
30

5

5

20

20

5

5

5

5

30

10

5

10

20

20

5

20

5

5

10

$10 \mathrm{~B}$

Ficha ASTM No 11-136 
crocita, calcocita, neodigenita, tennantita, tetraedrita,frei bergita, schwartzita, jamesonita, meneghinita, calcopirita e ouro nativo.

A variação da composição química da azurita é devida à sua formação a partir de gel (Edwards, 1954), porém não foram notadas texturas coloformes caracteristicas. A in cipiente estrutura fibrosa observada, pode tambëm ser devida a deposição repetida, que não se estende atravës dos cristais vizinhos de outra espëcie (Edwards, 1954).

A azurita $\vec{e}$ um mineral de origem secundäria (Arruda, 1971) proveniente da ação de äguas bicarbonatadas so bre minerais sulfetados de cobre ou de soluções cupriferas so bre minerais carbonatados. Na jazida do Ribeirão do Perau a segunda alternativa parece ser a verdadeira pois os exames à microsonda eletrônica revelam que a azurita se formou a par tir de soluções contendo $C u, F e, Z n, A s, A l, K, S b$ e $B a, q u e$ se cristalizaram nos intersticios dos grãos de dolomita. A ba rita precedeu a formação de azurita. Durante a precipitação da azurita essas soluções devem ter dissolvido parte da dolo mita. O arsênico e antimônio provieram da tennantita, pois esse e o unico sulfeto de cobre da jazida que contëm esses me tais e que se associa, sempre, à azurita.

malaquita.

A malaquita do Ribeiräo do Perau associa-se

as minerais da zona oxidada da jazida. Exibindo cristais fi bro-radiados, bem cristalizados, é observada em massas de cuprita que compóem os vieiros de minério lixiviado das gale rias de pesquisa. Os cristais aciculares se dispõem em forma de leque; formando tufos, aproximadamente esféricos, distribui dos caoticamente na cuprita, apresentando 1 a $2 \mathrm{~cm}$ de diâme tro (Fotos 137 e 138). Nas rochas carbonäticas a malaquita preenche fraturas, assim como ocorre nas diaclases dos quart zitos sotopostos. Associada a estas rochas, a malaquita pos sui aspecto pulverulento, friävel, ora com estrutura concên trica e ora formando crostas sobre essas rochas, com milimetros 


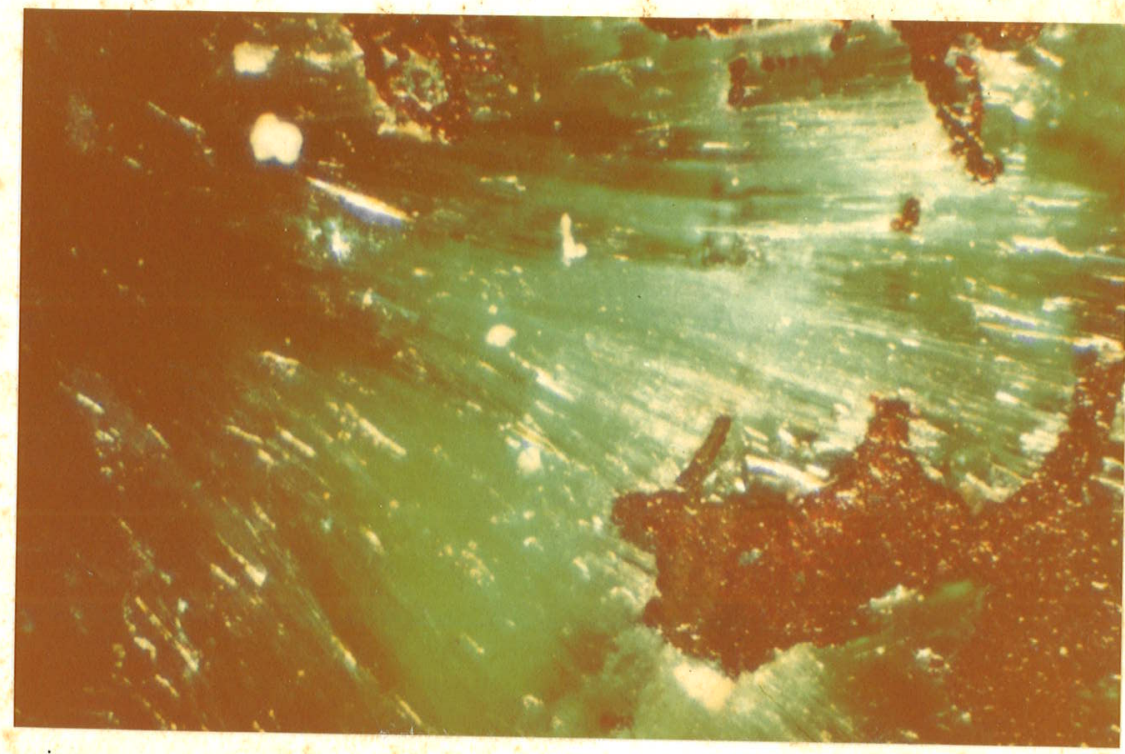

Foto 137 - Malaquita(vexde) exibindo estrutura fibro-radiada e quart zo limonitizado(marrom). Seção polida.Iluminação convergente. Nicois descruzados. Aumento 120 vezes

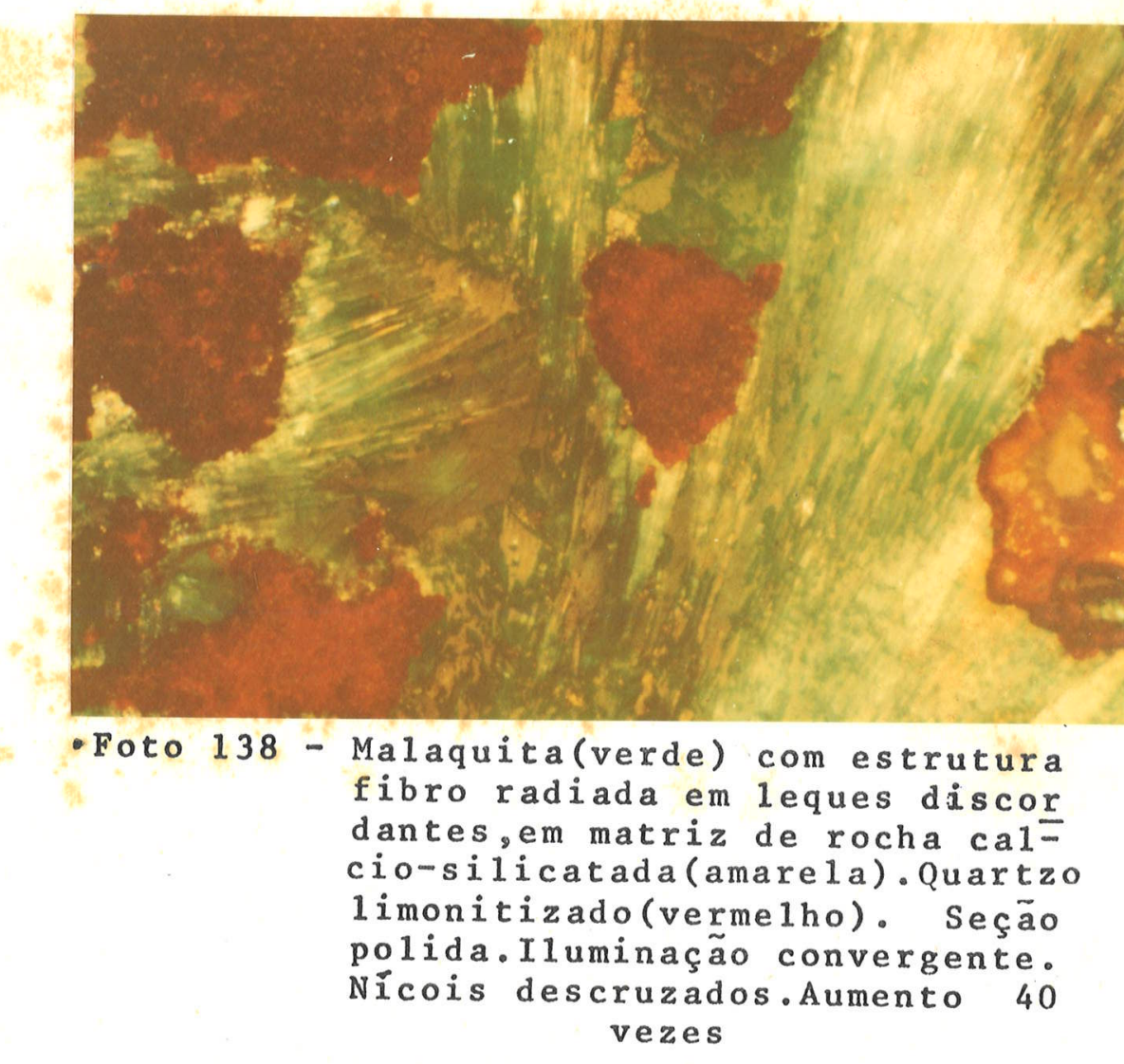


Tabe1a 17

Resumo dos resultados de ATD de Malaquita
T (-) S
$\mathrm{T}(-) \quad \mathrm{S}$
T (-)
S
Ref .

385 m 1

1090

m

1

$380 \mathrm{~m} 1$

2

410

3

$385 \mathrm{~m} 1$

42

$375 \mathrm{~m} 1$

$4 \mathrm{~b}$

$360 \mathrm{sb}$

5

$370 \pm 30 \mathrm{~m} 1$

930 v s

$1025-1050$

sb

6

$\mathrm{T}(-)=$ pico endotërmico; $\quad \mathrm{S}$ =intensidade; $\quad$ m = médio;

ml meio comprido; $s b=$ pequeno e largo; vs = muito pequeno

1 - Beck, Amer. Min., 1950, 35,985 (a curva termina a $1000^{\circ} \mathrm{C}$ ).

2 - Vitovskaya, Kora Vyvetrivaniya, 1960, 3, 74.

3 - Cocco, G. (1951) Carbonati basici di rame e zinco.

Periodico de Mineralogia - anno Xx, n. 1, p. 93.

4 - Arruda, M.R. (1972) Mineralogia da Mina de Cobre de

Santa Blandina, em Itapeva, Estado de São Paulo

(inëdito); 4 a = malaquita do Rib. do Perau. 4 b= malaquita de Itapeva.

5 - Malaquita do Ribeirão do Perau com crisocola.

6 - Godinho, M.M. (1968) Contribuição para o conhecimento

do comportamento tērmico da malaquite e azurite:

Memórias e Notícias, no 57, p . 7-19. 
de espessura.

Os difratogramas de raios $X$ pelo método do pó apresentam sequência de raias difusas que podem ser interpre tadas como devidas à amorfização, proveniente da trituração empregada na técnica desses exames roentgenogräficos (Camar go, 1965).

Propriedades físicas - A côr $\vec{e}$ verde intensa nos espëcimes bem cristalizados e verde com tonalidades escu ras e até quase brancas nas sequências alternadas nos "cris tais" com estrutura concêntrica. o brilho é sedoso, apresen tando clivagem e fratura irregular. Os häbitos exibem varie dades terrosas, maciças, aciculares, fibrosas e fibro-radiadas. Opticamente é biaxial negativa com fraco pleocroísmo. Em seções polidas mostra côr verde, translücida, clivagem e reflexões internas de tonalidades verdes.

Os diagramas de raios X(Tabela 18) obtidos a partir de monocristais exibem raias nitidas e distintas, ca racteristicas de material bem cristalizado. Secundariamente ocorrem espaçamentos interplanares devidos à calcocita, pseu domalaquita, $\mathrm{Cu}_{5}\left(\mathrm{PO}_{4}\right)_{2}(\mathrm{OH})_{4}$ e dolerophanita, $\mathrm{Cu}_{2}\left(\mathrm{SO}_{4}\right) 0$.

A Tabela 17 mostra os resultados de ATD de ma laquita do Ribeirão do Perau (colunas $4 a$ e 5) comparadas com as fornecidas pela literatura. A amostra 4 a foi descrita por Arruda (1971), comparando malaquita do Ribeirão do Perau com a de Itapeva. A malaquita se transforma em tenorita, ägua e $\mathrm{CO}_{2}$ por reação endotërmica que se inicia a $300^{\circ} \mathrm{C}$ (Go dinho, 1964). Se o aquecimento continuar, a tenoxita produz cuprita e libera oxigênio, em reação endotërmica que começa a $960^{\circ} \mathrm{C}$.

Microsonda eletrônica - Para estudo à micro sonda eletrônica foi escolhida parte de um cristal fibro-radiodo, numa região bastante redurida (aumento de 1200 vezes) pois os cristais de malaquita de estrutura concêntrica e tex tura coloforme apresontaram alternância com possiveis cama das microscópicas de crisocola. 


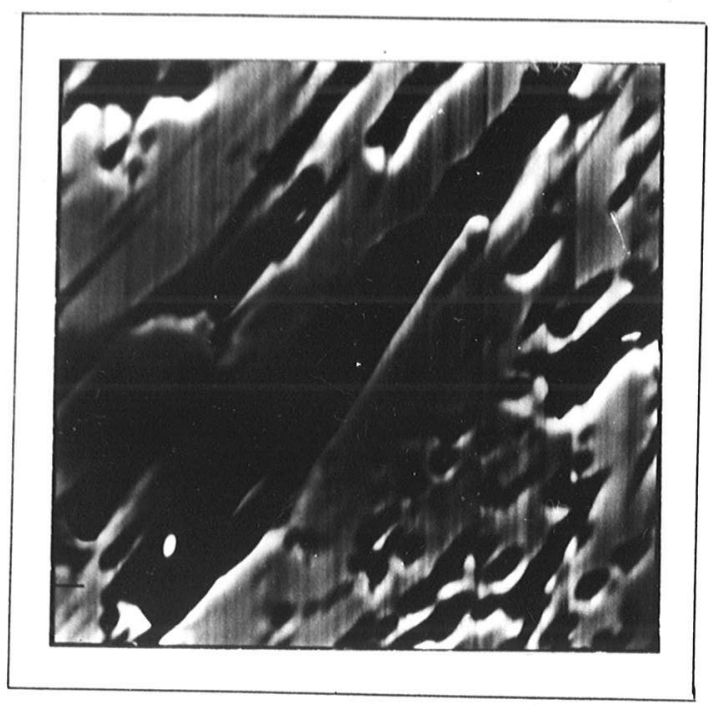

Foto 139 - Imagem eletrônica de malaquita fibro radiada. E, retroespalhados. $100 \times 100 \mu \mathrm{m}$.

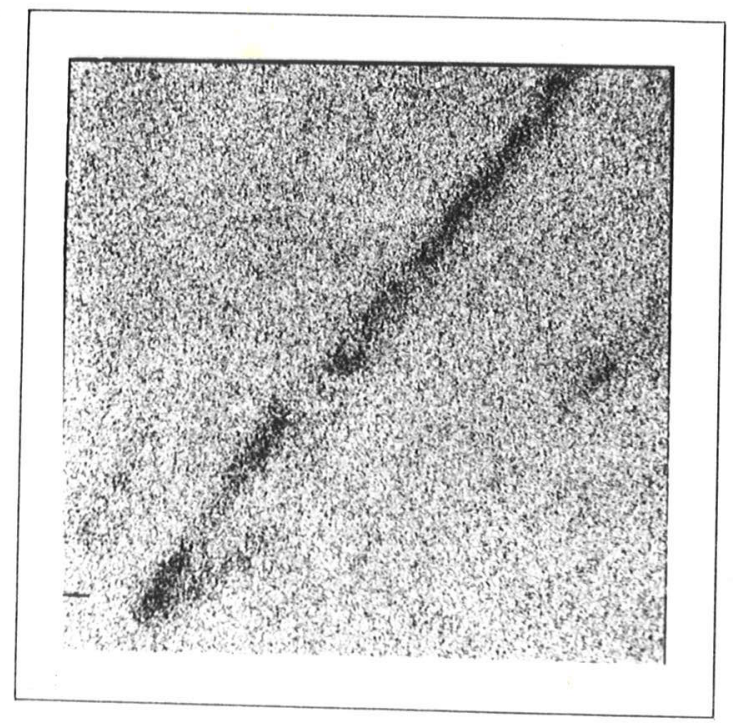

Foto 141 - Imagem "X" $\mathrm{Cu} \quad \mathrm{K} \alpha$ mesma zona

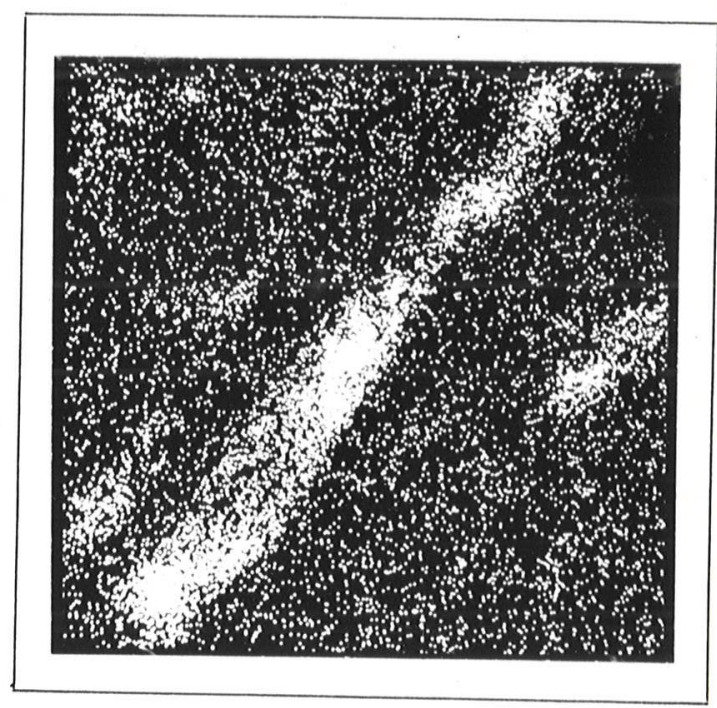

Foto 140 - Imagem "X" C $\mathrm{K} \alpha$ mesma zon a

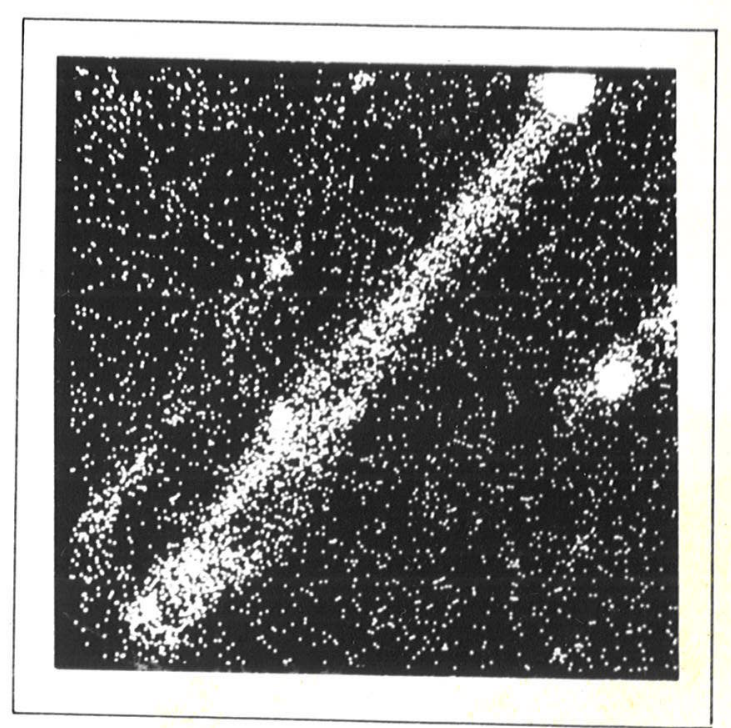

Foto 142 - Imagem "X" Fe K mesma zon a 


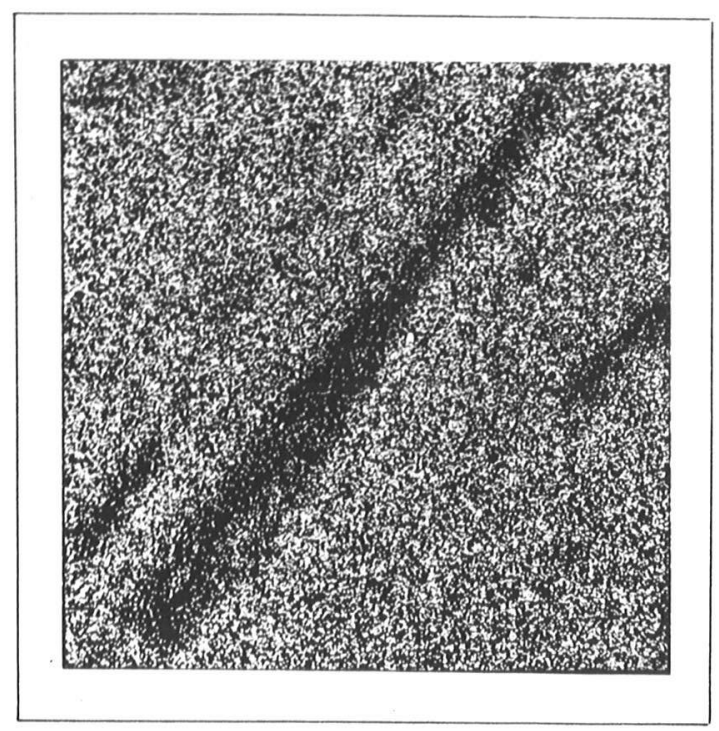

Foto 143 -Imagem "X"
mesma zona

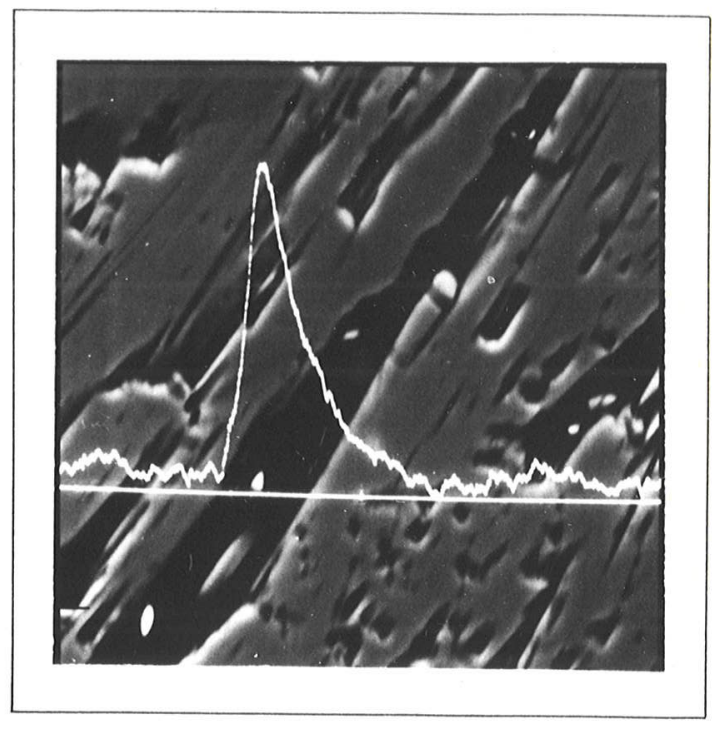

Foto 144 - Perfil de Pb L $\alpha$ mesma zona

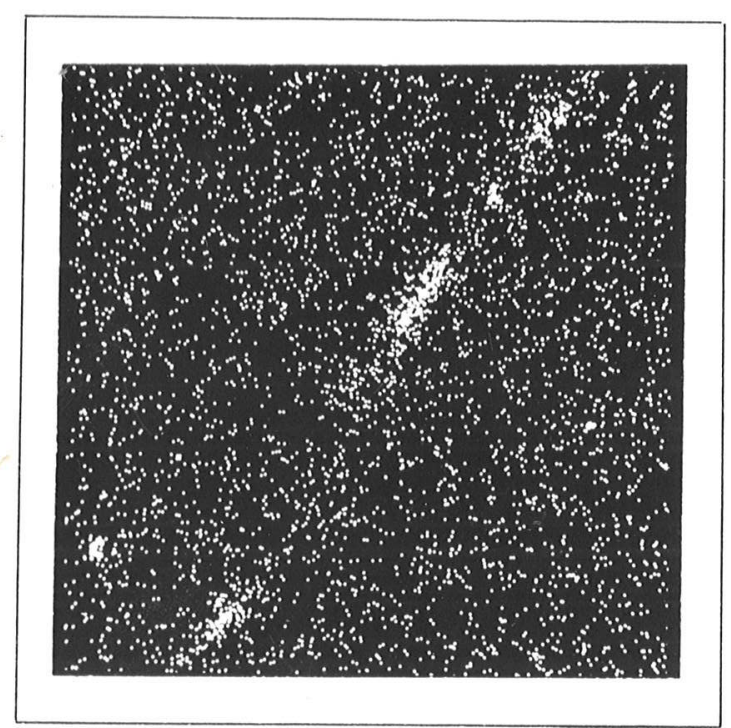

Foto 145 - Imagem "X" A1 K $\alpha$ mesma zona

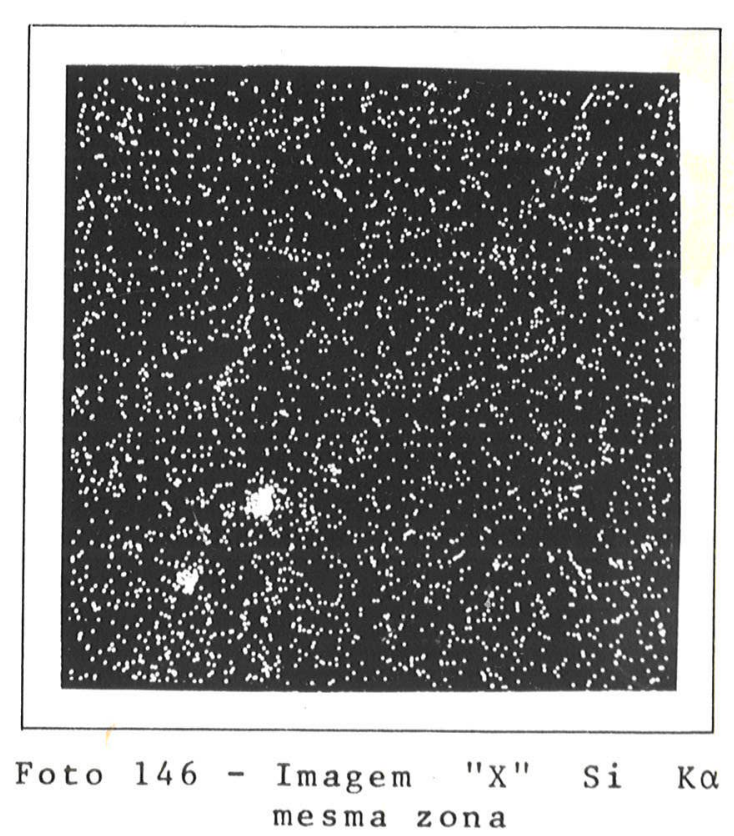


Tabela 18

Diagrama de Malaquita

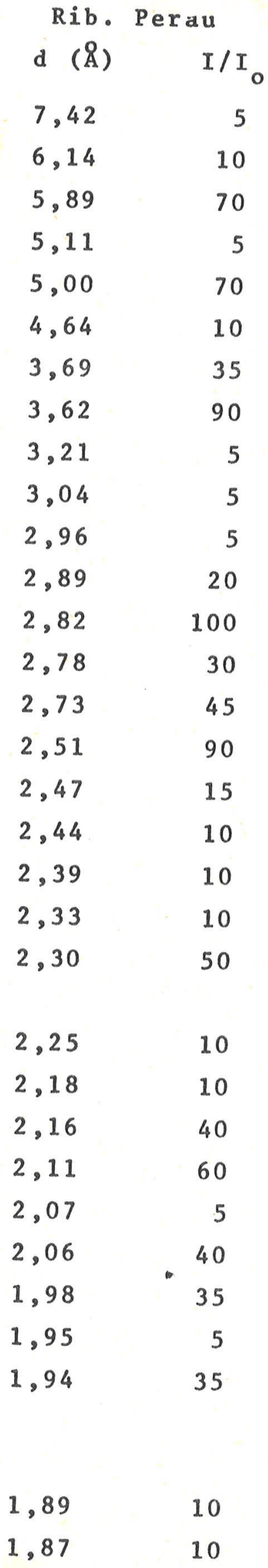

$\begin{array}{lll}d(\AA) & \text { I/I } & \text { hkl } \\ 7,41 & 11 & 110 \\ 5,993 & 55 & 020 \\ 5,055 & 75 & 120 \\ 4,699 & 13 & 200 \\ 3,693 & 85 & 220\end{array}$

3,028

17

310

2,988

17

040

2,857

100

2,828

40

$\overline{2} 01-140-186$

2,778

45

111-021

$320-\overline{2} 11$

2,520

55

240

2,477

30

201

2,464

35

330

2,349

13

400-131

2,316

17

$\overline{2} 31$

2,289

17

221

2,252

7

$\overline{3} 21$

2,186

20

2,160

7

$041-420-\overline{1} 41$

2,129

20

340

2,076

17

250

2,054

9

$\overline{3} 31$

1,991

11

311

1,969

17

060

1,947

15

321

1,941

160

1,911

9

$\overline{4} 21$

1,911

17

1,899

13

T52-241

1,885

3

350

510 
Tabela 18 (continuação)

Rib. Perau

$\begin{array}{cc}\text { d }(\AA) & \text { I/I。 } \\ 1,83 & 10 \\ 1,80 & 10 \\ 1,78 & 25 \\ 1,69 & 5\end{array}$

d (\&)

Sintētica

1,833

I/ I

hk 1

9

251

1,759

11

411

1,696

9

421-061

1,691

25

I 61

1,678

13

$1,65 \quad 70$

$1,65 \quad 5$

$1,63 \quad 5$

$1,61 \quad 10$

$1,59 \quad 15$

$1,57 \quad 70$

1,56

1,640

11

$\overline{2} 61$

1,616

17

431

1,589

17

$012-540$

1, 571

13

351

1,541

7

102

1,53

10

1,531

13

112

$1,53 \quad 20$

$1,52 \quad 20$

1,47

85

1,480

5

180

1,478

13

$\overline{6} 01$

1,45

1,476

17

$171-\overline{2} 32-550$

1,472

11

$\overline{3} 22-521$

1,41

30

1,422

7

$451-\overline{3} 32-531$

1,40

15

1,418

15

$\overline{4} 12$

1,406

5

242-551

1,38

30

1,386

640

1,362

232

1,352

380

mais 46 raias

1,349

11

308

$\mathrm{CuK \alpha}=1,5418 \mathrm{~A}, \mathrm{Fi} 1$ tro $\mathrm{Ni}$

24 horas $30 \mathrm{kV} \quad 15 \mathrm{~mA}$

Filme n: 26372

Ficha ASTM No 10399

Câmara de Gandoldi $114,6 \mathrm{~mm} \emptyset$ (monocristal) 
xas escuras com predominância de C, Fe e Al, respectivamente. Fotos 140, 142 e 145, alternando-se com faixas claras, onde é maior a concentração de $C u$ e 0 , fotos 141 e 143 , sendo que por todo campo focalizado hä distribuição de o e C. 0 sili cio (Foto 146) aparece concentrado em dois pontos isolados e - perfil de $\mathrm{Pb}$ (Foto 144) mostra que esse elemento se insta 12 preferencialmente nas äreas de ocorrência dos elementos $\bar{C}$, Fe e Al.

Na malaquita estudada não foram encontrados os seguintes elementos: $M n, Z n, N i, C o, C r, P t, A u, B i, S e$, $\mathrm{Ir}, \mathrm{Hg}, \mathrm{Na}, \mathrm{S}, \mathrm{P}, \mathrm{K}, \mathrm{Sb}, \mathrm{Ba}, \mathrm{Ag}, \mathrm{As}$.

A abundância de carbono e oxigênio não permi te confundir a malaquita estudada com o mineral atacamita (Winche11, 1967).

Paragênese - A malaquita ocorre nas zonas oxi dadas dos depósitos de cobre, especialmente em regióes cal cärias (Winchel1, 1967). A paragênese da malaquita do Ribeí rão do perau é em tudo semelhante à da azurita, mesmo para as variedades cristalinas e coloformes. E de se notar, porém que a azurita tem preferência paragenética com a tennan tita, embora nessa associação a malaquita ocorra em quantida des subordinadas em relação à azurita.

goethita

Diversos öxidos e hidröxidos de ferro ocorrem marida sendo a goerhita o mais facilmente identificävel em diagramas de raios X (Tabela 19).

A goethita é frequente em todos os niveis da jazida, estando presente no material de intemperismo mesmo nos xistos encaixantes dastrochas calcio-silicatadas, portado ras do minério. Pode ser observada microscopicamente formando as faixas que compõem a textura coloforme que circunda calcopirita e tennantita.

propriedades físicas - A côr ë marrom averme 1hado, sem brilho e o häbito é terroso, formando massas poro 
Tabela 19

Diagramas de Quartzo e Goethita

Rib. Perau

d ( $\quad I / I_{0}$ $4,25 \quad 5$

$3,33 \quad 100$

$2,70 \quad 40$

$2,51 \quad 60$

$2,44 \quad 10$

$1,91 \quad 10$

$1,81 \quad 10$

$1,54 \quad 20$

$1,45 \quad 10$

$1,37 \quad 10$

$\mathrm{CuK} \alpha=1,5418 \AA$,

Filtro Ni

24 horas

$30 \mathrm{kV}$

$15 \mathrm{~mA}$

Filme n: 8772

Câmara de Gan-

do1fi $114,6 \mathrm{~mm} \emptyset$

(monocrista 1)
Ficha ASTM No 5-0494 Quartzo Alfa

Lake Toxaway

Goethita

Cornwa11, Inglaterra

d ( $) \quad I / I_{0} \quad h k 1$

d ( $) \quad I / I_{0} \quad h k I$

$4,26 \quad 35 \quad 100$

$4,21 \quad 100$

110

$3,343 \quad 100 \quad 101$

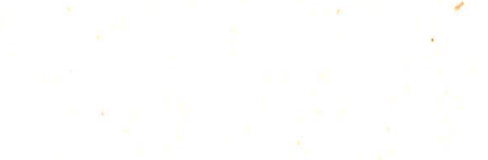

2,69

80

130

$2,51 \quad 10 \mathrm{R}$

$2,458 \quad 12 \quad 110$

$2,440 \quad 70$

111

$1,920 \quad 10 \quad 041$

$1,817 \quad 17 \quad 112$

$1,803 \quad 20$

211

$1,541 \quad 15 \quad 211$

$1,453 \quad 3 \quad 113$

1,452

20

022

$1,375 \quad 10 \quad 203$

$1,360 \quad 10$

170
Ficha ASTM № 8-97 
sas. Em luz refletida mostra côr cinza, fraca anisotropia e reflexões internas.

Paragênese - E mineral típico de zona de oxi dação, formado por intemperismo de minerais que contëm fer ro como magnetita, siderita, pirita, calcopirita, bornita. As socia-se a hematita, lepidocrocita, material limonitico, pi rolusita, psilomelano, manganita, calcita e quartzo. A goe thita é estável em presença de ägua entre $0^{\circ}$ a $100^{\circ} \mathrm{C}$ (Deer, 1962). transformando-se em hematita a $125^{\circ} \pm 15^{\circ} \mathrm{C}$ (Edwards, 1954) em meio neutro e, a $165^{\circ} \pm 5^{\circ} \mathrm{C}$, em meio alcalino.

óxido de manganês e óxido de cobre

No minério oxidado de forma filonar, que ocor re nas galerias de pesquisa, e frequente a associação de öxí dos de Mn e Cu, formando pseudo minerais de forma não bem dé finida, às vezes de contorno aproximadamente esfërico, de $2 \mathrm{~mm}$ de diâmetro, disseminados em matxiz de cuprita. Nessas massas de cuprita, associando-se aos öxidos de Mn, e Cu, sem pre ocorrem esférulas disseminadas de crisocola de 3 a $5 \mathrm{~mm}$ de diâmetro, de tonalidades azuis alternadas em faixas, com característica textura coloforme. Não é raro o aparecimento de öxidos de Mn e Cu dentro das esférulas de crisocola.

Propriedades físicas - A côr ê preta; o brilho macroscopicamente se confunde com vitreo ou metalico, a fra tura é tipicamente concóide. Microscopicamente a substância $\vec{e}$ transparente, isótropa, com tenue reflexão interna. Os da gramas de raios $X$, em câmara de Gandolfi, indicam tratar-se de substância amorfa. Alguns diagramas, obtidos pelo método do pó, mostraram impurezas de malaquita e $\mathrm{BMnSiO}_{3}$. $^{\circ}$

Microsonda eletrônica - A foto 147 mostra um espēcime de öxido de Mn e Cu em matriz de crisocola, em cam po de $400 \times 400 \mathrm{~mm}$. Pode-se notar uma incipiente estrutura concêntrica, cortada por filetes brancos mais ricos em sili cio (Foto 149). O manganês (Foto 150) è o metal predominante, estando concentrado nesse tipo de estrutura concêntrica, e ausente na matriz de crisocola. o cobre ocorre secundaria 


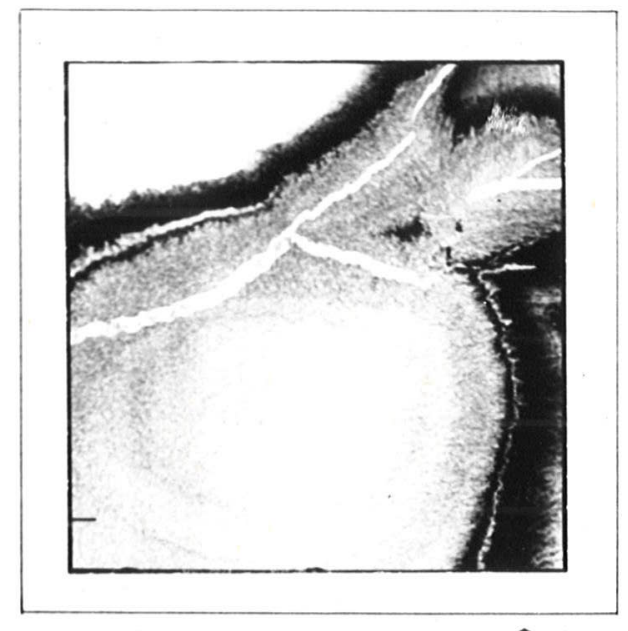

Foto 147 - Imagem eletrônica de óxido de Mn e de Cu.E. retroespalhados. $400 \times 400 \mu \mathrm{m}$. Ma triz de crisocola.
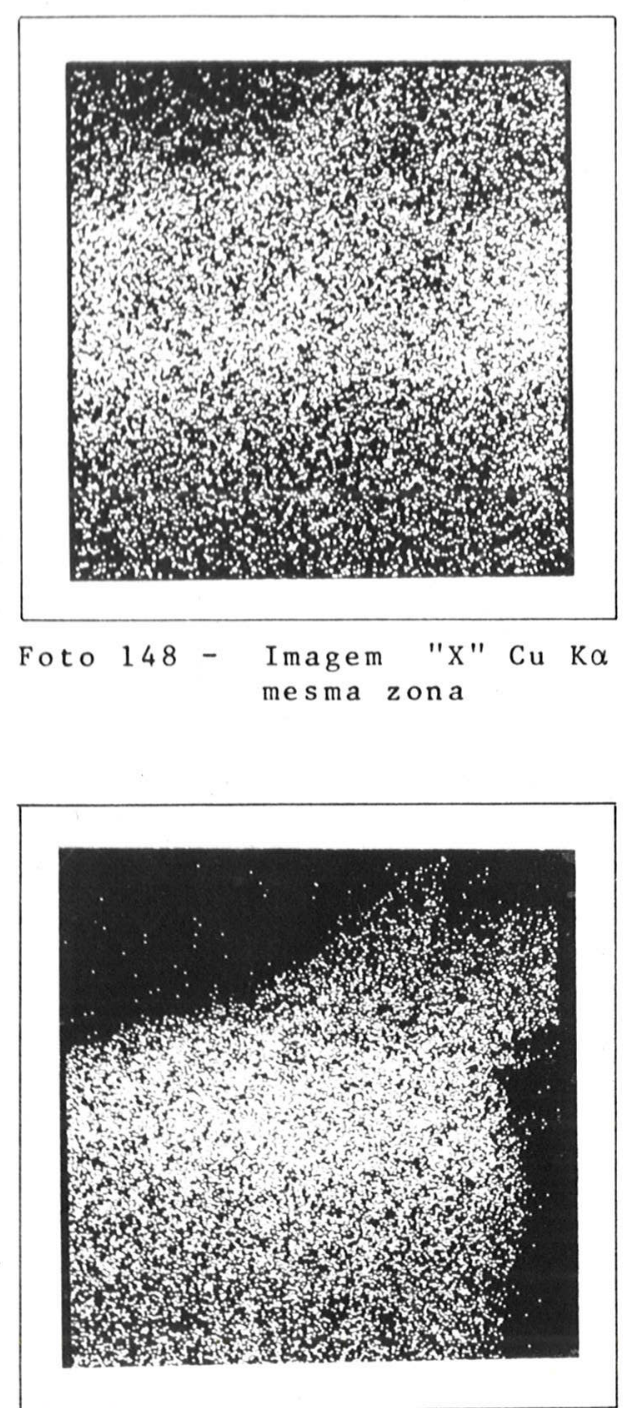

Foto 150 - Imagem "X" Mn K $\alpha$ mesma zona
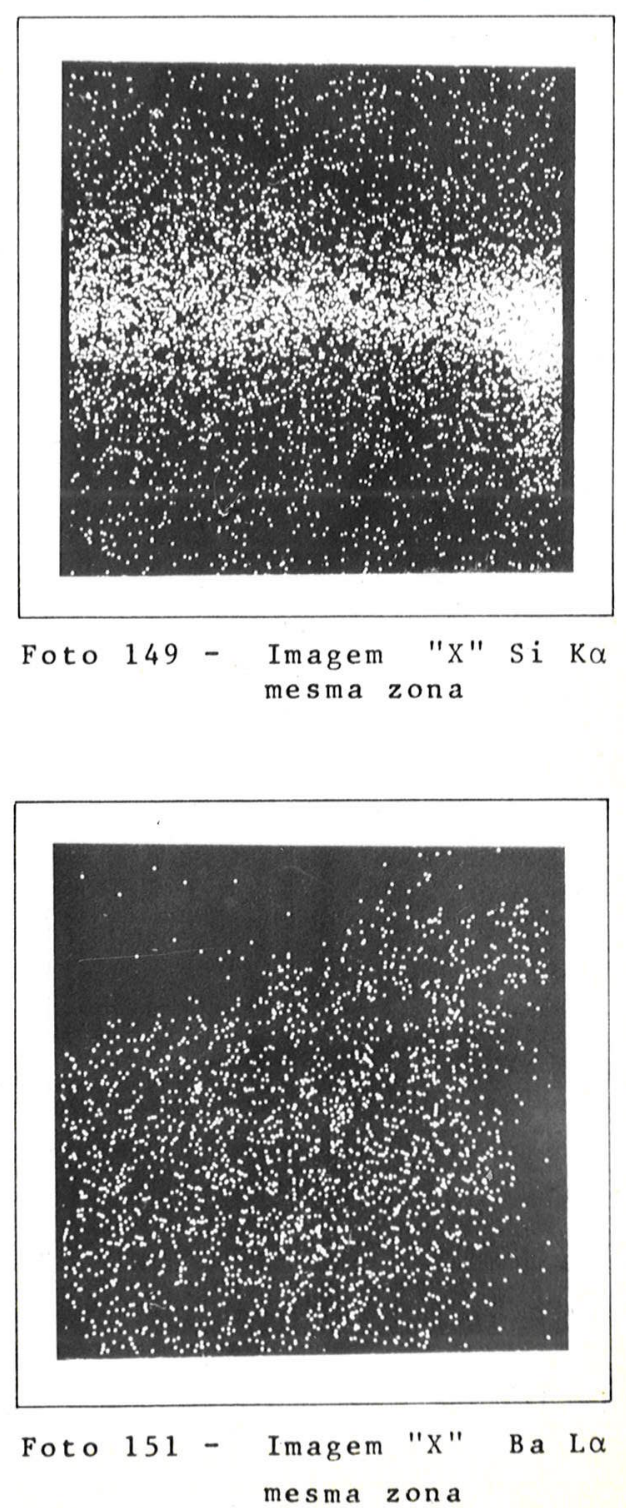
mente (Foto 148) estando regularmente distribuido por todo campo estudado. 0 bärio (Foto 151) em menor quantidade que Mn e Cu é restrito ao öxido focalizado.

o oxigênio é abundante, e um ponto interno à estrutura concêntrica forneceu 3260 cont/s, em $10 \mathrm{~s}$, contra $1870 \mathrm{cont} / \mathrm{s}$, na crisocola. O Fe e Co foram detectados em razão de ppm. São ausentes os seguintes elementos: $\mathrm{Zn}, \mathrm{Pb}$, $\mathrm{Ni}, \mathrm{Bi}, \mathrm{As}, \mathrm{Pt}, \mathrm{Au}, \mathrm{Na}, \mathrm{Se}, \mathrm{Ir}, \mathrm{Ca}, \mathrm{S}, \mathrm{P}, \mathrm{K}, \mathrm{Sb}, \mathrm{e} \mathrm{Ag}$.

A incipiente estrutura concêntrica e a associa ção com minerais oxidados de cobre indicam que os óxidos de Mn e Cu devem ter-se "solidificado" a partir de um gel, pro veniente de solução aquosa, na zona de oxidação da jazida.

Minerais de origem metamörfica

turmalina

A turmalina do Ribeirão do Perau ocorre associada a diversos minerais, formando veios de poucos centi metros de espessura com dezenas de metros de extensão, os quais cortam diagonalmente os xistos da jazida. Nos quartzi tos, sotopostos aos xistos, o prolongamento desses veios ainda não foi encontrado durante a pesquisa de campo.o quart zo $\bar{e}$ o mineral frequentemente associado à turmalina, ocorren do barita em quantidades subordinadas; cristais submilimétri cos de calcopirita podem ser encontrados excepcionalmente na associação turmalinífera.

Os cristais de turmalina formam agregados de centenas de indivíduos não orientados em relação uns aos ou tros, possuindo de 1 a $2 \mathrm{~mm}$ de espessura e cerca de $1 \mathrm{~cm}$ de comprimento. A turmalina ocorre também entre fraturas de veios de quartzo intensamente diaclasado onde apresenta häbi to pulverulento, côr cinza preto, podendo ser confundida, à primeira vista, com grafita ou matéria carbonosa, mas facil mente distinta pela sua alta dureza.

Propriedades morfolögicas - As formas cristalogräficas mais frequentes são $\{10 \overline{1} 0\}$ e $\{01 \overline{1} 0\}, 0$ häbito é 
prismätico acicular, conforme descrito por V.Goldschmidt (1913). As formas citadas não possuem combinação com pirâmi de trigonal e as faces prismäticas são estriadas longitudi nalmente.

Propriedades fisicas - A côr è preta e o bri Tho vítreo; a fratura apresenta-se com aspecto subconcoide, a clivagem é ausente (Camargo et al., 1970).

opticamente o mineral é uniaxial negativo,sen do verde escuro e claro em seção delgada, nas posições de má ximo pleocroísmo e, em lâminas espessas, apresenta pleocroís mo marrom escuro e marrom claro. Pelo método de imersão os indices revelaram os seguintes valores $\xi=1,629$ e $\omega=1,645$. Fazendo-se uso do gráfico de winchell (1951) para a "Série Dravita-Schorlita"(Fig. 24) os valores dos indices de refra ção, encontrados classificam os exemplares como dravita, com 20 a $40 \%$ de shorlita.

Fig. 24 - SÉRIE DRAVITA - SCHORLITA

(Winchell, 195I)

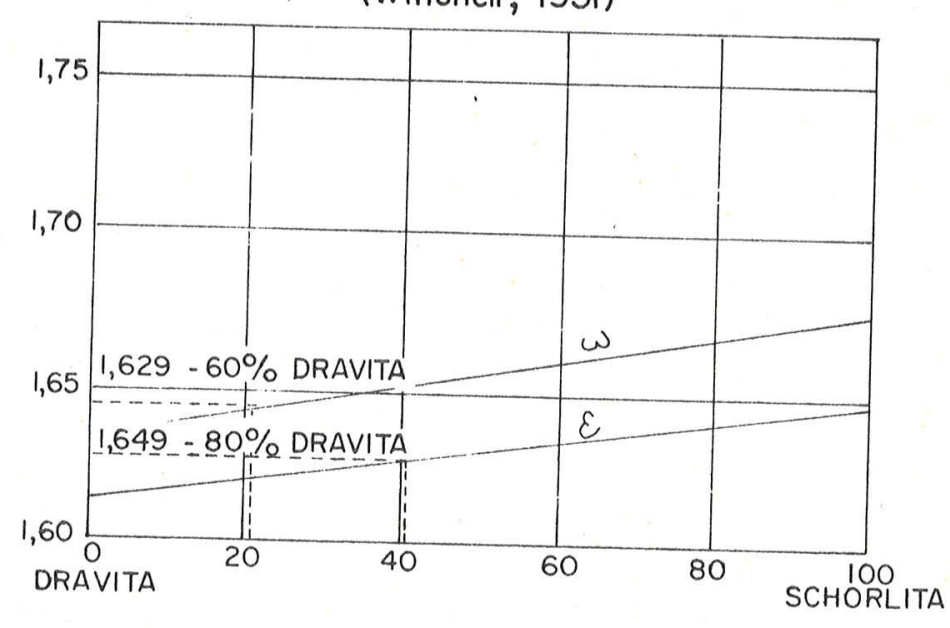


Tabela 20

\begin{tabular}{|c|c|c|c|c|c|c|c|c|}
\hline d $(\AA)$ & d $(\AA)$ & hk 1 & d. (§) & hk 1 & $Q$ & $f($ Taylor $)$ & $A_{0}$ & $c_{0}$ \\
\hline $\begin{array}{l}\text { urmalina } \\
\text { e } \\
\text { luorita }\end{array}$ & $\begin{array}{c}\text { Turmalina } \\
\text { ASTM }\end{array}$ & Turmalina & $\begin{array}{c}\text { Fluorita } \\
\text { ASTM }\end{array}$ & Fluorita & $\begin{array}{c}\text { Turmalina } \\
\text { e } \\
\text { Fluorita }\end{array}$ & $\begin{array}{l}\text { Turmalina } \\
\text { e } \\
\text { Fluorita }\end{array}$ & $\begin{array}{c}\text { Turmalina } \\
\text { e } \\
\text { Fluorita }\end{array}$ & Turmalina \\
\hline 6,322 & 6,38 & 101 & & & 0,02502 & 8,074 & 15,713 & 7,137 \\
\hline 4,925 & 4,98 & 021 & & & 0,04122 & 6,231 & 15,713 & 7,137 \\
\hline 4,588 & 4,60 & 300 & & & 0,04750 & 5,771 & 15,893 & 7,132 \\
\hline 4,203 & 4,22 & 211 & & & 0,05660 & 5,259 & 15,893 & 7,132 \\
\hline 3,963 & 3,99 & 220 & & & 0,06367 & 4,500 & 15,852 & 7,189 \\
\hline 3,478 & 3,48 & 012 & & & 0,08267 & 4,278 & 15,852 & 7,189 \\
\hline 3,332 & 3,38 & 131 & & & 0,09007 & 4,075 & 15,603 & $i, 256$ \\
\hline 3,153 & & & 3,153 & 111 & & 3,830 & 5,461 & \\
\hline 2,958 & 2,961 & 122 & & & 0,11428 & 3,561 & 15,603 & 7,256 \\
\hline 2,574 & 2,576 & 0.42 & & & 0,15093 & 3,020 & 15,913 & 7,199 \\
\hline 2,399 & 2,396 & 003 & & & 0,17375 & 2,774 & 15,913 & 7,199 \\
\hline 2,377 & 2,376 & 232 & & & 0,17690 & 2,736 & 15,933 & 7,199 \\
\hline 2,343 & 2,342 & 511 & & & 0,18210 & 2,639 & 15,933 & 7,199 \\
\hline 2,127 & 2,127 & 303 & & & 0,22103 & 2,372 & 15,933 & 7,199 \\
\hline 2,041 & 2,040 & 152 & & & 0,24006 & 2,245 & 15,933 & 7,199 \\
\hline 1,934 & & & 1,931 & 220 & & 2,084 & 5,470 & \\
\hline 1,822 & 1,828 & 710 & & & 0,30124 & 1,912 & 15,885 & 7,194 \\
\hline 1,783 & 1,784 & 104 & & & 0,31456 & 1,852 & 15,885 & 7,194 \\
\hline
\end{tabular}


Tabela 20 (continuação)

\begin{tabular}{|c|c|c|c|c|c|c|c|c|}
\hline d ( $(\AA)$ & d $(\AA)$ & hkl & d ( $(\AA)$ & hk 1 & $Q$ & $f($ Taylor $)$ & $A_{0}$ & $c_{0}$ \\
\hline $\begin{array}{l}\text { urmalina } \\
\text { e } \\
\text { luorita }\end{array}$ & $\begin{array}{c}\text { Turmalina } \\
\text { ASTM }\end{array}$ & Turmalina & $\begin{array}{c}\text { Fluorita } \\
\text { ASTM }\end{array}$ & Fluorita & $\begin{array}{c}\text { Turmalina } \\
\text { e } \\
\text { Fluorita }\end{array}$ & $\begin{array}{c}\text { Turmalina } \\
\text { e } \\
\text { Fluorita }\end{array}$ & $\begin{array}{c}\text { Turmalina } \\
\text { e } \\
\text { Fluorita }\end{array}$ & Turmal ina \\
\hline 1,744 & 1,742 & 024 & & & 0,32878 & 1,791 & 15,918 & 7,209 \\
\hline 1,689 & 1,690 & 262 & & & 0,35054 & 1,706 & 15,918 & 7,209 \\
\hline 1,661 & 1,660 & 603 & & & 0,36246 & 1,661 & 15,941 & 7,199 \\
\hline 1,648 & & & 1,647 & 311 & & 1,640 & 5,465 & \\
\hline 1,594 & 1,592 & 550 & & & 0,39357 & 1,554 & 15,941 & 7,199 \\
\hline 1,545 & 1,5456 & 461 & & & 0,41893 & 1,475 & 15,923 & 7,199 \\
\hline 1,508 & 1,5056 & 054 & & & 0,43975 & 1,413 & 15,923 & 7,199 \\
\hline 1,458 & 1,4555 & 514 & & & 0,47043 & 1,330 & 15,984 & 7,199 \\
\hline 1,432 & 1,4318 & 015 & & & 0,48765 & 1,286 & 15,984 & 7,199 \\
\hline 1,368 & & & 1,365 & 400 & & 1,179 & 5,471 & \\
\hline 1,315 & 1,3095 & 1010 & & & 0,57830 & 1,085 & 15,997 & 7,199 \\
\hline 1,282 & 1,2765 & 505 & & & 0,60760 & 1,028 & 15,997 & 7,199 \\
\hline 1,255 & & & 1,253 & 331 & & $0 ; 979$ & 5,470 & \\
\hline 1,117 & & & 1,115 & 422 & & 0,727 & 5,471 & \\
\hline 1,051 & & & 1,051 & 511 & & 0,597 & 5,461 & \\
\hline 0,9663 & & & 0,9657 & 440 & & 0,427 & 5,466 & \\
\hline 0,9235 & & & 0,9233 & 531 & & 0,335 & 5,463 & \\
\hline 0,8642 & & & 0,8637 & 620 & & 0,209 & 5,465 & \\
\hline 0,8331 & & & 0,8330 & 533 & & 0,140 & 5,462 & \\
\hline
\end{tabular}


Fig. 25 RELAÇÃO PARAMÉTRICA DA TURMALINA E DIMENSÕES DA CELA UNITÁRIA

(Epprecht, 1953 e W.A. Deer, 1962)
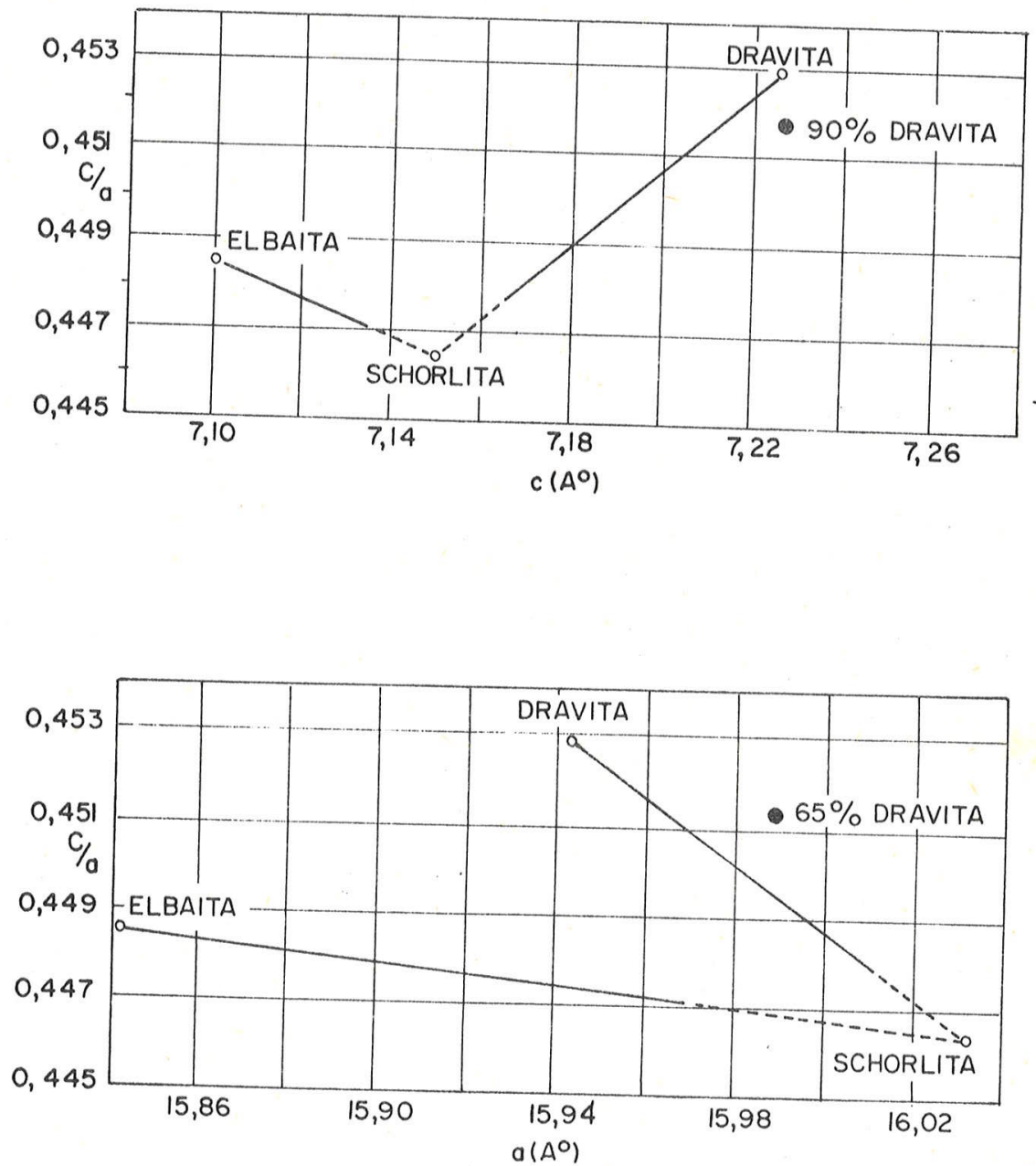
Cela unitäria - As dimensões da cela unitäria foram calculadas pelas distâncias interplanares medidas em filmes de difração de raios $x$, em câmara Debye-scherrer (diâ metro $114,6 \mathrm{~mm}, \operatorname{Cuk} \alpha)$.

A Tabela 20 exibe os valores de "d" da turma lina e da fluorita, esta servindo como padrão interno.

Pelas fórmulas $Q=\frac{4}{3} a *^{2}\left(h^{2}+h k+k^{2}\right)+1^{2} c *^{2} \quad$ e $Q=1 / d^{2}$, foram determinados os valores individuais de a* e $c^{*}$; associando-se duas oquações sucessivas de $Q$, e com os quais se calcularam os parâmetros $a_{0} e c_{0}$ correspondendo ao conjun to de duas medidas. Estes valores permitiram extrapolar, pe 1o método grä́ico-analítico (Camargo e Inglez, 1957) os parâa metros mais provāveis da turmalina:

$$
\begin{aligned}
& a_{0}=15,995 \pm 0,003 \\
& c_{0}=7,229 \pm 0,003
\end{aligned}
$$

tendo os exros sido calculados pela förmula e $= \pm \sqrt{\frac{\sum v_{i}^{2}}{n(n-1)}}$ onde $v_{i}$ corresponde aos desvios individuais.

A relação paramétrica e as dimensões da cela unitäria (Deer, 1962) (Sërie Elbaita-Schorlita-Dravita) indi cam (Fig. 25) a turmalina estudada como correspondente ao termo Dravita $(65-90 \%)$ - Schorlita $(35-10 \%)$.

\section{Microsonda eletrônica - A foto 152 mostra a} imagem eletrônica de dois cristais de turmalina, o menor em corte aproximadamente perpendicular ao eixo $E_{3}$. A Fig. 26 fornece os elementos encontrados no campo estudado.

o alumínio (Foto 153) demonstra bastante cons traste em relação à matriz de quartzo apesar de a metalização da seção polida ter sido preparada com aluminio. Este ele mento e o ferro (Foto 156) parecem estar mais concentrados na turmalina de tamanho maior donde se deduz que seria efei to de distorsão dos elétrons retroespalhados no centro do campo em estudo, ou sexia devido à posição dos cristais de turmalina pois os exames roentgenogräficos e de indices de refração classificam a turmalina na sẻrie $65-90 \%$ dravita- 
-35-10\% schorlita e segundo Epretch, 1953, em Deer, 1962, a dravita possui estrutura hexagonal do grupo $\mathrm{si}_{6}{ }^{0}{ }_{18}$, a elbai ta possui estrutura ditrigonal e a schorlita deve apresentar uma estrutura intermediäria.

$$
\text { o magnésio (Foto 155), o ferro (Foto 156) e }
$$

- södio (Foto 158), se recobrem nas turmalinas estudadas. o sódio pode ser substituído por potássio ou cálcio, satisfei tas as condições de valência.

A matriz de quartzo contëm essencialmente ti tânio (Foto 157) em quantidade maior que o silicio (Foto 154), secundariamente contẻm cälcio (Foto 160) e em menor proporção cobre (Foto 159). Essa matriz não deve ser Fe Ti $0_{3}$ porque não contēm ferro, mas sim um silicato ou óxido de cälcio e titânio.

A quantidade de ferro nas turmalinas é bem inferior à de alumínio e magnësio. o cálcio (Foto 160)ocor re nas amostras em pequena proporção em relação a cālcio existente na matriz e sem dúvida deve ter seu controle dado pelos minerais encaixantes (Deer, 1962). A presença de cä1 cio em pequena proporção não seria responsāvel pela molécu 1 a de uvita (Knitz, 1929 em Deer, 1962), mas pode aumentar os indices de refração e peso especifico e reduzir a birre fringência. 0 perfil de crômio (Foto 162) mostra que esse elemento ocorre nas turmalinas em quantidades subordinada mente inferiores aos demais elementos.

o cobre (Foto 159) se concentra nos pontos pretos da imagem eletrônica (Foto 152) onde estä distribuí do tambëm o oxigênio (Foto 161), portanto o cobre deve es tar ocorrendo sob a forma de öxido. o oxigênio (Foto 161) forneceu $368 \mathrm{cont} / \mathrm{s}$ em $10 \mathrm{~s}$ na região do silício,974 cont/s nas turmalinas e 1110 cont/s no campo do cobre. No campo estudado não foram encontrados: $\mathrm{Zn}, \mathrm{Sn}, \mathrm{Ba}, \mathrm{K}, \mathrm{S}, \mathrm{F}, \mathrm{Va}, \mathrm{P}$ e Mn .

A ausência de manganês excluiu a possibilida de de segregação dos termos tsilaisita e rubellita (Ito e Sadanaga, 1951, em Deer, 1962). O ferro, o manganês e o 


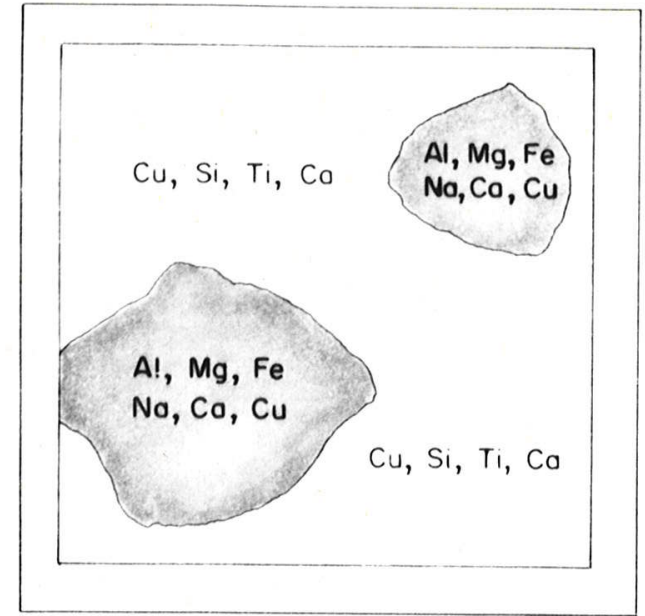

Fig.26-Síntese dos elementos presentes em dois cristais de turmalina, em matriz de quartzo.

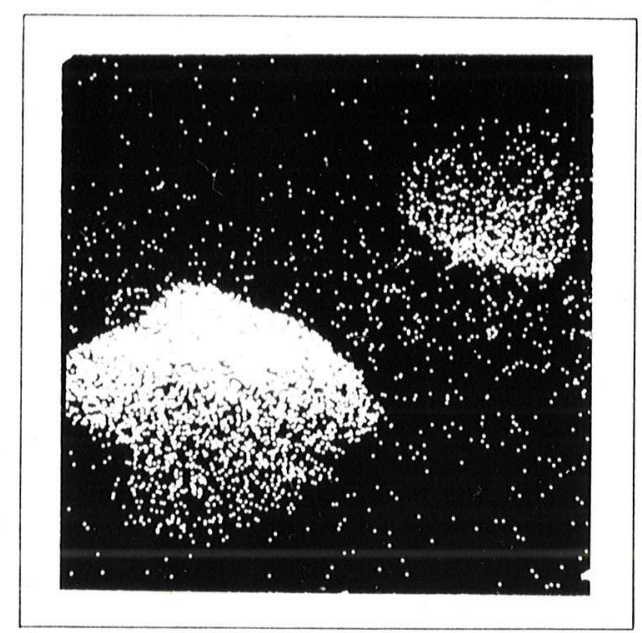

Foto 153 - Imagem "X" A1 K $\alpha$

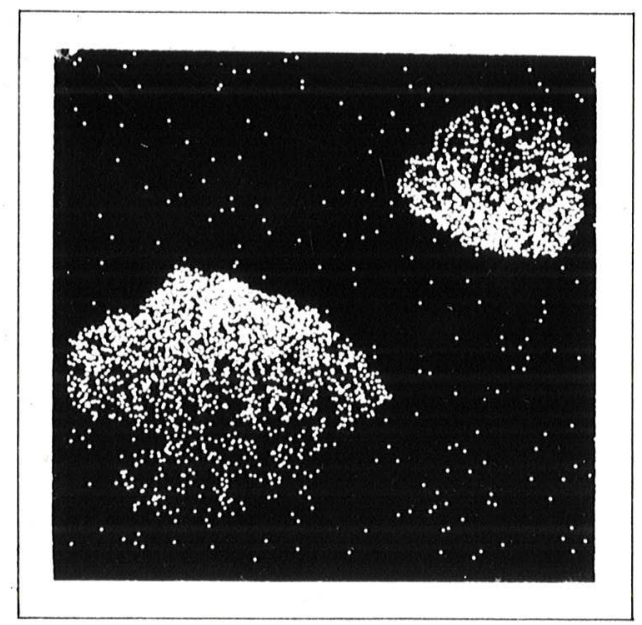

Foto 155 - Imagem "X" Mg Ka

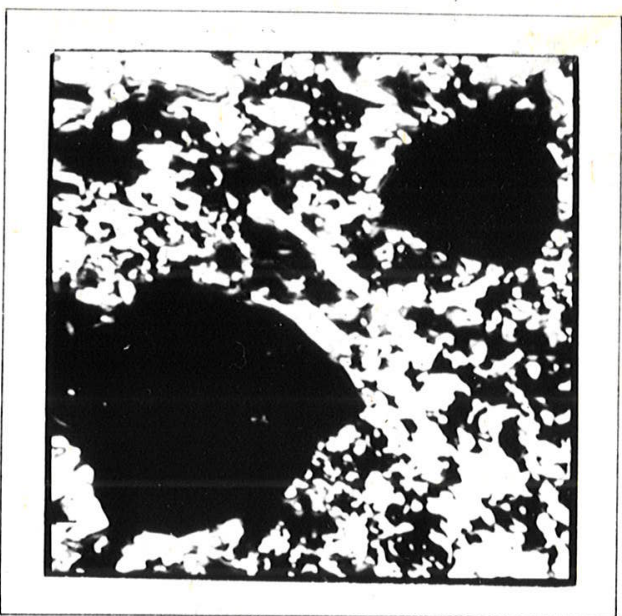

Foto 152 - Imagem eletrônica de dois cristais de turmalina. E.retroespalhados.400 x $400 \mu \mathrm{m}$.
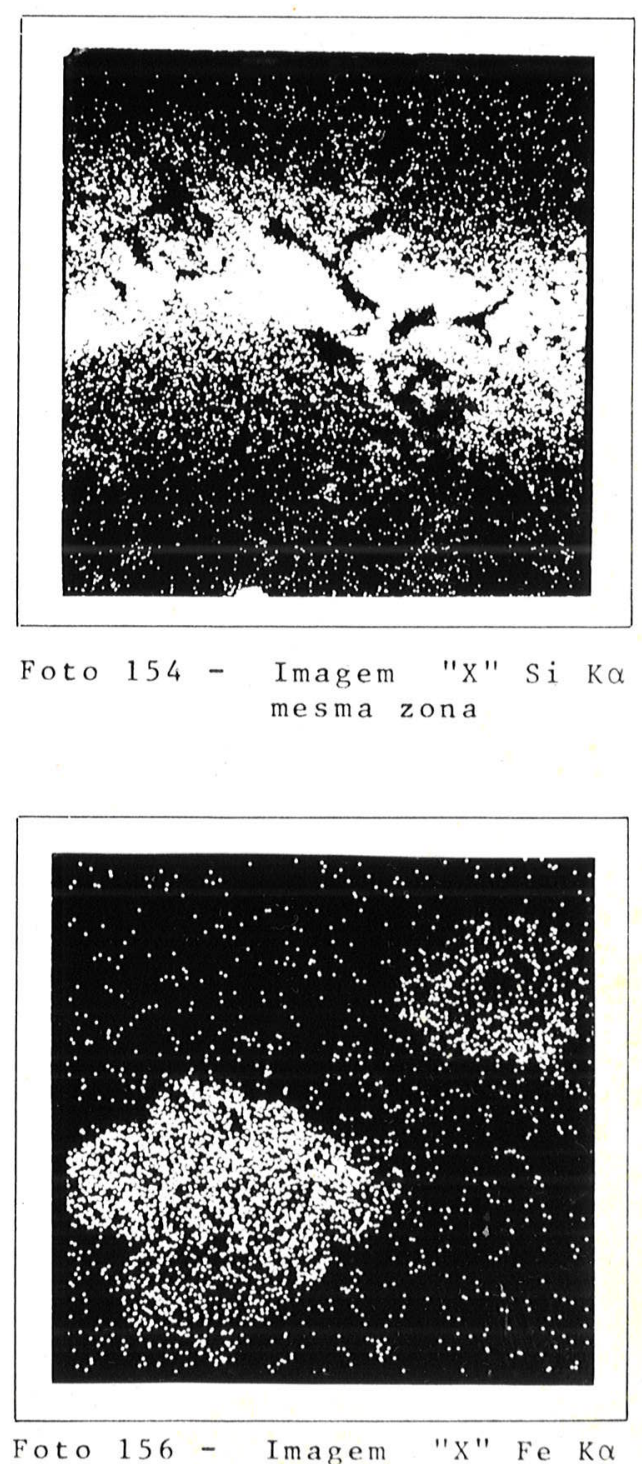

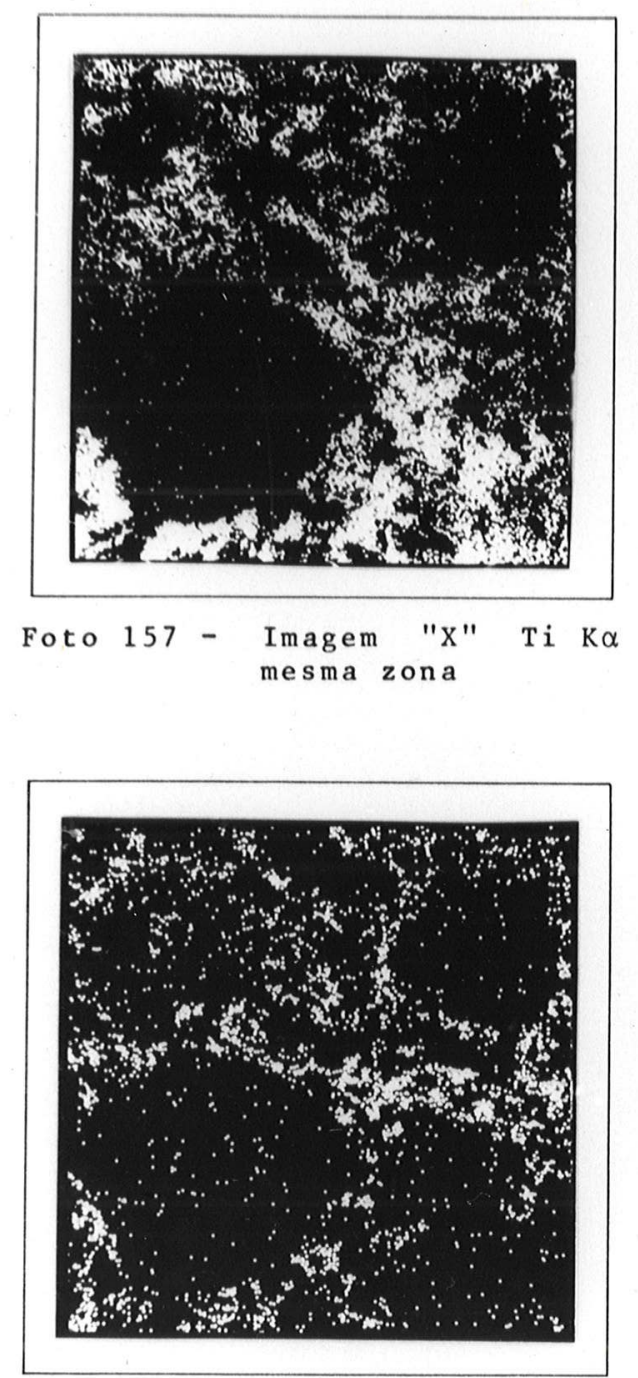

Foto 159 - Imagem "X" Cu K $\alpha$

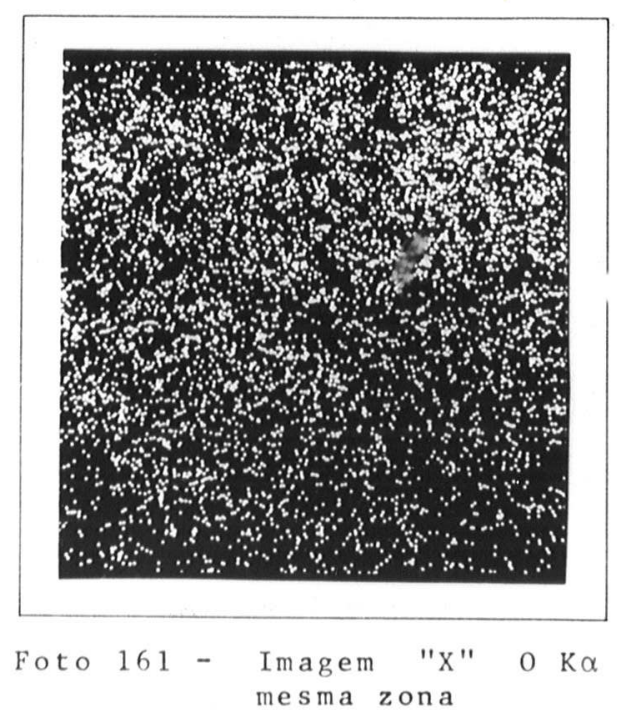

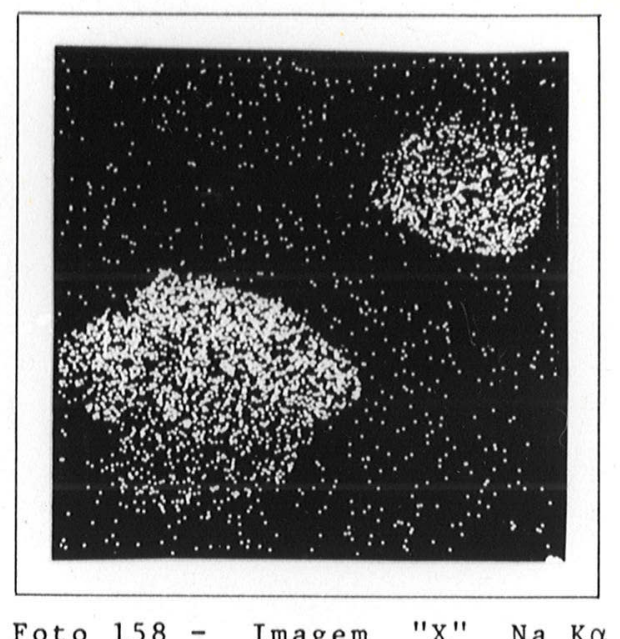

Foto 158 - Imagem "X" Na K $\alpha$
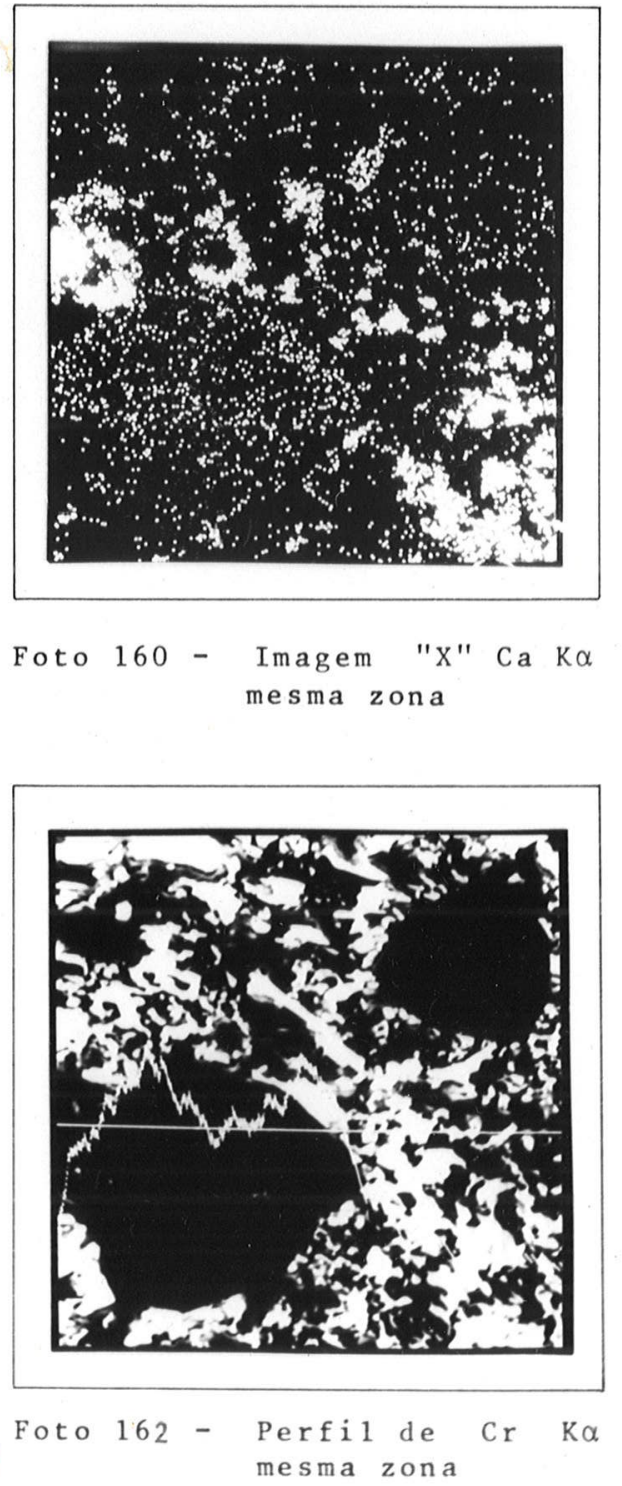
crômio controlam os índices de refração e o peso específico, enquanto que a birrefringência aumenta em razão do ferro con tido. o lítio não ocorre nos cristais estudados pois não hă miscibilidade entre as turmalinas magnesianas e as de lítio. Este elemento se concentra nas turmalinas das zonas centrais de pegmatitos.

Paragênese - A turmalina é um mineral formado em pegmatitos graniticos, em veios pneumatoliticos ou em ro chas metamōrficas, nestas ültimas produto de metassomatismo de boro ou como resultado da recristalização de gräos detrí ticos de sedimentos pré-existentes.

Nos pegmatitos graniticos (Brotzen, 1959, em Deer, 1962) está associada ao quartzo, muscovita, biotita e plagioclásio. Em veios penumatoliticos ocorre com topäzio, lepidolita, petalita, espodumênio, cassiterita, fluorita, apa tita, columbita e outros minerais.

A variedade magnesiana é frequentemente encon trada em rochas metamórficas em associação a minerais metas somäticos. Em quase todos os casos parece que um magma gra nitico deve ter sido a fonte inicial de boro, sendo que o fer ro, magnésio e cälcio devem ter seus controles dados pelos minerais ou rochas onde a turmalina se desenvolve.

Krynine (1946) (em Deer, 1962) distingue cin co possibilidades de gênese: granítica, pegmatítica, metamôr fica injetcada, sedimentação autigênica e sedimentar detrítí ca retrabalhada.

Os dados öpticos, roentgenográficos e de mi crosonda eletrônica especialmente a quantidade de ferro bem inferior a alumínio e magnésio, mostram que a turmalina preta do Ribeirão do Perau oscila entre os 1imites $65-90 \%$ de Dra vita, tratando-se por conseguinte do termo mais próximo de $\mathrm{Na} \mathrm{Mg}_{3} \mathrm{Al}_{6} \mathrm{~B}_{3} \mathrm{Si}_{6} \mathrm{O}_{27}(\mathrm{OH}, \mathrm{F})_{4}$, do tipo södico magnesiano e característico de rochas metamórficas.

granada

As granadas que ocorrem na ärea da jazida do 
Ribeirão do Perau apresentam-se como porfiroblastos, nos xis tos de coloração cinzenta escura. Essas rochas são compos tas, essencialmente por micas (muscovita ou a biotita) e quartzo, figurando como acessórios a granada e a estaurolita; ocorrem em quantidades menores: titanita, calcita, apatita e ainda clorita. Os porfiroblastos de granada, durante seu crescimento, deformaram os leitos micáceos (Foto 12) e englo baram quartzo e minerais opacos (Foto 13).

A granada também é citada no presente traba 1ho como mineral do granito Epitäcio, aflorante a $15 \mathrm{~km}$ a nordeste da confluência dos ribeirões Grande e Perau (Fig.2). Neste local o mineral possui coloração vermelha, granulação ao redor de $1 \mathrm{~mm}$, tendo grãos de quartzo como inclusões. Es tá fraturada do mesmo modo que os demais minerais da rocha e é o unico acessório do granito. Os estudos e anālises,a se guir descritos, foram executados tão somente nas granadas dos xistos.

Propriedades físicas - As granadas retiradas dos xistos apresentam diâmetro de 2 a $3 \mathrm{~mm}$, com forma mal de finida o que lhes confere um häbito aproximadamente esférico. o brilho é vítreo e a côr varia de castanho claro a escuro; sua fratura é concóide e opticamente é isótropa.

Para determinação da variedade de granda den tro do grupo desses minerais, foram empregados três constan tes: peso especifico, indice de refração e a diferença $2 \theta$ entre as raias mais intensas da granada e quartzo, visiveis no diagrama de pó sob difração de raios X (Tabela 21).

0 peso específico foi obtido com o auxilio da solução de clerici, determinando-se o indice de refração desta com o refratômetro Abbe. Com o auxílio do grä́ico de Jahns, (1939) obteve-se para o peso específico o valor de $4,19$.

o indice de refração foi determinado pelo mé todo de imersão e o líquido utilizado teve seu indice confe rido no refratômetro de Jelley, obtendo-se o valor 1,800 .

A anālise sob difração de raios X (Tabela 21) 
Tabe1a 21

Diagramas de pó de Granada e Quartzo

$2 \theta$

18,80

20,81

$\frac{26,62}{30,88}$

$\frac{34,64}{36,54}$

38,05

39,50

40,16

42,66

44,38

45,82

48,60

50,80

54,90

57,50

59,86

64,62

68,03

73,44

75,34

77,36

79,86

81,42

83,76

90,88

91,88

93,80

96,50

97,90

102,22

107,52

110,64

114,74

127,88

129,28

137,90

138,80

143,06

156,85
$\mathrm{I} / \mathrm{I}_{\mathrm{O}}$

10

100

40

100

5

20

20

5

20

10

30

30

70

30

40

50

20

5

20

30

10

5

5

5

5

20

10

10

5

5

10

5

5

10

5

5

20

30 d $(\AA)$

4,716

4, 264

3,345

2,893

2,587

2,457

2,362

2,279

2,243

2,117

2,039

1,978

1,871

1,796

1,670

1,601

1,543

1,441

1,376

1,288

1,260

1,232

1,200

1,180

1,153

1, 081

1,071

1,054

1,032

1,021

0,989

0,954

0,936

0,914

0,857

0,852

0,825

0,822

0,812

0,785 hk 1

$(Q z 2100)$

( $Q z 101)$

400

420

332

422

$(Q z \quad 110)$

$510 \quad(Q z \quad 102)$

(Qz 111)

$521 \quad(Q z 200)$

440

611

532

(Qz 201)

$(Q z \quad 112)$

444

640

642

800

822

840

842

664

754

844

941

10.2 .0

10.2 .2

10.4 .2

880

884

12.2 .0

11.5 .2

12.4 .4

12.6 .0

10.9 .3

12.8 .0

14.4 .0

14.4 .2
( $Q z 211)$

( Qz 113)

( $Q z$ 203)

$(Q z 2104)$

( $Q 2302)$

$(Q z 220)$

$(Q z 213)$

$(Q z \quad 114)$

( $Q z 204)$

$(Q z 312)$

( $Q z$ 400)

( $Q z 214)$

$\left(\begin{array}{ll}Q z & 23\end{array}\right)$

( $Q z$ 402)

(Q2 410) 


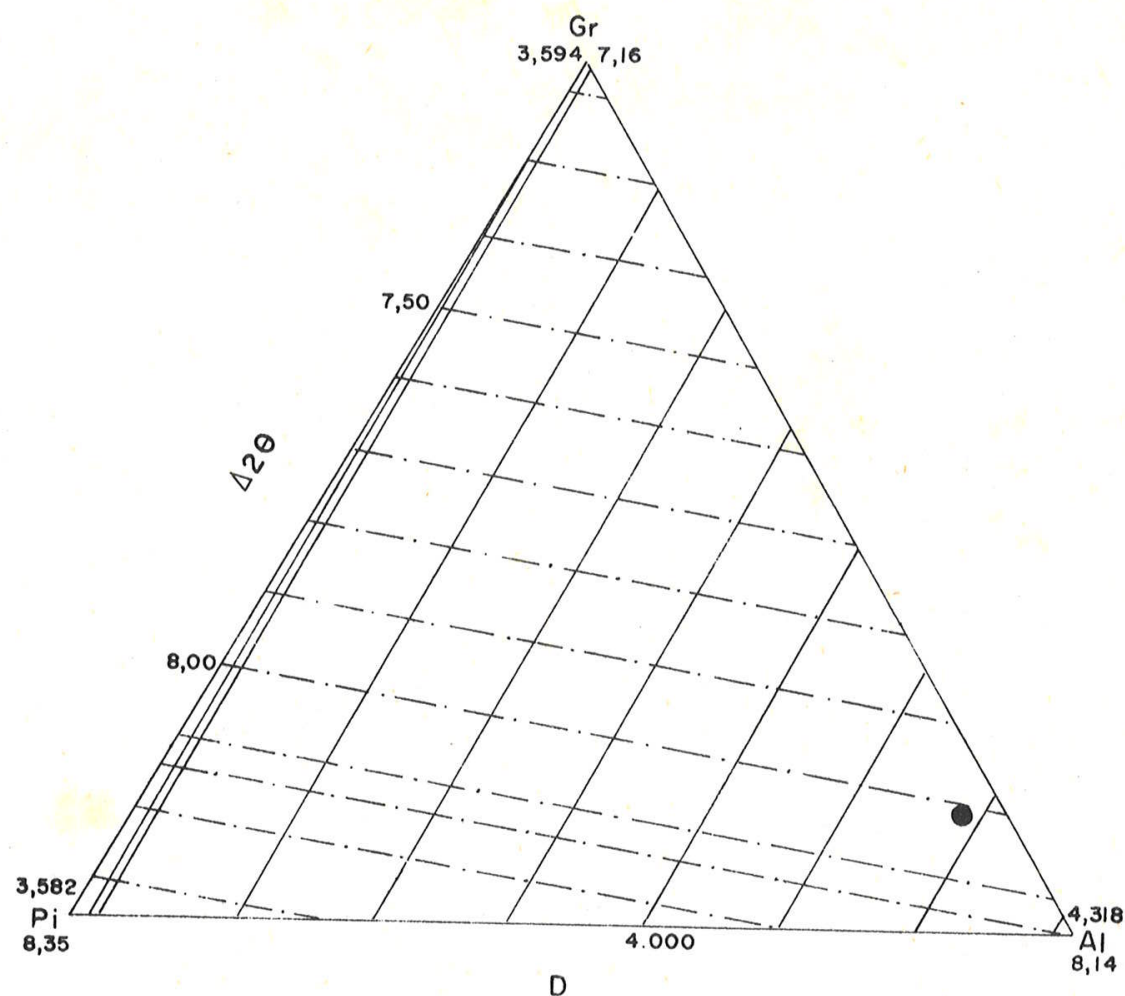

Fig. 27 - Gráfico no2, Madureira e Camargo, 1972

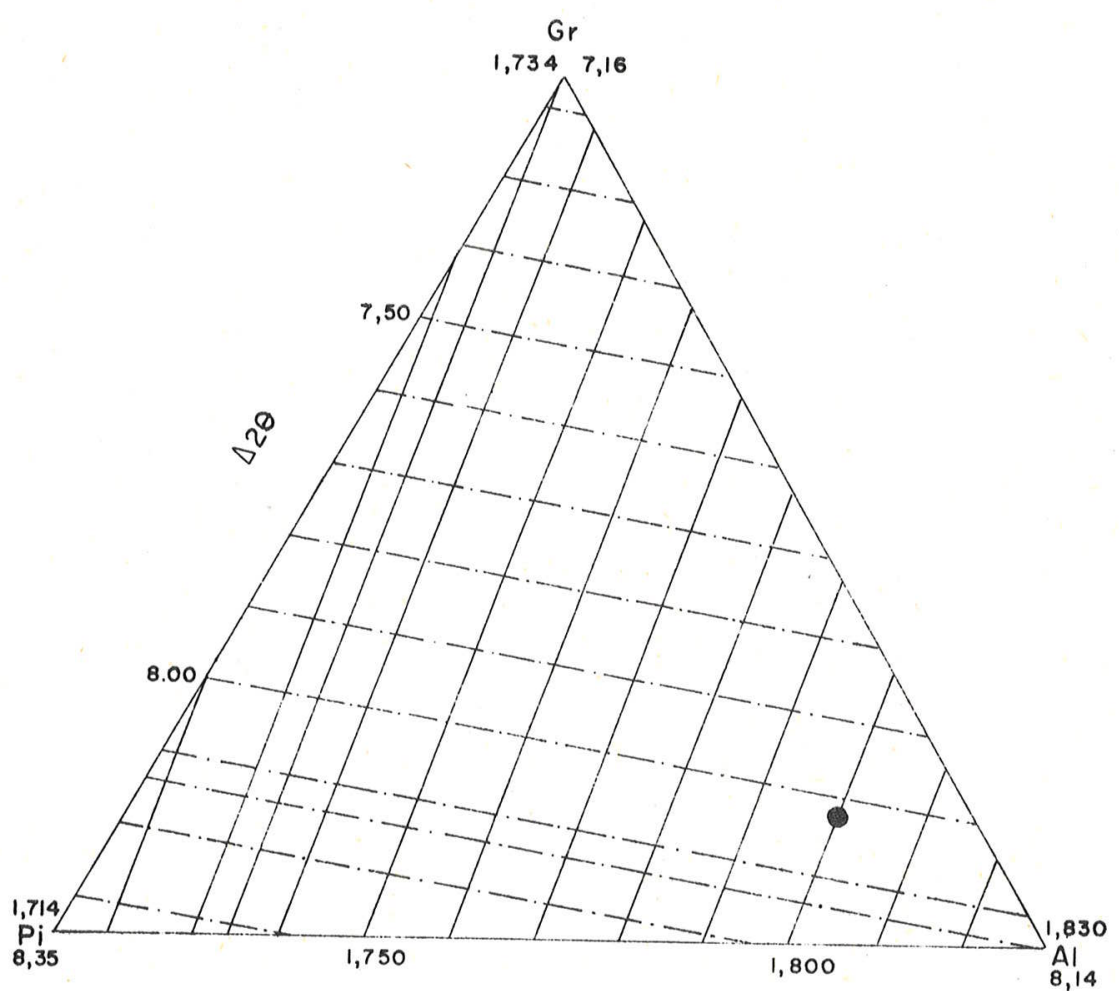

$\eta$

Fig. 28 -Gráfico n० 12, Madureira e Camargo, 1972 
fornece os espaçamentos interplanares de granada e

quart zo com os respectivos ângulos $2 \theta$ onde a diferença $\Delta 2 \theta$ en tre a raia intensa da granada (420) e do quartzo (10ī1) $\bar{e}=$ $8,02 \AA$.

Associando-se os três valores: p.e $=4,19$;

$\mathrm{n}=1,800$ e $\Delta 2 \theta=8,02 \AA$ e fazendo-se uso dos trinta diagra mas triangulares de Madureira e Camargo (1972), o espécime estudado foi localizado em dois dos gräficos (Figuras 27 e 28).

As porcentagens moleculares obtidas nas figuras 27 e 28, bem como a mëdia desses valores, são apresentadas na tabela abaixo:

$$
\text { Fig. } 27 \quad \text { Fig. } 28 \quad \text { Mëdia }
$$

$\begin{array}{lrrr}\text { Almandina } & 80 \% & 72 \% & 76 \% \\ \text { Piropo } & 5 \% & 13 \% & 9 \% \\ \text { Grossularia } & 15 \% & 15 \% & 15 \%\end{array}$

Microsonda eletrônica - o cristal escolhido
para estudo em microsonda eletrônica, Foto 164 e Figura 29 ,
esta contido em matriz de xisto, apresentando inclusões de
quartzo e de ilmenita, sendo que este último mineral possui
igual orientação na granada e nos minerais do xisto encai
xante.

Os elementos: aluminio (Foto 165), ferro (Fo to 167), manganês (Foto 169), cálcio (Foto 170) e magnésio (Foto 172) se recobrem perfeitamente no cristal de granada sendo que o magnésio é pouco concentrado. A foto 166 mostra a distribuição do silício nos cristais de quartzo e a foto 168 focaliza a concentração de titânio nos cristais de ilmenita. o potásio (Foto 171) ocorre somente na matriz da granada. (Foto 163)

Foram pesquisados o $\mathrm{Cr}, \mathrm{Zn}, \mathrm{Cu} \mathrm{C} 1, \mathrm{Y}, \mathrm{P}, \mathrm{Na}$, F, C, os quais não foran encontrados. O oxigênio se concen tra predominantemente na matriz de rocha, com $1850 \mathrm{cont} / \mathrm{s}$, em $10 \mathrm{~s}$, e secundariamente na ilmenita com $1250 \mathrm{cont} / \mathrm{s}$.

A anälise $\vec{a}$ microsonda revela que esse cris 


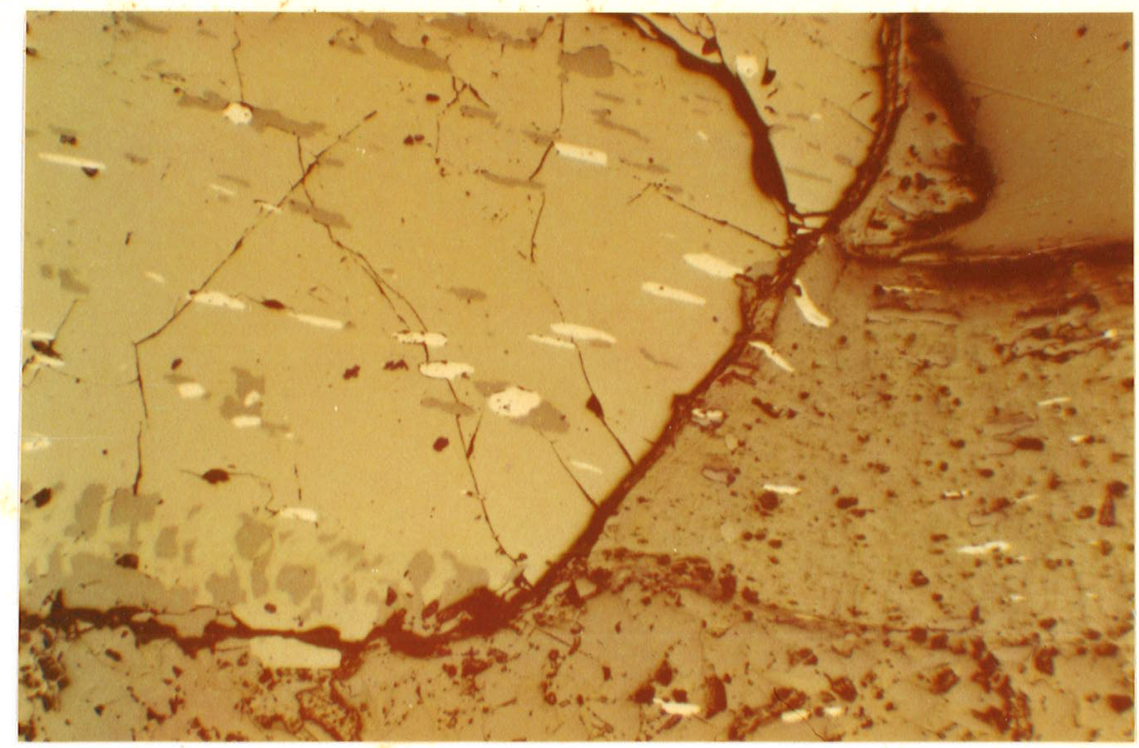

Foto 163 - Granada (marrom claro), quartzo (marrom escuro), feldspatos e titanita (branca). Notar a iso rientação da titanita atravēs dos minerais da rocha. Seção po lida. Nícois descruzados. Aumento 360 vezes.

tal do grupo das granadas é do termo rico em ferro (almandina), possuindo tambëm os termos em cälcio, manganês e mag nésio, respectivamente grossularia, espessartita e pouco pi ropo. A ausência de Ti na granada exclui o membro andradi ta e a falta de Cr, elimina o termo uvarovita. Os resulta dos obtidos pelos diagramas triangulares: $76 \%$ almandina, $15 \%$ grossularia e $9 \%$ piropo, estão de acordo com as anälises à microsonda eletrônica.

0 quarto termo, espessartita, acusado pela presença de manganês, não foi comprovado devido ao fato de - método dos diagramas ternärios utilizar-se de três varie dades de granadas apenas. A espessartita deveria ser com provada fazendo-se uso de diagramas quaternärios (Winchell, 1958), o que não foi possível por não terem sido executados călculos para determinação do a ${ }_{0}$

$$
\text { Paragênese - A almandina é uma granda típica }
$$
(Deer, 1962) de xistos granatiferos, resultando do metamor fismo regional de sedimentos argilosos; pox esse motivo é 


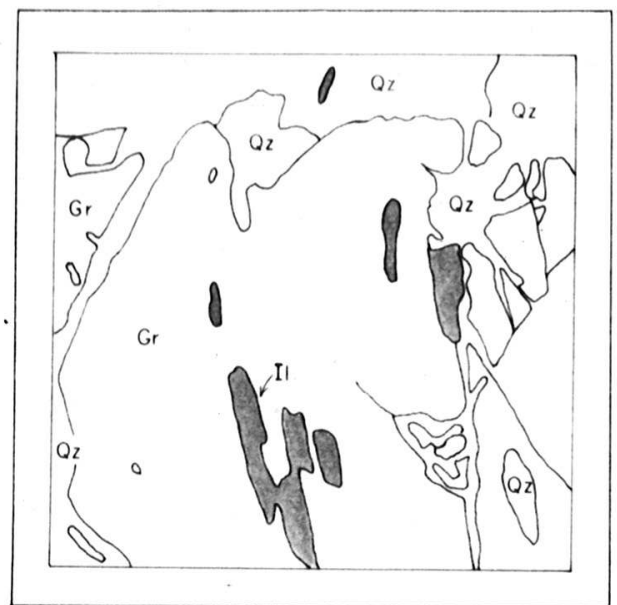

Fig. 29 - Distribuição dos minerais da foto 164. Gr=granada, I1 =ilmenita, Qz = quartzo.

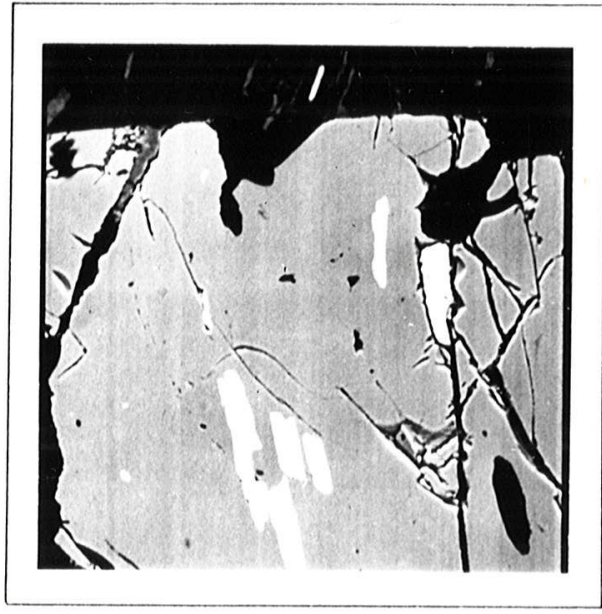

Foto 164 - Imagem eletrônica de granada. E. retroespalhados. $400 \times 400 \mu \mathrm{m}$.

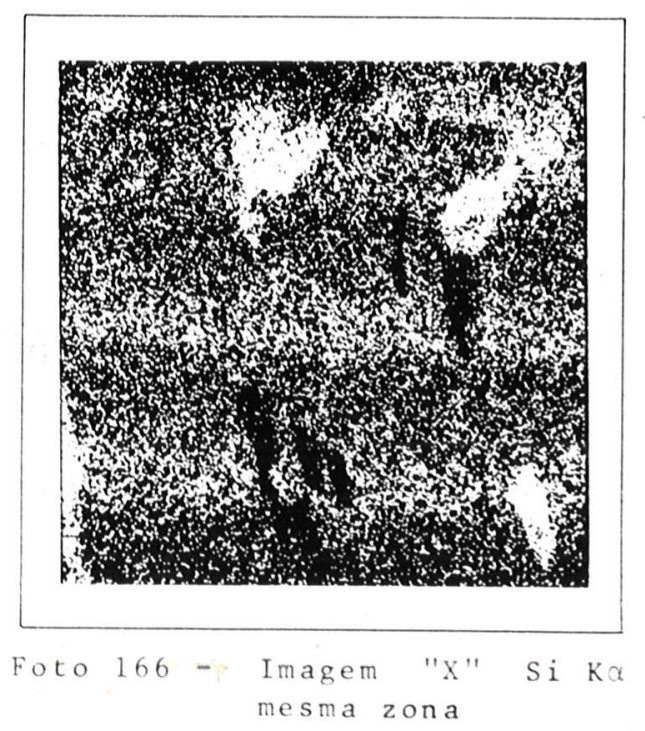

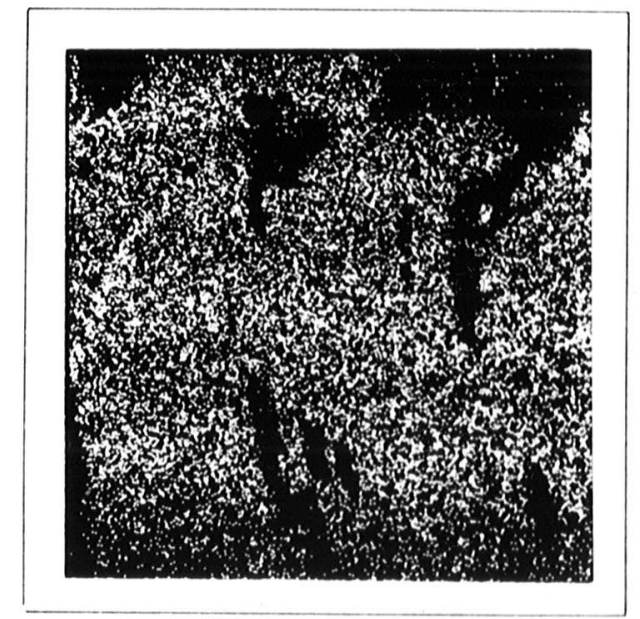

Foto 165 - Imagem "X" Al $K \alpha$ mesma zona

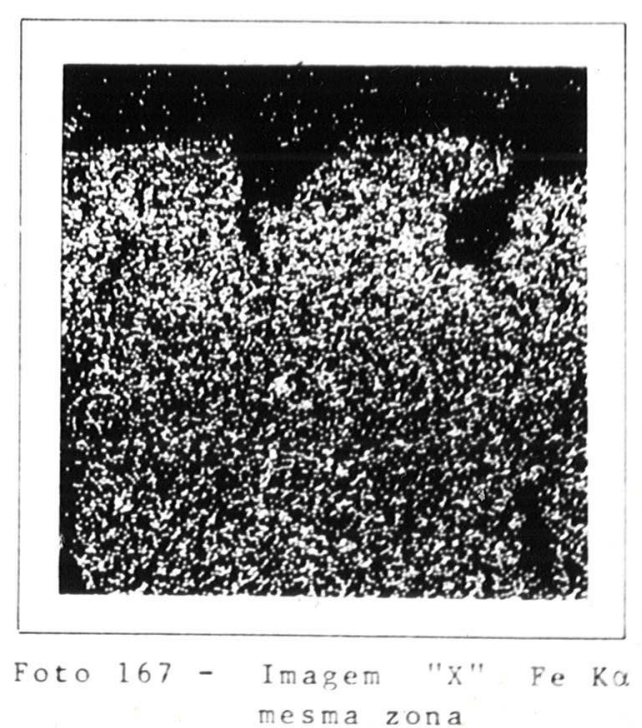




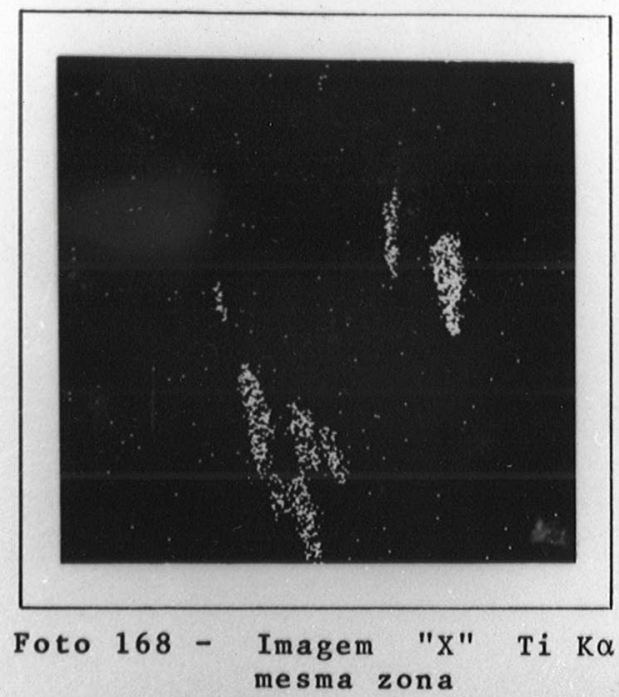

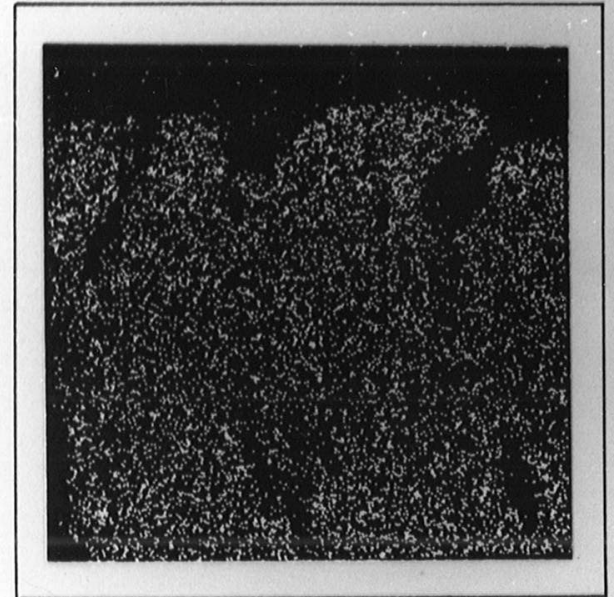

Foto 169 - Imagem "X" Mn K $\alpha$ mesma zona

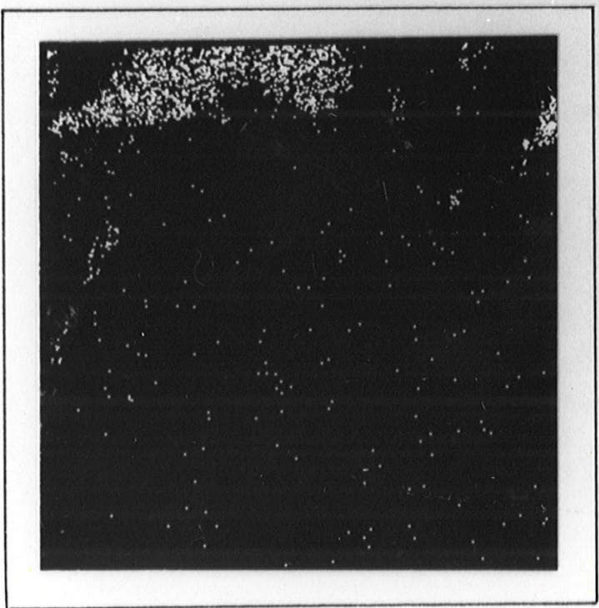

Foto 171 - Imagem "X" K Ko mesma zona

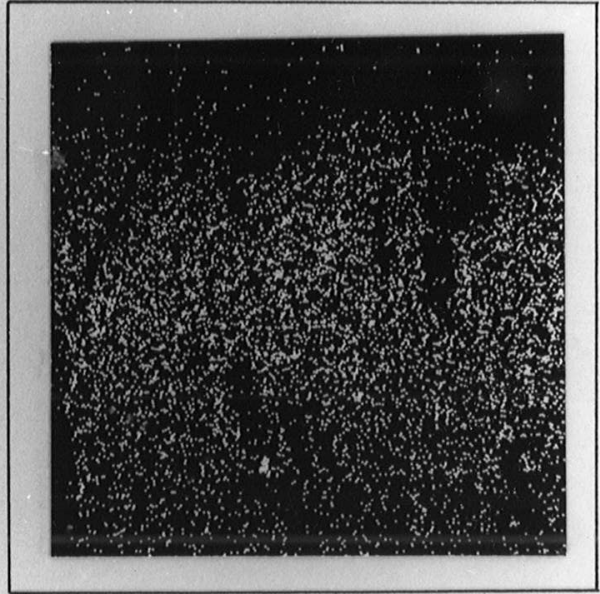

Foto 170 - Imagem "X" Ca K $\alpha$ mesma zona

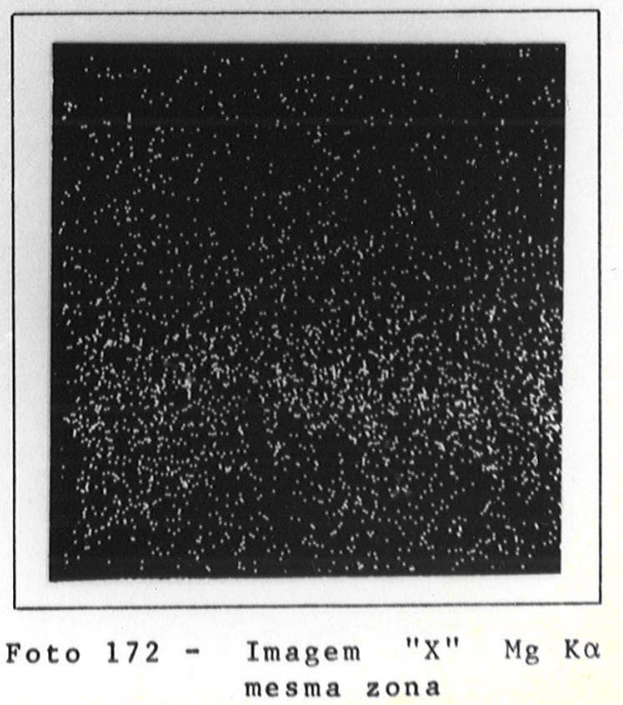




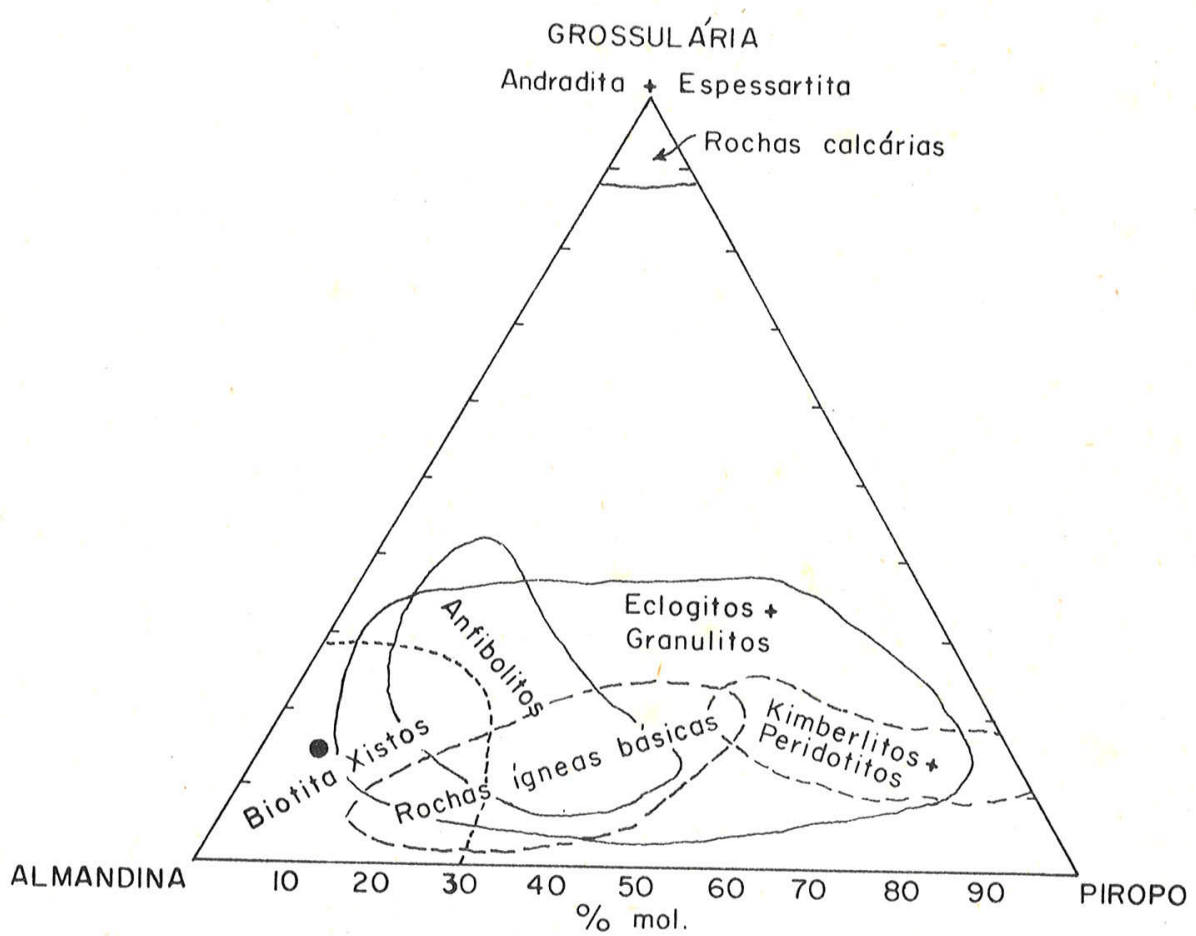

Fig. 30 Distribuição de granadas, pobres em andradita e espessartita, nas diversas rochas. (Wright, 1938, em Abelson P. H; Geophysical laboratory, 
usada como mineral zonal em regiões de metamorfismo progres sivo. Pode ocorrer como produto de metamorfismo termal ou de contato, em auréolas restritas que tipicamente contēm mi ca branca e onde falta feldspato potásico. A granada estú dada foi plotada na figura 30 (Wright, 1958) mostrando que é mineral característico de biotita xistos, rochas estas que constituem a maior parte aflorente da jazida do Ribeirão do Perau.

tremolita

A tremolita é depois do quartzo, o mineral de ganga mais abundante nas galerias de pesquisa, e nas encai xantes dos vieiros de minërios oxidados de cobre. As rochas encaixantes das galerias apresentam aspecto arenoso devido à alta friabilidade dos minerais, provocada pelo intenso fa 1hamento. A tremolita estä presente tambëm na zona sul da jazida acompanhando, às vezes, o contato rochas carbonáticas com quartzito em forma de cristais fibro radiados centimétri cos. E constituinte normal das rochas cäleio-silicatadas. Propriedades fisicas - Como ganga e encaixan te dos vieixos de minérios oxidados, apresenta côr amarela, häbito prismätico, brilho vítreo e fraturas intensas que lhe proporcionam grande friabilidade. Como mineral do contato calcārios-quartzitos apresenta côr azul a cinzenta, häbito prismático acicular, fibro-radiado, britho sedoso e clivagem perfeita..

Os diagramas de pö obtidos por raios $X$ mos tram que ha misturas das variedades tremolita e fluor-tremolita (Tabelas 22 e 23): A tremolita tem sido atribuída a al teração de piroxênios calco-magnesianos.

magnetita

A magnetita é mineral acessōxio de um quartzi to escuro de textura granoblástica aflorante em forma de len te intercalada no xisto (Fig. 3). Esse quartzito exibe quañ 
Tabela 22

Diagrama de Tremolita

Rib. Perau

d (\&)

9,30

9,06

8,41

5,10

4,87

4,76

4,51

4,24

4,20

3,37

3,34

3,26

3,12

3,02

2,94

2,80

2,70

2, 59

2,53

2,39

2,33

2,32

2,27

2,16

2,04

2,01

1,89

11

1,81

11

$\operatorname{CuK} \alpha=1,5418 \AA$, Filtro $\mathrm{Ni}$

24 horas

$30 \mathrm{kV}$

Filme no 27170

Câmara de Gandolfi $114,6 \mathrm{~mm} \emptyset$

40

26

100

50

15

15

37

13

9
11

16

10

11
St. Gotthard, Switzerland

d $(\AA)$

8,98

8,38

5,07

4,87

4,76

4,51

4,20

3,870

3,376

I / I

hk 1

3,268

3,121

3,028

2,938

2,805

2,730

2,705

2,592

2,529

2,407

2,380

2,335

2,321

2,298

2,273

2,206

2,181

2,163

2,042

2,015

2, 002

1,963

1,929

1,892

1,864

1,814

16

020

100

16

10

20

20

110

$130-001$

I11

200

040

35

16

40

220

I31

150-041

75

100

10

40

45

16

90

30

40

8

30

30

40

12

16

6

6

35

18

45

16

6

6

50

16

16

240

310

$3 \bar{I}-24 \bar{I}$

151

330

$42 \bar{I}$

151

I1 2-061

202-002

T32

350-400

$35 \bar{I}$

$42 \bar{I}$

420-071

112

242-042

$44 \overline{1}$

171-261

$081-280$

202

351-370

28 $\bar{I}-190$

152.

510

460-191

530

mais 13 linhas atê 1,439

Ficha ASTM No $33-437$ 
Tabela 23

Diagrama de Fluor-Tremolita

Rib. Perau

d ( 8 )

$$
I_{\text {/ I }}
$$

$9,05 \quad 50$

8,37

5,08

70

20

4,75

4,53

4,20

3,90

3,36

3,26

3,11

2,93

2,79

2,69

2,57

2,53

2,33

2,16

2,00

1,95

1,87

1,80

1,64

20

30

10

5

5
70

100

10

10

60

10

10

70

1,61

1,57

1,55

1,52

1,49

1,45

1,43

$\operatorname{CuK} \alpha=1,5418 \AA$, Filtro Ni

24 horas $\quad 30 \mathrm{kV} \quad 15 \mathrm{~mA}$

Filmes nos 116270 e 216270

Câmara de Gando1fi $114,6 \mathrm{~mm} \emptyset$
Ref. Comeforo and Kohn

d (\&)

9,02

8,37

5,073

4,856

4,736

4,501

3,867

3,377

3,262

3,106

2,934

2,792

2,718

2,702

2,587

2,526

2,373

2,326

2,308

2,292

2,263

2,177

2,157

2,040

2,012

1,995

1,883

1,806

1,645

1,631

1,613

1,578

1,575

1,525

1,501

1,497

1,453
$\mathrm{I} / \mathrm{I}_{\mathrm{o}} \quad \mathrm{hk} \mathrm{I}$

$\begin{array}{rl}7 & 020 \\ 100 & 110 \\ 7 & 130 \\ 5 & 11 \frac{1}{5} \\ 11 & 200 \\ & 040\end{array}$

$3 \quad 13 \bar{T}$

$131-041$

240

310

$15 \bar{I}-221$

330

$33 \overline{1}$

151

061

$20 \overline{2}$

350

$35 \overline{1}$

421

171

$31 \frac{1}{2}$

171

261

202

351

370

510

530

461

480

1. 11.0

600

$15 \overline{3}$

$570-35 \overline{3}$

0.12 .0

$551-48 \overline{2}$

3.11 .0

Ficha ASTM No 9-330 
tidades semelhantes de quartzo e de magnetita, perfazendo am bos 90 - $95 \%$ do volume dessa rocha (Fotos 17 e 173). Anfibó lio (do grupo tremolita-actinolita) ocorre em quantidades su bordinadas, sendo muito raros os cristais de calcita. A gra nulação média dos cristais justapostos de quartzo e magneti ta varia de 0,1 a $0,5 \mathrm{~mm}$, sendo que há faixas de maior con centração de magnetita, ao longo dos planos de xistosidade, com granulação variando entre 1 e $4 \mathrm{~mm}$ (Foto 173).

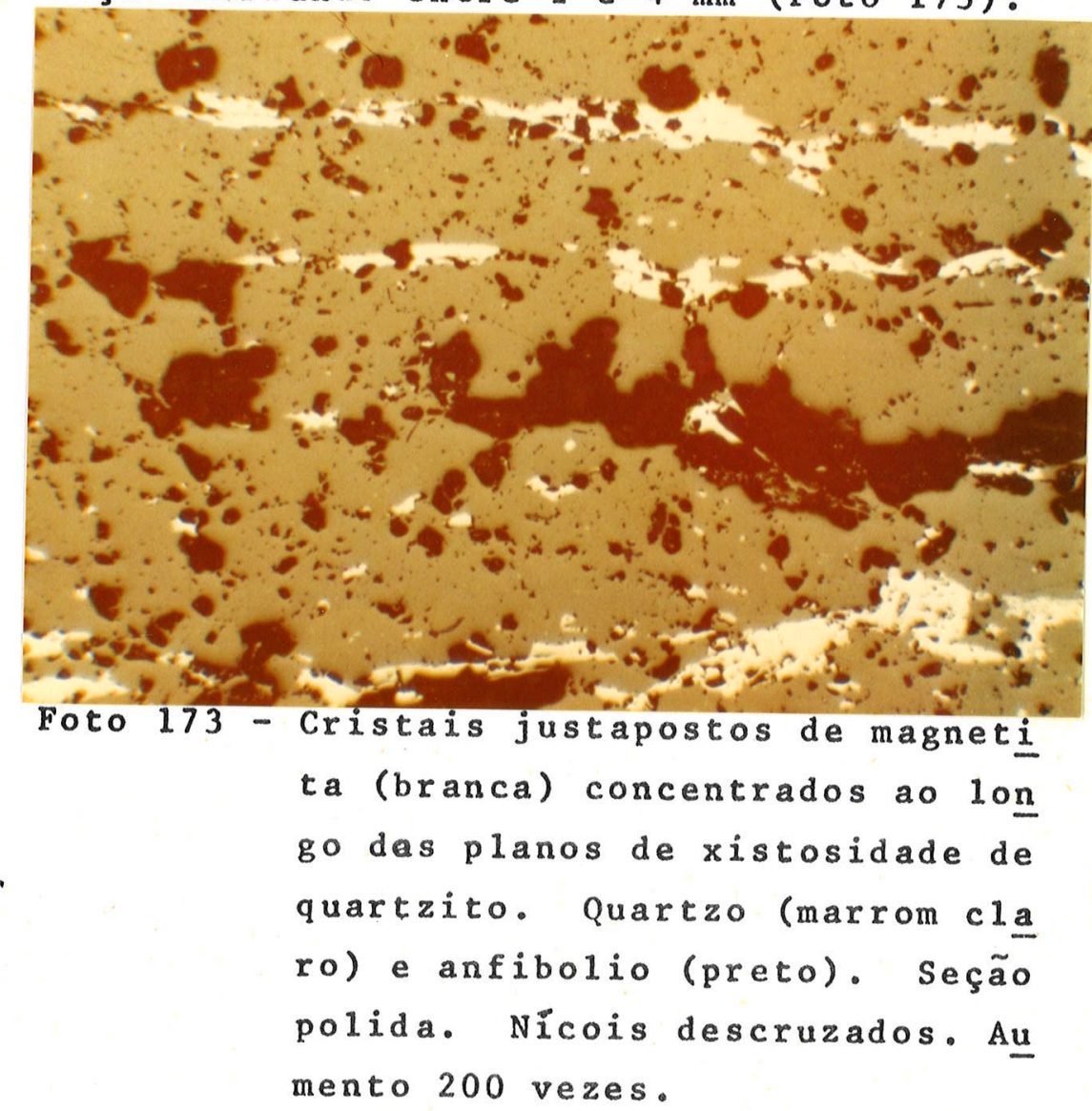

Propriedades físicas - Os cristais submilimé tricas são desproporcionados, com o maior alongamento concor dante com a xistosidade da rocha hospedeira. Em granulome tria milimétrica os cristais são idiomorfos com predominân cia da forma \{111\}. O häbito é granular a maciço, sendo às vezes reconhecidos macroscopicamente cristais octaëdricos. A côr ê preta, com película marrom nos espēcimes intemperiza dos e a fratura é subconcōide. Apresenta elevado magnetis mo. Sob luz refletida mostra alta dureza de polimento,baixa refletividade, côr cinza, isotropia e partição octaédrica (Winche11, 1967) (Foto 175). 
Microsonda eletrônica - A foto 174 é a imagem eletrônica de vārios cristais de magnetita em campo de 400 $\mathrm{x} 400 \mu \mathrm{m}$ e a foto 175, é um detalhe da magnetita do centro da foto 174 em campo de $100 \times 100 \mu m$ (aumento de 1200 vezes). Nesse campo ampliado pode-se perceber melhor o traço dos pla nos de clivagem, os contornos irregulares da fratura e a in clusão de quartzo euhedral.

As figuras 31 e 32 resumem a distribuição dos elementos presentes nos campos citados.

o ferro (Fotos 176 e 177) estä distribuido ho mogeneamente na magnetita, o mesmo ocorrendo com o silició (Fotos 178 e 179), em relaçäo à matriz e aos cristais de quartzo inclusos na magnetita. O Mg (Foto 180), o Ca (Foto 181) e A1 não estão presentes na magnetita, mas tão somente no mineral de côr cinza escuro. (Foto 174) que provavelmente deve ser um silicato desses metais.

Mereceram estudo cuidadoso o Mn, Ti, Ni, Cu, $\mathrm{Zn}, \mathrm{Co}, \mathrm{Cr}$ e $\mathrm{V}$, elementos que não foram encontrados no campo focalizado; portanto o Al, V e Cr não substituem o $\mathrm{Fe}^{+3}$ e $\mathrm{Ca}$, $\mathrm{Mn}, \mathrm{Mg}, \mathrm{Ni}, \mathrm{Co}$ não substituem $\mathrm{Fe}^{+2}$. Não hä Si na estrutura da magnetita (Vicent et Phillips, 1954, em Deer, 1962). O Cr pode ocorrer extremamente concentrado em magnetita e $\mathrm{Ni}$ e $\mathrm{V}$ podem ambos serem distribuidos entre magnetita e ilmenita, na razão 4:1, fato que não se observa na magnetita estudada. A magnetita pode conter cerca de 1 a $8 \%$ de $\mathrm{Ni}$, elemento também não encontrado nos cristais provenientes da jazida do Ribeirão do perāu.

A ausência de $M g, Z n$, $T i$ e $M n$ excluem, os exem plares estudados, dos termos respectivos: magnesioferrita, franklinita, ulvospinëlio e jacobsita dentro da sērie da mag netita (Winche11, 1967). A anälise de difração de raios $x$ (Tabela 24) e o estudo à microsonda eletrônica permitem consi derar as magnetitas estudadas como termos puros dentro da sé rie, isentas de soluções sólidas ou exsoluções.

Paragênese - E um dos öxidos mais abundantes em rochas ígneas e metamórficas sendo a variedade titanífera (Buddington et al., 1955, em Deer, 1962) termômetro geológico 


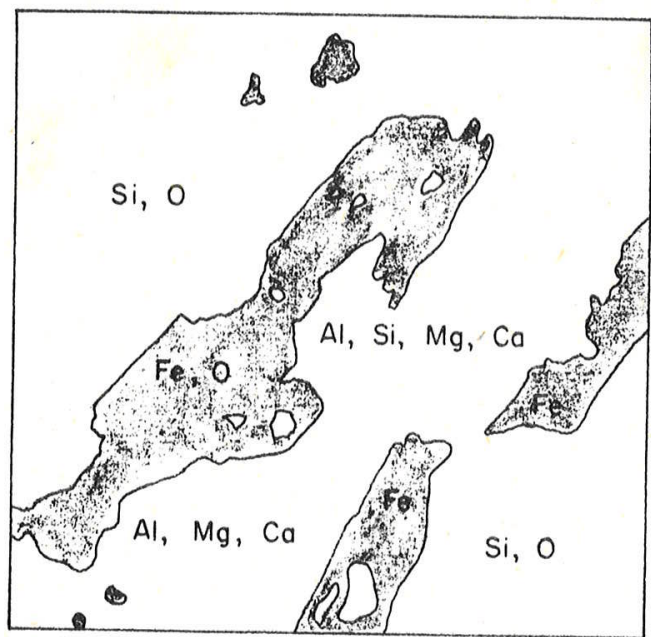

Fig.31 Distribuição dos elementos encontrados nos cristais de magnetita em matriz de quar $\uparrow$ zo.

Campo de $400 \times 400 \mu \mathrm{m}$

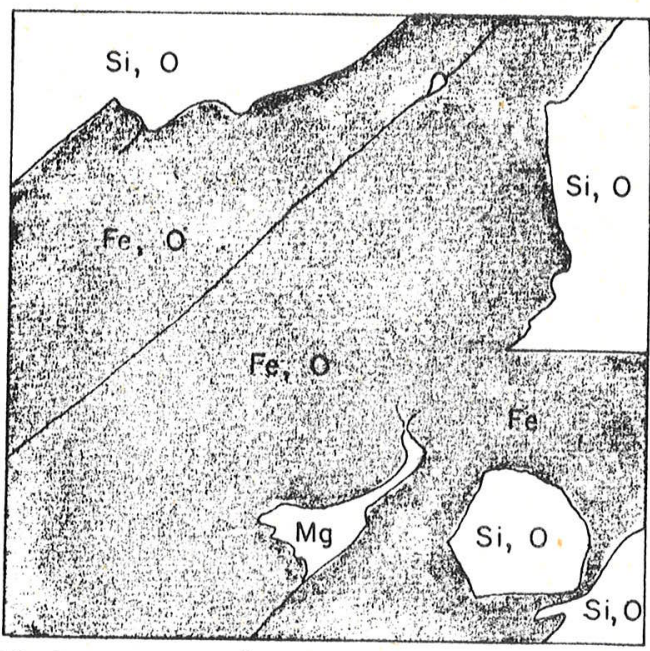

Fig.32 Distribuição dos elementos encontra dos em magnetita.

Campo de $100 \times 100 \mu \mathrm{m}$. 


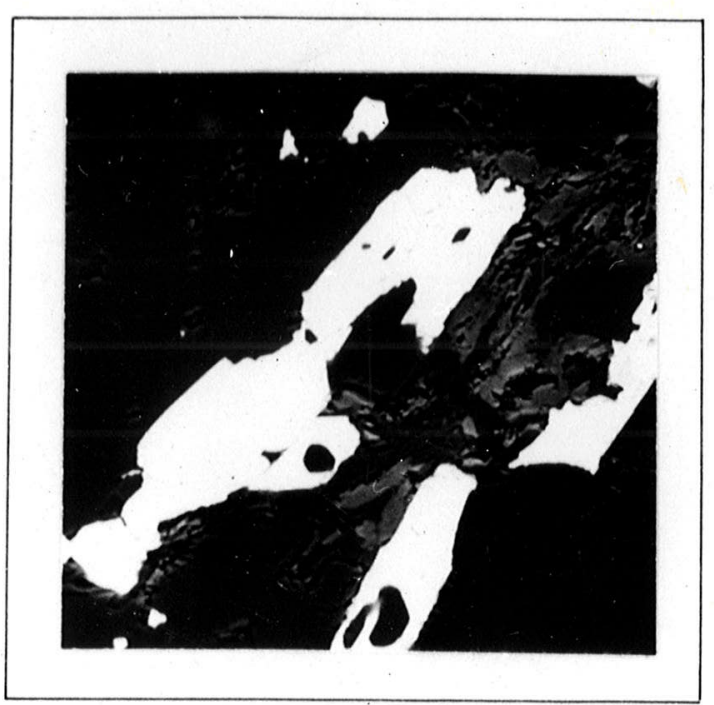

Foto 174 - Imagem eletrônica de cristais de magnetita. E. retroespalhados. 400 x $400 \mu \mathrm{m}$.

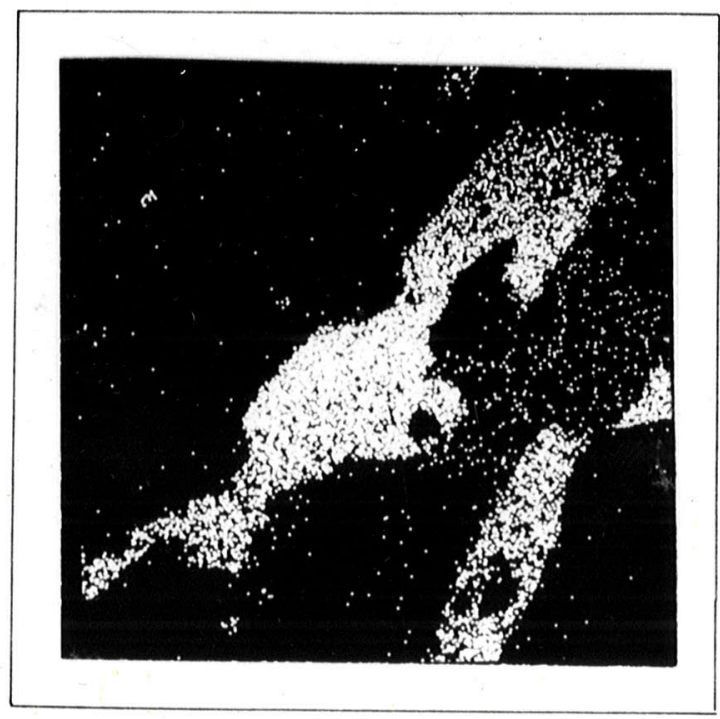

Foto 176 - Imagem "X" Fe K $\alpha$ $400 \times 400 \mu \mathrm{m}$, mesma zona foto 174

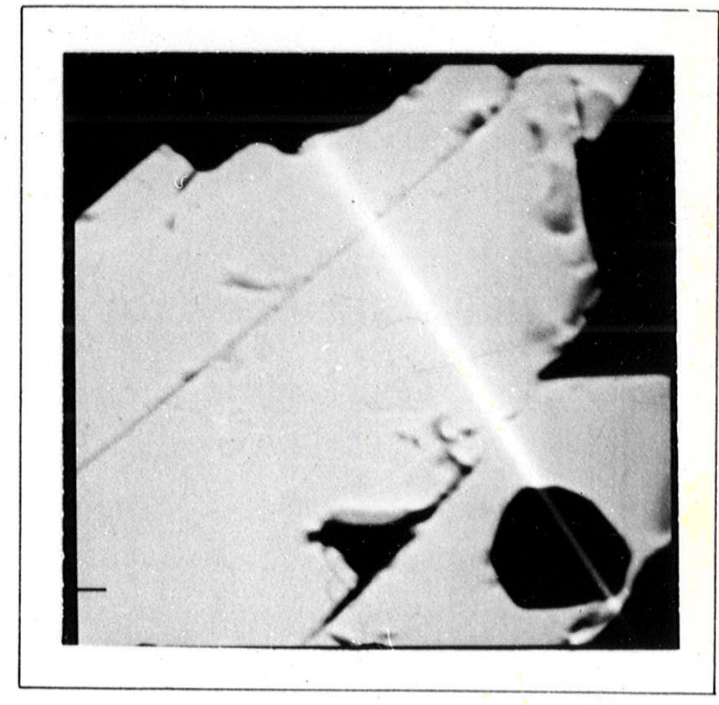

Foto 175 - Imagem eletrônica de magnetita - (detalhe). E. retroespa 1 hados . 100 x $100 \mu \mathrm{m}$.

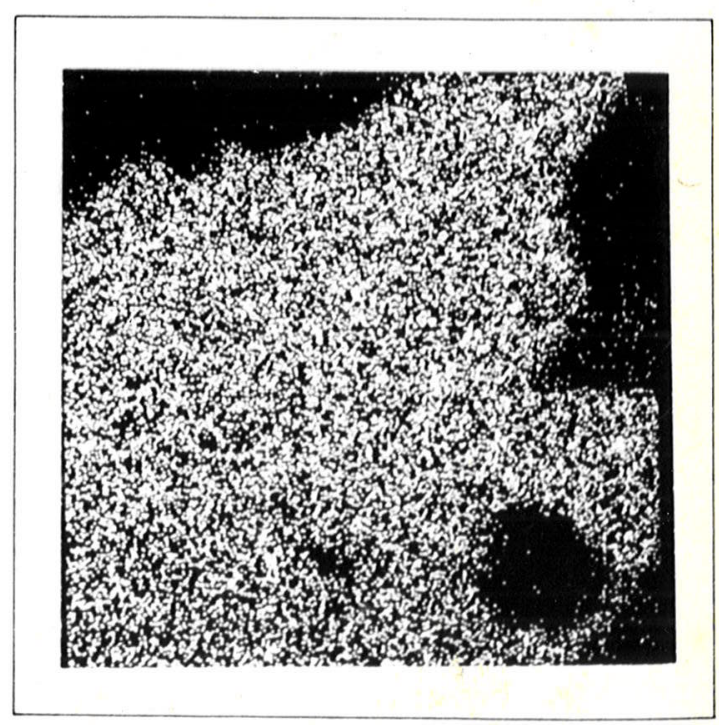

Foto 177 - Imagem "X" Fe $\mathrm{K} \alpha$ $100 \times 100 \mu \mathrm{m}$, mesma zona foto 175 


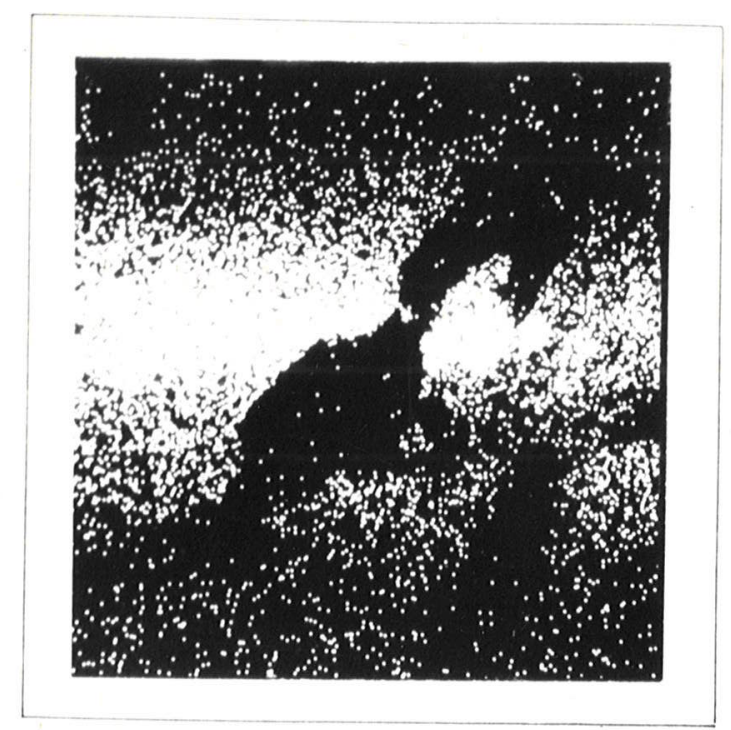

Foto 178 - Imagem "X" Si $\mathrm{K} \alpha$ $400 \times 400 \mu \mathrm{m}$, mesma zona foto 174

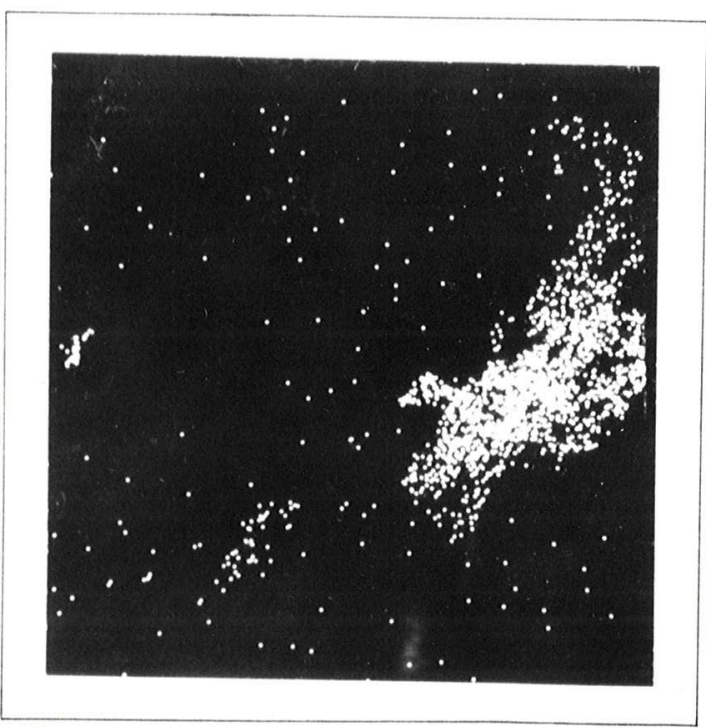

Foto 180 - Imagem "X" Mg Ka $400 \times 400 \mu \mathrm{m}$, mesma zona foto 174

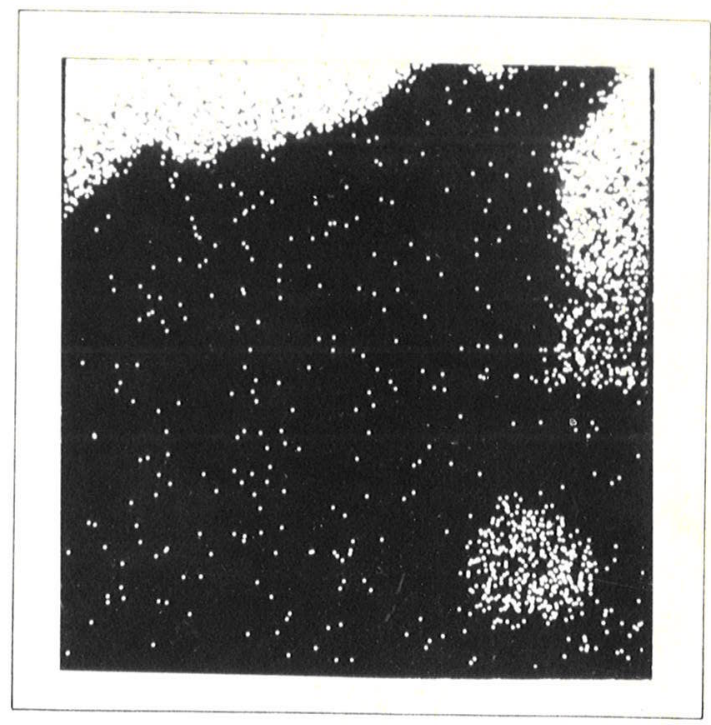

Foto 179 - Imagem "X" Si K $100 \times 100 \mu \mathrm{m}$, mesma zona foto 175

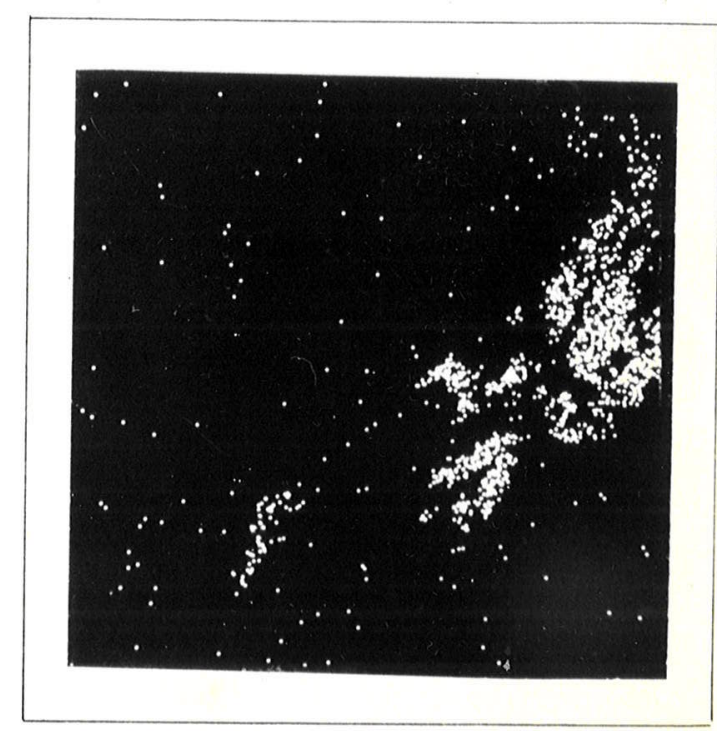

Foto 181 - Imagem "X" Ca $\mathrm{K} \alpha$ $400 \times 400 \mu \mathrm{m}$, mesma zona foto 174 
Tabela 24

Diagrama de Pö de Magnetita

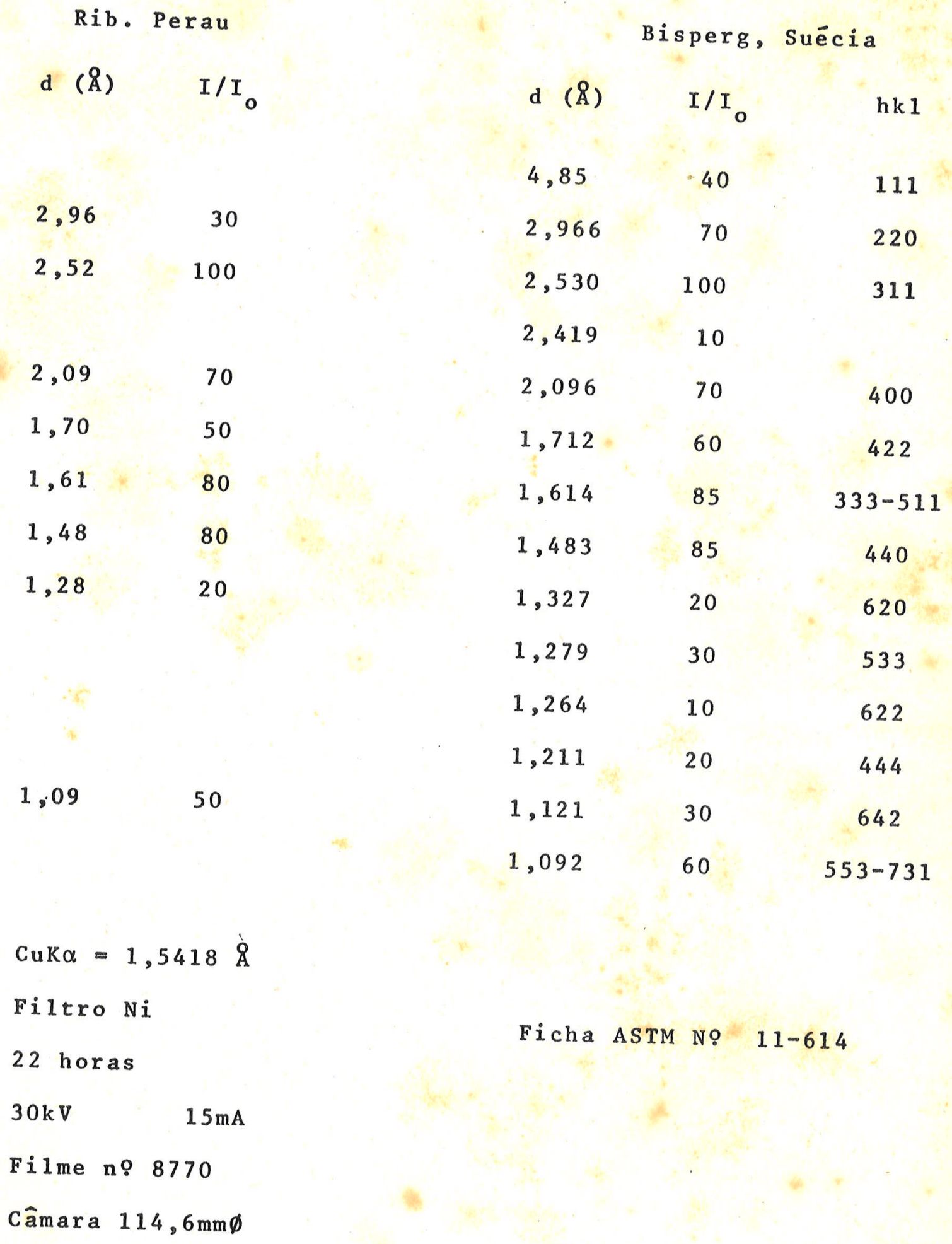


de valor relativo. Ocorre em quantidades apreciáveis em de pósitos tipo "skarn" por introdução metassomätica em calcā rios (Tilley, 1951, em Deér, 1962). E encontrada associada a atividades vulcânicas e, em metassedimentos, por ascenção hidrotermal ou pneumatolítica. Em rochas sedimentares ocor re como mineral detritico pesado. Na jazida em estudo a mag netita possui ocorrência restrita a rochas tipo quartzito, en caixadas em xistos.

hematita

A hematita do Ribeirão do Perau constitui uma lente de $80 \mathrm{~m}$ de comprimento por $10 \mathrm{~m}$ de largura localizada na TR $80 \mathrm{~N}$, (Fig. 3) encaixada em xistos ou fazendo parte co mo mineral formador dessas rochas. Parece não se relacionar com a mineralização de cobre da jazida.

Propriedades físicas - o mineral apresenta côr cinza preto, brilho metálico semelhante à especularita,fratu ra subconcóide e häbito tabular. Em seção polida exibe cốr cinza claro, elevada refletividade e fraco pleocroísmo. Sob nícois cruzados mostra reflexões internas. A Tabela 25 for nece os espaçamentos interplanares de difraça de raios $x$.

Paragênese - A hematita possui distribuição geológica muito ampla podendo ser formada em rochas igneas, metamörficas e sedimentares. No Ribeirão do Perau a hematita possui paragênese metamórfica.

calcita

A calcita e a dolomita constituem cerca de $95 \%$ do volume das rochas carbonäicas e são os constituintes prin cipais das faixas carbonáticas das rochas cālcio-silicatadas. Essas rochas merecem atenção especial porque a sua dissolução foi responsävel pela carbonatação da zona oxidada, produzindo carbonatos de cobre do tipo malaquita e azurita.

A calcita é encontrada com hābito estalactíti ca quando preenche cavidades e fraturas nos quartzitos. Quan 


\section{Tabe 1 a 25}

\section{Diagrama de Hematita}

Rib. Perau

\begin{tabular}{|c|c|c|c|c|}
\hline d $(\AA)$ & $I / I_{0}$ & d ( $(\AA)$ & $\mathrm{I} / \mathrm{I}_{0}$ & hk 1 \\
\hline 3,68 & 30 & 3,66 & 25 & 012 \\
\hline 2,68 & 100 & 2,69 & 100 & 104 \\
\hline \multirow[t]{2}{*}{2,50} & 80 & 2,51 & 50 & 110 \\
\hline & & 2,28 & 2 & 006 \\
\hline \multirow[t]{2}{*}{2,20} & 10 & 2,20 & 30 & 113 \\
\hline & & 2,07 & 2 & 202 \\
\hline 1,82 & 80 & 1,83 & 40 & 024 \\
\hline \multirow[t]{3}{*}{1,69} & 90 & 1,69 & 60 & 116 \\
\hline & & 1,63 & 4 & 211 \\
\hline & & 1,59 & 16 & 018 \\
\hline 1,48 & 50 & 1,48 & 35 & 214 \\
\hline \multirow{2}{*}{1,44} & 50 & 1,45 & 35 & 300 \\
\hline & & 1,34 & 4 & 208 \\
\hline 1,30 & 25 & 1,31 & 20 & $1010-119$ \\
\hline \multirow[t]{3}{*}{1,25} & 5 & 1,25 & 8 & 220 \\
\hline & & 1,22 & 2 & 036 \\
\hline & & 1,21 & 4 & 223 \\
\hline \multirow[t]{2}{*}{1,19} & 5 & 1,18 & 8 & 123 \\
\hline & & 1,16 & 10 & 0210 \\
\hline 1,13 & 5 & 1,14 & 12 & 134 \\
\hline \multirow[t]{2}{*}{1,09} & 5 & 1,10 & 14 & 226 \\
\hline & & 1,07 & 2 & 042 \\
\hline \multirow[t]{2}{*}{1,05} & 5 & 1,05 & 18 & $21 \underline{10}$ \\
\hline & & 1,04 & 2 & $11 \overline{12}$ \\
\hline 1,03 & 5 & 1,03 & 2 & $4 \overline{04}$ \\
\hline
\end{tabular}

$\operatorname{CuK} \alpha=1,5418 \AA$, Filtro Ni

24 horas $30 \mathrm{kV} \quad 15 \mathrm{~mA}$ Ficha ASTM No 13-534

Filme n? 6670

Câmara de Gandolfi $114,6 \mathrm{~mm} \emptyset$ 
Tabe 1 a 26

Diagrama de Calcita

Rib. Perau

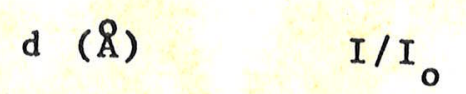

$3,91 \quad 10$

$3,06 \quad 100$

2,85

2,51

2,29

1,93

1,91

1,88

1,62

1,60

1,51

1,47

1,44

1,42

1,36

1,34

1,29

1,28

1,23

1,18

1,15

1,14

1,04

1,01

5

0,86

0,84

0,78

5

40

40

5

30

50

5

10

5

5

5

5

5

5

5

5

5

5

5

5

5
2,10

$\operatorname{CuK} \alpha=1,5418 \AA$, Filtro Ni

24 horas $\quad 30 \mathrm{kV} \quad 15 \mathrm{~mA}$

Câmara de Gando1fi $114,6 \mathrm{~mm} \emptyset$

(monocristal)

Filme no 13772
Ref. Swanson and Fuyat

d ( $\AA$ )

3,86

3,035

2,845

2,495

2,285

2,095

1,927

1,913

1,875

1,626

1,604

1,587

1,525

1,518

1,510

1,473

1,440

1,422

1,356

1,339

1,297

1,284

1,247

1,235

1,1795

1,1538

1,1425

1,1244

1,0613

1,0473

1,0447

1,0352

1,0234

1,0118

0,9895

0,9845

0,9767

0,9655
I/I.

12

3

14

18

18

5

17

17

4

8

2

5

4

3

2

5

3

1

2

2

1

1

2

3

3

1

1

1

3

2

1

2

1

1.

3

2 hk 1

102

104

006

110

113

202

204

108

116

211

212

1. 0.10

214

208

119

215

300

0.0 .12

217

2.0 .10

218

306

220

1.1 .12

2.1 .10

31.4

226

2.1 .11

2.0 .14

404

138

$0.1 .16-1.1 .15$

1.2 .13

3. 0.12

231

1.0 .17

2.1 .14

234

Ficha ASTM No 5-0586 
do essas fraturas são horizontais, a calcita se deposita em forma de camadas subparalelas, em faixas de coloração dis tinta, com centimetros a decimetros de espessura. Na jazí da em estudo a calcita das rochas carbonaticas se associa a todos minerais oxidados de cobre, e tambëm ao quartzo e à tremolita.

Propriedades físicas - Nas rochas carbonāti cas e cälcio-silicatadas, a calcita é submilimétrica, mos trando textura granoblástica. Mesmo individuos maiores, de ate $3 \mathrm{~mm}$, são xenomorfos e a coloração è branca a levemente amarelada. A Tabela 2 contēm o resultado da anälise quími ca de um calcärio cuja composição é essencialmente calcita.

Com häbito estalactítico a calcita exibe es trutura concêntrica, com faixas milimêtricas de coloração branca, creme e amarela. Os indivíduos são submilimétricos com predominância de cristais xenomorfos. A Tabela 26 for nece o diagrama de raios $X$ da calcita do Ribeirão do Perau.

Paragênese - A calcita é mineral formador de rochas sedimentares, tambẻm ocorrendo em rochas ígneas e me tamórficas, podendo ter origem hidrotermal e estar relacionada à mineralizaçães secundärias. A presença de calcita ao lado de quartzo, na jazida do Ribeirão do Perau, não ha vendo indícios de wolastonita, permite sugerir que o meta morfismo da ärea não atingiu a temperatura de $400^{\circ} \mathrm{C}$. A as sociação de calcita com tremolita evidencia metamorfismo re gional e termal (Deer, 1962).

dolomita

A dolomita e calcita constituem $95 \%$ do volume das rochas carbonäticas. A dolomita ocorre sempre asso ciada à calcita e nas faixas carbonáticas das rochas cal cio-silicatadas ocorre lado a lado, com quartzo. Associa-se aos minerais de minério oxidado da jazida não sendo notada em paragênese com minerais sulfetados. Do mesmo modo que a calcita é encontrada em associação com tremolita junto aos contatos com quartzito. 
Tabe 1a 27

Diagrama de Dolomita

\begin{tabular}{|c|c|}
\hline d $(\AA)$ & $I / I_{0}$ \\
\hline $\begin{array}{l}4,29 \\
4,02\end{array}$ & $\begin{array}{r}10 \\
5\end{array}$ \\
\hline 3,70 & $\begin{array}{r}5 \\
10\end{array}$ \\
\hline 3,34 & 40 \\
\hline 3,20 & 5 \\
\hline 2,88 & 100 \\
\hline 2,66 & 10 \\
\hline 2,53 & 10 \\
\hline 2,45 & 5 \\
\hline 2,39 & 10 \\
\hline 2,18 & 80 \\
\hline 2,06 & 5 \\
\hline 2,01 & 50 \\
\hline 1,80 & 60 \\
\hline 1,78 & 60 \\
\hline 1,56 & 10 \\
\hline 1,54 & 40 \\
\hline 1,46 & 20 \\
\hline 1,44 & 5 \\
\hline 1,42 & 5 \\
\hline 1,40 & 20 \\
\hline 1,38 & 5 \\
\hline 1,37 & 5 \\
\hline 1,33 & 10 \\
\hline 1,28 & 5 \\
\hline 1,26 & 5 \\
\hline 1,23 & 5 \\
\hline 1,20 & 5 \\
\hline 1,18 & 5 \\
\hline 1,16 & 5 \\
\hline 1,12 & 5 \\
\hline 1,10 & 5 \\
\hline 0,99 & 5 \\
\hline 0,95 & 5 \\
\hline
\end{tabular}

Howie e Broadhurst

d (\&)

4,03

I/ I

hk 1

3,69

2,886

2,670

2,540

3

101

2,405

2,192

2, 066

2,015

1,848

1,804

1,786

5

012

1,781

1,567

1,545

1,496

1,465

1,445

1,431

1,418

1,383

100

10

104

8

006

1,335

1,297

1,269

1,235

1,202

10

110

30

113

021

15

202

5

024

20

018

30

116

30

009

211

122

10

10.10

214

028

119

125

030

1,168

1,144

1,123

1,096

1,068

1,008

1,001

0,973

0,962

0,949

0,930

0,926

0,923

00.12

217

02.10

128

220

11.12

312

21.10

226-309

00.15

404

318

10.16

30.12

322

324

21.14

408

CuKa $\alpha 1,5418 \AA$, Filtro Ni

24 horas $\quad 30 \mathrm{kV} \quad 15 \mathrm{~mA}$

Filme no 219170

Ficha ASTM No 11-78

Câmara de Gando1fi $114,6 \mathrm{~mm} \emptyset$

(monocrista 1 ) 
E sempre mineral formador de rochas, não ocor rendo em veios ou formas pegmatiticas. Em läminas delgadas exibe textura granoblästica, com individuos apresentando di mensões submilimétricas. Macroscopicamente os agregados cristalinos mostram côr branca a amarela. A Tabela 27 con têm os resultados de difração de raios $x$, que a diferenciam da calcita. o estudo da azurita à microsonda eletrônica con tém dados sobre cristais de dolomita.

Paragênese - E encontrada em rochas sedimenta res, metamörficas e depösitos hidrotermais metassomäticos.As sociada a rochas ultrabásicas, ocorre com a magnesita. A do lomita de calcārios magnesianos, sob metamorfismo termal ou regional, se recristaliza paraformar märmore dolomitico. Na jazida, a presença rara de pericläsio nas rochas cälcio-sili catadas indica que o metamorfismo não atingiu um grau mais e levado que o do tipo termal ou regional (Deer, 1962). 
COMPARAÇÃO ENTRE ANĀLISES QUIMICAS E RESULTADOS DE MICROSON DA ELETRÔNICA

o teor de cobre é superior na zona oxidada, havendo maior concentração no minério carbonatado (Tabelas 28 e 29), sendo o teor de carbonato relacionado diretamente com o aumento de perda ao fogo e com a diminuição da sílica. o silício (Tabela 30), que provēm da ganga de quartzo e em menor proporção da crisocola, é menos abundante no minério carbonātico, podendo ser observada concentração oposta ao $\mathrm{Ca}, \mathrm{Mg}$ e $\mathrm{K}$.

o ferro (Tabela 30) è abundante no minério primärio e nos minerais de ganga, sendo pouco expressivo no minério secundário. o alumínio tem pouca expressão em teor, sendo entretanto abundante nos minerais metamörficos: grana da e turmalina.

o manganês deve provir das texturas colofor mes de "öxido de manganês e öxido de cobre" e de "óxido de chumbo". O sōdio, expressivo em três anālises químicas (Ta bela 28) de amostras de galeria e de testemunhos de sonda gens, foi determinado pela microsonda eletrônica (Tabela 30) na turmalina, embora tenha sido pesquisado nos minerais oxi dados de cobre.

0 enxofre ocorre em menor concentração nas anālises de testemunhos de sondagens, indicando que essas amostras provavelmente derivam da zona de oxidação da jazida. o fósforo, embora em pequena proporção, e o titânio, em quantidade menor, não foram determinados no minério (Tabela 30) analizado na microsonda eletrônica. O titânio tem como fonte a titanita. 0 chumbo, em proporção de traços (Tabela 28), provém da galena, que é rara, ou de seu oxido,sendo en contrado também em traços na cuprita e crisocola (Tabela 30).

A prata tem como fonte a tennantita, pois a galena parece não ser argentífera. O ouro se localiza na pirita, cuprita, cobre nativo e crisocola ocorrendo em sete 
amostras, analisadas quimicamente (Tabela 28), variando os teores entre 17 e $20 \mathrm{~g} / \mathrm{ton}$.

o arsênio è abundante na tennantita, ocorren do em menor proporção na azurita e em traços, na pirita e crisocola. Antimônio e zinco são abundantes na tennantita ocorrem na azurita. Crômio e sódio se localizam na turmalina. O bärio é restrito à barita e ao"óxido de Mn e Cu". O carbono aparece na malaquita, nos carbonatos de cálcio e mag nésio mas não foi pesquisado na azurita. o niquel e cobalto são elementos traços de pirita e de "öxido de Mn e Cu".

Nos minerais de minéxio não foram encontra dos os seguintes elementos: $F, C 1, S r, B i, P, L i, S n, T i, C r$, $P t, G e, S e, P d, H g, I r, V$ e . 
Tabela 28

Anàlises Químicas

\begin{tabular}{|c|c|c|c|c|c|c|c|c|c|c|}
\hline & 1 & 2 & 3 & 4 & 5 & 6 & 7 & 8 & 9 & 10 \\
\hline $\mathrm{CuO}$ & 1,41 & 11,52 & 7,10 & 6,11 & 0,24 & 8,20 & 0,33 & 4,07 & 9,33 & 0,10 \\
\hline $\mathrm{SiO}_{2}$ & 64,55 & 39,08 & 42,77 & 46,44 & 56,94 & 35,58 & 64,66 & 74,12 & 21,09 & 77,19 \\
\hline $\mathrm{Fe}_{2} \mathrm{O}_{3}$ & 5,35 & 27,37 & 18,01 & 24,09 & 12,37 & 26,16 & 5,11 & 8,61 & 4,11 & 9,78 \\
\hline $\mathrm{Al}_{2} \mathrm{O}_{3}$ & 0,75 & 0,69 & 0,47 & 1,17 & 4,72 & 0,56 & 0,92 & 1,32 & 0,32 & 0,94 \\
\hline $\mathrm{MnO}_{2}$ & 0,73 & 0,08 & 0,28 & 0,27 & 1,65 & 1,10 & 0,49 & 0,09 & 0,39 & $0 ; 12$ \\
\hline $\mathrm{TiO}_{2}$ & $\operatorname{tr}$ & tr & $\operatorname{tr}$ & tr & 0,06 & $\operatorname{tr}$ & $t r$ & 0,01 & $t r$ & 0,01 \\
\hline $\mathrm{CaO}$ & 7,28 & 1,68 & 7,90 & 1,54 & 1,33 & 2,80 & 4.95 & 0,06 & 12,52 & 4,00 \\
\hline$M g 0$ & 9,04 & 3,90 & 7,63 & 4,97 & 10,94 & 6,47 & 11,11 & 1,41 & 19,10 & 0,14 \\
\hline $\mathrm{K}_{2} \mathrm{O}$ & 0,45 & 0,07 & 0,17 & 0,69 & 1,77 & 0,18 & 0,27 & 0,53 & 0,24 & 0,65 \\
\hline $\mathrm{Na}_{2} \mathrm{O}$ & - & - & - & - & 1,08 & 1,08 & 1,08 & 0,07 & 0,07 & 0,08 \\
\hline S & 0,41 & 0,89 & 1,72 & 0,93 & 3,02 & 8,83 & 9,38 & 5,59 & 2,54 & 5,94 \\
\hline $\mathrm{P}_{2} \mathrm{O}_{5}$ & 2,38 & 0,11 & 3,94 & 2,38 & 0,43 & 1,54 & 0,29 & 0,21 & 0,59 & \\
\hline $\mathrm{PbO}_{2}$ & tr & tr & $\operatorname{tr}$ & tr & tr & $\operatorname{tr}$ & $t r$ & tr & tr & tr \\
\hline $\mathrm{Au}$ & $<0,002$ & $<0,002$ & $<0,012$ & $<0,002$ & $<0,002$ & & $<0 \cap 0 ?$ & - & - & - \\
\hline Umidade & 0,56 & 4,04 & 1,82 & $3,15^{\circ}$ & $\begin{array}{c}<0,002 \\
1,33\end{array}$ & & $<0,002$ & $<0,003$ & $<0,002$ & 0,0017 \\
\hline $\begin{array}{l}\text { Perda ao } \\
\text { fogo }\end{array}$ & 7,80 & 90 & 8.50 & 3,13 & & 3,96 & 0,19 & 0.89 & 1,61 & 0,04 \\
\hline & & 0,04 & &, 99 & 4,71 & 3,85 & 1,83 & 4,00 & $28,37=$ & 1,81 \\
\hline
\end{tabular}


Localização das amostras da Tabela 28

1 - Testemunho de sondagem, F5; 83,00 a $84,00 \mathrm{~m}, 10 c a l i z a d o$ entre TR80S e TR160S. Quartzito impregnado por malaquita.

2 - Testemunho de sondagem, F2; 69,49 a $69,70 \mathrm{~m}$, localizado sobre a TRO. Malaquita em quartzito.

3 - Idem; 71,30 a 71,52 m.

4 - Testemunho de sondagem, $F 1 ; 13,00$ a $14,00 \mathrm{~m}, 10 c a 1$ izado sobre a TRO. Malaquita e crisocola no quartzito.

5 - Testemunho de sondagem, F3; 13,30 a $20,00 \mathrm{~m}, 10 \mathrm{calizado}$ sobre a TR8OS.

6 - Vieiro de galeria, localizado em G3 (detalhe que não cons ta do mapa geológico) no ramo mais extenso das galerias, entre TR80N e TRO. Composição: malaquita, crisocola,cupri ta, calcopirita, material limonitico.

7 - Amostra de volume total da galeria G3, entre TRO e TR80N. Minério oxidado de cobre e ganga de quartzo, tremolita e material limonítico.

8 - Amostra de calha, de perfil, da trincheira do Faria, na TR1200S. Vieiros de minerais oxidados de cobre encaixa dos em fraturas dos quartzitos.

9 - Amostra de calha, de perfil, da trincheira sobre a TR35s. Azurita, tennantita e quartzo.

10 - Amostra de calha, de perfil, da trincheira do Faria, na TR1120S. Pirita disseminada em quartzito. 


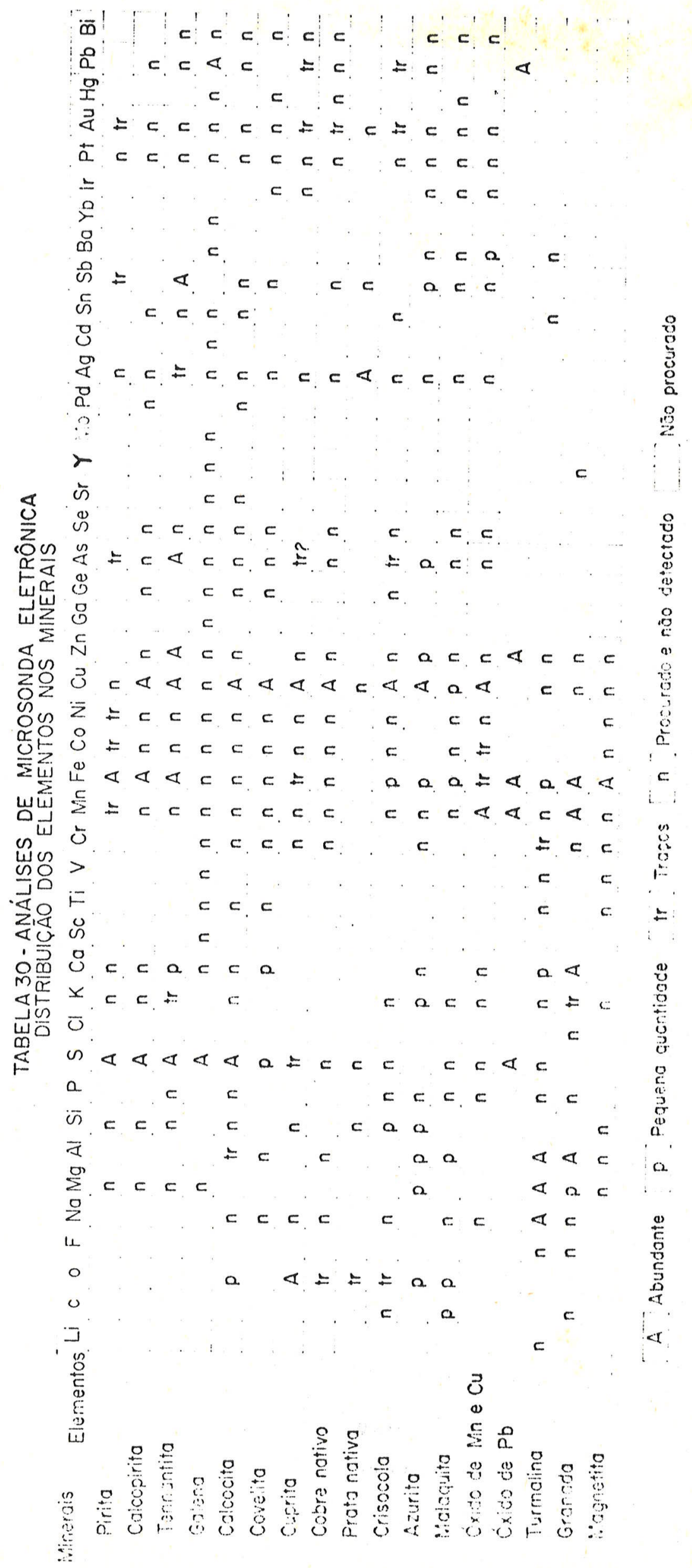


SEQUENCIA DE DEPOSIÇÃO E GÊNESE

Durante a anālise de cada mineral, värios tipos de texturas foram descritas, porem nem todas podem fornecer idéias razoāveis quanto à sequência mineralógica. o estudo microscópico e as relações de campo permitem divi dir os minerais da jazida em três grupos (Figura 33):

o primeiro é constituido por pirita, cal copirita e tennantita (Figura 33) cujas consideraçós, nos capitulos anteriores respectivos a cada mineral, permitem considerā-1as como minerais primärios, ocorrendo dissemina dos no quartzito, com larga distribuição horizontal e quena vertical, sendo a pirita predominante em relação à calcopirita e tennantita. A relação periférica (Noble, 1950) existente entre pirita e calcopirita poderia suge rir idade mais recente para a pirita. A tennantita, embo ra apresente o mesmo modo de ocorrência nos quartzitos, não foi encontrada junto à pirita e calcopirita. Na falta de evidências mais significativas quanto à sequência desses minerais no tempo, foi proposta uma fase de contemporaneidade para pirita, calcopirita e tennantita, sempre associa das ao quartzo dos quartzitos.

o segundo grupo dos minerais é composto por galena e barita (Figura 33) incluídos também numa fase primária, posterior, possivelmente hidrotermal de baixa temperatura com relações significantes, em forma de veios, ora dispostos discordantemente à estratificação dos xistos, ora associados aos minerais oxidados de cobre. Na galena e barita predominam o idiomorfismo sendo que na região oxi dada é comum a textura em cārie na galena.

o terceiro grupo é constituído pelos mine rais da fase secundāria, (Figura 33) não havendo propria mente na jazida uma zona de enriquecimento supérgeno pois hä nítida predominância de malaquita e crisocola sobre ca 1 cocita, covelita, bornita e demais minerais oxidados. Nes sa região os minerais exibem texturas em rede, coloforme, bandeada, esquelética e zonal. 
Fig. 33 Sequência mineralógica

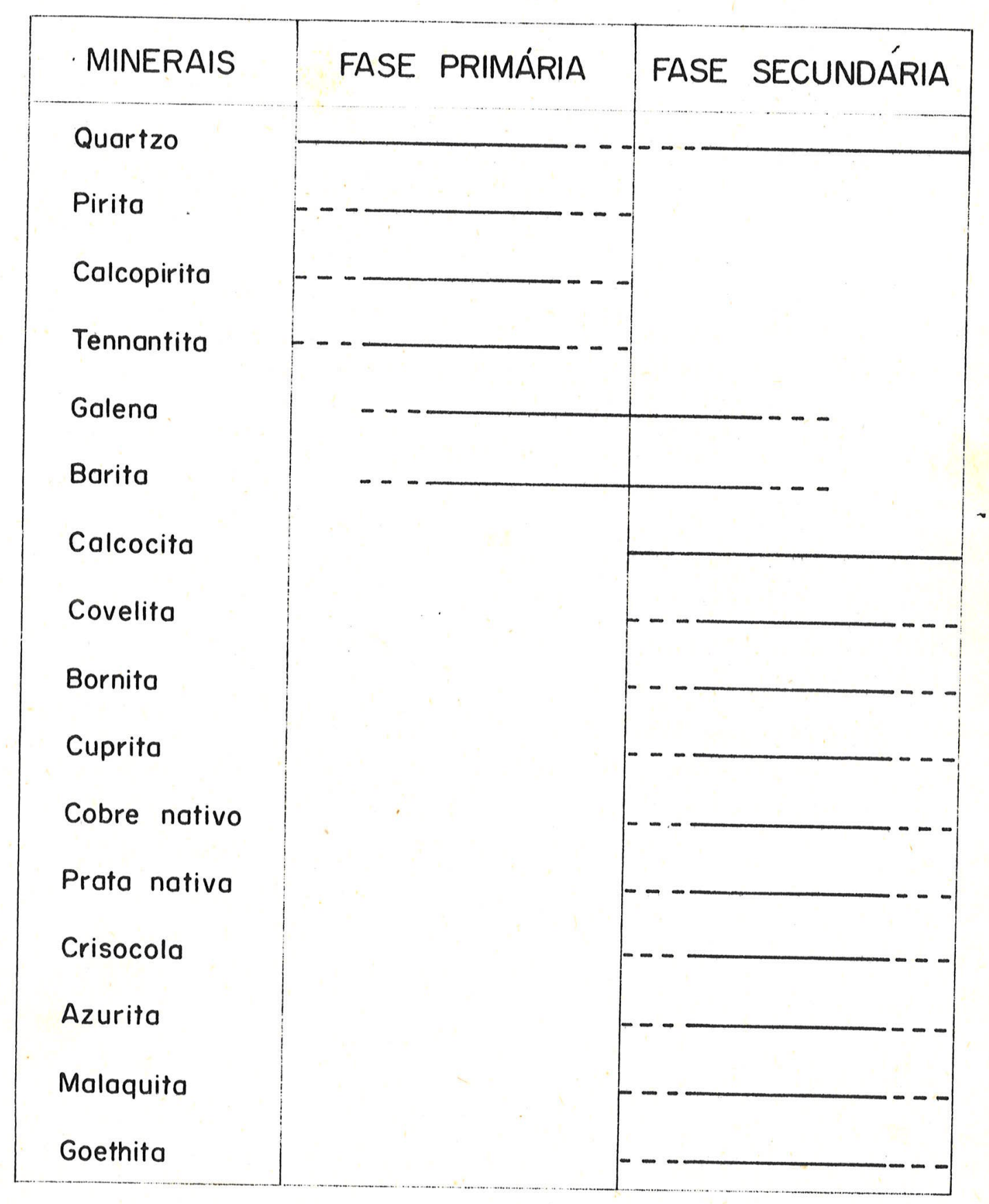


A jazida do Ribeirão do Perau pode ser con siderada como prolongamento do distrito mineral do Ribeira de Iguape, pois se encontra a $3 \mathrm{~km}$ abaixo do limite sul do "mapa geolögico do distrito mineral do Rio Ribeira de Iguape" (Melcher, 1968, p. 7) e com igual posição geogräfica, em re 1 ação aos "mapas de isoteores dos elementos acessōrios e ém traços nas galenas do Vale da Ribeira" (Cassedanne, 1971 , p. 116).

A unidade portadora do minērio,representada por camadas de quartzito com intercalações de rochas carbonā ticas, possui extensa distribuição horizontal e pequena es pessura, estando sobreposta a espesso pacote de quartzito sem intercalações carbonáticas e sotoposta a rochas xistosas com mais de uma centena de metros de espessura.

o controle litolögico é exercido pelo quart zito compacto, imediatamente sotoposto à sequência carbonäti ca, com nítido acamamento, onde o minério se encontra disse minado e confinado e, às vezes, em pequena concentração. Pe quenos veios de remobilização ocorrem pouco afastados da ro cha principal mineralizada. Na jazida, o minērio se confina no anticlinal principal (Figura 4 ).

Soluções hidrotermais precipitaram pirita, calcopirita e tennantita na barreira ao longo do contato en tre xisto e quartzito, na estrutura de anticlinal. Nos xis tos em niveis estratigräficos mais elevados, depositaram-se ao longo de fraturas: quartzo, barita, turmalina e galena. 


\section{AGRADEC IMENTOS}

Värias pessoas e entidades contribuiram para a realização deste trabalho:

o Professor Dr. William Gerson Rollim de Ca margo, Professor Catedrático de Mineralogia do Instituto de Geociências da Universidade de São Paulo orientou todas as fases do trabalho e reviu a redação.

A Eletro São Narco Ltda., na pessoa de seu söcio gerente Senhor Costabile Raso propiciou as condições necessárias para obtenção dos dados, sobretudo na pesquisa geológica e forneceu estägios de campo para diversos alunos do Curso de Geologia do Instituto de Geociências da U.S.P.

O Dr. Moacyr Rabelo de Arruda, Professor As sistente do Departamento de Mineralogia e Petrologia do Ins tituto de Geociências reviu toda redação e apresentou valio sas sugestões para aprimoramento do texto.

Os Professores Joel G. Valença, Othon Leonar dos Jr. e A. Braz, do Instituto de Geociências da Universida de Federal do Rio de Janeiro, gentilmente acolheram o autor em estágio de iniciação à técnica de rnicrosonda eletrônica.

o Dr. Kenkichi Fujimori, Professor Assisten te do Departamento de Mineralogia e Petrologia do Instituto de Geociências que introduziu e incentivou o pesquisador no estudo à microsonda eletrōnica.

o Capitão Aviador Julio Vasques Pato, chefe do Departamento de Materiais do Instituto de Pesquis as de De senvolvimento do Centro Tëcnico da Aeronäutica e o Engenhe ro Dr. Edmundo Antonio Chojnowski, Chefe da Divisão de Enge nharia de Materiais de Pesquisas de Metais Raros, do C.T.A., permitiram todas as facilidades no uso do laboratório de mi crosonda eletrônica do C.T.A., sem auxílio dos quais não há veria sido possível a realização das micro anālises.

Os Engenheiros João Renato S. Martins, Chefe do Laboratōrio de Microsonda do Departamento de Materiais do 
Instituto de Pesquisas e Desenvolvimento, do C.T.A. e Orlan do Eugenio de Carvalho, Químico do Laboratório de Microsondá, do mesmo Instituto, acompanharam e orientaram através de seus bons préstimos e competência, o desenrolar das anālises dos minerais da jazida estudada. O Senhor Antoninho Marcio de Azevedo, técnico especializado do mesmo laboratörio, muito contribuiu para o bom resultado das pesquisas.

Os Drs. Vicente A.V.Girardi e Marcos Aurelio Farias de oliveira do Departamento de Mineralogia e Petrolo gia do Instituto de Geociências deram valiosa colaboração no estudo petrográfico e preparação do texto respectivo.

O Dr. Yociteru Hasui, do Departamento de Geo logia do Instituto de Geociências, reviu o texto de geologia da jazida e apresentou valiosa colaboração para aprimoramento do conteūdo geolögico.

o Dr. Raphael Hypolito, do Departamento de Mineralogia e Petrologia do Instituto de Geociências, orien tou o uso do laboratório químico do referido departamento pá ra testes e exames químicos.

o Geólogo José Barbosa de Madureira Filho,do Departamento de llineralogia e Petrologia do Instituto de Geo ciências orientou e discutiu o estudo das granadas.

O Professor Dr. Reinholt Ellert, Chefe do De partamento de Geologia Econômica e Geofísica Aplicada do Ins tituto de Geociências apresentou sugestões valiosas no estü do de seções polidas e gênese da jazida.

O Dr. José Eduardo Siqueira Farjallat, Chefe do Departamento de Geologia do Instituto de Pesquisas Tecno lögicas da Universidade de são Paulo, executou e discutiu as anälises de A.T.D. apresentadas neste trabalho.

Um grupo de geólogos - mais de uma dezena quando ainda alunos, em estágios de campo oferecidos pela Eletro São Marco Ltda., muito contribuiram para o detalhamen to de geologia da jazida.

A Fundação de Amparo à Pesquisa do Estado de 
São Paulo financiou as análises químicas e o estudo à micro sonda eletrônica, assim como fornèceu bolsa de iniciação científica, durante dois anos, a aluno gildezio lessa, sob orientação do Professor Dr. José Vicente Valarelli, do De partamento de Mineralogia e Petrologia do Instituto de Geó ciências, de cujos estudos mineralógicos muito se utilizou o autor.

A todos os que ajudaram nas diversas fases do trabalho ou em serviços técnicos de desenhos, datilogra fia e impressão, sejam pessoas ou entidades, embora não men cionadas, o autor externa a sua gratidão. 


\section{BIBLIOGRA FIA}

ABELSON, P.H. (1958-1959) - Annual report of the director of the Geophysical Laboratory. Ceoph. Lab., p. 109.

ALNEIDA, F.F.H. (1964) - Fundamentos geolögicos do Relêvo Paulista. Inst.Geogr. Geolögico do Est.S.Paulo, Bol. 41. ARRUDA, H.R. (1971) - Mineralogia da Hina de Cobre santa Blandina, em ttapeva, Estado de são paulo. Tese de douto ramento apresentada ao Instituto de (ieociências, U.S.P. (inēdito).

ASTM (1963) - X-ray powder file: 1916 Race st., Philadelphia, $3, \mathrm{~Pa}$, USA.

AZAROFF, L.V. et BUERGER, H.J. (1958) - The powder method in X-ray crystallography: Nickraw Hill book Co., New York, USA. BATEMAN, A.M. et LASKY, S.G. (1932) - Covellite-chalcocite solid solution and ex-solution. Ec.Geol., v. 27,pp.52-86.

BATEMAN, A.M. (1968) - Yacimentos Minerales de Rendimiento Econônico: Ediciones Omega S.A., Barcelona. 3a. Ed.

BUERguer, N.W. (1941) - The chalcocite problem. Ec. Ceol.v. $36, p p .19-44$.

CAMARGO, W.G.R. (1972) - Minerais uraníferos de Perus, S.P. Tese para provimento de cargo de profiessor Catedrätico. Fac.Fil.Ciên.tetras, U.S.P. Bol. Y.A.A. n! 2, pp. 85-201. CAMARG0, W.G.R. et BRUDER, J. (1965) - Desordens cristalinas causadas por trituração. Ciên.Cultura, v. 17, no 2,p.100.

CAMARGO, W.G.R. et INGLEZ, A.G. (1967) - Determination of unit cell dimensions by a graphic analytical method., submitted at annual meeting, American crystallogranhic As sociation, Atlanta, Ceorgia. Ass.Acad.Bras.Ci. (no prelo) 1972

CAMARGO, W.G.R. et SoU\%A, I.H. (1970) - Novo häbito da Turma lina. An.Acad. Bras.Ciências, vol. 42, pp. 219-222. 
CASSEDANE, J. et MELlo, Z.F. (197.0) - Revisão das jazidas de chumbo e zinco do Grupo são Roque. $1 \stackrel{a}{a}$ parte. Rev.Min. Me talurgia, v. LI, n? 304, p. 156.

CASSEDANE, J. (1971) - Estudo dos elementos traços e acessó rios das galenas do Vale do Ribeira, S.P. XXV Congr.Bras. de Geologia, Bol. especial no 1, p. 180 e Anais do XXV Congr.da Soc.Bras.Geol., v. 1, p. 111 .

CASTAING, R. (1952) - Applications des sondes electroniques a une méthode de d'analyse ponctuelle chimique et cris tallographique. Office national d'E'tudes et Recherches Aéronautiques. Chatillon-Sons Bagneux (Seine).

CORDANI, U.G. et KAWASHITA, K. (1971) - Estudo geocronológi co, pelo método $\mathrm{Rb}-\mathrm{Sr}$, de rochas graníticas intrusivas no Grupo Açungui. Anais do XxV Congr. Bras.de Geologia, v. 1, pp. 105-109.

DANA, J.D. (1894) - The system of Mineralogy - Kegan Paul, Trench, Trubner \& Co., Ltd., London.

DAVINO, A. et KADEKARU, K. (1969). - Resultados preliminares de um levantamento por polarização espontânea da ocorrên cia de cobre da Barra do Perau, municipio de Adrianopólis, Paraná. Min.let., v. L, no 299, pp. 212-213.

DEER, W.A.; HOWIE, R.L. et ZUSSMAN, J. (1962) - Rock Forming Minerals, v. 1, Ortho and Ring silicates.

DEER, W.A.; HOWIE, R.A. et ZUSSSAN, J. (1963) - Rock Forming Minerals, v. 2, chain silicates.

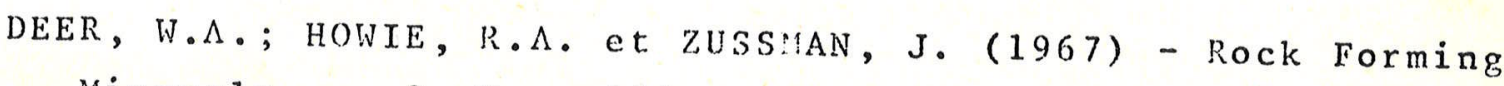
Minerals, v. 3 , Non silicates.

EBERT, H. (1971) - Observações sobre a litologia e subdivi são do "Grupo Setuva" no Estado do Paranā; com sugestões à tectônica geral do "Geossinclínio Açungui". Anais do XXV Congr.Bras. de Geologia, v. 1, pp. 132-146. 
EBERT, H.; BROCHINI, M.F. et MARINI, O.J. (1971) - Observa ções sobre os gnaisses da Formação Setuva, Estado do Pä ranā. XXV Congr. Bras. de Geologia, Bol. especial no 1 , pp. 185-186.

EDIVARDS, A.B. (1954) - Textures of the ore minerals and their significance: Australasian institute of mining and metallurgy (Inc.). Helbourne.

EINAUDI, M.T. (1968) - Copper zoning in pyrite from Cerro de Pasco, Peru. Am. Wineralogist, v. 53, pp. 1748-1752.

ELLERT, R. (1969) - Introdução a estudo de minerais opacos e tabelas de determinação. Cad. de Geol. Econômica, Fac. Fil.Ciên.letras, U.S.P.

FORBES, R.B. et BARSDATE, R. (1969) - Trace metal zonation in a Native Copper-nugget from the liccarthy District, Alaska. Ec. Geol., v. 64, pp. 455-459.

FORD, W.E. (1966) - Dana's Textbook of Mineralogy; John Wiley \& Sons, Inc., New York, 4th Edition. $22 \mathrm{th}$ printing. FREUND, H. (1966) - Applied ore microscopy. The Macmillan Company, New York.

FUCK, R.A.; MARINI, O.J. et TREIN, E. (1967) - Contribuição ao estudo das rochas graniticas do Estado do Parana. Bol. Paranaense de Geociências, no 23/25, pp. 183-220.

FUCK, R.A.; MARINI, O.J.; TREIN, E. et MURATORI, A. (1971) Geologia do leste naranaense. XXV Congr.Bras.de Geolo gia, Bol. especial no 1, p. 191.

FRUEH Jr., A.J. (1950) - Disorder in the Mineral bornite. Am. Min., v. 35, pp. 185-192.

GILBERT, G. (1925) - Antipathy of bornite and pyrrhotite. Ec.Geol., v. 20, no 4, pp. 364-370.

GODINHo, M.H. (1964) - Contribuição para o conhecimento do comportamento térmico da malaquite e azurite. Memórias e Notícias, n? 57, pp. 7-20, Coimbra. 
GOLDSCHMIDT, V. (1913) - At las der Krystalloformen, Heide1berg.

JOHNS, R. H. (1939) - Clerici solution for the specific gravity determination of small mineral grains. Am. Min., v. $24, \mathrm{n}: 2, \mathrm{p}, 117$.

JoST, H. (1971) - Geologia de Campo III (Tabelas, ābacos, con venções). Publicações CAEG, Porto Alegre.

KULLERUD, G.; DONNAY, G. et DONNAY, J.I.:i. (1960) -A second find of enhedral bornite crystals on barite. Am. Min.,v. 45, pp. 1062-1068.

LEINZ, V. et SOUZA CA:ipos, J.F. (1952) - Guia para determi nação de minerais. Fac.Fil.ciēn.letras, li.s.P.

LINDGREN, V. (1935) - The silver mine of Colquijirca, Peru. Ec.Geo1., v. 30, pp. 331-346.

HAACK, R. (1947) - Breves noticias sobre a Geologia do Para ná e Santa Catarina. Arq.Bio.Tecn., v. 2, Curitiba.

MADUREIRA FILHO,J.B.et CAMARGO,W.G.R.(1972)-Novos diagramas para determinação física das granadas. Inst. Geociêncỉas, U.S.P. (inēdito).

MARIMOTO, N. et KULLERUD; $G$. (1961) - Polymorphism in borni te. $\Delta \mathrm{m}$. Min., v. 46, pp. 1270-1282.

MARINI, O.J.; TREIN, E. et FUCK, R.A. (1967) - o Grupo $\Lambda$ çun gui no Estado do Paraná. Bol.Paranaense de Geociências, nrs. 23 a 25 , Curitiba.

MARINI, O.J. et PICARFLLA, J.J. (1967) - Rochas calcärias do Grupo Açungui. Bol.paranaense de Geociências, nrs. 23 a 25, p. 105, Curitiba.

MARINI, 0.J. et LEPROVOST, A. (1967) - Principais recursos minerais do Grupo Açungui, no Estado do Paraná. Bol. Pa ranaense de Ceociências, nrs. 23 a 25 , p. 180, Curitiba. MARTINEZ, E. (1963) - Chrysocolla studied by differential thermal analysis, thermal gravimetric analysis and in frared spectrophotometry: Transactions of the society of mining engineers, v. 226, december, 1963. 
MARTINS, J.R. (1972) - Aplicações da Microsonda Eletrônica. Rev. ITA Engenharia, v. 3, no 8 , pp. 45-48.

MASKE, S. et SBINNER, B.J. (1971) - Studies of the sulfosalts of cooper $I$. phases and phases relations in the system Cu-As-S. Ec.Geol., v. 66, pp. 901-918.

MAUCHER, A. et SCINEIDER, H.J. (1967) - The alpine lead-zinc ores; genesis of stratiform lead-zinc-barite-fluorite depo sits. Ec.Geo1., lonograph 3, pp 71-90.

MELCHER, G.C. (1968) - Contribuição ao conhecimento do distri to mineral do Ribeira de Iguane, Estados de São Paulo e Pa ranā. Tese de bocência Livre, Escola Politécnica, U.S.P. (inédito).

MELCHER, G.C.; CORDANT, U.G.; DAKASCENO, E.C.; GIRARDI, V.A., et GOMES, C.B. (1971) - Geologia da Folha de Apiaí. XXV Congr.Bras. de Geologia, Bol. especial no 1, p. 194 e Anais do XXV Congr.Bras. de Ceologia, v. 1, p. 101.

MELCHER, G.C.; CORDANI, U.G.; DAMASCENO, E.C.; GIRARDI, V.A., GOMES, C.B. et MELFI, A.J. (1971) - Geologia das rochas Pré-Cambrianas do Vale do Ribeira de Iguane. XXV Congr. Bras. de Geologia, Bol. especial ne 1, p. 193.

MELFI, A.J.; CORDANI, U.G. et BITTENCOURT, I. (1965) - Reconhecimento fotogeológico de parte do Grupo Açungui. Bragan tia, v. 24, n? 34 .

MERVIN, H.E. et LOABARI), R.H. (1937) - The system Cu-Fe-S. Ec. Geo1., v. 32, pp. 203-284.

MORAES, Ae. Ce1. JOÃO dE MELlo et pINHEIro, i. Sinval (1956) Primeira expedição científica à serra de paranapiacaba e Alto Ribeira, v. 1. Com. Defesa do Património, Natural do Parana.

NOBLE, J.A. (1950) - Ore mineralization in the homestake gold mine, lead, South Dakota. Geol. Soc. Am., Bu11., v. 61, pp. $221-252$.

OELSNER, 0. (1966) - Atlas of the most important ore mineral parageneses under the microscope. Pergamon Press. Edition Leipzig. 
PAULING, L. et NEWMAN, E.W. (1934), - The crystal structure of Binnite, $(\mathrm{Cu}, \mathrm{Fe})_{12} \mathrm{As}_{4} \mathrm{~S}_{13}$ and the chemical composi tion and structure of minerals of the thetrahedrite gru pe. Zeitschr. Krist. v. 88, pp. 54-62.

PETERSON, V.E. (1942) - A study of the geology and ore deposits of the Ashbrook silver mining, district, Utah. Ec. Geo1., v. 37, pp. 466-502.

PONSJACK, E.; ALLEU, E.T. et VERVIN, H.E. (1915) The sulphides of cooper. Ec. Geol., v. 10, pp. 491-535.

RAliDOHR, P. (1969) - The ore minerals and their intergrowts. Perganon Press. Germany.

ROSEBOOH, E.H. et KULLERUD, G. (1958) - The solidus in the system Cu $-\mathrm{Fe}-\mathrm{S}$ between $400^{\circ}$ and $800^{\circ} \mathrm{C}$. An. Rep. Dir. Geophs. Lab. of Carnegie Instit., Washington, USA.

ROSEBOOM, E.H. Jr. (1966) - An investigation of the system $\mathrm{Cu}-\mathrm{S}$ and some natural cooper sulfides between $25^{\circ}$ and $700^{\circ}$ C. Ec. Geo1., v. 61, pp. 641-672.

SCHWARTZ, G.M. (1931) - Intergrowth of bornite and chalco pyrite. Ec. Geol., v. 26, pp. 186-201.

SCIFAX (1970) - Differential Thermal Analysis Data Index. R. C. Mackenzie. Nacmillan \& Co. Ltd. Melbourne, Toronto. SOUZA, I.M. (1970) - Esboço geológico das ocorrências de co bre no Ribeirão do Perau, Município de Adrianöpolis, Es tado do Paraná. XXII Reunião Nnual da Soc.Bras. p/ Progr. da Ciência, Salvador, p. 79.

THROOP, A.H. et BUSECK, P.R. (1971) - vature and Origin of Black Crysocolla at the Inspiration Hine, Arizona. Ec. Geol., v. 66, pp. 1168-1176.

TREIN, E.; MURATORI, A.; FUCK, R.A. et MARINI, O.J. (1970)Tunas, Folha Geológica $(1: 70.000)$ - Paranä, Brasil. Comissão da Carta Geológica do Paraná. Imnressora Paranaen se S.A., Curitiba. 
TURNER, F.J. et VERHOOGEN, J. (1960) - Igneous and meta morphic Petrology. McGraw Hi11, New York.

UYTENBOGAARDT, W. (1951) - Tables for microscopic identifi cation of ore minerals. Princeton Iniv. Press.Princeton, New Jersey.

VASSAR, H.E. (1925) - Clerici solution for minerals separa tion by gravity. Am. 11in., v. 10, pp. 123-125.

YUND, R.A. et KULLERUD, G. (1963) - Stability of some cooper and cron sulfides assemblages. Ec.Geo1., v. 58, pp.1190-1191 .

WINCHELL, A.N. et WINCHELL, H. (1951) - Elements of optical mineralogy. John Villey \& Sons Inc., New York.

WINCHELL, H. (1958) - The composition and physical properties of garnet. Am. Min., v. 43, p. 595. WINCHELL, A.N. (1967) - Elements of Optical Hineralogy, New York, 4 th ed. 


\section{ABREVIAÇÕES E SIMBOLOS}

$\begin{array}{ll}\text { ATD } & \text { Anälise Térmica Diferencial } \\ \text { cont } & \text { contagem } \\ \text { cont/s } & \text { contagem por segundo } \\ \text { Eh } & \text { Elétron } \\ \text { Ev } & \text { escala horizontal } \\ \text { F } 1 & \text { escala vertical } \\ \text { LB } & \text { furo de sondagem } \\ \text { m.a. } & \text { linha base } \\ \text { n } & \text { milhões de anos } \\ \text { pe } & \text { indice de refração } \\ \text { ppm } & \text { peso específico } \\ \text { Qz. } & \text { partes por milhão } \\ \text { tr } & \text { quartzo } \\ \text { TR } & \text { traços } \\ x & \text { linha transversal } \\ " X " & \text { por } \\ \mu m & \text { raios X } \\ \sim & \text { micron } \\ & \text { cerca de }\end{array}$

